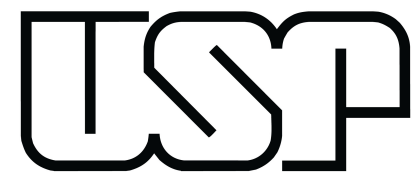

Universidade de São Paulo

Alexandre Prodóssimo Sohn

Avaliação da estabilidade de aerogeradores via método direto

Tese de doutorado

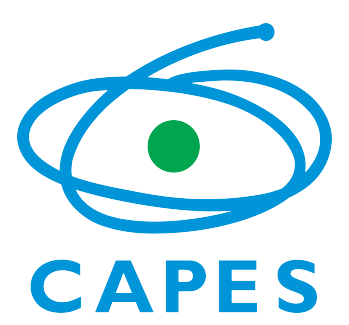

São Carlos

2019

O presente trabalho foi realizado com apoio da Coordenação de Aperfeiçoamento de Pessoal de Nível Superior - Brasil (CAPES) - Código de Financiamento 001. 



\section{Avaliação da estabilidade de aerogeradores via método direto}

Tese apresentada à Universidade de São Paulo como parte dos requisitos para a obtenção do título de Doutor em Ciências.

Programa: Pós-Graduação em Engenharia Elétrica.

Área de concentração: Sistemas Elétricos de Potência.

Orientador: Professor Titular Luís Fernando Costa Alberto.

Laboratório de Análise Computacional em Sistemas Elétricos de Potência Departamento de Engenharia Elétrica e de Computação Escola de Engenharia de São Carlos - Universidade de São Paulo

São Carlos

2019

Trata-se da versão corrigida da tese. A versão original se encontra disponível na EESC/USP que aloja o Programa de Pós-Graduação em Engenharia Elétrica. 
AUTORIZO A REPRODUÇÃO TOTAL OU PARCIAL DESTE TRABALHO POR QUALQUER MEIO CONVENCIONAL OU ELETROONICO, PARA FINS DE ESTUDO E PESQUISA, DESDE QUE CITADA A FONTE.

Ficha catalográfica elaborada pela Biblioteca Prof. Dr. Sérgio Rodrigues Fontes da EESC/USP com os dados inseridos pelo(a) autor(a).

Sohn, Alexandre Prodóssimo

Avaliação da estabilidade de aerogeradores via método direto / Alexandre Prodóssimo Sohn; orientador Luís Fernando Costa Alberto. São Carlos, 2019.

Tese (Doutorado) - Programa de Pós-Graduação em Engenharia Elétrica e Área de Concentração em Sistemas Elétricos de Potência -- Escola de Engenharia de São Carlos da Universidade de São Paulo, 2019.

1. Aerogerador. 2. Estabilidade de velocidade. 3. Fonte alternativa. 4. Função energia. 5. Limite operacional. 6. LVRT. 7. Método direto. 8. PEBS. I. Título.

Eduardo Graziosi Silva - CRB - 8/8907 


\section{FOLHA DE JULGAMENTO}

Candidato: Engenheiro ALEXANDRE PRODOSSIMO SOHN.

Título da tese: "Avaliação da estabilidade de aerogeradores via método direto".

Data da defesa: 23/04/2019

Comissão Julgadora:

Resultado:

Prof. Titular Luís Fernando Costa Alberto

(Orientador)

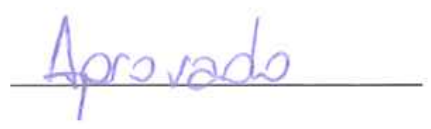

(Escola de Engenharia de São Carlos/EESC)

Prof. Associado José Carlos de Melo Vieira Júnior

APROVADO

(Escola de Engenharia de São Carlos/EESC)

Prof. Dr. Romeu Reginatto

(Universidade Estadual do Oeste do Paraná/UNIOESTE)

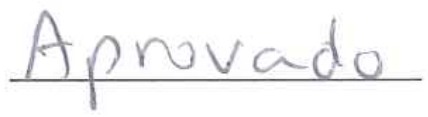

Profa. Dra. Ahda Pionkoski Grilo Pavani

APROVADO

(Universidade Federal do ABC/UFABC)

Prof. Dr. José Eduardo Onoda Pessanha

APROVADO

(Universidade Federal do Maranhão/UFMA)

Coordenador do Programa de Pós-Graduação em Engenharia Elétrica:

Prof. Associado Ivan Nunes da Silva

Presidente da Comissão de Pós-Graduação:

Prof. Titular Murilo Araujo Romero 



\section{Dedicatória}

Dedico este trabalho ao meu pai e à minha mãe. 


\section{Agradecimentos}

Agradeço aos meus pais pelo constante incentivo.

Agradeço ao colega Adriano Lima Abrantes pelas colaborações.

Agradeço aos colegas Taylon Gomez Landgraf e Francisco Rodrigues Lemes pelas assistências e considerações.

Agradeço ao professor Luís Fernando Costa Alberto pelas cooperações ao longo destes anos de trabalho.

Agradeço à professora Ahda Pionkoski Grilo Pavani e aos professores Romeu Reginatto, José Carlos de Melo Vieira Júnior, José Eduardo Onoda Pessanha e Luís Fernando Costa Alberto pelas avaliações e contribuições.

Agradeço à CAPES pela bolsa de estudo.

Agradeço à CAPES, CNPq e FAPESP pelo apoio financeiro ao laboratório de pesquisa. 
Metade do mal que é feito neste mundo vem de pessoas que querem se sentir importantes. Elas não querem fazer o mal, mas o mal que causam não interessa a elas. Ou elas não veem ou justificam o que foi feito por estarem absorvidas numa luta sem fim para ter uma boa imagem de si mesmas.

T. S. Eliot 


\section{Resumo}

A. P. Sohn. Avaliação da estabilidade de aerogeradores via método direto. 138 f. Tese de doutorado, Universidade de São Paulo, São Carlos, 2019.

Esta tese trata de dar um passo na direção de revisar o problema de estabilidade transitória e a teoria do método PEBS para incluir em seus fundamentos modelos de fontes alternativas e seus limites operacionais. A conceituação do método direto com restrição é estabelecida via teoria de sistemas dinâmicos restritos e do conceito de região de estabilidade restrita. Particularmente, avalia-se a estabilidade de velocidade das principais configurações de aerogeradores equipados com gerador de indução, considerando como requisito operacional a curva de suportabilidade a afundamentos de tensão, ou curva LVRT. Um sistema dinâmico auxiliar aumentado é desenvolvido para representar a curva LVRT, que é um requisito dependente do tempo, por meio de uma restrição invariante no tempo descrita em termos de uma variável de estado auxiliar. Este sistema auxiliar tem sua região de estabilidade irrestrita igual à região de estabilidade restrita do sistema dinâmico restrito. Os modelos são apresentados na forma de equações algébricas e diferenciais. O problema de estabilidade de velocidade e o problema de violação de limites de tensão são investigados via análises da região de estabilidade do ponto de equilíbrio estável do sistema pós-falta e dos tempos críticos de abertura obtidos para várias perturbações. Os resultados mostram que: i) para distintos limites operacionais e para distintos parâmetros da máquina de indução, as regiões de estabilidade para um dado ponto de equilíbrio podem ser significativamente diferentes, ii) na maioria dos casos analisados, os limites de tensão são violados antes dos aerogeradores perderem a estabilidade de velocidade, o que mostra como é importante considerar limites operacionais nas avaliações de estabilidade via método direto para evitar que o sistema elétrico de potência fique vulnerável e iii) as funções energia desenvolvidas, tanto para avaliar o problema de estabilidade de velocidade, como para avaliar o problema de violação de limites de tensão, são em geral capazes de realizar boas estimativas dos tempos críticos de abertura. Os estudos elaborados nesta tese sobre a avaliação da estabilidade de aerogeradores via método direto, contribuem com aplicações inéditas que podem ser utilizadas nas análises de segurança em tempo real de sistemas elétricos de potência que contemplem fontes alternativas e seus limites operacionais.

Palavras-chave: Aerogerador. Estabilidade de velocidade. Fonte alternativa. Função energia. Limite operacional. LVRT. Método direto. PEBS. 


\section{Abstract}

A. P. Sohn. Stability assessment of wind turbines via direct method. $138 \mathrm{f}$. Tese de doutorado, Universidade de São Paulo, São Carlos, 2019.

This thesis gives a step forward in the direction of reviewing the problem of transient stability and the theory of PEBS method to include models of renewable power plants and their operational limits. The formulation of direct methods with constraint is accomplished by exploring the theory of constrained dynamic systems and the concept of constrained stability region. In particular, the speed stability of the main wind turbine configurations equipped with an induction generator is analyzed, considering the low voltage ride-through requirement, or LVRT curve, as a constraint to the model. An augmented auxiliary dynamical system is developed to represent the time-dependent LVRT constraint as an equivalent time invariant constraint written in terms of an auxiliary state variable. This auxiliary system has its unconstrained stability region equals to the constrained stability region of the constrained dynamic system. The models are described in the form of algebraic and differential equations. The problem of speed stability and the problem of disconnection of wind turbines due to voltage limits violation are investigated via analysis of stability region of the post-fault equilibrium point and critical clearing times obtained for several perturbations. The results show that: i) for different operational limits and for different parameters of the induction machine, the stability regions for a given operating point can be significantly different, ii) in most cases, the violation of the LVRT curve occurs before the speed instability, which reveals the importance of include operational limits in transient stability analysis and in the formulation of direct methods and iii) in most cases, the developed energy functions to evaluate the problem of speed stability and the problem of voltage limits violation, are generally capable of making good estimates of critical clearing times. The developed studies about the transient stability assessment of different models of wind turbines via direct method contribute with applications that can be used in real-time security assessments of power systems that contemplate renewable power plants and their operational limits.

Keywords: Direct method. Energy function. LVRT. Operational limit. PEBS. Renewable power plant. Speed stability. Wind turbine. 


\section{Lista de figuras}

1.1 Classificação do problema de estabilidade. Adaptado de: (Kundur et al., 2004). 3

1.2 Trajetórias em falta e pós-falta na região de estabilidade $A\left(x_{s}\right) \ldots \ldots \ldots$

1.3 Estimativa da região de estabilidade $A\left(x_{s}\right) \ldots \ldots \ldots \ldots$

1.4 Capacidade global de geração de eletricidade por tipo de energia. Adaptado de: $($ IEA, 2016) . . . . . . . . . . . . . . . . . . . . . . . . . . . . 9

1.5 Trajetórias em falta e pós-falta na região de estabilidade $A\left(x_{s}\right)$ e na região de estabilidade restrita $A_{r}\left(x_{s}\right) \ldots \ldots \ldots \ldots \ldots$

2.1 Capacidade instalada global das plantas eólicas. Fonte: (GWEC, 2017). . . . . 17

2.2 Projeções da capacidade instalada global das plantas eólicas. Adaptado de: (GWEC, 2016) . . . . . . . . . . . . . . . . . . . . . . . . 18

2.3 Classificação típica para diferentes tecnologias de aerogeradores. . . . . . . 19

2.4 Configuração típica de aerogeradores do tipo A . . . . . . . . . . . . . . . 20

2.5 Configuração típica de aerogeradores do tipo B. . . . . . . . . . . . . . . . 21

2.6 Configuração típica de aerogeradores do tipo C . . . . . . . . . . . . . . 22

2.7 Configuração típica de aerogeradores do tipo D. . . . . . . . . . . . . . 23

2.8 Representação do PCC para um parque eólico. . . . . . . . . . . . . . . . . 27

2.9 Curvas limite de tensão inferior (LVRT) e superior (HVRT) para o PCC. . . . . 30

2.10 Curva LVRT e diferentes trajetórias da tensão no PCC . . . . . . . . . . . . 31

2.11 Curva LVRT definida por $($ E.ON, 2006). . . . . . . . . . . . . . . . 35

2.12 Curva LVRT definida por (Energinet, 2016) . . . . . . . . . . . . . 36

2.13 Curva LVRT definida por (EirGrid, 2015) . . . . . . . . . . . . . . 37

2.14 Curva LVRT definida por (NERSA, 2016) . . . . . . . . . . . . . . . 38

2.15 Curva LVRT definida por (REE, 2004) . . . . . . . . . . . . . . . . 39

2.16 Curva LVRT definida por (Tenaga, 2016). . . . . . . . . . . . . . . 39

2.17 Curva LVRT definida por (Hydro-Québec, 2009) . . . . . . . . . . . . . . . 40

2.18 Curva LVRT definida por (National Grid, 2018) . . . . . . . . . . . . . . . 41

2.19 Curva LVRT definida por (ONS, 2016) . . . . . . . . . . . . . . . . 41

2.20 Curva LVRT definida por $($ FERC, 2005) . . . . . . . . . . . . . . . . . 42

3.1 Sistema teste. . . . . . . . . . . . . . . . . . . . . . . . . . . . . . 43

3.2 Circuito equivalente da linha de transmissão. . . . . . . . . . . . . . . . . . . . 44 
3.3 Circuito equivalente do transformador . . . . . . . . . . . . . . 45

3.4 Injeção líquida de corrente em uma barra genérica. . . . . . . . . . . . . . 45

3.5 Transformação entre sistemas de coordenadas. . . . . . . . . . . . . . . . . 49

3.6 Representação dos eixos real, imaginário, em quadradura e direto. . . . . . . 69

3.7 Alinhamento entre eixos real e em quadratura e eixos imaginário e direto. . . 69

3.8 Configuração DFIG. . . . . . . . . . . . . . . . . . . . . . 77

3.9 Potência mecânica $\times$ frequência do rotor . . . . . . . . . . . 80

3.10 Curvas $P_{m}$ e erro absoluto. . . . . . . . . . . . . . . . . 81

3.11 Representação dos eixos real, imaginário, em quadradura e direto e ângulos utilizados para os controles. . . . . . . . . . . . . . . . . . . . . . . 82

3.12 RSC: controlador da potência $P_{g} \ldots \ldots \ldots \ldots \ldots \ldots$

3.13 RSC: controlador da potência $Q_{g} \ldots \ldots \ldots \ldots \ldots \ldots$

3.14 GSC: controlador da tensão $u_{D C} \ldots \ldots \ldots \ldots$. . . . . . . . . . . . 85

3.15 GSC: controlador da corrente $i_{d c}^{u} \ldots \ldots \ldots \ldots \ldots . \ldots \ldots$

3.16 Alinhamento entre eixos real e em quadratura e eixos imaginário e direto. . . 88

3.17 Circuito por fase da máquina de indução. . . . . . . . . . . . . . . . 98

3.18 Equivalente visto dos terminais $A-A^{\prime} \ldots \ldots \ldots$

3.19 Equivalente visto dos terminais B-B' . . . . . . . . . . . . . . . . . 100

4.1 Trajetórias em falta e pós-falta na região de estabilidade $A\left(x_{s}\right) \ldots \ldots$. . . . . 112

4.2 Trajetórias em falta e pós-falta na região de estabilidade $A\left(x_{s}\right)$ e na região de estabilidade restrita $A_{r}\left(x_{s}\right)$. Nesta representação conceitual, o ponto em que a restrição é violada $\left(x_{r}\right.$, em que $\Delta=0$ ) coincide com o ponto de saída da RER.113

4.3 Pseudo-equilíbrios. . . . . . . . . . . . . . . . . . . . . . . . . . . . . . . . 114

4.4 Regiões de estabilidade $A\left(x_{s}\right)$ e $A_{r}\left(x_{s}\right)$ e diferentes trajetórias. . . . . . . . . 115

4.5 Região de estabilidade $A\left(x_{s}\right)$ e energia potencial. A energia é avaliada ao longo da trajetória em falta sustentada.

4.6 Região de estabilidade $A\left(x_{s}\right)$ e função $V$, calculada ao longo da trajetória em falta sustentada, para um sistema não sujeito a um requisito operacional. . . 119

4.7 Regiões de estabilidade $A\left(x_{s}\right)$ e $A_{r}\left(x_{s}\right)$ e função $V_{r}$, calculada ao longo da trajetória em falta sustentada, para um sistema sujeito a um requisito operacional.120

4.8 Curvas LVRT real e LVRT aproximada para cada país. . . . . . . . . . . . . 121

4.9 Dimensões das regiões de estabilidade. . . . . . . . . . . . . . . . . . . 123

5.1 Tensão da barra infinita. . . . . . . . . . . . . . . . . . . . . . . . . . . . . 129

5.2 Tensão e potência ativa do estator. A tensão da barra infinita é alterada em $t_{0}=1 \mathrm{~s}$ de $u_{x 1}=1$ pu para $u_{x 1}=0,75$ pu, retornando a $u_{x 1}=1$ pu em $t_{a b}$ $=1,9 \mathrm{~s}$. 
5.3 Torques eletromagnético e mecânico e escorregamento. A tensão da barra infinita é alterada em $t_{0}=1 \mathrm{~s}$ de $u_{x 1}=1$ pu para $u_{x 1}=0,75 \mathrm{pu}$, retornando a $u_{x 1}=1$ pu em $t_{a b}=1,9 \mathrm{~s}$.

5.4 Potências reativas do estator e do capacitor. A tensão da barra infinita é alterada em $t_{0}=1 \mathrm{~s}$ de $u_{x 1}=1$ pu para $u_{x 1}=0,75 \mathrm{pu}$, retornando a $u_{x 1}=$ $1 \mathrm{pu}$ em $t_{a b}=1,9 \mathrm{~s}$.

5.5 Potência reativa total e no PCC. A tensão da barra infinita é alterada em $t_{0}$ $=1 \mathrm{~s}$ de $u_{x 1}=1$ pu para $u_{x 1}=0,75$ pu, retornando a $u_{x 1}=1 \mathrm{pu}$ em $t_{a b}=$ $1,9 \mathrm{~s}$.

5.6 Tensão no PCC. A tensão da barra infinita é alterada em $t_{0}=1 \mathrm{~s}$ de $u_{x 1}=$ 1 pu para $u_{x 1}=0,75 \mathrm{pu}$, retornando a $u_{x 1}=1 \mathrm{pu}$ em $t_{a b}=1,9 \mathrm{~s} . \ldots 133$

5.7 Curva torque $\times$ escorregamento.

5.8 Escorregamento e torques eletromagnético e mecânico. A tensão da barra infinita é alterada em $t_{0}=1 \mathrm{~s}$ de $u_{x 1}=1$ pu para $u_{x 1}=0,75 \mathrm{pu}$, retornando a $u_{x 1}=1$ pu em $t_{a b}=1,9 \mathrm{~s}$.

5.9 Torques eletromagnético e mecânico em função do escorregamento para a configuração SCIG.

5.10 Torques eletromagnético e mecânico em função do escorregamento para a configuração WRIG considerando diferentes resistências para o rotor.

5.11 Tensão do estator e potências ativas do estator, do GSC e total. A tensão da barra infinita é alterada em $t_{0}=1 \mathrm{~s}$ de $u_{x 1}=1$ pu para $u_{x 1}=0,75 \mathrm{pu}$, retornando a $u_{x 1}=1$ pu em $t_{a b}=1,9 \mathrm{~s}$.

5.12 Torques eletromagnético e mecânico e escorregamento. A tensão da barra infinita é alterada em $t_{0}=1 \mathrm{~s}$ de $u_{x 1}=1$ pu para $u_{x 1}=0,75 \mathrm{pu}$, retornando a $u_{x 1}=1 \mathrm{pu} \mathrm{em} t_{a b}=1,9 \mathrm{~s}$.

5.13 Potências reativas do estator, do GSC, total e no PCC. A tensão da barra infinita é alterada em $t_{0}=1 \mathrm{~s}$ de $u_{x 1}=1$ pu para $u_{x 1}=0,75 \mathrm{pu}$, retornando a $u_{x 1}=1$ pu em $t_{a b}=1,9 \mathrm{~s}$.

5.14 Potências ativas e correntes do RSC e do GSC. A tensão da barra infinita é alterada em $t_{0}=1 \mathrm{~s}$ de $u_{x 1}=1$ pu para $u_{x 1}=0,75 \mathrm{pu}$, retornando a $u_{x 1}=$ $1 \mathrm{pu} \mathrm{em} t_{a b}=1,9 \mathrm{~s}$.

5.15 Tensão no PCC. A tensão da barra infinita é alterada em $t_{0}=1 \mathrm{~s}$ de $u_{x 1}=$ 1 pu para $u_{x 1}=0,75 \mathrm{pu}$, retornando a $u_{x 1}=1 \mathrm{pu}$ em $t_{a b}=1,9 \mathrm{~s}$.

5.16 Regiões de estabilidade para a configuração SCIG considerando a curva LVRT do Brasil.

5.17 Trajetórias referentes ao ponto a. $\mathrm{O}$ torque mecânico é alterado em $t_{0}=1 \mathrm{~s}$ de $T_{m}=0,7$ pu para $T_{m}=1,6 \mathrm{pu}$, retornando a $T_{m}=0,7 \mathrm{pu}$ em $t_{a b}=1,6 \mathrm{~s}$. 142

5.18 Trajetórias referentes ao ponto b. O torque mecânico é alterado em $t_{0}=1 \mathrm{~s}$ de $T_{m}=0,7$ pu para $T_{m}=1,6$ pu, retornando a $T_{m}=0,7$ pu em $t_{a b}=2,2 \mathrm{~s}$. 143 
5.19 Trajetórias referentes ao ponto c. O torque mecânico é alterado em $t_{0}=1 \mathrm{~s}$ de $T_{m}=0,7$ pu para $T_{m}=1,6 \mathrm{pu}$, retornando a $T_{m}=0,7$ pu em $t_{a b}=2,5 \mathrm{~s}$. 143

5.20 Trajetórias referentes ao ponto $\mathrm{d}$. O torque mecânico é alterado em $t_{0}=1 \mathrm{~s}$ de $T_{m}=0,7$ pu para $T_{m}=2,5 \mathrm{pu}$, retornando a $T_{m}=0,7 \mathrm{pu}$ em $t_{a b}=1,6 \mathrm{~s}$. 144

5.21 Trajetórias referentes aos pontos e, f. O torque mecânico é alterado em $t_{0}=$ $1 \mathrm{~s}$ de $T_{m}=0,7$ pu para $T_{m}=1,8 \mathrm{pu}$, retornando a $T_{m}=0,7$ pu em $t_{a b}=$ $1,6571 \mathrm{~s}$.

5.22 Trajetórias referentes ao ponto g. O torque mecânico é alterado em $t_{0}=1 \mathrm{~s}$ de $T_{m}=0,7$ pu para $T_{m}=1,8$ pu, retornando a $T_{m}=0,7 \mathrm{pu}$ em $t_{a b}=1,8 \mathrm{~s}$. 145

5.23 Trajetórias referentes aos pontos h, i. . . . . . . . . . . . . . . 146

5.24 Trajetórias referentes ao ponto j. . . . . . . . . . . . . . . . 146

5.25 Regiões de estabilidade para a configuração SCIG considerando a curva LVRT dos EUA.

5.26 Trajetórias referentes ao ponto b. A susceptância da linha de transmissão é alterada em $t_{0}=1 \mathrm{~s}$ de $B_{12}=-10$ pu para $B_{12}=-1,75 \mathrm{pu}$, retornando a $B_{12}$ $=-10 \mathrm{pu}$ em $t_{a b}=3,9 \mathrm{~s}$.

5.27 Trajetórias em falta e pós-falta. A susceptância da linha de transmissão é alterada em $t_{0}=1 \mathrm{~s}$ de $B_{12}=-10$ pu para $B_{12}=-1,75 \mathrm{pu}$, retornando a $B_{12}$ $=-10$ pu em $t_{a b}=3 \mathrm{~s}$.

5.28 Regiões de estabilidade para a configuração SCIG considerando diferentes constantes de inércia.

5.29 Regiões de estabilidade para a configuração WRIG considerando diferentes resistências do rotor e a curva LVRT do Brasil.

5.30 Regiões de estabilidade para a configuração WRIG considerando diferentes resistências do rotor e a curva LVRT dos EUA.

5.31 Regiões de estabilidade para a configuração WRIG considerando $u_{q r}=0$ e diferentes tensões $u_{d r}$ e a curva LVRT do Brasil. .

5.32 Regiões de estabilidade para a configuração WRIG considerando $u_{q r}=0$ e diferentes tensões $u_{d r}$ e a curva LVRT dos EUA.

5.33 Funções energia e curva LVRT, tensão no PCC e escorregamento para a configuração SCIG modelada em primeira ordem nos eixos $d$ e $q$. A susceptância da linha de transmissão é alterada em $t_{0}=1 \mathrm{~s}$ de $B_{12}=-10$ pu para $B_{12}=$ $-0,8 \mathrm{pu}$, retornando a $B_{12}=-10 \mathrm{pu}$ em $t_{a b}=2,7 \mathrm{~s}$.

5.34 Trajetórias em falta e pós-falta. A susceptância da linha de transmissão é alterada em $t_{0}=1 \mathrm{~s}$ de $B_{12}=-10$ pu para $B_{12}=-0,8 \mathrm{pu}$, retornando a $B_{12}$ $=-10 \mathrm{pu} \mathrm{em} t_{a b}=2,7 \mathrm{~s}$.

5.35 Trajetórias em falta e pós-falta. A susceptância da linha de transmissão é alterada em $t_{0}=1 \mathrm{~s}$ de $B_{12}=-10$ pu para $B_{12}=-0,8 \mathrm{pu}$, retornando a $B_{12}$ $=-10 \mathrm{pu}$ em $t_{a b}=1,552 \mathrm{~s}$. 
5.36 Funções energia e curva LVRT, tensão no PCC e escorregamento para a configuração SCIG modelada em quinta ordem nos eixos $d$ e $q$. A susceptância da linha de transmissão é alterada em $t_{0}=1 \mathrm{~s}$ de $B_{12}=-10$ pu para $B_{12}=$ $-0,8 \mathrm{pu}$, retornando a $B_{12}=-10 \mathrm{pu}$ em $t_{a b}=2,7 \mathrm{~s}$.

5.37 Curva LVRT, tensão no PCC e escorregamento para a configuração SCIG modelada em terceira ordem nos eixos $d$ e $q$ considerando diferentes tempos de abertura.

5.38 Funções energia e curva LVRT, tensão no PCC e escorregamento para a configuração WRIG modelada em primeira ordem nos eixos $d$ e $q$ considerando $r_{r} \cdot 1$. A susceptância da linha de transmissão é alterada em $t_{0}=1 \mathrm{~s}$ de $B_{12}$ $=-10$ pu para $B_{12}=-0,8 \mathrm{pu}$, retornando a $B_{12}=-10 \mathrm{pu}$ em $t_{a b}=1,5 \mathrm{~s} .$.

5.39 Funções energia e curva LVRT, tensão no PCC e escorregamento para a configuração WRIG modelada em primeira ordem nos eixos $d$ e $q$ considerando $r_{r} \cdot 3$. A susceptância da linha de transmissão é alterada em $t_{0}=1 \mathrm{~s}$ de $B_{12}$ $=-10$ pu para $B_{12}=-0,8 \mathrm{pu}$, retornando a $B_{12}=-10 \mathrm{pu}$ em $t_{a b}=2,3 \mathrm{~s}$.

5.40 Velocidade do rotor atingindo $1,4 \mathrm{pu}(s=-0,4 \mathrm{pu})$ para a configuração DFIG com a máquina modelada em terceira ordem nos eixos $d$ e $q$. A tensão da barra infinita é alterada em $t_{0}=1 \mathrm{~s}$ de $u_{x 1}=1$ pu para $u_{x 1}=0,75 \mathrm{pu}$, retornando a $u_{x 1}=1$ pu em $t_{a b}=2.764 \mathrm{~s}$.

5.41 Funções energia e curva LVRT, tensão no PCC e escorregamento para a configuração DFIG com a máquina modelada em terceira ordem nos eixos $d$ e $q$. A tensão da barra infinita é alterada em $t_{0}=1 \mathrm{~s}$ de $u_{x 1}=1$ pu para $u_{x 1}=$ $0,75 \mathrm{pu}$, retornando a $u_{x 1}=1 \mathrm{pu}$ em $t_{a b}=2 \mathrm{~s}$.

D.1 Reta tangente para o ponto $\left(x^{0}, f\left(x^{0}\right)\right) \ldots \ldots \ldots \ldots$. . . . . . . . . . 201

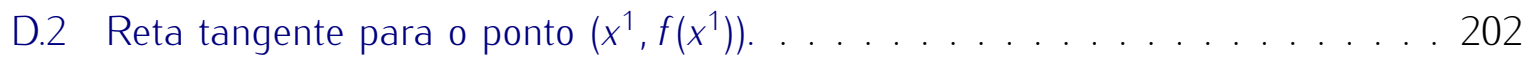

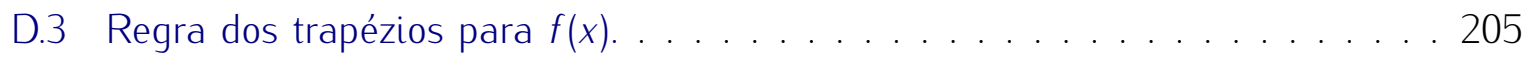

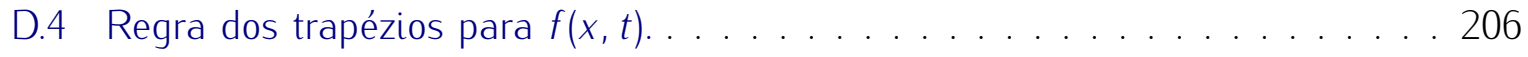

D.17 Resposta a partir dos métodos de Newton-Raphson e integração trapezoidal. 219

D.18 Resposta a partir das funções fsolve e ode15i. . . . . . . . . . . . . . . . 219

F.1 Fluxos magnéticos do estator para as configurações SCIG e WRIG. . . . . . 225

F.2 Fluxos magnéticos do rotor para as configurações SCIG e WRIG. . . . . . . . 225

F.3 Tensões internas para as configurações SCIG e WRIG . . . . . . . . . . . 226

F.4 Correntes do estator para as configurações SCIG e WRIG. . . . . . . . . . 226

F.5 Correntes do rotor para as configurações SCIG e WRIG. . . . . . . . . . 226

F.6 Fluxos magnéticos do estator e do rotor para a configuração DFIG. . . . . . . 227

F.7 Tensões internas e tensão do link DC para a configuração DFIG. . . . . . . . . 227

F.8 Tensões de eixos direto e em quadratura para a configuração DFIG. . . . . . . 227

F.9 Correntes de eixos direto e em quadratura para a configuração DFIG. . . . . . 228 
F.10 Tensões aplicadas ao rotor e correntes do rotor para a configuração DFIG. . . 228

F.11 Sinais dos controladores do RSC para a configuração DFIG. . . . . . . . . 228

F.12 Sinais dos controladores do GSC para a configuração DFIG. . . . . . . . . . 229

H.1 Trajetórias referentes ao ponto a. A susceptância da linha de transmissão é alterada em $t_{0}=1 \mathrm{~s}$ de $B_{12}=-10$ pu para $B_{12}=-1,75 \mathrm{pu}$, retornando a $B_{12}$ $=-10 \mathrm{pu}$ em $t_{a b}=2,5 \mathrm{~s}$.

H.2 Trajetórias referentes ao ponto c. A susceptância da linha de transmissão é alterada em $t_{0}=1 \mathrm{~s}$ de $B_{12}=-10$ pu para $B_{12}=-1,75 \mathrm{pu}$, retornando a $B_{12}$ $=-10 \mathrm{pu}$ em $t_{a b}=4 \mathrm{~s}$.

H.3 Trajetórias referentes ao ponto d. O torque mecânico e a susceptância da linha de transmissão são alterados em $t_{0}=1 \mathrm{~s}$ de $T_{m}=0,7 \mathrm{pu}$ e $B_{12}=-10 \mathrm{pu}$ para $T_{m}=1,8$ pu e $B_{12}=-1,3$ pu, retornando a $T_{m}=0,7$ pu e $B_{12}=-10 \mathrm{pu}$ em $t_{a b}=1,5 \mathrm{~s}$.

H.4 Trajetórias referentes ao ponto e, f. O torque mecânico e a susceptância da linha de transmissão são alterados em $t_{0}=1 \mathrm{~s}$ de $T_{m}=0,7$ pu e $B_{12}=-10$ pu para $T_{m}=1,5$ pu e $B_{12}=-1$ pu, retornando a $T_{m}=0,7$ pu e $B_{12}=-10$ pu em $t_{a b}=1,5032 \mathrm{~s}$.

H.5 Trajetórias referentes ao ponto g. O torque mecânico e a susceptância da linha de transmissão são alterados em $t_{0}=1 \mathrm{~s}$ de $T_{m}=0,7 \mathrm{pu}$ e $B_{12}=-10 \mathrm{pu}$ para $T_{m}=1,5$ pu e $B_{12}=-1 \mathrm{pu}$, retornando a $T_{m}=0,7$ pu e $B_{12}=-10 \mathrm{pu}$ em $t_{a b}=1,515 \mathrm{~s}$.

H.6 Trajetórias referentes ao ponto h, i. . . . . . . . . . . . . . . . 243

H.7 Trajetórias referentes ao ponto j. 


\section{Lista de tabelas}

5.1 Tempos críticos de abertura para a configuração SCIG . . . . . . . . . . . . . 155

5.2 Tempos críticos de abertura para a configuração SCIG $\left(H_{m}=0,6421\right.$ s). . . 159

5.3 Tempos críticos de abertura para a configuração WRIG. . . . . . . . . . . . . . 160

5.4 Tempos críticos de abertura para a configuração WRIG modelada em primeira ordem nos eixos $d$ e $q$ considerando diferentes resistências do rotor. . . . . . . 161

5.5 Tempos críticos de abertura para a configuração WRIG modelada em primeira ordem nos eixos $d$ e $q$ considerando diferentes tensões aplicadas ao rotor . . 163

5.6 Tempos críticos de abertura para a configuração DFIG. . . . . . . . . . . . . 164

5.7 Tempos críticos de abertura para as configurações SCIG, WRIG e DFIG mo-

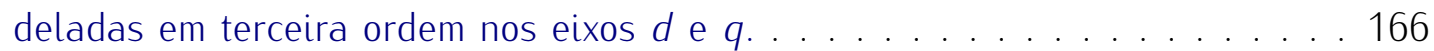

A.1 Parâmetros da rede elétrica. . . . . . . . . . . . . . . . . . . . . . . . . 193

B.1 Parâmetros do modelo SCIG . . . . . . . . . . . . . . . . . . 196

B.2 Parâmetros do modelo WRIG. . . . . . . . . . . . . . . . . . . . . . . . . 196

B.3 Parâmetros do modelo DFIG. . . . . . . . . . . . . . . . . . . . . 197

C.1 Parâmetros da curva $P_{m}$ real. . . . . . . . . . . . . . . . . . . . . . . . . . 199

C.2 Parâmetros utilizados para aproximar a curva $P_{m} \ldots \ldots$. . . . . . . . . 199

C.3 Parâmetros utilizados para aproximar a curva LVRT do Brasil. . . . . . . . . 200

C.4 Parâmetros utilizados para aproximar a curva LVRT dos EUA. . . . . . . . . . 200

E.1 Condições iniciais para a configuração SCIG modelada em regime permanente. 221

E.2 Condições iniciais para a configuração SCIG modelada nos eixos $d$ e q . . . . 221

E.3 Condições iniciais para a configuração WRIG considerando diferentes resistências do rotor . . . . . . . . . . . . . . . . . . . . . . . 221

E.4 Condições iniciais para a configuração WRIG modelada em regime permanente.222

E.5 Condições iniciais para a configuração WRIG modelada nos eixos $d$ e q. . . . 222

E.6 Condições iniciais para a configuração WRIG modelada nos eixos $d$ e $q$ com

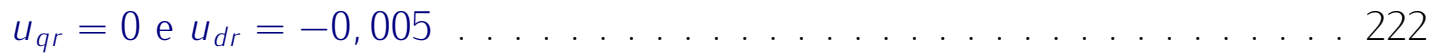

E.7 Condições iniciais para a configuração WRIG modelada nos eixos $d$ e $q$ com

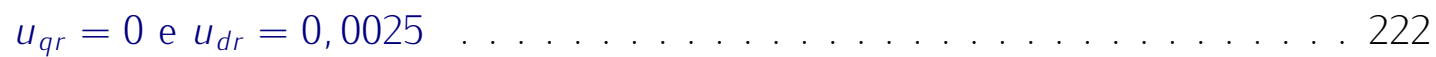

E.8 Fluxo de carga para a configuração DFIG. . . . . . . . . . . . . . . . . . 222 
E.9 Condições iniciais para a configuração DFIG. . . . . . . . . . . . . . . 223 


\section{Lista de siglas}

\begin{tabular}{|c|c|}
\hline CUEP & Controlling unstable equilibrium point \\
\hline DFIG & Doubly-fed induction generator \\
\hline DVR & Dynamic voltage restoration \\
\hline FACTS & Flexible alternating current transmission system \\
\hline $\mathrm{FCL}$ & Fault current limiter \\
\hline FERC & Federal Energy Regulatory Commission \\
\hline FSWT & Fixed speed wind turbine \\
\hline GSC & Grid side converter \\
\hline HVRT & High voltage ride-through \\
\hline LVRT & Low voltage ride-through \\
\hline MERS & Magnetic energy recovery switch \\
\hline ONS & Operador Nacional do Sistema Elétrico \\
\hline PCC & Point of common coupling \\
\hline PEBS & Potential energy boundary surface \\
\hline PMSG & Permanent magnet synchronous generator \\
\hline RE & Região de estabilidade \\
\hline RER & Região de estabilidade restrita \\
\hline $\mathrm{RSC}$ & Rotor side converter \\
\hline $\mathrm{SClG}$ & Squirrel cage induction generator \\
\hline SDBR & Series dynamic braking resistor \\
\hline SSC & Superconducting synchronous condenser \\
\hline SSSC & Static synchronous series compensator \\
\hline STATCOM & Static synchronous compensator \\
\hline SVC & Static var compensator \\
\hline TCA & Tempo crítico de abertura \\
\hline TCSC & Thyristor controlled series compensation \\
\hline TFRT & Transient fault ride-through \\
\hline UPFC & Unified power flow controller \\
\hline UPQC & Unified power quality conditioner \\
\hline VSWT & Variable speed wind turbine \\
\hline
\end{tabular}


WECS

WRIG

WRSG
Wind energy conversion system

Wound rotor induction generator

Wound rotor synchronous generator 


\section{Sumário}

Capa $\quad$ i

Folha de rosto $\quad$ iii

Ficha catalográfica $\quad$ iv

Folha de julgamento $\quad v$

Dedicatória $\quad$ vii

Agradecimentos $\quad$ ix

Epígrafe $\quad x i$

Resumo xiii

Abstract $\quad x v$

Lista de figuras $\quad$ xvii

Lista de tabelas $\quad$ xxiii

Lista de siglas $\quad$ xxv

1 Introdução 1

1.1 Estabilidade de sistemas elétricos de potência . . . . . . . . . . . . . . . . 1

1.2 Métodos diretos . . . . . . . . . . . . . . . . . . . . . . . . 5

1.3 Fontes alternativas e o problema de estabilidade . . . . . . . . . . . . 8

1.4 Estudos de estabilidade de aerogeradores . . . . . . . . . . . . . . . . 11

1.5 Justificativa . . . . . . . . . . . . . . . . . . . . . . . . . . . . . 13

1.6 Objetivo . . . . . . . . . . . . . . . . . . . . . . . . . . . . 13

1.7 Contribuições . . . . . . . . . . . . . . . . . . . . . . . . . . . . 14

1.8 Organização da tese . . . . . . . . . . . . . . . . . . . . . 15 
2 Aerogeradores 17

2.1 Introdução . . . . . . . . . . . . . . . . . . . . . . . . . . . . . . . 17

2.2 Energia eólica: quadro atual e projeções . . . . . . . . . . . . . . . . . 17

2.3 Principais configurações de aerogeradores . . . . . . . . . . . . . . . . 19

2.3.1 Aerogerador do tipo A . . . . . . . . . . . . . . . . . . . . . . . . . 19

2.3 .2 Aerogerador do tipo B . . . . . . . . . . . . . . . . . . . 20

2.3 .3 Aerogerador do tipo C . . . . . . . . . . . . . . . . . . . 21

2.3 .4 Aerogerador do tipo D . . . . . . . . . . . . . . . . . . . . 23

2.4 Estabilidade de velocidade . . . . . . . . . . . . . . . . . . . . . . . . . . 24

2.5 Requisitos de operação . . . . . . . . . . . . . . . . . . . . . . . . . 25

2.5.1 Controle da frequência . . . . . . . . . . . . . . . . . 26

2.5 .2 Controle da tensão . . . . . . . . . . . . . . . . . . . . 27

2.5.3 Suportabilidade a afundamentos e elevações de tensão . . . . . . . . . 28

2.5.3.1 Soluções para melhorar as respostas dos aerogeradores . . . 32

2.5.3.2 Suportabilidade a afundamentos de tensão para diferentes países . . . . . . . . . . . . . . . . . . . . . . . . 34

2.6 Comentários finais . . . . . . . . . . . . . . . . . . . . . . . . . . . . . . . . 42

3 Modelagem 43

3.1 Introdução . . . . . . . . . . . . . . . . . . . . . . . . . . . . . . . . . . . . . . 43

3.2 Rede elétrica . . . . . . . . . . . . . . . . . . . . . . . . . . . . 44

3.3 Máquina de indução nos eixos $d$ e $q \ldots \ldots \ldots \ldots \ldots \ldots$

3.3 .1 Equações elétricas . . . . . . . . . . . . . . . . . . . . . . . . 51

3.3 .2 Equação mecânica . . . . . . . . . . . . . . . . . . . . . . . 54

3.3 .3 Potências elétricas . . . . . . . . . . . . . . . . . . . . 56

3.3 .4 Representação fasorial. . . . . . . . . . . . . . . . . . . . . 57

3.3 .5 Representação por unidade . . . . . . . . . . . . . . . . . . 60

3.3.6 Representação em termos de tensões internas . . . . . . . . . . . . 66

3.4 Modelo completo do sistema teste com a configuração SCIG nos eixos $d$ e $q$. 69

3.4.1 Modelo completo para máquina em terceira ordem . . . . . . . . . . 71

3.4.2 Modelo completo para máquina em primeira ordem . . . . . . . . . 72

3.5 Modelo completo do sistema teste com a configuração WRIG nos eixos $d$ e $q \quad 72$

3.5.1 Modelo completo para máquina em terceira ordem . . . . . . . . . . 73

3.5.2 Modelo completo para máquina em primeira ordem . . . . . . . . . 74

3.6 Configuração DFIG . . . . . . . . . . . . . . . . . . . . . . . . . . . . . 74

3.6 .1 Máquina e conversores . . . . . . . . . . . . . . . . 76

3.6 .2 Curva $P_{m} \ldots \ldots \ldots \ldots \ldots \ldots . \ldots \ldots \ldots$

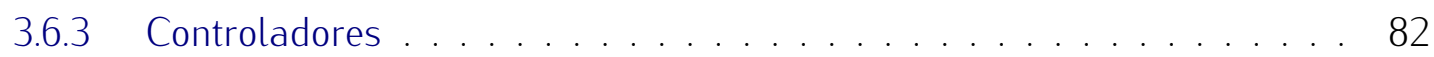

3.6.4 Processo de inicialização . . . . . . . . . . . . . . . . . . . 86 
3.6.4.1 Fluxo de carga ... . . . . . . . . . . . . 86

3.6.4.2 Inicialização da máquina . . . . . . . . . . . . . 88

3.6.4.3 Estimativa inicial . . . . . . . . . . . . . . . . . . 90

3.6.4.4 Demais variáveis . . . . . . . . . . . . . . . . . . . 92

3.7 Modelo completo do sistema teste com a configuração DFIG nos eixos $d$ e $q .93$

3.8 Máquina de indução em regime permanente . . . . . . . . . . . . . . . 97

3.9 Modelo completo do sistema teste com a configuração SCIG em regime permanente . . . . . . . . . . . . . . . . . . . . . . . . 103

3.10 Modelo completo do sistema teste com a configuração WRIG em regime permanente . . . . . . . . . . . . . . . . . . . . . . . . . 104

3.11 Comentários finais . . . . . . . . . . . . . . . . . . . . 106

4 Teoria de estabilidade e métodos diretos 109

4.1 Introdução . . . . . . . . . . . . . . . . . . . . . . . . . . . . . . . . . 109

4.2 Caracterização das regiões de estabilidade . . . . . . . . . . . . . . . . 110

4.3 Método PEBS e estimativa dos tempos críticos de abertura . . . . . . . . . 116

4.4 Limite operacional . . . . . . . . . . . . . . . . . . . . . . . . . . . . . . 120

4.5 Regiões de estabilidade . . . . . . . . . . . . . . . . . . . . . . . . 122

4.6 Funções energia . . . . . . . . . . . . . . . . . . . . . . . . . 123

4.7 Comentários finais . . . . . . . . . . . . . . . . . . . . . . . . . . . . . 125

5 Estudos de estabilidade 127

5.1 Introdução . . . . . . . . . . . . . . . . . . . . . . . . . . . . . . . . . . . . . . . 127

5.2 Comportamento dinâmico . . . . . . . . . . . . . . . . . . . . . . . . 128

5.2 .1 SCIG e WRIG . . . . . . . . . . . . . . . . . . . . . . . . . . . . . 129

5.2 .2 DFIG . . . . . . . . . . . . . . . . . . . . . . . . . . . . . . . .

5.3 Regiões de estabilidade e trajetórias . . . . . . . . . . . . . . . . . 140

5.3.1 Considerando a curva LVRT do Brasil . . . . . . . . . . . . . . . . 140

5.3.2 Considerando a curva LVRT dos EUA . . . . . . . . . . . . . . . 147

5.4 Variações das regiões de estabilidade . . . . . . . . . . . . . . . . . . . . . . . 149

5.5 Tempos críticos de abertura . . . . . . . . . . . . . . . . . . . . . 153

5.6 Comentários finais . . . . . . . . . . . . . . . . . . . . . . . . 166

6 Conclusões e trabalhos futuros 169

6.1 Conclusões . . . . . . . . . . . . . . . . . . . . . . . . . . . . . . . . . . . . 169

6.2 Trabalhos futuros . . . . . . . . . . . . . . . . . . . . . . . . . . . . 171

$\begin{array}{ll}\text { Referências bibliográficas } & 173\end{array}$

$\begin{array}{lll}\text { Apêndice A Parâmetros da rede elétrica } & 193\end{array}$ 
Apêndice D Sobre as simulações computacionais 201

D.1 Método de Newton-Raphson . . . . . . . . . . . . . . . . . . . . . . . . 201

D.2 Método de integração trapezoidal . . . . . . . . . . . . . . . . . . . . . 204

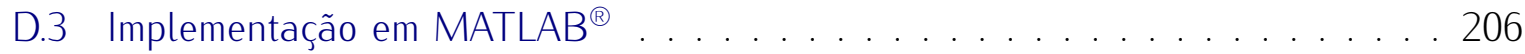

$\begin{array}{ll}\text { Apêndice E Condições iniciais } & 221\end{array}$

$\begin{array}{lll}\text { Apêndice } F \quad \text { Gráficos de simulações } & 225\end{array}$

Apêndice G Cálculo da RER e da RE do sistema auxiliar 231

$\begin{array}{lll}\text { Apêndice H Regiões de estabilidade e trajetórias } & 241\end{array}$

$\begin{array}{ll}\text { Sobre os trabalhos publicados } & 245\end{array}$ 


\section{Capítulo 1}

\section{Introdução}

\subsection{Estabilidade de sistemas elétricos de potência}

Os maiores sistemas dinâmicos construidos pela humanidade são, de acordo com Taylor (1994), os sistemas elétricos de potência. Esta afirmação torna-se evidente ao se observar a estrutura destes sistemas e os inúmeros elementos que os compõem, sendo que cada elemento apresenta um comportamento dinâmico próprio, normalmente, não linear. Geradores, transformadores, linhas de transmissão, motores, capacitores, conversores, dispositivos de proteção, reguladores e controladores são alguns exemplos destes elementos. Estes, entre muitos outros, distribuem-se pelos subsistemas de geração, transmissão e distribuição. Tais subsistemas devem operar em conjunto, formando o sistema elétrico de potência interligado.

O subsistema de geração é composto pelas unidades geradoras de energia, além das subestações elevadoras. Estas elevam a tensão gerada pelas unidades geradoras para que o transporte de energia elétrica pelas linhas de transmissão seja economicamente viável. O subsistema de transmissão é constituído principalmente pelas linhas de transmissão, que realizam o transporte de energia até o subsistema de distribuição. O subsistema de distribuição tem início nas subestações abaixadoras. Nestas, as tensões são reduzidas para a rede primária, cuja função é transportar energia elétrica até a rede secundária ou atender diretamente consumidores específicos, como grandes indústrias. Na rede secundária, as tensões da rede primária são reduzidas para as chamadas tensões de utilização (Creder, 2007).

Dada a dimensão física dos sistemas elétricos de potência modernos e visto que os mesmos estão sujeitos a inúmeras contingências, garantir o fornecimento de energia elétrica aos consumidores tornou-se uma tarefa difícil de ser executada, notadamente sob os aspectos econômico, de confiabilidade e de segurança (Fink e Carlsen, 1978). Confiabilidade de um sistema elétrico de potência refere-se à probabilidade deste em apresentar um desempenho satisfatório durante um longo período de tempo. Neste sentido, os elementos que compõem o sistema devem participar da entrega de energia aos consumidores de forma adequada e segura. Adequação refere-se à existência de instalações suficientes para satisfazer a demanda de energia pelos consumidores. As instalações resumem-se aos elementos necessários para gerar energia elétrica e aqueles indispensáveis para transportá-la. Segurança refere- 
se à capacidade do sistema em suportar as perturbações que eventualmente ocorram, sem interrupção do fornecimento de energia elétrica aos consumidores (Billinton e Allan, 1996).

As perturbações podem ser de pequena ou de grande magnitude. Perturbações de pequena magnitude são exemplificadas por pequenas oscilações provocadas por variações normais de carga. Os problemas que envolvem pequenas perturbações podem ser tratados por linearização das equações que modelam o sistema dinâmico. Perturbações de grande magnitude são exemplificadas por perdas de unidades geradoras, perdas de linhas de transmissão ou curtos-circuitos. Normalmente, estas perturbações causam elevadas oscilações na rede elétrica, alterando a sua topologia. Problemas que envolvem grandes perturbações devem ser tratados por modelos não lineares (Rogers, 2000). Um curto-circuito, por exemplo, em determinado elemento do sistema, pode provocar grandes variações nas tensões das barras, no fluxo de potência e na velocidade do rotor dos geradores. Se após a ocorrência desta grande perturbação, o sistema apresentar-se estável, significa que o mesmo foi capaz de atingir um ponto de operação em regime permanente após a ocorrência da perturbação.

No que se refere à segurança do sistema elétrico de potência, a operação deste sistema deve considerar análises estáticas e dinâmicas de segurança. As análises estáticas referemse às análises do sistema em regime permanente, no sentido de verificar se as condições necessárias ao funcionamento satisfatório dos seus elementos ainda são atendidas após a perturbação. As análises dinâmicas referem-se às análises dos transitórios elétricos e mecânicos do sistema durante e após a perturbação. A operação do sistema elétrico de potência deve considerar para as análises de segurança as seguintes condições: i) todos os seus elementos, especialmente aqueles envolvidos com a transmissão de energia elétrica, não devem estar sobrecarregados, ii) todas as tensões das barras devem estar dentro dos limites permitidos e iii) após a perturbação, o sistema deve ser estável. As primeiras condições requerem somente análises estáticas de segurança, já a última exige análises dinâmicas de segurança (Balu et al., 1992), uma vez que é necessário avaliar a estabilidade do sistema. Do ponto de vista computacional, as análises estáticas requerem a resolução do sistema de equações algébricas que modelam a rede elétrica. Para as análises dinâmicas devem ser consideradas, além destas equações, as equações algébricas e diferenciais relativas às máquinas elétricas e demais dispositivos de controle, inclusive aqueles presentes na transmissão, como o sistema de transmissão flexível em corrente alternada, do inglês flexible alternating current transmission system (FACTS) (Padiyar e Kulkarni, 2019).

A verificação da segurança dinâmica de um sistema elétrico de potência requer, portanto, a avaliação de sua estabilidade. O operador do sistema pode realizar tal avaliação tanto a priori (offline) como em tempo real (online), para uma lista de contingências consideradas críticas, isto é, aquelas que apresentam grandes chances de ocorrer ou que causariam grande impacto se porventura ocorrerem. Ao se conhecer as margens de estabilidade do sistema, ações de controle adequadas podem ser tomadas para evitar interrupções no fornecimento de energia aos consumidores. Assim, fica claro que se o problema de estabilidade for devidamente tratado 
pelo operador do sistema, contribui-se para o aumento da confiabilidade e da segurança do sistema elétrico de potência.

A estabilidade de um sistema elétrico de potência é definida como a capacidade que este apresenta, para uma dada condição inicial de operação, de readquirir um estado de equilíbrio após estar sujeito a um distúrbio físico, com a maioria de suas variáveis limitadas, de modo que praticamente todo o sistema permaneça intacto (Kundur et al., 2004). Devido à dimensão e à complexidade do problema de estabilidade de sistemas elétricos de potência, o mesmo é dividido em categorias e subcategorias. Uma classificação prática para o problema de estabilidade é exibida na Figura 1.1.

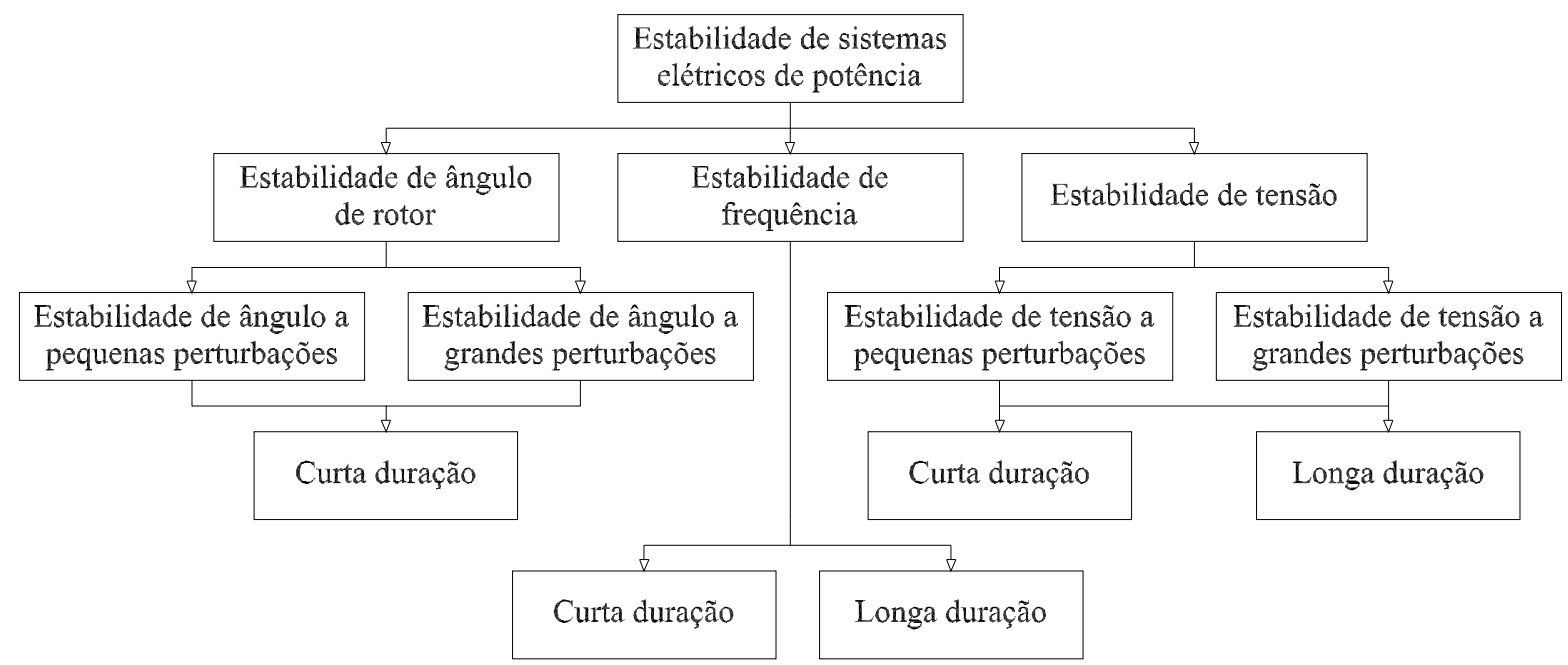

Figura 1.1: Classificação do problema de estabilidade. Adaptado de: (Kundur et al., 2004).

As categorias apresentadas na Figura 1.1, estabilidade de ângulo do rotor, estabilidade de frequência e estabilidade de tensão, assim como as subcategorias resultantes, foram concebidas após hipóteses simplificadoras, a fim de possibilitar análises específicas com determinado grau de detalhamento para modos de instabilidade de maior relevância. Para tanto, foram considerados os seguintes itens: i) a natureza física do modo de instabilidade, de acordo com a variável principal em que o fenômeno pode ser observado, ii) a magnitude da perturbação, que influencia o método de cálculo e a predição da estabilidade e iii) os dispositivos, processos e o período de tempo cujo fenômeno de instabilidade persiste. Evidentemente, separar todos os modos de instabilidade não é uma tarefa simples. Do ponto de vista prático, a engenharia de sistemas elétricos de potência se utiliza desta classificação.

A subcategoria estabilidade de ângulo a grandes perturbações, também denominada de estabilidade transitória, é tratada como um problema relacionado ao modo de instabilidade do ângulo do rotor de máquinas síncronas. Nesta subcategoria, as análises de estabilidade são realizadas em curtos intervalos de tempo. A estabilidade transitória é a capacidade que o sistema elétrico de potência apresenta de manter o sincronismo entre os geradores síncronos do sistema após a ocorrência de uma grande perturbação (Kundur, 1994). Se ao menos um gerador, ou grupo de geradores, acelera ou desacelera muito mais que outros gerado- 
res, de tal forma que as diferenças entre os ângulos e as velocidades tornem-se ilimitadas indefinidamente, o sistema é dito transitoriamente instável (Sauer e Pai, 1998).

Três intervalos de tempo são definidos para as análises de estabilidade transitória, referentes às topologias que o sistema elétrico de potência apresenta: i) pré-falta, ii) em falta e iii) pós-falta. O intervalo pré-falta corresponde ao sistema antes da ocorrência da perturbação. O intervalo em falta corresponde ao sistema durante a ocorrência da perturbação. Já o intervalo pós-falta corresponde ao sistema após a ocorrência da perturbação. Para cada intervalo de tempo, o sistema elétrico de potência é modelado por um conjunto de equações, definidos conforme

$$
\begin{aligned}
& \left(\begin{array}{c}
\text { Sistema } \\
\text { pré }-f_{\text {alta }}
\end{array}\right)\left\{\begin{array}{l}
\dot{x}=f_{\text {pré }}(x, y) \quad-\infty \leq t<t_{0}, \\
0=g_{\text {pré }}(x, y)
\end{array}\right. \\
& \left(\begin{array}{c}
\text { Sistema } \\
\text { em falta }
\end{array}\right)\left\{\begin{array}{l}
\dot{x}=f_{e m}(x, y) \\
0=g_{\text {em }}(x, y)
\end{array}\right.
\end{aligned}
$$

e

$$
\left(\begin{array}{c}
\text { Sistema } \\
\text { pós }- \text { falta }
\end{array}\right)\left\{\begin{array}{l}
\dot{x}=f_{\text {pós }}(x, y) \quad t_{a b} \leq t<+\infty . \\
0=g_{\text {pós }}(x, y)
\end{array}\right.
$$

em que $x$ é o vetor das variáveis de estado, y é o vetor das variáveis algébricas, (1.1) são as equações diferenciais do sistema pré-falta, (1.2) são as equações algébricas do sistema préfalta, (1.3) são as equações diferenciais do sistema em falta, (1.4) são as equações algébricas do sistema em falta, (1.5) são as equações diferenciais do sistema pós-falta, (1.6) são as equações algébricas do sistema pós-falta, $t_{0}$ é o instante de tempo referente ao início da perturbação e $t_{a b}$ é o instante de tempo referente ao fim da perturbação.

Para concluir sobre a estabilidade transitória pelo método clássico, resolve-se via algum método numérico o conjunto de equações algébricas e diferenciais que modelam o problema por completo, isto é, resolve-se numericamente os sistemas em falta e pós-falta. Via numerosas simulações em computador, encontra-se o tempo crítico de abertura (TCA). O conhecimento deste intervalo de tempo é importante para os relés de proteção, pois a eliminação do defeito em um tempo inferior ao registrado garante a estabilidade dos geradores no sistema pós-falta. Conhecer a margem de estabilidade do sistema elétrico de potência também é importante para evitar uma operação muito conservadora do mesmo.

Dada a dimensão física dos sistemas elétricos de potência modernos e das numerosas contingências que devem ser analisadas pelos operadores, fica claro que avaliar a estabilidade pelo método clássico é uma tarefa proibitiva do ponto de vista computacional, especialmente em tempo real. Exige-se atualmente uma estrutura computacional adequada, além de métodos 
e algoritmos eficazes para conseguir realizar as numerosas análises de contingências em sistemas elétricos de grande porte (Khaitan e Gupta, 2013). Neste sentido, métodos foram criados para que as análises de segurança dinâmica em tempo real se tornassem factíveis nos centros de operação. Tais métodos são denominados de métodos diretos, pois os mesmos avaliam uma função escalar auxiliar sobre a trajetória em falta, dispensando a resolução numérica das equações que modelam o sistema pós-falta. Assim, as análises de estabilidade transitória podem ser realizadas de forma muito rápida.

Salienta-se, portanto, que os métodos diretos são muito atrativos para avaliar a estabilidade transitória em tempo real, pois os mesmos permitem analisar mais contingências em um tempo muito inferior, comparativamente ao método clássico. A seguir, realiza-se uma breve introdução aos métodos diretos.

\subsection{Métodos diretos}

Os métodos diretos baseiam-se na teoria de estabilidade de sistemas dinâmicos criada pelo engenheiro e matemático Aleksandr Mikhailovich Lyapunov. Seu principal trabalho relacionado ao tema foi publicado pela primeira vez em russo, no ano 1892. Traduções para o francês foram publicadas nos anos 1907 e 1949. Mais tarde, no ano 1992, foi publicada uma tradução do francês para o inglês (Lyapunov, 1992). A teoria de estabilidade de Lyapunov, que se fundamenta no conceito de energia da mecânica, motivou o desenvolvimento de métodos diretos para aplicações em sistemas dinâmicos não lineares. Também conhecidos por métodos energéticos, os métodos diretos permitem concluir sobre a estabilidade de pontos de equilíbrio avaliando-se funções escalares auxiliares, chamadas de funções de Lyapunov. Não existem procedimentos sistemáticos para encontrar tais funções. No entanto, funções energia geralmente são boas tentativas para se obter funções de Lyapunov (Bretas e Alberto, 2000).

O primeiro método criado para realizar análises rápidas da estabilidade transitória de sistemas elétricos de potência refere-se ao método gráfico conhecido como critério das áreas iguais (Kimbark, 1948). Os métodos que se utilizam de funções energia foram inicialmente propostos por (Magnusson, 1947) e (Aylet, 1958). Desde então, uma série de avanços foram obtidos. Em (Grigsby, 2012), apresenta-se uma revisão da literatura referente a muitos dos principais trabalhos relacionados ao tema. Como exemplos de contribuições recentes para o desenvolvimento dos métodos diretos, podem ser citados os trabalhos elaborados por (Alberto, 2000), (Alberto, 2006), (Theodoro, 2010), (Theodoro, 2013) e (Pillco, 2015). Como os métodos diretos permitem que sejam realizadas avaliações rápidas da estabilidade do sistema elétrico de potência, os mesmos são ferramentas imprescindiveis para as análises em tempo real da segurança do sistema. Várias aplicações dos métodos diretos em sistemas elétricos de grande porte se tornaram realidade nos últimos anos (Chiang et al., 2009), (Tada et al., 2005) e (Takazawa et al., 2006).

Antes de descrever como são realizadas as análises de estabilidade transitória via método direto, faz-se necessário introduzir o conceito de região de estabilidade (RE). Os fundamentos 
dos métodos diretos são baseados não somente na teoria de funções energia, mas também na teoria de REs. Visto que os sistemas elétricos de potência são em geral modelados por sistemas de equações não lineares e sabendo que a estabilidade global nem sempre ocorre para sistemas deste tipo, conhecer a RE do ponto de equilíbrio estável de interesse se torna fundamental. Esta região pode ser entendida como o conjunto de todas as condições iniciais do sistema não linear cujas trajetórias convergem para o ponto de equilíbrio estável de interesse quando o tempo tende para o infinito (Chiang et al., 1988a). Obter a RE de um ponto de equilíbrio estável não é uma tarefa simples e sua determinação desempenha um importante papel em inúmeras áreas do conhecimento. Aplicações práticas podem ser encontradas nas áreas de sistemas elétricos de potência (Alberto et al., 2001), de biologia (Brauer e Soudack, 1979), de biomedicina (Sbarciog et al., 2010), de robótica (Kausar et al., 2011), de controle (Hu e Chen, 2007) e de redes neurais (Jessop e Campbell, 2010).

No que se refere aos sistemas elétricos de potência, o problema de estabilidade transitória pode ser interpretado matematicamente como a análise da RE do ponto de equilíbrio estável do sistema pós-falta, conforme o seguinte algoritmo conceitual:

1. Determina-se a RE do ponto de equilíbrio estável do sistema pós-falta;

2. Simula-se o sistema em falta até a sua trajetória abandonar a RE;

3. O intervalo de tempo para a trajetória do sistema em falta abandonar a RE corresponde ao TCA.

Para melhor compreender os passos do algoritmo, apresenta-se a Figura 1.2, onde $A\left(x_{s}\right)$ é a RE do ponto de equilíbrio estável do sistema pós-falta $x_{s}, \partial A\left(x_{s}\right)$ é a fronteira de $A\left(x_{s}\right)$, $x_{0}$ é o ponto de equilíbrio estável do sistema pré-falta e $x_{e}$ é o ponto pelo qual a trajetória do sistema em falta abandona $A\left(x_{s}\right)$.

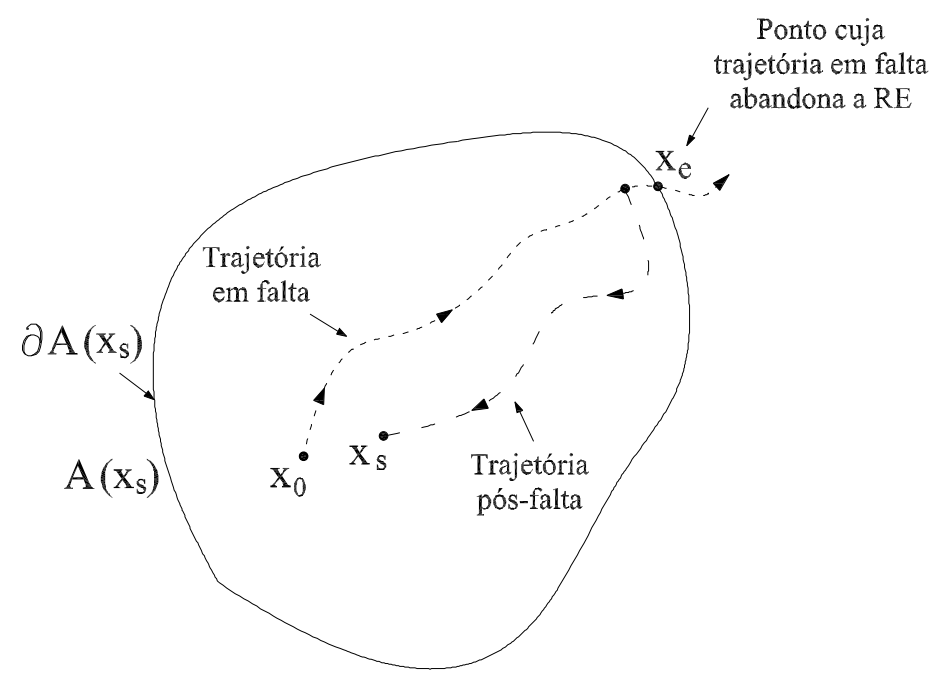

Figura 1.2: Trajetórias em falta e pós-falta na região de estabilidade $A\left(x_{S}\right)$. 
Na ocorrência de uma perturbação, o sistema passa a se afastar do ponto de operação inicial. O momento em que a trajetória em falta abandona $A\left(x_{s}\right)$ corresponde ao TCA. Se a perturbação for eliminada antes do TCA, a condição inicial do sistema pós-falta pertencerá à $A\left(x_{s}\right)$ e a trajetória pós-falta convergirá para $x_{s}$. A trajetória pós-falta que se iniciar fora de $A\left(x_{s}\right)$ poderá convergir para outro atrator ou tender ao infinito.

Verificado como o problema de estabilidade transitória pode ser estudado por meio da RE do ponto de equilíbrio estável do sistema pós-falta, introduz-se agora o algoritmo conceitual utilizado nas avaliações via método direto (Alberto et al., 2001):

1. Uma estimativa da RE do ponto de equilíbrio estável do sistema pós-falta é obtida na forma: $\Omega_{L}=\left\{x \in \mathbb{R}^{n}: V(x)<L\right\}$;

2. Avalie a função energia sobre a trajetória em falta e verifique o instante de tempo em que a função energia alcança o nível $L$;

3. O instante de tempo em que função energia alcança o nível $L$ corresponde ao TCA estimado.

Conforme descreve o algoritmo, uma função energia é avaliada sobre a trajetória em falta, no sentido de verificar o momento em que a mesma alcança o nível $L$, para então se estimar o TCA. O nível $L$ deve ser o maior possível tal que $\Omega_{L} \subset A\left(x_{S}\right)$. O máximo valor de $L$ é conhecido por energia crítica $V_{c r}$. A Figura 1.3 ilustra a RE estimada $\Omega_{L}$ e o ponto pelo qual a trajetória do sistema em falta abandona esta região, denotado por $x_{L}$. Neste ponto, a função energia assume o valor $V_{c r}$.

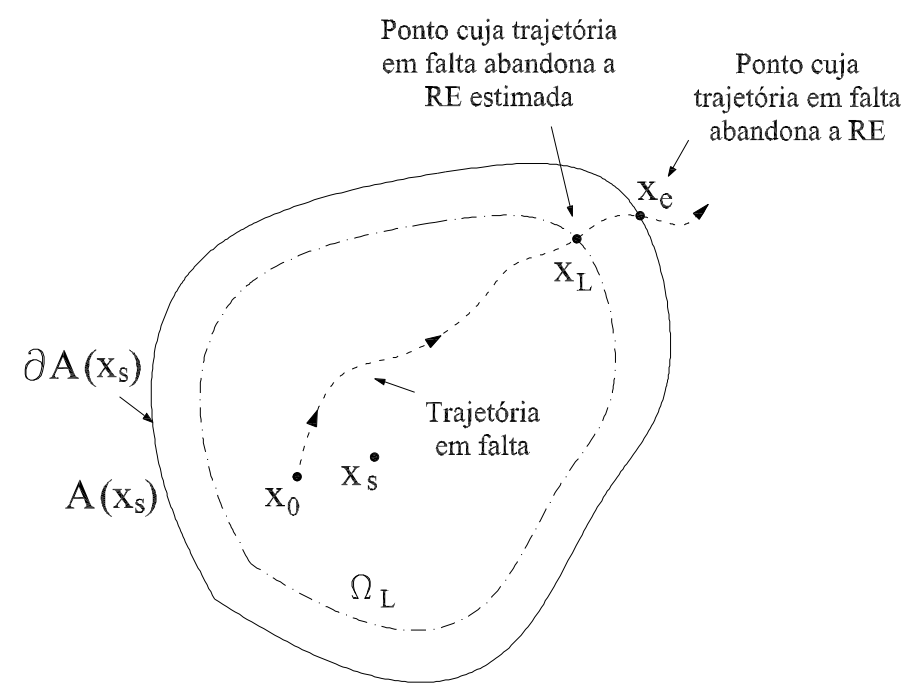

Figura 1.3: Estimativa da região de estabilidade $A\left(x_{s}\right)$.

O tempo necessário para a função energia atingir $V_{c r}$ corresponde ao TCA estimado, isto é, o tempo cuja trajetória em falta abandona $\Omega_{L}$. No exemplo, o TCA estimado é inferior ao tempo 
cuja trajetória em falta abandona $A\left(x_{s}\right)$. Obviamente, determinar $V_{c r}$ não é uma tarefa trivial, de modo que diversos métodos foram desenvolvidos para estimar tal valor. Os principais métodos criados, baseados nas teorias de Lyapunov, correspondem: i) ao ponto de equilíbrio de menor energia, ii) aos pontos de equilíbrio instáveis aproximados e modos de instabilidade, iii) ao critério de aceleração, iv) ao método potential energy boundary surface (PEBS) e v) ao método controlling unstable equilibrium point (CUEP). Estes métodos são devidamente descritos em (Kakimoto et al., 1978), (Chiang et al., 1985), (Chiang et al., 1988b), (Chiang et al., 1995), (Bretas e Alberto, 2000), (Nazareno, 2003), (Chiang, 2011) e (Chiang e Alberto, 2015).

Nesta tese será explorado o método PEBS, originalmente proposto por (Kakimoto et al., 1978), a ser discutido no capítulo 4. Neste método, o primeiro máximo da componente energia potencial da função energia do sistema pós-falta calculada ao longo da trajetória em falta corresponderá à $V_{c r}$. Desta forma, quando a função energia atingir $V_{c r}$, estima-se o ponto pelo qual a trajetória em falta abandona a RE estimada. Imediatamente, obtém-se o TCA estimado, avaliando-se a função energia somente sobre a trajetória do sistema em falta.

Sabendo que o problema de estabilidade transitória e que os métodos diretos associados foram definidos considerando o modo de instabilidade do ângulo do rotor de máquinas síncronas e que diante da crescente introdução de fontes alternativas nos sistemas elétricos de potência, novos modos de instabilidade podem estar presentes, deve-se investigar os novos problemas decorrentes. A seguir são apresentadas informações relevantes sobre as principais fontes alternativas introduzidas nos sistemas elétricos de potência e a influência destas no problema de estabilidade a grandes perturbações.

\subsection{Fontes alternativas e o problema de estabilidade}

De acordo com Twidell e Weir (2015), energia renovável é aquela obtida de fluxos persistentes e naturalmente repetitivos que ocorrem em determinado ambiente. A energia eólica, que é a energia cinética contida nas massas de ar em movimento (ventos, que são fluxos de ar), é um tipo de energia renovável. Em contrapartida, energia não renovável é aquela obtida de reservas estáticas armazenadas no subsolo. Materiais nucleares, carvão, óleo e gás natural são alguns dos recursos não renováveis, que através da interação humana, podem fornecer energia para fins práticos.

Políticas energéticas são implantadas para acompanhar a crescente demanda por energia elétrica. Neste sentido, projeções são elaboradas a fim de estimar diferentes cenários da matriz energética global. Tais projeções consideram, por exemplo, os aspectos econômicos de cada país, as políticas de desenvolvimento adotadas e as características de cada mercado de energia. Estudos mostram que a participação das energias renováveis para a produção de eletricidade tende a crescer, cujas energias eólica e solar fotovoltaica contribuirão significativamente para tal crescimento (REN21, 2017).

Na Figura 1.4 pode ser observada uma projeção sobre a capacidade global de geração de eletricidade por tipo de energia. Para um dos cenários globais propostos em (IEA, 2016), 
a utilização das energias não renováveis para a produção de eletricidade será reduzida de 69\% no ano 2015 para 54\% no ano 2040, em decorrência da crescente utilização das energias renováveis. A projeção otimista para as energias renováveis é liderada pela energia eólica, a ser utilizada principalmente em grandes parques eólicos onshore. Em seguida vem a energia solar fotovoltaica, a ser utilizada em pequenas ou grandes instalações. As energias renováveis terão uma representatividade de $46 \%$ no ano 2040, sendo metade correspondente às energias eólica e solar, formas de energia inerentemente variáveis.

2015

$6393 \mathrm{GW}$

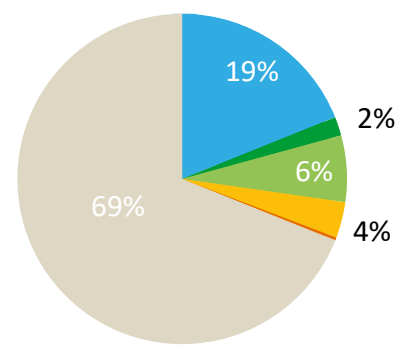

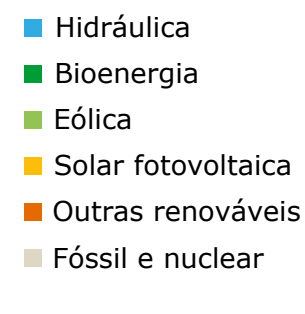

2040

$11170 \mathrm{GW}$

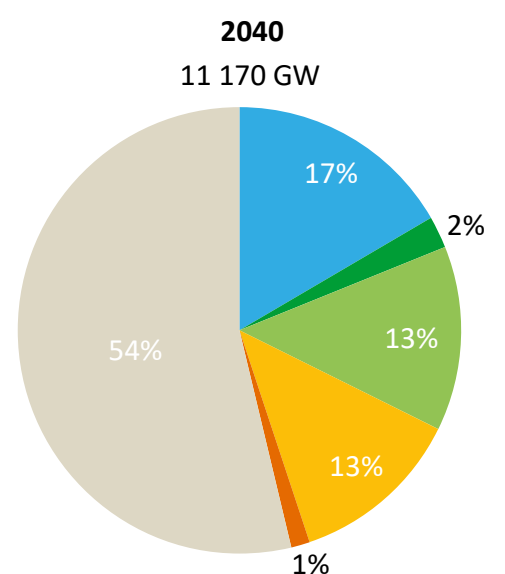

Figura 1.4: Capacidade global de geração de eletricidade por tipo de energia. Adaptado de: (IEA , 2016).

As diferentes formas de energia são utilizadas para diversas finalidades. Neste sentido, a ciência e a engenharia tratam de desenvolver dispositivos capazes de conduzir os mais variados processos de conversão. A energia elétrica destaca-se entre as formas finais de energia mais importantes para o desenvolvimento global. A sua produção tem origem nos sistemas de geração, capazes de converter a energia primária, renovável ou não, através de diferentes tecnologias. As fontes alternativas de energia elétrica são os sistemas de geração baseados nas energias renováveis e que se apresentam como alternativa à utilização das fontes tradicionais que compõem a matriz energética do país. Normalmente, as fontes alternativas mais adotadas correspondem aos aerogeradores, aos geradores fotovoltaicos e aos sistemas que se utilizam da biomassa. Já as fontes tradicionais são aquelas baseadas nos recursos não renováveis e na energia hidráulica.

O modelo tradicional de geração é bem conhecido: a energia elétrica é produzida por grandes e centralizadas plantas de energia, a exemplo das usinas hidrelétricas e termelétricas, cujos geradores são usualmente síncronos. Por muito tempo, os sistemas elétricos de potência foram operados seguindo o modelo tradicional. Diante da presença já considerável das fontes alternativas nos sistemas elétricos de potência e das projeções energéticas citadas, fica evidente que o modo de operar a rede elétrica deve ser atualizado (Morison et al., 2004).

As fontes alternativas podem apresentar inúmeras configurações, diferentemente das fontes tradicionais. No que se refere aos aerogeradores, por exemplo, os mesmos podem ser equipados com geradores de indução, cujo modo de instabilidade é notoriamente diferente 
daquele associado aos geradores síncronos. Especificamente, avalia-se neste caso a estabilidade de velocidade (Samuelsson e Lindahl, 2005). Ainda, tais fontes são muito mais sensíveis à violação de limites operacionais, sejam estes intrínsecos ao sistema de geração ou impostos pelo operador do sistema. Tais limites podem ser exemplificados por valores máximos de corrente ou mínimos de tensão (Akhmatov, 2003), (Mullane et al., 2005), (Mohseni e Islam, 2012). Neste sentido, o problema de estabilidade de sistemas elétricos de potência deve incluir, além do problema de estabilidade de velocidade, o problema de violação de limites operacionais. Uma vez os aerogeradores violando tais limites, os mesmos podem ser desconectados da rede, tornando o sistema elétrico de potência vulnerável.

No que se refere às fontes tradicionais, as análises de estabilidade transitória verificam o momento no qual a trajetória em falta abandona $A\left(x_{s}\right)$. Tipicamente, não são considerados limites operacionais nas análises de estabilidade transitória (Chiang et al., 1995), (Chiang et al. , 2009), (Chiang, 2011), (Chiang e Alberto, 2015). Entretanto, para os sistemas elétricos de potência na presença de fontes alternativas, tais limites devem ser considerados, pois a trajetória em falta pode abandonar $A\left(x_{s}\right)$ após já ter violado algum destes limites, conforme mostra a Figura 1.5. Esta situação pode ser observada nos resultados obtidos nesta tese.

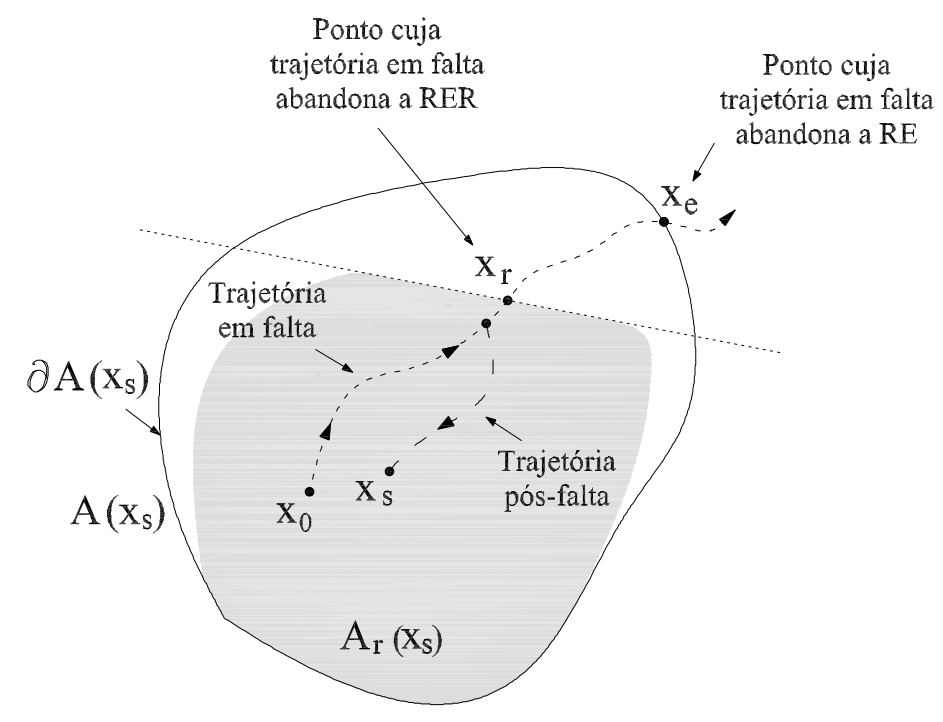

Figura 1.5: Trajetórias em falta e pós-falta na região de estabilidade $A\left(x_{S}\right)$ e na região de estabilidade restrita $A_{r}\left(x_{s}\right)$.

Para o sistema irrestrito, isto é, aquele que desconsidera quaisquer limites operacionais, tem-se a já conhecida região $A\left(x_{s}\right)$. Considerando um limite operacional, tem-se agora um sistema dinâmico restrito que apresenta para o ponto de equilíbrio estável do sistema pósfalta uma região de estabilidade restrita $(\mathrm{RER})$, representada por $A_{r}\left(x_{s}\right)$. Como pode ser observado na Figura 1.5, a região $A_{r}\left(x_{s}\right)$ está contida na região $A\left(x_{s}\right)$. Verifica-se também que o TCA do sistema restrito é inferior ao TCA do sistema irrestrito. Para que não se permita que a fonte alternativa seja desconectada da rede elétrica, o sistema de proteção da rede deverá atuar em um tempo inferior ao TCA relativo à violação do limite operacional. Para o 
exemplo da Figura 1.5, este TCA coincide com o tempo em que a trajetória em falta abandona $A_{r}\left(x_{s}\right)$. Eliminando a perturbação em um tempo inferior a este TCA, a trajetória em falta não viola o limite operacional e a condição inicial do sistema pós-falta permanece dentro de $A_{r}\left(x_{s}\right)$, conforme mostra a Figura 1.5. No caso dos aerogeradores equipados com gerador de indução, ao se desconsiderar o limite operacional, preocupa-se apenas com o TCA relativo à estabilidade de velocidade. Naturalmente, este TCA corresponde ao tempo cuja trajetória em falta abandona $A\left(x_{s}\right)$. Diferentes trajetórias em falta e pós-falta serão detalhadas mais adiante, especificamente nos capítulos 4 e 5 .

Neste trabalho, a avaliação da estabilidade transitória de sistemas elétricos de potência via método direto é revista, a fim de se considerar fontes alternativas e limites operacionais. Neste contexto, os modelos de sistemas elétricos de potência na presença de fontes alternativas são interpretados como sistemas dinâmicos restritos, cuja restrição está associada ao limite operacional da fonte alternativa. As análises de estabilidade para tais sistemas são embasadas na teoria de sistemas dinâmicos não lineares com restrições de desigualdade, desenvolvida por (Praprost e Loparo, 1996). Particularmente nesta tese, avalia-se a estabilidade de aerogeradores equipados com gerador de indução, cujo limite operacional escolhido corresponde ao requisito de suportabilidade a afundamentos de tensão, do inglês low voltage ride-through (LVRT), que exige do aerogerador ou do parque eólico, operação ininterrupta mesmo em níveis baixos de tensão (Howlader e Senjyu, 2016), (ONS, 2016). Naturalmente, são considerados neste caso os problemas de estabilidade de velocidade e de violação de limites de tensão. O método PEBS é utilizado para estimar o TCA relativo ao problema de estabilidade de velocidade. Para incluir o limite operacional nas análises de estabilidade, uma extensão do método PEBS é desenvolvida para estimar o TCA relativo ao problema de violação de limites de tensão. Funções energia numéricas para avaliar tais problemas são propostas. A extensão do método PEBS é obtida a partir da teoria de sistemas dinâmicos restritos e do conceito de RER. A seguir, são relacionados alguns trabalhos sobre o estudo de estabilidade de aerogeradores em sistemas elétricos de potência.

\subsection{Estudos de estabilidade de aerogeradores}

Em (Slootweg, 2003) estuda-se a estabilidade de diferentes sistemas teste, incluindo o sistema elétrico de potência holandês, cuja presença de aerogeradores é significativa. Neste trabalho são desenvolvidos modelos de diferentes tipos de aerogeradores para simulações computacionais. As análises de estabilidade são realizadas para grandes e pequenas perturbações. No que se refere às grandes perturbações, constata-se dentre as várias conclusões obtidas, que os aerogeradores de velocidade fixa são mais susceptíveis à instabilidade de velocidade. Em contrapartida, os aerogeradores de velocidade variável são menos susceptíveis, pois são capazes de recuperar a tensão de forma muito satisfatória. No entanto, tais aerogeradores tendem a ser rapidamente desconectados da rede para proteger os conversores, uma vez que estes são muito sensíveis a sobrecorrentes. 
Em (Akhmatov, 2003) estuda-se a estabilidade de tensão de sistemas elétricos de potência na presença de grandes parques eólicos. Neste trabalho são realizadas simulações computacionais sobre as principais configurações de aerogeradores existentes. Verifica-se, dentre as inúmeras conclusões obtidas, que o sistema elétrico de potência deve estar preparado para repor grandes níveis de potência, uma vez que os parques eólicos estão susceptíveis a eventuais desconexões da rede. Fica claro que afundamentos de tensão podem provocar a perda de grandes blocos de potência. Em uma situação deste tipo, é natural que ocorram variações nas tensões e na frequência da rede. Uma vez os parques eólicos sendo capazes de oferecer boas respostas frente aos requisitos de operação, mantendo a sua operação ininterrupta, contribui-se significativamente para que as variáveis do sistema permaneçam em níveis adequados, como observado também em (Margaris et al., 2011).

Na literatura podem ser encontrados muitos trabalhos cujos problemas de estabilidade de sistemas elétricos de potência são resolvidos por simulações computacionais. Diferentemente desta abordagem, métodos analíticos permitem avaliar a estabilidade sem recorrer à complexa resolução numérica dos modelos em computador. Em (Pavani, 2008) são desenvolvidas metodologias analíticas para verificar o comportamento de geradores de indução em gaiola de esquilo. Dentre os métodos analíticos elaborados, aquele que se refere à análise de estabilidade a grandes perturbações permite por exemplo, determinar o TCA para um dado ponto de operação (Grilo et al., 2007). Neste contexto, em (Salles, 2009) e (Grilo et al., 2015) são apresentados métodos analíticos para avaliações da estabilidade de geradores de indução duplamente alimentados. Os resultados obtidos pelos métodos analíticos são comparados com aqueles provenientes de programas dedicados a análises de sistemas elétricos de potência, de modo a validar os métodos desenvolvidos pela precisão dos resultados.

Sobre o uso de métodos diretos na avaliação da estabilidade de aerogeradores submetidos a limites operacionais, não foram encontrados trabalhos na literatura. Desconsiderando quaisquer limites operacionais, em (Ishigame e Taniguchi, 2003) se constrói uma função de Lyapunov analítica para estimar os TCAs de um sistema simples, porém tal função baseia-se em um modelo simplificado do motor de indução. Em (Yong e Lei, 2007) se estabelece uma função energia para um sistema teste também na presença de um motor de indução, cujos resultados não mostram estimativas de TCAs. Em (Schegner e La Seta, 2004) se obtém uma função de Lyapunov para o modelo em regime permanente do gerador de indução. Porém na obtenção desta função, são admitidas hipóteses que comprometem a verdadeira relação entre as variáveis do modelo. Em (Chowdhury et al., 2013) se avalia a estabilidade de geradores de indução em gaiola de esquilo e geradores de indução duplamente alimentados através de um índice baseado em uma função energia. Tal índice permite comparar os sistemas de geração citados para diferentes tempos de abertura e constantes de inércia, por exemplo. Em (Almeida, 2010) se obtém uma função energia numérica capaz de estimar os TCAs de um sistema teste na presença de um motor de indução. Baseada na equação do movimento da máquina, tal função energia mostra-se capaz de realizar estimativas muito boas dos TCAs. 
Considerando limites operacionais, em (Mishra et al., 2017) se constrói uma função de Lyapunov aproximada baseada na técnica de soma dos quadrados, de modo a estimar a RER de um sistema fotovoltaico conectado em uma rede simples, considerando o requisito de suportabilidade a afundamentos de tensão como limite operacional. Como resultado apresenta-se uma RER muito conservadora, visto que tal limite foi aproximado por uma constante. O sistema fotovoltaico não é modelado em detalhes e não são obtidas trajetórias das variáveis de estado, tampouco estimativas de TCAs.

\subsection{Justificativa}

Os fundamentos referentes ao problema de estabilidade transitória e em particular aos métodos diretos, foram desenvolvidos sob a suposição de que o modo de instabilidade de interesse é aquele associado à perda de sincronismo (estabilidade de ângulo) entre os geradores síncronos do sistema elétrico de potência. Do ponto de vista matemático, a perda de sincronismo está relacionada à trajetória em falta que abandona a RE do ponto de equilíbrio estável do sistema pós-falta. Tipicamente, a trajetória em falta abandona esta região antes de violar quaisquer limites operacionais.

Diante da crescente introdução de fontes alternativas no sistema elétrico de potência, diferentes sistemas de geração passaram a compô-lo e naturalmente novos problemas devem ser analisados. Por exemplo, aerogeradores são frequentemente desconectados da rede elétrica devido à aceleração do rotor (estabilidade de velocidade) ou devido à violação de limites de tensão. Particularmente, os aerogeradores ficam sujeitos à desconexão quando o requisito de suportabilidade a afundamentos de tensão (curva LVRT) é violado.

Para outros tipos de fontes alternativas, a desconexão da unidade geradora também é muitas vezes desencadeada pela violação de algum limite operacional. Normalmente, se qualquer limite operacional é violado durante ou após a perturbação, o gerador estará sujeito à desconexão. Neste cenário, tais limites são violados antes da trajetória em falta abandonar a RE do ponto de equilíbrio estável do sistema pós-falta e, consequentemente, as violações destes limites não são detectadas pelos métodos diretos.

Assim, é importante considerar limites operacionais nas análises de estabilidade transitória de sistemas elétricos de potência que empreguem fontes alternativas. Em particular, é imperativo considerar limites operacionais na formulação dos métodos diretos, especialmente quando o sistema elétrico de potência apresenta uma grande penetração de fontes alternativas. Visto o destaque assumido pelos aerogeradores nos últimos anos e suas projeções otimistas dentre as fontes alternativas, o problema de estabilidade de velocidade e o problema de violação de limites de tensão foram escolhidos para estudo nesta tese.

\subsection{Objetivo}

O objetivo desta tese é dar um passo na direção de revisar o problema de estabilidade transitória e a teoria dos métodos diretos para incluir em seus fundamentos modelos de fontes 
alternativas e seus limites operacionais. Explorando a teoria de sistemas dinâmicos restritos e o conceito de RER, objetiva-se estender o método PEBS para que avaliações rápidas da estabilidade de sistemas elétricos de potência, na presença de fontes alternativas e limites operacionais, se tornem viáveis. Neste contexto, particularmente, são estudados os problemas de estabilidade de velocidade e de violação de limites de tensão, estes definidos pela curva LVRT, considerando os principais tipos de aerogeradores equipados com gerador de indução.

\subsection{Contribuições}

Esta tese contribui com o desenvolvimento de métodos diretos para análises de estabilidade de sistemas elétricos de potência na presença de grandes penetrações de fontes alternativas e limites operacionais. Neste contexto, as contribuições específicas desta tese consistem em:

1. Modelar um sistema teste simples com as configurações mais comuns de aerogeradores equipados com gerador de indução (aerogeradores dos tipos $A, B$ e C), na forma de sistemas de equações algébricas e diferenciais. A modelagem do sistema por equações algébricas e diferenciais torna-se necessária para realizar os estudos desta tese, especialmente, para obter as REs e para implementar o método PEBS;

2. Utilizar a teoria de sistemas dinâmicos restritos, que caracteriza matematicamente a RER e a restrição de um sistema físico, para estudar a RER por meio de um sistema auxiliar de equações. A RE do sistema auxiliar de equações mostra-se irrestrita e igual à RER do sistema dinâmico restrito;

3. Formular a restrição de suportabilidade a afundamentos de tensão de modo que o sistema de equações sob análise permaneça autônomo, uma vez que esta condição é requerida pela teoria dos métodos diretos. Considerar para a restrição do problema diferentes curvas de suportabilidade a afundamentos de tensão (curvas adotadas pelo Brasil e EUA). Verificar a influência de cada curva nas análises de estabilidade;

4. Desenvolver funções energia capazes de realizar boas estimativas do TCA relativo ao problema de estabilidade de velocidade e do TCA relativo ao problema de violação dos limites de tensão, utilizando os conceitos do método PEBS;

5. Estudar o problema de estabilidade de velocidade e o problema de violação de limites de tensão: i) verificando trajetórias em falta e pós-falta no domínio do tempo e no espaço de estados e ii) comparando os TCAs estimados via método direto aos TCAs calculados via método clássico.

A principal contribuição desta tese consiste em conceituar a utilização do método direto em avaliações de estabilidade de sistemas elétricos de potência sujeitos a limites operacionais. Particularmente, esta tese contribui de forma inédita para que o problema de estabilidade de 
velocidade e o problema de violação de limites de tensão sejam avaliados via método direto. Os estudos elaborados fornecem técnicas que podem ser usadas nos centros de operação para realizar análises dinâmicas de segurança em tempo real de sistemas elétricos de potência na presença de fontes alternativas e seus limites operacionais.

\subsection{Organização da tese}

Além desta introdução, os seguintes capítulos compõem esta tese de doutorado:

- Capítulo 2 - Aerogeradores

O capítulo 2 cita dados globais e nacionais sobre a capacidade instalada de empreendimentos eólicos, descreve as principais configurações de aerogeradores existentes, explica a estabilidade de velocidade e apresenta requisitos de operação, com ênfase dada ao requisito de suportabilidade a afundamentos de tensão.

- Capítulo 3 - Modelagem

O capítulo 3 apresenta a modelagem do sistema teste. Especificamente: i) modela-se a rede elétrica e ii) modelam-se as configurações mais comuns de aerogeradores equipadas com gerador de indução. Neste contexto, obtêm-se modelos completos formados por equações algébricas e diferenciais, utilizados para obter as condições iniciais para um ponto de operação, verificar o comportamento dinâmico de diversas variáveis no tempo, caracterizar a RE e a RER, além de obter os TCAs via métodos clássico e direto.

- Capítulo 4 - Teoria de estabilidade e métodos diretos

O capítulo 4 apresenta de maneira sucinta as teorias referentes à RE, à RER e ao método PEBS, de modo a explicar como o problema de pesquisa desta tese é abordado. No que se refere à aplicação, descreve a representação do limite operacional, especifica os sistemas de equações utilizados para caracterizar a RE e a RER e estabelece as funções energia utilizadas para estimar os TCAs. Por fim, descreve o procedimento para estimar os TCAs.

- Capítulo 5 - Estudos de estabilidade

O capítulo 5 apresenta e discute os resultados obtidos via simulações computacionais. Basicamente: i) investiga-se o comportamento dinâmicos dos aerogeradores, verificando se ocorre ou não instabilidade de velocidade e violação de limites de tensão, ii) verifica-se como as trajetórias em falta e pós-falta se comportam no domínio do tempo e no espaço de estados para várias perturbações, iii) investiga-se como a RE e a RER é caracterizada com diferentes parâmetros e curvas de suportabilidade a afundamentos de tensão e iv) comparam-se os TCAs estimados pelo método direto aos TCAs obtidos pelo método clássico.

- Capítulo 6 - Conclusões e trabalhos futuros

O capítulo 6 resume as conclusões desta tese e sugere trabalhos futuros. 


\section{Capítulo 2}

\section{Aerogeradores}

\subsection{Introdução}

Neste capítulo são citados alguns dados globais e nacionais sobre a geração de energia elétrica por aerogeradores. São apresentadas as principais configurações de aerogeradores existentes. A estabilidade de velocidade é definida e os mecanismos de instabilidade sucintamente explicados. Requisitos de operação são brevemente descritos, com especial atenção dada ao requisito de suportabilidade a afundamentos de tensão.

\subsection{Energia eólica: quadro atual e projeções}

A presença de parques eólicos no mundo para a produção de eletricidade tem aumentado significativamente nos últimos anos. No que se refere à capacidade instalada global acumulada, até o fim do ano 2017 alcançou-se a marca de aproximadamente 539 GW, conforme mostra a Figura 2.1. Como pode ser observado, entre os anos 2001 e 2017 a capacidade instalada global cresceu cerca de 515 GW.

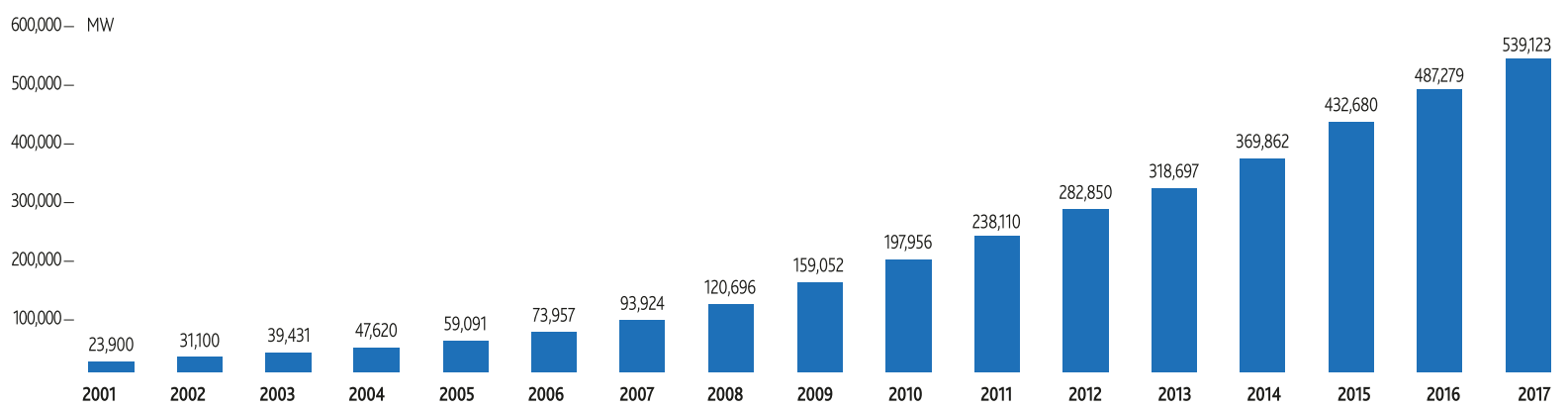

Figura 2.1: Capacidade instalada global das plantas eólicas. Fonte: (GWEC, 2017).

Estudos indicam que a utilização da energia eólica para a produção de energia elétrica será cada vez maior nos próximos anos. A energia eólica assume o protagonismo em vários cenários, cujas projeções indicam uma introdução significativa de aerogeradores nos sistemas elétricos de potência (REN21, 2017), (IEA, 2016), (GWEC, 2016). Os estudos elaborados consideram as políticas adotadas por muitos países para incentivarem o desenvolvimento tecnológico e o atendimento ao crescimento da demanda. Além das medidas de apoio em curso, as projeções fundamentam-se também na contínua redução dos custos de produção da 
energia elétrica pelos aerogeradores. A Figura 2.2 indica projeções da capacidade instalada global acumulada das plantas eólicas até o ano 2050.

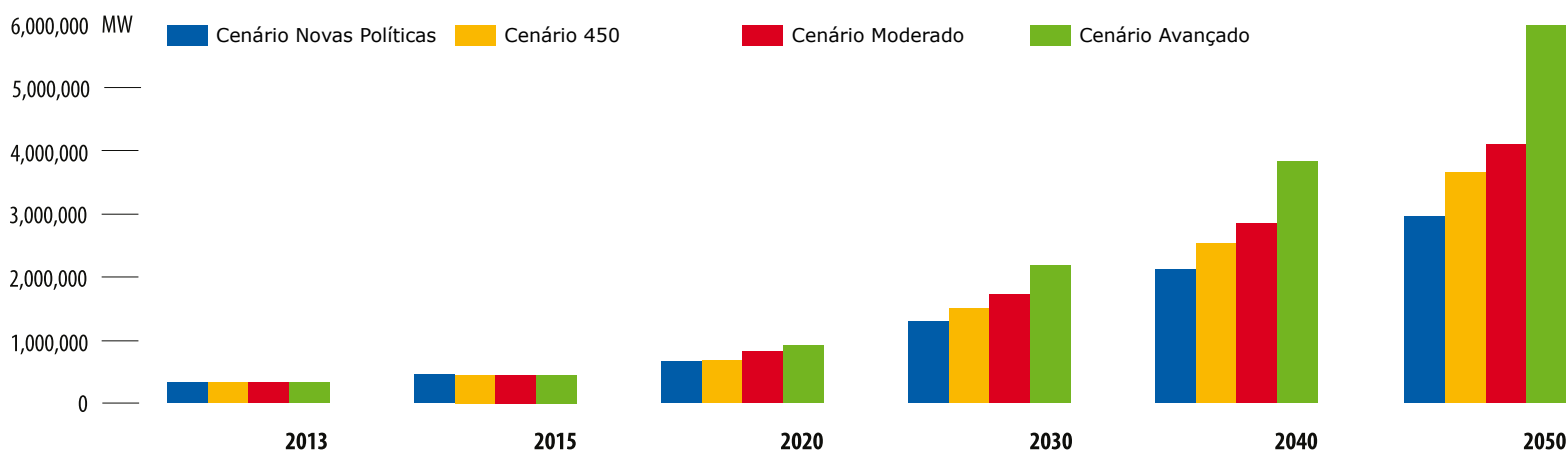

Figura 2.2: Projeções da capacidade instalada global das plantas eólicas. Adaptado de: (GWEC , 2016).

Como pode ser observado, para todas as projeções considera-se que a capacidade instalada global aumentará nos próximos anos. A projeção mais pessimista refere-se ao Cenário Novas Políticas, que indica para o ano 2050 uma potência aproximada de 2870 GW. Já o Cenário Avançado faz a projeção mais otimista, indicando cerca de 5805 GW de potência para o mesmo ano (GWEC, 2016).

No que se refere ao Brasil, o país dispõe um total de 614 empreendimentos eólicos em operação, totalizando aproximadamente $15 \mathrm{CW}$ de potência fiscalizada, o que representa $9,2 \%$ do total da potência instalada no país. Este valor confere às instalações eólicas a terceira posição na produção de energia elétrica, atrás somente das usinas hidrelétricas e termelétricas. Ainda, o país apresenta 51 centrais de geração eólica em construção e mais 160 empreendimentos cuja construção ainda não foi iniciada, totalizando aproximadamente 0,9 GW e 4,5 GW de potência outorgada, respectivamente (ANEEL, 2019).

É nítido o progresso das fontes alternativas, especialmente dos aerogeradores. Uma vez constatado o rápido crescimento e as projeções otimistas para os próximos anos, é natural que inúmeros desafios acompanhem esta evolução. Neste sentido, as pesquisas relacionadas à energia eólica devem considerar inúmeros aspectos para atender a demanda por tais sistemas de geração, como aqueles associados ao projeto e à fabricação das turbinas eólicas, ao desenvolvimento dos parques eólicos e à operação destas plantas (Willis et al., 2018). No que se refere a este último item, cita-se como exemplo o problema associado à variabilidade da energia eólica, que introduz incertezas na geração de eletricidade. Sistemas de armazenamento de energia são soluções aplicáveis para mitigar este problema, demandando portanto pesquisas neste contexto. Não menos importante, permitindo-se que um parque eólico seja desconectado por violação de limites operacionais, o sistema elétrico de potência pode se tornar inseguro. Para evitar esta situação, os aerogeradores devem ser capazes de oferecer boas respostas frente a perturbações que ocorram na rede. Considerando o potencial que a energia eólica apresenta, é certo que as pesquisas futuras deverão contemplar ao menos os aspectos mencionados. 


\subsection{Principais configurações de aerogeradores}

Os aerogeradores, também denominados de sistemas de conversão de energia eólica, do inglês wind energy conversion systems (WECSs), podem ser classificados segundo a velocidade de operação (Ibrahim, 2015), conforme exibe a Figura 2.3. Aerogeradores de velocidade fixa, do inglês fixed speed wind turbines (FSWTs), compreendem os aerogeradores equipados com gerador de indução em gaiola de esquilo, do inglês squirrel cage induction generator $(\mathrm{SCIG})$. Estes aerogeradores caracterizam-se pela velocidade praticamente fixa do rotor do gerador.

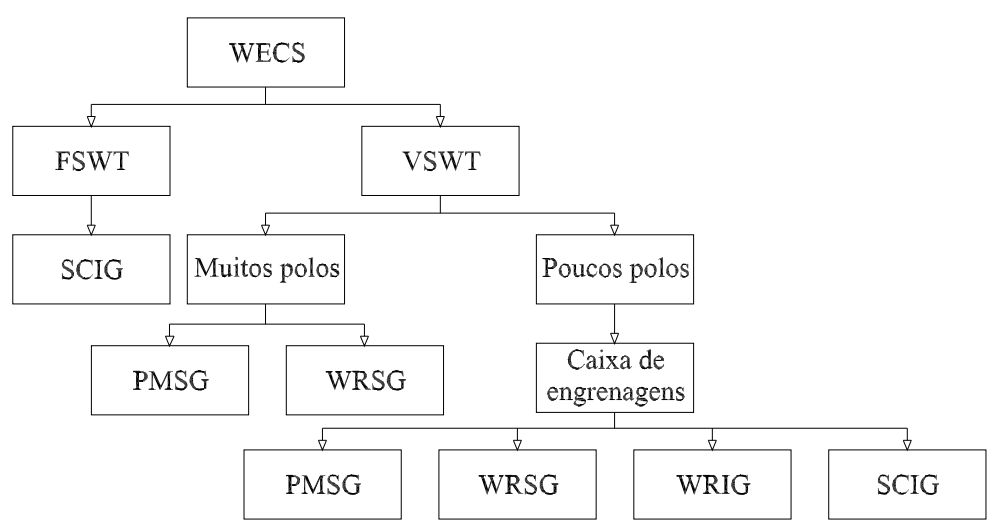

Figura 2.3: Classificação típica para diferentes tecnologias de aerogeradores.

Aerogeradores de velocidade variável, do inglês variable speed wind turbines (VSWTs), compreendem os aerogeradores equipados com variações do gerador de indução e do gerador síncrono. Para estes aerogeradores, a velocidade do rotor do gerador deixa de ser praticamente fixa, estendendo-se para diferentes faixas de velocidades, conforme a tecnologia empregada (Wu et al., 2011). Se o gerador síncrono apresentar muitos polos, dispensa-se o uso da caixa de engrenagens. Neste caso, podem ser empregados o gerador síncrono a ímã permanente, do inglês permanent magnet synchronous generator (PMSG) e o gerador síncrono com rotor bobinado, do inglês wound rotor synchronous generator (WRSG). Caso o gerador apresente poucos polos, necessita-se de uma caixa de engrenagens. Neste caso, podem ser empregados o gerador de indução com rotor bobinado, do inglês wound rotor induction generator (WRIG) e os já citados PMSG, WRSG e SCIG (Ackermann, 2012).

Os aerogeradores de velocidade fixa e de velocidade variável podem ainda ser classificados segundo configurações típicas, mais comumente encontradas nas instalações de parques eólicos existentes. Estas configurações seguem uma evolução histórica, conforme o desenvolvimento tecnológico e correspondem a quatro tipos principais (Mahela e Shaik, 2016), (Li e Chen, 2008), (Camm et al., 2009), brevemente apresentados a seguir.

\subsubsection{Aerogerador do tipo A}

O aerogerador do tipo A foi o primeiro conceito de aerogerador amplamente utilizado em parques eólicos. Sua configuração é exibida na Figura 2.4 . 


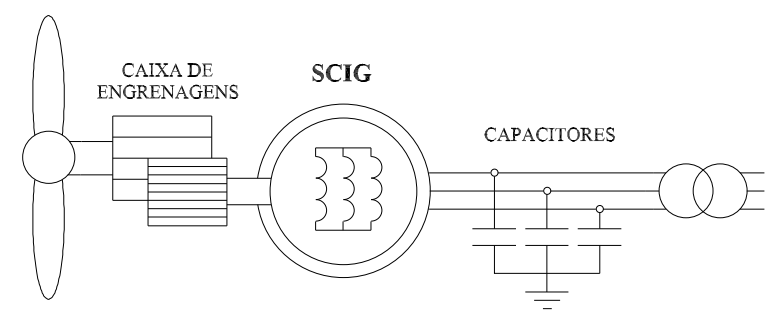

Figura 2.4: Configuração típica de aerogeradores do tipo A.

Nesta configuração, emprega-se o SCIG. Uma caixa de engrenagens é utilizada para relacionar as baixas velocidades da turbina com as altas velocidades do gerador. Capacitores são utilizados para a compensação de potência reativa. Na prática, um banco de capacitores é utilizado, chaveado conforme as condições de operação do aerogerador. Para limitar a corrente de magnetização, emprega-se um soft-starter. Este é capaz de ajustar a tensão no estator do gerador através do disparo controlado de tiristores. Após a sua breve atuação, o mesmo é separado do circuito para evitar perdas elétricas. A conexão do estator do gerador à rede elétrica é então realizada via um transformador.

A velocidade de operação do gerador é definida pela caixa de engrenagens, pelo número de polos do gerador e pela frequência da rede elétrica. Para diferentes velocidades dos ventos, a velocidade do gerador varia dentro de $2 \%$ de sua velocidade nominal. Visto a faixa de velocidades de operação ser muito pequena, a extração da energia disponível nos ventos torna-se pouco eficaz, pois nem sempre é possível ajustar as diferentes velocidades dos ventos ao coeficiente de potência ótimo da turbina. Como a conexão à rede elétrica é realizada de forma direta, efeitos de oscilações de tensão na rede elétrica e efeitos de flutuações dos ventos são transmitidos imediatamente ao aerogerador, podendo causar danos elétricos e mecânicos, além de prejudicar a qualidade da energia gerada (Ackermann, 2012).

A regulação dos fluxos de potência ativa e de potência reativa é muito debilitada. Três formas de controle da potência extraída do vento e da consequente potência ativa de saída podem ser aplicadas: o controle estol, o controle de passo e o controle estol ativo. No que se refere à potência reativa, o controle da tensão não é eficaz para esta configuração. Ainda assim, esta configuração mostra-se confiável, proporciona pouca manutenção, apresenta baixo custo em relação às demais configurações e encontra-se presente em muitos parques eólicos, principalmente na Europa (Moghadasi et al., 2016).

\subsubsection{Aerogerador do tipo B}

O aerogerador do tipo B foi o segundo conceito de aerogerador desenvolvido, considerado o primeiro de velocidade variável. Sua configuração é exibida na Figura 2.5. O mesmo também é classificado como um aerogerador de velocidade variável limitada (Ackermann, 2012), uma vez que não é possível aumentar consideravelmente a faixa de velocidades de operação do rotor do gerador. 


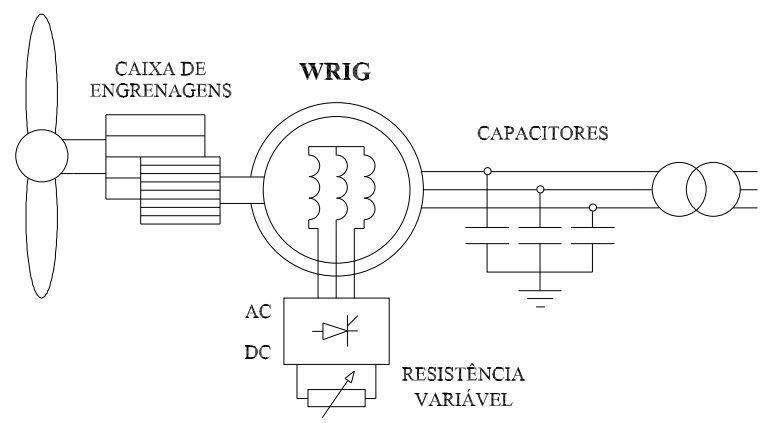

Figura 2.5: Configuração típica de aerogeradores do tipo B.

Para esta configuração utiliza-se o WRIG com resistência externa variável conectada em série com o rotor. Uma faixa de velocidades maior é obtida para o gerador, podendo chegar a 16\% acima da velocidade síncrona, dependendo da tecnologia aplicada para variar a resistência externa (Ackermann, 2012). Esta varia conforme a atuação de um circuito eletrônico, normalmente um circuito DC Chopper com frequência de trabalho variável, de modo que a relação torque-escorregamento seja então aprimorada. Uma vez que se consegue ampliar a faixa de velocidades de operação do gerador, naturalmente torna-se possível capturar mais energia dos ventos, assim como diminuir os esforços mecânicos e eventuais flutuações.

Necessita-se também de compensação de potência reativa para esta configuração. O controle dos fluxos de potência ativa e de potência reativa ainda é limitado, assim como o controle da tensão. Ainda que perdas elétricas ocorram na resistência externa, é possível produzir mais potência ativa, devido à capacidade de extrair mais energia dos ventos. Para controlar esta energia, normalmente utiliza-se o controle de passo (Bolik, 2004).

As demais características são semelhantes àquelas da configuração do tipo A, salvo os custos e a manutenção, que podem ser maiores, conforme a tecnologia aplicada para variar a resistência externa. Dentre os aerogeradores de velocidade variável, trata-se da configuração mais simples, confiável e barata, comparativamente às soluções mais complexas, a serem apresentadas a seguir.

\subsubsection{Aerogerador do tipo C}

O aerogerador do tipo C está entre os mais utilizadas nos parques eólicos (Vittal e Ayyanar , 2013). Empregam-se neste caso conversores eletrônicos de potência em escala parcial, dimensionados para aproximadamente $30 \%$ da potência nominal do gerador. O estator do WRIG é conectado diretamente à rede elétrica, enquanto que o rotor é conectado via conversores, proporcionando uma conexão mais suave com a rede. Sua configuração é exibida na Figura 2.6 e recebe o nome de gerador de indução duplamente alimentado, do inglês doubly-fed induction generator (DFIG) (Abad et al., 2011).

Os conversores correspondem ao conversor do lado do rotor, do inglês rotor-side converter (RSC) e ao conversor do lado da rede, do inglês grid-side converter (GSC), conectados na topologia back-to-back via um link DC, que permite o fluxo bidirecional. Os conversores 


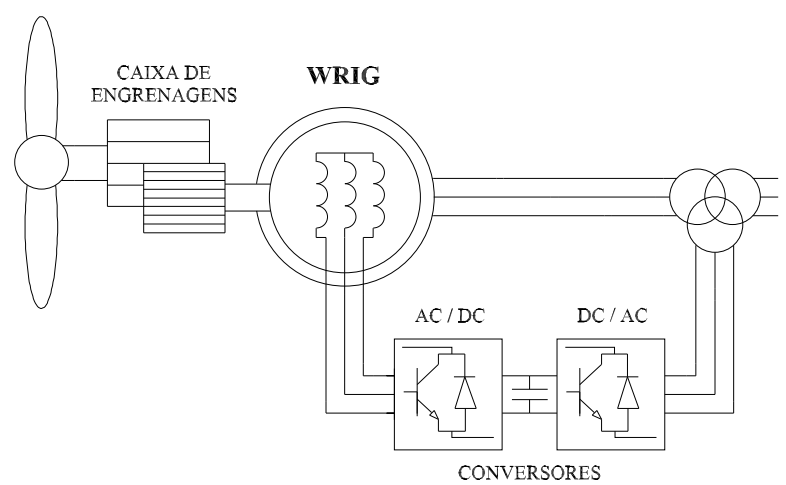

Figura 2.6: Configuração típica de aerogeradores do tipo $C$.

podem ser controlados independentemente um do outro (Pardalos et al., 2013), assim como as potências ativa e reativa de saída (Engelhardt et al., 2011). Através do controle da magnitude e da direção do fluxo de potência ativa no circuito do rotor, uma faixa de velocidades maior pode ser obtida em relação às configurações anteriores, em torno de 40\% abaixo e 30\% acima da velocidade síncrona. O estator sempre fornece potência à rede. Para velocidades superiores à síncrona, potência é inserida na rede elétrica pelo rotor através dos conversores. Para velocidades inferiores à síncrona, potência é absorvida ao invés de ser inserida. Para a velocidade síncrona, o escorregamento é nulo e não ocorre fluxo de potência no circuito do rotor (Bolik, 2004), (Anaya-Lara et al., 2009). A ampla faixa de velocidades permite maximizar a extração da energia contida nos ventos e produzir mais energia elétrica (Patel, 2006). O controle utilizado para controlar o ângulo da pá e consequentemente a potência extraída do vento refere-se quase sempre ao controle de passo. Ainda, visto os conversores proporcionarem o desacoplamento parcial entre as frequências da rede elétrica e as frequências da interação ventos-turbina-rotor, permite-se que o aerogerador seja menos susceptível às oscilações de tensão da rede elétrica e às flutuações dos ventos.

Diferentes estratégias de controle podem ser implementadas, mas tipicamente durante as condições normais de operação, o sistema de controle do RSC controla as potências ativa e reativa entregue pelo estator à rede elétrica, através do controle de cada componente da corrente do circuito do rotor. Já o sistema de controle do GSC controla a tensão no link DC e o fator de potência no GSC (Ibrahim, 2015), (Pardalos et al., 2013). Com o emprego dos conversores, não é mais necessária a compensação externa de potência reativa por capacitores. Ademais, como os conversores permitem a regulação da potência reativa, o controle da tensão torna-se uma realidade e a tensão terminal é melhor recuperada após a perturbação (Slootweg, 2003), (Akhmatov, 2003). Diante de perturbações que possam ocorrer na rede elétrica, os conversores devem ser protegidos de sobretensões e sobrecorrentes, exigindo portanto um sistema de proteção adequado. Como empregam-se anéis coletores para transferir potência via o RSC, perdas elétricas ocorrem e uma manutenção frequente é requerida. Comparativamente aos aerogeradores dos tipos $A$ e $B$, os aerogeradores do tipo $C$ são mais caros, devido essencialmente ao emprego dos conversores e aos sistemas de controle associados. 


\subsubsection{Aerogerador do tipo D}

O aerogerador do tipo D também está entre os mais utilizadas (Pinto, 2013). Sua configuração é exibida na Figura 2.7. Para aerogeradores deste tipo, empregam-se conversores eletrônicos de potência em escala completa, isto é, os mesmos são dimensionados para 100\% da potência nominal do gerador e estabelecem a conexão do estator à rede elétrica.

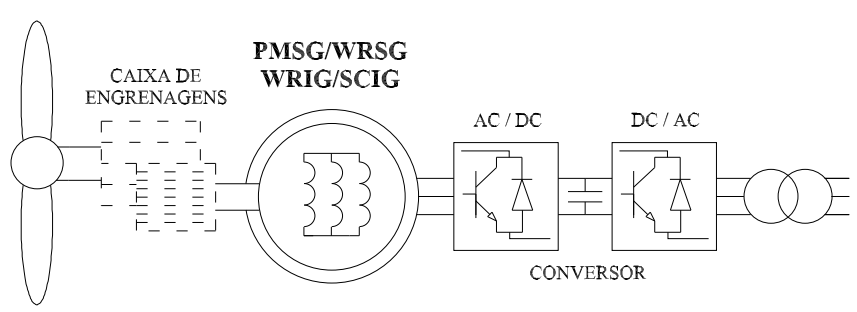

Figura 2.7: Configuração típica de aerogeradores do tipo D.

Vários geradores podem ser empregados nesta configuração. Normalmente, utiliza-se um gerador síncrono de muitos polos. Neste caso, o rotor possui um diâmetro extenso e consequentemente o volume e o peso da nacele tornam-se maiores, de modo que a torre deve ser mais resistente, elevando os custos da instalação. Como a caixa de engrenagens não é utilizada nesta situação, evita-se a manutenção neste elemento e os esforços mecânicos são reduzidos, assim como os ruídos proporcionados pelo aerogerador.

Os conversores em escala total permitem uma faixa de velocidades de operação de $0 \%$ a 100\% da velocidade síncrona (Pardalos et al., 2013). Como na configuração anterior, utiliza-se aqui tipicamente o controle de passo. Este aerogerador está habilitado para uma extração máxima da energia contida nos ventos e é ainda menos susceptível às oscilações de tensão da rede elétrica e às flutuações dos ventos. Visto que os conversores estabelecem a conexão do gerador à rede elétrica, maiores perdas elétricas ocorrem. Entretanto, comparativamente a qualquer outro conceito de aerogerador, a configuração do tipo D oferece o melhor suporte de potência reativa à rede elétrica e consequentemente, as melhores respostas frente aos afundamentos de tensão (Michalke, 2008). Ressalta-se que a maior capacidade de produzir potência reativa se deve à capacidade nominal dos conversores.

Ainda que os custos associados a esta configuração variem conforme o tipo de gerador utilizado, os conversores e os sistemas de controle associados são os principais responsáveis pelo encarecimento. Entretanto, a aplicabilidade do aerogerador do tipo D tem se tornado atrativa, principalmente devido a faixa de velocidades de operação, à capacidade de produzir mais energia, à possibilidade de dispensar a caixa de engrenagens e às melhores respostas frente aos afundamentos de tensão. Ao se considerar estes aspectos positivos, a utilização dos aerogeradores do tipo D tem se tornado cada vez mais comum nos parques eólicos, superando a desvantagem do custo elevado (Vittal e Ayyanar, 2013). 
Existem ainda outras topologias, variações das configurações apresentadas, menos comuns, que podem ser encontradas em (Li e Chen, 2008), (Kim e Lu, 2010) e (Mahela e Shaik, 2016).

\subsection{Estabilidade de velocidade}

No que diz respeito aos aerogeradores de velocidade fixa, o comportamento dinâmico é ditado pela relação entre os torques eletromagnético e mecânico, as potências ativa e reativa, a tensão terminal e a velocidade do rotor do gerador. Como bem descrito em (Slootweg , 2003), na ocorrência de um distúrbio na rede, a tensão terminal será reduzida. A potência ativa produzida pelo gerador também, visto a mesma ser proporcional à tensão do estator. Uma vez o torque eletromagnético se tornando inferior ao torque mecânico, a velocidade do rotor aumentará. Ao se eliminar a perturbação, o gerador ainda absorverá uma grande quantidade de potência reativa devido à alta velocidade do rotor. Se o mesmo continuar a acelerar de modo que a tensão terminal não seja restaurada, o consumo de potência reativa aumentará, reduzindo ainda mais a tensão terminal, intensificando o desequilíbrio entre os torques e por fim, aumentando ainda mais a velocidade do rotor.

Em (Samuelsson e Lindahl, 2005) atribuiu-se o termo estabilidade de velocidade para o fenômeno descrito anteriormente, uma vez que fica claro o aumento significativo da velocidade do rotor do gerador de indução frente a grandes perturbações.

Estabilidade de velocidade do rotor refere-se à capacidade da máquina de indução em permanecer conectada ao sistema elétrico de potência e funcionando a uma velocidade mecânica próxima à velocidade correspondente à frequência do sistema pós-falta.

É possível concluir que a instabilidade de velocidade é acompanhada pela instabilidade de tensão. Em outras palavras, o problema de estabilidade de velocidade e o problema de estabilidade de tensão são intrinsecamente acoplados em máquinas de indução. Não existe ainda uma definição clara de estabilidade de tensão associada exclusivamente aos geradores de indução (Samuelsson e Lindahl, 2005).

Uma vez que os aerogeradores de velocidade fixa são incapazes de realizar os controles da potência reativa e da tensão terminal de forma independente, equipamentos adicionais são então requeridos a fim de auxiliar a recuperação da tensão terminal e evitar tanto a instabilidade de velocidade como a instabilidade de tensão. No que se refere ao aerogerador do tipo B, ainda que se permita uma faixa de operação maior para esta configuração, os comportamentos da velocidade e da tensão terminal são semelhantes, de modo que as mesmas análises mencionadas são válidas para esta unidade de geração.

Em situações de instabilidade de velocidade e instabilidade de tensão, os aerogeradores podem ser desconectados da rede elétrica via proteção por sobre-velocidade ou subtensão, por exemplo. A fim de evitar a instabilidade, o conhecimento do TCA torna-se fundamental. 
Para que a estabilidade de velocidade da máquina de indução seja garantida, isto é, para que a máquina continue conectada à rede e a velocidade do rotor não cresça indefinidamente no sistema pós-falta, o sistema de proteção deverá atuar em um tempo inferior ao TCA.

Em relação ao aerogerador do tipo C, diferentes pontos de operação são factíveis (Slootweg , 2003). Uma vez que os conversores proporcionam o desacoplamento parcial entre o gerador e a rede, através de seus controladores é possível fornecer potência reativa e assim controlar a tensão terminal. Desta forma, permite-se que o comportamento dinâmico do gerador de indução seja ditado pelos conversores. Porém, estes são muito sensíveis a sobrecorrentes. Em uma situação desta natureza, o aerogerador pode ser imediatamente desconectado da rede via proteção específica.

Conhecer os mecanismos que causam a instabilidade dos aerogeradores é claramente importante para os estudos de estabilidade a grandes perturbações. Não obstante, considerar que o sistema elétrico de potência pode ficar vulnerável caso algum parque eólico seja desconectado da rede, é também fundamental. Isto posto, são apresentados a seguir alguns requisitos de operação.

\subsection{Requisitos de operação}

A crescente demanda por energia elétrica, a preocupação com a sustentabilidade ambiental e o progresso tecnológico, impulsionaram o desenvolvimento das fontes alternativas e a crescente introdução destas nos sistemas elétricos de potência. No que se refere aos aerogeradores, os mesmos foram inseridos inicialmente nos sistemas de distribuição, individualmente ou em pequenos grupos, fornecendo pequenas quantidades de energia elétrica. Os aerogeradores eram projetados com o principal objetivo de maximizar a extração de energia dos ventos e assim produzir a máxima potência ativa possível, sem se preocupar com a produção de potência reativa. Quando ocorriam afundamentos ou elevações de tensão decorrentes de eventuais distúrbios oriundos do sistema elétrico, o parque eólico podia ser desconectado da rede elétrica caso o proprietário assim o desejasse (Pinto, 2013).

Com o passar dos anos, aerogeradores de potências maiores foram construídos, sendo inseridos diretamente no sistema de transmissão, normalmente em grandes grupos, denominados parques eólicos. Estes são capazes de fornecer grandes quantidades de energia elétrica. A partir da presença significativa dos parques eólicos nos sistemas elétricos de potência, surge a necessidade destas plantas realizarem serviços ancilares (Ullah et al., 2009), de forma semelhante às fontes tradicionais, através dos próprios aerogeradores e/ou de equipamentos complementares, estrategicamente distribuídos na área de controle do parque eólico.

Adicionalmente ao objetivo de produzir a máxima potência ativa possível, os sistemas de conversão de energia eólica são hoje projetados para participar do controle da tensão e do controle da frequência do sistema elétrico de potência (Mohseni e Islam, 2012). Para tanto, os aerogeradores devem permanecer conectados à rede elétrica no período transitório 
da perturbação. Desta forma, permite-se que os mesmos contribuam para a estabilidade de tensão e para a estabilidade de frequência. Em outras palavras, os parques eólicos devem controlar os fluxos de potência ativa e reativa, participando ativamente da operação do sistema elétrico de potência. Evidentemente, uma eventual desconexão de um parque eólico resultaria em problemas na estabilidade da rede, afetando inclusive os geradores síncronos das fontes tradicionais (Edrah et al., 2015).

A crescente penetração de parques eólicos no sistema elétrico de potência motivou a criação de requisitos técnicos para a conexão e a operação destas plantas. Os operadores do sistema elétrico trataram de introduzir tais requisitos em seus códigos de rede. O principal objetivo é contribuir para a confiabilidade da rede elétrica. Os requisitos típicos para a maioria dos códigos de rede determinam que os parques eólicos devem (Singh e Singh , 2009), (Tsili e Papathanassiou, 2009):

1. Participar do controle da frequência do sistema elétrico, que se relaciona à regulação da potência ativa;

2. Participar do controle da tensão do sistema elétrico, que se relaciona à regulação da potência reativa;

3. Permanecer conectados à rede elétrica frente aos eventos de subtensão, sobretensão, subfrequência e sobrefrequência, no período transitório.

A seguir, apresentam-se as características gerais dos requisitos citados. Para o terceiro item, destaque é dado ao requisito associado ao evento de subtensão.

\subsubsection{Controle da frequência}

A frequência do sistema elétrico de potência é determinada pelo equilíbrio instantâneo entre a potência ativa total gerada pelas unidades geradoras e a potência ativa total consumida pelas cargas e dissipada na rede elétrica. Os parques eólicos devem operar dentro de limites de frequência pré-estabelecidos pelo operador do sistema elétrico, ajustando a produção de potência ativa conforme a demanda. Deve-se garantir que os parques eólicos permaneçam conectados à rede elétrica frente aos desvios de frequência que eventualmente ocorram. A capacidade dos parques eólicos de contribuir com o controle primário e também com o controle secundário, torna-se cada vez mais necessária para a estabilidade de frequência da rede elétrica (Pardalos et al., 2013), (Burton et al., 2011).

Através do controle primário, os aerogeradores devem adaptar sua produção de energia para obter o equilíbrio entre a produção e o consumo, de forma a estabilizar a frequência. O intervalo de tempo para este controle varia entre $1 \mathrm{~s}$ e $30 \mathrm{~s}$. Já o controle secundário ocorre entre 10 min e 15 min, através de reduções ou aumentos lentos da produção. Visto a intermitência dos ventos e as tecnologias empregadas nos aerogeradores serem diferentes das empregadas nas fontes convencionais, o controle da frequência torna-se um desafio. Ainda assim, muitos códigos de rede incluem tal requisito. 
Para responder aos desvios de frequência que eventualmente ocorram na rede elétrica, os parques eólicos devem ser capazes de controlar sua potência ativa de saída. Nas situações de sobrefrequência, o equilíbrio entre a produção e o consumo pode ser obtido através do controle do ângulo de passo das pás da turbina ou através da desconexão de determinadas unidades de geração (Ackermann, 2012).

Promover a participação dos parques eólicos no controle da frequência da rede não é uma tarefa simples. Além das limitações intrínsecas a este sistema de geração, a exemplo da intermitência dos ventos, que dificulta o despacho de potência, existem outros tipos de limitações. É natural que o proprietário do parque eólico tenha o interesse na máxima produção de potência e ao mesmo tempo, que seu parque seja protegido de eventuais distúrbios oriundos da rede elétrica, o que poderia acarretar a desconexão do mesmo frente aos eventos transitórios, interferindo na frequência da rede.

Para que os parques eólicos estejam habilitados a participar ativamente do controle da frequência do sistema elétrico de potência, alguns métodos foram concebidos para realizar o controle da potência ativa de saída. Exemplos de tais métodos correspondem ao controle de equilíbrio, ao controle do gradiente de potência e ao controle delta (Pardalos et al., 2013).

\subsubsection{Controle da tensão}

As tensões na rede elétrica são determinadas, essencialmente, pelo fluxo de potência reativa. Para manter as tensões constantes, a produção total de potência reativa deve equilibrarse com o consumo total. Os parques eólicos devem ser capazes de controlar a tensão no ponto de acoplamento comum, do inglês point of common coupling (PCC) e de trocar determinado nível de potência reativa com o sistema de transmissão. Somente a compensação de potência reativa para equilibrar a própria demanda do parque eólico não é suficiente (Pardalos et al., 2013), (Burton et al., 2011). A Figura 2.8 ilustra o PCC para um parque eólico.

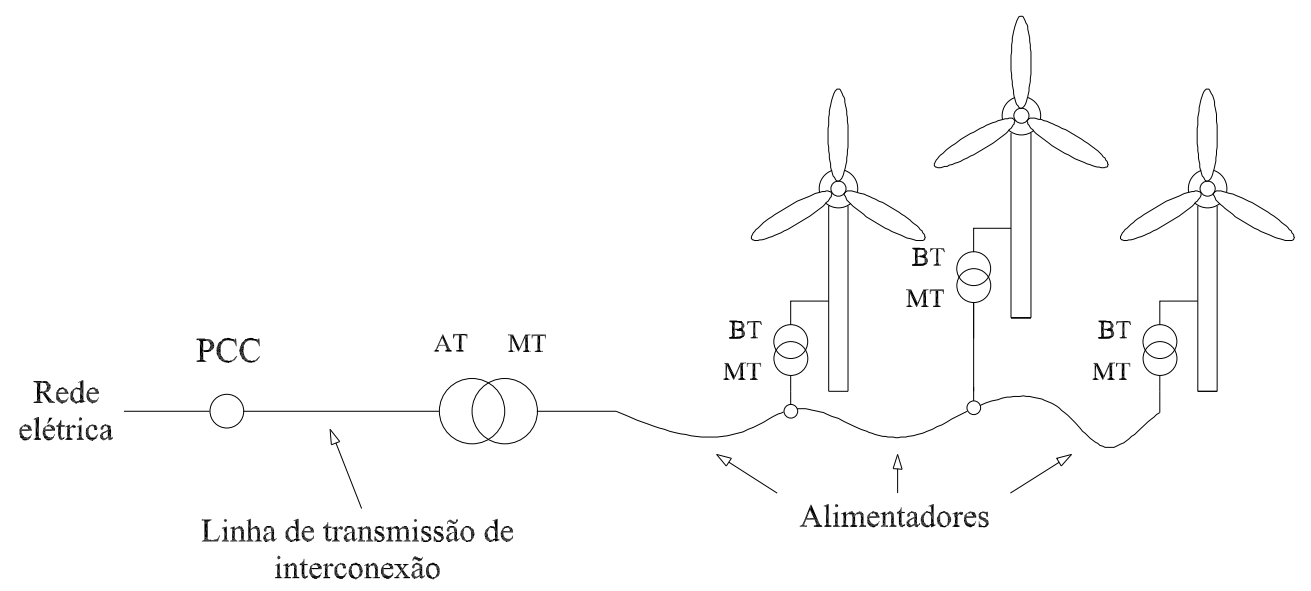

Figura 2.8: Representação do PCC para um parque eólico.

Perturbações na rede elétrica podem alterar as tensões em vários pontos do sistema. No sentido de restabelecer as tensões aos níveis considerados normais pelo operador do sis- 
tema elétrico, o parque eólico pode trocar potência reativa com a rede elétrica controlando o fator de potência, fixando a potência reativa para um determinado valor ou controlando a tensão no PCC. Dependendo das tecnologias empregadas, o parque eólico pode contribuir com o controle da tensão e com a regulação da potência reativa de forma muito satisfatória. Aerogeradores equipados com conversores eletrônicos de potência, permitem que através dos sistemas de controle associados, diferentes estratégias de controle sejam implementadas (Salles, 2009). No entanto, muitas vezes equipamentos adicionais são necessários para auxiliar na compensação de potência reativa, a exemplo de capacitores e dispositivos eletrônicos. Tipicamente, estes equipamentos são instalados no PCC ou próximos das dependências do parque eólico (Ibrahim, 2015).

No que se refere aos sistemas de transmissão, a relação entre resistência e reatância $\mathrm{R} / \mathrm{X}$ é menor, comparativamente aos sistemas de distribuição. Este fato reforça a necessidade dos parques eólicos de contribuir com a produção de potência reativa e com o controle da tensão da rede elétrica. Para parques eólicos distantes dos centros consumidores, a exemplo das instalações offshore, dificulta-se ainda mais o controle da tensão (Ackermann, 2012).

A capacidade dos parques eólicos de participar ativamente do controle da tensão contribui para a estabilidade de tensão do sistema elétrico de potência. Tratando-se dos afundamentos de tensão oriundos de grandes perturbações, a capacidade dos parques eólicos de controlar a tensão no PCC tornou-se fundamental. Já há alguns anos, países como a Alemanha e Espanha, por exemplo, exigem que durante afundamentos de tensão o parque eólico injete potência reativa no PCC, no sentido de recuperar a tensão e evitar uma possível desconexão do parque eólico (E.ON, 2006), (REE, 2004). Recentemente para o Brasil o Operador Nacional do Sistema Elétrico (ONS) também adotou esta medida (ONS, 2016).

\subsubsection{Suportabilidade a afundamentos e elevações de tensão}

A principal regra de segurança para o sistema elétrico de potência corresponde ao critério $N-1$. Tal critério tem por objetivo principal garantir que o sistema elétrico interligado do país seja capaz de permanecer operando sem a interrupção do fornecimento de energia elétrica na ocorrência de uma contingência simples. Para o ONS determina-se também a permanência da operação sem a perda de estabilidade, sem a violação dos padrões de certas grandezas elétricas (frequência, tensão, harmônicos, etc) e sem a infração dos limites de sobrecarga de equipamentos e instalações.

Uma contingência simples pode ser exemplificada pela perda de uma linha de transmissão por atuação do sistema de proteção frente a um curto-circuito. Em situações desta natureza, o sistema elétrico de potência experimenta variações de tensão e frequência, especialmente nas proximidades da contingência. No que se refere às variações de tensão, a principal preocupação corresponde aos afundamentos de tensão. Caso o sistema de proteção atue por subtensão, o mesmo eliminará a perturbação, mas poderá provocar a perda de um elemento importante do sistema elétrico. 
Outra possível consequência da ação de sistemas de proteção, não menos preocupante que a perda de uma linha de transmissão, corresponde ao ilhamento de unidades de geração. Até o início deste século, os aerogeradores eram obrigatoriamente desconectados do PCC na ocorrência de uma perturbação na rede elétrica. O objetivo da desconexão forçada era reduzir o risco de ilhamento. Tal exigência aplicava-se aos sistemas elétricos de potência com baixa penetração de aerogeradores. Estes eram equipados com relés de proteção de perda da rede para eventos de subtensão, sobretensão, subfrequência, sobrefrequência, taxa de variação de frequência e descolamento de fase. A possibilidade do disparo simultâneo de um grande número de relés era uma realidade. Caso muitos relés atuassem frente às perturbações que ocorressem na rede elétrica, uma quantidade significativa de produção de energia elétrica proveniente dos aerogeradores poderia ser perdida (Pinto, 2013).

A ocorrência da situação apresentada anteriormente traria sérias complicações à operação do sistema elétrico de potência. Diante da crescente introdução de aerogeradores na rede elétrica, notadamente nos últimos anos através de grandes parques eólicos, tais plantas não podem mais ser desconectadas da rede elétrica frente a quaisquer variações de tensão e frequência. Neste sentido, visando melhorar as margens de estabilidade do sistema elétrico de potência e assim contribuir para a sua confiabilidade, requisitos de suportabilidade, também conhecidos por requisitos de imunidade (Bollen e Hassan, 2011), foram estabelecidos pelos operadores do sistema elétrico para que os parques eólicos permaneçam conectados ao PCC frente às variações de tensão e frequência que eventualmente ocorram, decorrentes de perturbações ocorridas na rede elétrica. Tais requisitos são conhecidos por transient fault ride-through (TFRT). Para os eventos de subtensão, aplica-se o requisito de suportabilidade a afundamentos de tensão, do inglês low voltage ride-through (LVRT) (Mullane et al., 2005), (Boemer et al., 2011). Para os eventos de sobretensão, aplica-se o requisito de suportabilidade a elevações de tensão, do inglês high voltage ride-through (HVRT) (Feltes et al., 2008).

Embora exista uma tendência de aplicabilidade aos aerogeradores de menor potência, ambos os requisitos aplicam-se especialmente aos parques eólicos. A Figura 2.9 mostra os requisitos LVRT e HVRT, que são exemplificados por curvas genéricas, isto é, que não se referem a curvas adotadas por um operador do sistema de transmissão em específico.

Estes requisitos estabelecem faixas para diferentes condições de operação. As faixas de operação em que os parques eólicos podem ser desconectados foram concebidas pois os aerogeradores são notadamente mais sensíveis às perturbações ocorridas na rede, comparativamente às fontes tradicionais. A operação dos aerogeradores em níveis consideravelmente baixos ou altos de tensão pode ser prejudicial à máquina e demais elementos.

Conforme pode ser observado na Figura 2.9(a), a região entre as curvas LVRT e HVRT refere-se aos valores de tensão no PCC para os quais o parque eólico deve permanecer conectado. As regiões abaixo da curva LVRT e acima da curva HVRT, referem-se aos valores de tensão no PCC para os quais o parque eólico pode ser desconectado da rede elétrica. As trajetórias pré-falta, em falta e pós-falta da Figura 2.9(b) exemplificam uma situação de 


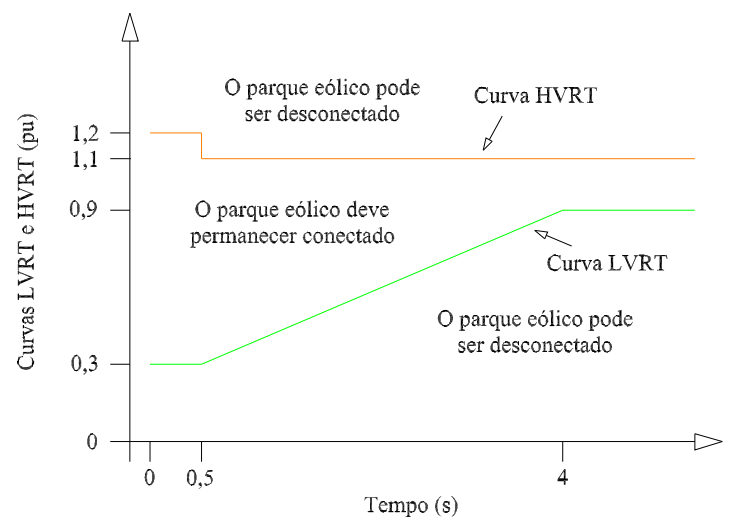

(a) Curvas LVRT e HVRT.

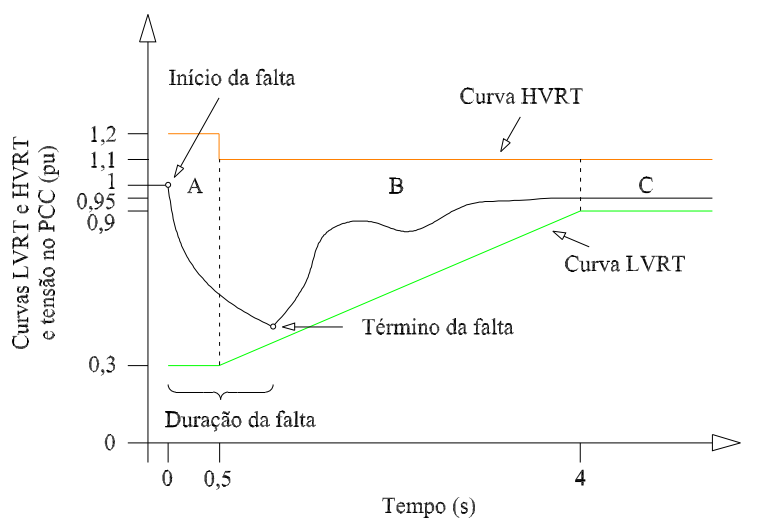

(b) Curvas LVRT e HVRT e tensão no PCC.

Figura 2.9: Curvas limite de tensão inferior (LVRT) e superior (HVRT) para o PCC.

não violação de ambos os requisitos. Portanto, para estas trajetórias o parque eólico deve permanecer conectado durante e após a falta.

As curvas LVRT e HVRT caracterizam-se tipicamente por três regiões relativas aos limites de tensão: para a ocorrência da falta, para a restauração do sistema e para o regime após a falta. Para o exemplo genérico da Figura 2.9:

- A - o parque eólico deve permanecer conectado ao PCC para afundamentos de tensão de até $70 \%$ ou elevações de tensão de até $20 \%$, durante o período de 0.5 s;

- B - o parque eólico deve permanecer conectado ao PCC para afundamentos de tensão que variam de forma linear, de $70 \%$ até $10 \%$, em 3.5 s ou elevações de tensão de até $10 \%$;

- C - o parque eólico deve permanecer conectado ao PCC para afundamentos de tensão de até $10 \%$ ou elevações de tensão de até $10 \%$, a partir do instante 4 s.

Visto as contingências serem acompanhadas, essencialmente, por afundamentos de tensão, o requisito LVRT é mais comumente encontrado nos códigos de rede. Este requisito torna-se fundamental para sistemas elétricos de potência na presença de fontes alternativas, especialmente quando as mesmas referem-se aos parques eólicos formados por um grande número de aerogeradores.

O requisito LVRT estabelece que o parque eólico deve, obrigatoriamente, permanecer conectado à rede elétrica diante de níveis reduzidos de tensão no PCC, definidos para intervalos de tempo específicos. Se a tensão no PCC violar qualquer limite de tensão, o proprietário do parque eólico tem a permissão para desconectá-lo da rede elétrica. 
A Figura 2.10 exemplifica algumas trajetórias possíveis para a tensão no PCC, considerando apenas o requisito LVRT. Todas as trajetórias apresentadas violam a curva LVRT. Em 2.10(a) viola-se durante a falta. Em 2.10(b) viola-se após a falta e durante o período de restauração do sistema. Em 2.10(c) viola-se em regime permanente. Para todas as situações, o parque eólico poderia ser desconectado do PCC.

É plausível que antes da violação da curva LVRT, algum limite operacional intrínseco ao aerogerador já tenha sido infringido, como um valor máximo de corrente, por exemplo. Neste trabalho, desconsidera-se tal situação, isto é, preocupa-se apenas em verificar se a tensão no PCC viola ou não a curva LVRT. Salienta-se que esta curva pode ser violada antes do gerador de indução perder a estabilidade de velocidade. Esta situação será observada nos resultados obtidos nesta tese, na maioria dos casos analisados, revelando a importância de se considerar tais limites de tensão nas análises de estabilidade transitória.

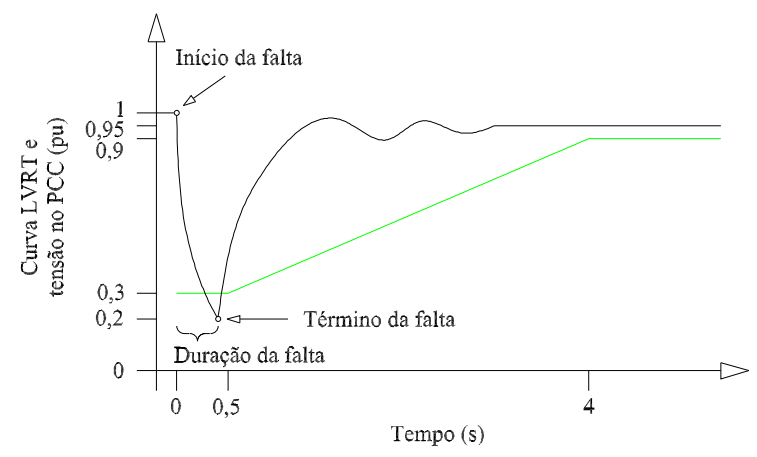

(a) Violação da curva LVRT durante a falta.

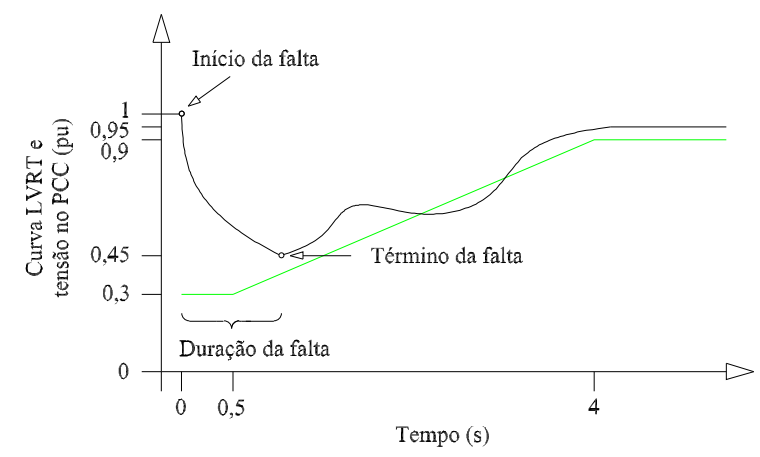

(b) Violação da curva LVRT após a falta.

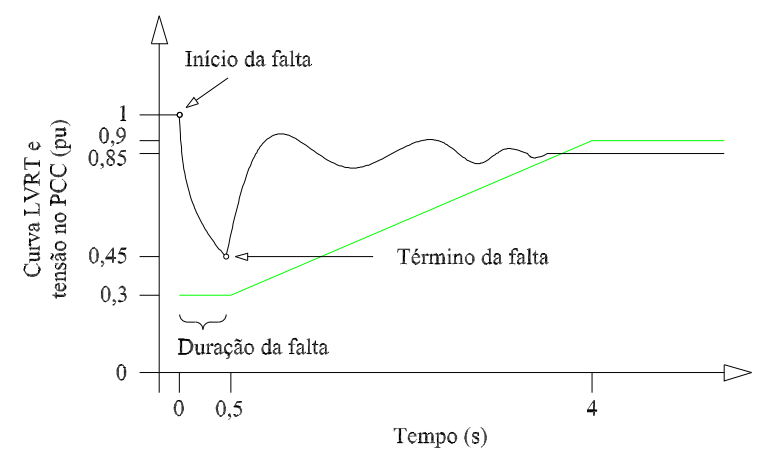

(c) Violação da curva LVRT em regime permanente, após a falta.

Figura 2.10: Curva LVRT e diferentes trajetórias da tensão no PCC.

Uma vez que os parques eólicos podem ser desconectados da rede elétrica em casos de afundamentos severos de tensão no PCC, o conhecimento do TCA relativo à violação da curva LVRT torna-se primordial. Conhecendo este TCA, elimina-se em um tempo inferior o defeito na rede elétrica, de modo a mitigar iminentes problemas de estabilidade e contribuir para a operação segura do sistema elétrico de potência. 
Para não permitir que o aerogerador ou o parque eólico possa ser desconectado da rede elétrica, o sistema de proteção da rede deverá atuar em um tempo inferior ao TCA.

Salienta-se que o TCA mencionado se refere à violação da curva LVRT. O TCA referente aos limites de corrente dos conversores, por exemplo, pode ser menor. Considerando tais limites e a situação citada, o sistema de proteção dos conversores atuaria em um tempo inferior ao TCA relativo à violação da curva LVRT, a fim de protegê-los de sobrecorrentes.

A seguir, citam-se algumas soluções criadas para que os parques eólicos sejam capazes de oferecer boas respostas frente ao requisito LVRT, fundamentalmente relacionadas a equipamentos complementares e aos conversores eletrônicos de potência.

\subsubsection{Soluções para melhorar as respostas dos aerogeradores}

Para que os parques eólicos contribuam para a estabilidade do sistema elétrico de potência, os mesmos devem continuar operando mesmo em situações de baixa tensão no PCC. Portanto, diante das exigências dos operadores do sistema elétrico, buscam-se soluções para que os parques eólicos sejam capazes de oferecer boas respostas quando condicionado ao requisito LVRT (Howlader e Senjyu, 2016).

As soluções referem-se não somente aos mecanismos de controle e operação aplicados exclusivamente aos aerogeradores, mas também a equipamentos complementares. As tecnologias envolvidas fundamentam-se na capacidade de injetar potência reativa durante e após a falta e de evitar que a máquina ou os conversores tenham seus limites de operação atingidos, de forma a reduzir os afundamentos de tensão e a auxiliar na recuperação desta após a eliminação da falta. Tais tecnologias aplicam-se às instalações do parque eólico, ao estator da máquina, de forma paralela ao PCC ou entre este e a rede elétrica (Ibrahim, 2015).

No que se refere aos aerogeradores de velocidade fixa, a curva LVRT pode ser facilmente violada, uma vez que o controle da tensão é muito limitado para estas unidades de geração, diferentemente dos aerogeradores de velocidade variável. Em (Moghadasi et al., 2016) apresenta-se uma revisão completa sobre as soluções aplicáveis aos aerogeradores de velocidade fixa. Comparações são realizadas em termos de desempenho dinâmico, complexidade de controle e custo. As soluções correspondem a:

- Compensação série controlada por tiristor, do inglês thyristor controlled series compensation (TCSC);

- Restauração dinâmica de tensão, do inglês dynamic voltage restoration (DVR);

- Resistor de frenagem dinâmica série, do inglês series dynamic braking resistor (SDBR);

- Chave de recuperação de energia magnética, do inglês magnetic energy recovery switch (MERS); 
- Limitador de corrente de falta, do inglês fault current limiter (FCL);

- Compensador de reativos estático, do inglês static var compensator (SVC);

- Compensador síncrono estático, do inglês static synchronous compensator (STATCOM);

- Condensador síncrono supercondutor, do inglês superconducting synchronous condenser (SSC);

- Condicionador unificado de qualidade de energia, do inglês unified power quality conditioner (UPQC);

- Sistema de compensação unificada, do inglês unified compensation system (UCS).

Em relação aos aerogeradores de velocidade variável, os conversores eletrônicos de potência, além de viabilizarem a injeção de potência reativa na rede e a sua regulação via sistemas de controle, permitem ao aerogerador oferecer melhores respostas frente aos afundamentos de tensão. Entretanto, durante tensões reduzidas, as correntes que passam pelos conversores tendem a aumentar para manter o fluxo de potência. Ainda, oscilações de tensão têm reflexo imediato na tensão do barramento DC. As variações de corrente e de tensão resultantes podem provocar o desligamento dos conversores por atuação do sistema de proteção. Normalmente os componentes dos conversores eletrônicos de potência são superdimensionados para suportar as eventuais variações de tensão e corrente (Bollen e Hassan, 2011).

Evidentemente, superdimensionar os conversores implica em limitações técnicas e econômicas. Desta forma, diferentes soluções foram concebidas a fim de evitar danos aos conversores e contribuir para a injeção de potência reativa. No que se refere aos aerogeradores de velocidade variável, em (Manonmani e Sruthi, 2014), (Hansen et al., 2007b), (Hansen e Michalke , 2007), (Rahimi e Parniani, 2010) e (Joos, 2008), diferentes soluções podem ser encontradas para a configuração DFIG. Em (Ibrahim et al., 2012), (Ibrahim, 2015), (Mali et al., 2014) e (Akhmatov, 2005), soluções aplicáveis aos aerogeradores equipados com PMSG são apresentadas. Adicionalmente às soluções TCSC, DVR, MERS, FCL, SVC e STATCOM, citam-se as seguintes opções:

- Controle do ângulo de passo;

- Crowbar;

- Diferentes estratégias de controle para os conversores;

- Sistemas de armazenamento de energia (inércia do rotor, bateria, supercapacitor);

- Compensador estático síncrono série, do inglês static synchronous series compensator (SSSC); 
- Controlador unificado de fluxo de potência, do inglês unified power flow controller (UPFC).

A seguir, apresenta-se o requisito LVRT para diferentes países. Relacionam-se algumas curvas LVRT e as características fundamentais associadas. A intenção é mostrar que o requisito LVRT aplica-se a vários códigos de rede, além de expor as particularidades deste requisito para diferentes operadores do sistema elétrico.

\subsubsection{Suportabilidade a afundamentos de tensão para diferentes países}

O requisito LVRT surgiu na Alemanha. Foi originalmente definido pelo operador E.ON no ano 2003 (Ibrahim et al., 2012), (Erlich e Bachmann, 2005). A partir de então outros países, inicialmente europeus, apresentaram seus próprios requisitos baseados no código de rede alemão. Em seguida inúmeros países ao redor do mundo também inseriram requisitos LVRT em seus códigos de rede (Ackermann, 2012), (Singh e Singh, 2009), (Tsili e Papathanassiou, 2009), (lov et al., 2007).

Para elaborar o requisito LVRT, inúmeros aspectos são considerados. Assim, o mesmo pode ser definido como:

- i) único para ambos os sistemas de transmissão e distribuição, ii) específico para o sistema de transmissão, iii) específico para o sistema de distribuição;

- i) único para todo o sistema elétrico, ii) específico para cada área do sistema elétrico;

- i) único para apenas uma forma de conexão da fonte alternativa à rede elétrica, ii) específico para cada forma de conexão da fonte alternativa à rede elétrica;

- i) único para todos os tipos de falta, ii) específico para faltas simétricas, iii) específico para faltas assimétricas, iv) específico para cada tipo de falta assimétrica, v) específico para determinada sequência de tensão;

- i) único para vários sistemas de geração alternativos, ii) específico para cada tipo de sistema de geração alternativo;

- i) único para todos os tipos de geradores, ii) específico para cada tipo de gerador;

- i) único para todas as tecnologias do sistema de geração alternativo, ii) específico para cada tecnologia do sistema de geração alternativo;

- i) único para vários níveis de potência, ii) específico para cada nível de potência.

É interessante observar que determinados países apresentam mais de um operador do sistema elétrico ou mais de uma autoridade reguladora, como o Canadá e os Estados Unidos da América. Normalmente nesta situação, cada operador ou autoridade reguladora estabelece o seu próprio código de rede. 
A fim de mostrar a importância do requisito LVRT, o mesmo é apresentado brevemente a seguir para o sistema de transmissão de doze países: Alemanha, Dinamarca, Irlanda, África do Sul, Espanha, Malásia, Canadá, Grã-Bretanha (Escócia, Inglaterra e País de Gales), Brasil e Estados Unidos da América. As curvas que representam os limites de tensão no PCC são exibidas com ênfase dada aos aerogeradores dentre as fontes alternativas. Em adição à exigência do parque eólico permanecer conectado ao PCC, maiores detalhes sobre as injeções de potência ativa e reativa, associadas ou não à curva LVRT, podem ser encontradas nas referências a serem apresentadas. Da mesma forma, informações específicas sobre o controle da frequência também podem ser encontradas nos respectivos códigos de rede. Ainda que muitos países não adotem especificações detalhadas sobre as injeções de potência ativa e reativa nas situações de afundamentos de tensão, constata-se que as fontes alternativas devem contribuir da melhor forma possível neste sentido.

- Alemanha

O requisito LVRT para a Alemanha exige que para faltas trifásicas, para plantas não equipadas com geradores síncronos, a tensão no PCC atenda aos limites de tensão exibidos na Figura 2.11 (as linhas preta e verde contínuas indicam limites de tensão), cujo limite de tensão a partir do instante 1,5 s pode ser variável conforme o nível de tensão da rede (E.ON, 2006).

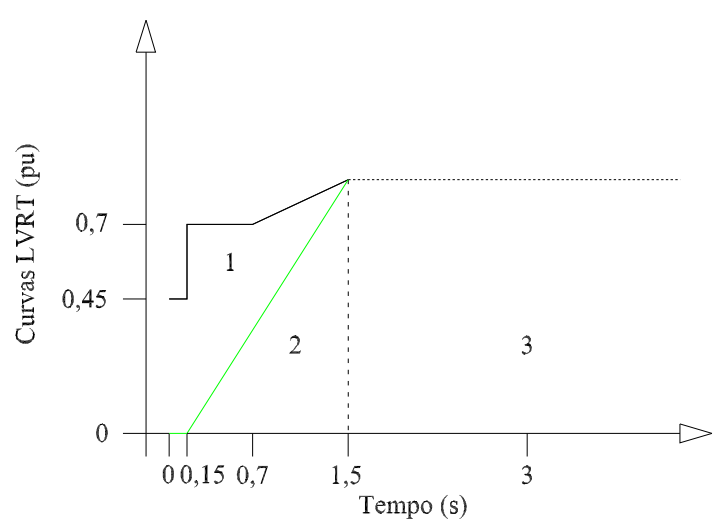

Figura 2.11: Curva LVRT definida por (E.ON, 2006).

Faltas trifásicas não devem levar o parque eólico à instabilidade ou à desconexão da rede elétrica acima da curva que delimita a área 1. Para a área 1, o parque eólico deve permanecer conectado ao PCC, retomar a geração de potência ativa imediatamente após a eliminação da perturbação e gerar potência reativa durante a falta. Uma breve desconexão somente é permitida, em concordância com o operador do sistema, caso algum gerador apresente instabilidade. O restabelecimento nesta área, a partir da desconexão, deve ocorrer na maioria das vezes em até 2 s e a produção de potência ativa deve retornar ao seu valor original a uma taxa de $10 \%$ da potência nominal dos aerogeradores, por segundo. 
Na área 2, desconexões momentâneas são sempre permitidas. O restabelecimento nesta área pode ocorrer após $2 \mathrm{~s}$ e permite-se o retorno da produção de potência ativa ao seu valor original para taxas inferiores a $10 \%$ da potência nominal dos aerogeradores, por segundo. Para todos os parques eólicos que permaneçam conectados ao PCC durante a falta, a produção de potência ativa pelos mesmos, logo após a eliminação da falta, deve aumentar a uma taxa mínima de $20 \%$ da potência nominal dos aerogeradores, por segundo, até se alcançar o valor original de produção do parque eólico. Na área 3, as desconexões dos aerogeradores devem ocorrer de forma seletiva, através de sistemas de proteção automáticos.

O parque eólico deve fornecer potência reativa durante os afundamentos de tensão que eventualmente ocorram, a fim de contribuir para a estabilidade de tensão do sistema elétrico. Para tanto, um sistema de controle particular deve ser ativado para afundamentos de tensão superiores a $10 \%$ da tensão dos aerogeradores. Este sistema deve atuar dentro do período de 20 ms após o reconhecimento da falta, viabilizando o fornecimento de corrente reativa no lado de baixa tensão do transformador dos aerogeradores, a uma taxa mínima de $2 \%$ da corrente nominal para cada $1 \%$ de afundamento de tensão.

\section{- Dinamarca}

O requisito LVRT para a Dinamarca exige que o parque eólico atenda aos limites de tensão exibidos na Figura 2.12 (Energinet, 2016). Para faltas simétricas ou não, o parque eólico deve manter a sua produção normalmente na região 1. Na região 2 o parque eólico deve prover suporte de potência reativa, de modo a contribuir da melhor maneira possível para os níveis de tensão. A desconexão somente é permitida na região 3. Caso a falta retorne à região 1 após 1,5 s, tem-se uma nova situação de falta e a curva LVRT deve ser avaliada novamente a partir deste ponto. Se sucessivas faltas ocorrerem na região 2 até culminar na região 3, a desconexão é permitida.

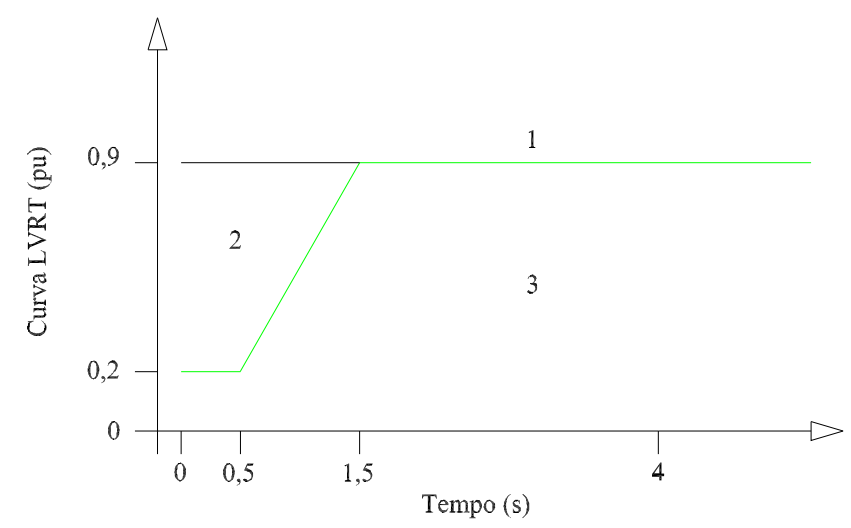

Figura 2.12: Curva LVRT definida por (Energinet, 2016).

As medidas de tensão terminal dos aerogeradores devem ser usadas para controlar a corrente reativa durante os afundamentos de tensão. Na região 2 o fornecimento de potência 
reativa deve ser uma prioridade com relação ao fornecimento de potência ativa. Se possível, o fornecimento de potência ativa deve ser mantido durante os afundamentos de tensão, mas uma redução é permitida conforme as limitações do sistema de geração.

- Irlanda

O requisito LVRT para a Irlanda exige que o parque eólico atenda aos limites de tensão exibidos na Figura 2.13 (EirGrid, 2015). Durante os afundamentos de tensão em qualquer fase, os aerogeradores devem fornecer potência ativa de forma proporcional à tensão disponível, além de fornecer potência reativa até as tensões atingirem níveis satisfatórios, ou pelo menos, durante o período de 500 ms, caso não seja possível atender à primeira condição. Os aerogeradores devem usar todos os recursos disponíveis para auxiliar na recuperação da tensão, como STATCOMs ou SVCs.

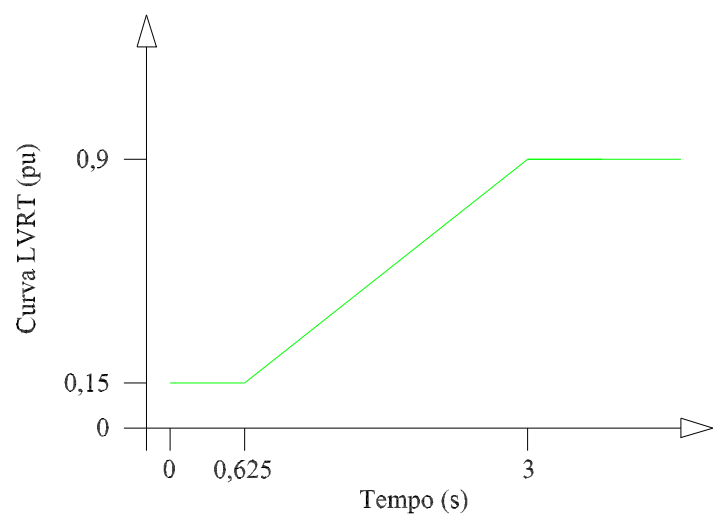

Figura 2.13: Curva LVRT definida por (EirGrid, 2015).

Os aerogeradores devem fornecer ao menos $90 \%$ de sua potência ativa máxima ou de sua potência ativa estabelecida como set-point, a menor das duas como referência, da forma mais rápida possível que a tecnologia utilizada permita, dentro do período de 500 ms, até recuperar a tensão em $90 \%$ da tensão nominal, para faltas eliminadas em até 140 ms. Para faltas mais longas, isto é, superiores a $140 \mathrm{~ms}$, o período máximo pode ser estendido para $1 \mathrm{~s}$.

Durante e após as faltas, prioridade sempre deve ser dada à resposta relacionada à potência ativa dos aerogeradores. A resposta referente à corrente reativa deve ser direcionada à recuperação da tensão ao seu valor nominal, cujo sistema de controle deve ser concebido para operar, ao menos, de forma diretamente proporcional ao afundamento de tensão. Esta corrente deve ser fornecida dentro dos limites nominais dos aerogeradores, com um tempo de subida não superior a 100 ms e um tempo de estabilização não superior a 300 ms. O fornecimento desta corrente deve ser realizado diretamente pelos aerogeradores, pelos dispositivos adicionais de suporte de potência reativa ou pela combinação de todos.

Os aerogeradores devem ser capazes de fornecer respostas às variações normais de tensão através de um sistema de controle independente do sistema de controle dedicado às situações de afundamentos severos de tensão. Os aerogeradores devem retomar o seu sistema 
de controle referente à condição pré-falta dentro do período de 500 ms quando as tensões apresentarem-se dentro dos níveis normais de operação.

- África do Sul

O requisito LVRT para a África do Sul foi elaborado para diferentes categorias de parques eólicos (NERSA, 2016). Para instalações de potência inferior a 100 kVA, adota-se um primeiro perfil de tensão. Para instalações de potência a partir de 100 kVA, adota-se um segundo perfil de tensão. Para faltas simétricas ou assimétricas, isto é, faltas trifásicas, bifásicas ou monofásicas, tanto no sistema de transmissão, como no sistema de distribuição, é exigido que a tensão no PCC atenda aos limites de tensão exibidos na Figura 2.14.

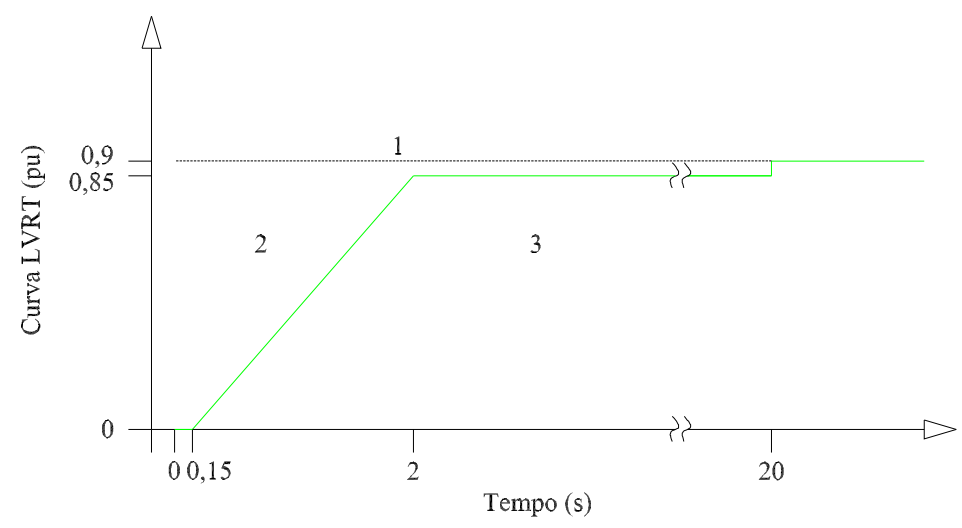

Figura 2.14: Curva LVRT definida por (NERSA, 2016).

Se a tensão retornar à área 1 durante a falta, afundamentos de tensão subsequentes devem referir-se a novas condições de falta. Se sucessivas faltas ocorrerem dentro da área 2 mas envolverem a área 3, permite-se a desconexão do parque eólico. Na área 1, o parque eólico deve permanecer conectado ao PCC.

$\mathrm{Na}$ área 2, o fornecimento de potência reativa deve ter prioridade em relação ao fornecimento de potência ativa. Para faltas simétricas que ocorram nesta área, os aerogeradores devem ter a capacidade de controlar a corrente reativa, conforme limites pré-determinados pelo operador do sistema elétrico. Ainda, o parque eólico deve permanecer conectado ao PCC e também: i) parques eólicos de potência a partir de 100 kVA e menores que 1 MVA, não devem injetar corrente reativa na rede elétrica, ii) parques eólicos de potência a partir de $1 \mathrm{MVA}$ devem fornecer o máximo suporte à recuperação da tensão aos níveis normais de operação, iii) parques eólicos de potência a partir de 1 MVA que apresentem aerogeradores equipados com conversores eletrônicos de potência, devem ser capazes de desabilitar o controle de injeção de corrente reativa na rede elétrica se requerido pelo operador do sistema.

A produção de potência ativa deve ser mantida para os afundamentos de tensão, mas deve ser diretamente proporcional à queda de tensão para valores inferiores a $85 \%$. Após a eliminação da falta, os aerogeradores devem restabelecer a produção de potência ativa para pelo menos 90\% do nível de tensão disponível anteriormente à falta, em até $1 \mathrm{~s}$. 
- Espanha

O requisito LVRT para a Espanha exige que para faltas trifásicas, bifásicas ou monofásicas, a tensão no PCC atenda aos limites de tensão exibidos na Figura 2.15 (REE, 2004).

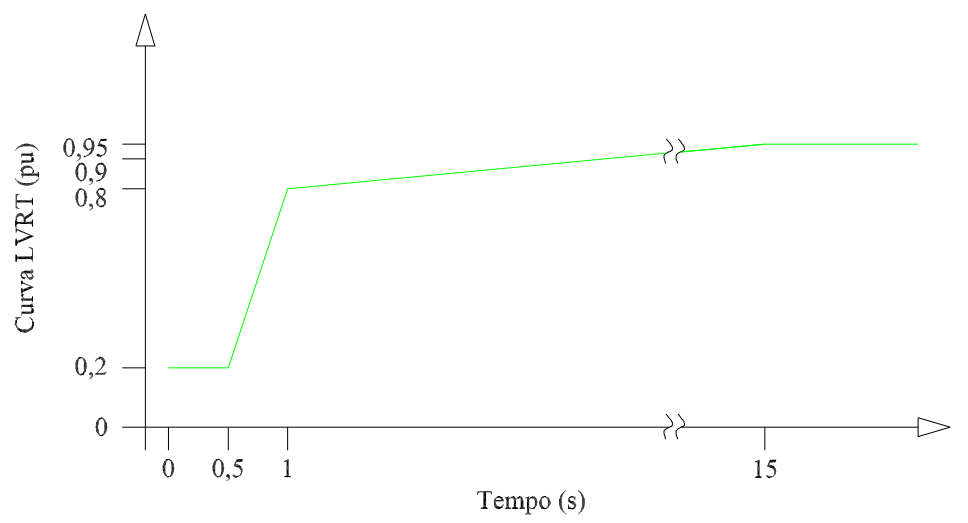

Figura 2.15: Curva LVRT definida por (REE, 2004).

Não se admite o consumo de potência ativa ou reativa durante os períodos de falta e recuperação do sistema. Tanto para o sistema em falta como para o sistema pós-falta, quando as tensões forem inferiores a 0,85 pu, os aerogeradores deverão gerar potência reativa, cuja injeção de corrente reativa seguirá um perfil pré-determinado pelo operador do sistema elétrico, aumentando gradativamente até um valor fixo.

- Malásia

O requisito LVRT para a Malásia exige que para faltas simétricas e assimétricas, a tensão no PCC atenda aos limites de tensão exibidos na Figura 2.16 (Tenaga, 2016).

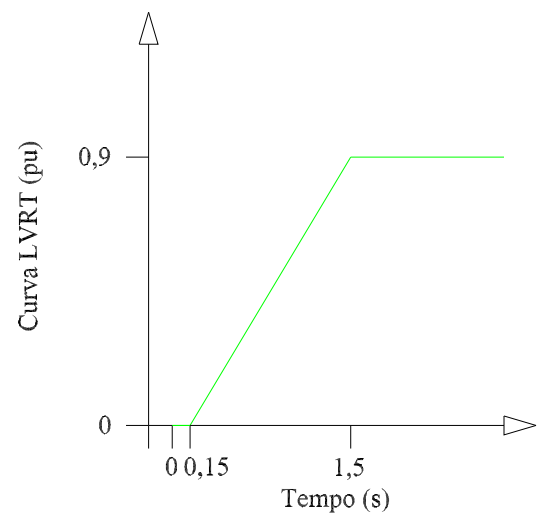

Figura 2.16: Curva LVRT definida por (Tenaga, 2016).

Para faltas eliminadas em até 300 ms, o parque eólico deve ser capaz de restaurar a produção de potência ativa para o mínimo de 90\% do nível de potência disponível anteriormente à falta, no período máximo de 1,5 s para a restauração da tensão ao valor mínimo 
permitido, referente ao PCC. Os limites para a excursão da tensão após a eliminação da falta correspondem a 0,7 pu durante 400 ms. Uma vez que a produção de potência ativa tenha sido restaurada para os níveis requeridos pelo operador do sistema elétrico, as oscilações de potência resultantes devem ser devidamente amortecidas.

Para faltas eliminadas após 300 ms, o parque eólico deve permanecer transitoriamente estável e conectado à rede, além de também ser capaz de produzir potência ativa durante os afundamentos de tensão e gerar o máximo possível de corrente reativa durante a falta, sem ultrapassar os limites dos aerogeradores.

Faltas simétricas e assimétricas com conexão à terra, podem resultar em tensões nulas para as fases do sistema trifásico. A duração máxima para eliminação destas faltas dependerá dos limites de tempo do sistema de proteção local e deverá ser adaptada às especificações do operador do sistema elétrico.

- Canadá

O requisito LVRT para o Canadá exige que para faltas simétricas ou não, a tensão no PCC atenda aos limites de tensão exibidos na Figura 2.17 (Hydro-Québec, 2009).

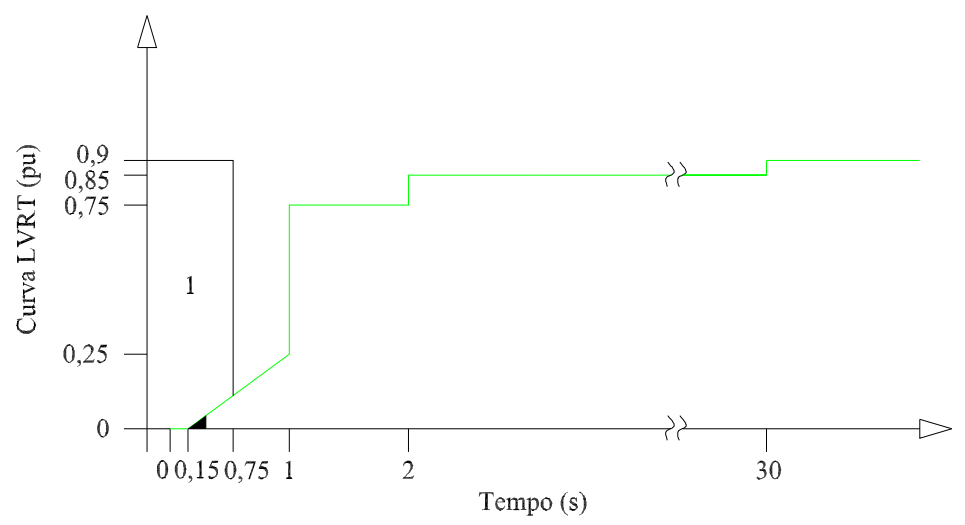

Figura 2.17: Curva LVRT definida por (Hydro-Québec, 2009).

O requisito LVRT baseia-se na medida de sequência positiva da tensão de fase no lado de alta tensão do sistema. A área 1 corresponde à área de ocorrência das faltas e aplica-se até $0,15 \mathrm{~s}$ às faltas trifásicas, bifásicas ou bifásicas-terra. A pequena parte hachurada aplica-se até $0,3 \mathrm{~s}$, apenas às faltas fase-terra. Até $0,75 \mathrm{~s}$, o perfil de tensão é aplicável para todas as faltas.

- Grã-Bretanha

O requisito LVRT para os países da Grã-Bretanha foi elaborado para parques eólicos onshore e offshore (National Grid, 2018). Considerando parques eólicos offshore, o requisito LVRT para os países da Grã-Bretanha exige que para faltas simétricas, a tensão no PCC atenda aos limites de tensão exibidos na Figura 2.18. 


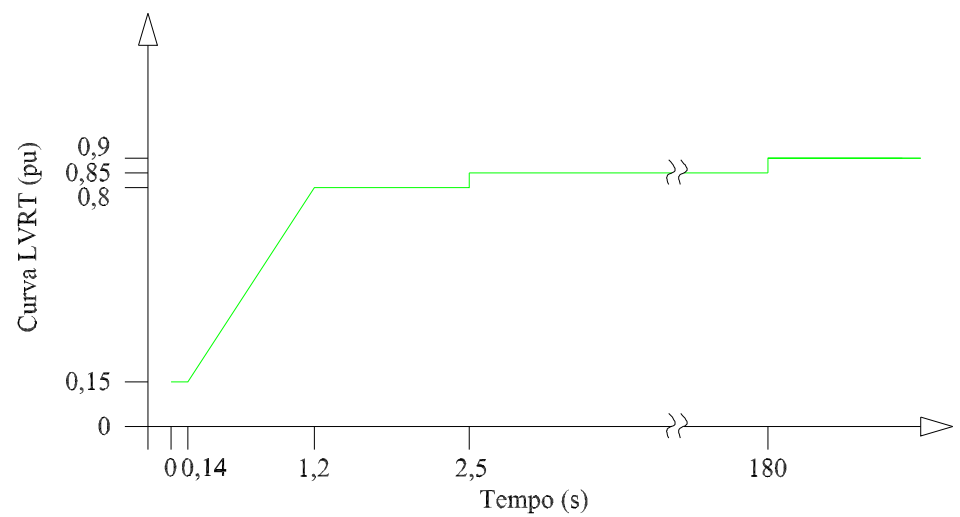

Figura 2.18: Curva LVRT definida por (National Grid, 2018).

Para faltas eliminadas em até 140 ms o parque eólico deve ser capaz de restaurar a produção de potência ativa para o mínimo de $90 \%$ do nível de potência disponível anteriormente à falta, no período máximo de 0,5 s para a restauração da tensão ao valor mínimo permitido, referente ao PCC. Uma vez que a produção de potência ativa tenha sido restaurada para os níveis requeridos pelo operador do sistema elétrico, as oscilações de potência resultantes devem ser devidamente amortecidas.

O parque eólico deve ser capaz de produzir potência ativa durante os afundamentos de tensão e gerar o máximo possível de corrente reativa durante a falta, sem ultrapassar os limites dos aerogeradores.

- Brasil

O requisito LVRT para o Brasil estabelece que caso haja variações temporárias em uma ou mais fases no PCC, o parque eólico deve continuar operando conforme os limites de tensão exibidos na Figura 2.19 (ONS, 2016).

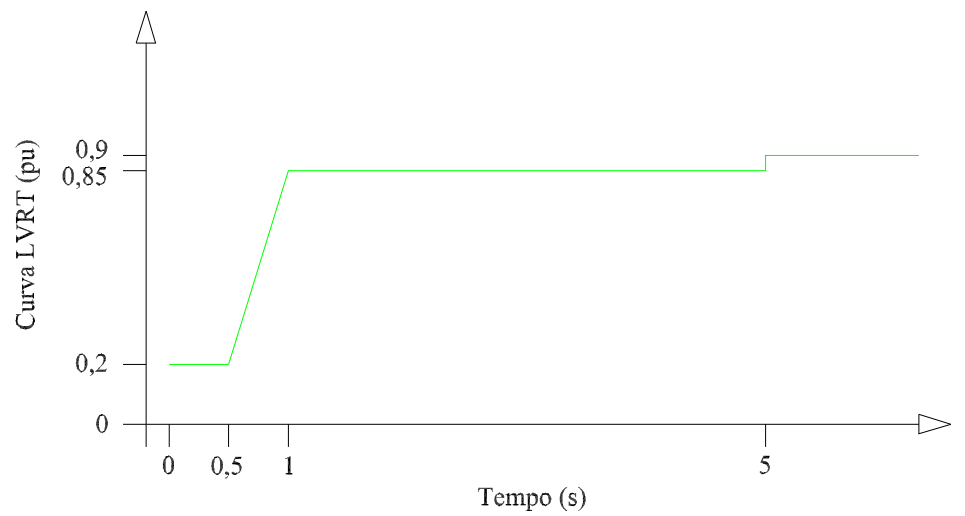

Figura 2.19: Curva LVRT definida por (ONS, 2016).

As variações temporárias decorrentes de distúrbios na rede básica podem corresponder a rejeições de carga, defeitos simétricos ou assimétricos, devendo-se avaliar sempre a fase 
que sofrer maior variação. Os aerogeradores também deverão injetar corrente reativa a fim de contribuir para os níveis de tensão da rede. Para tensões de sequência positiva inferiores a $85 \%$, os aerogeradores devem ser capazes de injetar potência reativa e assim evitar afundamentos de tensão ainda mais intensos.

- Estados Unidos da América

O requisito LVRT para os Estados Unidos da América, definido pela Federal Energy Regulatory Commission (FERC), aplica-se a instalações de energia eólica de potência superior a 20 MW (FERC, 2005). Exige-se que a tensão no PCC atenda aos limites de tensão exibidos na Figura 2.20.

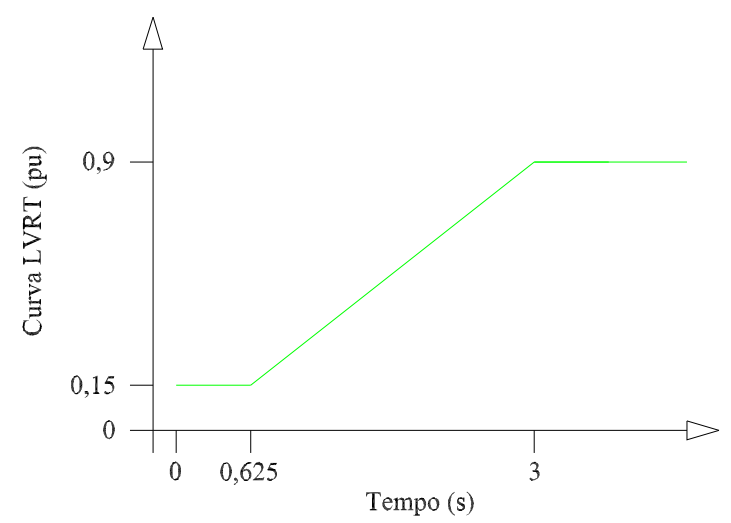

Figura 2.20: Curva LVRT definida por (FERC, 2005).

\subsection{Comentários finais}

Neste capítulo foram citados alguns dados globais e nacionais sobre a geração de eletricidade a partir de aerogeradores. Constata-se que houve nos últimos anos uma inserção significativa destes nos sistemas elétricos de potência e que as projeções indicam uma presença cada vez maior nas próximas décadas.

Foram apresentadas as configurações mais comuns de aerogeradores, sumarizando as principais características relacionadas à interação com a rede elétrica. Ainda, os mecanismos que causam a instabilidade de velocidade do gerador de indução foram explicados, destacando a definição da estabilidade de velocidade.

Por último, foram descritos requisitos de operação, com ênfase dada ao requisito de suportabilidade a afundamentos de tensão. Tal requisito foi explicado em detalhes, destacando também a sua definição. Foi possível ainda identificar as particularidades da curva LVRT para diferentes países.

No próximo capítulo desenvolve-se a modelagem do sistema teste, incluindo a rede elétrica e os aerogeradores dos tipos A, B e C. Os modelos resultantes serão necessários para realizar os estudos de estabilidade explicitados na introdução deste trabalho. 


\section{Capítulo 3}

\section{Modelagem}

\subsection{Introdução}

Neste capítulo é desenvolvida a modelagem do sistema teste. O mesmo pode ser observado na Figura 3.1. Tal sistema é composto por uma linha de transmissão, um transformador, um tipo de aerogerador ( $A, B$ ou $C$ ) e por três barras: i) uma barra infinita, ii) uma barra que representa o PCC e iii) uma barra na qual conecta-se o aerogerador. Um capacitor é aplicado a esta última barra no caso dos aerogeradores dos tipos A e B.

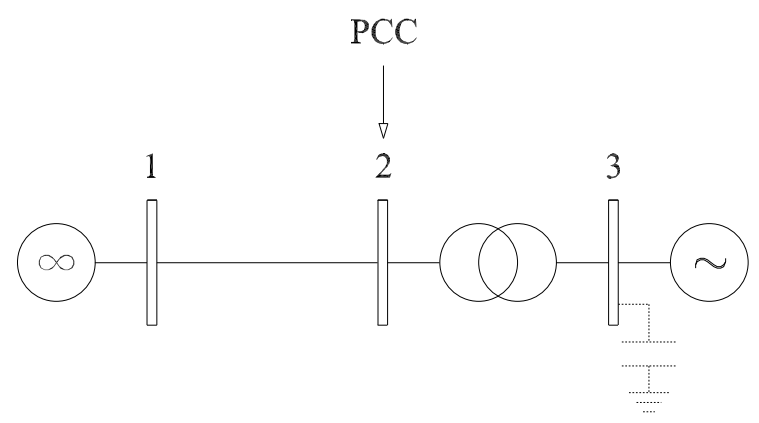

Figura 3.1: Sistema teste.

O aerogerador do tipo A será denominado de configuração SCIG. Para esta configuração é considerado apenas o modelo do gerador de indução em gaiola de esquilo. $\mathrm{O}$ aerogerador do tipo B será denominado de configuração WRIG. Para esta configuração é considerado apenas o modelo do gerador de indução com rotor bobinado. O aerogerador do tipo $C$ será denominado de configuração DFIG. Para esta configuração é considerado o modelo do gerador de indução com rotor bobinado, os modelos dos conversores eletrônicos de potência e dos controladores associados. Para as três configurações a turbina não é modelada em detalhes, porém na equação mecânica são consideradas as inércias da turbina e do rotor do gerador. O torque mecânico é considerado constante para as configurações SCIG e WRIG. Para a configuração DFIG, o torque mecânico é definido como uma função da frequência do rotor. Não são modelados quaisquer sistemas de proteção.

A princípio, são desenvolvidas as equações referentes ao modelo da rede elétrica. Em seguida, são desenvolvidas as equações referentes ao modelo da máquina de indução. Inicial- 
mente, os modelos são obtidos no sistema de coordenadas $d q$. Por último, são desenvolvidas as equações referentes ao modelo em regime permanente para as configurações SCIG e WRIG.

Uma vez que o sistema teste pode ser equipado com diferentes aerogeradores, o mesmo é descrito pelas equações que modelam cada unidade de geração acrescentadas às equações que modelam a rede elétrica. Para o sistema teste equipado com a configuração SCIG, dois conjuntos completos são obtidos, um com o modelo do gerador de indução desenvolvido no sistema de coordenadas $d q$ e outro com o modelo do gerador de indução desenvolvido em regime permanente. De forma análoga, para o sistema teste equipado com a configuração WRIG, dois conjuntos completos de equações são obtidos. Para o sistema teste equipado com a configuração DFIG, três conjuntos de equações são estabelecidos. Dois conjuntos para o processo de inicialização e um conjunto completo para as simulações dinâmicas. Uma vez que o modelo do gerador de indução pode ser simplificado de quinta ordem, para terceira e primeira ordens, novos conjuntos completos de equações são então obtidos, conforme será explicado mais adiante.

\subsection{Rede elétrica}

Desenvolve-se a partir de agora a modelagem da rede elétrica, com parâmetros e variáveis representados por unidade, definidos na base da máquina. Como já mencionado na introdução deste capítulo, a rede elétrica do sistema teste é composta por uma linha de transmissão e por um transformador. A linha de transmissão é descrita pelo modelo $\pi$ (Stevenson Jr., 1986). Tal modelo é ilustrado na Figura 3.2, onde são exibidas as admitâncias série $y_{k m}$ e shunt $y_{k m}^{s h}$ entre as barras $k$ e $m$.

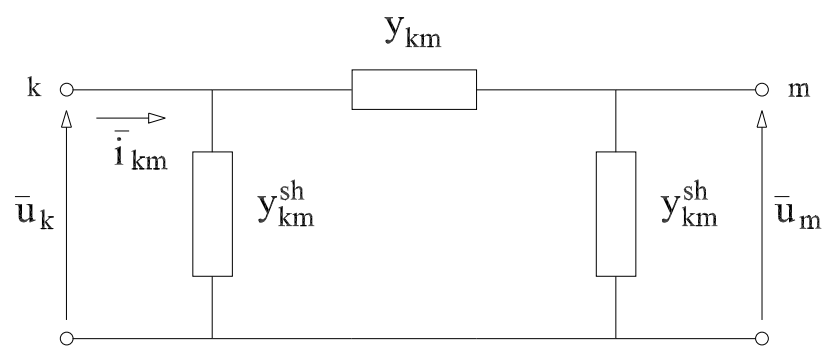

Figura 3.2: Circuito equivalente da linha de transmissão.

O transformador é utilizado para elevar o nível de tensão entre o aerogerador e a linha de transmissão. Escolhendo convenientemente os valores de base para o primário e para o secundário, é possível tornar a relação 1:1 para o transformador ideal (Oliveira et al., 2000). Em suma, escolhendo as tensões de base com valores iguais à relação de espiras, assim como a potência base do primário e a potência base do secundário iguais, é possível representar o transformador por unidade conforme mostra a Figura 3.3, onde são exibidas a resistência $r_{p}$ e a reatância $x_{p}$ shunt, assim como a resistência $r_{t}$ e a reatância $x_{t}$ série.

Como pode ser observado, a representação equivalente do transformador é semelhante à representação da linha de transmissão. Considerando a impedância shunt do transformador 


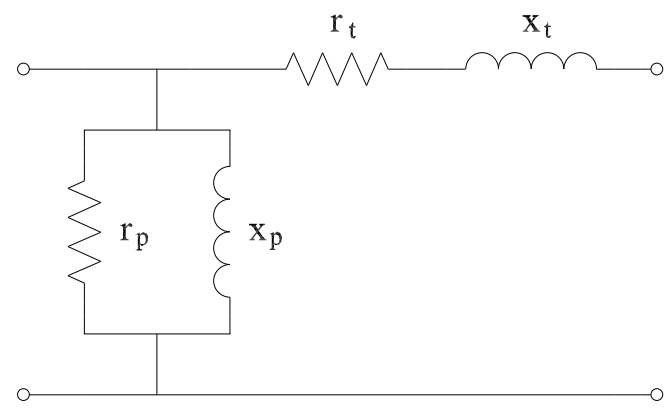

Figura 3.3: Circuito equivalente do transformador.

como infinita, implica que a respectiva admitância shunt torna-se nula e o transformador fica representado somente pela impedância, ou admitância, série.

A partir do modelo da linha de transmissão e do modelo do transformador, o equacionamento da rede elétrica torna-se possível. A Figura 3.4 mostra o esquema elétrico para correntes aplicadas em uma barra genérica $k$ (Almeida, 2010).

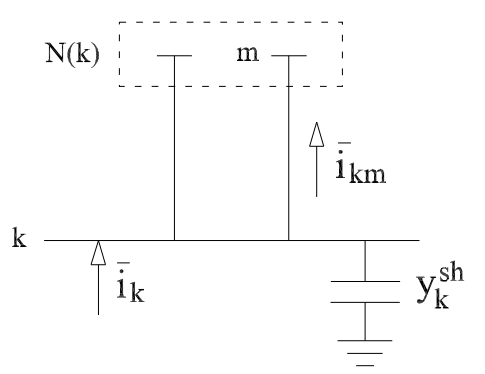

Figura 3.4: Injeção líquida de corrente em uma barra genérica.

Neste esquema podem ser observadas as barras $k$ e $m$ conectadas via uma linha de transmissão ou transformador, o conjunto de todas as barras conectadas à barra $k$ via uma linha de transmissão ou transformador $N(k)$, a admitância shunt conectada à barra $k y_{k}^{s h}$, que pode representar uma carga ou um capacitor, o fasor de corrente $\bar{i}_{k}$, que representa a corrente injetada na barra $k$ e o fasor de corrente $\bar{i}_{k m}$, que representa a corrente entre a barra $k$ e a barra $m$ do conjunto $N(k)$.

Aplicando a Lei das Correntes de Kirchoff na barra genérica k (Cutsem e Vournas, 1998), (Kundur, 1994), obtém-se

$$
\bar{i}_{k}-y_{k}^{s h} \bar{u}_{k}-\sum_{m \in N(k)} \bar{i}_{k m}=0
$$

sendo $\bar{u}_{k}$ o fasor de tensão para a barra $k$.

Os fasores de corrente $\bar{i}_{k}$ e $\bar{i}_{k m}$ e o fasor de tensão $\bar{u}_{k}$ podem ser desmembrados em suas partes real e imaginária. Considerando a componente relativa ao eixo real denotada com o subscrito $x$ e a componente relativa ao eixo imaginário denotada com o subscrito $y$, tal 
desmembramento proporciona

$$
\begin{gathered}
\bar{i}_{k}=i_{x k}+j i_{y k}, \\
\bar{i}_{k m}=i_{x k m}+j i_{y k m}
\end{gathered}
$$

e

$$
\bar{u}_{k}=u_{x k}+j u_{y k}
$$

A relação entre os fasores de corrente e tensão da linha de transmissão e transformador é dada por

$$
\bar{i}_{k m}=\left(y_{k m}+y_{k m}^{s h}\right) \bar{u}_{k}-y_{k m} \bar{u}_{m}
$$

sendo $\bar{u}_{m}$ o fasor de tensão para a barra $m$.

Para o fasor de tensão $\bar{u}_{m}$, o desmembramento nas partes real e imaginária proporciona

$$
\bar{u}_{m}=u_{x m}+j u_{y m} .
$$

A impedância $z_{k m}$ série é formada pela resistência $r_{k m}$ e pela reatância $x_{k m}$ conforme

$$
z_{k m}=r_{k m}+j x_{k m}
$$

A admitância $y_{k m}$ série, formada pela condutância $g_{k m}$ e pela susceptância $b_{k m}$, é obtida por

$$
y_{k m}=g_{k m}+j b_{k m}=\frac{1}{z_{k m}}=\frac{r_{k m}}{r_{k m}^{2}+x_{k m}^{2}}-j \frac{x_{k m}}{r_{k m}^{2}+x_{k m}^{2}} .
$$

De forma análoga para a impedância $z_{k m}^{s h}$ shunt e para a admitância $y_{k m}^{s h}$ shunt, tem-se

$$
z_{k m}^{s h}=r_{k m}^{s h}+j x_{k m}^{s h}
$$

e

$$
y_{k m}^{s h}=g_{k m}^{s h}+j b_{k m}^{s h}=\frac{1}{z_{k m}^{s h}}=\frac{r_{k m}^{s h}}{r_{k m}^{s h}+x_{k m}^{s h^{2}}}-j \frac{x_{k m}^{s h}}{r_{k m}^{s h}+x_{k m}^{s h^{2}}} .
$$

A admitância $y_{k}^{\text {sh }}$ shunt conectada à barra $k$ é definida como

$$
y_{k}^{s h}=j b_{k}^{s h} .
$$

Substituindo (3.2), (3.4), (3.5), (3.8), (3.10) e (3.11) em (3.1) e desmembrando a equação resultante nas suas componentes real e imaginária, obtém-se 


$$
i_{x k}+b_{k}^{s h} u_{y k}-\sum_{m \in N(k)}\left(g_{k m}^{s h} u_{x k}-b_{k m}^{s h} u_{y k}\right)-\sum_{m \in N(k)}\left[g_{k m}\left(u_{x k}-u_{x m}\right)-b_{k m}\left(u_{y k}-u_{y m}\right)\right]=0
$$

e

$$
i_{y k}-b_{k}^{s h} u_{x k}-\sum_{m \in N(k)}\left(b_{k m}^{s h} u_{x k}+g_{k m}^{s h} u_{y k}\right)-\sum_{m \in N(k)}\left[b_{k m}\left(u_{x k}-u_{x m}\right)+g_{k m}\left(u_{y k}-u_{y m}\right)\right]=0 .
$$

Aplicando (3.12) e (3.13) às barras do sistema teste, obtém-se para a barra 1

$$
i_{x 1}+\left(-g_{12}^{s h}-g_{12}\right) u_{x 1}+\left(b_{1}^{s h}+b_{12}^{s h}+b_{12}\right) u_{y 1}+g_{12} u_{x 2}-b_{12} u_{y 2}=0
$$

e

$$
i_{y 1}+\left(-b_{1}^{s h}-b_{12}^{s h}-b_{12}\right) u_{x 1}+\left(-g_{12}^{s h}-g_{12}\right) u_{y 1}+b_{12} u_{x 2}+g_{12} u_{y 2}=0 .
$$

Para a barra 2, que representa o PCC, obtém-se

$$
\begin{aligned}
& i_{x 2}+g_{12} u_{x 1}-b_{12} u_{y 1}+\left(-g_{12}^{s h}-g_{23}^{s h}-g_{12}-g_{23}\right) u_{x 2}+ \\
& \left(b_{2}^{s h}+b_{12}^{s h}+b_{23}^{s h}+b_{12}+b_{23}\right) u_{y 2}+g_{23} u_{x 3}-b_{23} u_{y 3}=0
\end{aligned}
$$

e

$$
\begin{aligned}
& i_{y 2}+b_{12} u_{x 1}+g_{12} u_{y 1}+\left(-b_{2}^{s h}-b_{12}^{s h}-b_{23}^{s h}-b_{12}-b_{23}\right) u_{x 2}+ \\
&\left(-g_{12}^{s h}-g_{23}^{s h}-g_{12}-g_{23}\right) u_{y 2}+b_{23} u_{x 3}+g_{23} u_{y 3}=0 .
\end{aligned}
$$

Já para a barra 3, na qual conecta-se o aerogerador, é possível escrever

$$
i_{x 3}+g_{23} u_{x 2}-b_{23} u_{y 2}+\left(-g_{32}^{s h}-g_{23}\right) u_{x 3}+\left(b_{3}^{s h}+b_{32}^{s h}+b_{23}\right) u_{y 3}=0
$$

e

$$
i_{y 3}+b_{23} u_{x 2}+g_{23} u_{y 2}+\left(-b_{3}^{s h}-b_{32}^{s h}-b_{23}\right) u_{x 3}+\left(-g_{32}^{s h}-g_{23}\right) u_{y 3}=0 .
$$

Para a barra 2 não há injeção de corrente. Desta forma $i_{x 2}=i_{y 2}=0$. Há admitância shunt apenas na barra 3, ou barra terminal do aerogerador. Na realidade, tal admitância consiste de uma susceptância shunt, que representa um capacitor, utilizado para elevar a tensão nesta barra e na barra 2. Desta forma $b_{1}^{s h}=b_{2}^{s h}=0$. A partir destas simplificações, obtém-se finalmente o conjunto de equações que modela a rede elétrica do sistema teste 


$$
\begin{gathered}
g_{12} u_{x 1}-b_{12} u_{y 1}+\left(-g_{12}^{s h}-g_{23}^{s h}-g_{12}-g_{23}\right) u_{x 2}+ \\
\left(b_{12}^{s h}+b_{23}^{s h}+b_{12}+b_{23}\right) u_{y 2}+g_{23} u_{x 3}-b_{23} u_{y 3}=0, \\
b_{12} u_{x 1}+g_{12} u_{y 1}+\left(-b_{12}^{s h}-b_{23}^{s h}-b_{12}-b_{23}\right) u_{x 2}+ \\
\left(-g_{12}^{s h}-g_{23}^{s h}-g_{12}-g_{23}\right) u_{y 2}+b_{23} u_{x 3}+g_{23} u_{y 3}=0, \\
i_{x 3}+g_{23} u_{x 2}-b_{23} u_{y 2}+\left(-g_{32}^{s h}-g_{23}\right) u_{x 3}+\left(b_{32}^{s h}+b_{23}+b_{3}^{s h}\right) u_{y 3}=0
\end{gathered}
$$

e

$$
i_{y 3}+b_{23} u_{x 2}+g_{23} u_{y 2}+\left(-g_{32}^{s h}-g_{23}\right) u_{y 3}+\left(-b_{32}^{s h}-b_{23}-b_{3}^{s h}\right) u_{x 3}=0 .
$$

Toma-se a barra 1 como referência angular e portanto as componentes de tensão na barra 1 são previamente conhecidas, $u_{x 1}=1$ e $u_{y 1}=0$. Todos os valores de susceptância e condutância são apresentados no apêndice $A$.

\subsection{Máquina de indução nos eixos $d$ e $q$}

Para a modelagem da máquina de indução no sistema de coordenadas $d q$, é necessário inicialmente realizar uma transformação de variáveis. Tal transformação permite que um sistema polifásico girante possa ser representado por um sistema bifásico equivalente, conservando as características dinâmicas do sistema original e reduzindo o número de variáveis para o modelo resultante (Gaspareto e Reginatto, 2006).

A transformação de variáveis entre os diferentes sistemas de coordenadas pode ser melhor compreendida a partir da Figura 3.5, que mostra três sistemas de coordenadas distintos. O sistema de coordenadas abcs refere-se ao estator e o mesmo é formado pelos eixos estacionários as, bs e cs, defasados 120 graus um do outro. Para o rotor, tem-se o sistema de coordenadas $a b c r$, formado pelos eixos ar, $b r$ e $c r$, defasados 120 graus um do outro e que giram à frequência do rotor $\omega_{r}$ em relação aos eixos estacionários. E por fim tem-se o sistema de coordenadas $d q$, formado pelos eixos ortogonais $d$ e $q$, que giram à frequência síncrona $\omega_{s}$ em relação aos eixos estacionários.

Como pode ser observado na Figura 3.5, o ângulo $\theta$ é medido em relação ao eixo $q$, assim como o ângulo $\theta_{r}$ é medido em relação ao eixo $a r$, tomando como referência para ambos o eixo estacionário as. O ângulo $\theta$ define o referencial em que as variáveis no sistema de coordenadas $d q$ serão vistas (Krause et al., 2013), (Ong, 1998). Verifica-se também que o eixo $q$ está atrasado em relação ao eixo $d$. É importante fazer esta observação, pois é mais comum encontrar na literatura a modelagem da máquina de indução elaborada a partir do eixo $q$ adiantado em relação ao eixo $d$. Como exemplo, citam-se as referências (Gaspareto e Reginatto, 2006), (Anaya-Lara et al., 2009), (Kundur, 1994), (Ekanayake et al., 2003a) e (Holdsworth et al., 2003a). 


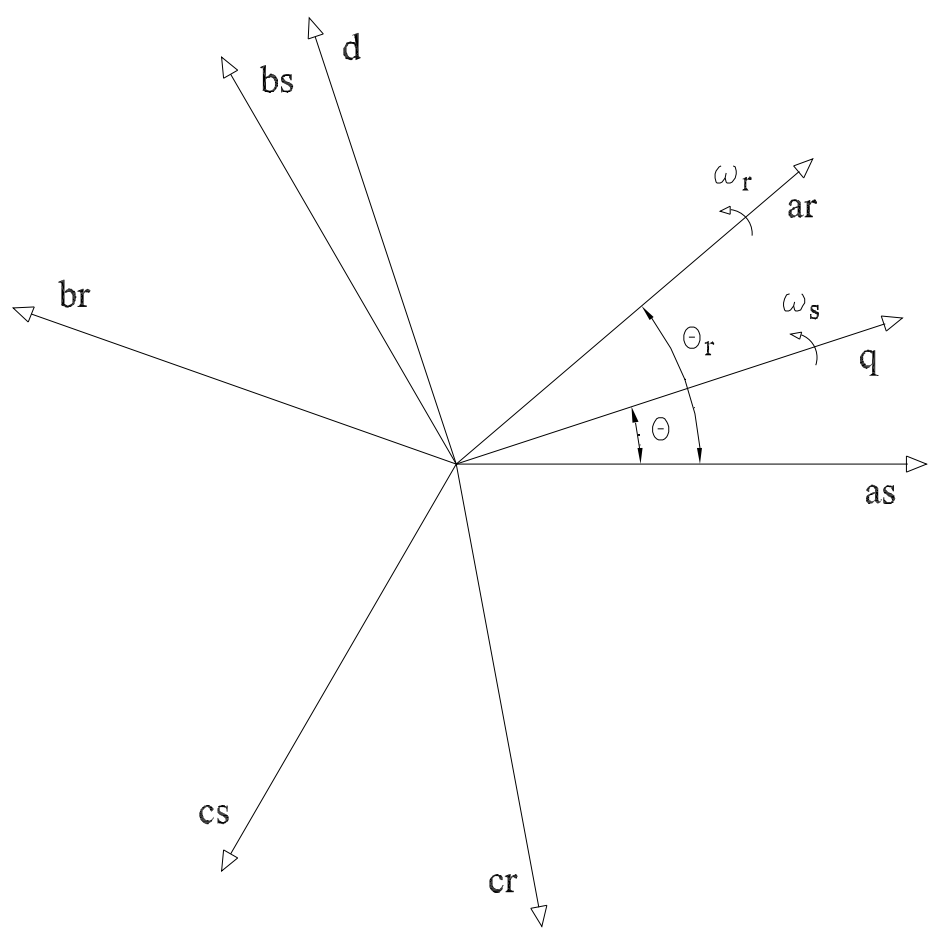

Figura 3.5: Transformação entre sistemas de coordenadas.

A mudança na ordem dos eixos, com respeito ao mesmo sentido de rotação, demandará alterações nas matrizes de transformação e consequentemente nas equações finais da máquina (Reginatto, 2006), (Lee et al., 1984). Evidentemente, para ambas suposições as equações resultantes devem fornecer os mesmos resultados para todas as variáveis do modelo. De fato, esta informação foi verificada neste trabalho através de simulações computacionais, uma vez que ambas suposições foram levadas em consideração. Em outras palavras, a modelagem da máquina de indução foi elaborada considerando tanto o eixo $q$ atrasado como adiantado em relação ao eixo $d$. Visto ser menos comum encontrar na literatura a modelagem da máquina de indução a partir do sistema de coordenadas com o eixo $q$ atrasado em relação ao eixo $d$, escolheu-se por apresentar a modelagem com esta disposição dos eixos, como ilustrado na Figura 3.5.

A modelagem da máquina de indução no sistema de coordenadas $d q$ é desenvolvida a seguir, tomando como referências principais (Gaspareto e Reginatto, 2006), (Reginatto, 2006), (Krause et al., 2013) e (Kundur, 1994). O objetivo aqui é obter as equações elétricas e a equação mecânica do sistema, que serão em seguida acrescentadas às equações que modelam a rede elétrica, de forma que o conjunto completo de equações que modela o sistema teste apresente a máquina operando no modo gerador. São consideradas as seguintes premissas para a modelagem da máquina: i) existe simetria elétrica e espacial entre as três fases, para o rotor e estator da máquina, ii) o fluxo magnético no entreferro apresenta distribuição senoidal, iii) o circuito magnético é linear, iv) não existem perdas magnéticas nem mecânicas, v) para as equações elétricas, as correntes positivas do rotor e do estator são aquelas que entram 
nos terminais da máquina, vi) para a equação mecânica, o torque mecânico proporciona a aceleração da máquina, enquanto que o torque eletromagnético provoca a desaceleração, vii) a componente $q$ é escolhida como a parte real e a componente $d$ como a parte imaginária no sistema fasorial e viii) assume-se que os eixos $d$ e $q$ sempre giram à frequência síncrona $\omega_{s}$, isto é, adota-se o sistema de referência síncrono.

Seja então, para o estator da máquina, o vetor genérico $\vec{f}_{a b c s}$ referente ao sistema de eixos estacionários, formado pelas variáveis genéricas $f_{a s}, f_{b s}$ e $f_{c s}$

$$
\vec{f}_{a b c s}=\left[\begin{array}{lll}
f_{a s} & f_{b s} & f_{c s}
\end{array}\right]^{T} .
$$

Tais variáveis genéricas podem ser representadas no sistema de coordenadas $d q$ através da transformação

$$
\vec{f}_{d q 0 s}=T_{d q 0}(\theta) \vec{f}_{a b c s}
$$

sendo $\vec{f}_{d q 0 s}$ o vetor

$$
\vec{f}_{d q 0 s}=\left[\begin{array}{lll}
f_{d s} & f_{q s} & f_{0 s}
\end{array}\right]^{T}
$$

cujas variáveis $f_{d s}, f_{q s}$ e $f_{0 s}$ representam as variáveis genéricas $f_{a s}, f_{b s}$ e $f_{c s}$ no sistema de coordenadas $d q$. A variável $f_{0 s}$, chamada de componente de sequência zero, assume o valor nulo quando considerado um conjunto simétrico de variáveis no sistema de coordenadas abcs. Assumindo que as tensões trifásicas são simétricas, o modelo resultante fica representado apenas nos eixos $d$ e $q$. Portanto, as variáveis passam de um sistema original trifásico para um novo sistema, agora bifásico.

A matriz de transformação $T_{d q 0}(\theta)$ é dada por

$$
T_{d q 0}(\theta)=\frac{2}{3}\left[\begin{array}{ccc}
-\operatorname{sen}(\theta) & -\operatorname{sen}\left(\theta-\frac{2 \pi}{3}\right) & -\operatorname{sen}\left(\theta+\frac{2 \pi}{3}\right) \\
\cos (\theta) & \cos \left(\theta-\frac{2 \pi}{3}\right) & \cos \left(\theta+\frac{2 \pi}{3}\right) \\
m & m & m
\end{array}\right],
$$

sendo $m$ uma constante arbitrária, incluída para tornar a matriz inversível.

O vetor $\vec{f}_{a b c s}$ pode ser obtido a partir da relação

$$
\vec{f}_{a b c s}=T_{d q 0}(\theta)^{-1} \vec{f}_{d q 0 s},
$$

em que a matriz de transformação $T_{d q 0}(\theta)^{-1}$ é dada por

$$
T_{d q 0}(\theta)^{-1}=\left[\begin{array}{ccc}
-\operatorname{sen}(\theta) & \cos (\theta) & \frac{1}{2 m} \\
-\operatorname{sen}\left(\theta-\frac{2 \pi}{3}\right) & \cos \left(\theta-\frac{2 \pi}{3}\right) & \frac{1}{2 m} \\
-\operatorname{sen}\left(\theta+\frac{2 \pi}{3}\right) & \cos \left(\theta+\frac{2 \pi}{3}\right) & \frac{1}{2 m}
\end{array}\right]
$$


Para o rotor da máquina, os passos anteriores são seguidos de forma análoga. Seja o vetor genérico $\vec{f}_{a b c r}$ referente ao sistema de eixos que giram à frequência do rotor $\omega_{r}$, formado pelas variáveis genéricas $f_{a r}, f_{b r}$ e $f_{c r}$

$$
\vec{f}_{a b c r}=\left[\begin{array}{lll}
f_{a r} & f_{b r} & f_{c r}
\end{array}\right]^{T}
$$

Tais variáveis podem ser representadas no sistema de coordenadas $d q$ através da transformação

$$
\vec{f}_{d q 0 r}=T_{d q 0}\left(\theta-\theta_{r}\right) \vec{f}_{a b c r}
$$

sendo $\vec{f}_{d q 0 r}$ o vetor

$$
\vec{f}_{d q 0 r}=\left[\begin{array}{lll}
f_{d r} & f_{q r} & f_{0 r}
\end{array}\right]^{T}
$$

cuja variável $f_{0 r}$ também assume o valor nulo, de modo que o modelo resultante fica representado apenas nos eixos $d$ e $q$.

A matriz de transformação $T_{d q 0}\left(\theta-\theta_{r}\right)$ é dada por

$$
T_{d q 0}\left(\theta-\theta_{r}\right)=\frac{2}{3}\left[\begin{array}{ccc}
-\operatorname{sen}\left(\theta-\theta_{r}\right) & -\operatorname{sen}\left(\theta-\theta_{r}-\frac{2 \pi}{3}\right) & -\operatorname{sen}\left(\theta-\theta_{r}+\frac{2 \pi}{3}\right) \\
\cos \left(\theta-\theta_{r}\right) & \cos \left(\theta-\theta_{r}-\frac{2 \pi}{3}\right) & \cos \left(\theta-\theta_{r}+\frac{2 \pi}{3}\right) \\
m & m & m
\end{array}\right]
$$

O vetor $\vec{f}_{a b c r}$ pode ser obtido a partir da relação

$$
\vec{f}_{a b c r}=T_{d q 0}(\theta)^{-1} \vec{f}_{d q 0 r},
$$

em que a matriz de transformação $T_{d q 0}\left(\theta-\theta_{r}\right)^{-1}$ é dada por

$$
T_{d q 0}\left(\theta-\theta_{r}\right)^{-1}=\left[\begin{array}{ccc}
-\operatorname{sen}\left(\theta-\theta_{r}\right) & \cos \left(\theta-\theta_{r}\right) & \frac{1}{2 m} \\
-\operatorname{sen}\left(\theta-\theta_{r}-\frac{2 \pi}{3}\right) & \cos \left(\theta-\theta_{r}-\frac{2 \pi}{3}\right) & \frac{1}{2 m} \\
-\operatorname{sen}\left(\theta-\theta_{r}+\frac{2 \pi}{3}\right) & \cos \left(\theta-\theta_{r}+\frac{2 \pi}{3}\right) & \frac{1}{2 m}
\end{array}\right]
$$

\subsubsection{Equações elétricas}

Segue a partir de agora a modelagem da máquina. Inicialmente as unidades dos parâmetros e variáveis correspondem às unidades adotadas pelo Sistema Internacional de Unidades (SI). Mais adiante será desenvolvida a modelagem por unidade.

Sejam as equações que representam as tensões da máquina, no sistema trifásico $a b c$ (Krause et al., 2013), expressas conforme

$$
\vec{u}_{a b c s}=R_{s} \vec{i}_{a b c s}+\frac{d \vec{\lambda}_{a b c s}}{d t}
$$




$$
\vec{u}_{a b c r}=R_{r} \vec{i}_{a b c r}+\frac{d \vec{\lambda}_{a b c r}}{d t}
$$

em que, para os circuitos estatórico e rotórico, $\vec{u}_{a b c s}$ e $\vec{u}_{a b c r}$ são os vetores das tensões de fase, $\vec{i}_{a b c s}$ e $\vec{i}_{a b c r}$ são os vetores das correntes, $\vec{\lambda}_{a b c s}$ e $\vec{\lambda}_{a b c r}$ são os vetores dos fluxos magnéticos de cada fase e $R_{s}$ e $R_{r}$ são as matrizes diagonais $3 \times 3$ que representam a resistência por fase para cada circuito.

É importante observar neste ponto que as variáveis do rotor serão consideradas referenciadas ao circuito do estator. Considerando a relação de transformação $k$

$$
k=\frac{n_{s}}{n_{r}}
$$

em que $n_{s}$ é o número de espiras do estator e $n_{r}$ é o número de espiras do rotor e que, por simplicidade, a mesma notação é utilizada para as variáveis, é possível escrever as relações

$$
\begin{aligned}
& \frac{1}{k} \vec{i}_{a b c r}=\vec{i}_{a b c r}, \\
& k \vec{u}_{a b c r}=\vec{u}_{a b c r}, \\
& k \vec{\lambda}_{a b c r}=\vec{\lambda}_{a b c r}, \\
& k^{2} \vec{r}_{a b c r}=\vec{r}_{a b c r}
\end{aligned}
$$

e

$$
k^{2} \vec{x}_{a b c r}=\vec{x}_{a b c r}
$$

sendo para o circuito rotórico, $\vec{r}_{a b c r}$ o vetor que representa as resistências por fase e $\vec{x}_{a b c r} 0$ vetor que representa as reatâncias por fase.

Fica registrado portanto que todas as variáveis do circuito rotórico serão representadas nas próximas equações já referenciadas ao estator, conforme as relações apresentadas.

Aplicando (3.28) em (3.36) para o estator, é possível escrever

$$
\vec{u}_{d q 0 s}=R_{s} \vec{i}_{d q 0 s}+T_{d q 0}(\theta) \frac{d T_{d q 0}(\theta)^{-1}}{d t} \vec{\lambda}_{d q 0 s}+T_{d q 0}(\theta) T_{d q 0}(\theta)^{-1} \frac{d \vec{\lambda}_{d q 0 s}}{d t}
$$


Uma vez que

$$
\frac{d T_{d q 0}(\theta)^{-1}}{d t}=\frac{d \theta}{d t}\left[\begin{array}{ccc}
-\cos (\theta) & -\operatorname{sen}(\theta) & 0 \\
-\cos \left(\theta-\frac{2 \pi}{3}\right) & -\operatorname{sen}\left(\theta-\frac{2 \pi}{3}\right) & 0 \\
-\cos \left(\theta+\frac{2 \pi}{3}\right) & -\operatorname{sen}\left(\theta+\frac{2 \pi}{3}\right) & 0
\end{array}\right]
$$

e

$$
T_{d q 0}(\theta) \frac{d T_{d q 0}(\theta)^{-1}}{d t}=\frac{d \theta}{d t}\left[\begin{array}{ccc}
0 & 1 & 0 \\
-1 & 0 & 0 \\
0 & 0 & 0
\end{array}\right]
$$

sendo

$$
\frac{d \theta}{d t}=\omega_{s}
$$

determinam-se as tensões no sistema de coordenadas $d q$ conforme

$$
\begin{aligned}
{\left[\begin{array}{l}
u_{d s} \\
u_{q s} \\
u_{0 s}
\end{array}\right] } & =\left[\begin{array}{ccc}
r_{s} & 0 & 0 \\
0 & r_{s} & 0 \\
0 & 0 & r_{s}
\end{array}\right]\left[\begin{array}{c}
i_{d s} \\
i_{q s} \\
i_{0 s}
\end{array}\right]+\omega_{s}\left[\begin{array}{ccc}
0 & 1 & 0 \\
-1 & 0 & 0 \\
0 & 0 & 0
\end{array}\right]\left[\begin{array}{c}
\lambda_{d s} \\
\lambda_{q s} \\
\lambda_{0 s}
\end{array}\right] \\
& +\frac{d}{d t}\left[\begin{array}{lll}
1 & 0 & 0 \\
0 & 1 & 0 \\
0 & 0 & 1
\end{array}\right]\left[\begin{array}{c}
\lambda_{d s} \\
\lambda_{q s} \\
\lambda_{0 s}
\end{array}\right] .
\end{aligned}
$$

Como o sistema é considerado simétrico, representam-se as variáveis resultantes apenas nos eixos $d$ e $q$. Desta forma, as duas primeiras equações elétricas, referentes ao estator, são

$$
u_{d s}=r_{s} i_{d s}+\omega_{s} \lambda_{q s}+\frac{d \lambda_{d s}}{d t}
$$

e

$$
u_{q s}=r_{s} i_{q s}-\omega_{s} \lambda_{d s}+\frac{d \lambda_{q s}}{d t}
$$

Para o rotor da máquina, os passos anteriores são seguidos de forma análoga. Aplicando (3.34) em (3.37), é possível escrever

$$
\vec{u}_{d q 0 r}=R_{r} \vec{i}_{d q 0 r}+T_{d q 0}\left(\theta-\theta_{r}\right) \frac{d T_{d q 0}\left(\theta-\theta_{r}\right)^{-1}}{d t} \vec{\lambda}_{d q 0 r}+T_{d q 0}\left(\theta-\theta_{r}\right) T_{d q 0}\left(\theta-\theta_{r}\right)^{-1} \frac{d \vec{\lambda}_{d q 0 r}}{d t}
$$


Uma vez que

$$
\frac{d}{d t} T_{d q 0}\left(\theta-\theta_{r}\right)^{-1}=\left(\frac{d \theta}{d t}-\frac{d \theta_{r}}{d t}\right)\left[\begin{array}{ccc}
-\cos (\theta) & -\operatorname{sen}(\theta) & 0 \\
-\cos \left(\theta-\frac{2 \pi}{3}\right) & -\operatorname{sen}\left(\theta-\frac{2 \pi}{3}\right) & 0 \\
-\cos \left(\theta+\frac{2 \pi}{3}\right) & -\operatorname{sen}\left(\theta+\frac{2 \pi}{3}\right) & 0
\end{array}\right]
$$

e

$$
T_{d q 0}\left(\theta-\theta_{r}\right) \frac{d T_{d q 0}\left(\theta-\theta_{r}\right)^{-1}}{d t}=\left(\frac{d \theta}{d t}-\frac{d \theta_{r}}{d t}\right)\left[\begin{array}{ccc}
0 & 1 & 0 \\
-1 & 0 & 0 \\
0 & 0 & 0
\end{array}\right]
$$

sendo

$$
\frac{d \theta}{d t}-\frac{d \theta_{r}}{d t}=\omega_{s}-\omega_{r}
$$

determinam-se as tensões no sistema de coordenadas $d q$ conforme

$$
\begin{aligned}
{\left[\begin{array}{c}
u_{d r} \\
u_{q r} \\
u_{0 r}
\end{array}\right] } & =\left[\begin{array}{ccc}
r_{r} & 0 & 0 \\
0 & r_{r} & 0 \\
0 & 0 & r_{r}
\end{array}\right]\left[\begin{array}{c}
i_{d r} \\
i_{q r} \\
i_{0 r}
\end{array}\right]+\left(\omega_{s}-\omega_{r}\right)\left[\begin{array}{ccc}
0 & 1 & 0 \\
-1 & 0 & 0 \\
0 & 0 & 0
\end{array}\right]\left[\begin{array}{c}
\lambda_{d r} \\
\lambda_{q r} \\
\lambda_{0 r}
\end{array}\right] \\
& +\frac{d}{d t}\left[\begin{array}{lll}
1 & 0 & 0 \\
0 & 1 & 0 \\
0 & 0 & 1
\end{array}\right]\left[\begin{array}{c}
\lambda_{d r} \\
\lambda_{q r} \\
\lambda_{0 r}
\end{array}\right]
\end{aligned}
$$

Como o sistema é considerado simétrico, representam-se as variáveis resultantes apenas nos eixos $d$ e $q$. Desta forma, as outras duas equações elétricas, referentes ao rotor, são

$$
u_{d r}=r_{r} i_{d r}+\left(\omega_{s}-\omega_{r}\right) \lambda_{q r}+\frac{d \lambda_{d r}}{d t}
$$

e

$$
u_{q r}=r_{r} i_{q r}-\left(\omega_{s}-\omega_{r}\right) \lambda_{d r}+\frac{d \lambda_{q r}}{d t}
$$

\subsubsection{Equação mecânica}

A equação mecânica que representa o sistema máquina-turbina e que rege o movimento da máquina, é de vital importância para as análises de estabilidade em sistemas elétricos de potência. A mesma descreve os efeitos de desequilíbrios entre os torques mecânico e eletromagnético, permitindo avaliar a estabilidade de velocidade da máquina. Tal equação 
pode ser obtida a partir da Segunda Lei de Newton para rotação

$$
J_{m} \frac{d^{2} \theta_{m}}{d t^{2}}=\left(J_{t}+J_{g}\right) \frac{d^{2} \theta_{m}}{d t^{2}}=T_{r}
$$

em que $J_{m}$ é o momento de inércia combinado, isto é, o momento de inércia da turbina $J_{t}$ somado ao momento de inércia do rotor do gerador $J_{g}, \theta_{m}$ é o ângulo mecânico do rotor com relação ao eixo de referência fixo no estator e $T_{r}$ é o torque resultante, expresso por

$$
T_{r}=T_{m}-T_{e}-F \frac{d \theta_{m}}{d t},
$$

sendo $T_{m}$ o torque mecânico, $T_{e}$ o torque eletromagnético e $F$ o coeficiente de atrito viscoso.

Uma vez que o ângulo $\theta_{m}$ é mecânico, torna-se necessário relacioná-lo ao ângulo elétrico da rede $\theta_{e}$ por meio da relação

$$
\theta_{e}=\rho \theta_{m}
$$

em que $\rho$ é o número de pares de polos da máquina.

Derivando (3.60) em relação ao tempo, obtém-se

$$
\frac{d \theta_{e}}{d t}=\rho \frac{d \theta_{m}}{d t} .
$$

Derivando agora (3.61), também em relação ao tempo, obtém-se

$$
\frac{d^{2} \theta_{e}}{d t^{2}}=\rho \frac{d^{2} \theta_{m}}{d t^{2}}
$$

Substituindo (3.59) e (3.62) em (3.58), é possível escrever

$$
J_{m} \frac{1}{\rho} \frac{d^{2} \theta_{e}}{d t^{2}}=T_{m}-T_{e}-F \frac{1}{\rho} \frac{d \theta_{e}}{d t}
$$

Fazendo

$$
\frac{d \theta_{e}}{d t}=\omega_{r}
$$

substituindo em (3.63) e rearranjando os termos da equação resultante, obtém-se a equação mecânica do sistema máquina-turbina na forma

$$
\frac{d \omega_{r}}{d t}=\frac{\rho}{J_{m}}\left(T_{m}-T_{e}\right)-\frac{F}{J_{m}} \omega_{r} .
$$

O torque mecânico será considerado constante para as configurações SCIG e WRIG. Para a configuração DFIG, o torque mecânico será uma função da frequência do rotor, conforme será explicado mais adiante. O torque eletromagnético origina-se da interação dos fluxos magnéticos do rotor e do estator. Sua expressão pode ser obtida a partir da energia armazenada no circuito magnético da máquina (Krause et al., 2013). A equação resultante para o 
torque eletromagnético, no sistema de coordenadas $d q$, pode ser expressa de várias formas. Por simples escolha, o torque eletromagnético é aqui representado em função das componentes do fluxo do estator $\lambda_{d s}$ e $\lambda_{q s}$ e das componentes da corrente do estator $i_{d s}$ e $i_{q s}$. Assim, tem-se (Krause et al., 2013)

$$
T_{e}=\frac{3}{2} \rho\left(\lambda_{d s} i_{q s}-\lambda_{q s} i_{d s}\right) .
$$

\subsubsection{Potências elétricas}

A partir do sistema de coordenadas $a b c$, as potências instantâneas que fluem para o estator $P_{s}$ e para o rotor $P_{r}$ da máquina são

$$
P_{s}=u_{a s} i_{a s}+u_{b s} i_{b s}+u_{c s} i_{c s}
$$

e

$$
P_{r}=u_{a r} i_{a r}+u_{b r} i_{b r}+u_{c r} i_{c r} .
$$

Realizando a transformação entre os sistemas de coordenadas, obtém-se para as variáveis nos eixos $d$ e $q$

$$
P_{s}=\frac{3}{2}\left(u_{d s} i_{d s}+u_{q s} i_{q s}\right)+3 u_{0 s} i_{0 s}
$$

$\mathrm{e}$

$$
P_{r}=\frac{3}{2}\left(u_{d r} i_{d r}+u_{q r} i_{q r}\right)+3 u_{0 r} i_{0 r} .
$$

Visto que a máquina é considerada simétrica, as componentes de eixo zero são nulas, de modo que as potências ficam então expressas nas formas

$$
P_{s}=\frac{3}{2}\left(u_{d s} i_{d s}+u_{q s} i_{q s}\right)
$$

$\mathrm{e}$

$$
P_{r}=\frac{3}{2}\left(u_{d r} i_{d r}+u_{q r} i_{q r}\right) .
$$

As potências instantâneas também podem ser obtidas no sistema de coordenadas $d q$ a partir de tensões e correntes na forma complexa. Para tanto, sejam estas variáveis, associadas ao estator ou ao rotor, definidas como

$$
\bar{u}_{d q}=u_{q}+j u_{d}
$$




$$
\bar{i}_{d q}=i_{q}+j i_{d}
$$

A partir da expressão que define a potência aparente complexa, a potência ativa $P$ e a potência reativa $Q$, para o estator ou para o rotor, são então dadas por

$$
P=\frac{3}{2} \Re\left\{\bar{u}_{d q} \bar{i}_{d q}^{*}\right\}
$$

e

$$
Q=\frac{3}{2} \Im\left\{\bar{u}_{d q} \bar{i}_{d q}^{*}\right\}
$$

Assim, obtém-se para o estator as potências $P_{s}$ e $Q_{s}$ e para o rotor as potências $P_{r}$ e $Q_{r}$ conforme

$$
\begin{aligned}
& P_{s}=\frac{3}{2}\left(u_{d s} i_{d s}+u_{q s} i_{q s}\right), \\
& Q_{s}=\frac{3}{2}\left(u_{d s} i_{q s}-u_{q s} i_{d s}\right), \\
& P_{r}=\frac{3}{2}\left(u_{d r} i_{d r}+u_{q r} i_{q r}\right)
\end{aligned}
$$

e

$$
Q_{r}=\frac{3}{2}\left(u_{d r} i_{q r}-u_{q r} i_{d r}\right)
$$

\subsubsection{Representação fasorial}

Seja para o estator da máquina um sistema trifásico equilibrado de tensões e correntes, representado pelas expressões

$$
\begin{gathered}
u_{a s}=\sqrt{2} u \cos \left(\omega_{s} t+\theta\right), \\
u_{b s}=\sqrt{2} u \cos \left(\omega_{s} t-\frac{2 \pi}{3}+\theta\right), \\
u_{c s}=\sqrt{2} u \cos \left(\omega_{s} t+\frac{2 \pi}{3}+\theta\right), \\
i_{a s}=\sqrt{2} i \cos \left(\omega_{s} t+\theta-\gamma\right),
\end{gathered}
$$




$$
i_{b s}=\sqrt{2} i \cos \left(\omega_{s} t-\frac{2 \pi}{3}+\theta-\gamma\right)
$$

e

$$
i_{c s}=\sqrt{2} i \cos \left(\omega_{s} t+\frac{2 \pi}{3}+\theta-\gamma\right),
$$

sendo $\theta$ o ângulo de referência da tensão $u_{a s}$, o mesmo ângulo representado na Figura (3.5) quando o eixo $q$ estiver alinhado com o eixo $a s, \gamma$ o ângulo de defasagem entre as tensões e correntes e $u$ e $i$ os valores eficazes de tensão e corrente, respectivamente.

Representando este sistema na notação fasorial, tem-se

$$
\begin{gathered}
\bar{u}_{a s}=u \cos (\theta)+j u \operatorname{sen}(\theta), \\
\bar{u}_{b s}=u \cos \left(-\frac{2 \pi}{3}+\theta\right)+j u \operatorname{sen}\left(-\frac{2 \pi}{3}+\theta\right), \\
\bar{u}_{c s}=u \cos \left(\frac{2 \pi}{3}+\theta\right)+j u \operatorname{sen}\left(\frac{2 \pi}{3}+\theta\right), \\
\bar{i}_{a s}=i \cos (\theta-\gamma)+j i \operatorname{sen}(\theta-\gamma), \\
\bar{i}_{b s}=i \cos \left(-\frac{2 \pi}{3}+\theta-\gamma\right)+j i \operatorname{sen}\left(-\frac{2 \pi}{3}+\theta-\gamma\right)
\end{gathered}
$$

e

$$
\bar{i}_{c s}=i \cos \left(\frac{2 \pi}{3}+\theta-\gamma\right)+j i \operatorname{sen}\left(\frac{2 \pi}{3}+\theta-\gamma\right) .
$$

Adotando o sistema de referência síncrono, isto é, considerando que os eixos $d$ e $q$ giram à frequência síncrona $\omega_{s}$ e que o eixo $q$ esteja alinhado com o eixo as, é possível representar as componentes de tensão $u_{d s}$ e $u_{q s}$ e as componentes de corrente $i_{d s}$ e $i_{q s}$ no sistema de coordenadas $d q$ como

$$
\begin{gathered}
u_{d s}=\sqrt{2} u \operatorname{sen}(\theta), \\
u_{q s}=\sqrt{2} u \cos (\theta), \\
i_{d s}=\sqrt{2} i \operatorname{sen}(\theta-\gamma)
\end{gathered}
$$




$$
i_{q s}=\sqrt{2} i \cos (\theta-\gamma) .
$$

A partir das definições (3.73) e (3.74) é possível relacionar as representações fasorial e complexa de acordo com as expressões

$$
\bar{u}_{d q s}=u_{q s}+j u_{d s}=\sqrt{2} u \cos (\theta)+j \sqrt{2} u \operatorname{sen}(\theta)=\sqrt{2} \bar{u}_{a s}
$$

e

$$
\bar{i}_{d q s}=i_{q s}+j i_{d s}=\sqrt{2} i \cos (\theta-\gamma)+j \sqrt{2} i \operatorname{sen}(\theta-\gamma)=\sqrt{2} \bar{i}_{a s}
$$

Como pode ser observado, a componente $d$ representa a parte imaginária e a componente $q$ representa a parte real dos fasores tensão e corrente. No entanto, as componentes $d$ e $q$ representam valores de pico, ao passo que na representação fasorial consideram-se valores eficazes. A fim de integrar o modelo da máquina ao modelo da rede elétrica, deseja-se então adequar as variáveis nos eixos $d$ e $q$, representadas em valores de pico, para valores eficazes.

Desta forma, considerando por simplicidade que tanto para valores de pico como eficazes a mesma notação é utilizada, para as componentes de tensão $u_{d s}, u_{q s}$, de corrente $i_{d s}$ e $i_{q s}$ e de fluxo $\lambda_{d s}, \lambda_{q s}$ do estator aplicam-se as relações

$$
\begin{aligned}
\frac{u_{d s}\left(V_{p}\right)}{\sqrt{2}} & \rightarrow u_{d s}\left(V_{r m s}\right), \\
\frac{u_{q s}\left(V_{p}\right)}{\sqrt{2}} & \rightarrow u_{q s}\left(V_{r m s}\right), \\
\frac{i_{d s}\left(A_{p}\right)}{\sqrt{2}} & \rightarrow i_{d s}\left(A_{r m s}\right), \\
\frac{i_{q s}\left(A_{p}\right)}{\sqrt{2}} & \rightarrow i_{q s}\left(A_{r m s}\right), \\
\frac{\lambda_{d s}\left(W b_{p}\right)}{\sqrt{2}} & \rightarrow \lambda_{d s}\left(W b_{r m s}\right)
\end{aligned}
$$

e

$$
\frac{\lambda_{q s}\left(W b_{p}\right)}{\sqrt{2}} \rightarrow \lambda_{q s}\left(W b_{r m s}\right)
$$

Fica registrado que a partir deste ponto todas as variáveis no sistema de coordenadas $d q$ serão representadas por seus valores eficazes. Uma vez o modelo da máquina de indução sendo representado em termos de componentes real e imaginária de fasores de tensão e corrente, as respectivas equações deste modelo e as equações que modelam a rede elétrica 
podem ser analisadas em conjunto com todas as variáveis em valores eficazes. Salienta-se que a partir do desenvolvimento adotado para as variáveis do estator, é possível obter as variáveis relativas ao rotor de forma similar.

As equações elétricas da máquina, assim como a equação mecânica do sistema máquinaturbina, não sofrem alterações em sua notação. As mesmas são repetidas aqui por conveniência

$$
\begin{gathered}
u_{d s}=r_{s} i_{d s}+\omega_{s} \lambda_{q s}+\frac{d \lambda_{d s}}{d t}, \\
u_{q s}=r_{s} i_{q s}-\omega_{s} \lambda_{d s}+\frac{d \lambda_{q s}}{d t}, \\
u_{d r}=r_{r} i_{d r}+\left(\omega_{s}-\omega_{r}\right) \lambda_{q r}+\frac{d \lambda_{d r}}{d t}, \\
u_{q r}=r_{r} i_{q r}-\left(\omega_{s}-\omega_{r}\right) \lambda_{d r}+\frac{d \lambda_{q r}}{d t}
\end{gathered}
$$

e

$$
\frac{d \omega_{r}}{d t}=\frac{\rho}{J_{m}}\left(T_{m}-T_{e}\right)-\frac{F}{J_{m}} \omega_{r}
$$

Já a expressão do torque eletromagnético e as expressões das potências elétricas sofrem alteração por uma constante, uma vez que agora utilizam-se valores eficazes de tensão, corrente e fluxo. Assim, tem-se como resultado

$$
\begin{aligned}
& T_{e}=3 \rho\left(\lambda_{d s} i_{q s}-\lambda_{q s} i_{d s}\right), \\
& P_{s}=3\left(u_{d s} i_{d s}+u_{q s} i_{q s}\right), \\
& Q_{s}=3\left(u_{d s} i_{q s}-u_{q s} i_{d s}\right), \\
& P_{r}=3\left(u_{d r} i_{d r}+u_{q r} i_{q r s}\right)
\end{aligned}
$$

e

$$
Q_{r}=3\left(u_{d r} i_{q r}-u_{q r} i_{d r}\right)
$$

\subsubsection{Representação por unidade}

Até o momento, as equações da máquina de indução foram desenvolvidas considerando todas as variáveis representadas no SI. Como é usual estudar um sistema elétrico de potência representado por unidade, faz-se necessário que as variáveis da máquina sejam normalizadas 
a partir de valores base pré-estabelecidos. Ainda, uma vez que as equações que modelam a máquina de indução são integradas às equações que modelam a rede elétrica, faz-se necessário que todas as variáveis sejam normalizadas na mesma base. Neste contexto, a potência aparente por fase base $S_{b}$, a tensão de fase em valor eficaz base $U_{b}$ e a frequência base $\omega_{b}$, dão origem à corrente base $I_{b}$, ao fluxo base $\wedge_{b}$, à impedância base $Z_{b}$, à indutância base $L_{b}$ e ao torque base $T_{b}$, conforme

$$
\begin{aligned}
I_{b}(A) & =\frac{S_{b}}{U_{b}}\left(\frac{V A}{V}\right), \\
\Lambda_{b}(W b) & =\frac{U_{b}}{\omega_{b}}\left(\frac{V}{r a d / s}\right), \\
Z_{b}(\Omega) & =\frac{U_{b}^{2}}{S_{b}}\left(\frac{V^{2}}{V A}\right), \\
L_{b}(H) & =\frac{Z_{b}}{\omega_{b}}\left(\frac{\Omega}{\mathrm{rad} / \mathrm{s}}\right)
\end{aligned}
$$

e

$$
T_{b}(N \cdot m)=3 \rho \frac{S_{b}}{\omega_{b}}\left(\frac{V A}{r a d / s}\right) .
$$

Considerando por simplicidade que a mesma notação é utilizada para as variáveis, à exceção da frequência síncrona $\omega_{s}$, é possível escrever a partir dos valores base as relações

$$
\begin{aligned}
& \frac{u_{d s}}{U_{b}}\left(\frac{V}{V}\right) \rightarrow u_{d s}(p u), \\
& \frac{u_{q s}}{U_{b}}\left(\frac{V}{V}\right) \rightarrow u_{q s}(p u), \\
& \frac{u_{d r}}{U_{b}}\left(\frac{V}{V}\right) \rightarrow u_{d r}(p u), \\
& \frac{u_{q r}}{U_{b}}\left(\frac{V}{V}\right) \rightarrow u_{q r}(p u), \\
& \frac{i_{d s}}{I_{b}}\left(\frac{A}{A}\right) \rightarrow i_{d s}(p u), \\
& \frac{i_{q s}}{I_{b}}\left(\frac{A}{A}\right) \rightarrow i_{q s}(p u), \\
& \frac{i_{d r}}{I_{b}}\left(\frac{A}{A}\right) \rightarrow i_{d r}(p u),
\end{aligned}
$$




$$
\begin{gathered}
\frac{i_{q r}}{I_{b}}\left(\frac{A}{A}\right) \rightarrow i_{q r}(p u), \\
\frac{\lambda_{d s}}{\Lambda_{b}}\left(\frac{W b}{W b}\right) \rightarrow \lambda_{d s}(p u), \\
\frac{\lambda_{q s}}{\Lambda_{b}}\left(\frac{W b}{W b}\right) \rightarrow \lambda_{q s}(p u), \\
\frac{\lambda_{d r}}{\Lambda_{b}}\left(\frac{W b}{W b}\right) \rightarrow \lambda_{d r}(p u)
\end{gathered}
$$

e

$$
\frac{\lambda_{q r}}{\Lambda_{b}}\left(\frac{W b}{W b}\right) \rightarrow \lambda_{q r}(p u)
$$

Para os torques eletromagnético e mecânico

$$
\frac{T_{e}}{T_{b}}=\frac{T_{e} \omega_{b}}{3 \rho S_{b}}\left(\frac{N \cdot m}{N \cdot m}\right) \rightarrow T_{e}(p u)
$$

e

$$
\frac{T_{m}}{T_{b}}=\frac{T_{m} \omega_{b}}{3 \rho S_{b}}\left(\frac{N \cdot m}{N \cdot m}\right) \rightarrow T_{m}(p u) .
$$

E para as potências elétricas

$$
\begin{aligned}
& \frac{P_{s}}{3 S_{b}}\left(\frac{W}{V A}\right) \rightarrow P_{s}(p u), \\
& \frac{Q_{s}}{3 S_{b}}\left(\frac{v a r}{V A}\right) \rightarrow Q_{s}(p u), \\
& \frac{P_{r}}{3 S_{b}}\left(\frac{W}{V A}\right) \rightarrow P_{r}(p u)
\end{aligned}
$$

e

$$
\frac{Q_{r}}{3 S_{b}}\left(\frac{v a r}{V A}\right) \rightarrow Q_{r}(p u)
$$

Já para as resistências e reatâncias

$$
\begin{aligned}
& \frac{r_{s}}{Z_{b}}\left(\frac{\Omega}{\Omega}\right) \rightarrow r_{s}(p u), \\
& \frac{r_{r}}{Z_{b}}\left(\frac{\Omega}{\Omega}\right) \rightarrow r_{r}(p u),
\end{aligned}
$$




$$
\begin{aligned}
& \frac{x_{l s}}{Z_{b}}\left(\frac{\Omega}{\Omega}\right)=\rightarrow x_{l s}(p u), \\
& \frac{x_{l r}}{Z_{b}}\left(\frac{\Omega}{\Omega}\right)=\rightarrow x_{l r}(p u)
\end{aligned}
$$

e

$$
\frac{x_{m}}{Z_{b}}\left(\frac{\Omega}{\Omega}\right)=\rightarrow x_{m}(p u),
$$

sendo $x_{l s}, x_{l r}$ e $x_{m}$ as reatâncias de dispersão do estator, de dispersão do rotor e magnetizante, respectivamente.

E para as indutâncias, as relações são dadas por

$$
\begin{aligned}
& \frac{L_{l s}}{L_{b}}\left(\frac{H}{H}\right) \rightarrow L_{l s}(p u), \\
& \frac{L_{l r}}{L_{b}}\left(\frac{H}{H}\right) \rightarrow L_{l r}(p u)
\end{aligned}
$$

e

$$
\frac{L_{m}}{L_{b}}\left(\frac{H}{H}\right) \rightarrow L_{m}(p u),
$$

sendo $L_{l s}, L_{l r}$ e $L_{m}$ as indutâncias de dispersão do estator, de dispersão do rotor e magnetizante, respectivamente.

Lembrando que as reatâncias e indutâncias podem ser iguais quando representadas por unidade. A partir das relações

$$
\begin{aligned}
& \frac{x_{l s}}{Z_{b}}\left(\frac{\Omega}{\Omega}\right)=\frac{\omega_{s} L_{l s}}{\omega_{b} L_{b}}\left(\frac{\Omega}{\Omega}\right), \\
& \frac{x_{l r}}{Z_{b}}\left(\frac{\Omega}{\Omega}\right)=\frac{\omega_{s} L_{l r}}{\omega_{b} L_{b}}\left(\frac{\Omega}{\Omega}\right)
\end{aligned}
$$

e

$$
\frac{x_{m}}{Z_{b}}\left(\frac{\Omega}{\Omega}\right)=\frac{\omega_{s} L_{m}}{\omega_{b} L_{b}}\left(\frac{\Omega}{\Omega}\right)
$$

e escolhendo

$$
\omega_{b}=\omega_{s}(\mathrm{rad} / \mathrm{s}),
$$

obtém-se

$$
x_{l s}(p u)=L_{l s}(p u),
$$




$$
x_{l r}(p u)=L_{l r}(p u)
$$

e

$$
x_{m}(p u)=L_{m}(p u)
$$

Para a frequência do rotor,

$$
\frac{\omega_{r}}{\omega_{b}}\left(\frac{\mathrm{rad} / \mathrm{s}}{\mathrm{rad} / \mathrm{s}}\right) \rightarrow \omega_{r}(p u)
$$

Já para a frequência síncrona por unidade, escolhe-se a simbologia $\omega_{e}$ para a sua representação. Assim,

$$
\omega_{e}(p u)=\frac{\omega_{s}}{\omega_{b}}\left(\frac{\mathrm{rad} / \mathrm{s}}{\mathrm{rad} / \mathrm{s}}\right)
$$

Fica registrado portanto, que todas as variáveis no sistema de coordenadas $d q$, além das constantes e demais variáveis, serão representadas a partir de agora por unidade, se não especificada a unidade. Os valores base serão representados com as unidades adotadas pelo $\mathrm{SI}$ e a frequência síncrona $\omega_{\mathrm{s}}$ em (rad/s). O tempo sempre será representado em segundos.

Faz-se necessário então verificar como ficam as equações desenvolvidas até o momento, agora com as variáveis definidas por unidade. Para as equações elétricas da máquina, tem-se como resultado

$$
\begin{gathered}
\frac{1}{\omega_{b}} \frac{d \lambda_{d s}}{d t}=u_{d s}-r_{s} i_{d s}-\omega_{e} \lambda_{q s}, \\
\frac{1}{\omega_{b}} \frac{d \lambda_{q s}}{d t}=u_{q s}-r_{s} i_{q s}+\omega_{e} \lambda_{d s}, \\
\frac{1}{\omega_{b}} \frac{d \lambda_{d r}}{d t}=u_{d r}-r_{r} i_{d r}-\left(\omega_{e}-\omega_{r}\right) \lambda_{q r}
\end{gathered}
$$

e

$$
\frac{1}{\omega_{b}} \frac{d \lambda_{q r}}{d t}=u_{q r}-r_{r} i_{q r}+\left(\omega_{e}-\omega_{r}\right) \lambda_{d r}
$$

Para a equação mecânica do sistema máquina-turbina, parte-se da expressão na forma

$$
\frac{J_{m} \omega_{b}}{T_{b} \omega_{b}} \frac{1}{\rho} \frac{d^{2} \theta_{e}}{d t^{2}}=\frac{\left(J_{t}+J_{g}\right) \omega_{b}}{T_{b} \omega_{b}} \frac{1}{\rho} \frac{d^{2} \theta_{e}}{d t^{2}}=T_{m}-T_{e}-\frac{F \omega_{b}}{T_{b} \omega_{b}} \frac{1}{\rho} \frac{d \theta_{e}}{d t},
$$

com $J_{m}, J_{t}$ e $J_{g}$ em $\left(k g \cdot m^{2}\right), F$ em $\left(k g^{2} \cdot m^{4} / s^{3}\right)$ e $T_{m}$ e $T_{e}$ em $(N \cdot m)$. 
Substituindo em (3.159) o número de pares de polos por

$$
\rho=\frac{p}{2},
$$

onde $p$ é o número de polos da máquina, obtém-se

$$
\frac{J_{m} \omega_{b}}{T_{b} \omega_{b}} \frac{2}{p} \frac{d^{2} \theta_{e}}{d t^{2}}=T_{m}-T_{e}-\frac{F \omega_{b}}{T_{b} \omega_{b}} \frac{2}{p} \frac{d \theta_{e}}{d t}
$$

Considerando que a constante de inércia combinada $H_{m}$, que corresponde à soma da constante de inércia da turbina $H_{t}$ com a constante de inércia do rotor da máquina $H_{g}$, seja definida como

$$
H_{m}=H_{t}+H_{g}=\frac{J_{m} \omega_{b}}{T_{b} p}=\frac{\left(J_{t}+J_{g}\right) \omega_{b}}{T_{b} p}(s)
$$

e o coeficiente de atrito viscoso $D$ por

$$
D=\frac{F \omega_{b} 2}{T_{b} p}
$$

além de verificar que

$$
\frac{d \theta_{e}}{d t}=\omega_{r}(\mathrm{rad} / \mathrm{s})
$$

é possível escrever (3.161) na forma

$$
\frac{d \omega_{r}}{d t}=\frac{1}{2 H_{m}}\left(T_{m}-T_{e}-D \omega_{r}\right) .
$$

Em relação ao torque eletromagnético e às potências elétricas, as expressões por unidade resultam em

$$
\begin{gathered}
T_{e}=\lambda_{d s} i_{q s}-\lambda_{q s} i_{d s}, \\
P_{s}=u_{d s} i_{d s}+u_{q s} i_{q s}, \\
Q_{s}=u_{d s} i_{q s}-u_{q s} i_{d s}, \\
P_{r}=u_{d r} i_{d r}+u_{q r} i_{q r s}
\end{gathered}
$$

e

$$
Q_{r}=u_{d r} i_{q r}-u_{q r} i_{d r} .
$$




\subsubsection{Representação em termos de tensões internas}

Como pode ser observado, as equações elétricas da máquina de indução foram obtidas em função dos fluxos e correntes. A fim de substituir os fluxos, serão introduzidas novas variáveis, que representarão as tensões internas da máquina. Desta forma, será obtido um modelo semelhante ao modelo dinâmico do gerador síncrono, representado por uma tensão atrás de uma reatância.

Sejam as relações entre as componentes dos fluxos e das correntes dadas por

$$
\begin{aligned}
& \lambda_{d s}=\left(L_{l s}+L_{m}\right) i_{d s}+L_{m} i_{d r}, \\
& \lambda_{q s}=\left(L_{l s}+L_{m}\right) i_{q s}+L_{m} i_{q r}, \\
& \lambda_{d r}=\left(L_{l r}+L_{m}\right) i_{d r}+L_{m} i_{d s}
\end{aligned}
$$

e

$$
\lambda_{q r}=\left(L_{l r}+L_{m}\right) i_{q r}+L_{m} i_{q s} .
$$

A partir de (3.173) e (3.174) é possível escrever

$$
i_{d r}=\frac{\lambda_{d r}-L_{m} i_{d s}}{L_{l r}+L_{m}}
$$

e

$$
i_{q r}=\frac{\lambda_{q r}-L_{m} i_{d s}}{L_{l r}+L_{m}} .
$$

Substituindo (3.175) em (3.171) e (3.176) em (3.172) e definindo

$$
x_{a}=L_{l s}+L_{m}-\frac{L_{m}^{2}}{L_{l r}+L_{m}},
$$

é possível estabelecer as relações entre fluxos e correntes na forma

$$
\lambda_{d s}=x_{a} i_{d s}+\frac{L_{m}}{L_{l r}+L_{m}} \lambda_{d r}
$$

e

$$
\lambda_{q s}=x_{a} i_{q s}+\frac{L_{m}}{L_{l r}+L_{m}} \lambda_{q r} .
$$

Definindo as tensões internas $e_{d}$ e $e_{q}$, em função dos fluxos do rotor como

$$
e_{d}=\frac{L_{m}}{L_{l r}+L_{m}} \lambda_{q r}
$$




$$
e_{q}=-\frac{L_{m}}{L_{l r}+L_{m}} \lambda_{d r}
$$

e substituindo (3.180) em (3.179) e (3.181) em (3.178), obtém-se

$$
\lambda_{d s}=x_{a} i_{d s}-e_{q}
$$

e

$$
\lambda_{q s}=x_{a} i_{q s}+e_{d}
$$

Para obter as duas primeiras equações elétricas substitui-se (3.182) e (3.183) em (3.155) e (3.156). Desta forma, obtém-se

$$
u_{d s}=r_{s} i_{d s}+\omega_{e} x_{a} i_{q s}+\omega_{e} e_{d}+\frac{x_{a}}{\omega_{b}} \frac{d i_{d s}}{d t}-\frac{1}{\omega_{b}} \frac{d e_{q}}{d t}
$$

e

$$
u_{q s}=r_{s} i_{q s}-\omega_{e} x_{a} i_{d s}+\omega_{e} e_{q}+\frac{x_{a}}{\omega_{b}} \frac{d i_{q s}}{d t}+\frac{1}{\omega_{b}} \frac{d e_{d}}{d t} .
$$

As outras duas equações elétricas são obtidas substituindo (3.175) em (3.157) e (3.176) em (3.158), além de substituir as componentes de fluxo do rotor $\lambda_{d r}$ e $\lambda_{q r}$ em termos das tensões internas $e_{d}$ e $e_{q}$, conforme (3.180) e (3.181). Assim, as equações resultantes são

$$
\frac{d e_{d}}{d t}=-\frac{1}{T_{o}}\left[e_{d}-\frac{L_{m}^{2}}{L_{l r}+L_{m}} i_{q s}\right]-\omega_{b}\left(\omega_{e}-\omega_{r}\right) e_{q}+\omega_{b} \frac{L_{m}}{L_{l r}+L_{m}} u_{q r}
$$

e

$$
\frac{d e_{q}}{d t}=-\frac{1}{T_{o}}\left[e_{q}+\frac{L_{m}^{2}}{L_{l r}+L_{m}} i_{d s}\right]+\omega_{b}\left(\omega_{e}-\omega_{r}\right) e_{d}-\omega_{b} \frac{L_{m}}{L_{l r}+L_{m}} u_{d r}
$$

em que

$$
T_{o}=\frac{L_{l r}+L_{m}}{\omega_{s} r_{r}}(s)
$$

Neste ponto, apresenta-se a variável escorregamento $s$, adimensional, estabelecida por

$$
s=\frac{\omega_{s}-\omega_{r} \omega_{b}}{\omega_{s}} .
$$

Escolhendo a frequência base $\omega_{b}$ igual à frequência síncrona $\omega_{s}$, a equação final para o escorregamento fica definida como

$$
s=1-\omega_{r}
$$


A partir da definição da variável escorregamento e considerando a partir deste ponto que a frequência base $\omega_{b}$ sempre assumirá o valor da frequência síncrona $\omega_{s}$, é possível escrever as equações elétricas da máquina na forma

$$
\begin{gathered}
u_{d s}=r_{s} i_{d s}+x_{a} i_{q s}+e_{d}+\frac{x_{a}}{\omega_{s}} \frac{d i_{d s}}{d t}-\frac{1}{\omega_{s}} \frac{d e_{q}}{d t}, \\
u_{q s}=r_{s} i_{q s}-x_{a} i_{d s}+e_{q}+\frac{x_{a}}{\omega_{s}} \frac{d i_{q s}}{d t}+\frac{1}{\omega_{s}} \frac{d e_{d}}{d t}, \\
\frac{d e_{d}}{d t}=-\frac{1}{T_{o}}\left[e_{d}-\frac{L_{m}^{2}}{L_{l r}+L_{m}} i_{q s}\right]-s \omega_{s} e_{q}+\omega_{s} \frac{L_{m}}{L_{l r}+L_{m}} u_{q r}
\end{gathered}
$$

e

$$
\frac{d e_{q}}{d t}=-\frac{1}{T_{o}}\left[e_{q}+\frac{L_{m}^{2}}{L_{l r}+L_{m}} i_{d s}\right]+s \omega_{s} e_{d}-\omega_{s} \frac{L_{m}}{L_{l r}+L_{m}} u_{d r} .
$$

Para a equação mecânica do sistema máquina-turbina, é possível expressar a mesma em termos do escorregamento como

$$
\frac{d s}{d t}=\frac{1}{2 H_{m}}\left[T_{e}-T_{m}+D(1-s)\right]
$$

Já para explicitar o torque eletromagnético em termos das tensões internas $e_{d}$ e $e_{q}$, basta substituir (3.182) e (3.183) em (3.166). Desta forma, obtém-se

$$
T_{e}=-e_{q} i_{q s}-e_{d} i_{d s}
$$

Como esperado, as expressões das potências elétricas não sofrem alterações. As mesmas são repetidas aqui por conveniência

$$
\begin{aligned}
& P_{s}=u_{d s} i_{d s}+u_{q s} i_{q s}, \\
& Q_{s}=u_{d s} i_{q s}-u_{q s} i_{d s}, \\
& P_{r}=u_{d r} i_{d r}+u_{q r} i_{q r s}
\end{aligned}
$$

e

$$
Q_{r}=u_{d r} i_{q r}-u_{q r} i_{d r}
$$




\subsection{Modelo completo do sistema teste com a configuração SCIG nos eixos $d$ e $q$}

É importante observar as diferentes representações das tensões e correntes. Na modelagem da rede elétrica, as componentes de tensão e corrente são representadas nos eixos real e imaginário, enquanto que na modelagem da máquina, nos eixos $d$ e $q$, conforme indica a Figura (3.6). Escolhendo representar as variáveis do modelo da máquina nos eixos real e imaginário da rede, efetua-se o alinhamento entre os eixos conforme a Figura (3.7).

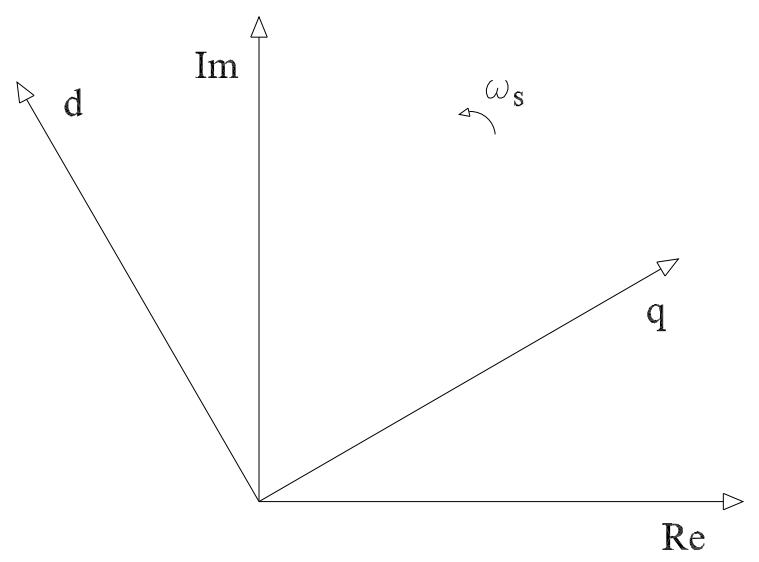

Figura 3.6: Representação dos eixos real, imaginário, em quadradura e direto.

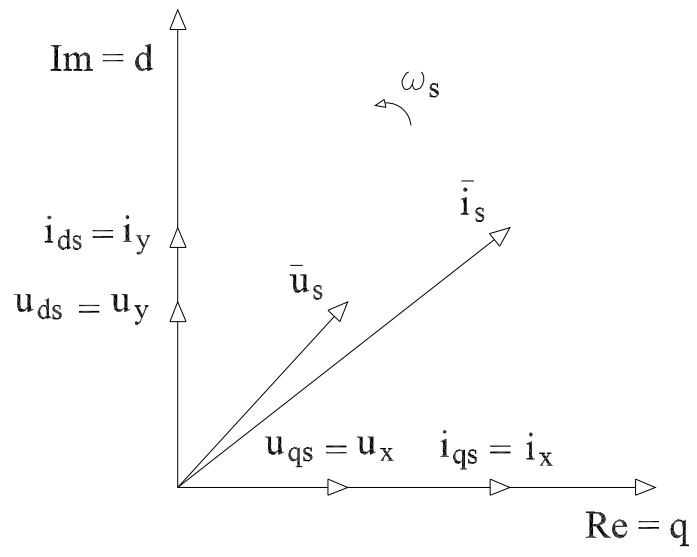

Figura 3.7: Alinhamento entre eixos real e em quadratura e eixos imaginário e direto.

Uma vez que o estator da máquina corresponde à barra 3 do sistema teste, como ilustrado na Figura (3.1), as componentes de tensão do estator $u_{d s}$ e $u_{q s}$ serão reescritas em termos de $u_{y 3}$ e $u_{x 3}$ conforme as relações $u_{d s}=u_{y 3}$ e $u_{q s}=u_{x 3}$. É fundamental observar que na modelagem da máquina, por convenção, as correntes positivas são aquelas absorvidas pelos terminais da mesma, enquanto que na modelagem da rede elétrica consideram-se injeções líquidas positivas de corrente nas barras. Assim, as componentes de corrente do estator $i_{d s}$ e $i_{q s}$ serão reescritas em termos de $i_{y 3}$ e $i_{x 3}$ conforme as relações $i_{d s}=-i_{y 3}$ e $i_{q s}=-i_{x 3}$. Tais observações também são válidas para a configuração WRIG. 
Para a máquina de indução em gaiola de esquilo, a tensão aplicada ao rotor é nula, $u_{d r}$ $=u_{q r}=0$, uma vez que não se tem acesso ao rotor. Acrescentando as equações que modelam a máquina de indução em gaiola de esquilo às equações que modelam a rede elétrica, formase um conjunto composto por nove equações. O modelo completo do sistema teste com a configuração SCIG fica então definido por

- Quatro equações referentes ao modelo da rede elétrica

$$
\begin{gathered}
g_{12} u_{x 1}-b_{12} u_{y 1}+\left(-g_{12}^{s h}-g_{23}^{s h}-g_{12}-g_{23}\right) u_{x 2}+ \\
\left(b_{12}^{s h}+b_{23}^{s h}+b_{12}+b_{23}\right) u_{y 2}+g_{23} u_{x 3}-b_{23} u_{y 3}=0, \\
b_{12} u_{x 1}+g_{12} u_{y 1}+\left(-b_{12}^{s h}-b_{23}^{s h}-b_{12}-b_{23}\right) u_{x 2}+ \\
\left(-g_{12}^{s h}-g_{23}^{s h}-g_{12}-g_{23}\right) u_{y 2}+b_{23} u_{x 3}+g_{23} u_{y 3}=0, \\
i_{x 3}+g_{23} u_{x 2}-b_{23} u_{y 2}+\left(-g_{32}^{s h}-g_{23}\right) u_{x 3}+\left(b_{32}^{s h}+b_{23}+b_{3}^{s h}\right) u_{y 3}=0
\end{gathered}
$$

e

$$
i_{y 3}+b_{23} u_{x 2}+g_{23} u_{y 2}+\left(-g_{32}^{s h}-g_{23}\right) u_{y 3}+\left(-b_{32}^{s h}-b_{23}-b_{3}^{s h}\right) u_{x 3}=0
$$

- Quatro equações referentes ao modelo elétrico da máquina

$$
\begin{gathered}
u_{y 3}=-r_{s} i_{y 3}-x_{a} i_{x 3}+e_{d}-\frac{x_{a}}{\omega_{s}} \frac{d i_{y 3}}{d t}-\frac{1}{\omega_{s}} \frac{d e_{q}}{d t} \\
u_{x 3}=-r_{s} i_{x 3}+x_{a} i_{y 3}+e_{q}-\frac{x_{a}}{\omega_{s}} \frac{d i_{x 3}}{d t}+\frac{1}{\omega_{s}} \frac{d e_{d}}{d t} \\
\frac{d e_{d}}{d t}=-\frac{1}{T_{o}}\left[e_{d}+\frac{L_{m}^{2}}{L_{l r}+L_{m}} i_{x 3}\right]-s \omega_{s} e_{q}
\end{gathered}
$$

e

$$
\frac{d e_{q}}{d t}=-\frac{1}{T_{o}}\left[e_{q}-\frac{L_{m}^{2}}{L_{l r}+L_{m}} i_{y 3}\right]+s \omega_{s} e_{d}
$$

- Uma equação referente ao movimento da máquina

$$
\frac{d s}{d t}=\frac{1}{2 H_{m}}\left[T_{e}-T_{m}+D(1-s)\right]
$$

com o torque mecânico constante e o torque eletromagnético dado por

$$
T_{e}=e_{q} i_{x 3}+e_{d} i_{y 3} .
$$


As equações (3.201) a (3.209) formam um sistema não linear composto por nove equações, cujo vetor de incógnitas é dado por

$$
k_{1}=\left[\begin{array}{lllllllll}
u_{x 3} & u_{y 3} & i_{x 3} & i_{y 3} & u_{x 2} & u_{y 2} & e_{d} & e_{q} & s
\end{array}\right]^{T} .
$$

Toma-se a barra 1 como referência angular e portanto as componentes de tensão na barra 1 são previamente conhecidas, $u_{x 1}=1$ e $u_{y 1}=0$. Os parâmetros da rede são apresentados no apêndice A. Os parâmetros da configuração SCIG são apresentados no apêndice B. As demais constantes e variáveis podem ser calculadas a partir da modelagem desenvolvida.

\subsubsection{Modelo completo para máquina em terceira ordem}

O modelo da máquina de indução em quinta ordem considera as dinâmicas de fluxo do estator e do rotor. Ao se considerar as dinâmicas de fluxo do estator, as dinâmicas da tensão e da corrente são levadas em conta no modelo da rede elétrica. Desta forma, as equações que modelam a rede tornam-se também diferenciais, visto o acoplamento existente entre o estator da máquina e o sistema elétrico. Para estudos de estabilidade, este fato tornase um problema, pois exige-se um passo de integração muito pequeno para as simulações computacionais. Além disso, sabe-se que a dinâmica de fluxo do estator é normalmente mais rápida do que a dinâmica de fluxo do rotor (Gaspareto e Reginatto, 2006). Assim, é comum reduzir a ordem do modelo da máquina, negligenciando a dinâmica do fluxo do estator, isto é, fazendo

$$
\frac{d \lambda_{d s}}{d t}=0
$$

e

$$
\frac{d \lambda_{q s}}{d t}=0
$$

em (3.155) e (3.156).

Como resultado, em termos de tensões internas, (3.155) e (3.156) tornam-se

$$
u_{y 3}=-r_{s} i_{y 3}-x_{a} i_{x 3}+e_{d}
$$

e

$$
u_{x 3}=-r_{s} i_{x 3}+x_{a} i_{y 3}+e_{q} .
$$

Portanto, ao se considerar (3.214) e (3.215) no lugar de (3.205) e (3.206), tem-se agora o modelo completo do sistema teste com a máquina em terceira ordem. 


\subsubsection{Modelo completo para máquina em primeira ordem}

Negligenciando também a dinâmica de fluxo do rotor em (3.157) e (3.158), o que equivale a fazer

$$
\frac{d e_{d}}{d t}=0
$$

e

$$
\frac{d e_{q}}{d t}=0
$$

em (3.207) e (3.208), obtém-se

$$
0=-\frac{1}{T_{o}}\left[e_{d}+\frac{L_{m}^{2}}{L_{l r}+L_{m}} i_{x 3}\right]-s \omega_{s} e_{q}
$$

e

$$
0=-\frac{1}{T_{o}}\left[e_{q}-\frac{L_{m}^{2}}{L_{l r}+L_{m}} i_{y 3}\right]+s \omega_{s} e_{d}
$$

Ao se considerar (3.214) e (3.215) no lugar de (3.205) e (3.206), assim como (3.218) e (3.219) no lugar de (3.207) e (3.208), obtém-se o modelo completo do sistema teste com a máquina em primeira ordem. Tal modelo no sistema de coordenadas $d q$ é equivalente ao modelo da máquina de indução em gaiola de esquilo em regime permanente, que será desenvolvido mais adiante.

\subsection{Modelo completo do sistema teste com a configuração WRIG nos eixos $d$ e $q$}

Para a máquina de indução com rotor bobinado, o acesso ao circuito rotórico permite aplicar uma tensão ao mesmo, de modo que as componentes $u_{d r}$ e $u_{q r}$ podem assumir diferentes valores. Partindo desta consideração, as equações que modelam a máquina de indução com rotor bobinado são acrescentadas às equações que modelam a rede elétrica, formando um conjunto composto por nove equações. O modelo completo do sistema teste com a configuração WRIG fica então definido por

- Quatro equações referentes ao modelo da rede elétrica

$$
\begin{gathered}
g_{12} u_{x 1}-b_{12} u_{y 1}+\left(-g_{12}^{s h}-g_{23}^{s h}-g_{12}-g_{23}\right) u_{x 2}+ \\
\left(b_{12}^{s h}+b_{23}^{s h}+b_{12}+b_{23}\right) u_{y 2}+g_{23} u_{x 3}-b_{23} u_{y 3}=0 \\
b_{12} u_{x 1}+g_{12} u_{y 1}+\left(-b_{12}^{s h}-b_{23}^{s h}-b_{12}-b_{23}\right) u_{x 2}+ \\
\left(-g_{12}^{s h}-g_{23}^{s h}-g_{12}-g_{23}\right) u_{y 2}+b_{23} u_{x 3}+g_{23} u_{y 3}=0,
\end{gathered}
$$




$$
i_{x 3}+g_{23} u_{x 2}-b_{23} u_{y 2}+\left(-g_{32}^{s h}-g_{23}\right) u_{x 3}+\left(b_{32}^{s h}+b_{23}+b_{3}^{s h}\right) u_{y 3}=0
$$

e

$$
i_{y 3}+b_{23} u_{x 2}+g_{23} u_{y 2}+\left(-g_{32}^{s h}-g_{23}\right) u_{y 3}+\left(-b_{32}^{s h}-b_{23}-b_{3}^{s h}\right) u_{x 3}=0 .
$$

- Quatro equações referentes ao modelo elétrico da máquina

$$
\begin{gathered}
u_{y 3}=-r_{s} i_{y 3}-x_{a} i_{x 3}+e_{d}-\frac{x_{a}}{\omega_{s}} \frac{d i_{y 3}}{d t}-\frac{1}{\omega_{s}} \frac{d e_{q}}{d t}, \\
u_{x 3}=-r_{s} i_{x 3}+x_{a} i_{y 3}+e_{q}-\frac{x_{a}}{\omega_{s}} \frac{d i_{x 3}}{d t}+\frac{1}{\omega_{s}} \frac{d e_{d}}{d t}, \\
\frac{d e_{d}}{d t}=-\frac{1}{T_{o}}\left[e_{d}+\frac{L_{m}^{2}}{L_{l r}+L_{m}} i_{x 3}\right]-s \omega_{s} e_{q}+\omega_{s} \frac{L_{m}}{L_{l r}+L_{m}} u_{q r}
\end{gathered}
$$

e

$$
\frac{d e_{q}}{d t}=-\frac{1}{T_{o}}\left[e_{q}-\frac{L_{m}^{2}}{L_{l r}+L_{m}} i_{y 3}\right]+s \omega_{s} e_{d}-\omega_{s} \frac{L_{m}}{L_{l r}+L_{m}} u_{d r} .
$$

- Uma equação referente ao movimento da máquina

$$
\frac{d s}{d t}=\frac{1}{2 H_{m}}\left[T_{e}-T_{m}+D(1-s)\right] .
$$

com o torque mecânico constante e o torque eletromagnético dado por

$$
T_{e}=e_{q} i_{x 3}+e_{d} i_{y 3} .
$$

As equações (3.201) a (3.209) formam um sistema não linear composto por nove equações, cujo vetor de incógnitas é dado por

$$
\kappa_{2}=\left[\begin{array}{lllllllll}
u_{x 3} & u_{y 3} & i_{x 3} & i_{y 3} & u_{x 2} & u_{y 2} & e_{d} & e_{q} & s
\end{array}\right]^{T} .
$$

Toma-se a barra 1 como referência angular e portanto as componentes de tensão na barra 1 são previamente conhecidas, $u_{x 1}=1$ e $u_{y 1}=0$. Os parâmetros da rede são apresentados no apêndice A. Assume-se que as componentes de tensão no rotor $u_{d r}$ e $u_{q r}$ são também conhecidas. Os parâmetros da configuração WRIG são apresentados no apêndice B. As demais constantes e variáveis podem ser calculadas a partir da modelagem desenvolvida.

\subsubsection{Modelo completo para máquina em terceira ordem}

A partir das explicações elaboradas para a máquina de indução em gaiola de esquilo, o modelo completo do sistema teste com a máquina de indução com rotor bobinado em terceira ordem é obtido substituindo (3.224) e (3.225) por (3.214) e (3.215). 


\subsubsection{Modelo completo para máquina em primeira ordem}

Já para o modelo completo do sistema teste com a máquina em primeira ordem, basta substituir (3.224), (3.225), (3.226) e (3.227) por (3.214), (3.215),

$$
0=-\frac{1}{T_{o}}\left[e_{d}+\frac{L_{m}^{2}}{L_{l r}+L_{m}} i_{x 3}\right]-s \omega_{s} e_{q}+\omega_{s} \frac{L_{m}}{L_{l r}+L_{m}} u_{q r}
$$

e

$$
0=-\frac{1}{T_{o}}\left[e_{q}-\frac{L_{m}^{2}}{L_{l r}+L_{m}} i_{y 3}\right]+s \omega_{s} e_{d}-\omega_{s} \frac{L_{m}}{L_{l r}+L_{m}} u_{d r} .
$$

Tal modelo no sistema de coordenadas $d q$ é equivalente ao modelo da máquina de indução com rotor bobinado em regime permanente, que será desenvolvido mais adiante.

\subsection{Configuração DFIG}

Representar modelos de aerogeradores para estudos de estabilidade em sistemas elétricos de potência não é uma tarefa simples, especialmente para a configuração DFIG. No que se refere a esta configuração, a maioria dos modelos disponíveis na literatura representam fenômenos dinâmicos muito mais rápidos do que aqueles que realmente interessam aos estudos de estabilidade a grandes perturbações. Os modelos em geral não são adequados para interagir com o modelo da rede elétrica, uma vez que as tensões e correntes na rede são concebidas na forma fasorial. A maioria dos modelos disponíveis destacam o projeto de sistemas de controle associados aos conversores eletrônicos de potência, concentrando-se em representar os elementos em questão por diagramas de blocos. Raramente os modelos são descritos por completo na forma de equações algébricas e diferenciais, de modo que não fica clara a interação entre as variáveis da máquina e as variáveis da rede elétrica. O processo de simulação computacional mostra-se geralmente confuso, uma vez que os modelos apresentam muitas variáveis, a modelagem da rede não é discutida e as etapas de implementação não são apresentadas.

Como já apresentado, os modelos completos do sistema teste com as configurações SCIG e WRIG foram obtidos na forma de conjuntos de equações algébricas e diferenciais. Para estes modelos, o torque mecânico de entrada do gerador (saída da turbina) é fixado em um determinado valor. Para a barra na qual o aerogerador é conectado, emprega-se um capacitor para definir um valor de tensão na respectiva barra. Deste modo, as potências ativa e reativa são resultantes, calculadas posteriormente. Para tais modelos, as simulações em software podem ser realizadas de forma direta, uma vez que o número de incógnitas corresponde ao número de equações do modelo. Através de um único conjunto de equações, é possível então encontrar as condições iniciais e verificar o comportamento dinâmico das variáveis no tempo.

Para o sistema teste com a configuração DFIG, a barra na qual o aerogerador é conectado pode ser uma barra PV ou uma barra PQ. É necessário em um primeiro momento, simular o fluxo de carga da rede elétrica, para que se possa em um segundo momento, calcular 
as variáveis da máquina de indução, dos conversores e dos controladores. Uma observação importante, é que normalmente não são consideradas as perdas da máquina e dos conversores na inicialização das variáveis da máquina, o que pode levar a instabilidades numéricas no início das simulações. Em (Nikolaev et al., 2014) tratou-se de resolver este problema. O método proposto trata de resolver o fluxo de carga e um conjunto específico de equações, a ser detalhado mais adiante, para encontrar as condições iniciais exatas do modelo. Para executar o processo de inicialização, primeiro é determinado o conjunto de equações relativas ao fluxo de carga da rede elétrica. Após, é definido o conjunto de equações para a inicialização das variáveis da máquina. Em seguida, dadas as equações que modelam o sistema por completo, as demais condições iniciais (relativas aos controladores) são calculadas, permitindo que as simulações no tempo sejam realizadas.

No sentido de descrever o modelo do sistema teste com o DFIG através de um conjunto completo de equações, adequado aos estudos de estabilidade propostos nesta tese, além de sistematizar o processo de simulação computacional, tratou-se de investigar uma série de trabalhos neste contexto.

Em (Ekanayake et al., 2003a) a configuração DFIG é modelada com o gerador de indução em quinta e terceira ordens, além de incluir dois controladores, cujas descrições não são claras. Em (Ekanayake et al., 2003b) e (Tennakoon et al., 2007) controladores semelhantes são apresentados, porém suas descrições não são suficientes para o entendimento dos modelos. Em (Anaya-Lara et al., 2009) e (Anaya-Lara et al., 2005), os modelos da configuração DFIG não são detalhados o suficiente para implementação, seja por diagramas de blocos, ou por sistemas de equações. A integração dos conversores eletrônicos de potência com a rede elétrica, por exemplo, não é devidamente descrita.

Em (Canedo, 2007) e (Rocha, 2005) os modelos apresentados são mais adequados para a implementação por diagramas de blocos. No entanto, tais diagramas deveriam ser mais detalhados, assim como os sistemas de referência utilizados para os controladores. Em (Pena et al., 1996) e (Erlich et al., 2007) os modelos apresentados omitem uma série de informações, o que torna inviável a implementação e a consequente reprodução dos resultados exibidos. Em (Hamon, 2010) e (Slootweg et al., 2003) os modelos elaborados também omitem muitas informações importantes. Ainda, tais modelos foram concebidos para integração em softwares proprietários, o que também dificulta a reprodução dos resultados expostos. Em (Hansen et al., 2007a) são desenvolvidos diversos modelos, com rico volume de detalhes. Entretanto, enfoque é dado aos modelos da máquina e aos modelos dos controladores, minimizando a integração com a rede elétrica. Em (Slootweg et al., 2001a) não foram apresentados detalhes sobre os controladores do ângulo da pá e da tensão terminal da máquina.

Em (Ledesma e Usaola, 2005) é proposto um modelo da configuração DFIG descrito por equações, cuja resolução se dá por um processo iterativo. Porém as dinâmicas de fluxo do estator e do rotor são desprezadas, o que resulta em um modelo elétrico composto apenas por equações algébricas. Em (Sundeep, 2008), a configuração DFIG é modelada com o gerador em 
terceira ordem, com dois controladores, cujas variáveis de saída correspondem às componentes de tensão no rotor. São também apresentadas as equações da rede elétrica, porém as mesmas são desenvolvidas na forma de fluxos de potência. Em (Holdsworth et al., 2003a), onde os mesmos controladores foram implementados, negligencia-se a equação do capacitor e as equações dos conversores e da rede não são apresentadas. Além disso, os resultados obtidos foram examinados e constatou-se que a reprodução dos mesmos somente é possível após realizar simplificações que não foram previamente estabelecidas.

Em (Holdsworth et al., 2003b) é proposto um processo de inicialização das variáveis para a configuração DFIG equipada com os mesmos controladores utilizados em (Holdsworth et al. , 2003a). Neste caso, o método está intrinsecamente ligado aos controladores utilizados. Em (Hansen et al., 2003) é apresentado um método capaz de calcular as condições iniciais tanto para a máquina como para a turbina. A partir dos resultados do fluxo de carga e das especificações da velocidade do vento e do ângulo da pá, é possível determinar as condições iniciais do modelo. Porém o equilíbrio pode não ser encontrado, ocorrendo transitórios iniciais caso as potências elétrica e mecânica sejam diferentes. Em (Slootweg et al., 2001b) são apresentados procedimentos para inicializar as configurações mais comuns de aerogeradores. No que se refere à configuração DFIG, o método proposto negligencia as perdas da máquina. Ainda, é assumido que o conversor do lado da rede opera sob fator de potência unitário.

Em (Nikolaev et al., 2014) é proposto um procedimento de inicialização exato para a configuração DFIG. Baseado em duas etapas, as equações são descritas sem considerar simplificações, de modo que são obtidas condições iniciais exatas para os modelos da máquina e da turbina. Em suma, o método é capaz de evitar oscilações e instabilidades numéricas no início das simulações. Dentre as características principais, citam-se: i) as perdas da máquina e dos conversores são consideradas, ii) a potência reativa trocada entre o conversor CSC e a rede elétrica pode ser especificada, iii) os modelos do gerador de indução em quinta e terceira ordens podem ser utilizados, iv) a curva de potência-velocidade ótima pode ser utilizada e v) o método não depende de uma estratégia de controle específica.

Neste trabalho, o processo de inicialização da configuração DFIG segue o procedimento descrito por (Nikolaev et al., 2014). Embora não seja apresentada a modelagem da rede elétrica em detalhes, tal modelagem já foi aqui elaborada e o fluxo de carga será desenvolvido mais adiante. Uma vez que (Nikolaev et al., 2014) trata apenas da parte estática, as equações para as simulações dinâmicas devem então ser obtidas. A partir dos modelos da máquina, dos conversores eletrônicos de potência e dos controladores associados, serão obtidas as equações necessárias para as simulações no tempo. Segue então a modelagem da configuração DFIG.

\subsubsection{Máquina e conversores}

A configuração DFIG é ilustrada na Figura 3.8, onde também são exibidas algumas variáveis. As potências ativa e reativa $P_{r}$ e $Q_{r}$ referem-se ao rotor, $P_{c}$ e $Q_{c}$ ao conversor GSC, $P_{s}, Q_{s}$ ao estator e $P_{g}$ e $Q_{g}$ à barra na qual o aerogerador é conectado. As componentes de 
tensão e corrente $u_{d r}, u_{q r}, i_{d r}$ e $i_{q r}$ referem-se ao rotor, $u_{d c}, u_{q c}, i_{d c}$ e $i_{q c}$ ao conversor GSC, $u_{d s}, u_{q s}, i_{d s}$ e $i_{q s}$ ao estator e $i_{d g}$ e $i_{q g}$ à rede elétrica. A tensão $u_{D C}$ corresponde à tensão no link DC. A tensão $u_{s}$ corresponde ao módulo da tensão no estator e $\theta$ ao ângulo desta barra, ambos resultado do fluxo de carga para uma barra PQ. A resistência $r_{f}$ e a reatância $x_{f}$ referem-se ao filtro do conversor GSC.

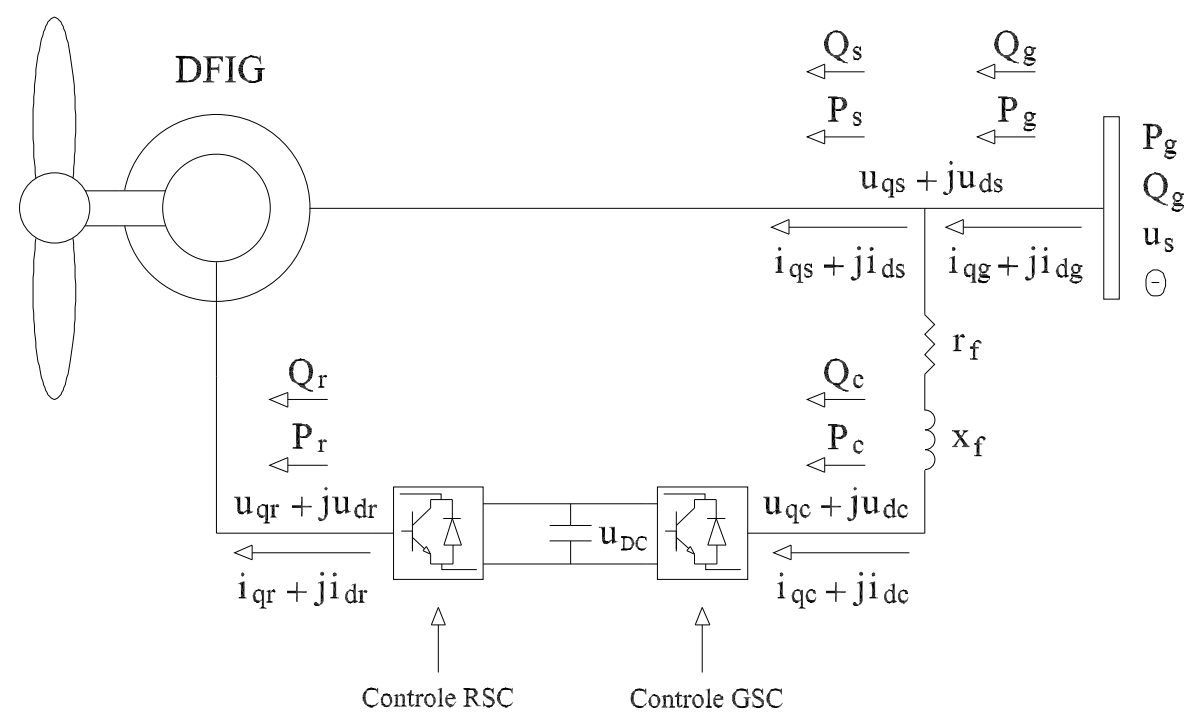

Figura 3.8: Configuração DFIG.

O modelo da máquina de indução com rotor bobinado corresponde ao modelo desenvolvido anteriormente. As equações finais, portanto em termos de tensões internas, são repetidas aqui por conveniência. Tais equações são

$$
\begin{gathered}
u_{d s}=r_{s} i_{d s}+x_{a} i_{q s}+e_{d}+\frac{x_{a}}{\omega_{s}} \frac{d i_{d s}}{d t}-\frac{1}{\omega_{s}} \frac{d e_{q}}{d t}, \\
u_{q s}=r_{s} i_{q s}-x_{a} i_{d s}+e_{q}+\frac{x_{a}}{\omega_{s}} \frac{d i_{q s}}{d t}+\frac{1}{\omega_{s}} \frac{d e_{d}}{d t}, \\
\frac{d e_{d}}{d t}=-\frac{1}{T_{o}}\left[e_{d}-\frac{L_{m}^{2}}{L_{l r}+L_{m}} i_{q s}\right]-s \omega_{s} e_{q}+\omega_{s} \frac{L_{m}}{L_{l r}+L_{m}} u_{q r}, \\
\frac{d e_{q}}{d t}=-\frac{1}{T_{o}}\left[e_{q}+\frac{L_{m}^{2}}{L_{l r}+L_{m}} i_{d s}\right]+s \omega_{s} e_{d}-\omega_{s} \frac{L_{m}}{L_{l r}+L_{m}} u_{d r}
\end{gathered}
$$

e

$$
\frac{d s}{d t}=\frac{1}{2 H_{m}}\left[T_{e}-T_{m}+D(1-s)\right]
$$

com o torque eletromagnético definido por

$$
T_{e}=-e_{q} i_{q s}-e_{d} i_{d s}
$$


e as tensões internas por

$$
e_{d}=\frac{L_{m}}{L_{l r}+L_{m}}\left[\left(L_{l r}+L_{m}\right) i_{q r}+L_{m} i_{q s}\right]
$$

e

$$
e_{q}=-\frac{L_{m}}{L_{l r}+L_{m}}\left[\left(L_{l r}+L_{m}\right) i_{d r}+L_{m} i_{d s}\right]
$$

O torque mecânico de entrada para as configurações SCIG e WRIG é considerado constante neste trabalho. Já para a configuração DFIG, o mesmo obedece a relação

$$
T_{m}=\frac{P_{m}}{1-s}
$$

cuja potência mecânica $P_{m}$ varia de acordo com uma curva pré-estabelecida, conforme será apresentado mais adiante. Assim, a equação que descreve o movimento da máquina fica representada na forma

$$
\frac{d s}{d t}=\frac{1}{2 H}\left[T_{e}-\frac{P_{m}}{1-s}-D(1-s)\right]
$$

As equações

$$
u_{d c}=u_{d s}-r_{f} i_{d c}-x_{f} i_{q c}
$$

e

$$
u_{q c}=u_{q s}-r_{f} i_{q c}+x_{f} i_{d c}
$$

referem-se à malha do conversor do lado da rede.

A equação que descreve a dinâmica do capacitor (Carlsson, 1998), de capacitância $C$, é

$$
C \frac{d u_{D C}}{d t}=\frac{u_{d c} i_{d c}+u_{q c} i_{q c}-u_{d r} i_{d r}-u_{q r} i_{q r}}{u_{D C}}
$$

cujo numerador do lado direito da equação corresponde ao balanço de potência entre o rotor e o conversor. Em regime permanente, a derivada no tempo é igualada a zero e o equilíbrio entre as potências ativas do rotor e do conversor é dado por

$$
P_{c}=P_{r}=u_{d c} i_{d c}+u_{q c} i_{q c}=u_{d r} i_{d r}+u_{q r} i_{q r}
$$

No que se refere à potência reativa, não necessariamente as potências reativas do rotor e do conversor serão iguais.

O balanço de corrente é obtido por

$$
i_{d g}=i_{d s}+i_{d c}
$$




$$
i_{q g}=i_{q s}+i_{q c}
$$

As potências ativa e reativa podem ser calculadas a partir da definição da potência aparente complexa. Assim, as mesmas correspondem a

$$
\begin{gathered}
P_{r}=u_{d r} i_{d r}+u_{q r} i_{q r s}, \\
Q_{r}=u_{d r} i_{q r}-u_{q r} i_{d r}, \\
P_{c}=u_{d s} i_{d c}+u_{q s} i_{q c}, \\
Q_{c}=u_{d s} i_{q c}-u_{q s} i_{d c}, \\
P_{s}=u_{d s} i_{d s}+u_{q s} i_{q s}, \\
Q_{s}=u_{d s} i_{q s}-u_{q s} i_{d s}, \\
P_{g}=P_{s}+P_{c}=u_{d s} i_{d s}+u_{q s} i_{q s}+u_{d s} i_{d c}+u_{q s} i_{q c}
\end{gathered}
$$

e

$$
Q_{g}=Q_{s}+Q_{c}=u_{d s} i_{q s}-u_{q s} i_{d s}+u_{d s} i_{q c}-u_{q s} i_{d c}
$$

\subsubsection{Curva $P_{m}$}

Para o melhor aproveitamento da energia eólica disponível, o aerogerador deve operar na velocidade correspondente ao máximo desempenho aerodinâmico (Burton et al., 2011), (Abad et al., 2011). Para os aerogeradores de velocidade variável, caso da configuração DFIG, é factível controlar a velocidade do gerador, de modo que tal velocidade seja ajustada para diferentes velocidades do vento. Assim, as potências mecânica e elétrica conseguem ser maximizadas (Patel, 2006).

Neste trabalho, a curva que associa a potência mecânica $P_{m}$ de entrada do gerador (saída da turbina) com a frequência do rotor do gerador $\omega_{r}$, é expressa em termos de uma função contínua que aproxima as relações lineares entre $P_{m}$ e $\omega_{r}$ apresentadas em (Nikolaev et al., 2014). A Figura 3.9 ilustra estas relações. Ainda que esta curva tenha sido escolhida, outras curvas, a exemplo das citadas em (Salles, 2009) e (Ackermann, 2012), também poderiam ter sido adotadas para implementação e análise. 


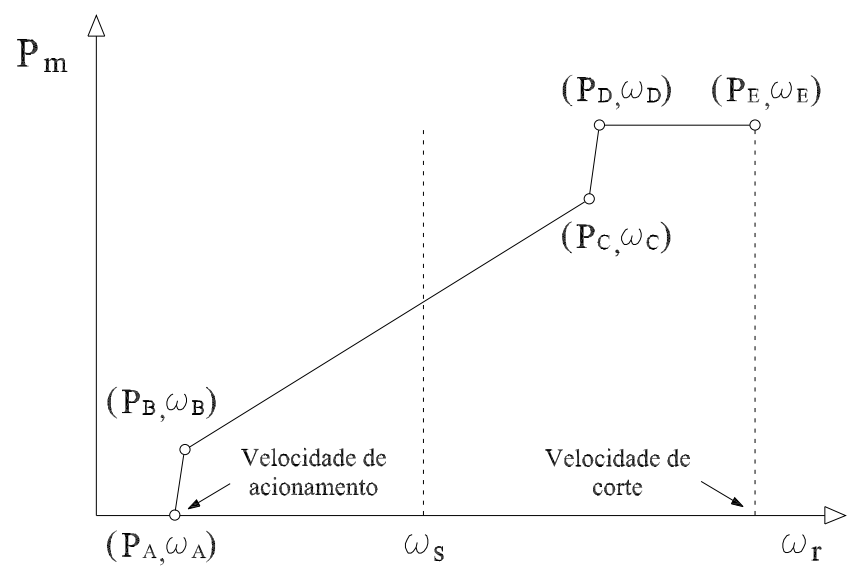

Figura 3.9: Potência mecânica $\times$ frequência do rotor.

Quando a frequência do rotor $\omega_{r}$ for igual à frequência síncrona $\omega_{s}$, o escorregamento será nulo. A faixa de frequências de operação inferiores à $\omega_{s}, \omega_{A} \leq \omega_{r}<\omega_{s}$, proporcionará escorregamentos positivos. Já a faixa de frequências de operação superiores à $\omega_{s}, \omega_{s}<\omega_{r}$ $\leq \omega_{E}$, proporcionará escorregamentos negativos. Para velocidades do vento muito baixas, a potência mecânica será nula. Para velocidades baixas do vento, a partir da frequência de acionamento $\omega_{A}$ a potência mecânica se situará entre $P_{A}$ e $P_{B}$. A extração ótima de potência ocorrerá entre $P_{B}$ e $P_{C}$. Para velocidades altas do vento, a potência mecânica poderá variar entre $P_{C}$ e $P_{D}$. E para velocidades muito altas do vento, a potência mecânica permanecerá constante até a frequência de corte $\omega_{E}$.

As equações que resultam na potência mecânica são

$$
\begin{gathered}
P_{m}=0 \quad \text { se } \omega_{r} \leq \omega_{A}, \\
P_{m}+P_{A}+\left(\omega_{r}-\omega_{A}\right) S L_{A B}=0 \text { se } \omega_{r}>\omega_{A} \text { e } \omega_{r} \leq \omega_{B}, \\
P_{m}+P_{B}+\left(\omega_{r}-\omega_{B}\right) S L_{B C}=0 \text { se } \omega_{r}>\omega_{B} \text { e } \omega_{r} \leq \omega_{C}, \\
P_{m}+P_{C}+\left(\omega_{r}-\omega_{C}\right) S L_{C D}=0 \text { se } \omega_{r}>\omega_{C} \text { e } \omega_{r} \leq \omega_{D}, \\
P_{m}-P_{D}=0 \text { se } \omega_{r}>\omega_{D}
\end{gathered}
$$

e

$$
P_{m}=0 \quad \text { se } \omega_{r}>\omega_{E}
$$




$$
\begin{aligned}
& S L_{A B}=\frac{\left(P_{B}-P_{A}\right)}{\omega_{B}-\omega_{A}}, \\
& S L_{B C}=\frac{\left(P_{C}-P_{B}\right)}{\omega_{C}-\omega_{B}}
\end{aligned}
$$

e

$$
S L_{C D}=\frac{\left(P_{D}-P_{C}\right)}{\omega_{D}-\omega_{C}}
$$

As relações lineares entre $P_{m}$ e $\omega_{r}$ apresentadas na Figura 3.9 serão denominadas neste trabalho de curva $P_{m}$ real. Os parâmetros desta curva são apresentados no apêndice $C$.

Para facilitar a implementação computacional, optou-se por aproximar a curva $P_{m}$ real por uma função contínua, de modo que a potência mecânica seja uma função da frequência de rotação do rotor, descrita por mais uma equação a ser incluída no modelo. Assim, para obter uma equação capaz de realizar uma boa aproximação da curva $P_{m}$ real, tratou-se de investigar a ferramenta Curve Fitting do software MATLAB ${ }^{\circledR}$, capaz de encontrar equações para pontos pré-definidos (MathWorks, 2018d). Dentre os testes realizados, a equação que melhor aproxima as relações lineares da Figura 3.9 é aquela definida por uma série de Fourier de ordem oito, conforme

$$
\begin{aligned}
P_{m} & =a_{0}+a_{1} \cos \left(\omega_{r} c\right)+b_{1} \operatorname{sen}\left(\omega_{r} c\right)+a_{2} \cos \left(2 \omega_{r} c\right)+b_{2} \operatorname{sen}\left(2 \omega_{r} c\right) \\
& +a_{3} \cos \left(3 \omega_{r} c\right)+b_{3} \operatorname{sen}\left(3 \omega_{r} c\right)+a_{4} \cos \left(4 \omega_{r} c\right)+b_{4} \operatorname{sen}\left(4 \omega_{r} c\right) \\
& +a_{5} \cos \left(5 \omega_{r} c\right)+b_{5} \operatorname{sen}\left(5\left(\omega_{r} c\right)+a_{6} \cos \left(6 \omega_{r} c\right)+b_{6} \operatorname{sen}\left(6 \omega_{r} c\right)\right. \\
& +a_{7} \cos \left(7 \omega_{r} c\right)+b_{7} \operatorname{sen}\left(7 \omega_{r} c\right)+a_{8} \cos \left(8 \omega_{r} c\right)+b_{8} \operatorname{sen}\left(8 \omega_{r} c\right) .
\end{aligned}
$$

A Figura 3.10 mostra as curvas $P_{m}$ real, $P_{m}$ aproximada e o erro absoluto entre as mesmas.

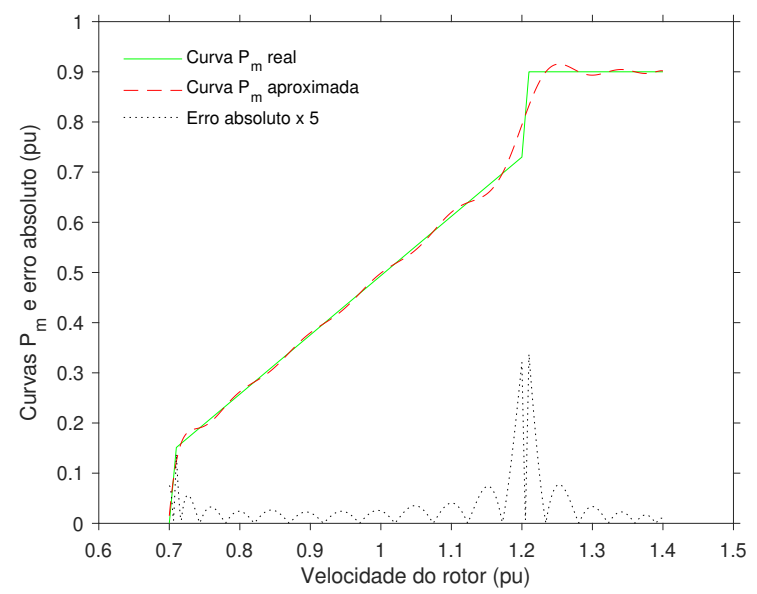

Figura 3.10: Curvas $P_{m}$ e erro absoluto. 
Como pode ser observado, a curva $P_{m}$ real consegue ser bem aproximada por (3.266). No presente caso, foram utilizados 701 pontos que relacionam a potência $P_{m}$ com a frequência $\omega_{r}$. As constantes em (3.266) são apresentadas no apêndice C.

\subsubsection{Controladores}

O conversor RSC e o conversor GSC são controlados por reguladores PI. Cada controlador processa as variáveis transformadas em um sistema de referência específico (Nikolaev et al., 2014). A Figura 3.11 ilustra os sistemas de referência adotados. O ângulo $\alpha$ refere-se ao fasor de tensão interna $\bar{e}=e_{q}+j e_{d}$ e o ângulo $\theta$ ao fasor de tensão do estator $\bar{u}_{s}=u_{q s}+j u_{d s}$. O RSC controla as potências ativa e reativa, com as variáveis transformadas no referencial $d^{e} q^{e}$. O GSC controla a tensão no link DC e a potência reativa injetada na rede elétrica, com as variáveis transformadas no referencial $d^{u} q^{u}$.

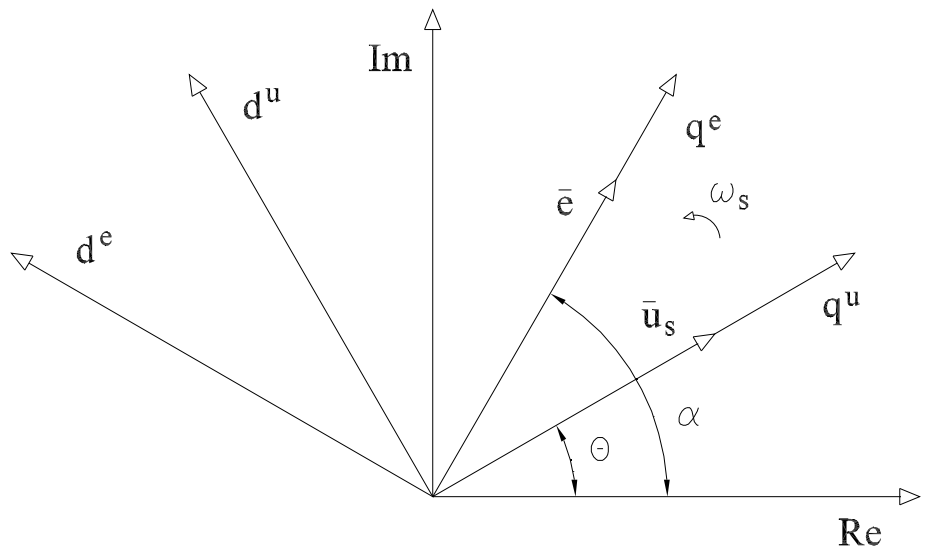

Figura 3.11: Representação dos eixos real, imaginário, em quadradura e direto e ângulos utilizados para os controles.

O ângulo $\alpha$ é calculado por

$$
\alpha=\operatorname{tg}^{-1}\left(\frac{e_{d}}{e_{q}}\right)
$$

e o ângulo $\theta$ por

$$
\theta=\operatorname{tg}^{-1}\left(\frac{u_{d s}}{u_{q s}}\right)
$$

Para obter as variáveis nos novos sistemas de referência, as transformações utilizadas são

$$
\left[\begin{array}{l}
f_{q}^{e} \\
f_{d}^{e}
\end{array}\right]=\left[\begin{array}{cc}
\cos (\alpha) & \operatorname{sen}(\alpha) \\
-\operatorname{sen}(\alpha) & \cos (\alpha)
\end{array}\right]\left[\begin{array}{l}
f_{q} \\
f_{d}
\end{array}\right]
$$




$$
\left[\begin{array}{l}
f_{q}^{u} \\
f_{d}^{u}
\end{array}\right]=\left[\begin{array}{cc}
\cos (\theta) & \operatorname{sen}(\theta) \\
-\operatorname{sen}(\theta) & \cos (\theta)
\end{array}\right]\left[\begin{array}{l}
f_{q} \\
f_{d}
\end{array}\right]
$$

onde $f_{d}$ e $f_{q}$ representam as variáveis no referencial $d q$, $f_{d}^{e}$ e $f_{q}^{e}$ no referencial $d^{e} q^{e}$ e $f_{d}^{u}$ e $f_{q}^{u}$ no referencial $d^{u} q^{u}$.

Para retornar ao referencial $d q$, as transformações aplicadas são

$$
\left[\begin{array}{l}
f_{q} \\
f_{d}
\end{array}\right]=\left[\begin{array}{cc}
\cos (\alpha) & -\operatorname{sen}(\alpha) \\
\operatorname{sen}(\alpha) & \cos (\alpha)
\end{array}\right]\left[\begin{array}{c}
f_{q}^{e} \\
f_{d}^{e}
\end{array}\right]
$$

e

$$
\left[\begin{array}{l}
f_{q} \\
f_{d}
\end{array}\right]=\left[\begin{array}{cc}
\cos (\theta) & -\operatorname{sen}(\theta) \\
\operatorname{sen}(\theta) & \cos (\theta)
\end{array}\right]\left[\begin{array}{c}
f_{q}^{u} \\
f_{d}^{u}
\end{array}\right] .
$$

Os controladores do RSC são ilustrados nas Figuras 3.12 e 3.13.

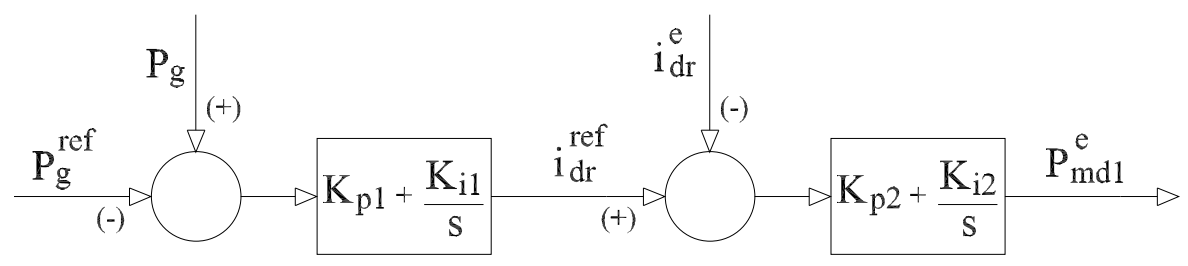

Figura 3.12: RSC: controlador da potência $P_{g}$.

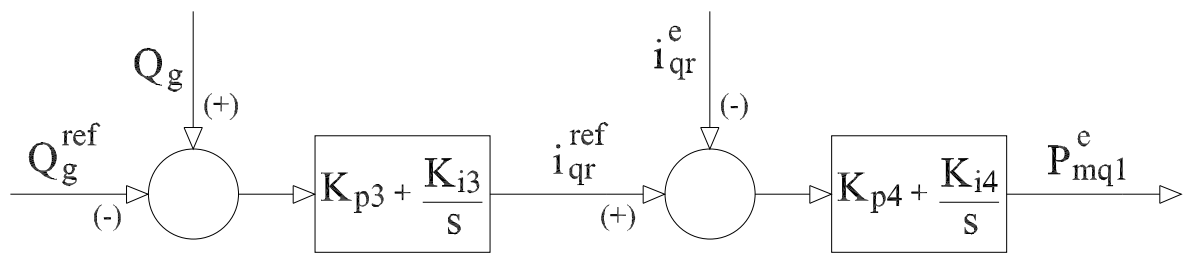

Figura 3.13: RSC: controlador da potência $Q_{g}$.

As equações correspondentes são

$$
\frac{d i_{d r}^{r e f}}{d t}=K_{p 1}\left(\frac{d P_{g}}{d t}\right)+K_{i 1}\left(P_{g}-P_{g}^{r e f}\right)
$$




$$
\begin{gathered}
\frac{d P_{m d 1}^{e}}{d t}=K_{p 2}\left(\frac{d i_{d r}^{r e f}}{d t}-\frac{d i_{d r}^{e}}{d t}\right)+K_{i 2}\left(i_{d r}^{r e f}-i_{d r}^{e}\right), \\
\frac{d i_{q r}^{r e f}}{d t}=K_{p 3}\left(\frac{d Q_{g}}{d t}\right)+K_{i 3}\left(Q_{g}-Q_{g}^{r e f}\right)
\end{gathered}
$$

e

$$
\frac{d P_{m q 1}^{e}}{d t}=K_{p 4}\left(\frac{d i_{q r}^{r e f}}{d t}-\frac{d i_{q r}^{e}}{d t}\right)+K_{i 4}\left(i_{q r}^{r e f}-i_{q r}^{e}\right) .
$$

Os parâmetros de referência $P_{g}^{r e f}$ e $Q_{g}^{r e f}$ correspondem aos valores especificados para o fluxo de carga. As variáveis $P_{g}$ e $Q_{g}$ referem-se aos valores atuais. As correntes nos novos referenciais são

$$
i_{d r}^{e}=-i_{q r} \operatorname{sen}(\alpha)+i_{d r} \cos (\alpha)
$$

e

$$
i_{q r}^{e}=i_{q r} \cos (\alpha)+i_{d r} \operatorname{sen}(\alpha)
$$

Os sinais de saída $P_{m d 1}^{e}$ e $P_{m q 1}^{e}$ correspondem às componentes PWM. Estes sinais dão origem às componentes de tensão no rotor $u_{d r}^{e}$ e $u_{d r}^{e}$ através das relações (Achilles e Pöller, 2003)

$$
u_{d r}^{e}=P_{m d 1}^{e} \frac{\sqrt{3} u_{D C}}{2 \sqrt{2}}
$$

e

$$
u_{q r}^{e}=P_{m q 1}^{e} \frac{\sqrt{3} u_{D C}}{2 \sqrt{2}} .
$$

Uma vez que as componentes $u_{d r}^{e}$ e $u_{d r}^{e}$ estão no referencial $d^{e} q^{e}$, as mesmas devem retornar ao referencial $d q$. Desta forma, obtém-se

$$
u_{d r}=u_{q r}^{e} \operatorname{sen}(\alpha)+u_{d r}^{e} \cos (\alpha)
$$

e

$$
u_{q r}=u_{q r}^{e} \cos (\alpha)-u_{d r}^{e} \operatorname{sen}(\alpha),
$$

para que possam ser aplicadas em (3.235) e (3.236). 
Os controladores do GSC são ilustrados nas Figuras 3.14 e 3.15.

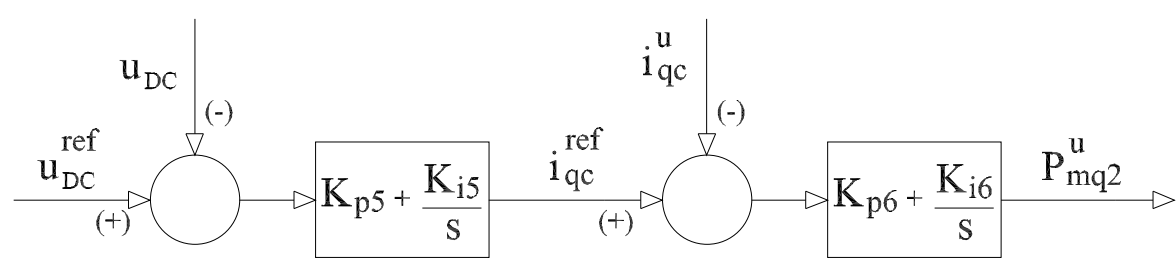

Figura 3.14: GSC: controlador da tensão u $D C$.

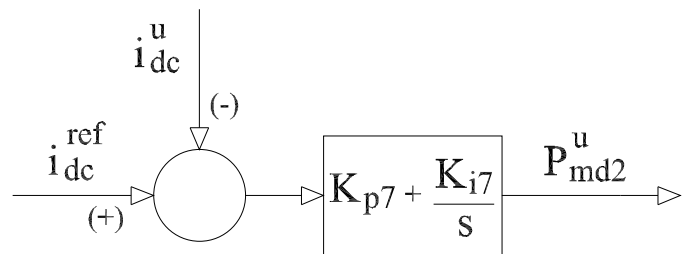

Figura 3.15: GSC: controlador da corrente $i_{d c}^{u}$

As equações correspondentes são

$$
\begin{gathered}
\frac{d i_{q c}^{r e f}}{d t}=K_{p 5}\left(-\frac{d u_{D C}}{d t}\right)+K_{i 5}\left(u_{D C}^{r e f}-u_{D C}\right), \\
\frac{d P_{m q 2}^{u}}{d t}=K_{p 6}\left(\frac{d i_{q c}^{r e f}}{d t}-\frac{d i_{q c}^{u}}{d t}\right)+K_{i 6}\left(i_{q c}^{r e f}-i_{q c}^{u}\right)
\end{gathered}
$$

e

$$
\frac{d P_{m d 2}^{u}}{d t}=K_{p 7}\left(\frac{d i_{d c}^{r e f}}{d t}-\frac{d i_{d c}^{u}}{d t}\right)+K_{i 7}\left(i_{d c}^{r e f}-i_{d c}^{u}\right)
$$

De forma análoga às equações apresentadas para os controladores do RSC, as variáveis de interesse para os controladores do GSC são calculadas como

$$
\begin{gathered}
i_{d c}^{u}=-i_{q c} \operatorname{sen}(\theta)+i_{d c} \cos (\theta), \\
i_{q c}^{u}=i_{q c} \cos (\theta)+i_{d c} \operatorname{sen}(\theta), \\
u_{d c}^{u}=P_{m d 2}^{u} \frac{\sqrt{3} u_{D c}}{2 \sqrt{2}}, \\
u_{q c}^{u}=P_{m q 2}^{u} \frac{\sqrt{3} u_{D C}}{2 \sqrt{2}},
\end{gathered}
$$




$$
u_{d c}=u_{q c}^{u} \operatorname{sen}(\theta)+u_{d c}^{u} \cos (\theta)
$$

e

$$
u_{q c}=u_{q c}^{u} \cos (\theta)-u_{d c}^{u} \operatorname{sen}(\theta)
$$

\subsubsection{Processo de inicialização}

O processo de inicialização da configuração DFIG é composto pelo fluxo de carga e pela inicialização das variáveis da máquina. Neste trabalho, considera-se a barra 3 do sistema teste, a barra terminal da máquina, como uma barra PQ. Após obtidos os valores da tensão terminal e do respectivo ângulo, as variáveis da máquina podem ser inicializadas. Em seguida, são calculadas as demais variáveis através das equações já desenvolvidas, para compor o vetor de condições iniciais do modelo completo.

\subsubsection{Fluxo de carga}

Os parâmetros e variáveis aqui apresentados seguem as definições da modelagem desenvolvida para a rede elétrica. O objetivo agora é obter as equações da rede na forma de potências elétricas. Isto posto, seja a relação entre o vetor das injeções de corrente $\vec{i}$ e o vetor das tensões nodais na rede $\vec{u}$

$$
\vec{i}=Y \vec{u},
$$

onde $Y$ corresponde à matriz de admitâncias (Monticelli, 1983).

Os elementos da matriz $Y$ são

$$
Y_{k m}=-y_{k m}
$$

e

$$
Y_{k k}=y_{k}^{s h}+\sum_{m \in N(k)}\left(y_{k m}^{s h}+y_{k m}\right)
$$

A injeção de corrente $\bar{i}_{k}$ pode ser colocada na forma

$$
\bar{i}_{k}=Y_{k k} \bar{u}_{k}+\sum_{m \in N(k)} Y_{k m} \bar{u}_{m}=\sum_{m \in K} Y_{k m} \bar{u}_{m}
$$

sendo $K$ o conjunto das barras conectadas à barra $k$, incluindo a própria barra $k$ e $\bar{u}_{k}$ e $\bar{u}_{m}$ os fasores de tensão

$$
\bar{u}_{k}=u_{k} e^{j \theta_{k}}
$$




$$
\bar{u}_{m}=u_{m} e^{j \theta_{m}} .
$$

Considerando

$$
Y_{k m}=g_{k m}+j b_{k m},
$$

a expressão da corrente (3.295) pode ser escrita na forma

$$
\bar{i}_{k}=\sum_{m \in K}\left(g_{k m}+j b_{k m}\right) u_{m} e^{j \theta_{m}} .
$$

Susbstituindo (3.299) na expressão da potência aparente complexa

$$
\bar{S}_{k}^{*}=P_{k}-j Q_{k}=\bar{u}_{k}^{*} \bar{i}_{k}
$$

além de considerar

$$
\bar{u}_{k}^{*}=u_{k} e^{-j \theta_{k}},
$$

é possível escrever

$$
\bar{S}_{k}^{*}=u_{k} e^{-j \theta_{k}} \sum_{m \in K}\left(g_{k m}+j b_{k m}\right) u_{m} e^{j \theta_{m}} .
$$

Separando as partes real e imaginária de (3.302), obtém-se

$$
P_{k}=u_{k} \sum_{m \in K} u_{m}\left[g_{k m} \cos \left(\theta_{k}-\theta_{m}\right)+b_{k m} \operatorname{sen}\left(\theta_{k}-\theta_{m}\right)\right]
$$

e

$$
Q_{k}=u_{k} \sum_{m \in K} u_{m}\left[g_{k m} \operatorname{sen}\left(\theta_{k}-\theta_{m}\right)-b_{k m} \cos \left(\theta_{k}-\theta_{m}\right)\right] .
$$

Aplicando (3.303) e (3.304) às barras do sistema teste, considerando que para a barra 1 $u_{1}=1$ e $\theta_{1}=0$ e que para a barra 2 não há injeção de potência, isto é, $P_{2}=0$ e $Q_{2}=0$, as equações resultantes são

$$
\begin{aligned}
& -P_{3}+u_{3}^{2} g_{33}+u_{3} u_{2} g_{32} \cos \left(\theta_{3}-\theta_{2}\right)+u_{3} u_{2} b_{32} \operatorname{sen}\left(\theta_{3}-\theta_{2}\right)=0, \\
& -Q_{3}-u_{3}^{2} b_{33}+u_{3} u_{2} g_{32} \operatorname{sen}\left(\theta_{3}-\theta_{2}\right)-u_{3} u_{2} b_{32} \cos \left(\theta_{3}-\theta_{2}\right)=0,
\end{aligned}
$$




$$
\begin{aligned}
u_{2}^{2} g_{22}+u_{2} g_{21} \cos \left(\theta_{2}\right)+u_{2} b_{21} \operatorname{sen}\left(\theta_{2}\right) & + \\
u_{2} u_{3} g_{23} \cos \left(\theta_{2}-\theta_{3}\right)+u_{2} u_{3} b_{23} \operatorname{sen}\left(\theta_{2}-\theta_{3}\right) & =0
\end{aligned}
$$

e

$$
\begin{aligned}
-u_{2}^{2} b_{22}+u_{2} g_{21} \operatorname{sen}\left(\theta_{2}\right)-u_{2} b_{21} \cos \left(\theta_{2}\right) & + \\
u_{2} u_{3} g_{23} \operatorname{sen}\left(\theta_{2}-\theta_{3}\right)-u_{2} u_{3} b_{23} \cos \left(\theta_{2}-\theta_{3}\right) & =0 .
\end{aligned}
$$

As equações (3.305) a (3.308) formam um sistema não linear composto por quatro equações. Uma vez que se considera a barra 3 do sistema teste como uma barra $\mathrm{PQ}$, os valores $P_{3}=P_{g}$ e $Q_{3}=Q_{g}$ são previamente conhecidos. Desta forma, o vetor de incógnitas é dado por

$$
\kappa_{3}=\left[\begin{array}{llll}
u_{3} & u_{2} & \theta_{3} & \theta_{2}
\end{array}\right]^{T}
$$

\subsubsection{Inicialização da máquina}

Para a configuração DFIG também é necessário representar as variáveis do modelo da máquina nos eixos real e imaginário da rede. Como já citado para o modelo da máquina de indução, uma vez que o estator da máquina corresponde à barra 3 do sistema teste, como ilustrado na Figura (3.1), as componentes de tensão do estator $u_{d s}$ e $u_{q s}$ serão reescritas como $u_{y 3}$ e $u_{x 3}$, respectivamente. E como as componentes de corrente associadas à rede elétrica são $i_{d g}$ e $i_{q g}$, estas serão reescritas como $i_{y 3}$ e $i_{x 3}$, de acordo com o alinhamento entre os eixos mostrado na Figura (3.16).

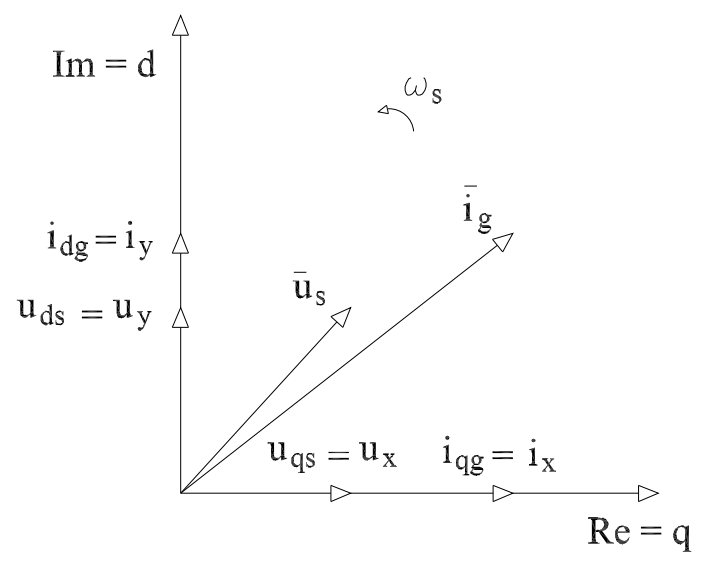

Figura 3.16: Alinhamento entre eixos real e em quadratura e eixos imaginário e direto.

Sendo $u_{3}=u_{5}$ e $\theta_{3}=\theta$, é possível escrever 


$$
\begin{gathered}
\bar{u}_{3}=\bar{u}_{s}=u_{3} \angle \theta_{3}=u_{s} \angle \theta=u_{3} \cos \left(\theta_{3}\right)+j u_{3} \operatorname{sen}\left(\theta_{3}\right)= \\
u_{s} \cos (\theta)+j u_{s} \operatorname{sen}(\theta)=u_{x 3}+j u_{y 3}=u_{q s}+j u_{d s}
\end{gathered}
$$

e

$$
u_{2} \angle \theta_{2}=u_{2} \cos \left(\theta_{2}\right)+j u_{2} \operatorname{sen}\left(\theta_{2}\right)=u_{x 2}+j u_{y 2}
$$

A partir do conhecimento do fasor de tensão do estator e dos valores de impedância da rede, é possível calcular as componentes de corrente da rede elétrica por

$$
\bar{i}_{3}=\bar{i}_{g}=\frac{1-\bar{u}_{3}}{z_{12}+z_{23}}=i_{q g}+j i_{d g}=i_{x 3}+j i_{y 3} .
$$

Com os valores de $u_{x 3}, u_{y 3}, i_{x 3}, i_{y 3}$ e $\theta$ conhecidos, é possível encontrar as condições iniciais para as variáveis da máquina através das equações seguintes. Em regime permanente as derivadas no tempo são nulas nas equações da máquina e na equação que descreve a dinâmica do link DC. Sendo assim, as seis primeiras equações utilizadas são

$$
\begin{gathered}
-u_{y 3}+r_{s} i_{d s}+x_{a} i_{q s}+e_{d}=0, \\
-u_{x 3}+r_{s} i_{q s}-x_{a} i_{d s}+e_{q}=0, \\
-\frac{1}{T_{o}}\left[e_{d}-\frac{L_{m}^{2}}{L_{l r}+L_{m}} i_{q s}\right]-s \omega_{s} e_{q}+\omega_{s} \frac{L_{m}}{L_{l r}+L_{m}} u_{q r}=0, \\
-\frac{1}{T_{o}}\left[e_{q}+\frac{L_{m}^{2}}{L_{l r}+L_{m}} i_{d s}\right]+s \omega_{s} e_{d}-\omega_{s} \frac{L_{m}}{L_{l r}+L_{m}} u_{d r}=0, \\
-\frac{P_{m}}{(1-s)}-e_{q} i_{x 3}-e_{d} i_{y 3}=0
\end{gathered}
$$

e

$$
u_{d c} i_{d c}+u_{q c} i_{q c}-u_{d r} i_{d r}-u_{q r} i_{q r}=0 .
$$

As equações referentes às componentes da tensão interna

$$
-e_{d}+\frac{L_{m}}{L_{l r}+L_{m}}\left[\left(L_{l r}+L_{m}\right) i_{q r}+L_{m} i_{q s}\right]=0
$$

e

$$
-e_{q}-\frac{L_{m}}{L_{l r}+L_{m}}\left[\left(L_{l r}+L_{m}\right) i_{d r}+L_{m} i_{d s}\right]=0
$$


também são necessárias, assim como as equações referentes à malha do conversor do lado da rede

$$
-u_{d c}+u_{y 3}-r_{f} i_{d c}-x_{f} i_{q c}=0
$$

$\mathrm{e}$

$$
-u_{q c}+u_{x 3}-r_{f} i_{q c}+x_{f} i_{d c}=0 .
$$

Outra equação necessária refere-se à curva $P_{m}$ aproximada, escrita agora em função do escorregamento

$$
\begin{array}{rc}
-P_{m}+a_{0}+a_{1} \cos ((1-s) c)+b_{1} \operatorname{sen}((1-s) c)+a_{2} \cos (2(1-s) c) & + \\
b_{2} \operatorname{sen}(2(1-s) c)+a_{3} \cos (3(1-s) c)+b_{3} \operatorname{sen}(3(1-s) c) & + \\
a_{4} \cos (4(1-s) c)+b_{4} \operatorname{sen}(4(1-s) c)+a_{5} \cos (5(1-s) c) & + \\
b_{5} \operatorname{sen}\left(5((1-s) c)+a_{6} \cos (6(1-s) c)+b_{6} \operatorname{sen}(6(1-s) c)\right. & + \\
a_{7} \cos (7(1-s) c)+b_{7} \operatorname{sen}(7(1-s) c)+a_{8} \cos (8(1-s) c) & + \\
b_{8} \operatorname{sen}(8(1-s) c) & =0 .
\end{array}
$$

Outras duas equações necessárias correspondem ao balanço de corrente

$$
-i_{y 3}+i_{d c}+i_{d s}=0
$$

e à equação referente à componente de referência $i_{d c}^{r e f}$

$$
-i_{q c} \operatorname{sen}(\theta)+i_{d c} \cos (\theta)-i_{d c}^{r e f}=0
$$

cujo valor é previamente conhecido.

Por fim, utiliza-se

$$
P_{g}+r_{s}\left(i_{d s}^{2}+i_{q s}^{2}\right)+r_{r}\left(i_{d r}^{2}+i_{q r}^{2}\right)+r_{f}\left(i_{d c}^{2}+i_{q c}^{2}\right)-P_{m}=0
$$

que relaciona as potências mecânica e elétrica com as perdas no estator, rotor e conversor.

As equações (3.313) a (3.326) formam um sistema não linear composto por quatorze equações, cujo vetor de incógnitas é dado por

$$
\kappa_{4}=\left[\begin{array}{llllllllllllll}
P_{m} & u_{d r} & u_{q r} & i_{d r} & i_{q r} & u_{d c} & u_{q c} & i_{d c} & i_{q c} & i_{d s} & i_{q s} & s & e_{d} & e_{q}
\end{array}\right]^{T} .
$$

\subsubsection{Estimativa inicial}

Para que o método de resolução do sistema (3.313) a (3.326) consiga alcançar uma solução e também convirja para um valor coerente, é necessário que os valores iniciais para as variáveis sejam escolhidos de forma adequada. Um "chute" inicial apropriado torna-se portanto 
fundamental. As equações seguintes são capazes de proporcionar valores que estejam próximos do equilíbrio de interesse.

Considerando $P_{3}=P_{m}=P_{g}$, verifica-se a frequência do rotor associada a esta potência na curva $P_{m}$ aproximada. Em seguida, calcula-se o escorregamento da máquina. Como se conhece o valor de $i_{d c}^{r e f}$, se considera $i_{d c}=i_{d c}^{r e f}$ e os demais valores necessários são então calculados conforme

$$
\begin{aligned}
& P_{s}=\frac{P_{m}}{1-s} \\
& P_{r}=\frac{s}{1-s} P_{m}, \\
& i_{q c}=\frac{P_{r}-u_{y 3} i_{d c}}{u_{x 3}}, \\
& i_{d s}=i_{y 3}-i_{d c}, \\
& i_{q s}=\frac{P_{s}-u_{y 3} i_{d s}}{u_{x 3}}, \\
& u_{d c}=u_{y 3}-r_{f} i_{d c}-x_{f} i_{q c}, \\
& u_{q c}=u_{x 3}-r_{f} i_{q c}+x_{f} i_{d c}, \\
& i_{d r}=\frac{-u_{x 3}+r_{s} i_{q s}-\left(L_{l s}+L_{m}\right) i_{d s}}{L_{m}}, \\
& i_{q r}=\frac{u_{y 3}-r_{s} i_{d s}-\left(L_{l s}+L_{m}\right) i_{q s}}{L_{m}}, \\
& u_{d r}=r_{r} i_{d r}+s\left(\left(L_{l r}+L_{m}\right) i_{q r}+L_{m} i_{q s}\right), \\
& u_{q r}=r_{r} i_{q r}-s\left(\left(L_{l r}+L_{m}\right) i_{d r}+L_{m} i_{d s}\right), \\
& e_{d}=\frac{L_{m}}{L_{l r}+L_{m}}\left[\left(L_{l r}+L_{m}\right) i_{q r}+L_{m} i_{q s}\right]
\end{aligned}
$$

e

$$
e_{q}=-\frac{L_{m}}{L_{l r}+L_{m}}\left[\left(L_{l r}+L_{m}\right) i_{d r}+L_{m} i_{d s}\right]
$$




\subsubsection{Demais variáveis}

Após encontrada a solução do sistema (3.313) a (3.326), as demais variáveis necessárias para compor o vetor de condições iniciais para o modelo completo são calculadas, a partir das equações desenvolvidas para o modelo, como

$$
\begin{aligned}
& u_{D C}=u_{D C}^{r e f} \\
& i_{d c}^{u}=-i_{q c} \operatorname{sen}(\theta)+i_{d c} \cos (\theta), \\
& i_{q c}^{u}=i_{q c} \cos (\theta)+i_{d c} \operatorname{sen}(\theta), \\
& i_{q c}^{r e f}=i_{q c}^{u} \\
& u_{d c}^{u}=-u_{q c} \operatorname{sen}(\theta)+u_{d c} \cos (\theta), \\
& u_{q c}^{u}=u_{q c} \cos (\theta)+u_{d c} \operatorname{sen}(\theta), \\
& P_{m d 2}^{u}=\frac{u_{d c}^{u} 2 \sqrt{2}}{\sqrt{3} u_{D C}} \\
& P_{m q 2}^{u}=\frac{u_{q c}^{u} 2 \sqrt{2}}{\sqrt{3} u_{D C}} \\
& \alpha=\operatorname{tg}^{-1}\left(\frac{e_{d}}{e_{q}}\right) \\
& i_{d r}^{e}=-i_{q r} \operatorname{sen}(\alpha)+i_{d r} \cos (\alpha), \\
& i_{q r}^{e}=i_{q r} \cos (\alpha)+i_{d r} \operatorname{sen}(\alpha), \\
& i_{d r}^{r e f}=i_{d r}^{e} \\
& i_{q r}^{r e f}=i_{q r}^{e}, \\
& u_{d r}^{e}=-u_{q r} \operatorname{sen}(\alpha)+u_{d r} \cos (\alpha),
\end{aligned}
$$




$$
\begin{gathered}
u_{q r}^{e}=u_{q r} \cos (\alpha)+u_{d r} \operatorname{sen}(\alpha), \\
P_{m d 1}^{e}=\frac{u_{d r}^{e} 2 \sqrt{2}}{\sqrt{3} u_{D C}}
\end{gathered}
$$

e

$$
P_{m q 1}^{e}=\frac{u_{q r}^{e} 2 \sqrt{2}}{\sqrt{3} u_{D C}} .
$$

O processo de inicialização da configuração DFIG estabelece portanto as condições iniciais para o modelo completo, totalizando quarenta variáveis. O vetor das condições iniciais fica então descrito como

$$
\begin{aligned}
k_{5}= & {\left[\begin{array}{llllllllllll}
s & i_{d r} & i_{q r} & i_{d s} & i_{q s} & u_{d r} & u_{q r} & u_{x 3} & u_{y 3} & u_{d c} \\
& u_{q c} & i_{d c} & i_{q c} & i_{y 3} & i_{x 3} & u_{D c} & \theta & i_{d c}^{u} & i_{q c}^{u} & i_{q c}^{r e f} \\
& P_{m d 2}^{u} & P_{m q 2}^{u} & e_{d} & e_{q} & \alpha & i_{d r}^{e} & i_{q r}^{e} & i_{d r}^{r e f} & i_{q r}^{r e f} & P_{m d 1}^{e} \\
& P_{m q 1}^{e} & u_{d r}^{e} & u_{q r}^{e} & u_{d c}^{u} & u_{q c}^{u} & P_{g} & Q_{g} & P_{m} & u_{x 2} & u_{y 2}
\end{array}\right]^{T} . }
\end{aligned}
$$

\subsection{Modelo completo do sistema teste com a configuração DFIG nos eixos $d$ e $q$}

Visto que na modelagem da configuração DFIG as componentes $i_{d s}$ e $i_{q s}$ estão sendo absorvidas pelo estator e as componentes $i_{d c}$ e $i_{q c}$ estão sendo absorvidas pelo conversor do lado da rede, faz-se necessário inverter os seus sinais (exceto nas equações de balanço), visto que na modelagem da rede elétrica consideram-se injeções líquidas de corrente nas barras. Acrescentando as equações que modelam a configuração DFIG às equações que modelam a rede elétrica, forma-se um conjunto composto por quarenta equações. O modelo completo do sistema teste com a configuração DFIG fica então definido por

- Quatro equações referentes ao modelo da rede elétrica

$$
\begin{gathered}
g_{12} u_{x 1}-b_{12} u_{y 1}+\left(-g_{12}^{s h}-g_{23}^{s h}-g_{12}-g_{23}\right) u_{x 2}+ \\
\left(b_{12}^{s h}+b_{23}^{s h}+b_{12}+b_{23}\right) u_{y 2}+g_{23} u_{x 3}-b_{23} u_{y 3}=0, \\
b_{12} u_{x 1}+g_{12} u_{y 1}+\left(-b_{12}^{s h}-b_{23}^{s h}-b_{12}-b_{23}\right) u_{x 2}+ \\
\left(-g_{12}^{s h}-g_{23}^{s h}-g_{12}-g_{23}\right) u_{y 2}+b_{23} u_{x 3}+g_{23} u_{y 3}=0, \\
i_{x 3}+g_{23} u_{x 2}-b_{23} u_{y 2}+\left(-g_{32}^{s h}-g_{23}\right) u_{x 3}+\left(b_{32}^{s h}+b_{23}+b_{3}^{s h}\right) u_{y 3}=0
\end{gathered}
$$


e

$$
i_{y 3}+b_{23} u_{x 2}+g_{23} u_{y 2}+\left(-g_{32}^{s h}-g_{23}\right) u_{y 3}+\left(-b_{32}^{s h}-b_{23}-b_{3}^{s h}\right) u_{x 3}=0 .
$$

- Quatro equações referentes ao modelo elétrico da máquina

$$
\begin{gathered}
u_{y 3}=-r_{s} i_{d s}-x_{a} i_{q s}+e_{d}-\frac{x_{a}}{\omega_{s}} \frac{d i_{d s}}{d t}-\frac{1}{\omega_{s}} \frac{d e_{q}}{d t}, \\
u_{x 3}=-r_{s} i_{q s}+x_{a} i_{d s}+e_{q}-\frac{x_{a}}{\omega_{s}} \frac{d i_{q s}}{d t}+\frac{1}{\omega_{s}} \frac{d e_{d}}{d t}, \\
\frac{d e_{d}}{d t}=-\frac{1}{T_{o}}\left[e_{d}+\frac{L_{m}^{2}}{L_{l r}+L_{m}} i_{q s}\right]-s \omega_{s} e_{q}+\omega_{s} \frac{L_{m}}{L_{l r}+L_{m}} u_{q r}
\end{gathered}
$$

e

$$
\frac{d e_{q}}{d t}=-\frac{1}{T_{o}}\left[e_{q}-\frac{L_{m}^{2}}{L_{l r}+L_{m}} i_{d s}\right]+s \omega_{s} e_{d}-\omega_{s} \frac{L_{m}}{L_{l r}+L_{m}} u_{d r} .
$$

- Uma equação referente ao movimento da máquina

$$
\frac{d s}{d t}=\frac{1}{2 H}\left[T_{e}-\frac{P_{m}}{1-s}-D(1-s)\right] .
$$

com o torque eletromagnético dado por

$$
T_{e}=e_{q} i_{q s}+e_{d} i_{d s} .
$$

- Uma equação referente à potência mecânica

$$
\begin{aligned}
-P_{m}+a_{0}+a_{1} \cos ((1-s) c)+b_{1} \operatorname{sen}((1-s) c)+a_{2} \cos (2(1-s) c) & + \\
b_{2} \operatorname{sen}(2(1-s) c)+a_{3} \cos (3(1-s) c)+b_{3} \operatorname{sen}(3(1-s) c) & + \\
a_{4} \cos (4(1-s) c)+b_{4} \operatorname{sen}(4(1-s) c)+a_{5} \cos (5(1-s) c) & + \\
b_{5} \operatorname{sen}\left(5((1-s) c)+a_{6} \cos (6(1-s) c)+b_{6} \operatorname{sen}(6(1-s) c)\right. & + \\
a_{7} \cos (7(1-s) c)+b_{7} \operatorname{sen}(7(1-s) c)+a_{8} \cos (8(1-s) c) & + \\
b_{8} \operatorname{sen}(8(1-s) c) & =0 .
\end{aligned}
$$

- Duas equações referentes às componentes da tensão interna

$$
e_{d}=\frac{L_{m}}{L_{l r}+L_{m}}\left[\left(L_{l r}+L_{m}\right) i_{q r}-L_{m} i_{q s}\right]
$$

e

$$
e_{q}=-\frac{L_{m}}{L_{l r}+L_{m}}\left[\left(L_{l r}+L_{m}\right) i_{d r}-L_{m} i_{d s}\right]
$$


- Uma equação referente à dinâmica do link DC

$$
C \frac{d u_{D C}}{d t}=\frac{-u_{d c} i_{d c}-u_{q c} i_{q c}-u_{d r} i_{d r}-u_{q r} i_{q r}}{u_{D C}} .
$$

- Duas equações referentes ao balanço de corrente

$$
i_{y 3}=i_{d c}+i_{d s}
$$

e

$$
i_{x 3}=i_{q s}+i_{q c}
$$

- Duas equações referentes ao balanço de potência

$$
P_{g}=-u_{y 3} i_{d s}-u_{x 3} i_{q s}-u_{y 3} i_{d c}-u_{x 3} i_{q c}
$$

e

$$
Q_{g}=-u_{y 3} i_{q s}+u_{x 3} i_{d s}-u_{y 3} i_{q c}+u_{x 3} i_{d c} .
$$

- Duas equações referentes à malha do conversor do lado da rede

$$
u_{d c}=u_{y 3}+r_{f} i_{d c}+x_{f} i_{q c}
$$

e

$$
u_{q c}=u_{x 3}+r_{f} i_{q c}-x_{f} i_{d c} .
$$

- Duas equações referentes aos ângulos dos sistemas de referência

$$
\theta=\operatorname{tg}^{-1}\left(\frac{u_{y 3}}{u_{x 3}}\right)
$$

e

$$
\alpha=\operatorname{tg}^{-1}\left(\frac{e_{d}}{e_{q}}\right)
$$


- Doze equações referentes às variáveis transformadas

$$
\begin{gathered}
i_{d c}^{u}=i_{q c} \operatorname{sen}(\theta)-i_{d c} \cos (\theta), \\
i_{q c}^{u}=-i_{q c} \cos (\theta)-i_{d c} \operatorname{sen}(\theta), \\
i_{d r}^{e}=-i_{q r} \operatorname{sen}(\alpha)+i_{d r} \cos (\alpha), \\
i_{q r}^{e}=i_{q r} \cos (\alpha)+i_{d r} \operatorname{sen}(\alpha), \\
u_{d c}^{u}=P_{m d 2}^{u} \frac{\sqrt{3} u_{D c}}{2 \sqrt{2}}, \\
u_{q c}^{u}=P_{m q 2}^{u} \frac{\sqrt{3} u_{D c}}{2 \sqrt{2}}, \\
u_{q r}^{e}=P_{m q 1}^{e} \frac{\sqrt{3} u_{D c}}{2 \sqrt{2}}, \\
u_{d r}^{e}=u_{q c}^{u} \operatorname{sen}(\theta)+u_{d c}^{u} \cos (\theta), \\
u_{q c}=u_{m d 1}^{e} \frac{\sqrt{3} u_{D c}}{2 \sqrt{2}}, \\
\cos (\theta)-u_{d c}^{u} \operatorname{sen}(\theta),
\end{gathered}
$$

e

$$
u_{q r}=u_{q r}^{e} \cos (\alpha)-u_{d r}^{e} \operatorname{sen}(\alpha)
$$

- Sete equações referentes aos controladores

$$
\frac{d i_{d r}^{r e f}}{d t}=K_{p 1}\left(\frac{d P_{g}}{d t}\right)+K_{i 1}\left(P_{g}-P_{g}^{r e f}\right)
$$




$$
\begin{gathered}
\frac{d P_{m d 1}^{e}}{d t}=K_{p 2}\left(\frac{d i_{d r}^{r e f}}{d t}-\frac{d i_{d r}^{e}}{d t}\right)+K_{i 2}\left(i_{d r}^{r e f}-i_{d r}^{e}\right), \\
\frac{d i_{q r}^{r e f}}{d t}=K_{p 3}\left(\frac{d Q_{g}}{d t}\right)+K_{i 3}\left(Q_{g}-Q_{g}^{r e f}\right), \\
\frac{d P_{m q 1}^{e}}{d t}=K_{p 4}\left(\frac{d i_{q r}^{r e f}}{d t}-\frac{d i_{q r}^{e}}{d t}\right)+K_{i 4}\left(i_{q r}^{r e f}-i_{q r}^{e}\right), \\
\frac{d i_{q c}^{r e f}}{d t}=K_{p 5}\left(-\frac{d u_{D C}}{d t}\right)+K_{i 5}\left(u_{D C}^{r e f}-u_{D C}\right), \\
\frac{d P_{m q 2}^{u}}{d t}=K_{p 6}\left(\frac{d i_{q c}^{r e f}}{d t}-\frac{d i_{q c}^{u}}{d t}\right)+K_{i 6}\left(i_{q c}^{r e f}-i_{q c}^{u}\right)
\end{gathered}
$$

e

$$
\frac{d P_{m d 2}^{u}}{d t}=K_{p 7}\left(\frac{d i_{d c}^{r e f}}{d t}-\frac{d i_{d c}^{u}}{d t}\right)+K_{i 7}\left(i_{d c}^{r e f}-i_{d c}^{u}\right)
$$

As equações (3.359) a (3.399) formam um sistema não linear composto por quarenta equações. Ao se considerar o modelo da máquina de indução com rotor bobinado em quinta, terceira e primeira ordens, obtêm-se sistemas de ordens treze, onze e nove, respectivamente. O vetor de incógnitas é dado por

$$
\begin{aligned}
k_{6}= & {\left[\begin{array}{llllllllllll}
s & i_{d r} & i_{q r} & i_{d s} & i_{q s} & u_{d r} & u_{q r} & u_{x 3} & u_{y 3} & u_{d c} \\
& u_{q c} & i_{d c} & i_{q c} & i_{y 3} & i_{x 3} & u_{D c} & \theta & i_{d c}^{u} & i_{q c}^{u} & i_{q c}^{r e f} \\
& P_{m d 2}^{u} & P_{m q 2}^{u} & e_{d} & e_{q} & \alpha & i_{d r}^{e} & i_{q r}^{e} & i_{d r}^{r e f} & i_{q r}^{r e f} & P_{m d 1}^{e} \\
& P_{m q 1}^{e} & u_{d r}^{e} & u_{q r}^{e} & u_{d c}^{u} & u_{q c}^{u} & P_{g} & Q_{g} & P_{m} & u_{x 2} & u_{y 2}
\end{array}\right]^{T} . }
\end{aligned}
$$

Toma-se a barra 1 como referência angular e portanto as componentes de tensão na barra 1 são previamente conhecidas, $u_{x 1}=1$ e $u_{y 1}=0$. Os parâmetros da rede são apresentados no apêndice $A$. Os parâmetros da configuração DFIG, incluindo os valores dos ganhos dos controladores, são apresentados no apêndice B. As demais constantes e variáveis podem ser calculadas a partir da modelagem desenvolvida.

\subsection{Máquina de indução em regime permanente}

Nesta seção é apresentada a modelagem da máquina de indução em regime permanente. $\mathrm{O}$ modelo final ainda representará a dinâmica mecânica e proporcionará os mesmos resultados do modelo de primeira ordem nos eixos $d$ e $q$. Optou-se por apresentar esta modelagem em virtude da diferente abordagem utilizada. O equacionamento da máquina de indução em regime permanente parte do circuito elétrico mostrado na Figura 3.17, onde são exibidos 
os fasores de corrente do estator $\bar{i}_{s}$, de corrente do rotor $\bar{i}_{r}$, de tensão do estator $\bar{u}_{s}$, de tensão do rotor $\bar{u}_{r}$, as resistências e reatâncias, já definidos anteriormente e a influência do escorregamento no circuito (McPherson e Laramore, 1990), (Anaya-Lara et al., 2009).

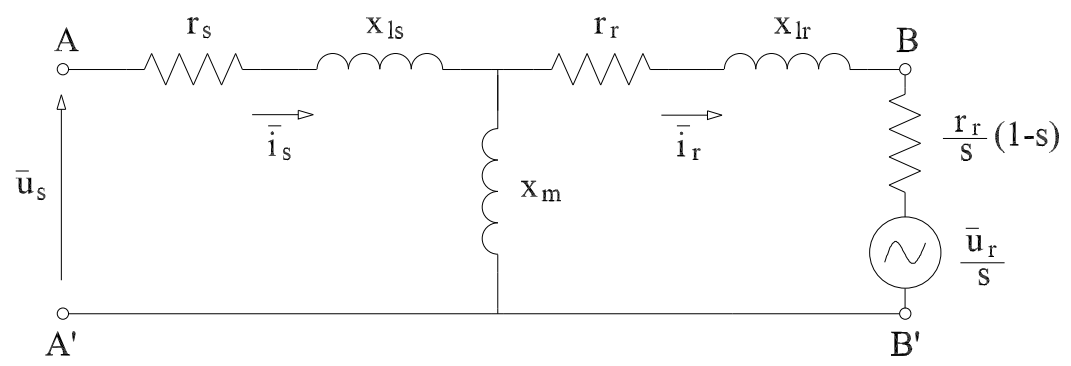

Figura 3.17: Circuito por fase da máquina de indução.

As premissas i) a vi) adotadas para o modelo dinâmico da máquina de indução no sistema de coordenadas $d q$ são aqui admitidas. Também, admite-se que as variáveis do rotor são referenciadas ao estator e todos os parâmetros e variáveis são agora representados diretamente por unidade, na base da máquina. No que diz respeito à nomenclatura, considera-se também a componente relativa ao eixo real denotada pelo subscrito $x$ e a componente relativa ao eixo imaginário pelo subscrito $y$.

Podem ser utilizados circuitos equivalentes de Thévenin para obter a expressão final do torque elétrico (Cutsem e Vournas, 1998), assim como as expressões das potências envolvidas, a partir das relações entre correntes, tensões, resistências, reatâncias e escorregamento presentes no circuito da Figura 3.17. O primeiro equivalente de Thévenin pode ser observado na Figura 3.18, onde são exibidas agora novas variáveis, que são a resistência equivalente $r_{e}$, a reatância equivalente $x_{e}$ e a tensão equivalente $\bar{u}_{1}^{t h}$.

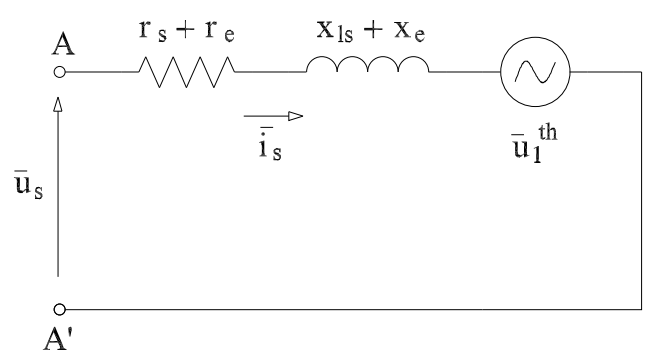

Figura 3.18: Equivalente visto dos terminais $A-A^{\prime}$.

Para o circuito da Figura 3.18, o fasor de corrente do estator $\bar{i}_{s}$ é obtido por

$$
\bar{i}_{s}=i_{x 3}+j i_{y 3}=\frac{\bar{u}_{s}-\bar{u}_{1}^{t h}}{\left(r_{s}+r_{e}\right)+j\left(x_{l s}+x_{e}\right)}=\frac{\left(u_{x 3}+j u_{y 3}\right)-\left(u_{x 1}^{t h}+j u_{y 1}^{t h}\right)}{\left(r_{s}+r_{e}\right)+j\left(x_{l s}+x_{e}\right)}
$$


cujas partes real e imaginária são

$$
i_{x 3}=\frac{\left(r_{s}+r_{e}\right) u_{x 3}-\left(r_{s}+r_{e}\right) u_{x 1}^{t h}+\left(x_{l s}+x_{e}\right) u_{y 3}-\left(x_{l s}+x_{e}\right) u_{y 1}^{t h}}{\left(r_{s}+r_{e}\right)^{2}+\left(x_{l s}+x_{e}\right)^{2}}
$$

e

$$
i_{y 3}=\frac{\left(r_{s}+r_{e}\right) u_{y 3}-\left(r_{s}+r_{e}\right) u_{y 1}^{t h}-\left(x_{l s}+x_{e}\right) u_{x 3}+\left(x_{l s}+x_{e}\right) u_{x 1}^{t h}}{\left(r_{s}+r_{e}\right)^{2}+\left(x_{l s}+x_{e}\right)^{2}} .
$$

Para o fasor da tensão equivalente $\bar{u}_{1}^{t h}$, é possível escrever

$$
\bar{u}_{1}^{t h}=u_{x 1}^{t h}+j u_{y 1}^{t h}=\frac{\frac{\bar{t}_{r}}{s} j x_{m}}{\frac{r_{r}}{s}+j\left(x_{m}+x_{l r}\right)}=\frac{\frac{u_{x r}+j u_{y r}}{s} j x_{m}}{\frac{r_{r}}{s}+j\left(x_{m}+x_{l r}\right)}
$$

cujas partes real e imaginária são

$$
u_{x 1}^{t h}=\frac{-u_{y r} \frac{x_{m} r_{r}}{s^{2}}+u_{x r} \frac{x_{m}\left(x_{m}+x_{l r}\right)}{s}}{\frac{r_{r}^{2}}{s^{2}}+\left(x_{m}+x_{l r}\right)^{2}}
$$

$\mathrm{e}$

$$
u_{y 1}^{t h}=\frac{u_{x r} \frac{x_{m} r_{r}}{s^{2}}+u_{y r} \frac{x_{m}\left(x_{m}+x_{l r}\right)}{s}}{\frac{r_{r}^{2}}{s^{2}}+\left(x_{m}+x_{l r}\right)^{2}} .
$$

Já a resistência equivalente $r_{e}$ e a reatância equivalente $x_{e}$ são definidas manipulando algebricamente

$$
r_{e}+j x_{e}=\frac{j x_{m}\left(\frac{r_{r}}{s}+j x_{l r}\right)}{j x_{m}+\frac{r_{r}}{s}+j x_{l r}},
$$

cujas partes real e imaginária são então separadas em

$$
r_{e}=\frac{x_{m}^{2} r_{r} s}{r_{r}^{2}+s^{2}\left(x_{m}+x_{l r}\right)^{2}}
$$

e

$$
x_{e}=\frac{x_{m} r_{r}^{2}+s^{2} x_{m} x_{l r}\left(x_{m}+x_{l r}\right)}{r_{r}^{2}+s^{2}\left(x_{m}+x_{l r}\right)^{2}} .
$$

Como pode ser constatado, as equações obtidas até o momento não envolvem a corrente do rotor. A fim de verificar a relação desta corrente com as demais variáveis do modelo, utiliza-se o segundo equivalente de Thévenin, que pode ser observado na Figura 3.19, onde são exibidas agora novas variáveis, que são a resistência equivalente $r_{1}$, a reatância equivalente $x_{1}$ e a tensão equivalente $\bar{u}_{2}^{\text {th }}$. Para este circuito, o fasor de corrente do rotor $\bar{i}_{r}$ é obtido por

$$
\bar{i}_{r}=\frac{\bar{u}_{2}^{t h}-\frac{\bar{u}_{r}}{s}}{r_{1}+\frac{r_{r}}{s}+j\left(x_{1}+x_{l r}\right)}=\frac{\left(u_{x 2}^{t h}+j u_{y 2}^{t h}\right)-\frac{u_{x r}+j u_{y r}}{s}}{r_{1}+\frac{r_{r}}{s}+j\left(x_{1}+x_{l r}\right)} .
$$




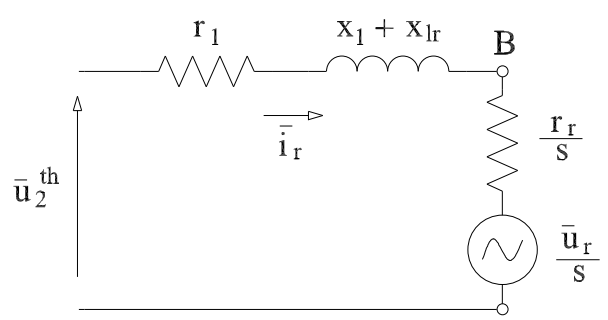

Figura 3.19: Equivalente visto dos terminais $B-B$ '.

Já o fasor de tensão equivalente $\bar{u}_{2}^{\text {th }}$ é obtido por

$$
\bar{u}_{2}^{t h}=\frac{j x_{m} \bar{u}_{s}}{r_{s}+j\left(x_{m}+x_{l s}\right)}=\frac{j x_{m}\left(u_{x 3}+j u_{y 3}\right)}{r_{s}+j\left(x_{m}+x_{l s}\right)} .
$$

Substituindo (3.411) em (3.410) e manipulando algebricamente a equação resultante, obtém-se

$$
\begin{aligned}
\bar{i}_{r}= & {\left[-x_{m} u_{y 3}-u_{x r} \frac{r_{s}}{s}+u_{y r} \frac{\left(x_{m}+x_{l s}\right)}{s}\right] r_{2}+\left[x_{m} u_{x 3}-u_{y r} \frac{r_{s}}{s}-u_{x r} \frac{\left(x_{m}+x_{l s}\right)}{s}\right] x_{2}+} \\
& \frac{j\left\{\left[x_{m} u_{x 3}-u_{y r} \frac{r_{s}}{s}-u_{x r} \frac{\left(x_{m}+x_{l s}\right)}{s}\right] r_{2}-\left[-x_{m} u_{y 3}-u_{x r} \frac{r_{s}}{s}+u_{y r} \frac{\left(x_{m}+x_{l s}\right)}{s}\right] x_{2}\right\}}{r_{2}^{2}+x_{2}^{2}},
\end{aligned}
$$

cujo módulo correspondente é

$$
\begin{aligned}
i_{r}= & \frac{\left\{\left\{\left[-x_{m} u_{y 3}-u_{x r} \frac{r_{s}}{s}+u_{y r} \frac{\left(x_{m}+x_{l s}\right)}{s}\right] r_{2}+\left[x_{m} u_{x 3}-u_{y r} \frac{r_{s}}{s}-u_{x r} \frac{\left(x_{m}+x_{l s}\right)}{s}\right] x_{2}\right\}^{2}+\right.}{} \\
& \frac{\left.\left\{\left[x_{m} u_{x 3}-u_{y r} \frac{r_{s}}{s}-u_{x r} \frac{\left(x_{m}+x_{l s}\right)}{s}\right] r_{2}-\left[-x_{m} u_{y 3}-u_{x r} \frac{r_{s}}{s}+u_{y r} \frac{\left(x_{m}+x_{l s}\right)}{s}\right] x_{2}\right\}^{2}\right\}^{\frac{1}{2}}}{r_{2}^{2}+x_{2}^{2}} .
\end{aligned}
$$

sendo que a resistência $r_{1}$ e a reatância $x_{1}$ são definidas manipulando algebricamente

$$
r_{1}+j x_{1}=\frac{\left(r_{s}+j x_{l s}\right) j x_{m}}{r_{s}+j\left(x_{l s}+x_{m}\right)}
$$

cujas partes real e imaginária são então separadas em

$$
r_{1}=\frac{r_{s} x_{m}^{2}}{r_{s}^{2}+\left(x_{l s}+x_{m}\right)^{2}}
$$

e

$$
x_{1}=\frac{r_{s}^{2} x_{m}+x_{m} x_{l s}\left(x_{l s}+x_{m}\right)}{r_{s}^{2}+\left(x_{l s}+x_{m}\right)^{2}}
$$

Já os novos termos $r_{2}$ e $x_{2}$ são definidos como

$$
r_{2}=r_{s} r_{1}+\frac{r_{s} r_{r}}{s}-\left(x_{m}+x_{l s}\right)\left(x_{1}+x_{l r}\right)
$$




$$
x_{2}=r_{s}\left(x_{1}+x_{l r}\right)+\left(x_{m}+x_{l s}\right) r_{1}+\left(x_{m}+x_{l s}\right) \frac{r_{s}}{s} .
$$

A equação do movimento da máquina é definida da mesma forma que para o modelo dinâmico no sistema de coordenadas $d q$. Assume-se como já citado que o torque mecânico $T_{m}$ provoca aceleração do rotor da máquina, enquanto que o torque eletromagnético $T_{e}$ provoca desaceleração. Considerando para a equação do movimento o escorregamento como variável de estado, (3.195) é repetida aqui por conveniência

$$
\frac{d s}{d t}=\frac{1}{2 H_{m}}\left[T_{e}-T_{m}+D(1-s)\right] .
$$

O torque mecânico é considerado sempre constante. Já o torque eletromagnético é variável e assume a forma

$$
T_{e}=-\frac{P_{e}}{1-s}=-i_{r}^{2} \frac{r_{r}}{s}-\Re\left\{\frac{\bar{u}_{r}}{s} \bar{i}_{r}^{*}\right\}=-i_{r}^{2} \frac{r_{r}}{s}-\frac{P_{r}}{s} .
$$

Como pode ser observado, o torque eletromagnético é dado pela relação entre a potência do entreferro $P_{e}$ e o escorregamento da máquina (Salles, 2009). Tal relação mostra como o torque eletromagnético depende da corrente no rotor, assim como da tensão aplicada ao rotor da máquina. Em outras palavras, o torque eletromagnético pode ser dividido em duas parcelas. Para a primeira parcela, já foi definido o módulo da corrente do rotor. Para a segunda parcela, tem-se a potência no rotor $P_{r}$ calculada a partir da expressão da potência complexa

$$
P_{r}=\Re\left\{\bar{u}_{r} \bar{i}_{r}^{*}\right\}=u_{y r} i_{y r}+u_{x r} i_{x r}
$$

onde as componentes real e imaginária do fasor corrente do rotor são definidas a partir de (3.412) como

$$
i_{x r}=\frac{\left[-x_{m} u_{y 3}-u_{x r} \frac{r_{s}}{s}+u_{y r} \frac{\left(x_{m}+x_{l s}\right)}{s}\right] r_{2}+\left[x_{m} u_{x 3}-u_{y r} \frac{r_{s}}{s}-u_{x r} \frac{\left(x_{m}+x_{s}\right)}{s}\right] x_{2}}{r_{2}^{2}+x_{2}^{2}}
$$

e

$$
i_{y r}=\frac{\left[x_{m} u_{x 3}-u_{y r} \frac{r_{s}}{s}-u_{x r} \frac{\left(x_{m}+x_{l s}\right)}{s}\right] r_{2}-\left[-x_{m} u_{y 3}-u_{x r} \frac{r_{s}}{s}+u_{y r} \frac{\left(x_{m}+x_{l s}\right)}{s}\right] x_{2}}{r_{2}^{2}+x_{2}^{2}} .
$$

Substituindo (3.422) e (3.423) em (3.421), obtém-se

$$
\begin{aligned}
P_{r}= & \frac{u_{x r}\left\{\left[-x_{m} u_{y 3}-u_{x r} \frac{r_{s}}{s}+u_{y r} \frac{\left(x_{m}+x_{l s}\right)}{s}\right] r_{2}+\left[x_{m} u_{x 3}-u_{y r} \frac{r_{s}}{s}-u_{x r} \frac{\left(x_{m}+x_{l s}\right)}{s}\right] x_{2}\right\}}{} \\
& \frac{u_{y r}\left\{\left[x_{m} u_{x 3}-u_{y r} \frac{r_{s}}{s}-u_{x r} \frac{\left(x_{m}+x_{l s}\right)}{s}\right] r_{2}-\left[-x_{m} u_{y 3}-u_{x r} \frac{r_{s}}{s}+u_{y r} \frac{\left(x_{m}+x_{l s}\right)}{s}\right] x_{2}\right\}}{r_{2}^{2}+x_{2}^{2}} .
\end{aligned}
$$


E a potência reativa no rotor $Q_{r}$ pode ser calculada por

$$
Q_{r}=\Im\left\{\bar{u}_{r} \bar{i}_{r}^{*}\right\}=u_{y r} i_{x r}-u_{x r} i_{y r} .
$$

Já para o estator, obtém-se as potências ativa $P_{s}$ e reativa $Q_{s}$ de forma análoga ao rotor conforme

$$
P_{s}=\Re\left\{\bar{u}_{s} \bar{i}_{s}^{*}\right\}=u_{y 3} i_{y 3}+u_{x 3} i_{x 3}
$$

e

$$
Q_{s}=\Im\left\{\bar{u}_{s} \bar{i}_{s}^{*}\right\}=u_{y 3} i_{x 3}-u_{x 3} i_{y 3} .
$$

Para a máquina de indução em gaiola de esquilo, tem-se que tensão aplicada ao rotor é nula, uma vez que não se tem acesso ao circuito rotórico. Fazendo

$$
u_{x r}=0
$$

e

$$
u_{y r}=0,
$$

obtém-se as equações resultantes que modelam tal máquina.

Para calcular o torque eletromagnético da máquina de indução em gaiola de esquilo de uma maneira simples, parte-se da relação

$$
T_{e}=-\frac{P_{e}}{1-s}=-i_{r}^{2} \frac{r_{r}}{s}
$$

Uma vez que o módulo da corrente do rotor pode ser calculado a partir de (3.410) por

$$
i_{r}=\frac{u_{2}^{t h}}{\sqrt{\left(r_{1}+\frac{r_{r}}{s}\right)^{2}+\left(x_{1}+x_{l r}\right)^{2}}},
$$

basta substituir esta expressão em (3.430) para obter

$$
T_{e}=-\frac{u_{2}^{t h} \frac{r_{r}}{s}}{\left(r_{1}+\frac{r_{r}}{s}\right)^{2}+\left(x_{1}+x_{l r}\right)^{2}},
$$

sendo o módulo da tensão equivalente obtido a partir de (3.411) por

$$
u_{2}^{t h}=\frac{x_{m} u_{s}}{\sqrt{r_{s}^{2}+\left(x_{m}+x_{l s}\right)^{2}}} .
$$

Assim, tem-se que o torque eletromagnético para a máquina de indução em gaiola de esquilo fica definido por 


$$
T_{e}=-\frac{u_{s}^{2} x_{m}^{2} \frac{r_{r}}{s}}{\left[\left(r_{1}+\frac{r_{r}}{s}\right)^{2}+\left(x_{1}+x_{l r}\right)^{2}\right]\left[r_{s}^{2}+\left(x_{l s}+x_{m}\right)^{2}\right]}
$$

\subsection{Modelo completo do sistema teste com a configuração SCIG em re- gime permanente}

É importante observar que (3.401) modela a corrente do estator absorvida pela máquina. No entanto, a modelagem da rede elétrica considera injeções líquidas de corrente nas barras. Faz-se necessário então inverter o sinal do fasor de corrente do estator em (3.401), assim como de suas componentes real (3.402) e imaginária (3.403). Desta forma, as equações que modelam a máquina de indução em gaiola de esquilo são acrescentadas às equações que modelam a rede elétrica, lembrando que $u_{x r}=u_{y r}=0$ para esta máquina. Forma-se então um conjunto composto por nove equações. O modelo completo do sistema teste com a configuração SCIG em regime permanente fica então definido por

- Quatro equações referentes ao modelo da rede elétrica

$$
\begin{gathered}
g_{12} u_{x 1}-b_{12} u_{y 1}+\left(-g_{12}^{s h}-g_{23}^{s h}-g_{12}-g_{23}\right) u_{x 2}+ \\
\left(b_{12}^{s h}+b_{23}^{s h}+b_{12}+b_{23}\right) u_{y 2}+g_{23} u_{x 3}-b_{23} u_{y 3}=0, \\
b_{12} u_{x 1}+g_{12} u_{y 1}+\left(-b_{12}^{s h}-b_{23}^{s h}-b_{12}-b_{23}\right) u_{x 2}+ \\
\left(-g_{12}^{s h}-g_{23}^{s h}-g_{12}-g_{23}\right) u_{y 2}+b_{23} u_{x 3}+g_{23} u_{y 3}=0, \\
i_{x 3}+g_{23} u_{x 2}-b_{23} u_{y 2}+\left(-g_{32}^{s h}-g_{23}\right) u_{x 3}+\left(b_{32}^{s h}+b_{23}+b_{3}^{s h}\right) u_{y 3}=0
\end{gathered}
$$

e

$$
i_{y 3}+b_{23} u_{x 2}+g_{23} u_{y 2}+\left(-g_{32}^{s h}-g_{23}\right) u_{y 3}+\left(-b_{32}^{s h}-b_{23}-b_{3}^{s h}\right) u_{x 3}=0
$$

- Duas equações referentes à corrente do estator da máquina

$$
i_{x 3}=-\frac{\left(r_{s}+r_{e}\right) u_{x 3}+\left(x_{l s}+x_{e}\right) u_{y 3}}{\left(r_{s}+r_{e}\right)^{2}+\left(x_{l s}+x_{e}\right)^{2}}
$$

e

$$
i_{y 3}=-\frac{\left(r_{s}+r_{e}\right) u_{y 3}-\left(x_{l s}+x_{e}\right) u_{x 3}}{\left(r_{s}+r_{e}\right)^{2}+\left(x_{l s}+x_{e}\right)^{2}} .
$$


- Duas equações referentes às variáveis equivalentes

$$
r_{e}=\frac{x_{m}^{2} r_{r} s}{r_{r}^{2}+s^{2}\left(x_{m}+x_{l r}\right)^{2}}
$$

e

$$
x_{e}=\frac{x_{m} r_{r}^{2}+s^{2} x_{m} x_{l r}\left(x_{m}+x_{l r}\right)}{r_{r}^{2}+s^{2}\left(x_{m}+x_{l r}\right)^{2}}
$$

- Uma equação referente ao movimento da máquina

$$
\frac{d s}{d t}=\frac{1}{2 H_{m}}\left[T_{e}-T_{m}+D(1-s)\right]
$$

com o torque mecânico constante e o torque eletromagnético dado por

$$
T_{e}=-\frac{u_{s}^{2} x_{m}^{2} \frac{r_{r}}{s}}{\left[\left(r_{1}+\frac{r_{r}}{s}\right)^{2}+\left(x_{1}+x_{l r}\right)^{2}\right]\left[r_{s}^{2}+\left(x_{l s}+x_{m}\right)^{2}\right]} .
$$

As equações (3.435) a (3.443) formam um sistema não linear composto por nove equações, cujo vetor de incógnitas é dado por

$$
k_{7}=\left[\begin{array}{lllllllll}
u_{x 3} & u_{y 3} & i_{x 3} & i_{y 3} & u_{x 2} & u_{y 2} & r_{e} & x_{e} & s
\end{array}\right]^{T} .
$$

Toma-se a barra 1 como referência angular e portanto as componentes de tensão na barra 1 são previamente conhecidas, $u_{x 1}=1$ e $u_{y 1}=0$. Os parâmetros da rede são apresentados no apêndice A. Os parâmetros da configuração SCIG são apresentados no apêndice B. As demais constantes e variáveis podem ser calculadas a partir da modelagem desenvolvida.

\subsection{Modelo completo do sistema teste com a configuração WRIG em regime permanente}

Como já explicado, faz-se necessário inverter o sinal do fasor de corrente do estator em (3.401), assim como de suas componentes real (3.402) e imaginária (3.403). Salienta-se que o acesso ao circuito rotórico permite aplicar uma tensão ao mesmo, de modo que as componentes $u_{x r}$ e $u_{y r}$ podem assumir diferentes valores. Desta forma, as equações que modelam a máquina de indução com rotor bobinado são acrescentadas às equações que modelam a rede elétrica, formando um conjunto composto por quinze equações. O modelo completo do sistema teste com a configuração WRIG em regime permanente fica então definido por

- Quatro equações referentes ao modelo da rede elétrica

$$
\begin{aligned}
& g_{12} u_{x 1}-b_{12} u_{y 1}+\left(-g_{12}^{s h}-g_{23}^{s h}-g_{12}-g_{23}\right) u_{x 2}+ \\
&\left(b_{12}^{s h}+b_{23}^{s h}+b_{12}+b_{23}\right) u_{y 2}+g_{23} u_{x 3}-b_{23} u_{y 3}=0
\end{aligned}
$$




$$
\begin{aligned}
& b_{12} u_{x 1}+g_{12} u_{y 1}+\left(-b_{12}^{s h}-b_{23}^{s h}-b_{12}-b_{23}\right) u_{x 2}+ \\
& \left(-g_{12}^{s h}-g_{23}^{s h}-g_{12}-g_{23}\right) u_{y 2}+b_{23} u_{x 3}+g_{23} u_{y 3}=0
\end{aligned}
$$

$$
i_{x 3}+g_{23} u_{x 2}-b_{23} u_{y 2}+\left(-g_{32}^{s h}-g_{23}\right) u_{x 3}+\left(b_{32}^{s h}+b_{23}+b_{3}^{s h}\right) u_{y 3}=0
$$

e

$$
i_{y 3}+b_{23} u_{x 2}+g_{23} u_{y 2}+\left(-g_{32}^{s h}-g_{23}\right) u_{y 3}+\left(-b_{32}^{s h}-b_{23}-b_{3}^{s h}\right) u_{x 3}=0 .
$$

- Duas equações referentes à corrente do estator da máquina

$$
i_{x 3}=-\frac{\left(r_{s}+r_{e}\right) u_{x 3}-\left(r_{s}+r_{e}\right) u_{x 1}^{t h}+\left(x_{l s}+x_{e}\right) u_{y 3}-\left(x_{l s}+x_{e}\right) u_{y 1}^{t h}}{\left(r_{s}+r_{e}\right)^{2}+\left(x_{l s}+x_{e}\right)^{2}}
$$

e

$$
i_{y 3}=-\frac{\left(r_{s}+r_{e}\right) u_{y 3}-\left(r_{s}+r_{e}\right) u_{y 1}^{t h}-\left(x_{l s}+x_{e}\right) u_{x 3}+\left(x_{l s}+x_{e}\right) u_{x 1}^{t h}}{\left(r_{s}+r_{e}\right)^{2}+\left(x_{l s}+x_{e}\right)^{2}} .
$$

- Seis equações referentes às variáveis equivalentes

$$
\begin{gathered}
r_{e}=\frac{x_{m}^{2} r_{r} s}{r_{r}^{2}+s^{2}\left(x_{m}+x_{l r}\right)^{2}}, \\
x_{e}=\frac{x_{m} r_{r}^{2}+s^{2} x_{m} x_{l r}\left(x_{m}+x_{l r}\right)}{r_{r}^{2}+s^{2}\left(x_{m}+x_{l r}\right)^{2}}, \\
r_{2}=r_{s} r_{1}+\frac{r_{s} r_{r}}{s}-\left(x_{m}+x_{l s}\right)\left(x_{1}+x_{l r}\right), \\
x_{2}=r_{s}\left(x_{1}+x_{l r}\right)+\left(x_{m}+x_{l s}\right) r_{1}+\left(x_{m}+x_{l s}\right) \frac{r_{s}}{s}, \\
u_{x 1}^{t h}=\frac{-u_{y r} \frac{x_{m} r_{r}}{s^{2}}+u_{x r} \frac{x_{m}\left(x_{m}+x_{l r}\right)}{s}}{\frac{r_{r}^{2}}{s^{2}}+\left(x_{m}+x_{l r}\right)^{2}}
\end{gathered}
$$

e

$$
u_{y 1}^{t h}=\frac{u_{x r} \frac{x_{m} r_{r}}{s^{2}}+u_{y r} \frac{x_{m}\left(x_{m}+x_{l r}\right)}{s}}{\frac{r_{r}^{2}}{s^{2}}+\left(x_{m}+x_{l r}\right)^{2}} .
$$


- Uma equação referente ao módulo da corrente do rotor

$$
\begin{aligned}
i_{r}= & \frac{\left\{\left\{\left[-x_{m} u_{y 3}-u_{x r} \frac{r_{s}}{s}+u_{y r} \frac{\left(x_{m}+x_{l s}\right)}{s}\right] r_{2}+\left[x_{m} u_{x 3}-u_{y r} \frac{r_{s}}{s}-u_{x r} \frac{\left(x_{m}+x_{l s}\right)}{s}\right] x_{2}\right\}^{2}+\right.}{} \\
& \frac{\left.\left\{\left[x_{m} u_{x 3}-u_{y r} \frac{r_{s}}{s}-u_{x r} \frac{\left(x_{m}+x_{l s}\right)}{s}\right] r_{2}-\left[-x_{m} u_{y 3}-u_{x r} \frac{r_{s}}{s}+u_{y r} \frac{\left(x_{m}+x_{l s}\right)}{s}\right] x_{2}\right\}^{2}\right\}^{\frac{1}{2}}}{r_{2}^{2}+x_{2}^{2}} .
\end{aligned}
$$

- Uma equação referente à potência ativa no rotor

$$
\begin{aligned}
P_{r}= & \frac{u_{x r}\left\{\left[-x_{m} u_{y 3}-u_{x r} \frac{r_{s}}{s}+u_{y r} \frac{\left(x_{m}+x_{l s}\right)}{s}\right] r_{2}+\left[x_{m} u_{x 3}-u_{y r} \frac{r_{s}}{s}-u_{x r} \frac{\left(x_{m}+x_{l s}\right)}{s}\right] x_{2}\right\}}{} \\
& \frac{u_{y r}\left\{\left[x_{m} u_{x 3}-u_{y r} \frac{r_{s}}{s}-u_{x r} \frac{\left(x_{m}+x_{l s}\right)}{s}\right] r_{2}-\left[-x_{m} u_{y 3}-u_{x r} \frac{r_{s}}{s}+u_{y r} \frac{\left(x_{m}+x_{l s}\right)}{s}\right] x_{2}\right\}}{r_{2}^{2}+x_{2}^{2}} .
\end{aligned}
$$

- Uma equação referente ao movimento da máquina

$$
\frac{d s}{d t}=\frac{1}{2 H_{m}}\left[T_{e}-T_{m}+D(1-s)\right]
$$

com o torque mecânico constante e o torque eletromagnético dado por

$$
T_{e}=-i_{r}^{2} \frac{r_{r}}{S}-\frac{P_{r}}{S}
$$

As equações (3.446) a (3.460) formam um sistema não linear composto por quinze equações, cujo vetor de incógnitas é dado por

$$
k_{8}=\left[\begin{array}{llllllllllllllllll}
u_{x 3} & u_{y 3} & i_{x 3} & i_{y 3} & u_{x 2} & u_{y 2} & r_{e} & x_{e} & s & r_{2} & x_{2} & P_{r} & i_{r} & u_{x 1}^{t h} & u_{y 1}^{t h}
\end{array}\right]^{T} .
$$

Toma-se a barra 1 como referência angular e portanto as componentes de tensão na barra 1 são previamente conhecidas, $u_{x 1}=1$ e $u_{y 1}=0$. Os parâmetros da rede são apresentados no apêndice A. Assume-se que as componentes de tensão no rotor $u_{x r}$ e $u_{y r}$ são também conhecidas. Os parâmetros da configuração WRIG são apresentados no apêndice B. As demais constantes e variáveis podem ser calculadas a partir da modelagem desenvolvida.

\subsection{Comentários finais}

Neste capítulo foi desenvolvida a modelagem da rede elétrica do sistema teste ilustrado na Figura 3.1, assim como a modelagem da máquina de indução. Para conexão ao sistema teste, três tipos de aerogeradores foram considerados. Para o aerogerador do tipo A, denominado de configuração SCIG, foi modelado o gerador de indução em gaiola de esquilo. Para o aerogerador do tipo $\mathrm{B}$, denominado de configuração WRIG, foi modelado o gerador de indução com rotor bobinado. Para o aerogerador do tipo C, denominado de configuração DFIG, foi modelado o gerador de indução com rotor bobinado, os conversores eletrônicos de potência e os controladores associados ao RSC e ao GSC. Para as três configurações, considerou-se o sistema mecânico máquina-turbina de uma massa. 
Para o modelo da rede elétrica foram obtidas quatro equações, como descrito na seção 3.2. Considerando a modelagem no sistema de coordenadas $d q$ : i) para o modelo completo do sistema teste com a configuração SCIG foi obtido um conjunto de nove equações, descrito na seção 3.4, ii) para o modelo completo do sistema teste com a configuração WRIG foi obtido um conjunto de nove equações, descrito na seção 3.5 e iii) para o modelo completo do sistema teste com a configuração DFIG foram obtidos três conjuntos de equações. Um conjunto de quatro equações para o fluxo de carga da rede elétrica, descrito no item 3.6.4.1 da seção 3.6. Um conjunto de quatorze equações para a inicialização das variáveis da máquina, descrito no item 3.6.4.2 da seção 3.6. E um conjunto de quarenta equações para o modelo completo, descrito na seção 3.7. Para a máquina de indução, a partir do modelo em quinta ordem, foram obtidas as representações em terceira e primeira ordens. Considerando a modelagem em regime permanente: i) para o modelo completo do sistema teste com a configuração SCIG foi obtido um conjunto de nove equações, descrito na seção 3.9 e ii) para o modelo completo do sistema teste com a configuração WRIG foi obtido um conjunto de quinze equações, descrito na seção 3.10. Cada conjunto completo de equações será necessário para elaborar os estudos de estabilidade citados na introdução deste trabalho.

No próximo capítulo apresenta-se brevemente as teorias relacionadas à $R E$, à $R E R$ e ao método PEBS. No que se refere à aplicação, são descritas a representação da curva LVRT como requisito operacional, as funções energia e as etapas para estimar os TCAs. 


\section{Capítulo 4}

\section{Teoria de estabilidade e métodos diretos}

\subsection{Introdução}

Nas análises de estabilidade via método clássico, as equações diferenciais e algébricas que modelam os sistemas em falta e pós-falta precisam ser resolvidas numericamente. Por meio de várias simulações, os TCAs são então determinados. Uma vez que esta tarefa demanda um grande esforço computacional, especialmente para modelos de sistemas elétricos de potência interligados, as análises de estabilidade em tempo real de tais sistemas se tornam comprometidas. Para contornar este problema, foram criados os métodos diretos, também chamados de métodos energéticos, uma vez que os mesmos são baseados em funções energia. Utilizando-se de tais métodos, o esforço computacional é reduzido consideravelmente, pois a integração numérica das equações que modelam o sistema pós-falta não é mais necessária. Assim, podem ser realizadas avaliações rápidas da estabilidade do sistema elétrico.

Ao se avaliar a estabilidade de sistemas elétricos de potência via métodos diretos, somente a integração numérica das equações que modelam o sistema em falta é necessária para concluir sobre a estabilidade ou instabilidade do sistema pós-falta. Tais métodos verificam se o sistema pós-falta será estável ou instável após a perturbação, comparando a energia do sistema na condição inicial pós-falta a uma energia crítica. Se a energia nesta condição inicial for menor que a energia crítica, o sistema pós-falta será estável. Do contrário, será instável. Ao se atingir a energia crítica, uma estimativa do ponto de saída da RE do ponto de equilíbrio estável do sistema pós-falta é realizada. Uma vez que o TCA corresponde ao instante de tempo cuja trajetória em falta abandona a RE, uma estimativa do TCA é naturalmente obtida.

O objetivo desta tese é avaliar via método direto o problema de estabilidade de velocidade e o problema de violação de limites de tensão de aerogeradores equipados com gerador de indução. Uma vez que os métodos diretos baseiam-se em modelos de geradores síncronos, faz-se necessário revisitar a teoria de tais métodos, assim como a teoria de sistemas dinâmicos não lineares, para incluir agora os modelos desenvolvidos no capítulo 3. Como já explicitado na introdução desta tese, ao se considerar os limites de tensão, o sistema elétrico de potência é interpretado como um sistema dinâmico com restrição. Neste sentido, faz-se necessário também revisitar a teoria de sistemas dinâmicos restritos, a fim de compreender como a 
restrição do problema pode ser incluída nas análises de estabilidade.

Em (Venkatasubramanian et al., 1995) desenvolve-se a teoria de região de estabilidade de sistemas dinâmicos não lineares representados por equações algébricas e diferenciais, onde as equações algébricas representam restrições de igualdade. Nesta tese, as equações citadas formam o que se denomina de sistema original. Em (Praprost e Loparo, 1996) estende-se esta teoria adicionando-se restrições na forma de desigualdades. Isto é feito para que o requisito operacional do sistema físico, que normalmente é requerido para que certa variável permaneça dentro de uma faixa aceitável de operação, seja devidamente modelado. A teoria desenvolvida pelos autores define o que se denomina de sistema dinâmico restrito, cujas trajetórias estão restritas a um subespaço do espaço de estados, chamado de região factível de operação. Os autores também definem um sistema auxiliar de equações, cuja RE mostra-se igual à RER.

Dentre os métodos diretos existentes, o método PEBS foi escolhido para ser explorado nos estudos de estabilidade desta tese. Tal método, originalmente proposto por (Kakimoto et al., 1978), avalia uma função energia ao longo da trajetória em falta, tal que o primeiro máximo da energia potencial é utilizada como energia crítica (Chiang, 2011). Mais adiante, este método será explicado em mais detalhes. Formula-se uma função energia para avaliar a estabilidade de velocidade dos diferentes modelos de aerogeradores apresentados no capítulo 3. Utilizando-se da definição de restrição estabelecida em (Praprost e Loparo, 1996), formulase outra função energia, esta construída para estimar o TCA relativo à violação dos limites de tensão. Desta forma, é estabelecida nesta tese a conceituação do método direto para ser utilizado em sistemas elétricos de potência sujeitos a limites operacionais.

Cada modelo completo apresentado no capítulo 3 representa o que se denomina de sistema original. O requisito operacional é representado ou pela curva LVRT do Brasil ou pela curva LVRT dos EUA. Para modelar tais curvas de modo que o sistema dinâmico sob análise seja autônomo, utiliza-se uma técnica inédita para a modelagem de requisitos operacionais. Tal técnica consiste em introduzir uma variável de estado auxiliar de modo a formular as curvas por equações diferenciais auxiliares, dependentes unicamente desta nova variável de estado. Como será visto, outros requisitos operacionais, diferentes da curva LVRT, podem ser representados por meio desta técnica. A partir desta representação, da formulação da restrição do problema e da modelagem desenvolvida para o sistema teste, são especificados os conjuntos de equações utilizados para obter a RE do ponto de equilíbrio estável do sistema pós-falta para os sistemas original e auxiliar, assim como para obter a RER para o sistema dinâmico restrito. São formuladas as funções energia a partir da equação mecânica do gerador de indução e da restrição do problema. Por fim, é descrito o procedimento para estimar os TCAs referentes à estabilidade de velocidade e à violação de limites de tensão.

\subsection{Caracterização das regiões de estabilidade}

Um sistema elétrico de potência é normalmente modelado por um sistema dinâmico não linear e autônomo, composto por equações diferenciais e algébricas conforme 


$$
\left(\begin{array}{c}
\text { Sistema } \\
\text { original }
\end{array}\right) \begin{cases}\dot{x}=f(x, y) & f: \mathbb{R}^{n+m} \rightarrow \mathbb{R}^{n} \\
0=g(x, y) & g: \mathbb{R}^{n+m} \rightarrow \mathbb{R}^{m}\end{cases}
$$

em que $x \in \mathbb{R}^{n}$ é o vetor das variáveis de estado, $y \in \mathbb{R}^{m}$ é o vetor das variáveis algébricas, $f(x, y)$ é a função suave que representa as equações diferenciais e $g(x, y)$ é a função suave que representa as equações algébricas.

O sistema formado por (4.1) e (4.2) é denominado aqui de sistema original. As trajetórias do mesmo estão restritas a um subconjunto de $\mathbb{R}^{n+m}$ definido por

$$
L=\left\{(x, y) \in \mathbb{R}^{n+m}: 0=g(x, y)\right\}
$$

O conjunto $L$ é usualmente conhecido por variedade algébrica ou variedade de restrição. Um ponto que pertence a esta variedade é regular se a derivada das equações algébricas em relação às variáveis algébricas

$$
g_{y}(x, y)=\frac{\partial g(x, y)}{\partial y}
$$

é inversível. Os pontos onde esta derivada não é inversível são chamados de pontos singulares. A coleção destes pontos em $L$ é denominada de superfície singular, definida conforme

$$
S=\left\{(x, y) \in L \mid \operatorname{det}\left(g_{y}(x, y)\right)=0\right\},
$$

em que $\operatorname{det}\left(g_{y}(x, y)\right)$ é o determinante da matriz formada pelas derivadas das equações algébricas em relação às variáveis algébricas.

Seja $L_{s}$ uma componente conexa de $L$ e $\left(x_{s}, y_{s}\right) \in L_{s}$ um ponto de equilíbrio assintoticamente estável do sistema original. Considere também que este ponto se refere ao sistema pós-falta. A RE do ponto $\left(x_{s}, y_{s}\right)$ é definida conforme

$$
A\left(x_{s}, y_{s}\right):=\left\{(x, y) \in L_{s}: \lim _{t \rightarrow \infty} \phi(t,(x, y))=\left(x_{s}, y_{s}\right)\right\}
$$

em que $\phi(t,(x, y))$ é a solução do sistema original iniciando em $(x, y)$ no tempo $t=0$.

Em (Venkatasubramanian et al., 1995) é desenvolvida a teoria sobre a RE de sistemas dinâmicos não lineares autônomos representados por equações diferenciais e algébricas. Foi mostrado que a fronteira de $A\left(x_{s}, y_{s}\right)$ consiste de duas partes. A primeira parte corresponde às variedades estáveis de pontos de equilíbrio na fronteira. A segunda parte corresponde aos pontos cujas trajetórias atingem a superfície singular. Esta pode ser composta pela união de variedades estáveis de pseudo-equilíbrios e pontos semi-singulares na fronteira, além de partes da superfície singular. A fundamentação teórica completa pode ser encontrada na referência citada e também em (Venkatasubramanian et al., 1992a), (Venkatasubramanian et al., 1992b) e (Venkatasubramanian et al., 1994). 
Considerando, por simplicidade de notação, que o ponto de equilíbrio assintoticamente estável do sistema pós-falta $\left(x_{s}, y_{s}\right)$ possa ser representado apenas por $x_{s}$ e que o ponto de equilíbrio estável do sistema pré-falta $\left(x_{0}, y_{0}\right)$ possa ser representado apenas por $x_{0}$, a Figura 4.1 mostra, além destes pontos, a região $A\left(x_{s}\right)$, que se refere à $R E$ do ponto $x_{s}$ e a respectiva fronteira desta região, denotada por $\partial A\left(x_{s}\right)$. Exibe também as trajetórias em falta e pós-falta e o ponto $x_{e}$, ponto no qual a trajetória em falta abandona a RE, isto é, cruza a fronteira de $A\left(x_{s}\right)$. Este ponto é denominado de ponto de saída, do inglês exit point.

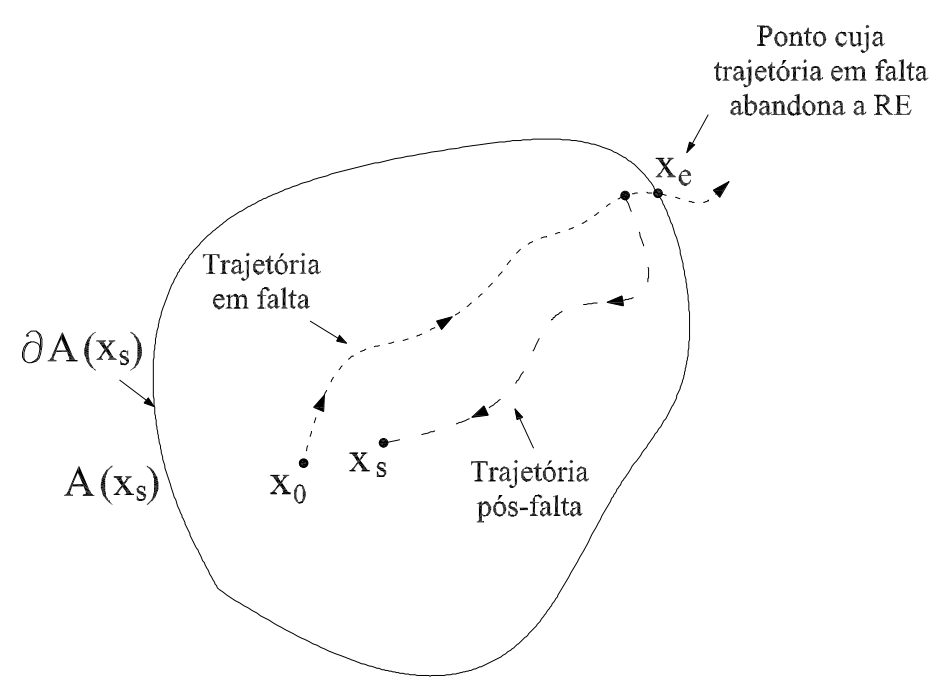

Figura 4.1: Trajetórias em falta e pós-falta na região de estabilidade $A\left(x_{s}\right)$.

Como citado na introdução deste trabalho, o intervalo de tempo que a trajetória em falta leva para abandonar $A\left(x_{s}\right)$ corresponde ao TCA. Em outras palavras, a trajetória em falta sustentada abandona $A\left(x_{s}\right)$ no exit point $x_{e}$ no TCA. Se a perturbação for eliminada antes do TCA, a condição inicial do sistema pós-falta pertencerá à $A\left(x_{S}\right)$ e a trajetória pós-falta convergirá para $x_{s}$. A trajetória pós-falta que se iniciar fora de $A\left(x_{s}\right)$ poderá convergir para outro atrator, desinteressante para o sistema elétrico de potência ou tender ao infinito. Consequentemente, o problema de estabilidade a grandes perturbações se traduz em verificar se no tempo de abertura (tempo de eliminação do defeito) a condição inicial pós-falta estará dentro da RE do ponto de equilíbrio estável do sistema pós-falta $x_{S}$.

Visto a teoria de RE e a teoria dos métodos diretos não levarem em consideração limites operacionais e muitos sistemas físicos necessitarem faixas aceitáveis de operação para determinadas variáveis, em (Praprost, 1993) e (Praprost e Loparo, 1996) desenvolve-se a teoria sobre a RER de sistemas dinâmicos não lineares autônomos representados por equações diferenciais e algébricas e restrições na forma de desigualdades. Para tais sistemas, as trajetórias estão restritas a uma região particular dentro do espaço de estados, chamada de região factível de operação. A restrição do problema, que incorpora a informação do limite operacional do sistema físico, é definida por uma função na forma 


$$
\Delta(x, y): \mathbb{R}^{n+m} \rightarrow \mathbb{R} \begin{cases}\Delta(x, y)>0, & x, y \in X \\ \Delta(x, y)=0, & x, y \in \partial X \\ \Delta(x, y)<0, & x, y \in \bar{X}^{c}\end{cases}
$$

onde $X \subseteq \mathbb{R}^{n+m}$ é um conjunto aberto e conexo que representa a região factível de operação, $\partial X$ é a fronteira de $X$ e $\bar{X}^{c}$ é o complemento do fecho de $X$. Fora da região $X$, a unidade geradora estará sujeita à desconexão, uma vez que a restrição do problema já foi violada neste cenário.

A RER do ponto de equilíbrio assintoticamente estável $\left(x_{s}, y_{s}\right)$ é o conjunto de pontos cujas trajetórias iniciam e permanecem dentro da região factível de operação para todo $t \geq$ 0 e convergem para este ponto quando $t \rightarrow \infty$, sem violar a restrição do problema. Assim, a RER é definida conforme

$$
A_{r}\left(x_{s}, y_{s}\right):=\left\{(x, y) \in \mathbb{R}^{n+m}: \lim _{t \rightarrow \infty} \phi(t,(x, y))=\left(x_{s}, y_{s}\right) \text { e } \Delta(x, y)>0 \forall t \geq 0\right\},
$$

O sistema original não inclui a função $\Delta(x, y)$. Portanto a região $A\left(x_{s}\right)$ é considerada irrestrita. A Figura 4.2 mostra esta região, a região $A_{r}\left(x_{s}\right)$, a função $\Delta(x, y)$ e a mesma trajetória em falta da Figura 4.1. Como pode ser observado, a RER $A_{r}\left(x_{s}\right)$ está contida em $A\left(x_{s}\right)$. Para a situação apresentada, constata-se que a trajetória em falta abandona $A_{r}\left(x_{s}\right)$ violando o requisito operacional. O TCA relativo à violação deste requisito é nitidamente inferior ao intervalo de tempo necessário para a trajetória em falta abandonar $A\left(x_{s}\right)$.

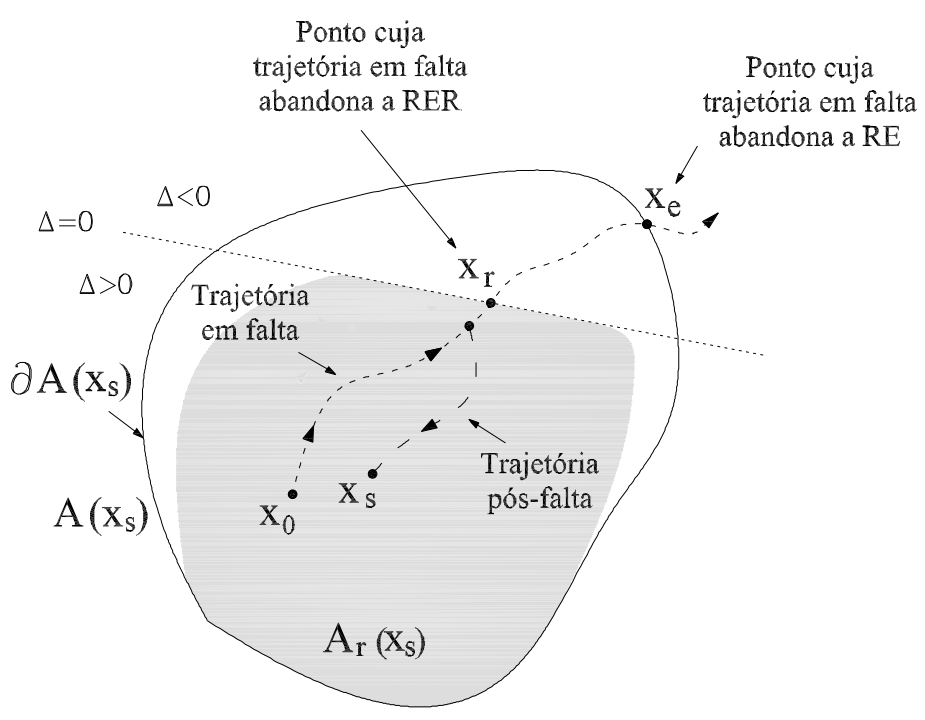

Figura 4.2: Trajetórias em falta e pós-falta na região de estabilidade $A\left(x_{S}\right)$ e na região de estabilidade restrita $A_{r}\left(x_{s}\right)$. Nesta representação conceitual, o ponto em que a restrição é violada ( $x_{r}$, em que $\Delta=$ 0) coincide com o ponto de saída da RER. 
Para não permitir que a fonte alternativa possa ser desconectada da rede elétrica, o conhecimento do TCA relativo à violação do requisito operacional é fundamental. Os dispositivos de proteção deverão atuar em um tempo inferior a este TCA, de modo a evitar que a trajetória em falta viole o requisito operacional e a trajetória pós-falta permaneça dentro de $A_{r}\left(x_{s}\right)$, conforme mostra a Figura 4.2.

Definindo o sistema auxiliar como uma perturbação do sistema original por

$$
\left(\begin{array}{l}
\text { Sistema } \\
\text { auxiliar }
\end{array}\right)\left\{\begin{array}{l}
\dot{x}=f(x, y) \Delta(x, y) \\
0=g(x, y)
\end{array}\right.
$$

é possível obter um modelo cuja RE irrestrita mostra-se igual à RER. O campo vetorial do sistema auxiliar é pontualmente escalonado por $\Delta(x, y)$, resultando em uma mudança da escala de tempo. Apesar desta mudança, as trajetórias do sistema dinâmico restrito e do sistema auxiliar são iguais quando $\Delta(x, y)>0$, ou seja, as trajetórias têm a mesma direção dentro da região factível de operação.

A Figura 4.3 mostra o comportamento dinâmico do sistema auxiliar nas vizinhanças da fronteira $\partial X$. A fronteira $\partial X$, onde $\Delta(x, y)=0$, é formada por pseudo-equilíbrios. Em cada região o comportamento dinâmico é diferente. Na região $X$, onde $\Delta(x, y)>0$, as trajetórias são semelhantes àquelas de pontos de sela. Em um tempo finito, a fronteira $\partial X$ é tocada em um ponto por uma destas trajetórias. O respectivo ponto é denominado de semi-sela. $\mathrm{Na}$ região $\bar{X}^{c}$, onde $\Delta(x, y)<0$, as trajetórias invertem de sentido, de modo que os pseudoequilíbrios sobre a fronteira $\partial X$ são semelhantes a pontos de foco, denominados no caso de pontos de semi-foco. Como pode ser observado, os pontos de semi-foco podem ser estáveis e instáveis, sendo os mesmos separados pela semi-sela.

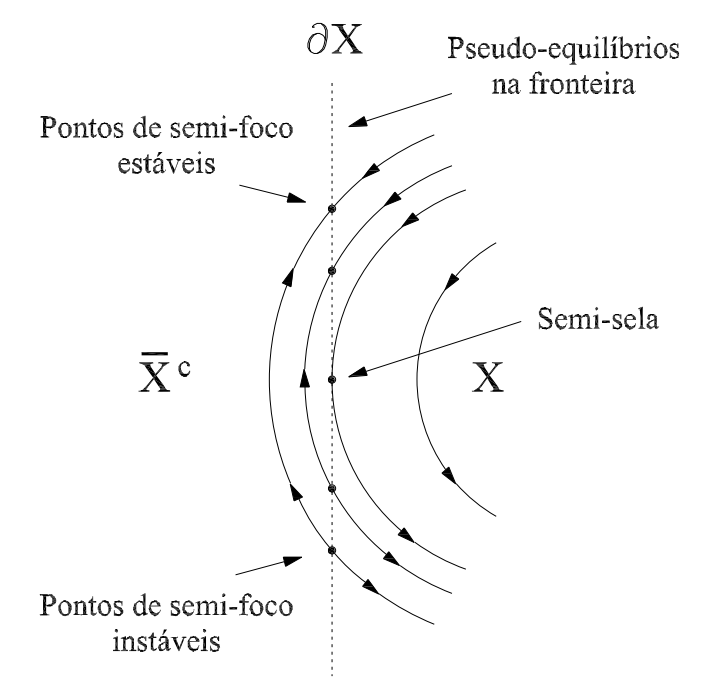

Figura 4.3: Pseudo-equilíbrios.

A construção do sistema auxiliar define portanto um sistema não linear de equações 
diferenciais e algébricas que tem uma RE irrestrita igual à RER do sistema dinâmico restrito. Desta forma, o sistema auxiliar permite obter a RER, uma vez que a RE deste sistema leva em consideração os efeitos do requisito operacional em sua caracterização. A fronteira de $A_{r}\left(x_{S}\right)$ é formada por pontos de equilíbrio instáveis e variedades estáveis destes pontos, por pseudo-equilíbrios e por partes da fronteira de $A\left(x_{s}\right)$. O desenvolvimento matemático detalhado sobre a caracterização de $A_{r}\left(x_{s}\right)$ pode ser encontrado nas referências (Praprost , 1993) e (Praprost e Loparo, 1996).

Além do exemplo ilustrado na Figura 4.2, outras situações podem ocorrer tanto para a trajetória em falta como para a trajetória pós-falta. Os casos possíveis são ilustrados na Figura 4.4. Na primeira ilustração, os pontos $a, b, c, d$ correspondem à condição inicial do sistema pós-falta. A partir do ponto $x_{0}$ tem-se a trajetória em falta e a partir de cada ponto, tem-se a trajetória pós-falta. A trajetória que se inicia em $a$ converge para $x_{S}$ e não viola o requisito operacional, pois o ponto a pertence à $A_{r}\left(x_{s}\right)$. A trajetória que se inicia em $b$ converge para $x_{s}$, mas viola o requisito operacional durante a falta. Conforme pode ser observado, a posição do ponto $b$ indica que já houve violação da restrição do problema. A trajetória que se inicia em $c$ não converge para $x_{s}$, uma vez que se o ponto $c$ não pertence à $A\left(x_{s}\right)$, também não pertence à $A_{r}\left(x_{S}\right)$. A trajetória que se inicia em $d$ também não converge para $x_{s}$. Neste caso, a trajetória em falta abandona $A\left(x_{s}\right)$ antes de violar o requisito operacional.

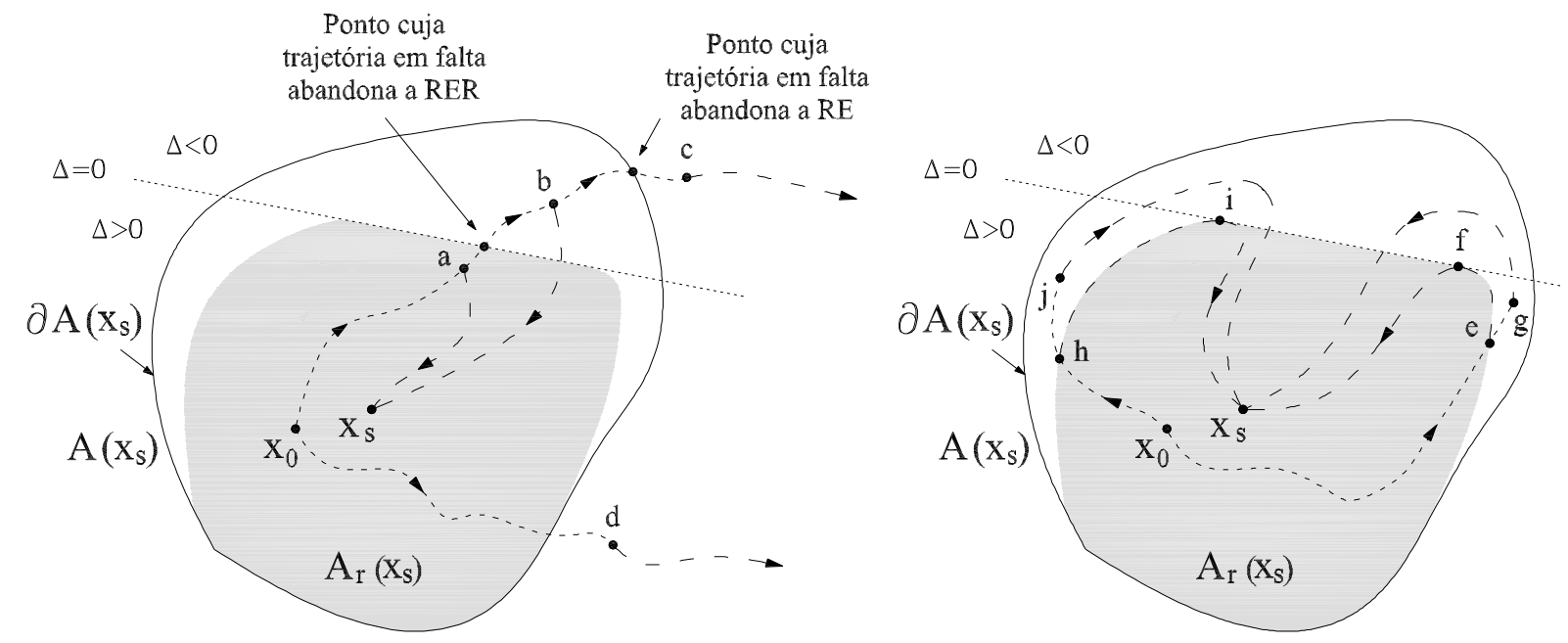

Figura 4.4: Regiões de estabilidade $A\left(x_{S}\right)$ e $A_{r}\left(x_{S}\right)$ e diferentes trajetórias.

Na segunda ilustração, os pontos $e, g, h, j$ correspondem à condição inicial do sistema pósfalta e os pontos $f, i$ correspondem aos pontos que tangenciam a superfície $(x, y): \Delta(x, y)=0$. Analogamente à primeira ilustração, a partir do ponto $x_{0}$ tem-se a trajetória em falta e a partir dos pontos $e, g, h, j$ tem-se a trajetória pós-falta. Como pode ser observado, as trajetórias pós-falta que se iniciam a partir dos pontos $e, h$ contornam $A_{r}\left(x_{s}\right)$ e tangenciam a superfície $(x, y): \Delta(x, y)=0$ nos pontos $f, i$, respectivamente. As trajetórias em falta não violam 0 requisito operacional até os pontos $g, j$. A partir destes pontos, as trajetórias convergem para $x_{s}$, mas violam o requisito operacional no período pós-falta. 
A seguir, o método PEBS é brevemente apresentado. Para estimar o TCA desconsiderando o requisito operacional, avalia-se uma função energia construída para o sistema original. Para estimar o TCA considerando o requisito operacional, avalia-se outra função energia, onde a restrição $\Delta(x, y)$ é utilizada em sua formulação.

\subsection{Método PEBS e estimativa dos tempos críticos de abertura}

O método PEBS foi originalmente proposto para o modelo clássico do gerador síncrono. Ao se analisar a energia potencial de um sistema gradiente reduzido associado ao modelo original, verificou-se que ao redor do ponto de equilíbrio estável do sistema pós-falta existe uma bacia energética. A fronteira desta bacia é formada por pontos extremos da energia potencial e por linhas perpendiculares às curvas de nível desta energia, de modo que as respectivas linhas interligam os pontos extremos, dando origem ao que se conhece por superfície de fronteira da energia potencial (Bretas e Alberto, 2000), do inglês potential energy boundary surface (PEBS).

Para estimar o TCA, o método PEBS avalia uma função energia sobre a trajetória em falta sustentada, verificando o momento em que a energia potencial atinge um primeiro máximo, isto é, atinge um valor crítico de energia. Este máximo de energia potencial é tomado como valor crítico de energia e o exit point e o TCA podem ser estimados verificando o instante em que a energia total do sistema atinge este valor crítico ao longo da trajetória em falta. Tratase de um método muito rápido, pois se exige a resolução numérica apenas das equações que modelam o sistema em falta para então se concluir sobre a estabilidade do sistema pós-falta, sem a necessidade de calcular pontos de equilíbrio instáveis na fronteira da RE. Ainda que este método seja bastante atrativo para análises de segurança em tempo real de sistemas elétricos, estimativas nem sempre conservadoras podem ocorrer (Chiang, 2011).

Uma breve explicação para entender este método direto consiste em comparar o sistema sob análise a uma bola dentro de uma bacia energética. O ponto de equilíbrio estável está localizado no fundo desta bacia, isto é, no ponto de menor energia potencial da superfície. Na fronteira desta bacia estão localizados os pontos de máxima energia potencial e pontos de sela. Nestes pontos, o gradiente da função energia potencial é nulo, indicando que os pontos citados são pontos de equilíbrio instáveis do sistema. O PEBS corresponde à fronteira desta bacia, que é formada pela união dos pontos de equilíbrio instáveis com trajetórias que ligam estes pontos. Tais linhas são perpendiculares às curvas de nível da função energia potencial. A fundamentação teórica do método PEBS pode ser encontrada em (Chiang et al., 1985), (Chiang et al., 1988b) e (Chiang, 2011).

A Figura 4.5 apresenta uma visão conceitual do método PEBS, onde se mostra a RE e a energia potencial associada ao sistema. O ponto cuja trajetória em falta cruza o PEBS corresponde ao ponto $x_{e}$, isto é, o ponto de saída da RE do sistema gradiente. O ponto $x_{e}$ pode ser um primeiro máximo da energia potencial (energia crítica). Já para o ponto $x_{S}$ tem-se um ponto de mínima energia potencial, que se refere portanto à parte mais baixa da bacia 
energética. Como já citado, para estimar a RE do ponto $x_{s}$, avalia-se a energia potencial via resolução numérica do modelo em falta, até se encontrar o primeiro máximo, que corresponde ao valor de energia crítica, momento em que a trajetória em falta cruza o PEBS. A partir do momento em que o distúrbio é eliminado, tem-se a trajetória pós-falta. Caso se elimine a perturbação antes da trajetória em falta atingir o valor crítico de energia, a trajetória pós-falta convergirá para $x_{S}$ e o sistema pós-falta será dito estável nesta situação. Caso o distúrbio seja eliminado após a trajetória em falta atingir o valor crítico de energia, o sistema pós-falta será dito instável (Rahimi et al., 1993).
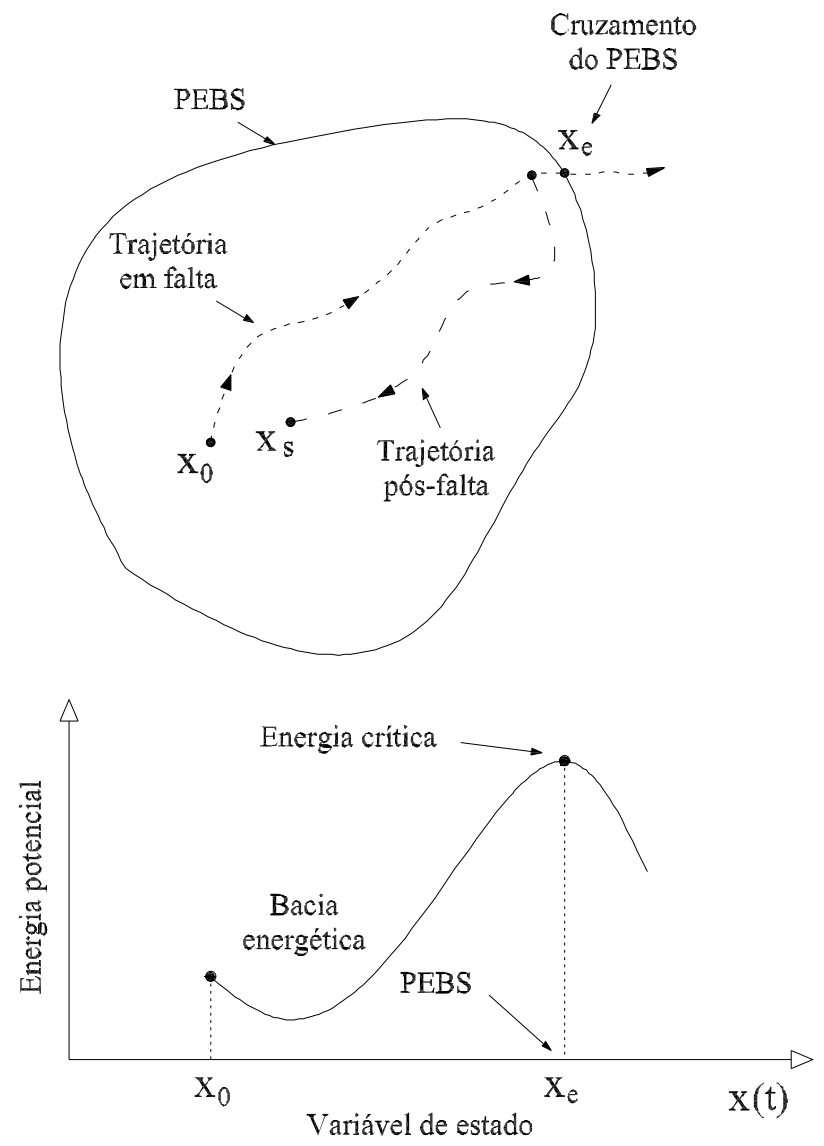

Figura 4.5: Região de estabilidade $A\left(x_{s}\right)$ e energia potencial. A energia é avaliada ao longo da trajetória em falta sustentada.

No que se refere aos geradores síncronos, a variável de estado sob análise é o ângulo do rotor. No caso dos geradores de indução, a variável de estado a ser analisada pode ser escolhida como sendo a velocidade ou o escorregamento do rotor. Obter funções energia de modelos de sistemas elétricos de potência é uma tarefa complicada (Fouad e Vittal, 1991), (Pai, 1989), (Pavella e Murthy, 1994), (Qiang e Zhong, 2005) e (Sasaki, 1979), especialmente para os modelos completos desenvolvidos no capítulo 3. Suponha a existência de uma função energia $V$ para o sistema original, tal que o sistema seja um sistema gradiente

$$
f(x, y)=-\frac{\partial V}{\partial x}
$$




$$
g(x, y)=-\frac{\partial V}{\partial y}
$$

Desta forma, obtém-se

$$
\frac{d x}{d t}=-\frac{\partial V}{\partial x}
$$

e

$$
0=-\frac{\partial V}{\partial y}
$$

Derivando $V$ em relação ao tempo e utilizando (4.13) e (4.14), é possível escrever

$$
\frac{d V}{d t}=\frac{\partial V}{\partial x} \frac{\partial x}{\partial t}+\frac{\partial V}{\partial y} \frac{\partial y}{\partial t}=-\left(\frac{\partial V}{\partial x}\right)^{2} \leq 0
$$

Se $\dot{V} \leq 0 \forall t$, o valor de $V$ se manterá constante ou sempre diminuirá ao longo de trajetórias. Os valores de mínima energia sempre indicarão pontos de equilíbrio estáveis. Já os valores de máxima energia sempre indicarão pontos de equilíbrio instáveis. O algoritmo a seguir descreve o método PEBS:

1. Verifica-se o ponto no qual a trajetória do sistema em falta cruza o PEBS. Em outras palavras, verifica-se o ponto no qual a energia potencial indica um primeiro máximo em cima da trajetória em falta. Seja $x_{e}$ este ponto;

2. O valor da energia em $x_{e}$ será a energia crítica $V_{c r}=V\left(x_{e}\right)$. Se no tempo de abertura $t_{a b}, V\left(t_{a b}\right)<V_{c r}$ o sistema pós-falta será estável. Em contrapartida, o sistema pós-falta será instável.

A Figura 4.6 ilustra o algoritmo exposto. Simulando o sistema em falta até se atingir $V_{c r}$, é possível então estimar o TCA para o sistema original, isto é, para o sistema que desconsidera o requisito operacional.

Neste trabalho, é proposta uma função energia para estimar o TCA relativo à violação do requisito operacional. Tal função, denotada por $V_{r}$, é obtida por

$$
V_{r}=\int \frac{d V}{d x} \Delta(x, y) d x
$$

A função $\Delta(x, y)$ força uma mudança de sinal do integrando, criando um máximo de $V_{r}$ no ponto $x_{r}$ onde o limite operacional é violado. Desta forma, o ponto em que $V_{r}$ atinge um máximo sobre a trajetória em falta sustentada será $x_{e}$ ou $x_{r}$, dependendo se o limite é violado antes ou depois da trajetória abandonar a RE.

Para $\Delta(x, y)>0$, a função energia $V_{r}$ indica os pontos que pertencem à $A\left(x_{s}, y_{s}\right)$ e $A_{r}\left(x_{s}, y_{s}\right)$. Quando $\Delta(x, y)=0$, a função energia $V_{r}$ assume um primeiro valor máximo $V_{c r}=$ 


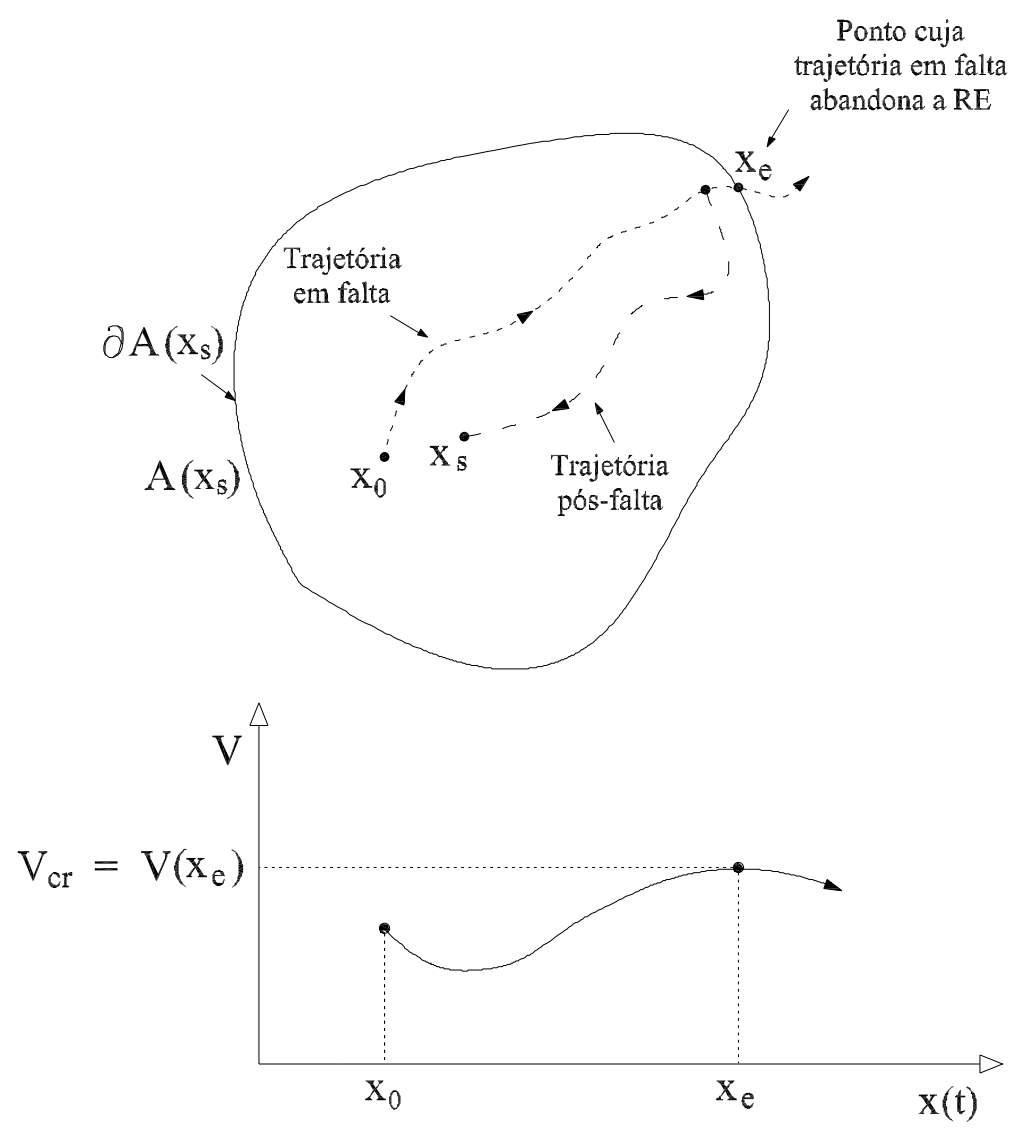

Figura 4.6: Região de estabilidade $A\left(x_{S}\right)$ e função $V$, calculada ao longo da trajetória em falta sustentada, para um sistema não sujeito a um requisito operacional.

$V_{r}\left(x_{r}\right)$, sendo $x_{r}$ o ponto cuja trajetória em falta viola o requisito operacional. Prolongando-se a perturbação, tem-se $\Delta(x, y)<0$ e a energia de $V_{r}$ começa a diminuir até se atingir 0 primeiro valor mínimo $V_{r}\left(x_{e}\right)$, de modo a se permitir estimar o TCA para o sistema original. Caso a trajetória em falta abandone $A\left(x_{s}\right)$ antes de violar o requisito operacional, o primeiro máximo da função energia $V_{r}$ estimará o mesmo ponto de saída e o mesmo TCA estimados pela função $V$. A Figura 4.7 ilustra a RE do sistema original, a RE do sistema auxiliar e a função energia $V_{r}$.

O algoritmo a seguir descreve os passos para obter o TCA relativo à violação do requisito operacional de um sistema gradiente:

1. Verifica-se o ponto no qual a função energia $V_{r}$ indica um primeiro máximo em cima da trajetória em falta. Seja $x_{r}$ este ponto;

2. O valor da energia em $x_{r}$ será a energia crítica $V_{c r}=V_{r}\left(x_{r}\right)$. Se no tempo de abertura $t_{a b}, V_{r}\left(t_{a b}\right)<V_{c r}$ o sistema pós-falta será estável e sua trajetória permanecerá dentro da RER, isto é, não ocorrerá violação do requisito operacional. Em contrapartida, ou a trajetória em falta viola o limite operacional ou o sistema pós-falta será instável. 

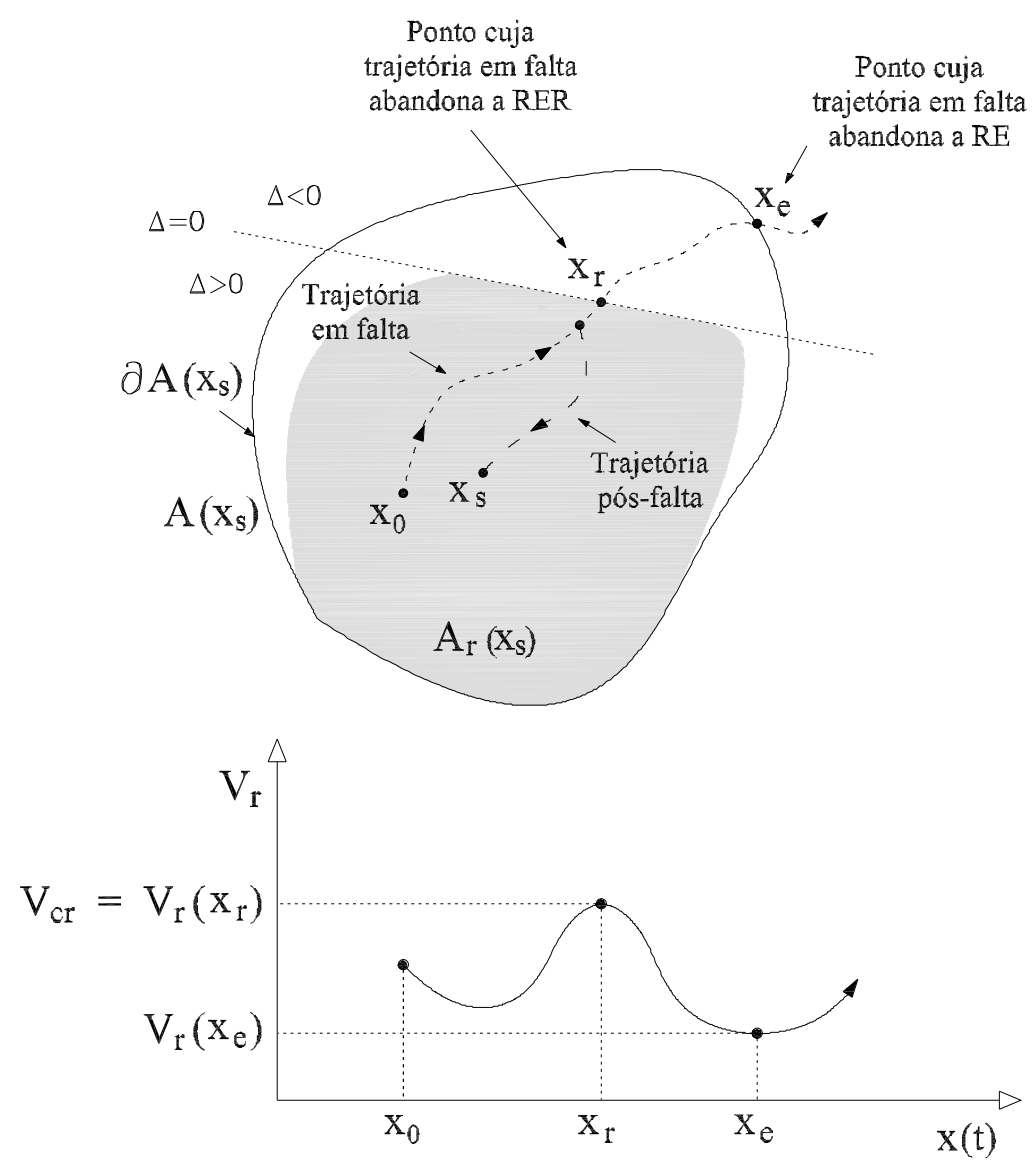

Figura 4.7: Regiões de estabilidade $A\left(x_{S}\right)$ e $A_{r}\left(x_{S}\right)$ e função $V_{r}$, calculada ao longo da trajetória em falta sustentada, para um sistema sujeito a um requisito operacional.

No que se refere à aplicação da teoria brevemente exposta, apresenta-se a seguir a formulação do requisito operacional para a restrição do problema. A partir das modelagens desenvolvidas para o sistema teste e para a restrição do problema, são descritas as equações necessárias para caracterizar a RE do ponto de equilíbrio estável do sistema pós-falta para os sistemas original e auxiliar. São apresentadas também as funções energia $V$ e $V_{r}$ e o procedimento para estimar os respectivos TCAs.

\subsection{Limite operacional}

A teoria dos métodos diretos é fundamentada para sistemas dinâmicos não lineares autônomos. Os fundamentos do método PEBS assumem que o sistema dinâmico e a restrição $\Delta(x, y)$ não dependem explicitamente do tempo. Entretanto, sabe-se que a curva LVRT consiste de um limite operacional dependente do tempo, de modo que o seu tratamento nesta forma se torna muito difícil nos métodos diretos. Assim, surge a imediata necessidade de representar os limites de tensão desta curva de forma independente do tempo. Para resolver este problema, é introduzida uma variável de estado auxiliar e formula-se o requisito LVRT por uma equação diferencial auxiliar dependente unicamente desta variável. Desta forma, o sistema auxiliar é autônomo e o limite operacional é modelado por uma função que depende 
apenas das variáveis originais e da variável de estado auxiliar. A curva LVRT real é então aproximada pela solução da equação diferencial auxiliar. Assim, todos os fundamentos relativos aos métodos diretos e aos sistemas dinâmicos autônomos podem ser aplicadas. A proposição desta equação diferencial auxiliar é uma das contribuições desta tese. A complexidade da equação diferencial auxiliar depende do perfil da curva LVRT sob análise. A equação diferencial auxiliar deve ser capaz de realizar uma boa aproximação da curva LVRT real, de modo que a sua utilização proporcione resultados precisos. Foram escolhidas duas curvas LVRT para serem estudadas separadamente neste trabalho: a curva LVRT do Brasil e a curva LVRT dos EUA.

Para o requisito LVRT do Brasil, a equação diferencial auxiliar construída para aproximar a respectiva curva LVRT real é descrita por

$$
\begin{aligned}
\dot{r}= & \frac{k_{0}}{\pi}\left\{\operatorname{tg}^{-1}\left[k_{1}\left(r-r_{0}\right)\right]-\operatorname{tg}^{-1}\left[k_{1}\left(r-r_{1}\right)\right]\right\}+ \\
& \frac{k_{2}}{\pi}\left\{\operatorname{tg}^{-1}\left[k_{1}\left(r-r_{2}\right)\right]-2 \operatorname{tg}^{-1}\left[0.2 k_{1}\left(r-r_{3}\right)\right]\right\}+k_{3} .
\end{aligned}
$$

Já para o requisito LVRT dos EUA, a equação elaborada corresponde a

$$
\dot{r}=\frac{k_{0}}{\pi}\left\{\operatorname{tg}^{-1}\left[k_{1}\left(r-r_{0}\right)\right]-\operatorname{tg}^{-1}\left[k_{1}\left(r-r_{1}\right)\right]\right\} .
$$

Escolhidas as condições iniciais $r\left(t_{0}\right)=0,1951$ para (4.17) e $r\left(t_{0}\right)=0,15$ para (4.18), ambas as equações se mostraram capazes de realizar boas aproximações das respectivas curvas LVRT real, conforme mostra a Figura 4.8. Observando esta figura, verifica-se que o erro máximo absoluto é menor que 0,05 pu e 0,01 pu para as curvas LVRT do Brasil e dos EUA, respectivamente. Os parâmetros destas equações podem ser vistos no apêndice $C$.

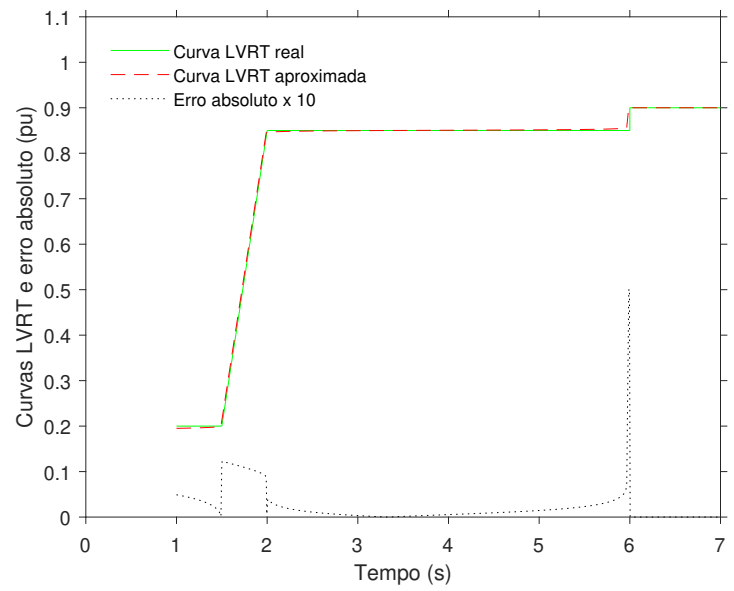

(a) Curvas LVRT do Brasil e erro absoluto.

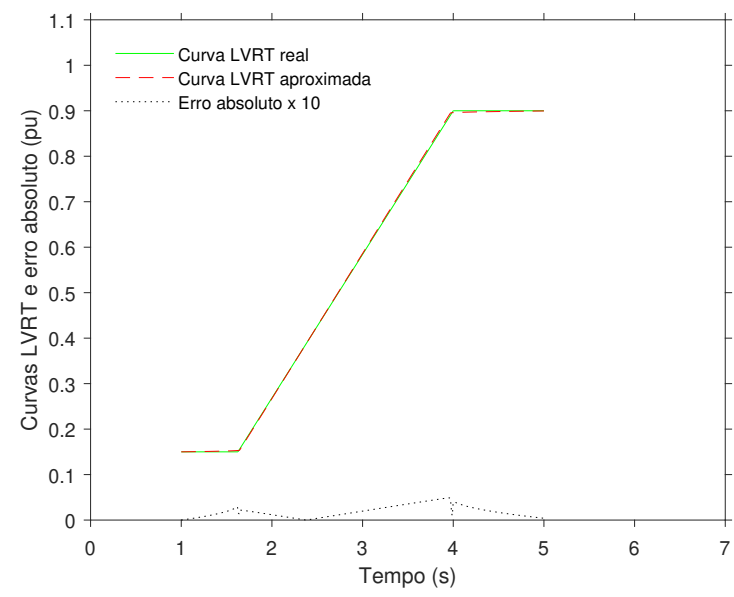

(b) Curvas LVRT dos EUA e erro absoluto.

Figura 4.8: Curvas LVRT real e LVRT aproximada para cada país. 
Com a inclusão da nova variável de estado $r$, a restrição do problema para cada curva LVRT aproximada é dada por

$$
\Delta(x, y)=\Delta\left(r, u_{x 2}, u_{y 2}\right)=\sqrt{u_{x 2}^{2}+u_{y 2}^{2}}-r=v_{P C C}-r
$$

onde $u_{x 2}$ e $u_{y 2}$ são as componentes real e imaginária, respectivamente, do fasor de tensão na barra 2 (barra do PCC do aerogerador com a rede) do sistema teste da Figura 3.1. Estas componentes são utilizadas no cálculo da tensão no PCC, denotada por $v_{P C C}$. A restrição $\Delta\left(r, u_{x 2}, u_{y 2}\right)$ pode assumir valores positivos, negativos ou o valor nulo, conforme (4.7). Valores positivos indicam que a tensão no PCC é maior do que a tensão mínima especificada pela curva LVRT.

\subsection{Regiões de estabilidade}

No capítulo 3 foi desenvolvida a modelagem do sistema teste. Considerando as configurações SCIG e WRIG nos eixos $d$ e $q$, foram obtidos modelos completos de ordem cinco, três e um. Para estas configurações em regime permanente, evidentemente foram obtidos modelos completos de ordem um. Considerando a configuração DFIG, foram obtidos modelos completos de ordem treze, onze e nove. Os modelos completos formam o sistema original definido neste capítulo. No que se refere ao sistema auxiliar, a inclusão da nova variável de estado $r$ exige que a equação diferencial que aproxima a curva LVRT real seja adicionada a cada modelo completo obtido no capítulo 3, assim como a equação algébrica referente à restrição (4.19). Além disso, deve-se multiplicar as equações diferenciais destes modelos por (4.19). Ao se considerar uma nova variável de estado, cada modelo tem a ordem aumentada em uma unidade.

Será exibida no espaço de estados a RE do ponto de equilíbrio estável do sistema pósfalta para o sistema auxiliar de ordem dois, considerando os modelos em primeira ordem das configurações SCIG e WRIG nos eixos $d$ e $q$. Para o sistema teste com a configuração SCIG são consideradas as equações apresentadas na seção 3.4 e subseção 3.4 .2 com (4.19) e (4.17) ou (4.18). Para o sistema teste com a configuração WRIG são consideradas as equações apresentadas na seção 3.5 e subseção 3.5 .2 com (4.19) e (4.17) ou (4.18). Os modelos são compostos portanto por onze equações, sendo nove algébricas e duas diferenciais. Desta forma, para o sistema original tem-se somente a variável de estado $s$, que corresponde ao escorregamento. A fronteira da RE deste sistema de ordem um é formada por pontos de equilíbrio, sendo o ponto de saída o ponto de equilíbrio instável localizado na fronteira da RE. A RE referente ao sistema original é identificada portanto em $\mathbb{R}$, conforme mostra a Figura 4.9(a).

Para o sistema auxiliar tem-se agora as variáveis dinâmicas $s$ e $r$, sendo $r$ a variável de estado referente à equação diferencial auxiliar que aproxima a curva LVRT real. A RE do sistema auxiliar é identificada portanto em $\mathbb{R}^{2}$, conforme mostra a Figura 4.9(b). A RE do sistema auxiliar reúne as condições iniciais pós-falta em que a restrição do problema não 
foi violada no período em falta e cujas trajetórias que partem destas condições convergem para o ponto de equilíbrio estável do sistema pós-falta sem violar a restrição do problema. A RER do sistema dinâmico restrito reúne as condições iniciais que pertencem à $R E$ do sistema original e os valores correspondentes da curva LVRT real cuja tensão no PCC não viola esta curva para todo o tempo. No apêndice G são apresentados os scripts implementados em MATLAB ${ }^{\circledR}$ para calcular tanto a RER como a RE do sistema auxiliar para a configuração SCIG considerando a curva LVRT do Brasil.

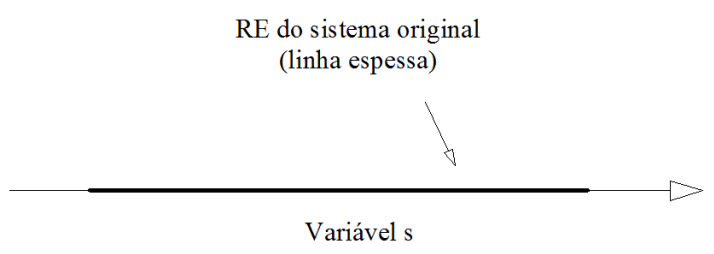

(a) Região de estabilidade definida em $\mathbb{R}$.

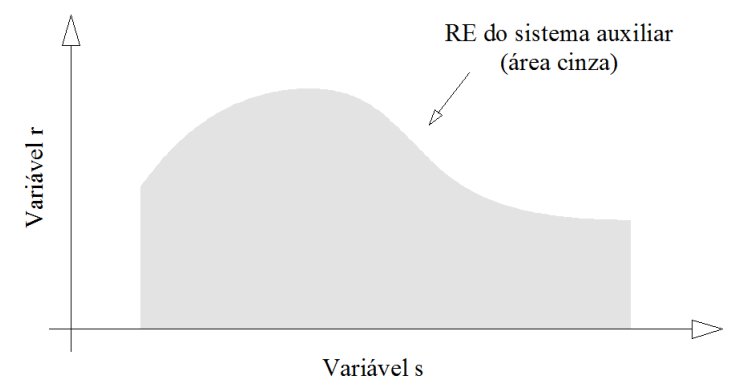

(b) Região de estabilidade definida em $\mathbb{R}^{2}$.

Figura 4.9: Dimensões das regiões de estabilidade.

A RER do sistema dinâmico restrito é calculada considerando as equações do sistema original e a curva LVRT real para a restrição do problema. Será exemplificado nos resultados deste trabalho que a RE do sistema auxiliar e a RER do sistema dinâmico restrito são numericamente equivalentes.

Seria possível reproduzir também a RE do sistema auxiliar considerando os modelos das configurações SCIG e WRIG em regime permanente. Porém as mesmas não serão exibidas neste trabalho, pois verificou-se que tais REs são numericamente equivalentes às REs dos modelos em primeira ordem nos eixos $d$ e $q$.

\subsection{Funções energia}

É sabido que a equação mecânica da máquina de indução descreve os efeitos de desequilíbrios entre os torques mecânico e eletromagnético, permitindo que a estabilidade de velocidade da máquina seja investigada. Em (Almeida, 2010), avaliou-se a estabilidade de velocidade de um motor de indução via método direto, por meio de uma função energia numérica baseada na equação mecânica da máquina. A partir de pontos levantados nas simulações computacionais, calculou-se uma aproximação da função energia $V$ via método numérico. Os resultados obtidos pelo autor indicaram que o sistema sob análise pôde ser interpretado como um sistema gradiente. Nesta tese, a função energia proposta em (Almeida, 2010) é adaptada para avaliar a estabilidade do gerador de indução, para todos os modelos completos de aerogeradores apresentados no capítulo 3.

Como já citado, para avaliar a estabilidade de velocidade do gerador de indução é possível considerar a variável velocidade do rotor $\omega_{r}$ ou a variável escorregamento s. Nesta tese, 
optou-se pela variável escorregamento. Seja então a função energia $V$ retirada da relação

$$
\frac{d s}{d t}=-\frac{d V}{d s}
$$

Considerando nulo o coeficiente de atrito viscoso em (3.195), a equação mecânica do gerador de indução é definida como

$$
\frac{d s}{d t}=\frac{1}{2 H_{m}}\left(T_{e}-T_{m}\right)
$$

Substituindo (4.20) em (4.21), a expressão para obter a função energia $V$ fica definida por

$$
\frac{d V}{d s}=\frac{1}{2 H_{m}}\left(T_{m}-T_{e}\right) .
$$

Já para obter a função energia $V_{r}$, utiliza-se

$$
\frac{d V_{r}}{d s}=\frac{1}{2 H_{m}}\left(T_{m}-T_{e}\right) \Delta\left(r, u_{x 2}, u_{y 2}\right)
$$

Integrando-se via método numérico (4.22) e (4.23), é possível obter as funções energia $V$ e $V_{r}$, respectivamente. Nesta tese, escolheu-se o método de integração trapezoidal para aproximar as funções energia, via ferramenta cumtrapz (MathWorks, 2018e), disponível no software MATLAB ${ }^{\circledR}$. Para que as mesmas sejam capazes de estimar adequadamente os TCAs, tais funções devem levar em conta como estará o sistema pós-falta no momento de eliminação da perturbação. Desta forma, algumas orientações devem ser seguidas para calcular as funções energia a partir de dados obtidos nas simulações:

1. Todos os valores em falta devem ser armazenados para: o torque mecânico, o escorregamento e a restrição do problema;

2. Para cada valor de escorregamento em falta, deve-se resolver o conjunto de equações que modela o sistema pós-falta. Para o modelo dinâmico da máquina em terceira ordem ou em quinta ordem, deve-se considerar $\dot{e}_{d}=\dot{e}_{q}=0$. Para o modelo da máquina em quinta ordem, deve-se considerar também $\dot{i}_{x 3}=\dot{i}_{y 3}=0$. Em outras palavras, deve-se utilizar o modelo da máquina em primeira ordem nesta etapa;

3. Com os valores do escorregamento em falta e das demais variáveis obtidas na etapa 2 $\left(e_{d}, e_{q}, i_{x 3}\right.$ e $\left.i_{y 3}\right)$, calcula-se o torque eletromagnético;

4. Resolve-se (4.22) e (4.23) para todos os valores do torque eletromagnético calculados na etapa 3, ao longo da trajetória em falta. Em outras palavras, utilizam-se os valores armazenados na etapa 1 para resolver via método numérico (4.22) e (4.23).

Salienta-se que os valores em falta citados na etapa 1 devem considerar as dinâmicas $\dot{e}_{d}$ e $\dot{e}_{q}$ para os modelos da máquina em terceira e quinta ordens e também devem considerar $\dot{i}_{x 3}$ e 
$i_{y 3}$ para o modelo da máquina em quinta ordem, diferentemente da etapa 2, que desconsidera tais dinâmicas no cálculo das condições pós-falta. As variáveis $e_{d}$ e $e_{q}$ apresentam dinâmicas rápidas, isto é, tais variáveis apresentam variações muito grandes em um intervalo de tempo muito curto. A inclusão de dinâmicas rápidas em geral compromete as análises de estabilidade via método direto, conforme pode ser observado em (Almeida, 2010) para o motor de indução e em (Sauer et al., 1989) e (Rahimi et al., 1993) para o gerador síncrono. Nesta tese, verificouse que as funções energia foram incapazes de fornecer resultados satisfatórios para estimar os TCAs quando tais dinâmicas rápidas foram consideradas. Desta forma, para que as funções energia forneçam resultados satisfatórios, as dinâmicas $\dot{\dot{e}_{d}}$ e $\dot{e_{q}}$ não devem ser incluídas na etapa 2. Por último, verificou-se via simulações que para obter resultados mais precisos para

o modelo da máquina em quinta ordem, as dinâmicas $i_{x 3}$ e $i_{y 3}$ também não devem ser incluídas na etapa 2 .

Uma vez obtidas as funções energia $V$ e $V_{r}$, o ponto de mínima energia indicará o escorregamento referente ao ponto de equilíbrio estável do sistema pós-falta. Para a função energia $V$, o ponto de máxima energia indicará o escorregamento no momento em que a trajetória em falta abandona a RE estimada para o sistema original. Como consequência, obtém-se o respectivo TCA estimado. Já para a função energia $V_{r}$, o ponto de máxima energia indicará o escorregamento no momento em que a tensão no PCC viola a curva LVRT durante a falta. Como consequência, obtém-se o respectivo TCA estimado. Sustentando a falta, o ponto de mínima energia subsequente proporcionado pela função energia $V_{r}$ indicará os mesmos valores de escorregamento e de TCA fornecidos pela função energia $V$.

\subsection{Comentários finais}

Neste capítulo foi explicado como o problema de estabilidade de velocidade e o problema de violação de limites de tensão de aerogeradores são analisados via método direto. Foi definido que cada modelo completo apresentado no capítulo 3 é representado por um sistema denominado de sistema original. Neste caso, a restrição do problema é desconsiderada. Assim, a RE do ponto de equilíbrio estável do sistema pós-falta para este sistema é irrestrita e analisou-se neste caso somente o problema de estabilidade de velocidade. Ao se considerar uma restrição, utilizou-se a teoria de sistemas dinâmicos restritos, que caracteriza matematicamente a RER e a restrição de um sistema físico, para estudar a RER por meio de um sistema auxiliar de equações que apresenta uma RE irrestrita igual à RER.

Ao se considerar uma restrição, foram escolhidas as curvas LVRT do Brasil e dos EUA para serem analisadas separadamente. Uma vez que as curvas LVRT representam limites de tensão dependentes do tempo e a teoria de métodos diretos é fundamentada para sistemas dinâmicos autônomos, introduziu-se uma variável de estado auxiliar para modelar cada curva por meio de uma equação diferencial auxiliar própria, dependente unicamente desta nova variável de estado. Ainda que a modelagem por uma equação diferencial autônoma seja relativamente complexa, as equações propostas foram capazes de realizar aproximações muito 
boas para ambas as curvas. Salienta-se que embora o requisito operacional escolhido se refira à curva LVRT, a técnica proposta para representar este requisito pode ser usada para modelar outros requisitos, de modo que o sistema sob análise seja autônomo e possa ser explorado nas análises de estabilidade via métodos diretos. Vale ressaltar portanto, que no contexto das análises de estabilidade via método direto de sistemas elétricos de potência sujeitos a restrições, a técnica proposta para modelar diferentes requisitos operacionais pode ser considerada uma contribuição desta tese.

As funções energia foram formuladas a partir da equação mecânica do gerador de indução. Como não foram construídas funções analíticas, funções energia aproximadas foram consideradas, obtidas via método numérico seguindo um procedimento específico. Utilizando-se dos conceitos do método PEBS, foram estabelecidas duas funções energia para estimar os TCAs. A função energia $V$ foi determinada para estimar o TCA relativo ao problema de estabilidade de velocidade. Ao se considerar a restrição do problema, a função energia $V_{r}$ foi determinada para estimar o TCA relativo à violação do requisito operacional.

No próximo capítulo, investiga-se o problema de estabilidade de velocidade e o problema de violação de limites de tensão, realizando-se simulações para o sistema teste da Figura 3.1. Tais estudos se resumem em verificar as trajetórias em falta e pós-falta no domínio do tempo e no espaço de estados e comparar os TCAs estimados via método direto aos TCAs calculados via método clássico. 


\section{Capítulo 5}

\section{Estudos de estabilidade}

\subsection{Introdução}

Neste capítulo são apresentados resultados de simulações computacionais para o sistema teste da Figura 3.1, modelado no capítulo 3 para as configurações de aerogeradores SCIG, WRIG e DFIG. Com relação ao requisito operacional, são consideradas as curvas LVRT do Brasil e dos EUA, apresentadas nos capítulos 2 e 4. Os parâmetros de cada aerogerador são típicos de unidades comerciais (Yaramasu e Wu, 2017). A potência mecânica (saída da turbina) nominal para os três aerogeradores corresponde a $3 \mathrm{MW}$. Os parâmetros da rede do sistema teste e de cada aerogerador são apresentados nos apêndices $A$ e B, respectivamente. As simulações são realizadas no software MATLAB ${ }^{\circledR}$. Informações sobre as mesmas podem ser consultadas no apêndice D. As condições iniciais para todas as simulações são apresentadas no apêndice $E$.

Os estudos de estabilidade são separados em quatro partes:

1. Seção 5.2 - Comportamento dinâmico

Para uma dada perturbação, é analisado em linhas gerais o comportamento dinâmico de cada aerogerador. Os objetivos são: i) mostrar um caso de instabilidade de tensão e de instabilidade de velocidade, ii) mostrar como se comporta a tensão no PCC, examinando se ocorre ou não violação de cada curva LVRT.

2. Seção 5.3 - Regiões de estabilidade e trajetórias

Para o aerogerador SCIG, são obtidas a RER para cada curva LVRT real e a RE do sistema auxiliar para cada curva LVRT aproximada, além de trajetórias em falta e pósfalta no domínio do tempo e no espaço de estados. Os objetivos são: i) comparar a RE do sistema auxiliar com a RER do sistema dinâmico restrito, de modo a confirmar que o sistema auxiliar é capaz de automaticamente levar em consideração os efeitos de limites operacionais nas análises de estabilidade, ii) mostrar trajetórias em falta e pós-falta na RE do sistema auxiliar, relacionando as trajetórias no domínio do tempo com as trajetórias no espaço de estados para exemplificar e explicar os casos da Figura 4.4, iii) mostrar as diferenças entre as REs ao se considerar diferentes curvas LVRT. 
3. Seção 5.4 - Variações das regiões de estabilidade

Para o aerogerador SCIG, é obtida a RE do sistema auxiliar para diferentes constantes de inércia. Para o aerogerador WRIG, é obtida a RE do sistema auxiliar para diferentes resistências do rotor e tensões aplicadas ao rotor. O objetivo é verificar a caracterização da RE do sistema original e da RE do sistema auxiliar para diferentes parâmetros do gerador de indução e para cada curva LVRT, de modo que se possa verificar na sequência a relação entre as REs e os TCAs obtidos para algumas perturbações.

4. Seção 5.5 - Tempos críticos de abertura

Para várias perturbações aplicadas ao sistema teste, são obtidos os respectivos TCAs, tanto para o sistema sujeito como não sujeito às curvas LVRT. Os TCAs estimados via método direto são comparados aos TCAs calculados via método clássico. São apresentadas trajetórias no domínio do tempo e energias referentes às funções $V$ e $V_{r}$. O objetivo é aplicar as funções energia aos modelos obtidos no capítulo 3, tanto para o sistema original como para o sistema sujeito a cada curva LVRT, de modo a verificar se tais funções são capazes de realizar boas estimativas dos TCAs.

\subsection{Comportamento dinâmico}

Os próximos gráficos mostram o comportamento dinâmico de algumas variáveis referentes ao modelo do aerogerador em terceira ordem nos eixos $d$ e $q^{1}$. Inicialmente são apresentados os resultados para as configurações SCIG e WRIG. Vale ressaltar que para cada configuração utiliza-se um conjunto específico de parâmetros, pois são máquinas diferentes, de modo que o ponto de operação e o comportamento dinâmico de cada unidade sejam naturalmente particulares. Os parâmetros da configuração SCIG são apresentados na Tabela B.1, enquanto que da configuração WRIG na Tabela B.2. Para a configuração WRIG considera-se para a resistência do rotor o seu valor nominal $\left(r_{r} \cdot 1\right)$ e também este valor três vezes maior $\left(r_{r} \cdot 3\right)$. Para as configurações SCIG e WRIG considera-se um torque mecânico de entrada (saída da turbina) $T_{m}=0,7$ pu. Considerando este torque, as potências ativa e reativa total (potências entregues à rede) correspondem a $P_{s}=0,6960 \mathrm{pu}$ e $Q_{s}=0,0728$ pu para a configuração SCIG e $P_{s}=0,6905$ pu e $Q_{s}=0,0716$ pu para a configuração WRIG $\left(r_{r} \cdot 1\right.$ e $\left.r_{r} \cdot 3\right)$. Em seguida, são apresentados os resultados obtidos para a configuração DFIG. Os parâmetros da configuração DFIG são apresentados na Tabela B.3. Para esta configuração, a barra terminal é considerada uma barra $\mathrm{PQ}$ com $P_{g}=0,6933$ pu e $Q_{g}=0,0722$ pu. O torque mecânico resultante em regime permanente corresponde a $T_{m}=0,5976$ pu. Como já apresentado no capítulo 3, o torque mecânico para a configuração DFIG não é considerado constante, mas variável de acordo com a relação entre a potência mecânica aproximada e a velocidade do rotor, conforme mostra a Figura 3.10.

\footnotetext{
${ }^{1}$ Para as potências ativa e reativa, adotou-se a convenção de gerador, diferentemente da convenção de motor adotada na modelagem da máquina.
} 
A perturbação aplicada ao sistema teste da Figura 3.1 corresponde a uma mudança na tensão da barra 1, a barra infinita, por um período de tempo específico. A tensão desta barra é reduzida no instante $t_{0}=1 \mathrm{~s}$ em $25 \%$, permanecendo durante $0,9 \mathrm{~s}$ com o valor $u_{x 1}=0,75$ pu e retornando ao valor $u_{x 1}=1$ pu no instante $t_{a b}=1,9 \mathrm{~s}$, conforme mostra a Figura 5.1.

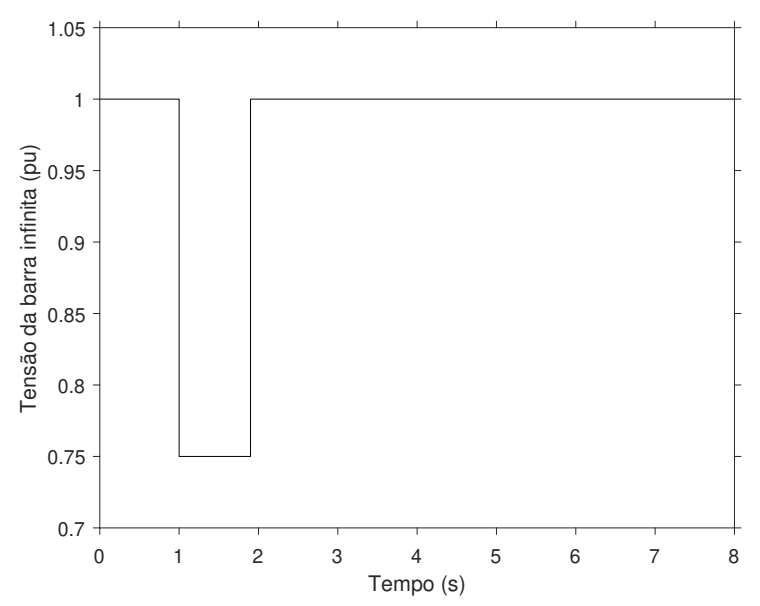

Figura 5.1: Tensão da barra infinita.

Ao se alterar a variável algébrica $u_{x 1}$, que faz parte das equações que modelam a rede elétrica, as demais variáveis algébricas respondem imediatamente ao comportamento da tensão da barra 1. Em outras palavras, as variáveis algébricas têm os seus valores modificados instantaneamente no instante de aplicação ou de eliminação da perturbação, diferentemente da variável de estado, conforme será visto nos próximos gráficos. As topologias dos sistemas pré-falta e pós-falta são iguais.

\subsubsection{SCIG e WRIG}

A Figura 5.2(a) mostra a tensão do estator, ou tensão terminal, que corresponde à tensão da barra 3 do sistema teste da Figura 3.1. Conforme pode ser visto, em decorrência da tensão da barra 1 sofrer uma redução de $25 \%$ de seu valor original, a tensão do estator sofre um decréscimo significativo logo no instante de ocorrência da perturbação. É visível que os aerogeradores não são capazes de recuperar a tensão terminal durante o distúrbio e que o afundamento de tensão se torna mais acentuado neste período para a configuração WRIG $\left(r_{r}\right.$ 1). No instante de eliminação da perturbação, a tensão do estator imediatamente aumenta. No sistema pós-falta, apenas para as configurações SCIG e WRIG $\left(r_{r} \cdot 3\right)$ ocorre o retorno ao valor pré-falta, nos instantes $t=3 \mathrm{~s}$ e $t=7,5 \mathrm{~s}$, respectivamente. A instabilidade de tensão ocorre somente para a configuração WRIG $\left(r_{r} \cdot 1\right)$.

A Figura 5.2(b) mostra a potência ativa do estator. Os valores positivos indicam quantidades produzidas pelo gerador. Verifica-se que a potência ativa também sofre uma redução logo no instante de ocorrência da perturbação, uma vez que esta potência é proporcional à tensão terminal. Conforme pode ser observado para a configuração SCIG, a potência ativa do estator atinge um nível próximo do original ao fim do distúrbio, o que não ocorre para as 


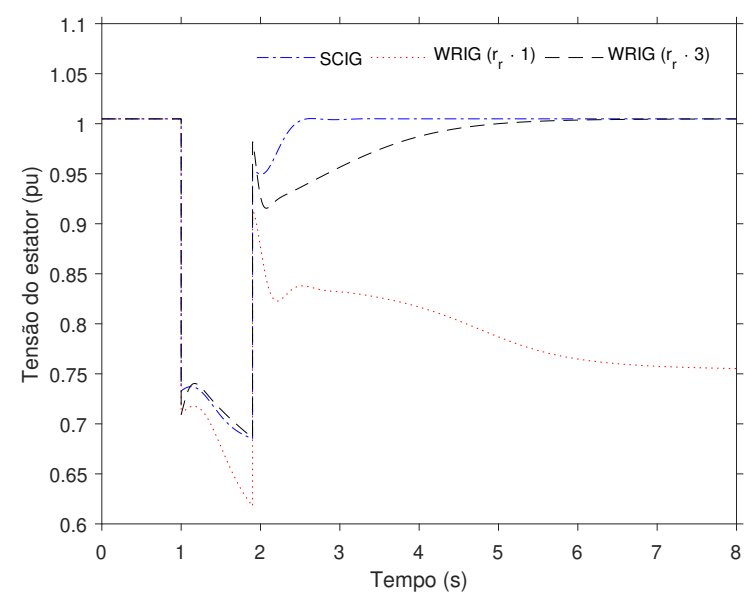

(a) Tensão do estator.

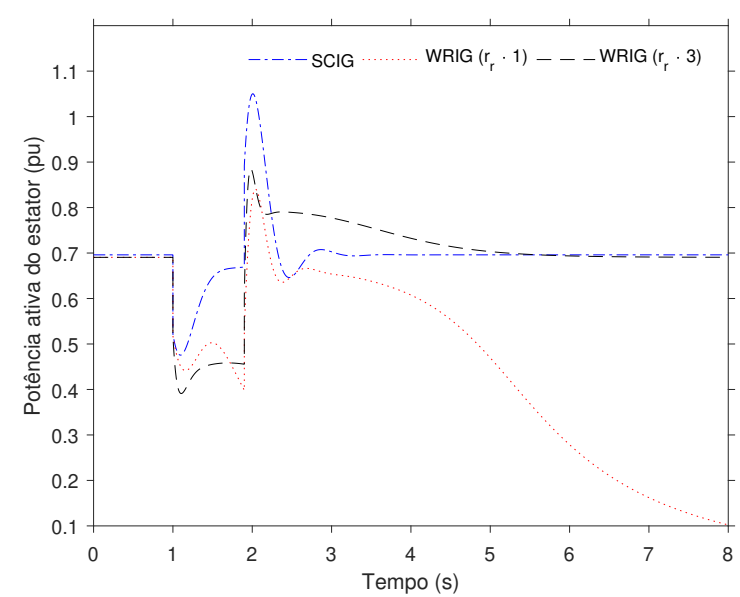

(b) Potência ativa do estator.

Figura 5.2: Tensão e potência ativa do estator. A tensão da barra infinita é alterada em $t_{0}=1 \mathrm{~s}$ de $u_{x 1}=1$ pu para $u_{x 1}=0,75 p u$, retornando a $u_{x 1}=1$ pu em $t_{a b}=1,9 \mathrm{~s}$.

configurações WRIG. Após a eliminação do distúrbio, a potência retorna ao seu valor original para as unidades SCIG e WRIG $\left(r_{r} \cdot 3\right)$, após a ocorrência de oscilações, que embora sejam mais acentuadas para a configuração SCIG, são amortecidas de forma mais rápida para este aerogerador. Como ocorre a instabilidade de tensão para a configuração WRIG $\left(r_{r} \cdot 1\right)$, é natural que a potência não retorne ao seu valor inicial.

Uma vez que o torque mecânico de entrada do gerador (saída da turbina) é considerado sempre constante, durante o período em falta o torque mecânico será maior que o torque eletromagnético, como mostra a Figura 5.3(a). O desequilíbrio entre os torques é suficiente para acelerar o rotor do gerador, tornando o escorregamento cada vez mais negativo, conforme exibe a Figura 5.3(b).

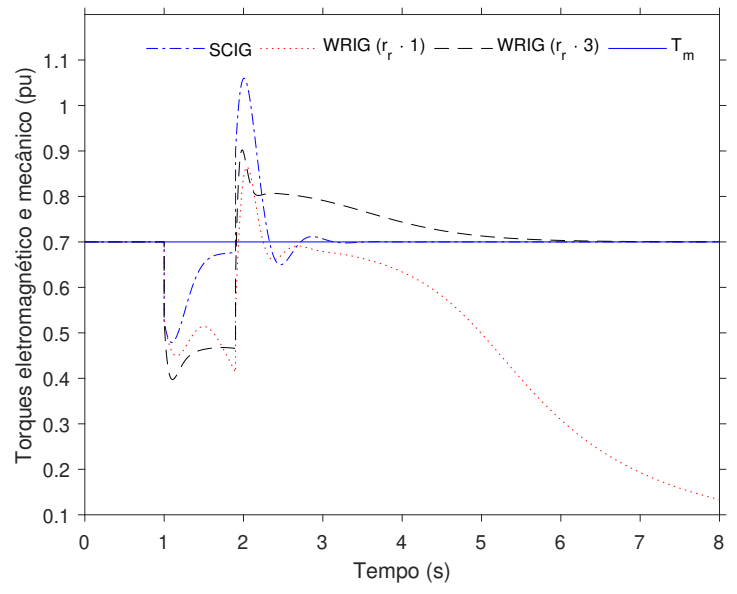

(a) Torques eletromagnético e mecânico.

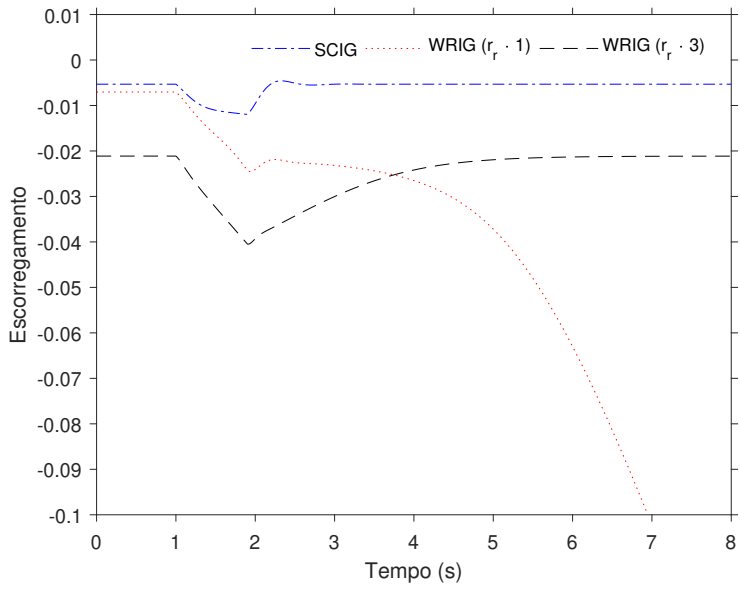

(b) Escorregamento.

Figura 5.3: Torques eletromagnético e mecânico e escorregamento. A tensão da barra infinita é alterada em $t_{0}=1 \mathrm{~s}$ de $u_{x 1}=1$ pu para $u_{x 1}=0,75 \mathrm{pu}$, retornando a $u_{x 1}=1 \mathrm{pu} \mathrm{em} t_{a b}=1,9 \mathrm{~s}$. 
Após eliminar o distúrbio, o escorregamento retorna ao valor pré-falta para as configurações SCIG e WRIG $\left(r_{r} \cdot 3\right)$. Verifica-se que os torques eletromagnético e mecânico se equilibram e permanecem iguais a partir do instante $t=3 \mathrm{~s}$ para a configuração SCIG e do instante $t=7,5 \mathrm{~s}$ para a configuração WRIG $\left(r_{r} \cdot 3\right)$. Assim como a tensão do estator, o torque mecânico e também o escorregamento retornam aos seus valores iniciais e se estabilizam a partir do mesmo instante de tempo. A instabilidade de velocidade ocorre somente para a configuração WRIG $\left(r_{r} \cdot 1\right)$. Percebe-se que aumentar a resistência do rotor do gerador para o aerogerador WRIG foi suficiente para evitar a sua instabilidade.

A Figura 5.4(a) mostra a potência reativa do estator. Os valores negativos indicam quantidades consumidas pelo gerador. Analisando o sistema pré-falta, a configuração WRIG consome mais potência reativa em relação à configuração SCIG. Para a configuração SCIG tem-se $Q_{g}$ $=-0,3951$ pu e para as configurações WRIG tem-se $Q_{g}=-0,7593$ pu. Verifica-se que o consumo é diminuído durante o período em falta, porém o gerador não é capaz de fornecer potência reativa à rede neste intervalo de tempo. Este fato impede melhores resultados para a tensão do estator e consequentemente para as demais variáveis do sistema. Após a eliminação da perturbação, a potência reativa retorna ao seu valor original para as configurações SCIG e WRIG $\left(r_{r} \cdot 3\right)$. No caso da configuração WRIG $\left(r_{r} \cdot 1\right)$, o consumo de potência reativa cresce indefinidamente, uma vez que a instabilidade de velocidade e a instabilidade de tensão impedem o seu retorno ao valor inicial.

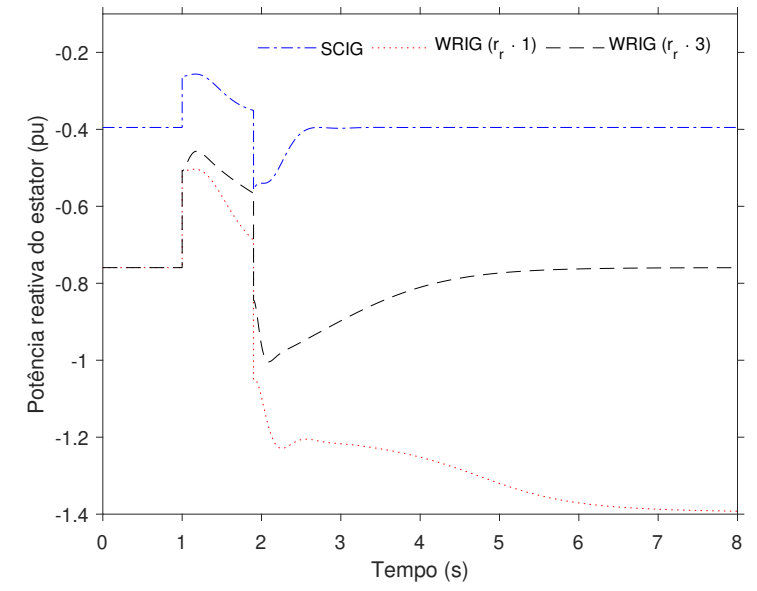

(a) Potência reativa do estator.

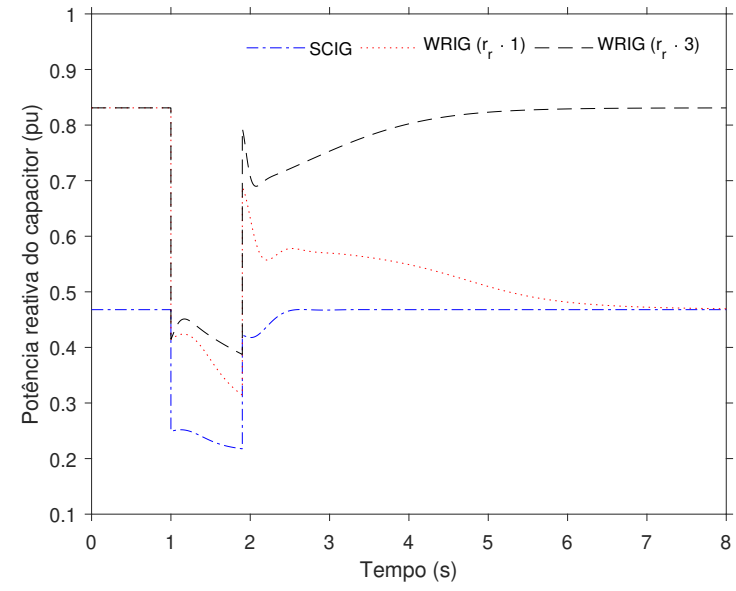

(b) Potência reativa do capacitor.

Figura 5.4: Potências reativas do estator e do capacitor. A tensão da barra infinita é alterada em to $=1 \mathrm{~s}$ de $u_{x 1}=1$ pu para $u_{x 1}=0,75 \mathrm{pu}$, retornando $a u_{x 1}=1 \mathrm{pu}$ em $t_{a b}=1,9 \mathrm{~s}$.

O caso de instabilidade ocorrido para a configuração WRIG $\left(r_{r} \cdot 1\right)$ exemplifica o mecanismo de instabilidade apresentado na seção 2.4, mostrando que os problemas de estabilidade de velocidade e de estabilidade de tensão são intrinsecamente acoplados em máquinas de indução. Na ocorrência da perturbação, a tensão terminal é reduzida, assim como a potência ativa, visto a mesma ser proporcional à tensão. O torque mecânico tornando-se maior que o 
torque eletromagnético durante o período em falta provoca a aceleração do rotor do gerador. Ao se eliminar a perturbação, o gerador ainda consome potência reativa. Como o gerador continua acelerando e a tensão não consegue ser restaurada, o consumo de potência reativa cresce ainda mais, intensificando o desequilíbrio entre os torques e potências e aumentando ainda mais a velocidade.

A Figura 5.4(b) mostra a potência reativa produzida pelo capacitor, instalado na barra terminal do gerador. Embora existam diferentes possibilidades de ajustes, os capacitores foram dimensionados para que a tensão terminal apresente o mesmo valor em regime permanente para as configurações sob análise, sendo os mesmos mantidos constantes durante as simulações. Em decorrência dos diferentes valores dos parâmetros da máquina (máquinas SCIG e WRIG apresentam parâmetros distintos, em especial as reatâncias), os capacitores foram dimensionados com valores muito distintos (estes valores podem ser consultados na Tabela A.1), o que revela a diferença entre as potências fornecidas pelos mesmos ao observar o intervalo pré-falta. Para a configuração SCIG tem-se $Q_{g}=0,4679$ pu e para as configurações WRIG tem-se $Q_{g}=0,8310$ pu. Como as capacitâncias são fixas e a tensão terminal é reduzida durante a perturbação, é natural que a potência fornecida pelo capacitor também sofra uma diminuição considerável neste período. Visto que a tensão terminal retorna ao seu valor original na situação pós-falta para as configurações SCIG e WRIG $\left(r_{r} \cdot 3\right)$, a potência fornecida pelo capacitor também retorna ao seu valor inicial, diferentemente do que ocorre para a configuração WRIG $\left(r_{r} \cdot 1\right)$, devido ao comportamento instável deste aerogerador.

As Figuras 5.5(a) e 5.5(b) mostram a potência reativa total (potência entregue à rede) e a potência reativa no PCC, respectivamente. Valores positivos de potência indicam quantidades saindo das barras no sentido da barra 3 para a barra 1. A potência reativa total é obtida pela diferença entre a potência fornecida pelo capacitor e a potência absorvida pelo estator.

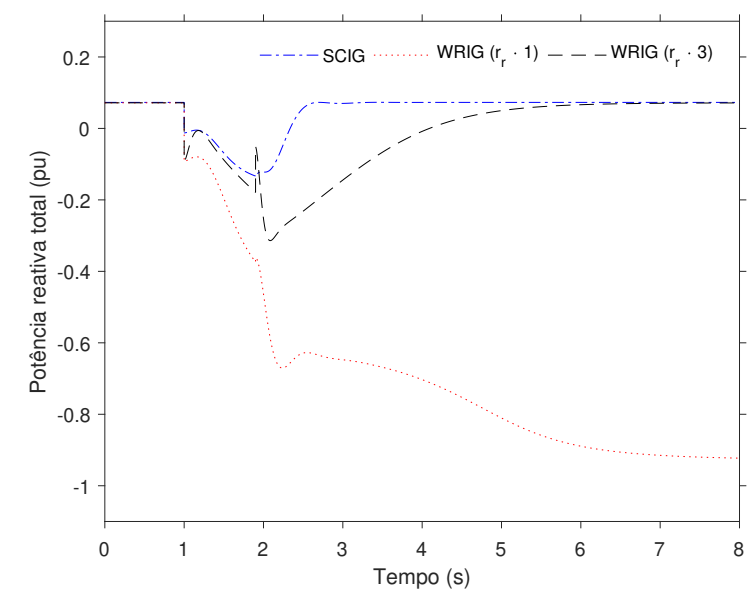

(a) Potência reativa total.

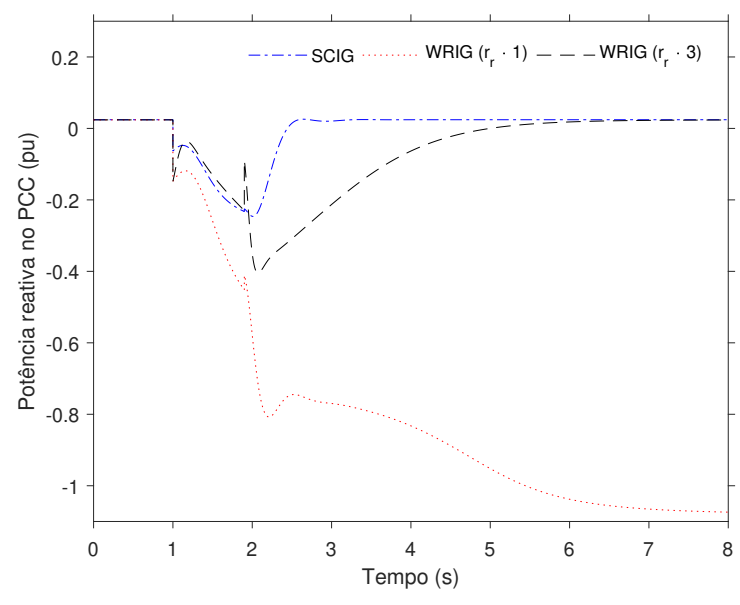

(b) Potência reativa no PCC.

Figura 5.5: Potência reativa total e no PCC. A tensão da barra infinita é alterada em $t_{0}=1 \mathrm{~s}$ de $u_{x 1}$ $=1$ pu para $u_{x 1}=0,75 \mathrm{pu}$, retornando a $u_{x 1}=1$ pu em $t_{a b}=1,9 \mathrm{~s}$. 
Em regime permanente, para a configuração SCIG tem-se $Q_{g}=0,0728$ pu e para as configurações WRIG tem-se $Q_{g}=0,0717$ pu. A potência reativa no PCC apresenta valores inferiores, devido à presença do transformador entre as barras 3 e 2. Para a configuração SCIG tem-se $Q_{g}=0,0243$ pu e para as configurações WRIG tem-se $Q_{g}=0,0239$ pu. Segundo a Figura 5.5, ambas as potências apresentam perfis semelhantes.

A Figura 5.6 mostra a tensão no PCC, que corresponde à barra 2 do sistema teste da Figura 3.1. Para a Figura 5.6(a) considera-se a curva LVRT do Brasil, enquanto que para a Figura 5.6(b) considera-se a curva LVRT dos EUA. Conforme pode ser observado, durante a perturbação somente a curva LVRT do Brasil é violada, o que permite a desconexão dos aerogeradores da rede neste caso. Na situação pós-falta, ambas as curvas são violadas para a configuração WRIG $\left(r_{r} \cdot 1\right)$, devido à instabilidade de velocidade e de tensão ocorrida para este aerogerador.

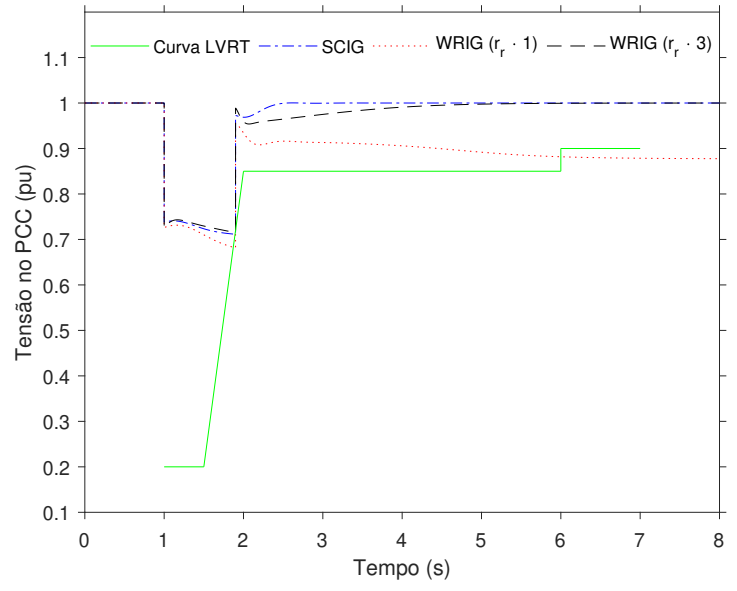

(a) Tensão no PCC e curva LVRT do Brasil.

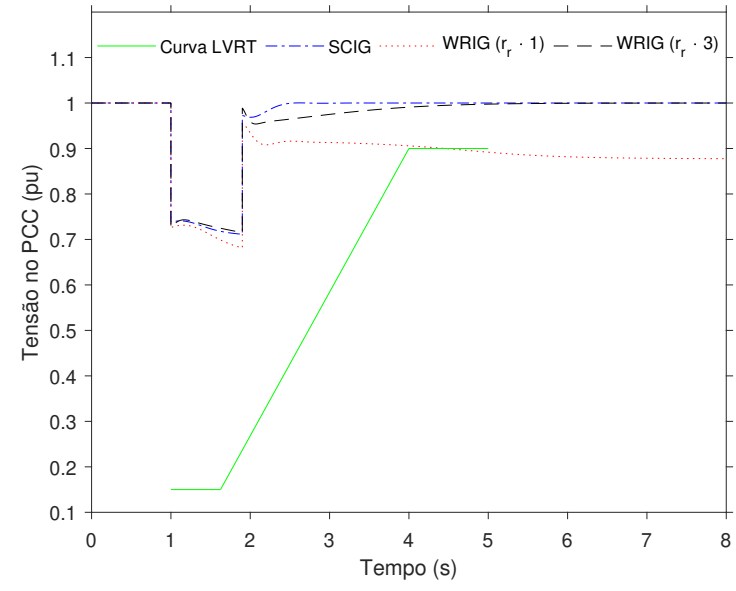

(b) Tensão no PCC e curva LVRT dos EUA.

Figura 5.6: Tensão no PCC. A tensão da barra infinita é alterada em $t_{0}=1 \mathrm{~s}$ de $u_{x 1}=1$ pu para $u_{x 1}=0,75 \mathrm{pu}$, retornando a $u_{x 1}=1 \mathrm{pu} \mathrm{em} t_{a b}=1,9 \mathrm{~s}$.

A estabilidade de velocidade do gerador de indução também pode ser estudada pela curva que relaciona os torques eletromagnético e mecânico com o escorregamento. A Figura 5.7 apresenta uma visão conceitual desta curva, onde estão representados os torques eletromagnético $T_{e}$ e mecânico $T_{m}$, além dos escorregamentos estável $s_{e}$ e instável $s_{i}$.

Os escorregamentos $s_{e}$ e $s_{i}$ se referem aos pontos em que os torques mecânico e eletromagnético são iguais. Na situação $s_{e}<s<0$, o torque mecânico é maior que o torque eletromagnético e o rotor do gerador acelera. Para $s_{i}<s<s_{e}$, o torque mecânico é menor que o torque eletromagnético e o rotor do gerador desacelera. Portanto, a relação entre os torques provoca o retorno da velocidade para o escorregamento estável. Se $s<s_{i}$, o torque mecânico será sempre superior ao torque eletromagnético, de modo que a instabilidade de velocidade se torna inevitável nesta situação. 


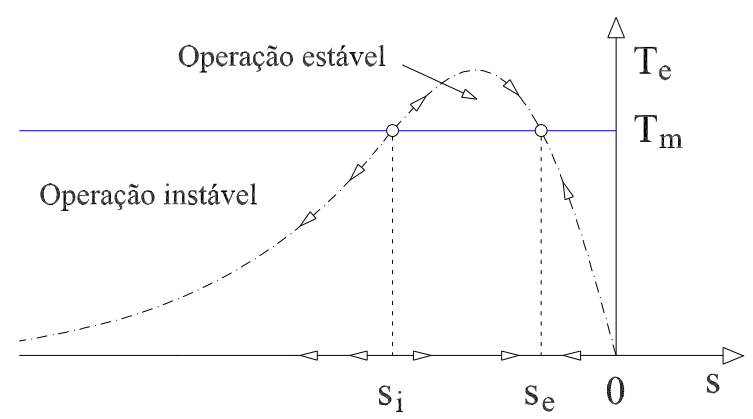

Figura 5.7: Curva torque $\times$ escorregamento.

Considerando o modelo em primeira ordem nos eixos $d$ e $q$ para os aerogeradores SCIG e WRIG, a Figura 5.8 mostra o escorregamento e os torques eletromagnético e mecânico em função do tempo e as Figuras 5.9 e 5.10 mostram os respectivos torques em função do escorregamento. Os pontos destacados se referem à condição inicial pós-falta.

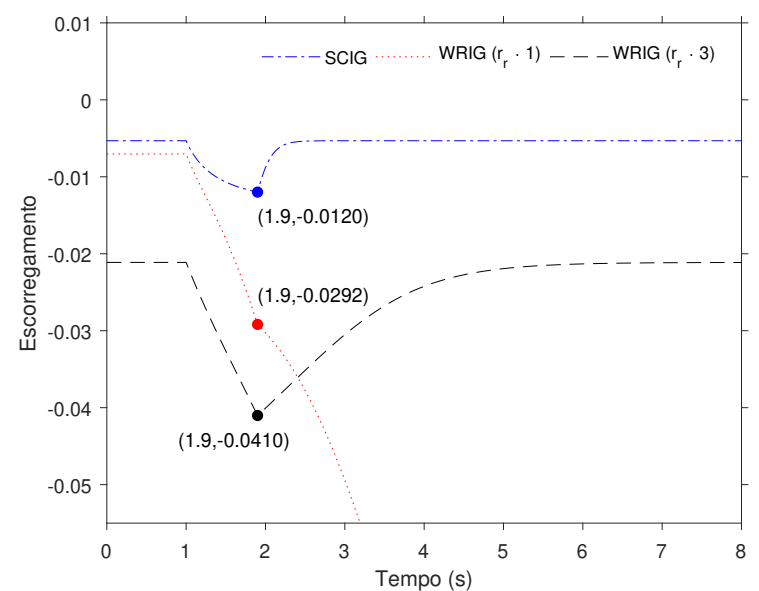

(a) Escorregamento.

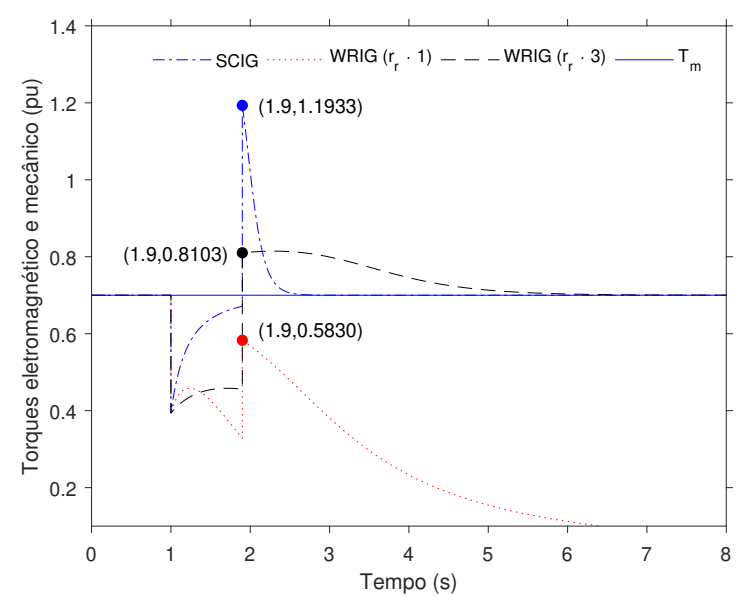

(b) Torques eletromagnético e mecânico.

Figura 5.8: Escorregamento e torques eletromagnético e mecânico. A tensão da barra infinita é alterada em $t_{0}=1 \mathrm{~s}$ de $u_{x 1}=1$ pu para $u_{x 1}=0,75 \mathrm{pu}$, retornando a $u_{x 1}=1 \mathrm{pu} \mathrm{em} t_{a b}=1,9 \mathrm{~s}$.

De acordo com a Figura 5.9, para a configuração SCIG a condição inicial pós-falta se encontra na região de operação estável. Desta forma, não ocorrerá a instabilidade de velocidade após a eliminação da perturbação, conforme mostra a Figura 5.8(a). Para a configuração WRIG, a Figura 5.10 mostra os torques eletromagnético e mecânico em função do escorregamento, considerando diferentes resistências para o rotor. Verifica-se que à medida que se aumenta a resistência do rotor, a região de operação estável do gerador de indução também aumenta e o torque eletromagnético máximo não se altera. Para $\left(r_{r} \cdot 1\right)$, a condição inicial pós-falta se encontra na região de operação instável. Portanto, ocorrerá instabilidade de velocidade, que pode ser confirmada ao se observar a Figura 5.8(a).

Ao se considerar $\left(r_{r} \cdot 3\right)$, a região de operação estável se torna maior, de modo que para a mesma perturbação sob análise, o gerador de indução é capaz de encontrar um ponto 


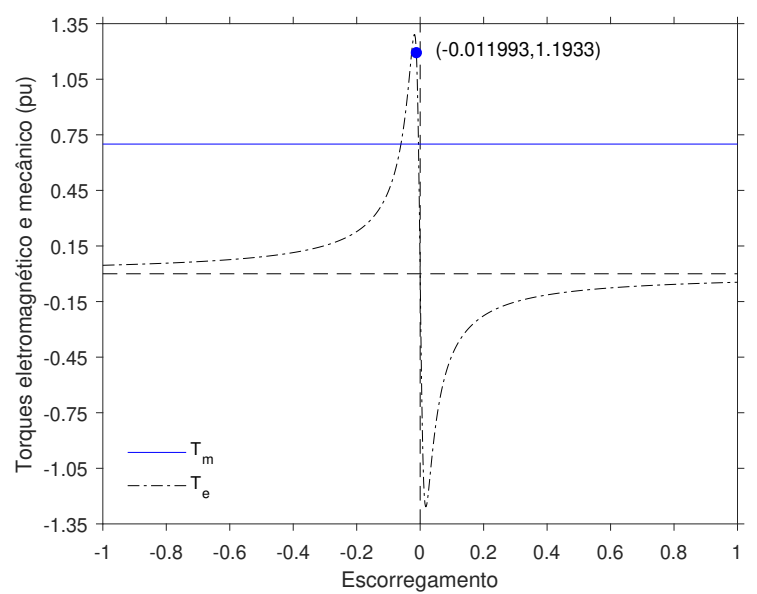

(a) Torques eletromagnético e mecânico em função do escorregamento.

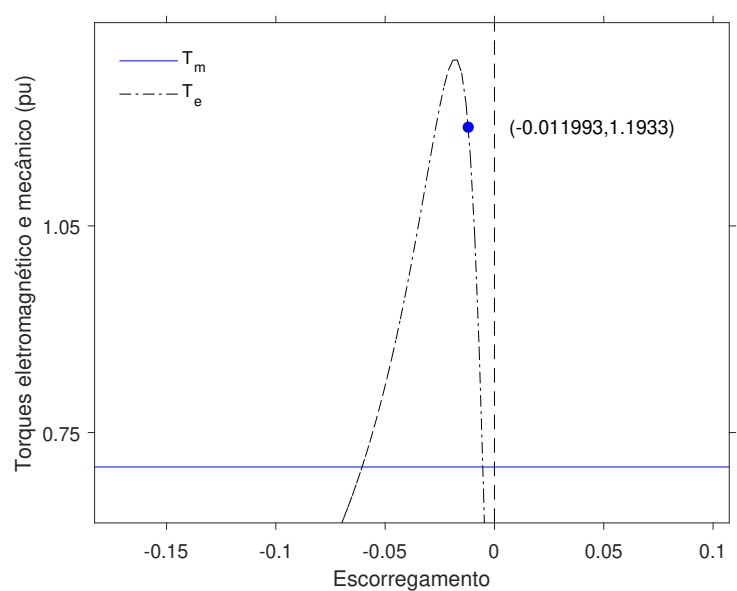

(b) Ampliação da região de interesse para melhor visualização da condição inicial pós-falta.

Figura 5.9: Torques eletromagnético e mecânico em função do escorregamento para a configuração SCIG.

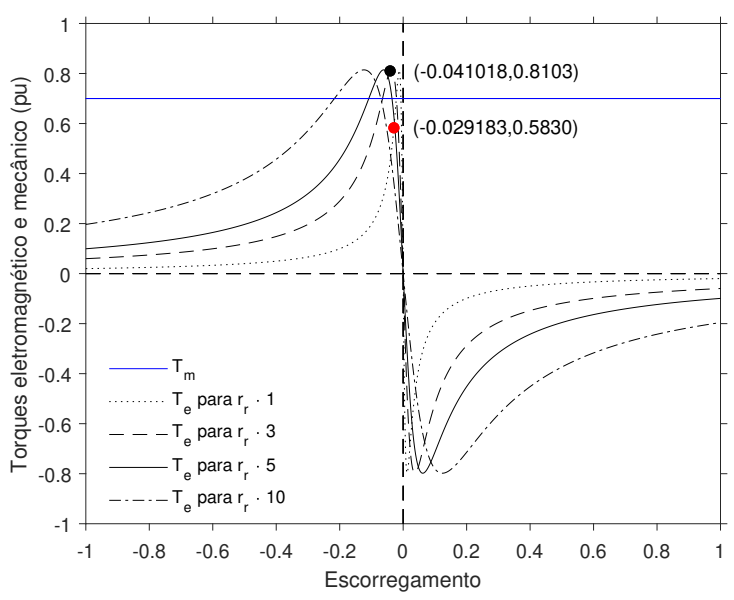

(a) Torques eletromagnético e mecânico em função do escorregamento.

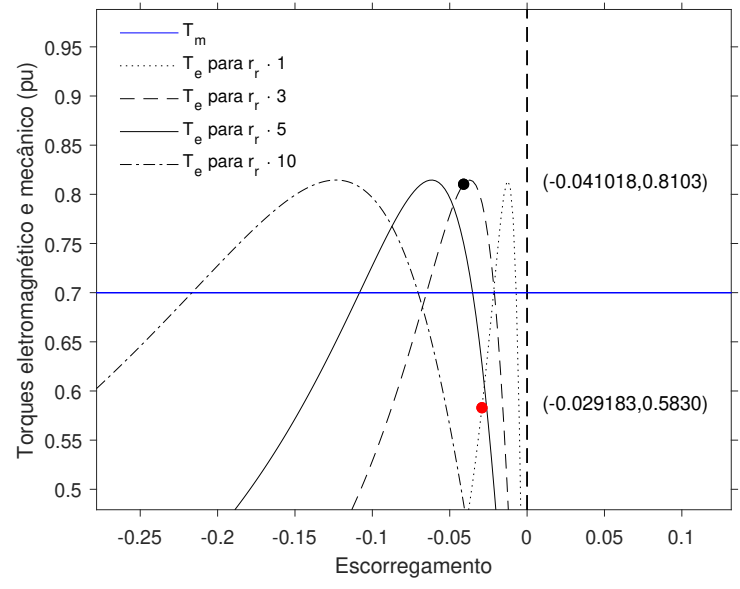

(b) Ampliação da região de interesse para melhor visualização das condições iniciais pós-falta.

Figura 5.10: Torques eletromagnético e mecânico em função do escorregamento para a configuração WRIG considerando diferentes resistências para o rotor.

de operação estável no sistema pós-falta. Em outras palavras, a condição inicial pós-falta passa a se localizar em uma região de operação estável. Assim, não ocorrerá instabilidade de velocidade, como mostra a Figura 5.8(a).

Ressalta-se que não houve instabilidade para as outras variáveis dos modelos. No apêndice $\mathrm{H}$ são apresentadas outras variáveis, como fluxos magnéticos, correntes e tensões.

\subsubsection{DFIG}

Algumas variáveis para a configuração DFIG são apresentadas nos próximos gráficos. Considera-se nas análises seguintes o modelo em terceira ordem para a máquina (ordem 
onze para o sistema completo) nos eixos $d$ e $q$, assim como a mesma perturbação da Figura 5.1. Salienta-se que o distúrbio sob análise não sensibiliza a proteção da corrente do rotor. Em outras palavras, não se considera qualquer proteção neste contexto. Destaca-se também que os sistemas de controle foram ajustados para que as potências ativa e reativa apresentem os valores $P_{g}=0,6933$ pu e $Q_{g}=0,0722$ pu em regime permanente. Ainda, as tensões $u_{d r}$ e $u_{q r}$ variam no período transitório e os controladores são fixos (não são alterados nos períodos em falta e pós-falta).

Isto posto, a primeira variável a ser apresentada corresponde à tensão do estator, que pode ser observada na Figura 5.11(a). Conforme pode ser constatado, esta tensão sofre uma redução significativa logo no instante de aplicação da perturbação, atingindo 0,63 pu ao final do período em falta. Após a eliminação da perturbação, esta variável retorna ao seu valor inicial de forma muito mais rápida, comparativamente às configurações SCIG e WRIG $\left(r_{r} \cdot 3\right)$.

A Figura 5.11(b) apresenta as potências ativas do estator $P_{s}$ do GSC $P_{c}$ e total $P_{g}$. Os valores positivos indicam quantidades produzidas, isto é, potências que estão sendo injetadas na rede elétrica. A potência total é obtida pela soma entre as potências do GSC e do estator. Em regime permanente, tem-se $P_{s}=0,5945 \mathrm{pu}, P_{c}=0,09884$ pu e $P_{g}=0,6933$ pu. Ressaltase que para o valor apresentado para a potência $P_{c}$ já está descontada a parcela referente ao filtro do GSC. Salienta-se também que esta potência está saindo do GSC em direção à rede pois o aerogerador opera no modo supersíncrono, isto é, para o ponto de operação sob análise, o escorregamento é negativo, o que revela a Figura 5.12(b). Deste modo, a velocidade do rotor do gerador é superior à velocidade síncrona.

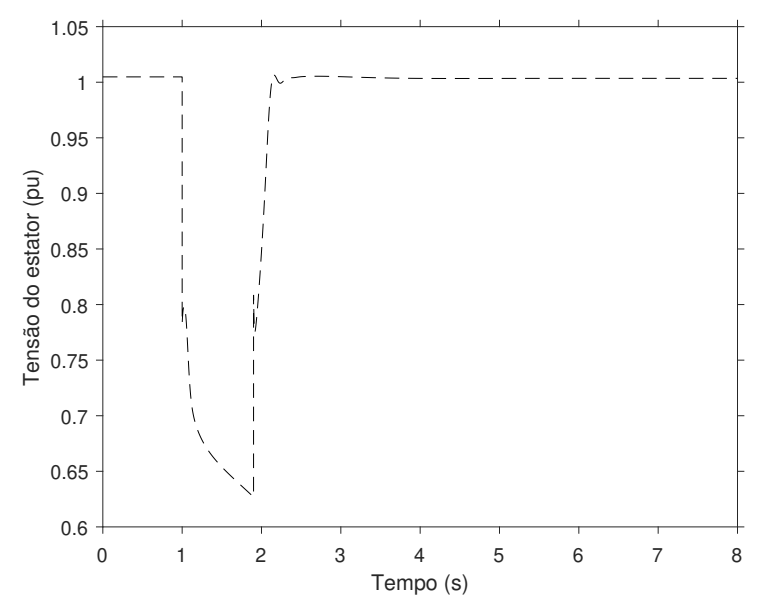

(a) Tensão do estator.

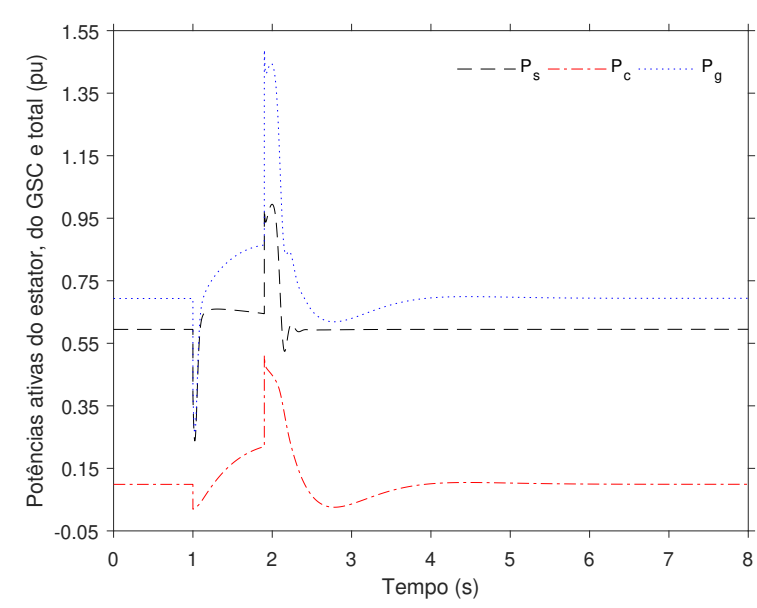

(b) Potências ativas do estator, do GSC e total.

Figura 5.11: Tensão do estator e potências ativas do estator, do GSC e total. A tensão da barra infinita é alterada em $t_{0}=1 \mathrm{~s}$ de $u_{x 1}=1$ pu para $u_{x 1}=0,75 \mathrm{pu}$, retornando a $u_{x 1}=1 \mathrm{pu}$ em $t_{a b}$ $=1,9 \mathrm{~s}$.

No instante de ocorrência da perturbação, as potências sofrem um decréscimo significativo, porém imediatamente após ocorre uma recuperação de modo que a potência total ultrapassa o seu valor inicial e cresce à medida que a perturbação persiste. No instante de eliminação 
do distúrbio, ocorre uma elevação abrupta em decorrência dos comportamentos das variáveis algébricas, que instantaneamente mudam de valor e também em decorrência da energia cinética acumulada, que é naturalmente liberada.

A Figura 5.12(a) mostra os torques eletromagnético e mecânico. No instante de aplicação da perturbação o torque eletromagnético diminui, diferentemente do torque mecânico, que aumenta. A partir deste desequilíbrio entre os torques, o rotor do gerador passa a acelerar, conforme exibe a Figura 5.12(b).

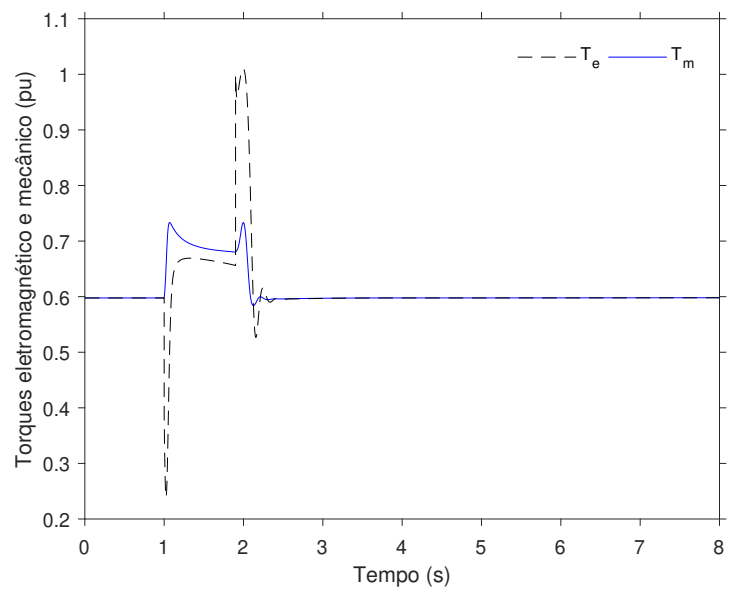

(a) Torques eletromagnético e mecânico.

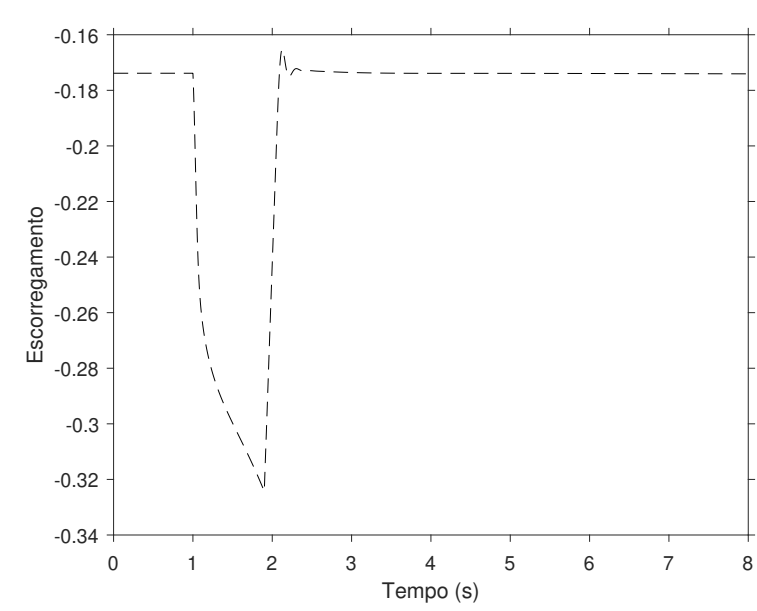

(b) Escorregamento.

Figura 5.12: Torques eletromagnético e mecânico e escorregamento. A tensão da barra infinita é alterada em $t_{0}=1 \mathrm{~s}$ de $u_{x 1}=1$ pu para $u_{x 1}=0,75 \mathrm{pu}$, retornando a $u_{x 1}=1 \mathrm{pu}$ em $t_{a b}=1,9 \mathrm{~s}$.

A partir de $t_{0}=1 \mathrm{~s}$ até o instante $t=1,066 \mathrm{~s}$, o torque mecânico passa de $T_{m}=0,5977$ pu com um escorregamento $s=-0,1739$ para $T_{m}=0,7333$ pu com um escorregamento $s=$ $-0,2422$. Esta mudança significativa entre os valores ocorre de forma muito rápida devido à relação entre a potência mecânica e a velocidade do rotor do gerador, regida pela curva $P_{m}$ aproximada apresentada na Figura 3.10. A partir do instante $t=1,066 \mathrm{~s}$, ao passo que 0 escorregamento se torna cada vez mais negativo, o torque mecânico passa a diminuir, uma vez que a potência mecânica se mantém em torno do mesmo nível, dado o perfil da curva $P_{m}$ aproximada (ver Figura 3.10). Ao eliminar a perturbação, o torque eletromagnético passa a ser maior que torque mecânico e o rotor do gerador passa a desacelerar, ocorrendo o equilíbrio entre os torques na situação pós-falta. É nítido para os resultados obtidos que para a configuração DFIG não ocorre instabilidade de tensão, tampouco instabilidade de velocidade.

A Figura 5.13(a) apresenta as potências reativas do estator $Q_{s}$, do GSC $Q_{c}$ e total $Q_{g}$. Analogamente às potências ativas, os valores positivos indicam quantidades produzidas, isto é, potências que estão sendo injetadas na rede elétrica. A potência total é obtida pela soma entre as potências do GSC e do estator. Em regime permanente, tem-se $Q_{s}=-0,0283 \mathrm{pu}, Q_{c}=$ 0,1005 pu e $Q_{g}=0,0722$ pu. Assim, o estator do gerador de indução está absorvendo potência 
reativa da rede enquanto que o conversor do lado da rede está fornecendo potência reativa à rede. Desta forma, tem-se uma potência reativa resultante sendo inserida na rede elétrica. Para o valor apresentado para a potência $Q_{c}$ já está descontada a parcela referente ao filtro do GSC. Ao se aplicar a perturbação, percebe-se que a potência reativa entregue à rede aumenta. Porém o aerogerador não consegue manter o nível atingido, ou um valor próximo da condição pré-falta. Ao fim desta perturbação o estator consome potência reativa da rede, em virtude do elevado escorregamento atingido. Eliminando a perturbação, as potências retornam aos valores originais antes de $t=3 \mathrm{~s}$. A potência reativa no PCC, naturalmente, seguirá o mesmo perfil da potência elétrica entregue à rede. Seu comportamento é exibido na Figura 5.13(b).

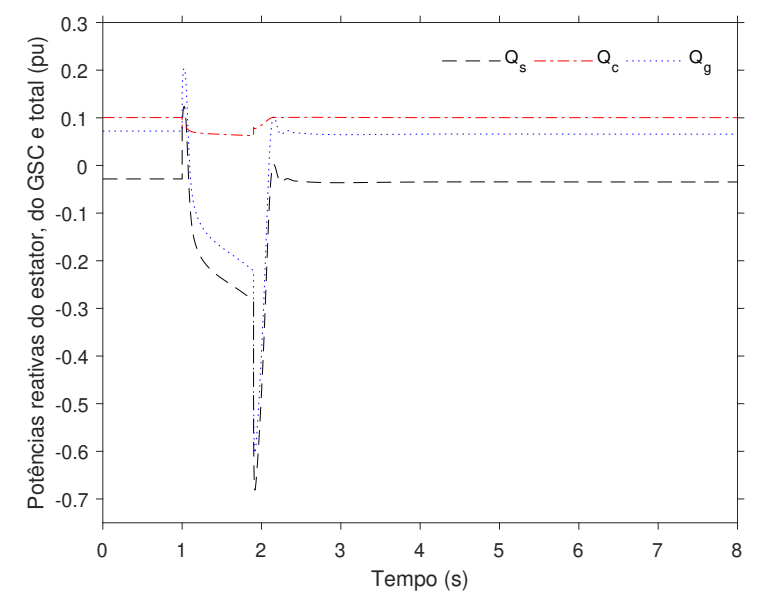

(a) Potências reativas do estator, do GSC e total.

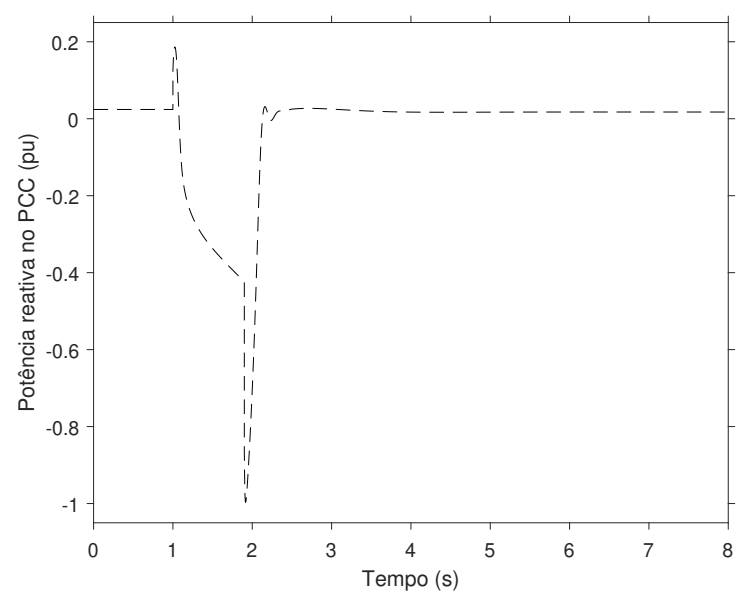

(b) Potência reativa no PCC.

Figura 5.13: Potências reativas do estator, do GSC, total e no PCC. A tensão da barra infinita é alterada em $t_{0}=1 \mathrm{~s}$ de $u_{x 1}=1$ pu para $u_{x 1}=0,75 \mathrm{pu}$, retornando a $u_{x 1}=1 \mathrm{pu} \mathrm{em} t_{a b}=1,9 \mathrm{~s}$.

Em equilíbrio, as potências ativas referentes à saída do RSC e à saída do GSC devem ser iguais. Essa característica pode ser vista na Figura 5.14(a). As tensões em cada conversor são diferentes, assim como as correntes, que podem ser visualizadas na Figura 5.14(b).

Verifica-se que durante o período transitório, as correntes podem assumir valores elevados. A corrente referente ao conversor RSC atinge os valores $i_{r}=1,1640 \mathrm{pu}$ ao fim da perturbação e $i_{r}=1,4705$ pu após eliminar o distúrbio. Já a corrente referente ao conversor GSC atinge os valores $i_{c}=0,3645 \mathrm{pu}$ e $i_{c}=0,6397 \mathrm{pu}$, respectivamente. Uma vez que os conversores são muito sensíveis a sobrecorrentes, sistemas de proteção são normalmente aplicados para proteger tanto os conversores como o próprio gerador. A atuação destes sistemas pode ocorrer inclusive antes da violação da curva LVRT. Porém neste trabalho, modelos de proteção não são considerados. Desta forma, analisa-se somente se a tensão no PCC viola ou não a curva LVRT, de acordo com a Figura 5.15.

Assim como para as configurações SCIG e WRIG, a tensão no PCC viola somente a curva LVRT do Brasil. Esta curva apresenta limites de tensão que não permitem a tensão no PCC 


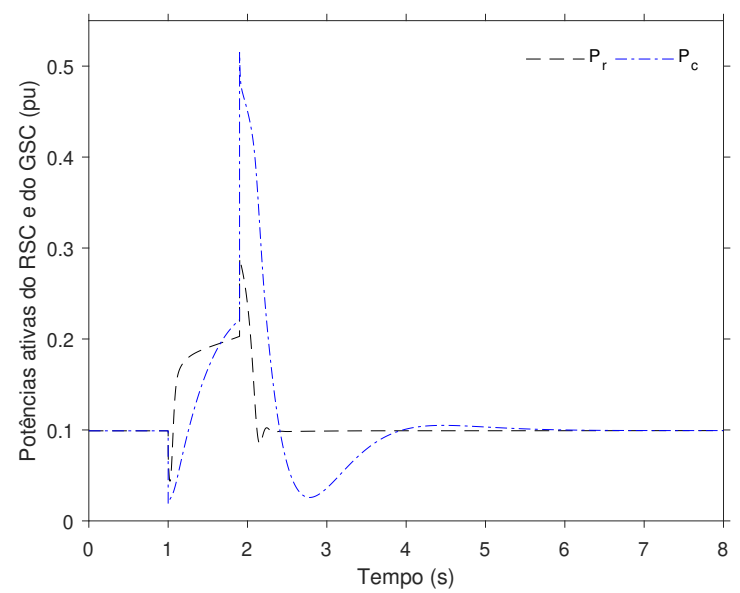

(a) Potências ativas do RSC e do GSC.

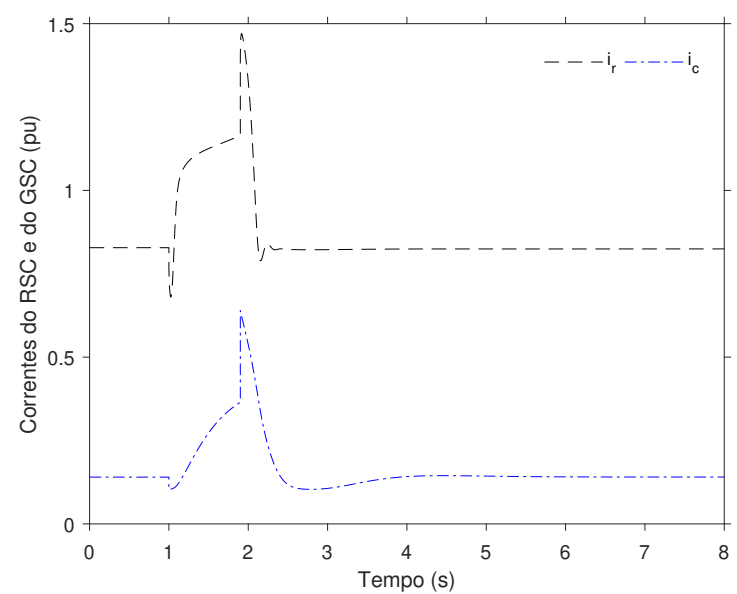

(b) Correntes do RSC e do GSC.

Figura 5.14: Potências ativas e correntes do RSC e do GSC. A tensão da barra infinita é alterada em $t_{0}=1 \mathrm{~s}$ de $u_{x 1}=1$ pu para $u_{x 1}=0,75$ pu, retornando a $u_{x 1}=1$ pu em $t_{a b}=1,9 \mathrm{~s}$.

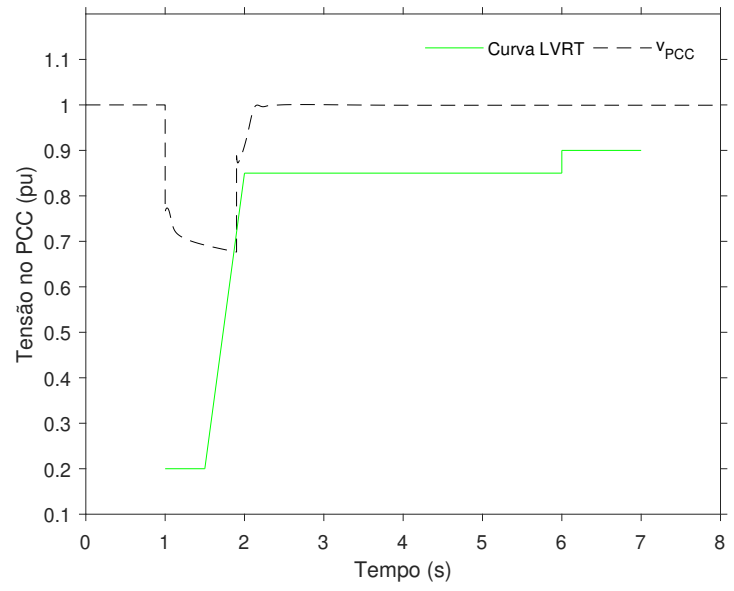

(a) Tensão no PCC e curva LVRT do Brasil.

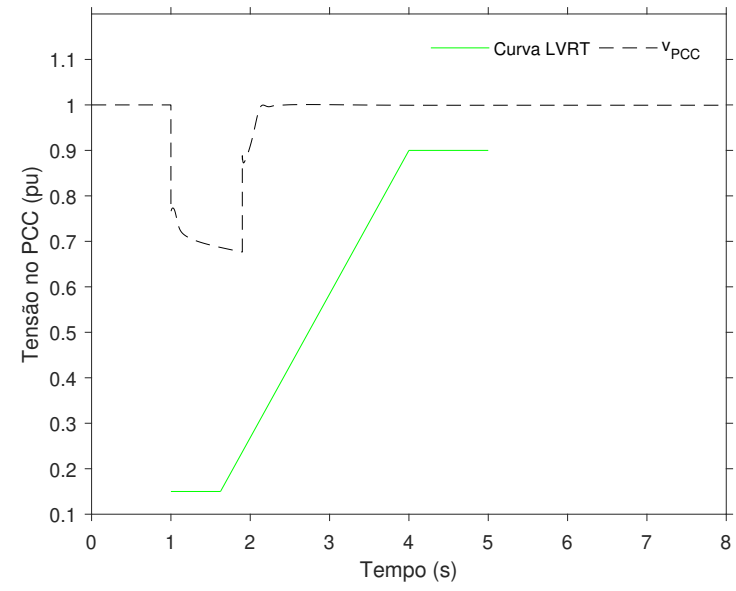

(b) Tensão no PCC e curva LVRT dos EUA.

Figura 5.15: Tensão no PCC. A tensão da barra infinita é alterada em $t_{0}=1 \mathrm{~s}$ de $u_{x 1}=1$ pu para $u_{x 1}=0,75$ pu, retornando a $u_{x 1}=1$ pu em $t_{a b}=1,9 \mathrm{~s}$.

experimentar valores baixos em períodos mais longos, diferentemente da curva LVRT dos EUA. Como já explicado, ao se violar a curva LVRT o proprietário do aerogerador ou do parque eólico tem a permissão para desconectar o sistema de geração da rede elétrica.

De acordo com o que normalmente se encontra na literatura, comparativamente às configurações SCIG e WRIG, a configuração DFIG deveria apresentar resultados consideravelmente melhores frente aos afundamentos de tensão. Como pôde ser constatado, ainda que a perturbação seja consideravelmente severa, o aerogerador não foi capaz de injetar potência reativa em níveis adequados durante o período transitório. Este problema, assim como os valores elevados obtidos ao se eliminar a perturbação, especialmente para as potências e correntes, podem ser mitigados pelo ajuste dos controladores ou a partir da inclusão de outro sistema 
de controle, como o controle de velocidade. Tais medidas podem ser capazes de melhorar as respostas da configuração DFIG frente à perturbação aplicada. No apêndice H são apresentadas outras variáveis, como fluxos magnéticos, correntes, tensões e os sinais dos controladores. Assim como foi ponderado para as configurações SCIG e WRIG, para o aerogerador DFIG não houve instabilidade para as outras variáveis do modelo.

Verificou-se via simulações computacionais que os comportamentos dinâmicos apresentados são aceitáveis, de modo que os modelos obtidos no capítulo 3 podem ser utilizados para realizar os demais estudos de estabilidade propostos neste trabalho. Os modelos com a máquina de indução em primeira e quinta ordens, assim como os modelos em regime permanente, foram testados para a mesma perturbação, sendo obtidos resultados muito próximos.

\subsection{Regiões de estabilidade e trajetórias}

Os próximos resultados se referem ao sistema teste com a configuração SCIG para a máquina modelada em primeira ordem nos eixos $d$ e $q$. Considerando para o ponto de operação $T_{m}=0,7$ pu, obtém-se no equilíbrio pré e pós-falta o valor -0,005316 para a variável de estado s. A RE deste ponto de equilíbrio está compreendida no intervalo $(-0,06055,+\infty)$, em que $-0,06055$ se refere ao valor do escorregamento no ponto de equilíbrio instável localizado na fronteira da RE do sistema original. Este valor se refere portanto ao escorregamento crítico $S_{c r}$ do sistema original. Para qualquer condição inicial pós-falta do escorregamento de valor inferior a -0,06055, ocorrerá a instabilidade de velocidade. Para qualquer condição inicial pós-falta de valor superior a -0,06055, ocorrerá a convergência para o escorregamento do ponto de equilíbrio estável -0,005316.

Visto que para aproximar a curva LVRT real do Brasil por (4.17) e para aproximar a curva LVRT dos EUA por (4.18), são utilizadas as condições iniciais 0,1951 e 0,15, respectivamente, para a variável auxiliar $r$, o ponto de equilíbrio estável do sistema pré-falta $x_{0}$ apresenta os valores -0,005316 para s e 0,1951 ou 0,15 para $r$. Uma vez que a variável de estado auxiliar de (4.17) e (4.18) sempre convergirá para o valor 0,9 ao final do período de tempo sob análise (7 s para a curva LVRT do Brasil e 5 s para a curva LVRT dos EUA) e considerando que a perturbação seja eliminada antes da variável de estado $s$ abandonar a RE do sistema original $(-0.06055,+\infty)$, tem-se para o ponto de equilíbrio estável do sistema pós-falta $x_{s}$ os valores $-0,005316$ para s e 0,9 para $r$.

Isto posto, a RER, a RE do sistema auxiliar e várias trajetórias em falta e pós-falta são apresentadas a seguir, separadamente para cada curva LVRT.

\subsubsection{Considerando a curva LVRT do Brasil}

A Figura 5.16 mostra a RER e a RE do sistema auxiliar, além da linha sólida vertical que indica a fronteira da RE do sistema original $(s=-0.06055)$ e da curva $v_{P C C} \times s$, que corresponde à tensão no PCC para os valores de escorregamento indicados, considerando o modelo do sistema com parâmetros pós-falta (vale lembrar que os sistemas pré-falta e 
pós-falta são considerados iguais). Conforme pode ser observado, a RE do sistema auxiliar pode ser considerada equivalente à RER do sistema dinâmico restrito. As regiões não são exatamente iguais devido às diferenças entre as curvas LVRT real e aproximada.

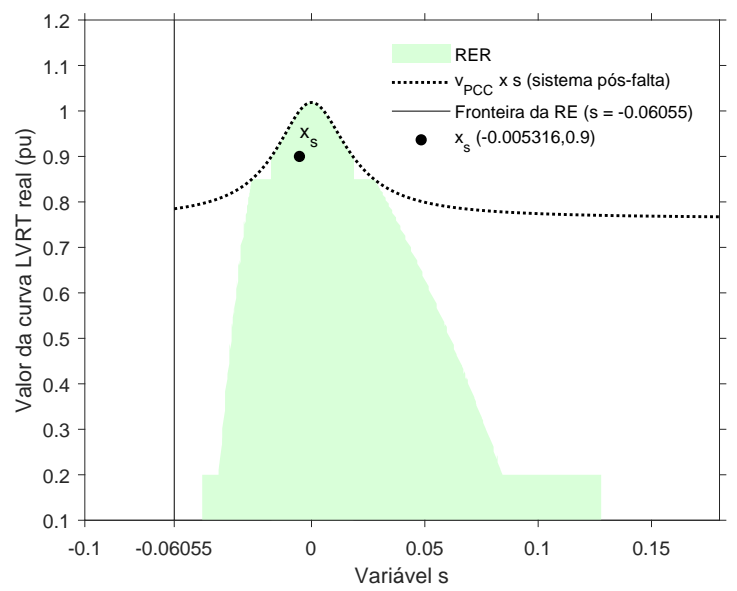

(a) Região de estabilidade restrita.

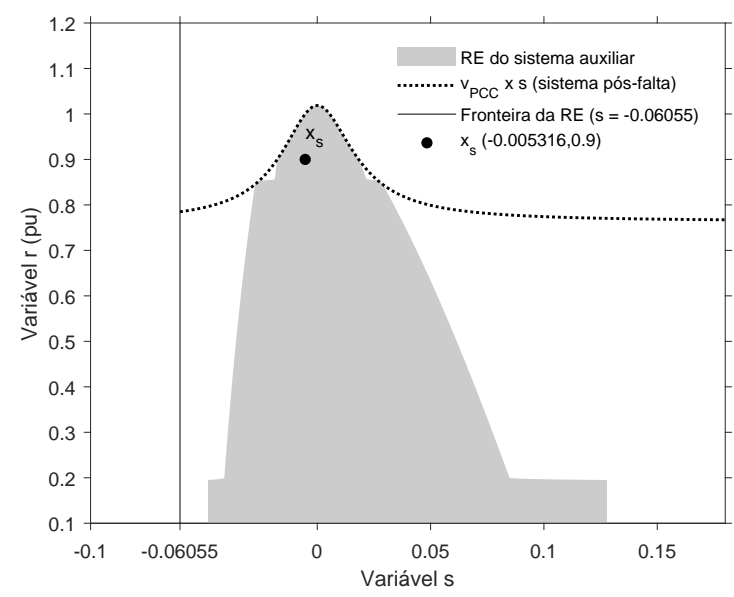

(b) Região de estabilidade do sistema auxiliar.

Figura 5.16: Regiões de estabilidade para a configuração SCIG considerando a curva LVRT do Brasil.

As condições iniciais pós-falta localizadas à esquerda da linha vertical não pertencem à RE do sistema original (e portanto não pertencem à RE do sistema auxiliar), de modo que neste caso está configurada a instabilidade de velocidade. Condições iniciais pós-falta que pertencem à RE do sistema original, mas não pertencem à $R E$ do sistema auxiliar, localizadas abaixo da curva $v_{P C C} \times s$, garantem a estabilidade de velocidade, porém referemse às trajetórias que violam a restrição do problema no período pós-falta, isto é, a curva LVRT é violada após a eliminação da perturbação. Condições iniciais pós-falta que pertencem à $\mathrm{RE}$ do sistema original mas não pertencem à RE do sistema auxiliar, localizadas acima da curva $v_{P C C} \times s$, garantem a estabilidade de velocidade, porém referem-se às trajetórias que violam a restrição do problema no período em falta, isto é, a curva LVRT é violada durante a perturbação. Condições iniciais pós-falta que pertencem à RE do sistema auxiliar (e portanto pertencem à RE do sistema original), além de garantir a estabilidade de velocidade, indicam trajetórias que não violam a restrição do problema para todo o tempo, isto é, a curva LVRT não é violada nos períodos em falta e pós-falta.

As Figuras 5.17 à 5.24 mostram trajetórias em falta e pós-falta no domínio do tempo e no espaço de estados, referentes aos pontos apresentados na Figura 4.4, além dos pontos cuja tensão no PCC é igual à tensão da curva LVRT aproximada. No domínio do tempo, para os pontos $a$ até $j$ são indicados o instante de tempo e o valor da variável de estado $(t, s),(t, r)$. No espaço de estados são indicados os valores das variáveis de estado para os respectivos pontos $(s, r)$. A seta indica o sentido da trajetória, que parte do ponto de equilíbrio estável do sistema pré-falta $x_{0}(-0.005316,0.1951)$. Os pontos $f$, $i$ são aqueles que tangenciam a restrição do problema. Os demais pontos correspondem à condição inicial pós-falta. Em outras palavras, 
partindo de $x_{0}$ até o primeiro ponto destacado tem-se a trajetória em falta e a partir deste ponto tem-se a trajetória pós-falta. A perturbação referente a cada ponto, descrita no título de cada figura, consiste em elevar o torque mecânico de saída da turbina.

Sendo assim, a Figura 5.17 mostra as trajetórias em falta e pós-falta referentes ao ponto a. Como pode ser visto na Figura 5.17(a), não ocorre instabilidade de velocidade, tampouco violação da curva LVRT. Assim, o ponto a pertence à RE do sistema auxiliar, como mostra a Figura 5.17(b). Uma vez que a trajetória em falta não sai da RE do sistema auxiliar, é natural que tanto esta trajetória como a trajetória pós-falta não violem a restrição do problema. Portanto, em nenhum momento a restrição (4.19) será nula ou negativa, pois a variável $V_{P C C}$ sempre apresentará um valor maior que a variável de estado $r$.

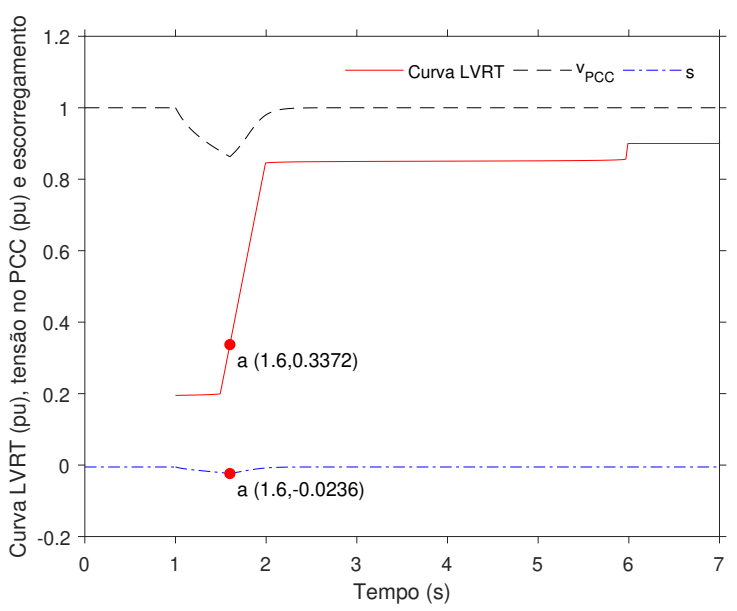

(a) Trajetórias no domínio do tempo.

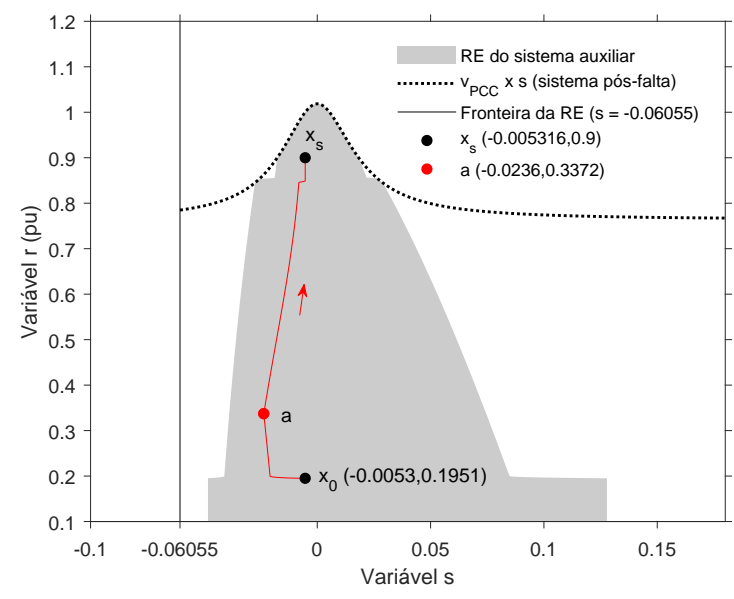

(b) Trajetórias no espaço de estados.

Figura 5.17: Trajetórias referentes ao ponto a. O torque mecânico é alterado em $t_{0}=1 \mathrm{~s}$ de $T_{m}=$ 0,7 pu para $T_{m}=1,6$ pu, retornando a $T_{m}=0,7$ pu em $t_{a b}=1,6 \mathrm{~s}$.

Considerando um tempo de abertura superior, é possível verificar na Figura 5.18(a) que o gerador de indução ainda permanece estável, porém ocorre a violação da curva LVRT durante a perturbação. Desta forma, o ponto $b$ está localizado fora da RE do sistema auxiliar e acima da curva $v_{P C C} \times s$, como mostra a Figura 5.18(b). Nota-se pela localização do ponto $b$ que a restrição do problema foi violada durante a perturbação, especificamente no ponto destacado sobre a curva $v_{P C C} \times s$ (ponto verde). Como o sistema não perdeu a estabilidade de velocidade para o distúrbio sob análise, naturalmente a trajetória pós-falta cruzará esta curva em outro ponto (ponto amarelo) antes de convergir para $x_{s}$.

Prolongando-se ainda mais o tempo de abertura, verifica-se na Figura 5.19(a) que além de ocorrer a violação da curva LVRT durante a perturbação, o gerador de indução perde a estabilidade de velocidade. Desta forma, a condição inicial pós-falta está localizada à esquerda da linha vertical referente à fronteira da RE do sistema original, conforme mostra a Figura 5.19(b). Nesta situação, a trajetória pós-falta naturalmente não converge para $x_{s}$, pois se o ponto c não pertence à RE do sistema original, também não pertence à RE do sistema auxiliar. 


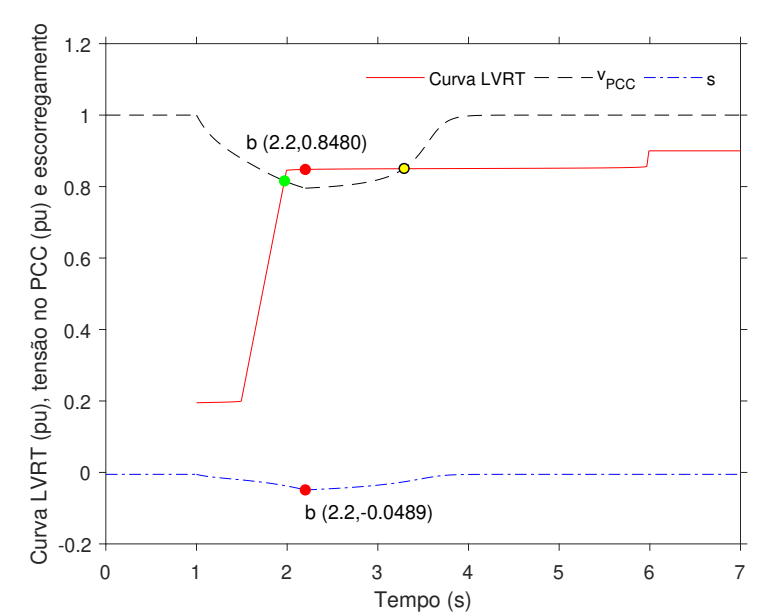

(a) Trajetórias no domínio do tempo.

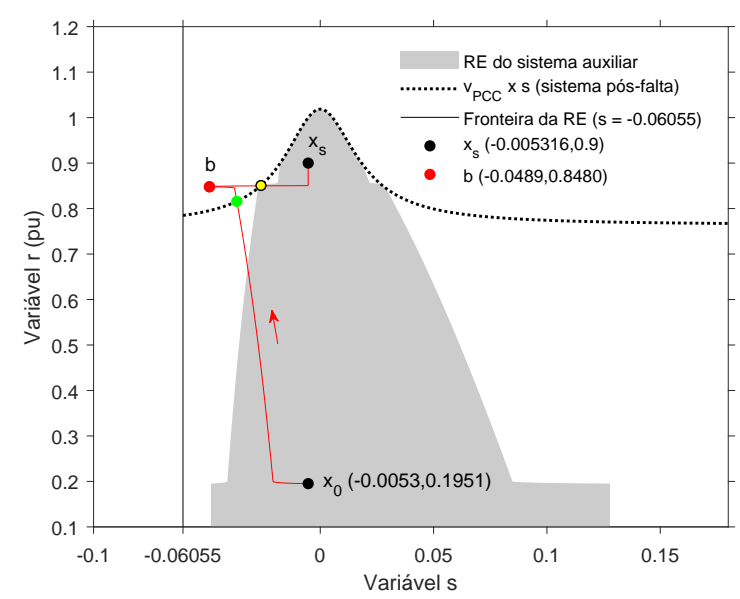

(b) Trajetórias no espaço de estados.

Figura 5.18: Trajetórias referentes ao ponto b. $O$ torque mecânico é alterado em $t_{0}=1 \mathrm{~s}$ de $T_{m}=$ 0,7 pu para $T_{m}=1,6 \mathrm{pu}$, retornando a $T_{m}=0,7$ pu em $t_{a b}=2,2 \mathrm{~s}$.

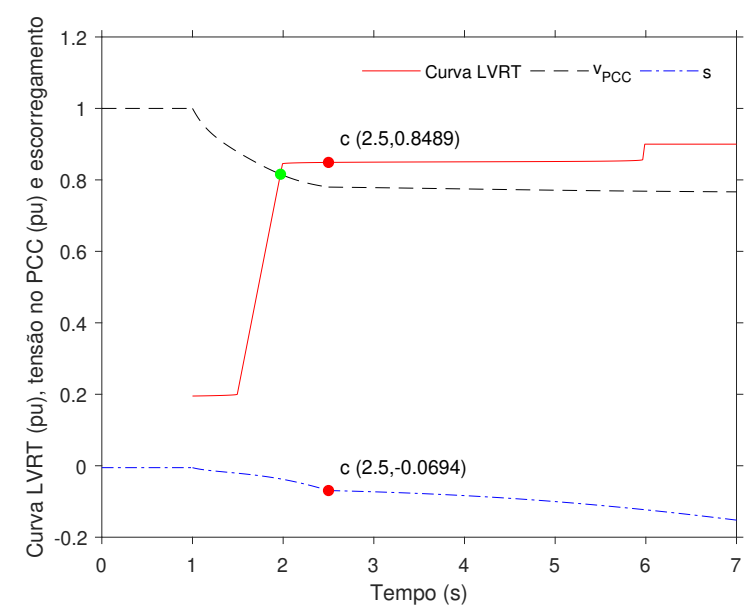

(a) Trajetórias no domínio do tempo.

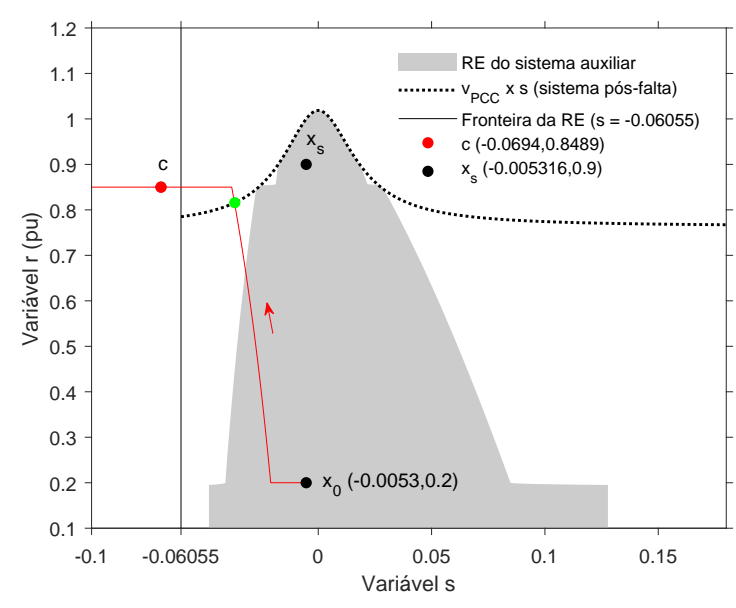

(b) Trajetórias no espaço de estados.

Figura 5.19: Trajetórias referentes ao ponto c. O torque mecânico é alterado em $t_{0}=1 \mathrm{~s}$ de $T_{m}=$ 0,7 pu para $T_{m}=1,6$ pu, retornando a $T_{m}=0,7$ pu em $t_{a b}=2,5 \mathrm{~s}$.

Ao se aplicar uma perturbação mais severa ao sistema teste sob análise, o aerogerador perde a estabilidade de velocidade antes de violar a curva LVRT, conforme mostra a Figura 5.20(a). Em outras palavras, a trajetória em falta abandona a RE do sistema original antes de violar a restrição do problema. Tal afirmação pode ser verificada na Figura 5.20(b). Uma vez que a condição inicial pós-falta, representada pelo ponto $d$, não pertence à RE do sistema original, a mesma também não pertence à RE do sistema auxiliar, de modo que não ocorre a convergência para $x_{s}$ no período pós-falta.

Para outra perturbação aplicada ao sistema teste, a Figura 5.21 exibe trajetórias em falta e pós-falta para os pontos e, f. Conforme mostra a Figura 5.21(a), a trajetória pós-falta tangencia a curva LVRT no ponto $f$. O ponto $f$ é um ponto particular, denominado de ponto 


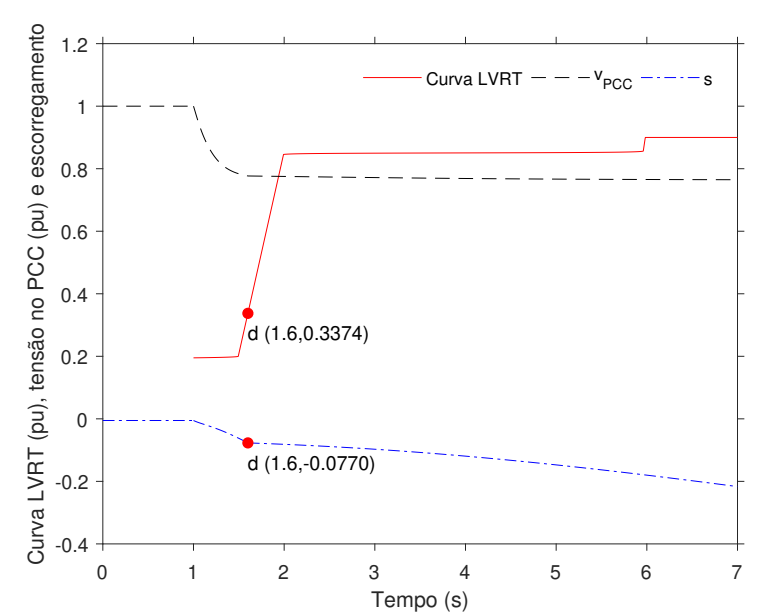

(a) Trajetórias no domínio do tempo.

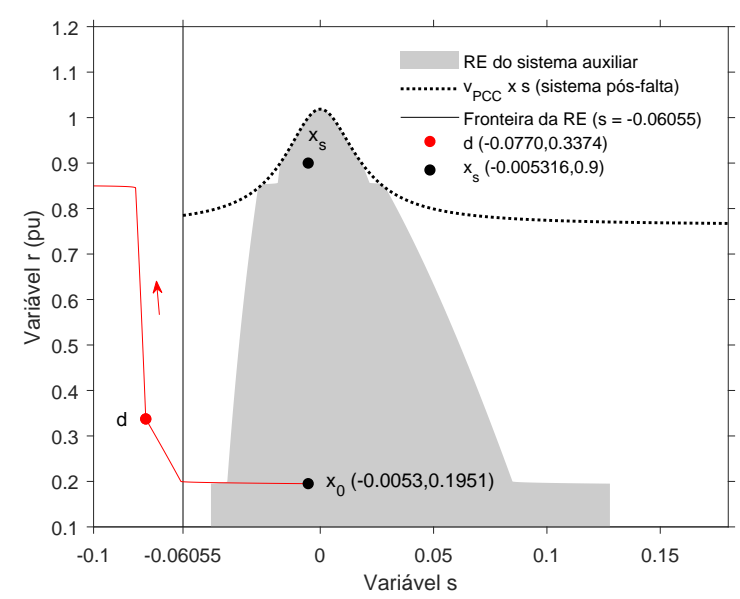

(b) Trajetórias no espaço de estados.

Figura 5.20: Trajetórias referentes ao ponto d. O torque mecânico é alterado em $t_{0}=1 \mathrm{~s}$ de $T_{m}=$ 0,7 pu para $T_{m}=2,5 \mathrm{pu}$, retornando a $T_{m}=0,7$ pu em $t_{a b}=1,6 \mathrm{~s}$.

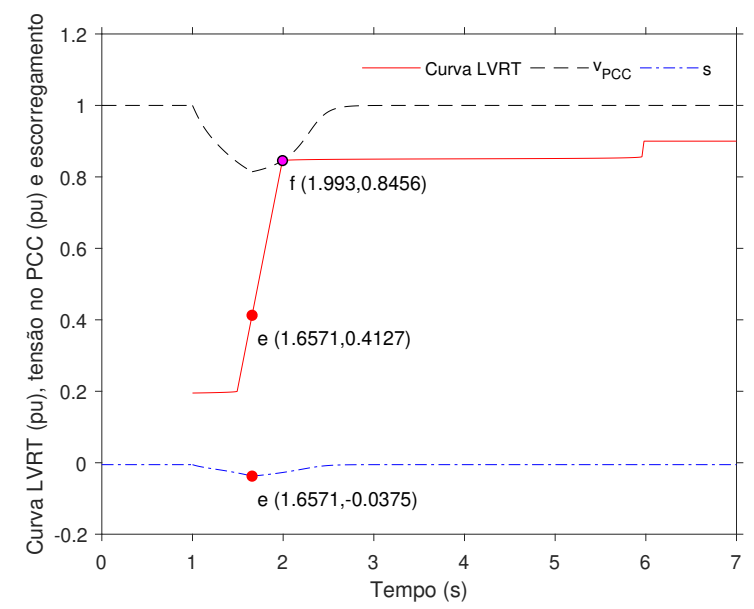

(a) Trajetórias no domínio do tempo.

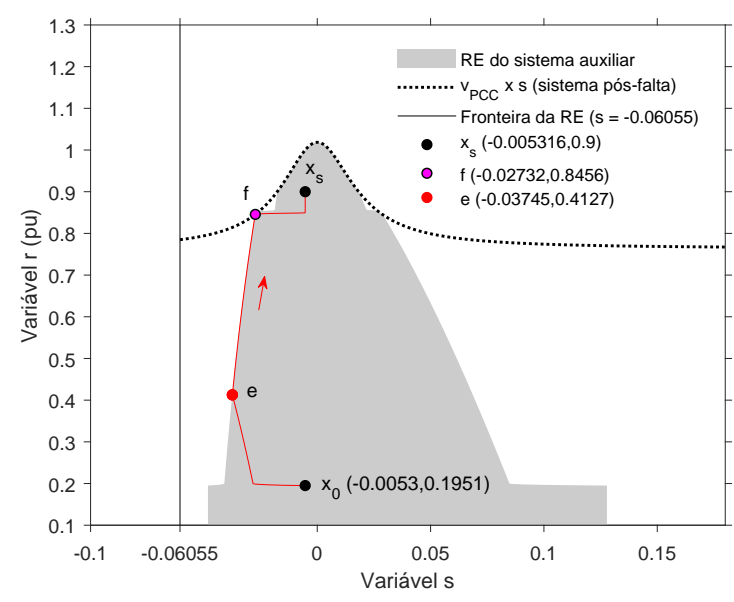

(b) Trajetórias no espaço de estados.

Figura 5.21: Trajetórias referentes aos pontos e, $f$. O torque mecânico é alterado em $t_{0}=1 \mathrm{~s}$ de $T_{m}$ $=0,7$ pu para $T_{m}=1,8$ pu, retornando a $T_{m}=0,7 \mathrm{pu} \mathrm{em} t_{a b}=1,6571 \mathrm{~s}$.

de tangência ou de grazing point. Este ponto é um pseudo-equilíbrio cuja variedade estável é parte da fronteira da RE do sistema auxiliar. O ponto e é um ponto sobre esta variedade e a trajetória pós-falta acompanha a mesma em direção ao ponto de tangência $f$. Assim, a trajetória pós-falta tangencia a restrição do problema no ponto $f$ antes de convergir para $x_{S}$, conforme mostra a Figura 5.21(b).

Para um tempo de abertura superior, a trajetória em falta não viola a curva LVRT, mas a violação da mesma ocorre no período pós-falta, conforme exibe a Figura 5.22(a). Desta forma, a condição inicial pós-falta está localizada fora da RE do sistema auxiliar e abaixo da curva $v_{P C C} \times$ s, como mostra a Figura 5.22(b). Nesta situação, como não ocorre a instabilidade de velocidade, a trajetória pós-falta retorna para $x_{s}$, porém como a condição inicial pós-falta não 


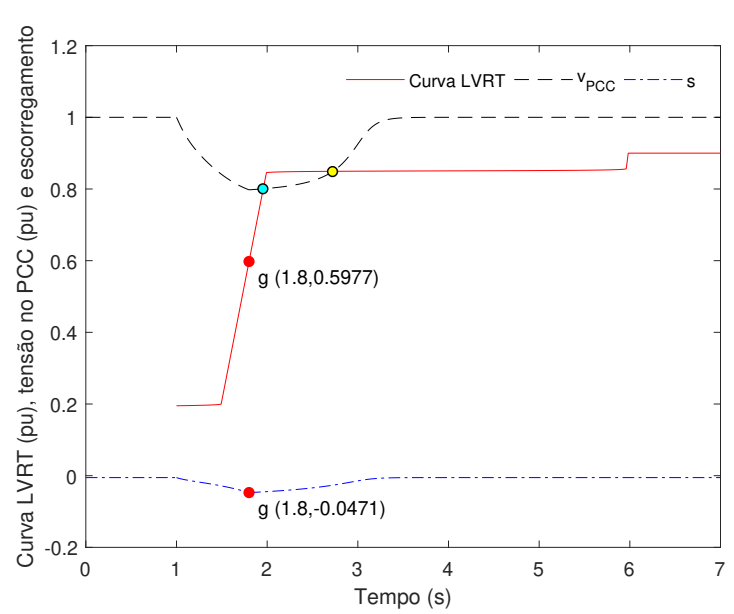

(a) Trajetórias no domínio do tempo.

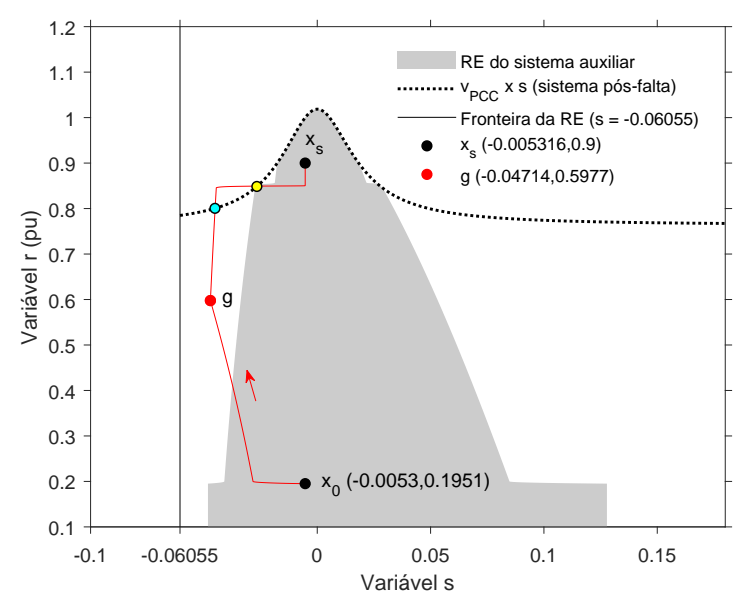

(b) Trajetórias no espaço de estados.

Figura 5.22: Trajetórias referentes ao ponto $g$. O torque mecânico é alterado em $t_{0}=1 \mathrm{~s}$ de $T_{m}=$ 0,7 pu para $T_{m}=1,8 \mathrm{pu}$, retornando a $T_{m}=0,7$ pu em $t_{a b}=1,8 \mathrm{~s}$.

pertence à RE do sistema auxiliar, a restrição do problema é violada no período pós-falta (ponto azul).

Uma vez que o presente aerogerador opera com um escorregamento negativo em regime permanente, as perturbações que podem ocorrer no sistema tipicamente levarão o escorregamento do gerador de indução a um valor cada vez mais negativo. Desta forma, ao se observar o espaço de estados, a trajetória em falta parte de $x_{0}$ e segue em alguma direção à esquerda deste ponto. A parte da RE do sistema original e da RE do sistema auxiliar mais importante se refere portanto àquela localizada à esquerda de $x_{0}$ e $x_{s}$.

A fim de mostrar outro ponto que tangencia a restrição do problema, referente agora ao lado direito da RE do sistema auxiliar, não se aplica uma perturbação para que a trajetória em falta se inicie em $x_{0}$ e siga em alguma direção à direita deste ponto até a condição inicial pós-falta, pois não há como justificar do ponto de vista prático uma perturbação que leve a trajetória em falta até este ponto. Considera-se então uma condição inicial pós-falta que esteja localizada na parte direita da RE do sistema auxiliar e na fronteira deste sistema. Desta forma, a trajetória em falta não é obtida e considera-se somente a trajetória pós-falta.

Isto posto, a Figura 5.23 mostra o ponto $i$, que assim como o ponto $f$, se refere ao ponto cuja trajetória pós-falta tangencia a restrição do problema. $\mathrm{O}$ ponto $h$, analogamente ao ponto e, é um ponto sobre a variedade estável do ponto $i$, cuja trajetória pós-falta a acompanha na mesma direção, passando por $i$ antes de convergir para $x_{S}$.

Ao se considerar outra condição inicial pós-falta, ainda com um escorregamento positivo, mas agora localizada fora da RE do sistema auxiliar, espera-se que a trajetória pós-falta viole a restrição do problema. A Figura 5.24 mostra justamente esta situação. 


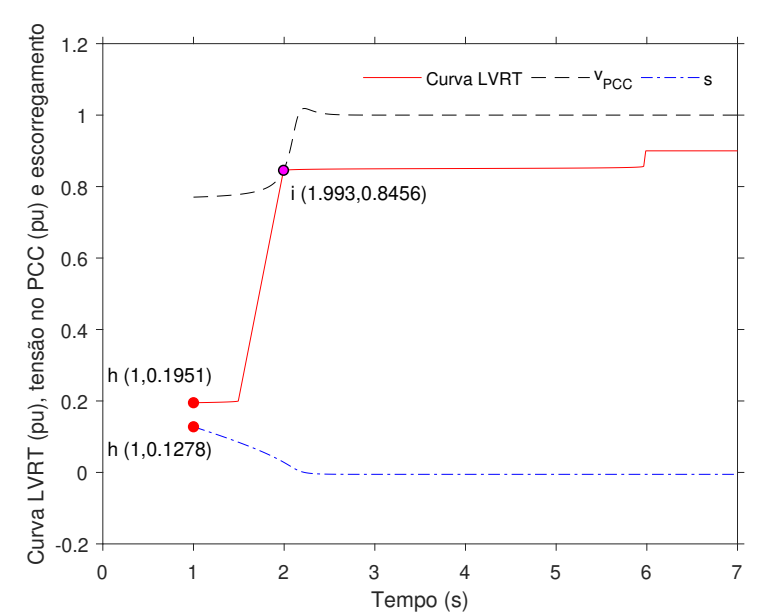

(a) Trajetórias no domínio do tempo.

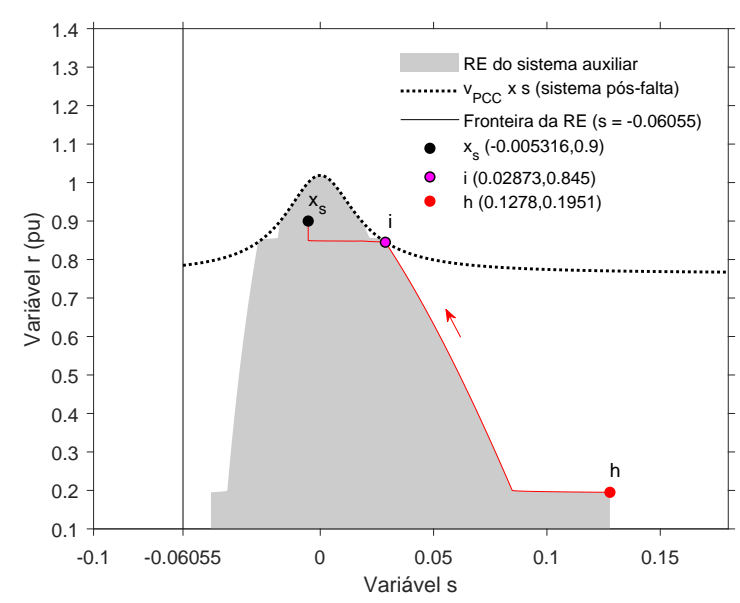

(b) Trajetórias no espaço de estados.

Figura 5.23: Trajetórias referentes aos pontos $h, i$.

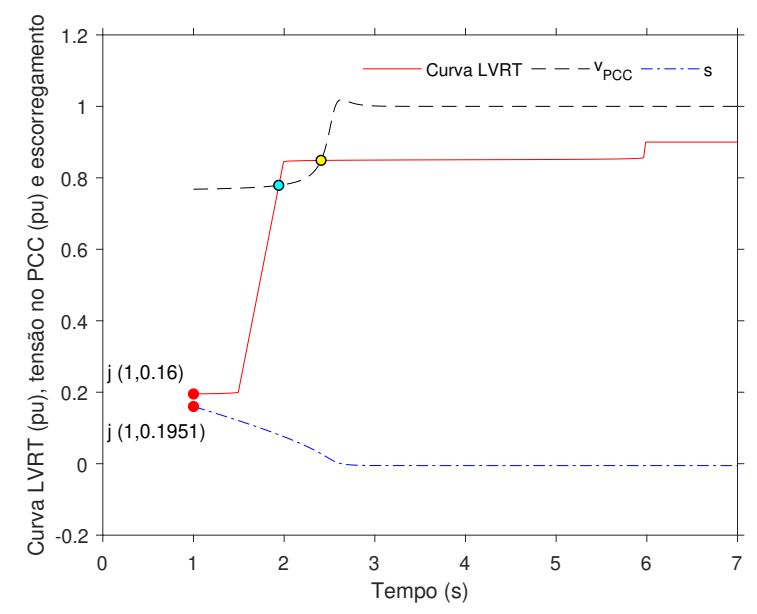

(a) Trajetórias no domínio do tempo.

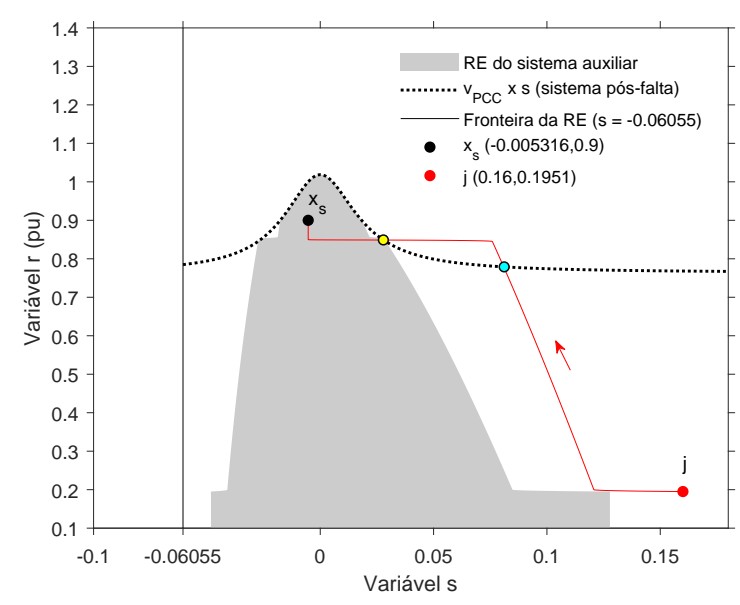

(b) Trajetórias no espaço de estados.

Figura 5.24: Trajetórias referentes ao ponto $j$.

O ponto $j$, analogamente ao ponto $g$ apresentado na Figura 5.22, representa a condição inicial pós-falta cuja trajetória viola a restrição do problema antes de convergir para $x_{s}$. Salienta-se que as situações apresentadas nas Figuras 5.23 e 5.24 não são típicas. As mesmas são apresentadas apenas para mostrar que para escorregamentos positivos as conclusões são análogas àquelas das Figuras 5.21 e 5.22.

Vale ressaltar que para qualquer condição inicial pós-falta pertencente à RE do sistema original, mas não pertencente à $R E$ do sistema auxiliar, a trajetória correspondente ou já violou a restrição do problema no período em falta ou violará a mesma no período pós-falta. Assim, ao submeter o sistema à curva LVRT, impõe-se um limite mais severo ao escorregamento crítico, pois o valor de escorregamento localizado na fronteira da RE do sistema auxiliar sempre será maior que o valor de escorregamento crítico do sistema original $\left(s_{c r}=-0,06055\right)$. 


\subsubsection{Considerando a curva LVRT dos EUA}

Para o mesmo sistema original e para o mesmo ponto de operação, a Figura 5.25 mostra a RER e a RE do sistema auxiliar considerando agora a curva LVRT dos EUA, além da linha sólida vertical que indica a fronteira da $R E$ do sistema original em $\mathbb{R}$ ( $s=-0.06055$ ) e da curva $V_{P C C} \times s$ para o sistema pós-falta. As REs obtidas ao se considerar a curva LVRT do Brasil são sobrepostas, a fim de evidenciar as diferenças em relação às REs obtidas ao se considerar a curva LVRT dos EUA. Tais diferenças se devem às particularidades de cada curva LVRT (verifique as diferenças entre as curvas na Figura 4.8), que impactam na caracterização tanto da RER como da RE do sistema auxiliar. Como será visto mais adiante para a configuração WRIG (Figuras 5.29 e 5.30), ao se considerar a curva LVRT dos EUA, as REs obtidas se mostram menores, o que revela que nem sempre a RER e a RE do sistema auxiliar serão maiores ao se considerar a curva LVRT dos EUA. Tal fato se explica pela dinâmica particular de cada modelo, de modo que a tensão no PCC vai violar cada curva LVRT de maneira naturalmente distinta (verifique que a curva LVRT dos EUA nem sempre apresenta limites de tensão inferiores a aqueles especificados pela curva LVRT do Brasil). A $R E$ do sistema original não se altera, assim como a curva $v_{P C C} \times s$ e o ponto $x_{S}$, visto que 0 sistema original e o ponto de operação permanecem iguais. Conforme pode ser constatado, a RER e a RE do sistema auxiliar também podem ser consideradas numericamente equivalentes neste caso, dada a boa aproximação da curva LVRT real dos EUA por (4.18).

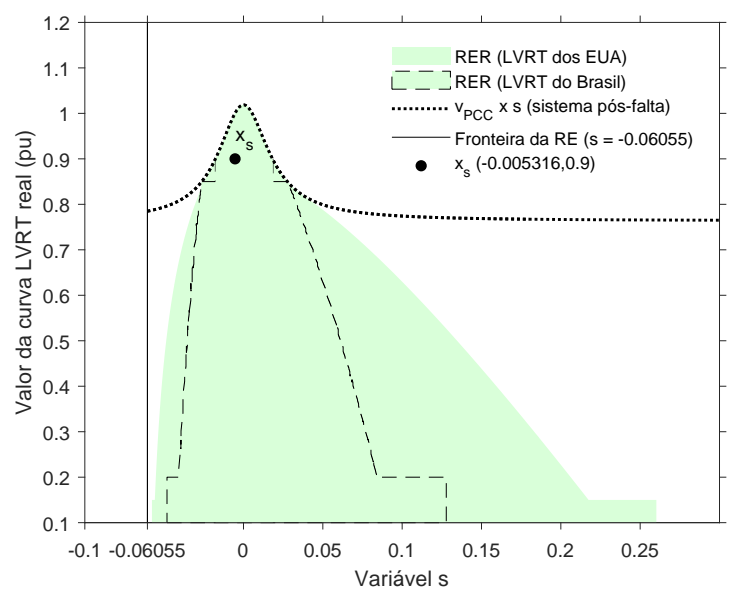

(a) Região de estabilidade restrita.

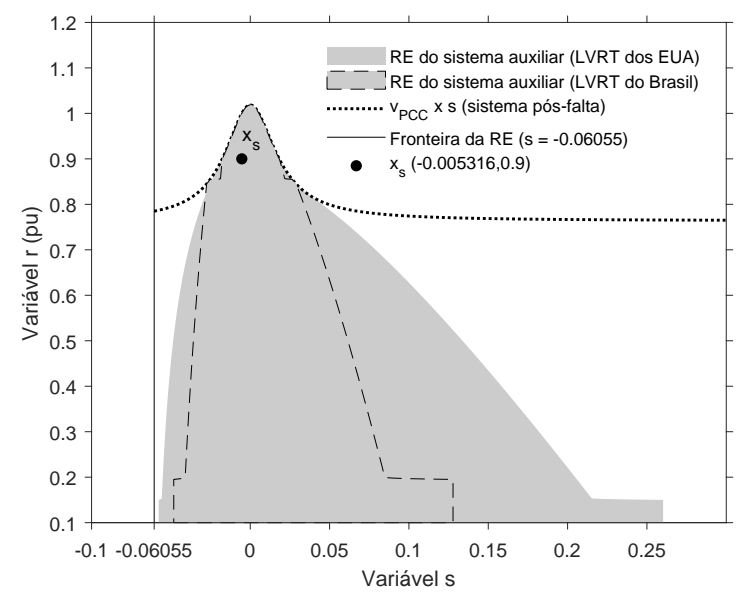

(b) Região de estabilidade do sistema auxiliar.

Figura 5.25: Regiões de estabilidade para a configuração SCIG considerando a curva LVRT dos EUA.

É visível também que a RER apresentada na Figura 5.25(a) é maior que a RER apresentada na Figura 5.16(a). Tal fato se deve à curva LVRT dos EUA permitir que a tensão no PCC experimente mais valores que não violam a restrição do problema. Ao se comparar as diferentes curvas LVRT apresentadas na Figura 4.8, fica claro que ao se considerar a curva LVRT dos EUA, a tensão no PCC pode excursionar mais sem que os limites de tensão desta curva sejam violados. 
No que se refere às trajetórias em falta e pós-falta para os pontos $a$ até $j$, não serão apresentados exemplos nesta seção para todos estes pontos, uma vez que do ponto de vista qualitativo as conclusões são equivalentes. Sendo assim, apresenta-se apenas um exemplo, para uma perturbação de outro tipo. Diferentemente de se alterar o torque mecânico durante um período de tempo específico, altera-se agora a susceptância da linha de transmissão. Especificamente para o caso da Figura 5.26, que se refere ao ponto $b$ da Figura 4.4, a susceptância $B_{12}$ é alterada em $t_{0}=1 \mathrm{~s}$ de $B_{12}=-10$ pu para $B_{12}=-1,75$ pu, permanecendo neste valor por $2,9 \mathrm{~s}$ e retornando ao valor $B_{12}=-10 \mathrm{pu}$ no instante $t_{a b}=3,9 \mathrm{~s}$. Esta perturbação é equivalente a uma diminuição da capacidade de transferência de potência da linha de transmissão. Uma vez que a condição inicial da variável de estado $r$ é igual a 0,15, o ponto $x_{0}$ se altera, conforme pode ser observado na Figura 5.26(b).

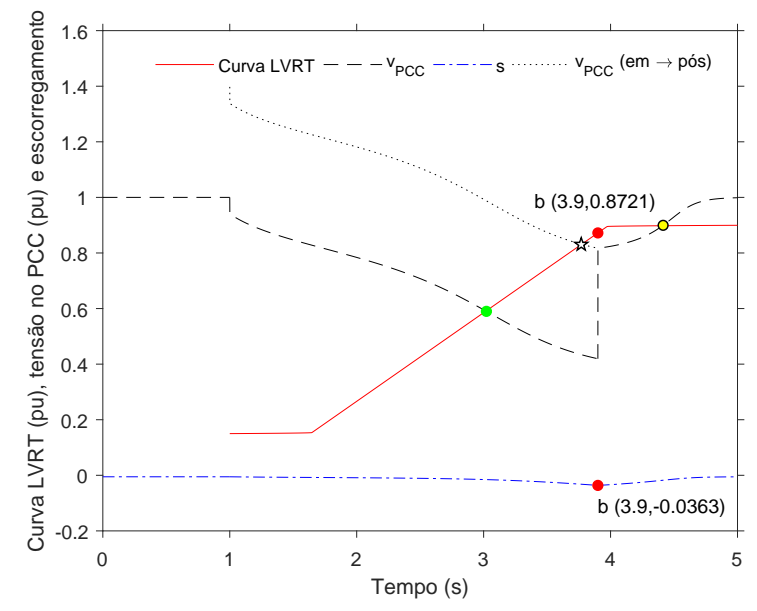

(a) Trajetórias no domínio do tempo.

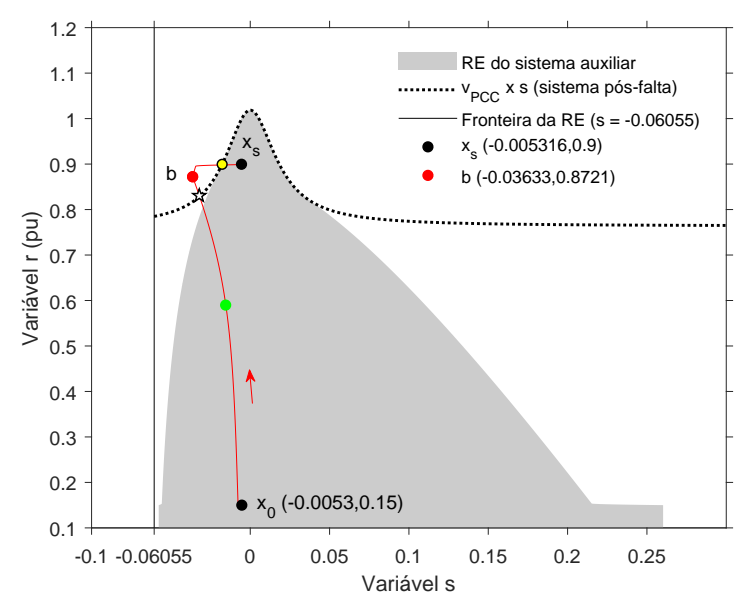

(b) Trajetórias no espaço de estados.

Figura 5.26: Trajetórias referentes ao ponto b. A susceptância da linha de transmissão é alterada em $t_{0}=1 \mathrm{~s}$ de $B_{12}=-10$ pu para $B_{12}=-1,75 \mathrm{pu}$, retornando a $B_{12}=-10 \mathrm{pu}$ em $t_{a b}=3,9 \mathrm{~s}$.

Ao se observar a Figura 5.26, verifica-se que a trajetória em falta referente ao ponto $b$ cruza a curva LVRT em um ponto localizado dentro da RE do sistema auxiliar. Este resultado pode parecer incorreto, pois a restrição do problema não pode ser negativa dentro da RE do sistema auxiliar. Porém na realidade, deve-se analisar a projeção da trajetória em falta no sistema pós-falta ( $V_{P C C}$ em $\rightarrow$ pós), conforme mostra a Figura 5.26(a). O salto observado na tensão $V_{P C C}$ decorre da mudança realizada nas equações algébricas da rede ao se alterar a susceptância da linha de transmissão. Considerando a trajetória ( $V_{P C C}$ em $\rightarrow$ pós), é possível verificar no espaço de estados o ponto em que esta projeção cruza a curva $v_{P C C} \times s$ referente ao sistema pós-falta (ponto branco), conforme mostra a Figura 5.26(b), de modo que a restrição passa a ser negativa a partir deste ponto. Estas observações são também válidas para o ponto $c$, apresentado no apêndice $H$. Trajetórias para os demais pontos ( $a, c$ até $j)$ também são exibidas no apêndice $\mathrm{H}$.

Mais adiante serão apresentados os TCAs, tanto para o sistema original como para o sistema submetido a cada curva LVRT, onde serão exibidos os resultados das funções energia 
para algumas perturbações e os TCAs organizados em tabelas. No que se refere à avaliação deste sistema, a função energia desenvolvida nesta tese tem por objetivo estimar o tempo cuja tensão no PCC viola a curva LVRT. Conhecendo este tempo, elimina-se o defeito na rede em um tempo inferior, de modo que a trajetória em falta e pós-falta permaneçam dentro da RE do sistema auxiliar, como mostra a Figura 5.27.

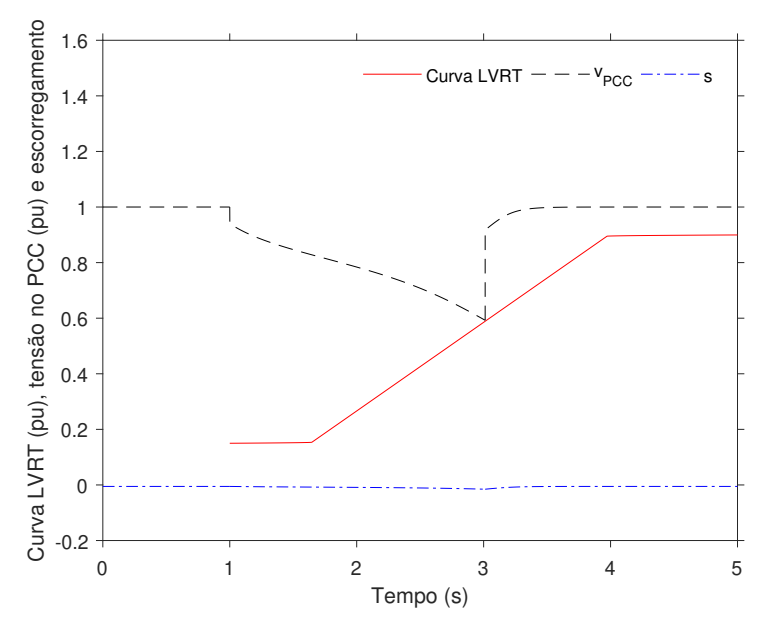

(a) Trajetórias no domínio do tempo.

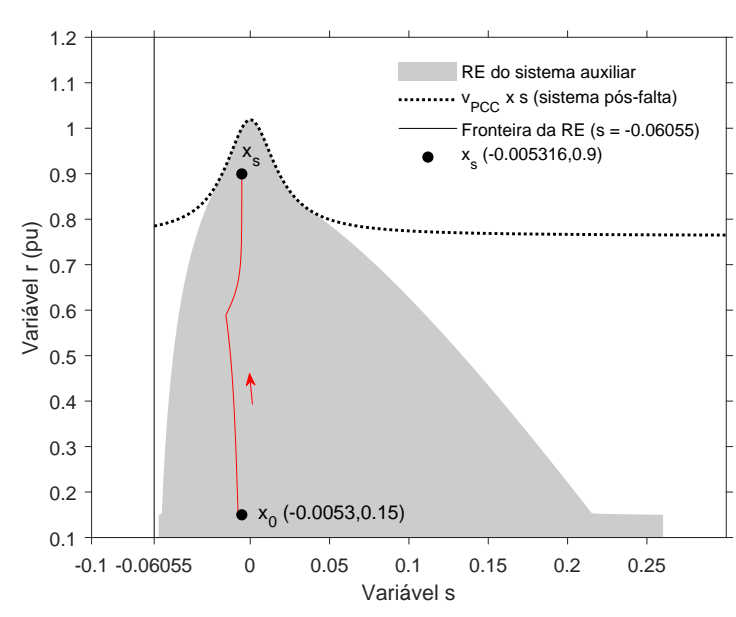

(b) Trajetórias no espaço de estados.

Figura 5.27: Trajetórias em falta e pós-falta. A susceptância da linha de transmissão é alterada em $t_{0}=1 \mathrm{~s}$ de $B_{12}=-10$ pu para $B_{12}=-1,75 \mathrm{pu}$, retornando a $B_{12}=-10 \mathrm{pu}$ em $t_{a b}=3 \mathrm{~s}$.

No caso da Figura 5.26, considerando a curva LVRT aproximada, o TCA obtido via método clássico (via sucessivas simulações) corresponde a 3,020 s. Utilizando-se da curva LVRT real obteve-se um TCA praticamente igual. O TCA estimado (obtido via função energia) corresponde a 3,022 s. Ainda que o TCA estimado seja ligeiramente superior ao TCA obtido via método clássico, verifica-se que a estimativa é muito próxima. Eliminando a perturbação em $t_{a b}=3 \mathrm{~s}$, por exemplo, obtém-se o resultado da Figura 5.27.

\subsection{Variações das regiões de estabilidade}

Os próximos resultados se referem às configurações SCIG e WRIG para as máquinas modeladas em primeira ordem nos eixos $d$ e $q$. Para a configuração SCIG são apresentadas REs do sistema auxiliar para diferentes constantes de inércia. Para a configuração WRIG são apresentadas REs do sistema auxiliar para diferentes resistências do rotor e para diferentes tensões aplicadas ao rotor. Os resultados são apresentados para cada curva LVRT. O objetivo é verificar como fica caracterizada a RE do sistema auxiliar, assim como a RE do sistema original para as diferentes condições citadas. Considera-se para ambas as configurações que o ponto de operação utiliza um torque mecânico $T_{m}=0,7$ pu. Não são apresentadas trajetórias, apenas as REs e as respectivas fronteiras da RE do sistema original. Na seção 5.5 serão apresentados, para algumas perturbações, TCAs relativos a cada RE.

A Figura 5.28 mostra as REs do sistema auxiliar para a configuração SCIG, além da linha vertical que indica a fronteira da RE do sistema original. Ao se desconsiderar a inércia 


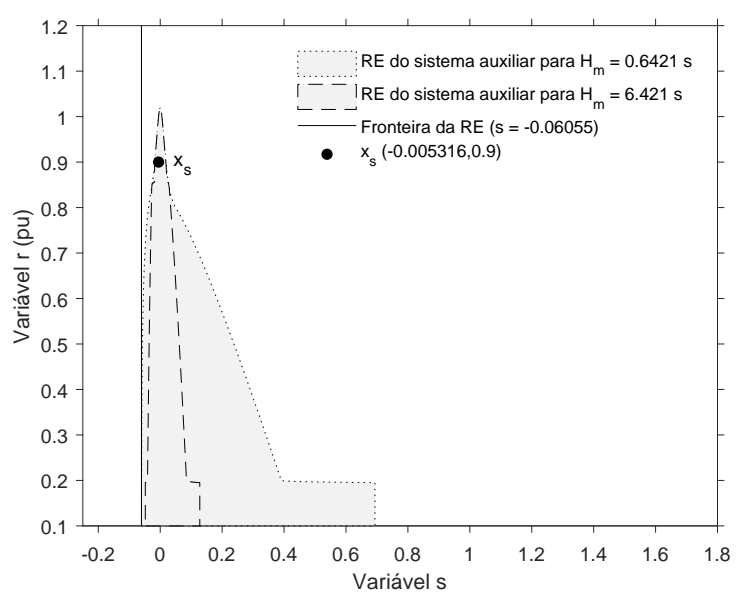

(a) Regiões de estabilidade do sistema auxiliar considerando a curva LVRT do Brasil.

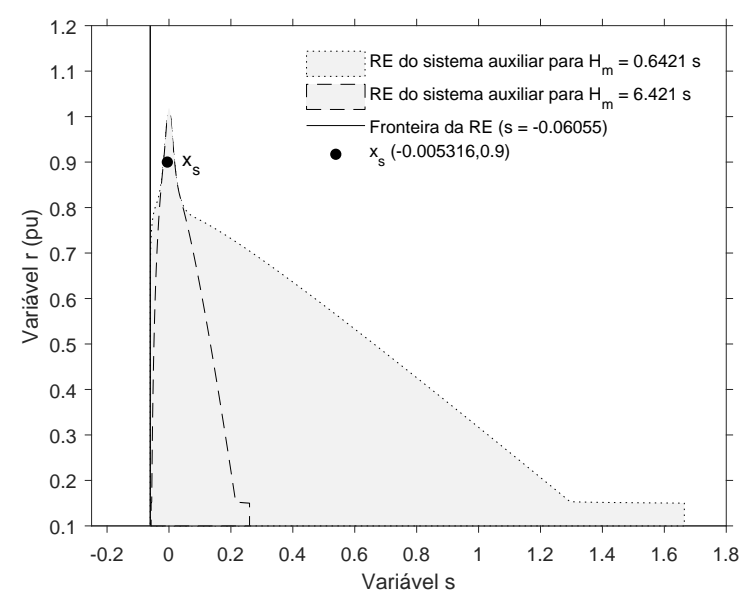

(b) Regiões de estabilidade do sistema auxiliar considerando a curva LVRT dos EUA.

Figura 5.28: Regiões de estabilidade para a configuração SCIG considerando diferentes constantes de inércia.

da turbina $\left(H_{t}=0\right.$ e $H_{m}=H_{g}=0,6421$ s) na equação mecânica (4.21), a $R E$ do sistema auxiliar se torna significativamente maior. Ao analisar a equação citada, constata-se que para uma constante de inércia menor, a variação do escorregamento no tempo se torna maior, de modo que surgem mais condições iniciais pós-falta cujas trajetórias não violam a restrição do problema para todo o tempo, o que justifica a diferença entre as REs obtidas.

Não obstante, nota-se que para valores negativos de escorregamento, a fronteira da RE do sistema auxiliar se torna mais próxima da linha vertical que indica a fronteira da RE do sistema original. Naturalmente, para uma constante de inércia menor, existe maior chance da instabilidade de velocidade ocorrer antes da violação do limite operacional e menor chance de ocorrer a situação representada pelo ponto $g$, exemplificada na Figura 5.22. Constatase também que ao se considerar a curva LVRT do Brasil, as REs obtidas neste caso são bem menores em comparação àquelas obtidas para a curva LVRT dos EUA. Como já citado, isto não é uma regra, pois dependendo da dinâmica da máquina, a violação de cada curva pode ser significativamente diferente, impactando na caracterização da RE do sistema auxiliar. Observa-se por último que a fronteira da RE do sistema original não se altera, permanecendo a respectiva RE definida pelo intervalo $(-0.06055,+\infty)$.

Será visto mais adiante que os TCAs obtidos para o sistema que considera a inércia da turbina $\left(H_{m}=H_{t}+H_{g}=6,421 \mathrm{~s}\right)$ serão bem maiores em relação a aqueles obtidos para o sistema que considera apenas a inércia do gerador de indução. Destaca-se neste contexto que uma RE do sistema auxiliar menor não implica em um TCA menor. Será mostrado também que desconsiderando a inércia da turbina para a configuração SCIG $\left(H_{t}=0, H_{m}=H_{t}+H_{g}\right.$ $=0,6421 \mathrm{~s}$ ), surgem várias situações em que a instabilidade de velocidade ocorre antes da tensão no PCC violar a curva LVRT.

As Figuras 5.29 e 5.30 mostram REs do sistema auxiliar obtidas para a configuração WRIG 
considerando diferentes resistências do rotor. Salienta-se que não é aplicada qualquer tensão ao rotor, permanecendo a mesma com o valor sempre nulo. Conforme pode ser observado, a RE do sistema auxiliar cresce à medida que se aumenta a resistência do rotor. Verifica-se também que a fronteira da RE do sistema original é diretamente proporcional a tal resistência. Como exemplo, cita-se que para $\left(r_{r} \cdot 1\right)$ tem-se $s_{c r}=-0,02165707$ e para $\left(r_{r} \cdot 10\right)$ tem-se $s_{c r}$ $=-0,2165707$. Assim, a RE do sistema original é alterada de $(-0,02165707,+\infty)$ para $(-$ $0,2165707,+\infty)$

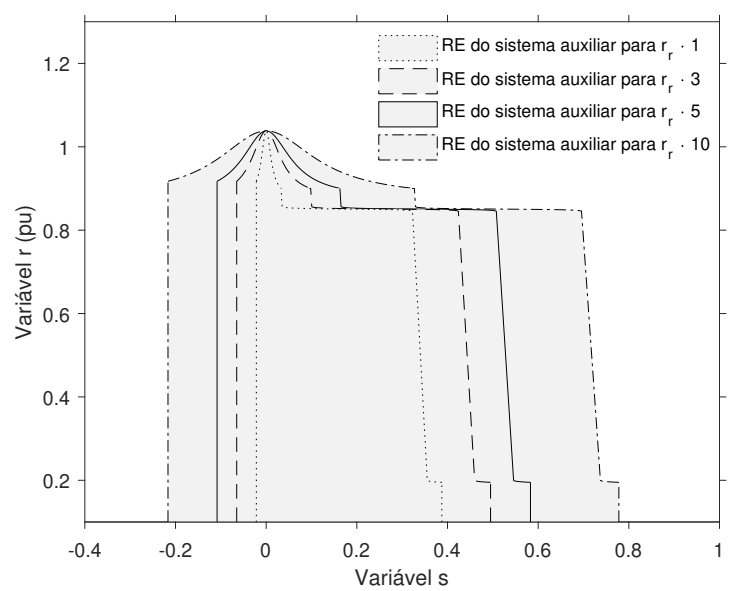

(a) Regiões de estabilidade do sistema auxiliar.

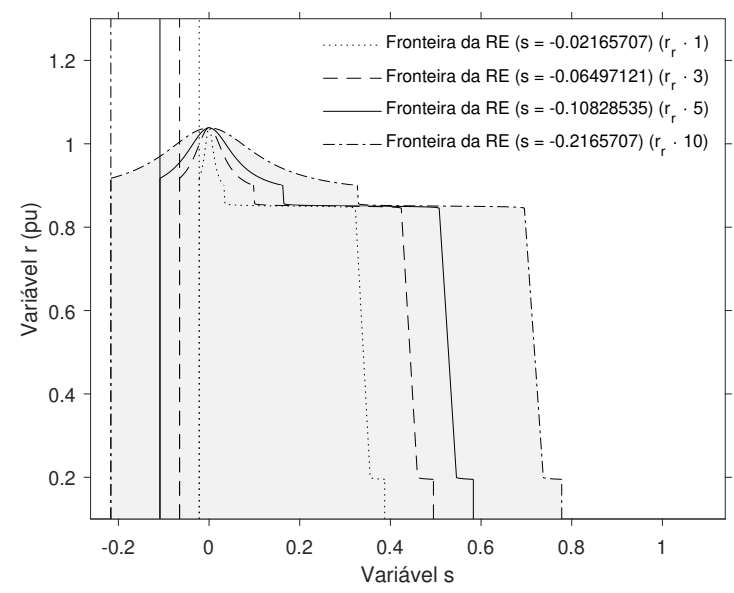

(b) Fronteiras da região de estabilidade.

Figura 5.29: Regiões de estabilidade para a configuração WRIG considerando diferentes resistências do rotor e a curva LVRT do Brasil.

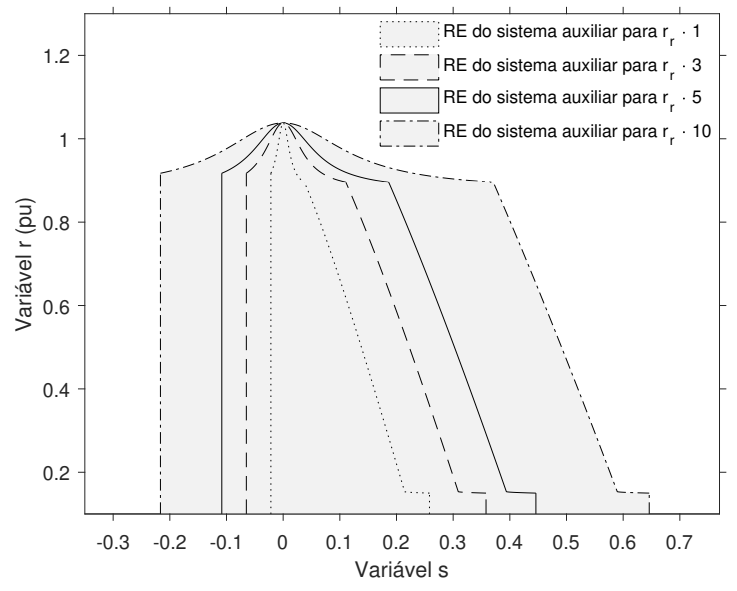

(a) Regiões de estabilidade do sistema auxiliar.

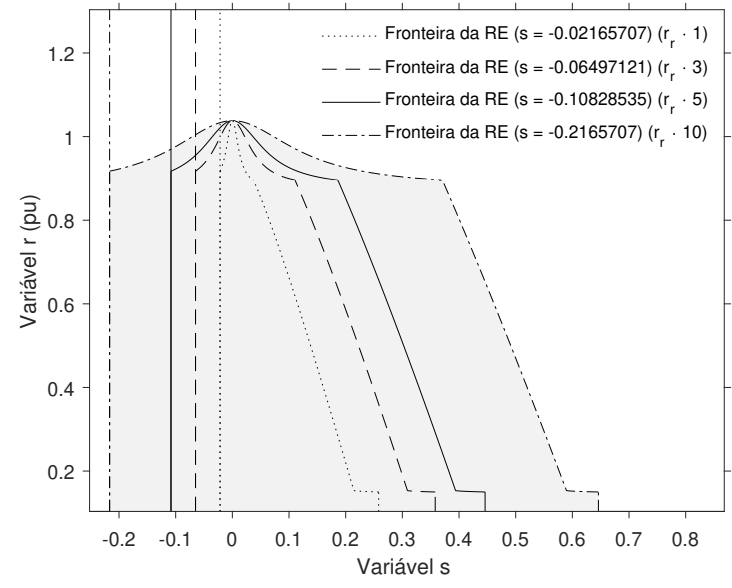

(b) Fronteiras da região de estabilidade.

Figura 5.30: Regiões de estabilidade para a configuração WR/G considerando diferentes resistências do rotor e a curva LVRT dos EUA.

Uma vez que a resistência do rotor aumenta, a dinâmica se altera, de modo que as REs do sistema original e do sistema auxiliar se tornam maiores. Para a RE do sistema original, o escorregamento pode assumir mais valores antes de abandonar a RE. Para a RE do sistema auxiliar, mais valores para s e $r$ são possíveis no período em falta sem que a restrição do problema seja violada e novas condições iniciais pós-falta cujas trajetórias não violarão a 
restrição do problema se tornam presentes, de modo que tal região naturalmente seja maior.

Ao se observar a linha vertical que indica a fronteira da RE do sistema original, percebese que para valores negativos de escorregamento não há possibilidade de ocorrer a situação representada pelo ponto $g$, exemplificada na Figura 5.22. Verifica-se também que as REs do sistema auxiliar obtidas considerando a curva LVRT do Brasil são bem diferentes daquelas obtidas considerando a curva LVRT dos EUA. Por último, comparando as Figuras 5.28(a) e 5.28(b) às Figuras 5.29 e 5.30, respectivamente, nota-se que para as diferentes máquinas as REs são bem diferentes. Mais adiante será mostrado que os TCAs crescem à medida que se aumenta a resistência do rotor. Em outras palavras, será verificado que os TCAs serão maiores para as REs maiores.

Por fim, as Figuras 5.31 e 5.32 mostram as REs obtidas para a configuração WRIG considerando diferentes tensões aplicadas ao rotor.

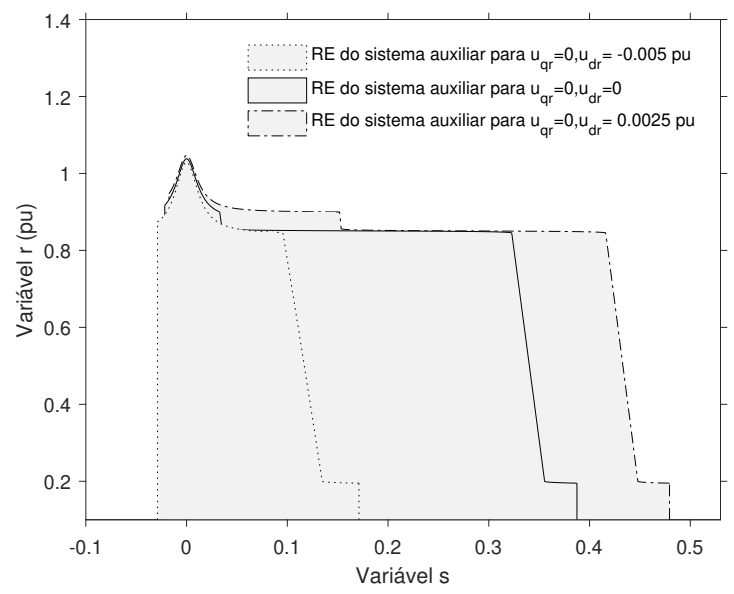

(a) Regiões de estabilidade do sistema auxiliar.

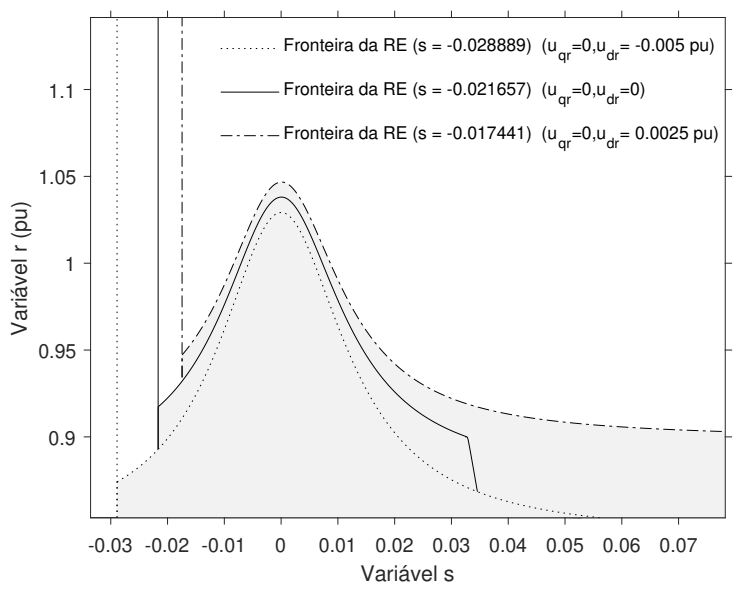

(b) Fronteiras da região de estabilidade.

Figura 5.31: Regiões de estabilidade para a configuração WRIG considerando $u_{q r}=0$ e diferentes tensões $u_{d r}$ e a curva LVRT do Brasil.

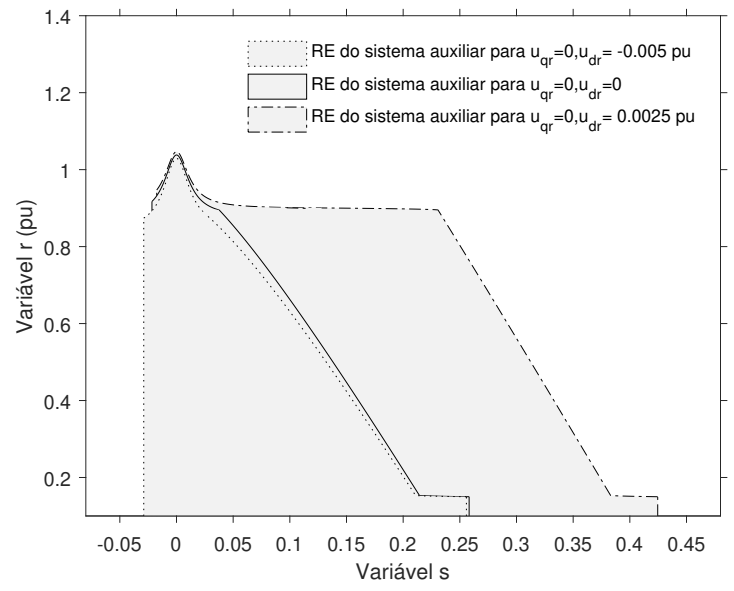

(a) Regiões de estabilidade do sistema auxiliar.

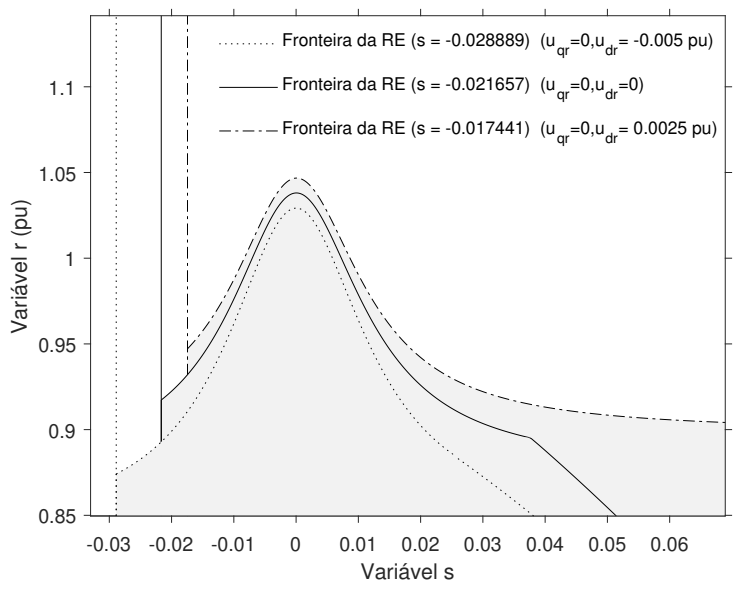

(b) Fronteiras da região de estabilidade.

Figura 5.32: Regiões de estabilidade para a configuração $W R / G$ considerando $u_{q r}=0$ e diferentes tensões $u_{d r}$ e a curva LVRT dos EUA. 
Especificamente escolheu-se $u_{q r}=0$ e duas tensões $u_{d r}$ diferentes de zero. Salienta-se que a resistência do rotor é mantida em seu valor original $\left(r_{r} \cdot 1\right)$ e que para as diferentes tensões o capacitor foi ajustado para a tensão no PCC apresentar o valor 1 pu em regime permanente.

De acordo com o que mostram as Figuras 5.31 e 5.32, a maior RE para o sistema auxiliar é obtida quando se aplica $u_{d r}=0,0025$ pu. Porém ao se considerar este valor de tensão, a RE do sistema original se torna menor, conforme mostram as Figuras 5.31(b) e 5.32(b). Da mesma forma, a parte interessante da RE do sistema auxiliar (aquela obtida para valores negativos de escorregamento), também se torna menor.

A seguir será mostrado que para a mesma perturbação, os TCAs obtidos para o gerador com tensão $u_{d r}=0,0025$ pu serão menores em relação aos TCAs obtidos para o gerador com $u_{d r}=0$ pu e $u_{d r}=-0,005$ pu, nesta sequência. Evidentemente, ao se alterar a resistência do rotor ou a tensão aplicada ao rotor, os pontos de equilíbrio $x_{0}$ e $x_{s}$ se alteram, pois a variável de estado $s$ muda. Os valores de $s$ nestes casos podem ser vistos no apêndice $E$.

\subsection{Tempos críticos de abertura}

Nesta seção são apresentados TCAs para algumas perturbações, tanto para o sistema original, isto é, para o sistema que desconsidera o requisito operacional, como também para o sistema sujeito aos limites de tensão definidos tanto pela curva LVRT do Brasil como pela curva LVRT dos EUA. Os TCAs estimados pelas funções energia $V$ e $V_{r}$ definidas por (4.22) e (4.23), respectivamente, são comparados a aqueles obtidos via método clássico. São apresentadas trajetórias no domínio do tempo e energias referentes às funções citadas, no sentido de exemplificar como estas funções são coerentes à teoria apresentada no capítulo 4.

São apresentados resultados para o sistema teste com cada configuração de aerogerador, para os modelos da máquina em primeira, terceira e quinta ordens nos eixos $d$ e $q$. Para as configurações modeladas em regime permanente, verificou-se que todos os TCAs se mostraram idênticos a aqueles obtidos para a máquina modelada em primeira ordem nos eixos $d$ e $q$. O ponto de operação escolhido é o mesmo estudado até o momento. Para as configurações SCIG e WRIG utiliza-se um torque mecânico de entrada $T_{m}=0,7 \mathrm{pu}$, de modo que $P_{\mathrm{s}}=$ 0,6960 pu e $Q_{s}=0,0728$ pu para a configuração SCIG e $P_{s}=0,6905$ pu e $Q_{s}=0,0716 \mathrm{pu}$ para a configuração WRIG (considerando tensão nula no rotor). Para a configuração DFIG, a barra terminal é considerada uma barra PQ com $P_{g}=0,6933$ pu e $Q_{g}=0,0722$ pu.

Os TCAs são organizados em tabelas para comparar, para a mesma perturbação, os resultados estimados pelo método direto (via funções energia) a aqueles obtidos pelo método clássico (via sucessivas simulações). Nas Tabelas 5.1 à 5.7, a primeira coluna indica o tipo de perturbação. Se indicado $B_{12}$, a susceptância da linha de transmissão é alterada em $t_{0}$ $=1 \mathrm{~s}$ de $B_{12}=-10$ pu para o valor indicado, retornando a $B_{12}=-10 \mathrm{pu}$ em um tempo de abertura superior ao maior TCA registrado. Se indicado $u_{x 1}$, a tensão na barra 1 do sistema teste é alterada em $t_{0}=1 \mathrm{~s}$ de $u_{x 1}=1$ pu para o valor indicado, retornando a $u_{x 1}=1 \mathrm{pu}$ em 
um tempo de abertura novamente superior ao maior TCA registrado. Para o sistema original (sem limites de tensão), a segunda e a terceira colunas indicam os TCAs obtidos via método clássico e direto, respectivamente. Para o sistema submetido aos limites de tensão, a quarta e a quinta colunas indicam os TCAs obtidos via método clássico e direto, respectivamente, considerando a curva LVRT do Brasil. Já a sexta e sétima colunas indicam os TCAs obtidos via método clássico e direto, respectivamente, considerando a curva LVRT dos EUA.

Naturalmente, o tempo de cruzamento da tensão no PCC com a curva LVRT real não será exatamente igual ao tempo de cruzamento com a curva LVRT aproximada, muito embora via simulações estes tempos se mostraram muito próximos. Ressalta-se que para o sistema submetido aos limites de tensão, são consideradas as curvas LVRT real para obter os TCAs via método clássico, pois para obter os tempos de abertura mais próximos dos considerados verdadeiros, ou reais, deve-se utilizar tais curvas. Já para estimar os TCAs por meio da função energia (4.23), são utilizadas evidentemente as curvas LVRT aproximadas.

Para o sistema sem limites de tensão, se o TCA estimado for menor que aquele obtido via método clássico, tem-se uma estimativa conservadora, de modo que o sistema será estável no período pós-falta para qualquer tempo de abertura igual ou inferior ao estimado. Em contrapartida, se o TCA estimado for maior que aquele obtido via método clássico, significa que para qualquer tempo de abertura entre o obtido via método clássico e o estimado, incluindo ambos, ocorrerá a instabilidade de velocidade no período pós-falta. Caso o TCA estimado seja igual ao obtido via método clássico, a eliminação do distúrbio em qualquer tempo inferior permitirá que o sistema seja estável no período pós-falta.

Para o sistema submetido aos limites de tensão, se o TCA estimado for menor que aquele obtido via método clássico, tem-se uma estimativa conservadora, de modo que não ocorrerá violação da curva LVRT para qualquer tempo de abertura igual ou inferior ao estimado. Em contrapartida, se o TCA estimado for maior que aquele obtido via método clássico, significa que para qualquer tempo de abertura entre o obtido via método clássico e o estimado, incluindo ambos, ocorrerá a violação da curva LVRT. Caso o TCA estimado seja igual ao obtido via método clássico, a eliminação do distúrbio em qualquer tempo inferior permitirá que a tensão no PCC não viole a curva LVRT. Evidentemente, a eliminação da perturbação em um tempo inferior ao menor TCA registrado para o sistema submetido aos limites de tensão, além de evitar a violação da curva LVRT, permitirá que o sistema seja estável no sistema pós-falta.

No que se refere ainda ao sistema submetido aos limites de tensão, a função energia $V_{r}$ estima o momento em que a tensão no PCC viola a curva LVRT no período em falta. Na maioria dos casos, a violação da curva LVRT ocorre justamente neste período. Entretanto, sabe-se que para tempos de abertura inferiores, pode ocorrer violação dos limites de tensão no período pós-falta. Esta situação se refere ao ponto $g$ apresentado na Figura 5.22. Para registrar o TCA via método clássico, atentou-se para encontrar o primeiro tempo de abertura cuja tensão no PCC violasse a curva LVRT, seja durante ou após a perturbação. Os casos em que a tensão no PCC violou a curva LVRT no período pós-falta, para um tempo de abertura inferior ao 
tempo referente à violação da curva no período em falta, são devidamente apontados.

Vale ressaltar também que na maioria dos casos a instabilidade de velocidade ocorre após a violação da curva LVRT. Quando a instabilidade de velocidade ocorre primeiro, situação referente ao ponto $d$ apresentado na Figura 5.20, as estimativas de TCAs pelas funções energia $V$ e $V_{r}$ são iguais. Os casos em que a instabilidade de velocidade ocorreu antes da violação dos limites de tensão são devidamente apontados. Por último, salienta-se que o TCA estimado menor que aquele obtido via método clássico (resultado conservador) é destacado em cada tabela.

A Tabela 5.1 apresenta os resultados para a configuração SCIG. Como pode ser observado, os TCAs estimados são em geral bem próximos daqueles obtidos via método clássico.

Tabela 5.1: Tempos críticos de abertura para a configuração SCIG.

\begin{tabular}{|c|c|c|c|c|c|c|}
\hline \multirow{2}{*}{$B_{12}(\mathrm{pu})$} & \multicolumn{2}{|c|}{$\begin{array}{l}\text { Sem limite } \\
\text { de tensão }\end{array}$} & \multicolumn{2}{|c|}{$\begin{array}{l}\text { Com limite de tensão } \\
\text { Curva LVRT do Brasil }\end{array}$} & \multicolumn{2}{|c|}{$\begin{array}{l}\text { Com limite de tensão } \\
\text { Curva LVRT dos EUA }\end{array}$} \\
\hline & $\begin{array}{l}\text { TCA método } \\
\text { clássico (ms) }\end{array}$ & $\begin{array}{l}\text { TCA método } \\
\text { direto (ms) }\end{array}$ & $\begin{array}{l}\text { TCA método } \\
\text { clássico (ms) }\end{array}$ & $\begin{array}{l}\text { TCA método } \\
\text { direto (ms) }\end{array}$ & $\begin{array}{l}\text { TCA método } \\
\text { clássico (ms) }\end{array}$ & $\begin{array}{l}\text { TCA método } \\
\text { direto (ms) }\end{array}$ \\
\hline \multicolumn{7}{|c|}{ Primeira ordem $d q$} \\
\hline$-0,3$ & 1055 & 1055 & 130 & 135 & 238 & 235 \\
\hline$-0,4$ & 1086 & 1089 & 238 & 244 & 457 & 448 \\
\hline$-0,6$ & 1171 & 1173 & 511 & 504 & 747 & 758 \\
\hline$-0,8$ & 1293 & 1297 & 560 & 553 & 894 & 906 \\
\hline$-1,0$ & 1461 & 1460 & 613 & 606 & 1035 & 1045 \\
\hline \multicolumn{7}{|c|}{ Terceira ordem $d q$} \\
\hline$-0,3$ & 1282 & 1137 & $696^{a}$ & 906 & $1094^{a}$ & 1139 \\
\hline$-0,4$ & 1331 & 1197 & $720^{a}$ & 877 & $1146^{a}$ & 1199 \\
\hline$-0,6$ & 1462 & 1351 & 625 & 626 & 1054 & 1056 \\
\hline$-0,8$ & 1645 & 1542 & 647 & 646 & 738 & 740 \\
\hline$-1,0$ & 1899 & 1797 & 709 & 704 & 929 & 931 \\
\hline \multicolumn{7}{|c|}{ Quinta ordem $d q$} \\
\hline$-0,3$ & 1172 & 1136 & $419^{a}$ & 916 & $906^{a}$ & 1133 \\
\hline$-0,4$ & 1217 & 1198 & $477^{a}$ & 882 & $971^{a}$ & 1198 \\
\hline$-0,6$ & 1337 & 1354 & 571 & 620 & 1056 & 1052 \\
\hline$-0,8$ & 1515 & 1546 & 649 & 648 & 737 & 740 \\
\hline$-1,0$ & 1776 & 1800 & 704 & 703 & 928 & 931 \\
\hline
\end{tabular}

${ }^{a}$ Este TCA se refere à situação em que violação da curva LVRT se deu no período pós-falta.

Verifica-se também que os TCAs relativos ao sistema submetido à curva LVRT dos EUA são maiores em relação a aqueles referentes ao sistema submetido à curva LVRT do Brasil. 
Tais resultados são esperados, uma vez que o perfil da curva LVRT dos EUA permite que a tensão no PCC excursione mais antes de violar os limites de tensão.

A Figura 5.33 mostra para o modelo em primeira ordem e perturbação $B_{12}=-0,8$ pu, as estimativas realizadas via funções energia $V$ e $V_{r}$, assim como a curva LVRT do Brasil, a tensão no PCC, o escorregamento e os pontos de interesse. Para a Figura 5.33(a) são apresentadas as energias das funções $V$ e $V_{r}$, obtidas para a perturbação sustentada. A trajetória parte do equilíbrio pré-falta $s=-0,0053$, com energia nula, seguindo no sentido indicado pelas setas. Para ambas as funções são indicados o escorregamento e a energia crítica $\left(s, V_{c r}\right)$. Para a função $V_{r}$ mostra-se também o ponto de energia mínima, cujo valor de escorregamento é igual ao indicado pelo primeiro máximo da função $V$.

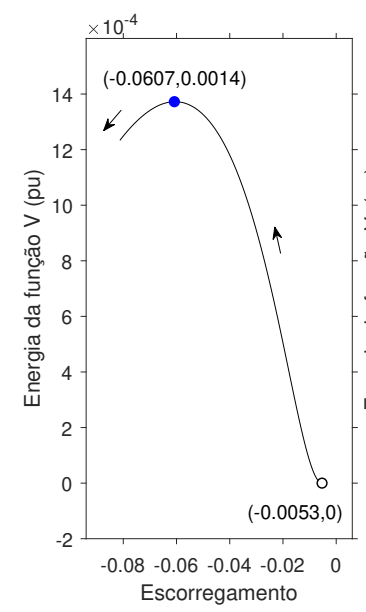

(a) Funções energia.

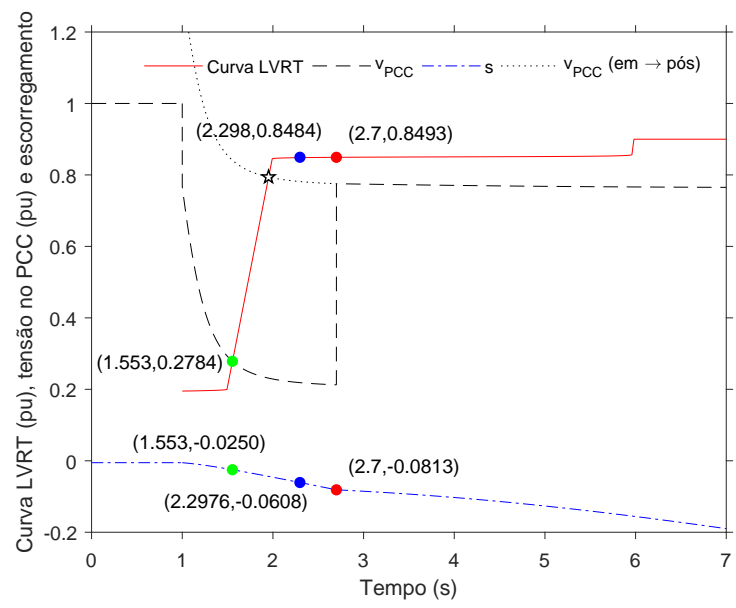

(b) Curva LVRT, tensão no PCC e escorregamento.

Figura 5.33: Funções energia e curva LVRT, tensão no PCC e escorregamento para a configuração SCIG modelada em primeira ordem nos eixos d e $q$. A susceptância da linha de transmissão é alterada em $t_{0}=1 \mathrm{~s}$ de $B_{12}=-10$ pu para $B_{12}=-0,8$ pu, retornando a $B_{12}=-10$ pu em $t_{a b}=2,7 \mathrm{~s}$.

Para a Figura 5.33(b) são indicados o instante de tempo e o valor da variável correspondente. Conforme pode ser observado, os valores de escorregamento indicados pelas funções $V(s=-0,0607)$ e $V_{r}(s=-0,0250)$ podem ser conferidos na Figura 5.33(b) nos respectivos pontos (2.2976,-0.0608) e (1.553,-0.0250). Para os tempos indicados, os pontos são refletidos na curva LVRT aproximada, de modo a indicar o respectivo valor da variável de estado $r$. Uma vez que a perturbação é aplicada no instante $t_{0}=1 \mathrm{~s}$, os TCAs obtidos correspondem a 1297 ms e 553 ms, respectivamente, conforme registrado na Tabela 5.1. São indicados também os pontos referentes ao tempo de eliminação da perturbação, além do ponto cuja projeção da trajetória em falta no sistema pós-falta viola a curva LVRT.

A Figura 5.34 mostra as trajetórias em falta e pós-falta na RE do sistema auxiliar. Os pontos relacionam os valores das variáveis de estado s e $r$ apresentados na Figura 5.33(b). Uma vez que a fronteira da RE do sistema original é formada por pontos de equilíbrio, o ponto de saída desta região corresponde ao ponto de equilíbrio instável localizado na fronteira desta região. Desta forma, o escorregamento indicado pelo primeiro máximo da função $V$ 
corresponde a uma estimativa da fronteira da RE do sistema original. Ao observar a Figura 5.34 , verifica-se que a estimativa realizada $(s=-0,0607)$ é muito próxima da fronteira do sistema original $(s=-0,06055)$. Já o primeiro máximo da função $V_{r}$ indica a estimativa do escorregamento referente ao instante de tempo cuja curva LVRT é violada durante a falta. Ao eliminar a perturbação em um tempo imediatamente inferior ao respectivo TCA, a tensão no PCC não viola a curva LVRT, de modo que as trajetórias em falta e pós-falta permanecem dentro da RE do sistema auxiliar, como mostra a Figura 5.35.

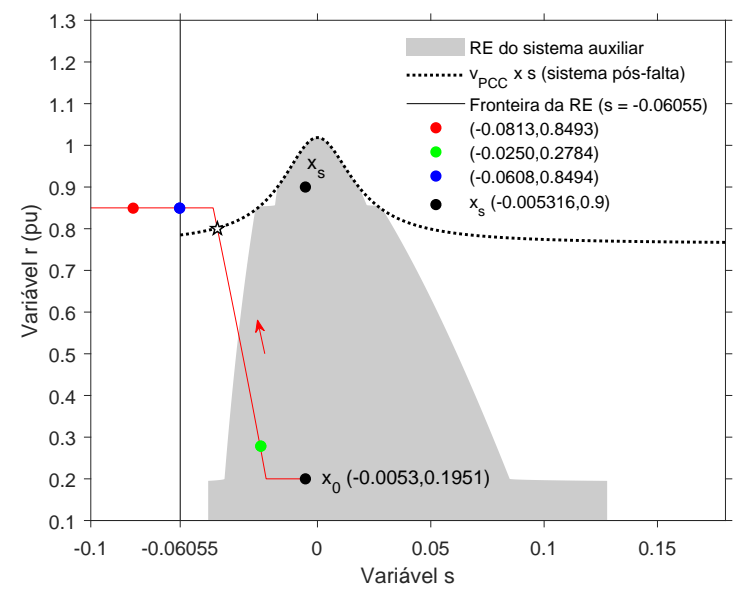

Figura 5.34: Trajetórias em falta e pós-falta. A susceptância da linha de transmissão é alterada em $t_{0}=1 \mathrm{~s}$ de $B_{12}=-10$ pu para $B_{12}=-0,8$ pu, retornando a $B_{12}=-10$ pu em $t_{a b}=2,7 \mathrm{~s}$.

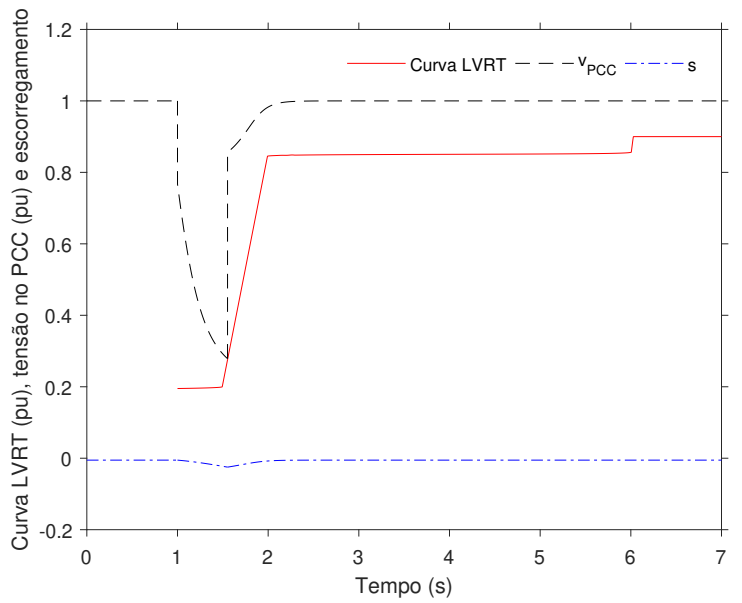

(a) Curva LVRT, tensão no PCC e escorregamento.

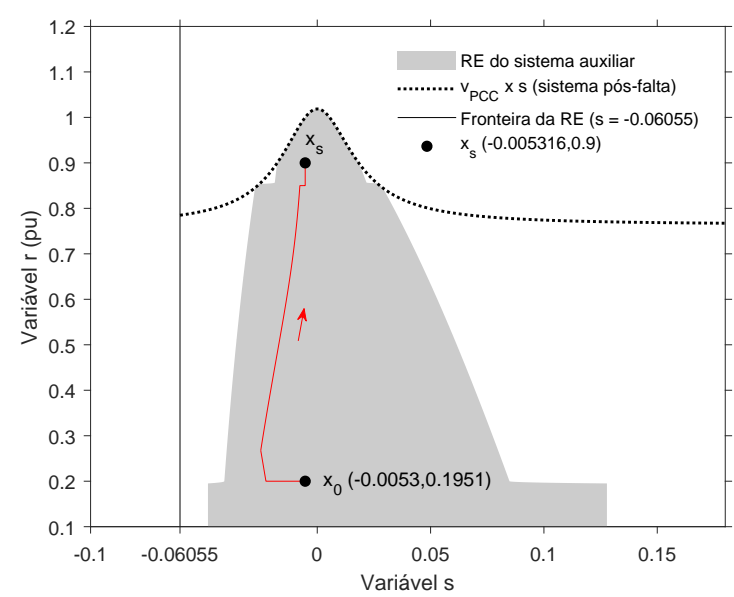

(b) Funções energia.

Figura 5.35: Trajetórias em falta e pós-falta. A susceptância da linha de transmissão é alterada em $t_{0}=1 \mathrm{~s}$ de $B_{12}=-10$ pu para $B_{12}=-0,8$ pu, retornando a $B_{12}=-10$ pu em $t_{a b}=1,552 \mathrm{~s}$.

Comparando-se cada perturbação entre os modelos de primeira, terceira e quinta ordens, nota-se que o TCA é diferente. Este fato pode ser explicado pelo comportamento dinâmico de cada modelo. Via simulações, observou-se que para os modelos em terceira e quinta ordens, o comportamento dinâmico durante e após a perturbação são distintos. Nota-se que para os modelos em terceira e quinta ordens ocorrem oscilações para muitas variáveis, incluindo a tensão no PCC, durante e após a perturbação, especialmente para o modelo em quinta ordem. 
Para este modelo, a Figura 5.36 mostra como o comportamento da tensão no PCC é bem diferente daquele obtido para o modelo em primeira ordem apresentado na Figura 5.33(b).

De acordo com a Tabela 5.1, ocorreram alguns casos em que a tensão no PCC violou a curva LVRT no período pós-falta, em um TCA inferior a aquele relativo à violação da curva no período em falta. Situações deste tipo se referem ao ponto $g$ estudado na seção 5.3.1. Para exemplificar um caso da Tabela 5.1, a Figura 5.37 é apresentada para o modelo em terceira ordem e perturbação $B_{12}=-0,4$ pu.
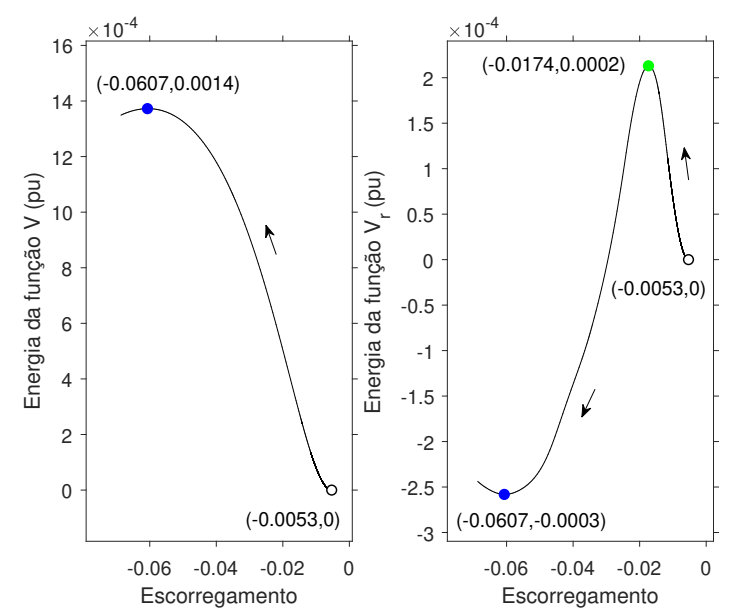

(a) Funções energia.

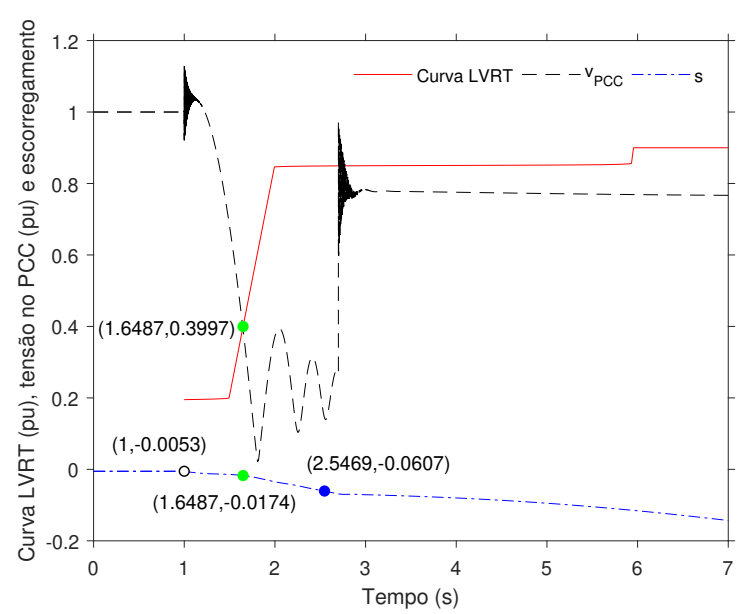

(b) Curva LVRT, tensão no PCC e escorregamento.

Figura 5.36: Funções energia e curva LVRT, tensão no PCC e escorregamento para a configuração SCIG modelada em quinta ordem nos eixos d e $q$. A susceptância da linha de transmissão é alterada em $t_{0}=1 \mathrm{~s}$ de $B_{12}=-10$ pu para $B_{12}=-0,8$ pu, retornando a $B_{12}=-10 \mathrm{pu} \mathrm{em} t_{a b}=2,7 \mathrm{~s}$.

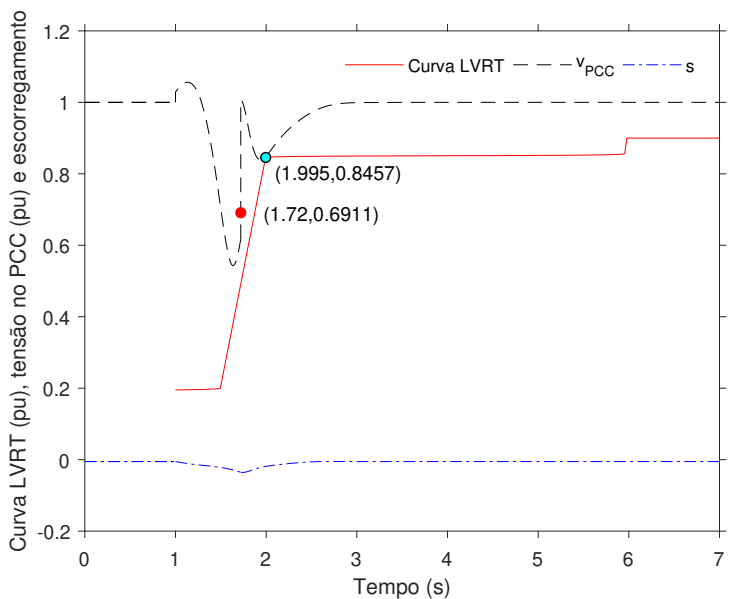

(a) Curva LVRT, tensão no PCC e escorregamento para $t_{a b}=720 \mathrm{~ms}$.

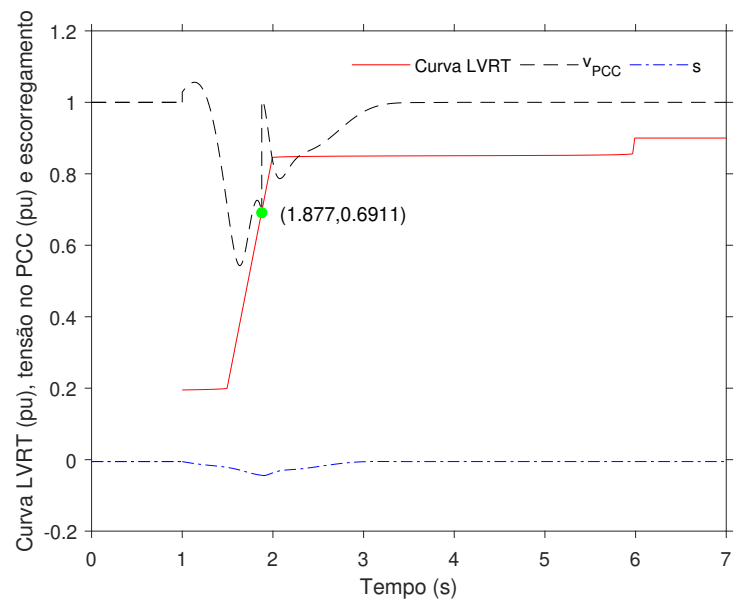

(b) Curva LVRT, tensão no PCC e escorregamento para $t_{a b}=877 \mathrm{~ms}$.

Figura 5.37: Curva LVRT, tensão no PCC e escorregamento para a configuração SClG modelada em terceira ordem nos eixos d e q considerando diferentes tempos de abertura.

Conforme mostra a Figura 5.37(a), ao se eliminar a perturbação em $t_{a b}=1,720 \mathrm{~s}$, a tensão no PCC viola a curva LVRT no período pós-falta em $t=1,995 \mathrm{~s}$. Ao se prolongar a perturbação para um tempo superior a $t=1,720 \mathrm{~s}$, o comportamento da tensão no PCC 
segue como indicado na Figura 5.37(b), violando a curva LVRT no instante $t=t_{a b}=1,877$ s. Uma vez que a função energia $V_{r}$ detecta o cruzamento da tensão no PCC com a curva LVRT somente durante a perturbação, esta função não é capaz de estimar o tempo 1,720 s, pois neste instante não ocorre o cruzamento citado.

Desprezando a constante de inércia da turbina $\left(H_{t}=5,7789 \mathrm{~s}\right)$ e considerando portanto somente a constante de inércia do gerador de indução $\left(H_{g}=H_{m}=0,6421 \mathrm{~s}\right)$, os TCAs se tornam muito menores, conforme mostra a Tabela 5.2 para a configuração SCIG.

Tabela 5.2: Tempos críticos de abertura para a configuração SCIG $\left(H_{m}=0,6421\right.$ s).

\begin{tabular}{|c|c|c|c|c|c|c|}
\hline \multirow{2}{*}{$B_{12}(\mathrm{pu})$} & \multicolumn{2}{|c|}{$\begin{array}{l}\text { Sem limite } \\
\text { de tensão }\end{array}$} & \multicolumn{2}{|c|}{$\begin{array}{l}\text { Com limite de tensão } \\
\text { Curva LVRT do Brasil }\end{array}$} & \multicolumn{2}{|c|}{$\begin{array}{l}\text { Com limite de tensão } \\
\text { Curva LVRT dos EUA }\end{array}$} \\
\hline & $\begin{array}{l}\text { TCA método } \\
\text { clássico (ms) }\end{array}$ & $\begin{array}{l}\text { TCA método } \\
\text { direto (ms) }\end{array}$ & $\begin{array}{l}\text { TCA método } \\
\text { clássico (ms) }\end{array}$ & $\begin{array}{l}\text { TCA método } \\
\text { direto (ms) }\end{array}$ & $\begin{array}{l}\text { TCA método } \\
\text { clássico (ms) }\end{array}$ & $\begin{array}{l}\text { TCA método } \\
\text { direto (ms) }\end{array}$ \\
\hline \multicolumn{7}{|c|}{ Primeira ordem $d q$} \\
\hline$-0,3$ & 106 & 106 & 13 & 13 & 24 & 24 \\
\hline$-0,4$ & 109 & 109 & 24 & 25 & 46 & 46 \\
\hline$-0,6$ & 118 & 117 & 62 & 65 & $x^{a}$ & 117 \\
\hline$-0,8$ & 130 & 129 & $x^{a}$ & 129 & $x^{a}$ & 129 \\
\hline$-1,0$ & 147 & 145 & $x^{a}$ & 145 & $x^{a}$ & 145 \\
\hline \multicolumn{7}{|c|}{ Terceira ordem $d q$} \\
\hline$-0,3$ & 238 & 144 & $x^{a}$ & 144 & $x^{a}$ & 144 \\
\hline$-0,4$ & 249 & 162 & $x^{a}$ & 162 & $x^{a}$ & 162 \\
\hline$-0,6$ & 277 & 210 & $x^{a}$ & 210 & $x^{a}$ & 210 \\
\hline$-0,8$ & 318 & 257 & $x^{a}$ & 257 & $x^{a}$ & 257 \\
\hline$-1,0$ & 385 & 124 & 316 & 124 & $x^{a}$ & 124 \\
\hline \multicolumn{7}{|c|}{ Quinta ordem $d q$} \\
\hline$-0,3$ & 145 & 142 & $x^{a}$ & 142 & $x^{a}$ & 142 \\
\hline$-0,4$ & 155 & 162 & $x^{a}$ & 162 & $x^{a}$ & 162 \\
\hline$-0,6$ & 179 & 208 & $x^{a}$ & 208 & $x^{a}$ & 208 \\
\hline$-0,8$ & 215 & 258 & $x^{a}$ & 258 & $x^{a}$ & 258 \\
\hline$-1,0$ & 274 & 121 & 122 & 121 & 122 & 121 \\
\hline
\end{tabular}

${ }^{a}$ Ocorre a instabilidade de velocidade antes da tensão no PCC violar a curva LVRT.

Conforme já explicado na seção 5.4, ao se considerar uma constante de inércia menor na equação mecânica que descreve o movimento do rotor do gerador, a variação do escorregamento no tempo se torna maior. Assim, no mesmo período de tempo sob análise, o escorregamento assumirá mais valores em relação ao caso que considera a inércia combinada $\left(H_{m}=H_{t}+H_{g}=6,421 \mathrm{~s}\right)$. Como a fronteira da RE do sistema original não se altera, 
conforme mostra a Figura 5.28, a trajetória em falta cruzará a mesma em um tempo menor. Por esta razão, surgem muitos casos em que instabilidade de velocidade ocorre antes da tensão no PCC violar a curva LVRT. Situações deste tipo se referem ao ponto $d$ estudado na seção 5.3.1. Casos deste tipo também ocorrem para a configuração WRIG, conforme mostra a Tabela 5.3. As funções energia $V$ e $V_{r}$ realizam as mesmas estimativas nestes casos. Como exemplo, mostra-se a Figura 5.38 para a configuração WRIG.

Tabela 5.3: Tempos críticos de abertura para a configuração WRIG.

\begin{tabular}{|c|c|c|c|c|c|c|}
\hline \multirow{2}{*}{$B_{12}(p u)$} & \multicolumn{2}{|c|}{$\begin{array}{l}\text { Sem limite } \\
\text { de tensão }\end{array}$} & \multicolumn{2}{|c|}{$\begin{array}{l}\text { Com limite de tensão } \\
\text { Curva LVRT do Brasil }\end{array}$} & \multicolumn{2}{|c|}{$\begin{array}{l}\text { Com limite de tensão } \\
\text { Curva LVRT dos EUA }\end{array}$} \\
\hline & $\begin{array}{l}\text { TCA método } \\
\text { clássico (ms) }\end{array}$ & $\begin{array}{l}\text { TCA método } \\
\text { direto (ms) }\end{array}$ & $\begin{array}{l}\text { TCA método } \\
\text { clássico (ms) }\end{array}$ & $\begin{array}{l}\text { TCA método } \\
\text { direto (ms) }\end{array}$ & $\begin{array}{l}\text { TCA método } \\
\text { clássico (ms) }\end{array}$ & $\begin{array}{l}\text { TCA método } \\
\text { direto }(\mathrm{ms})\end{array}$ \\
\hline \multicolumn{7}{|c|}{ Primeira ordem $d q$} \\
\hline$-0,3$ & 266 & 264 & $x^{a}$ & 264 & $x^{a}$ & 264 \\
\hline$-0,4$ & 283 & 285 & $x^{a}$ & 285 & $x^{a}$ & 285 \\
\hline$-0,6$ & 327 & 322 & $x^{a}$ & 322 & $x^{a}$ & 322 \\
\hline$-0,8$ & 385 & 380 & $x^{a}$ & 380 & $x^{a}$ & 380 \\
\hline$-1,0$ & 458 & 454 & $x^{a}$ & 454 & $x^{a}$ & 454 \\
\hline \multicolumn{7}{|c|}{ Terceira ordem $d q$} \\
\hline$-0,3$ & 582 & 401 & $x^{a}$ & 401 & $x^{a}$ & 401 \\
\hline$-0,4$ & 607 & 454 & $x^{a}$ & 454 & $x^{a}$ & 454 \\
\hline$-0,6$ & 668 & 563 & 577 & 752 & $x^{a}$ & 563 \\
\hline$-0,8$ & 751 & 676 & 609 & 607 & 676 & 682 \\
\hline$-1,0$ & 862 & 804 & 675 & 674 & $x^{a}$ & 804 \\
\hline \multicolumn{7}{|c|}{ Quinta ordem $d q$} \\
\hline$-0,3$ & 345 & 400 & $x^{a}$ & 400 & $x^{a}$ & 400 \\
\hline$-0,4$ & 379 & 456 & $x^{a}$ & 456 & $x^{a}$ & 456 \\
\hline$-0,6$ & 458 & 571 & $x^{a}$ & 571 & $x^{a}$ & 571 \\
\hline$-0,8$ & 559 & 677 & $x^{a}$ & 677 & $x^{a}$ & 677 \\
\hline$-1,0$ & 688 & 810 & $x^{a}$ & 810 & $x^{a}$ & 810 \\
\hline
\end{tabular}

${ }^{a}$ Ocorre a instabilidade de velocidade antes da tensão no PCC violar a curva LVRT.

As estimativas de TCAs apresentadas nas Tabelas 5.2 e 5.3 se mostram boas para os modelos em primeira ordem. Para os modelos em terceira e quinta ordens, boa parte das estimativas são muito conservadoras. Para os modelos em quinta ordem, os TCAs estimados se mostram em geral maiores que os TCAs obtidos via método clássico. Especificamente para estes modelos, as oscilações que ocorrem para a tensão no PCC muitas vezes impedem que as funções energia estimem adequadamente os TCAs, pois o ponto de cruzamento com a curva 

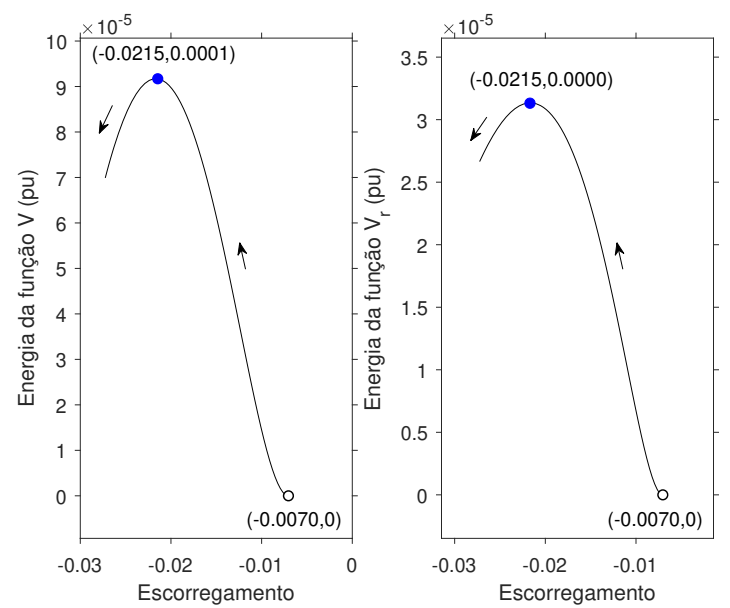

(a) Funções energia.

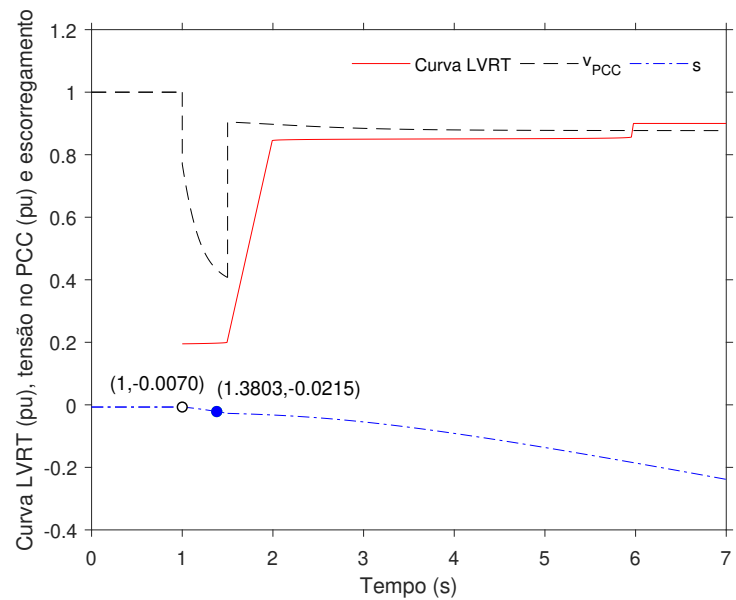

(b) Curva LVRT, tensão no PCC e escorregamento.

Figura 5.38: Funções energia e curva LVRT, tensão no PCC e escorregamento para a configuração WRIG modelada em primeira ordem nos eixos d e q considerando $r_{r} \cdot 1$. A susceptância da linha de transmissão é alterada em $t_{0}=1 \mathrm{~s}$ de $B_{12}=-10$ pu para $B_{12}=-0,8$ pu, retornando a $B_{12}=-10 \mathrm{pu}$ em $t_{a b}=1,5 \mathrm{~s}$.

LVRT não consegue ser devidamente detectado pelas funções.

A Tabela 5.4 mostra os TCAs obtidos para a configuração WRIG modelada em primeira ordem, considerando diferentes resistências para o rotor.

Tabela 5.4: Tempos críticos de abertura para a configuração WR/G modelada em primeira ordem nos eixos d e q considerando diferentes resistências do rotor.

\begin{tabular}{|c|c|c|c|c|c|c|}
\hline \multirow{2}{*}{$B_{12}(\mathrm{pu})$} & \multicolumn{2}{|c|}{$\begin{array}{l}\text { Sem limite } \\
\text { de tensão }\end{array}$} & \multicolumn{2}{|c|}{$\begin{array}{l}\text { Com limite de tensão } \\
\text { Curva LVRT do Brasil }\end{array}$} & \multicolumn{2}{|c|}{$\begin{array}{l}\text { Com limite de tensão } \\
\text { Curva LVRT dos EUA }\end{array}$} \\
\hline & $\begin{array}{l}\text { TCA método } \\
\text { clássico (ms) }\end{array}$ & $\begin{array}{l}\text { TCA método } \\
\text { direto (ms) }\end{array}$ & $\begin{array}{l}\text { TCA método } \\
\text { clássico (ms) }\end{array}$ & $\begin{array}{l}\text { TCA método } \\
\text { direto (ms) }\end{array}$ & $\begin{array}{l}\text { TCA método } \\
\text { clássico (ms) }\end{array}$ & $\begin{array}{l}\text { TCA método } \\
\text { direto (ms) }\end{array}$ \\
\hline
\end{tabular}

\begin{tabular}{l|l|l|l|l|l|l}
\hline \multicolumn{8}{c}{$r_{r} \cdot 1$ (resistência nominal do rotor) } \\
\hline$-0,3$ & 266 & 264 & $x^{a}$ & 264 & $x^{a}$ & 264 \\
$-0,4$ & 283 & 285 & $x^{a}$ & 285 & $x^{a}$ & 285 \\
$-0,6$ & 327 & 322 & $x^{a}$ & 322 & $x^{a}$ & 322 \\
$-0,8$ & 385 & 380 & $x^{a}$ & 380 & $x^{a}$ & 380 \\
$-1,0$ & 458 & 454 & $x^{a}$ & 454 & $x^{a}$ & 454 \\
\hline
\end{tabular}

$r_{r} \cdot 3$ (três vezes a resistência nominal do rotor)

\begin{tabular}{c|c|c|c|c|c|c}
\hline$-0,3$ & 798 & 796 & 526 & 518 & 798 & 802 \\
$-0,4$ & 848 & 847 & 572 & 567 & 848 & 847 \\
$-0,6$ & 980 & 982 & 653 & 642 & 983 & 982 \\
$-0,8$ & 1154 & 1156 & 724 & 715 & 1157 & 1156 \\
$-1,0$ & 1372 & 1370 & 789 & 786 & 1372 & 1371 \\
\hline
\end{tabular}


Tabela 5.4 - Continuação da página anterior

\begin{tabular}{c|c|c|c|c|c|c}
\hline \multicolumn{7}{c}{$r_{r} \cdot 5$ (cinco vezes a resistência nominal do rotor) } \\
\hline$-0,3$ & 1330 & 1328 & 550 & 540 & 888 & 896 \\
$-0,4$ & 1413 & 1414 & 602 & 598 & 1055 & 1060 \\
$-0,6$ & 1633 & 1629 & 694 & 693 & 1341 & 1345 \\
$-0,8$ & 1923 & 1923 & 775 & 764 & 1586 & 1583 \\
$-1,0$ & 2286 & 2287 & 845 & 842 & 1808 & 1809 \\
\hline & \multicolumn{7}{|c|}{$r_{r} \cdot 10($ dez vezes a resistência nominal do rotor) } \\
\hline$-0,3$ & 2651 & 2663 & 584 & 577 & 1008 & 1016 \\
$-0,4$ & 2821 & 2824 & 645 & 642 & 1204 & 1211 \\
$-0,6$ & 3253 & 3265 & 751 & 748 & 1541 & 1546 \\
$-0,8$ & 3827 & 3850 & 837 & 834 & 1832 & 1836 \\
$-1,0$ & 4556 & 4568 & 906 & 897 & 2094 & 2091 \\
\hline
\end{tabular}

${ }^{a}$ Ocorre a instabilidade de velocidade antes da tensão no PCC violar a curva LVRT.

Conforme pode ser observado na Tabela 5.4, os TCAs aumentam à medida que se aumenta a resistência do rotor. Constata-se pelas Figuras 5.29 e 5.30 que quanto maiores as REs dos sistemas original e auxiliar, mais tempo as trajetórias levarão para cruzar a sua fronteira, implicando naturalmente em maiores TCAs. Nota-se que os TCAs estimados são muito próximos daqueles obtidos via método clássico. A Figura 5.39 mostra os resultados referentes à configuração WRIG com uma resistência do rotor três vezes maior $\left(r_{r} \cdot 3\right)$.

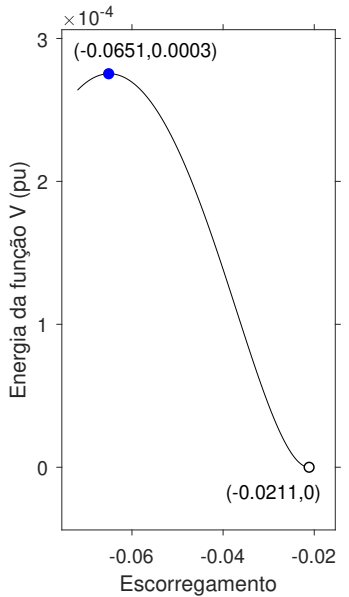

(a) Funções energia.

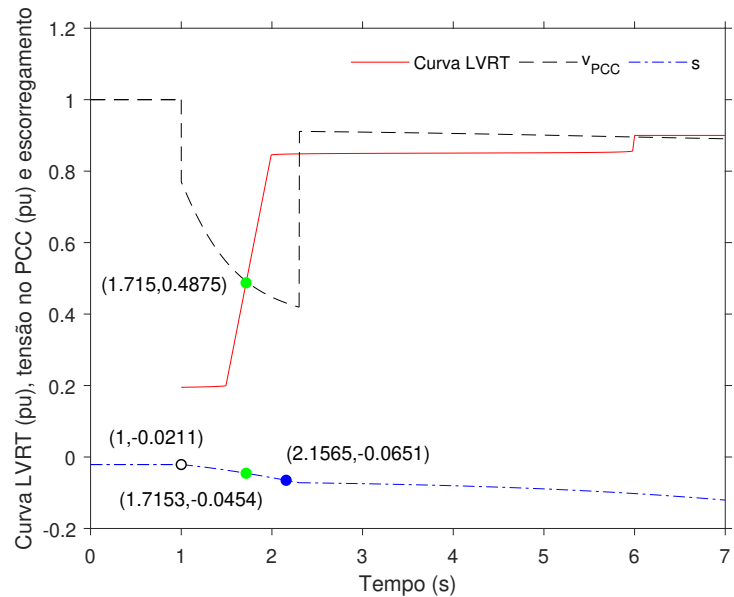

(b) Curva LVRT, tensão no PCC e escorregamento.

Figura 5.39: Funções energia e curva LVRT, tensão no PCC e escorregamento para a configuração WRIG modelada em primeira ordem nos eixos d e q considerando $r_{r}$. 3. A susceptância da linha de transmissão é alterada em $t_{0}=1 \mathrm{~s}$ de $B_{12}=-10$ pu para $B_{12}=-0,8$ pu, retornando a $B_{12}=-10 \mathrm{pu}$ em $t_{a b}=2,3 \mathrm{~s}$.

Ao se comparar as Figuras 5.38 e 5.39, verifica-se que a instabilidade de velocidade ocorre neste último caso após a violação da curva LVRT. Constata-se portanto, que mais valores são 
possíveis para as variáveis de estado s e $r$ sem que o sistema se torne instável e sem que a tensão no PCC viole a curva LVRT.

A Tabela 5.5 mostra os TCAs obtidos para a configuração WRIG modelada em primeira ordem considerando diferentes tensões aplicadas ao rotor.

Tabela 5.5: Tempos críticos de abertura para a configuração WRIG modelada em primeira ordem nos eixos $d$ e $q$ considerando diferentes tensões aplicadas ao rotor

\begin{tabular}{|c|c|c|c|c|c|c|}
\hline \multirow{2}{*}{$B_{12}(\mathrm{pu})$} & \multicolumn{2}{|c|}{$\begin{array}{l}\text { Sem limite } \\
\text { de tensão }\end{array}$} & \multicolumn{2}{|c|}{$\begin{array}{l}\text { Com limite de tensão } \\
\text { Curva LVRT do Brasil }\end{array}$} & \multicolumn{2}{|c|}{$\begin{array}{l}\text { Com limite de tensão } \\
\text { Curva LVRT dos EUA }\end{array}$} \\
\hline & $\begin{array}{l}\text { TCA método } \\
\text { clássico (ms) }\end{array}$ & $\begin{array}{c}\text { TCA } \\
\text { PEBS (ms) }\end{array}$ & $\begin{array}{l}\text { TCA método } \\
\text { clássico (ms) }\end{array}$ & $\begin{array}{c}\text { TCA } \\
\text { PEBS (ms) }\end{array}$ & $\begin{array}{l}\text { TCA método } \\
\text { clássico (ms) }\end{array}$ & $\begin{array}{c}\text { TCA } \\
\text { PEBS (ms) }\end{array}$ \\
\hline \multicolumn{7}{|c|}{$u_{q r}=0, u_{d r}=0$} \\
\hline$-0,3$ & 266 & 264 & $x^{a}$ & 264 & $x^{a}$ & 264 \\
\hline$-0,4$ & 283 & 285 & $x^{a}$ & 285 & $x^{a}$ & 285 \\
\hline$-0,6$ & 327 & 322 & $x^{a}$ & 322 & $x^{a}$ & 322 \\
\hline$-0,8$ & 385 & 380 & $x^{a}$ & 380 & $x^{a}$ & 380 \\
\hline$-1,0$ & 458 & 454 & $x^{a}$ & 454 & $x^{a}$ & 454 \\
\hline \multicolumn{7}{|c|}{$u_{q r}=0, u_{d r}=-0,005 \mathrm{pu}$} \\
\hline$-0,3$ & 453 & 451 & $x^{a}$ & 451 & $x^{a}$ & 451 \\
\hline$-0,4$ & 483 & 483 & $x^{a}$ & 483 & $x^{a}$ & 483 \\
\hline$-0,6$ & 550 & 552 & $x^{a}$ & 552 & $x^{a}$ & 552 \\
\hline$-0,8$ & 631 & 634 & $x^{a}$ & 634 & $x^{a}$ & 634 \\
\hline$-1,0$ & 725 & 721 & 689 & 683 & $x^{a}$ & 721 \\
\hline \multicolumn{7}{|c|}{$u_{q r}=0, u_{d r}=0,0025 \mathrm{pu}$} \\
\hline$-0,3$ & 155 & 152 & $x^{a}$ & 152 & $x^{a}$ & 152 \\
\hline$-0,4$ & 163 & 160 & $x^{a}$ & 160 & $x^{a}$ & 160 \\
\hline$-0,6$ & 187 & 183 & $x^{a}$ & 183 & $x^{a}$ & 183 \\
\hline$-0,8$ & 224 & 225 & $x^{a}$ & 225 & $x^{a}$ & 225 \\
\hline$-1,0$ & 274 & 270 & $x^{a}$ & 270 & $x^{a}$ & 270 \\
\hline
\end{tabular}

${ }^{a}$ Ocorre a instabilidade de velocidade antes da tensão no PCC violar a curva LVRT.

Percebe-se que os maiores TCAs registrados se referem ao caso em que $u_{q r}=0$ pu e $u_{d r}$ $=-0,005$ pu. Para estas tensões, apenas para a perturbação $B_{12}=-1,0$ pu a instabilidade de velocidade ocorre após a tensão no PCC violar a curva LVRT. Para os demais casos, a instabilidade de velocidade sempre ocorre antes. As estimativas realizadas pelas funções energia são em sua maioria bem próximas dos TCAs obtidos via método clássico.

A Tabela 5.6 mostra os TCAs obtidos para a configuração DFIG com as máquinas modeladas em primeira, terceira e quinta ordens. Para esta configuração de aerogerador, algumas situações diferentes ocorrem, sendo as mesmas devidamente destacadas. 
Tabela 5.6: Tempos críticos de abertura para a configuração DFIG.

\begin{tabular}{|c|c|c|c|c|c|c|}
\hline \multirow{2}{*}{$u_{x 1}(\mathrm{pu})$} & \multicolumn{2}{|c|}{$\begin{array}{l}\text { Sem limite } \\
\text { de tensão }\end{array}$} & \multicolumn{2}{|c|}{$\begin{array}{l}\text { Com limite de tensão } \\
\text { Curva LVRT do Brasil }\end{array}$} & \multicolumn{2}{|c|}{$\begin{array}{l}\text { Com limite de tensão } \\
\text { Curva LVRT dos EUA }\end{array}$} \\
\hline & $\begin{array}{l}\text { TCA método } \\
\text { clássico (ms) }\end{array}$ & $\begin{array}{l}\text { TCA método } \\
\text { direto (ms) }\end{array}$ & $\begin{array}{l}\text { TCA método } \\
\text { clássico (ms) }\end{array}$ & $\begin{array}{l}\text { TCA método } \\
\text { direto (ms) }\end{array}$ & $\begin{array}{l}\text { TCA método } \\
\text { clássico (ms) }\end{array}$ & $\begin{array}{l}\text { TCA método } \\
\text { direto (ms) }\end{array}$ \\
\hline \multicolumn{7}{|c|}{ Primeira ordem $d q$} \\
\hline 0,75 & $1191^{b}$ & $x^{a}$ & 803 & 849 & $x^{c}$ & $x^{c}$ \\
\hline 0,80 & $x^{a}$ & $x^{a}$ & 916 & 924 & 2436 & 2523 \\
\hline 0,85 & $x^{a}$ & $x^{a}$ & 991 & 990 & 2803 & 2794 \\
\hline \multicolumn{7}{|c|}{ Terceira ordem $d q$} \\
\hline 0,75 & $1764^{b}$ & $x^{a}$ & 831 & 857 & $x^{c}$ & $x^{c}$ \\
\hline 0,80 & $x^{a}$ & $x^{a}$ & 903 & 915 & 2469 & 2469 \\
\hline 0,85 & $x^{a}$ & $x^{a}$ & 969 & 978 & 2729 & 2756 \\
\hline \multicolumn{7}{|c|}{ Quinta ordem $d q$} \\
\hline 0,75 & $1335^{b}$ & $x^{a}$ & 821 & 842 & $x^{c}$ & $x^{c}$ \\
\hline 0,80 & $x^{a}$ & $x^{a}$ & 900 & 889 & 2470 & 2478 \\
\hline 0,85 & $x^{a}$ & $x^{a}$ & 962 & 960 & 2722 & 2650 \\
\hline
\end{tabular}

a Não ocorre instabilidade de velocidade. ${ }^{b}$ Não ocorre instabilidade de velocidade, mas a velocidade atinge 1,4 pu no tempo especificado. c Não ocorre violação da curva LVRT antes da velocidade atingir 1,4 pu.

A nota referente ao ponto a diz respeito aos casos em que a perturbação foi mantida durante $10 \mathrm{~s}$ e mesmo assim a instabilidade de velocidade não ocorreu. Para o ponto $b$, indicam-se os casos em que a instabilidade de velocidade não ocorreu, porém a velocidade do rotor atingiu a marca de 1,4 pu no TCA registrado. Esta velocidade corresponde à velocidade de corte especificada pela relação entre a potência mecânica e a velocidade do rotor, exibida na Figura 3.9. A fim de exemplificar esta situação, apresenta-se a Figura 5.40. Para o ponto c, a violação da curva LVRT não ocorreu antes da velocidade atingir o valor 1,4 pu.

Ainda que nem todos os TCAs estimados sejam iguais ou imediatamente inferiores aos TCAs obtidos via método clássico, pode-se dizer que para as perturbações aplicadas, as funções energia foram capazes de realizar estimativas próximas dos resultados obtidos via método clássico na maioria dos casos. Para ilustrar um caso da Tabela 5.6, apresenta-se a Figura 5.41. De acordo com o que se mostra nesta figura, o escorregamento estimado pela função energia $V_{r}$ implica em um TCA estimado igual a 857 ms, um pouco distante do TCA obtido via método clássico, que apresenta o valor $831 \mathrm{~ms}$. Conforme pode ser observado na Figura 5.41(b), o cruzamento da tensão no PCC com a curva LVRT ocorre em um tempo diferente do TCA estimado. 


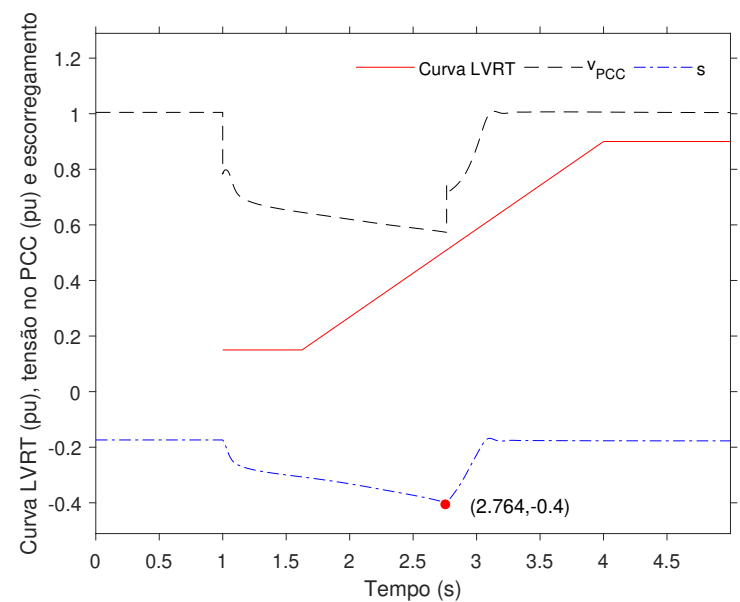

Figura 5.40: Velocidade do rotor atingindo 1,4 pu $(s=-0,4$ pu) para a configuração DFIG com a máquina modelada em terceira ordem nos eixos $d$ e $q$. A tensão da barra infinita é alterada em $t_{0}=$ $1 \mathrm{~s}$ de $u_{x 1}=1$ pu para $u_{x 1}=0,75 \mathrm{pu}$, retornando $a u_{x 1}=1 \mathrm{pu} \mathrm{em} t_{a b}=2.764 \mathrm{~s}$.

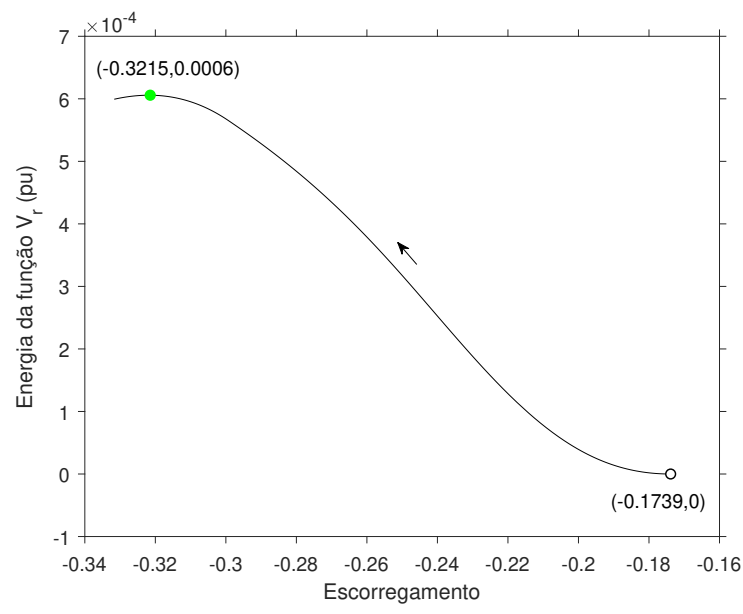

(a) Função energia.

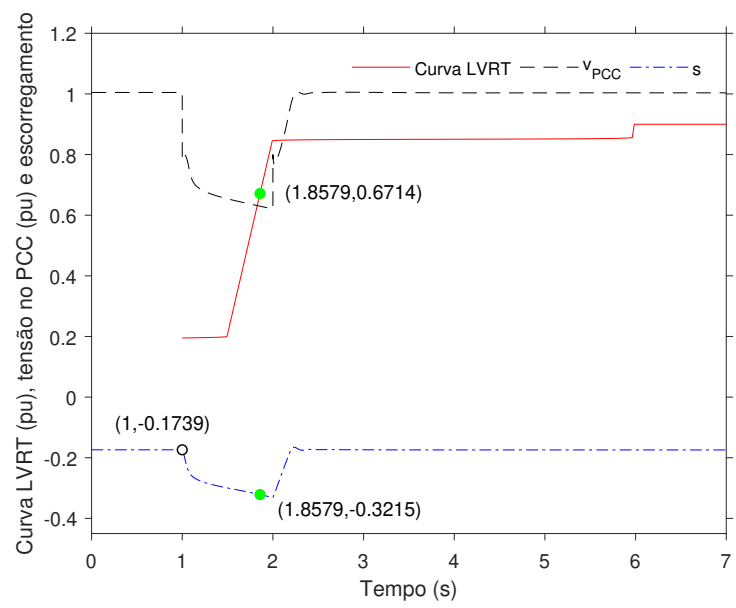

(b) Curva LVRT, tensão no PCC e escorregamento.

Figura 5.41: Funções energia e curva LVRT, tensão no PCC e escorregamento para a configuração DFIG com a máquina modelada em terceira ordem nos eixos $d$ e $q$. A tensão da barra infinita é alterada em $t_{0}=1 \mathrm{~s}$ de $u_{x 1}=1$ pu para $u_{x 1}=0,75 \mathrm{pu}$, retornando a $u_{x 1}=1 \mathrm{pu} \mathrm{em} t_{a b}=2 \mathrm{~s}$.

Por fim, apresenta-se a Tabela 5.7, com o intuito de exibir os TCAs para a perturbação testada na seção 5.2 no início deste capítulo, além de mostrar os TCAs para outras duas perturbações, aplicadas mais uma vez na tensão da barra infinita.

De acordo com o que apresenta a Tabela 5.7, boa parte das estimativas realizadas se mostram próximas dos TCAs obtidos via método clássico. Percebe-se também que a maioria das estimativas são conservadoras. Apenas para a configuração SCIG e perturbação $u_{x 1}=$ 0,85 pu, as funções energia realizaram estimativas muito distantes dos TCAs obtidos via método clássico. 
Tabela 5.7: Tempos críticos de abertura para as configurações SCIG, WRIG e DFIG modeladas em terceira ordem nos eixos $d$ e $q$.

\begin{tabular}{|c|c|c|c|c|c|c|}
\hline \multirow{2}{*}{$u_{x 1}(\mathrm{pu})$} & \multicolumn{2}{|c|}{$\begin{array}{l}\text { Sem limite } \\
\text { de tensão }\end{array}$} & \multicolumn{2}{|c|}{$\begin{array}{l}\text { Com limite de tensão } \\
\text { Curva LVRT do Brasil }\end{array}$} & \multicolumn{2}{|c|}{$\begin{array}{l}\text { Com limite de tensão } \\
\text { Curva LVRT dos EUA }\end{array}$} \\
\hline & $\begin{array}{l}\text { TCA método } \\
\text { clássico (ms) }\end{array}$ & $\begin{array}{l}\text { TCA método } \\
\text { direto (ms) }\end{array}$ & $\begin{array}{l}\text { TCA método } \\
\text { clássico (ms) }\end{array}$ & $\begin{array}{l}\text { TCA método } \\
\text { direto (ms) }\end{array}$ & $\begin{array}{l}\text { TCA método } \\
\text { clássico (ms) }\end{array}$ & $\begin{array}{l}\text { TCA método } \\
\text { direto (ms) }\end{array}$ \\
\hline \multicolumn{7}{|c|}{ SCIG } \\
\hline 0,75 & $x^{a}$ & $x^{a}$ & 893 & 894 & 2371 & 2365 \\
\hline 0,80 & $x^{a}$ & $x^{a}$ & 940 & 938 & 2591 & 2586 \\
\hline 0,85 & $x^{a}$ & $x^{a}$ & 986 & 500 & 2785 & 500 \\
\hline \multicolumn{7}{|c|}{ WRIG $\left(r_{r} \cdot 1\right)$} \\
\hline 0,75 & 881 & 791 & 871 & 791 & 881 & 791 \\
\hline 0,80 & 1152 & 1059 & 915 & 917 & 1152 & 1059 \\
\hline 0,85 & 1727 & 1638 & 965 & 965 & 1727 & 1638 \\
\hline \multicolumn{7}{|c|}{ WRIG $\left(r_{r} \cdot 3\right)$} \\
\hline 0,75 & 2021 & 1987 & 896 & 895 & 2021 & 1987 \\
\hline 0,80 & 2626 & 2590 & 937 & 929 & 2479 & 2477 \\
\hline 0,85 & 3882 & 3853 & 980 & 973 & 2672 & 2662 \\
\hline \multicolumn{7}{|c|}{ DFIG } \\
\hline 0,75 & $1764^{b}$ & $x^{a}$ & 831 & 857 & 1935 & $x^{c}$ \\
\hline 0,80 & $x^{a}$ & $x^{a}$ & 903 & 915 & 2469 & 2469 \\
\hline 0,85 & $x^{a}$ & $x^{a}$ & 969 & 978 & 2729 & 2756 \\
\hline
\end{tabular}

${ }^{a}$ Não ocorre instabilidade de velocidade. ${ }^{b}$ Não ocorre instabilidade de velocidade, mas a velocidade atinge 1,4 pu no tempo especificado. ${ }^{c}$ Não ocorre violação da curva LVRT antes da velocidade atingir 1,4 pu.

Assim como para o modelo em primeira ordem, os TCAs obtidos para a configuração WRIG em terceira ordem também são maiores quando se considera uma resistência do rotor maior. Evidentemente, quanto mais severa a perturbação, menor o TCA.

\subsection{Comentários finais}

Neste capítulo foram apresentados resultados de simulações computacionais realizadas para o sistema teste modelado no capítulo 3. Foram investigados os comportamentos dinâmicos dos aerogeradores SCIG, WRIG e DFIG, avaliando-se o problema de estabilidade de velocidade e o problema de violação de limites de tensão frente a grandes perturbações.

Inicialmente, foram apresentadas simulações no domínio do tempo. Mostrou-se um caso em que o aerogerador se tornou instável após a perturbação, de modo que foi possível verificar os mecanismos de instabilidade envolvidos. Para outros casos constatou-se que mesmo 
permanecendo estáveis, os aerogeradores violaram os limites de tensão impostos pela curva LVRT do Brasil, de modo que tais unidades de geração ficaram susceptíveis à desconexão da rede nesta situação. Concluiu-se que os modelos apresentaram resultados satisfatórios.

Utilizando-se da teoria apresentada no capítulo 4, foram apresentadas para a configuração SCIG a RER e a RE do sistema auxiliar, além de trajetórias em falta e pós-falta no domínio do tempo e no espaço de estados, para exemplificar e explicar as várias situações possíveis ao se considerar um sistema sob restrição. Foi possível mostrar que a RER é igual à RE do sistema auxiliar, dada a boa aproximação proporcionada pelas curvas LVRT. Foi possível também verificar que a RE do sistema auxiliar pode variar significativamente conforme o perfil do requisito operacional.

Em seguida foram apresentadas diferentes REs para o sistema auxiliar, tanto para a configuração SCIG como para a configuração WRIG. Para o aerogerador SCIG foram consideradas diferentes constantes de inércia e para o aerogerador WRIG foram consideradas diferentes resistências do rotor e diferentes tensões aplicadas ao rotor. Desprezando a inércia da turbina, verificou-se que as REs se tornaram maiores. Aumentando-se a resistência do rotor, observou-se que as REs também se tornaram maiores. Ao se considerar diferentes tensões aplicadas ao rotor, verificou-se que as REs podem se tornar menores ou maiores. Ao se alterar os parâmetros das máquinas foi possível verificar os efeitos na caracterização das REs.

Para várias perturbações aplicadas ao sistema teste, o problema de estabilidade de velocidade e o problema de violação de limites de tensão foram avaliados em termos de TCAs. Os resultados estimados pelas funções energia construídas no capítulo 4 foram comparados aos resultados obtidos via método clássico. Para a grande maioria das perturbações aplicadas, verificou-se que as estimativas realizadas se mostraram muito próximas dos resultados obtidos via método clássico, ainda que nem todas as estimativas tenham se apresentado conservadoras. Foi possível verificar que ao desprezar a inércia da turbina, os TCAs se tornaram significativamente menores. À medida que se aumentou a resistência do rotor, os TCAs se tornaram cada vez maiores. Ao se considerar diferentes tensões aplicadas ao rotor do gerador, TCAs maiores ou menores puderam ser obtidos em relação ao caso de não se aplicar tensão ao rotor. Para os modelos em primeira, terceira e quinta ordens da máquina, diferentes TCAs foram obtidos, dada a dinâmica específica de cada modelo.

Em suma, os resultados numéricos obtidos permitem concluir que: i) os modelos de aerogeradores sob estudo apresentaram resultados satisfatórios, isto é, o comportamento dinâmico de cada modelo mostrou-se coerente com aqueles disponíveis na literatura, ii) para cada ordem do modelo de um mesmo aerogerador, distintos comportamentos dinâmicos foram obtidos, implicando naturalmente em diferentes tempos críticos de abertura, iii) observando-se as trajetórias no domínio do tempo e no espaço de estados, foi possível compreender as diferentes situações que podem ocorrer para as trajetórias em falta e pós-falta, iv) para distintos requisitos operacionais e para distintos parâmetros da máquina de indução, as regiões de estabilidade para um dado ponto de equilíbrio mostraram-se significativamente diferentes e 
v) os tempos críticos de abertura para a mesma perturbação mostraram-se bastante distintos ao se considerar diferentes curvas LVRT e configurações de aerogerador.

É possível concluir que as funções energia foram capazes de realizar boas estimativas na maioria dos casos estudados, para todos os modelos, ainda que nem sempre os resultados obtidos se mostraram conservadores. Tratou-se de identificar via método clássico o primeiro tempo de abertura cuja curva LVRT fosse violada, seja no período em falta ou no período pósfalta. Constatou-se para certos casos, que o tempo de abertura relativo a situação em que a curva é violada no período pós-falta é menor que o tempo de abertura relativo à situação em que a curva é violada no período em falta. Em outras palavras, verificou-se que durante a perturbação, a violação não foi observada, mas ao se eliminar o distúrbio, a violação ocorreu em algum momento no período pós-falta. Visto que a função energia proposta (método PEBS estendido) detecta apenas violações que ocorrem no período em falta, não foi possível detectar a violação no período pós-falta. Em situações deste tipo, o TCA estimado se mostrou muito maior que o TCA obtido via método clássico, pois foi necessário sustentar a perturbação para que a função energia pudesse detectar a violação, realizando assim uma estimativa distante do valor verdadeiro. Demais divergências entre as estimativas e os resultados obtidos via método clássico se devem à simplicidade das funções energia propostas para analisar os diferentes modelos de aerogeradores.

Para a maioria dos casos analisados, verificou-se que os limites de tensão foram violados antes dos aerogeradores perderem a estabilidade de velocidade, evidenciando a importância de se representar tais limites na formulação dos métodos diretos, para assim contribuir com as análises de segurança em tempo real de sistemas elétricos de potência na presença de aerogeradores. 


\section{Capítulo 6}

\section{Conclusões e trabalhos futuros}

\subsection{Conclusões}

Visto que as teorias referentes à região de estabilidade, à função energia e aos métodos diretos foram concebidas para estudar modos de instabilidade associados aos geradores síncronos (estabilidade de ângulo) das fontes tradicionais, esta tese tratou de dar um passo na direção de revisar o problema de estabilidade transitória e a teoria dos métodos diretos para incluir em seus fundamentos modelos de fontes alternativas e seus limites operacionais. Particularmente, o método PEBS foi aplicado para avaliar o problema de estabilidade de velocidade e o problema de violação de limites de tensão definidos pela curva LVRT, considerando as principais configurações de aerogeradores equipados com gerador de indução, especificamente os aerogeradores dos tipos A, B e C.

Para realizar os estudos propostos nesta tese, especialmente no que diz respeito à obtenção das regiões de estabilidade, das trajetórias no espaço de estados, além das estimativas dos tempos críticos de abertura via método direto, houve a necessidade de conhecer as equações diferenciais e algébricas que modelam cada configuração de aerogerador. Desta forma, optou-se por desenvolver a modelagem passo a passo, o que permitiu tornar clara a compreensão de cada modelo, assim como o seu processo de simulação computacional, que é particularmente mais complicado para a configuração do tipo C.

Ao se desconsiderar o limite operacional, para cada modelo completo foi analisado somente o problema de estabilidade de velocidade. Ao se considerar o limite operacional, além do problema de estabilidade de velocidade, analisou-se também o problema de violação de limites de tensão. A conceituação do método direto com limites operacionais foi estabelecida via teoria de sistemas dinâmicos restritos e via conceito de região de estabilidade restrita. Explorando estes itens, foi possível compreender como a região de estabilidade de um sistema sujeito a uma restrição é caracterizada. Tal região, definida como uma região de estabilidade restrita, foi estudada por meio de um sistema auxiliar de equações cuja região de estabilidade é irrestrita e igual à região de estabilidade restrita do sistema dinâmico restrito.

Visto a curva LVRT representar limites inferiores de tensão em função do tempo e a teoria dos métodos diretos ser fundamentada em sistemas dinâmicos autônomos, introduziu- 
se uma variável de estado auxiliar para modelar este requisito por meio da solução de uma equação diferencial auxiliar, dependente unicamente desta nova variável de estado, de modo que o sistema dinâmico sob estudo seja autônomo. Escolhendo-se duas curvas LVRT distintas (Brasil e EUA), as equações diferenciais auxiliares construídas mostraram-se capazes de realizar boas aproximações das curvas LVRT reais. Os resultados mostraram que dada a boa aproximação de cada curva LVRT, a região de estabilidade do sistema auxiliar pôde ser considerada numericamente muito próxima da região de estabilidade restrita, permitindo que os efeitos de cada curva LVRT sejam automaticamente levados em consideração nas análises de estabilidade. Constatou-se também que esta técnica pode ser usada para modelar outros limites operacionais, sendo uma das contribuições desta tese.

Para estimar os tempos críticos de abertura frente a várias perturbações, tanto para o modo de instabilidade associado à aceleração do rotor (estabilidade de velocidade) como para o problema de violação de limites de tensão, novas funções energia numéricas foram propostas, considerando as configurações de aerogeradores supracitadas. A primeira função energia foi definida para estimar tempos críticos de abertura relativos ao sistema original, isto é, relativos ao sistema não submetido à quaisquer limites operacionais, utilizando-se do método PEBS. Explorando a teoria de sistemas dinâmicos restritos e o conceito de região de estabilidade restrita, o método PEBS foi estendido para incluir o problema de violação de limites de tensão definidos pela curva LVRT. Neste sentido, foi possível conceituar a avaliação da estabilidade via método direto de um sistema elétrico sujeito a um limite operacional.

Verificou-se, para a maioria dos casos analisados, que estimativas muito boas dos verdadeiros tempos críticos de abertura foram obtidas por meio das funções energia propostas. Na maioria das simulações elaboradas, as estimativas dos tempos críticos de abertura foram restringidas pela violação dos limites de tensão, isto é, a violação de tais limites ocorreu antes da instabilidade de velocidade, mostrando a importância de se considerar limites operacionais nas análises de estabilidade transitória e na formulação dos métodos diretos, a fim de evitar que o sistema elétrico de potência fique vulnerável.

Dentre os resultados obtidos, destaca-se que: i) para distintos limites operacionais e para distintos parâmetros da máquina de indução, as regiões de estabilidade para um dado ponto de equilíbrio podem ser significativamente diferentes, ii) para a maioria dos casos analisados, os limites de tensão são violados antes dos aerogeradores perderem a estabilidade de velocidade, o que mostra como é importante considerar limites operacionais nas avaliações de estabilidade via método direto para evitar que o sistema elétrico de potência fique vulnerável e iii) as funções energia desenvolvidas, tanto para avaliar o problema de estabilidade de velocidade, como para avaliar o problema de violação de limites de tensão, são em geral capazes de realizar boas estimativas dos tempos críticos de abertura.

Os estudos realizados permitem concluir que a abordagem utilizada para tratar os problemas de estabilidade de velocidade e de violação de limites de tensão foi capaz de proporcionar resultados satisfatórios. Avaliando-se diferentes modelos de aerogeradores, verificou-se que 
para o modelo da máquina em primeira ordem as funções energia foram capazes de realizar estimativas muito próximas, porém nem sempre conservadoras, dos tempos críticos obtidos via método clássico. Por outro lado, para o modelo da máquina em terceira ordem, estimativas nem sempre muito próximos foram obtidas, porém resultados conservadores foram obtidos na maioria dos casos analisados. Já considerando o modelo da máquina em quinta ordem, houve maior diferença em relação aos tempos críticos obtidos via método clássico. Sendo assim, para os modelos de aerogeradores analisados, aqueles que consideram a máquina em terceira ordem correspondem às opções cujas funções energia propostas são capazes de realizar as melhores estimativas dos tempos críticos de abertura.

Ainda que um sistema teste simples tenha sido considerado nesta tese, de forma inédita foram avaliados via método direto o problema de estabilidade de velocidade e o problema de violação de limites de tensão de aerogeradores equipados com gerador de indução. A metodologia utilizada para abordar ambos os problemas pode ser aplicada para estudar outros problemas relativos a sistemas compostos por diferentes unidades de geração e distintos limites operacionais. Os estudos inéditos elaborados nesta tese, em especial as avaliações de estabilidade via método direto de um sistema elétrico de potência sob restrição, contribuem com análises e técnicas que podem ser utilizadas nos centros de operação para realizar análises dinâmicas de segurança em tempo real de sistemas elétricos de potência mais complexos, compostos por fontes tradicionais e também por fontes alternativas e seus limites operacionais.

\subsection{Trabalhos futuros}

No contexto desta tese, sugere-se para estudos de estabilidade via método direto:

- Considerar modelos mais detalhados para os aerogeradores. É possível por exemplo melhorar a representação do sistema mecânico (Muyeen et al., 2007) e da turbina (Milano, 2010), além de incluir diferentes sistemas de controle (Ackermann, 2012);

- Avaliar o aerogerador do tipo D e também outras fontes alternativas, como sistemas fotovoltaicos;

- Analisar sistemas multi-máquinas, considerando diferentes sistemas de geração;

- Analisar limites operacionais em smart-grids;

- Investigar outros métodos diretos capazes de oferecer resultados ainda melhores. O método CUEP é uma escolha interessante (Chiang, 2011), pois o mesmo não é baseado em conjecturas físicas que possam levar a estimativas não conservadoras, como é o caso do PEBS;

- Investigar outras funções energia, sejam numéricas ou analíticas; 
- Elaborar análises detalhadas sobre as escalas de tempo das variáveis dinâmicas dos modelos;

- Utilizar a técnica proposta para representar outros tipos de limites operacionais, como limites de corrente referentes aos conversores da configuração DFIG;

- Incluir diferentes tipos de limites operacionais no mesmo problema. 


\section{Referências bibliográficas}

Abad et al. (2011) G. Abad, J. López, M. A. Rodríguez, L. Marroyo e G. Iwanski. Doubly fed induction machine: modeling and control for wind energy generation. 1. ${ }^{a}$ edição. Hoboken: John Wiley \& Sons, 2011. 640 p. Citado na(s) página(s). 21, 79

Achilles e Pöller (2003) S. Achilles e M. Pöller. Direct drive synchronous machine models for stability assessment of wind farms. In: Proceedings of Forth International Workshop on Large-Scale Integration of Wind Power and Transmission Networks for Offshore Wind Farms, 2003, Billund. Anais... Billund: 2003. Citado na(s) página(s). 84

Ackermann (2012) T. Ackermann, editor. Wind power in power systems. 2. ${ }^{a}$ edição. Chichester: John Wiley \& Sons, 2012. 1049 p. Citado na(s) página(s). 19, 20, 21, 27, 28, 34, 79, 171

Akhmatov (2003) V. Akhmatov. Analysis of dynamic behaviour of electric power systems with large amount of wind power. $135 \mathrm{f}$. Tese de doutorado, Technical University of Denmark, Kongens Lyngby, 2003. Citado na(s) página(s). 10, 12, 22

Akhmatov (2005) V. Akhmatov. Modelling and ride-through capability of variable speed wind turbines with permanent magnet generators. Wind Energy. v. 9, n. 4, p. 313-326, nov. 2005. Citado na(s) página(s). 33

Alberto (2006) L. F. C. Alberto. Caracterização e estimativas da área de atração de sistemas dinâmicos não lineares. 52 f. Tese de livre docência, Universidade de São Paulo, São Carlos, 2006. Citado na(s) página(s). 5 
Alberto (2000) L. F. C. Alberto. O princípio de invariância de LaSalle estendido aplicado ao estudo de coerência de geradores e à análise de estabilidade transitória multi-“swing". 78 f. Tese de doutorado, Universidade de São Paulo, São Carlos, 2000. Citado na(s) página(s). 5

Alberto et al. (2001) L. F. C. Alberto, F. H. J. R. Silva e N. G. Bretas. Direct methods for transient stability analysis in power systems: state of art and future perspectives. In: IEEE Power Tech Conference, 2001, Porto. Anais... Porto: set. 2001. Citado na(s) página(s). 6, 7

Almeida (2010) B. Almeida. Modelagem do motor de indução em estudos de estabilidade de tensão. 65 f. Trabalho de conclusão de curso, Universidade de São Paulo, São Carlos, 2010. Citado na(s) página(s). 12, 45, 123, 125

Anaya-Lara et al. (2005) O. Anaya-Lara, X. Wu, P. Cartwright, J. B. Ekanayake e N. Jenkins. Performance of doubly fed induction generator (DFIG) during network faults. Wind Engineering. v. 29, n. 1, p. 49-66, 2005. Citado na(s) página(s). 75

Anaya-Lara et al. (2009) O. Anaya-Lara, N. Jenkins e J. Ekanayake. Wind energy generation: modelling and control. 1. ${ }^{a}$ edição. West Sussex: John Wiley \& Sons, 2009. 269 p. Citado na(s) página(s). 22, 48, 75, 98

ANEEL (2019) ANEEL. Banco de informações de geração, 2019. Disponível em: http://www2. aneel.gov.br/aplicacoes/capacidadebrasil/capacidadebrasil.cfm. Acesso em: 29/04/2019. citado na(s) página(s). 18

Aylet (1958) P. D. Aylet. The energy-integral criterion of transient stability limits of power systems. Proceedings of the IEE - Part C: Monographs. v. 105, n. 8, p. 527-536, set. 1958. Citado na(s) página(s). 5

Balu et al. (1992) N. Balu, T. Bertram, A. Bose, V. Brandwajn, G. Cauley, D. Curtice, A. Fouad, L. Fink, M. G. Lauby, B. F. Wollenberg e J. N. Wrubel. On-line power system security analysis. Proceedings of the IEEE. v. 80, n. 2, p. 262-280, fev. 1992. Citado na(s) página(s). 2

Billinton e Allan (1996) R. Billinton e R. N. Allan. Reliability evaluation of power systems. 2. ${ }^{a}$ edição. New York: Plenum, 1996. 532 p. Citado na(s) página(s). 2 
Boemer et al. (2011) J. C. Boemer, A. A. van der Meer, B. G. Rawn, R. L. Hendriks, A. R. Ciupuliga, M. Gibescu, W. L. Kling e J. A. Ferreira. Fault ride-through requirements for onshore wind power plants in Europe: the needs of the power system. In: IEEE Power and Energy Society General Meeting, 2011, San Diego. Anais... San Diego: jul. 2011. Citado na(s) página(s). 29

Bolik (2004) S. M. Bolik. Modelling and analysis of variable speed wind turbines with induction generator during grid fault. $106 \mathrm{f}$. Tese de doutorado, Institute of Energy Technology Aalborg University, Aalborg, 2004. Citado na(s) página(s). 21, 22

Bollen e Hassan (2011) M. Bollen e F. Hassan. Integration of distributed generation in the power system. 1. ${ }^{a}$ edição. Hoboken: John Wiley \& Sons, 2011. 520 p. Citado na(s) página(s). 29,33

Brauer e Soudack (1979) F. Brauer e A. C. Soudack. Stability regions in predator-prey systems with constant-rate prey harvesting. Journal of Mathematical Biology - Springer. v. 8, n. 1, p. 55-71, 1979. Citado na(s) página(s). 6

Bretas e Alberto (2000) N. G. Bretas e L. F. C. Alberto. Estabilidade transitória em sistemas eletroenergéticos. 1. ${ }^{a}$ edição. São Carlos: EESC-USP, 2000. 155 p. Citado na(s) página(s). 5, 8, 116

Burton et al. (2011) T. Burton, N. Jenkins, D. Sharpe e E. Bossanyi. Wind energy handbook. 2. ${ }^{a}$ edição. Chichester: John Wiley \& Sons, 2011.780 p. Citado na(s) página(s). 26, 27, 79

Camm et al. (2009) E. H. Camm, M. R. Behnke, O. Bolado, M. Bollen, M. Bradt, C. Brooks, W. Dilling, M. Edds, W. J. Hejdak, D. Houseman, S. Klein, F. Li, J. Li, P. Maibach, T. Nicolai, J. Patino, S. V. Pasupulati, N. Samaan, S. Saylors, T. Siebert, T. Smith, M. Starke e R. Walling. Characteristics of wind turbine generators for wind power plants. In: IEEE Power and Energy Society General Meeting, 2009, Calgary. Anais... Calgary: jul. 2009. Citado na(s) página(s). 19 
Canedo (2007) L. S. Canedo. Ajuste do desempenho dinâmico de um sistema de geração eólica com gerador de indução duplamente alimentado. $61 \mathrm{f}$. Dissertação de mestrado, Universidade Federal do Rio de Janeiro, Rio de Janeiro, 2007. Citado na(s) página(s). 75

Carlsson (1998) A. Carlsson. The back to back converter: control and design. $57 \mathrm{f}$. Tese de doutorado, Lund Institute of Technology, Lund, 1998. Citado na(s) página(s). 78

Chiang (2011) H.-D. Chiang. Direct methods for stability analysis of electric power systems: theoretical foundation, BCU methodologies and applications. 1. ${ }^{a}$ edição. Hoboken: John Wiley \& Sons, 2011. 494 p. Citado na(s) página(s). 8, 10, 110, 116, 171

Chiang e Alberto (2015) H.-D. Chiang e L. F. C. Alberto. Stability regions of nonlinear dynamical systems: theory, estimation, and applications. $1 .^{a}$ edição. Cambridge: Cambridge University Press, 2015. 450 p. Citado na(s) página(s). 8, 10

Chiang et al. (1985) H.-D. Chiang, F. F. Wu, P. P. Varaiya e C.-W Tan. Theory of the potential energy boundary surface. In: IEEE Conference on Decision and Control, 1985, Fort Lauderdale. Anais... Fort Lauderdale: dez. 1985. p. 49-51. Citado na(s) página(s). 8, 116

Chiang et al. (1988a) H.-D. Chiang, M. W. Hirsch e F. F. Wu. Stability regions of nonlinear autonomous dynamical systems. IEEE Transactions on Automatic Control. v. 33, n. 1, p. 16-27, jan. 1988. Citado na(s) página(s). 6

Chiang et al. (1988b) H.-D. Chiang, F. F. Wu e P. P. Varaiya. Foundations of the potential energy boundary surface method for power system transient stability analysis. IEEE Transactions on Circuits and Systems. v. 35, n. 6, p. 712-728, jun. 1988. Citado na(s) página(s). 8, 116

Chiang et al. (1995) H.-D. Chiang, C.-C Chu e G. Cauley. Direct stability analysis of electric power systems using energy functions: theory, applications, and perspective. Proceedings of the IEEE. v. 83, n. 11, p. 1497-1529, nov. 1995. Citado na(s) página(s). 8, 10

Chiang et al. (2009) H.-D. Chiang, Y. Tada, H. Li e T. Takazawa. TEPCO-BCU for on-line dynamic security assessments of large-scale power systems. In: International Conference 
on Advances in Power System Control, Operation and Management Hong Kong APSCOM, 2009, Hong Kong. Anais... Hong Kong: nov. 2009. Citado na(s) página(s). 5, 10

Chowdhury et al. (2013) M. A. Chowdhury, N. Hosseinzadeh, W. Shen e H. R. Pota. Comparative study on fault responses of synchronous generators and wind turbine generators using transient stability index based on transient energy function. International Journal of Electrical Power \& Energy Systems. v. 51, p. 145-152, 2013. Citado na(s) página(s). 12

Creder (2007) H. Creder. Instalações elétricas. 15. ${ }^{a}$ edição. Rio de Janeiro: LTC, 2007. 440 p. Citado na(s) página(s). 1

Cutsem e Vournas (1998) T. V. Cutsem e C. Vournas. Voltage stability of electric power systems. 1. ${ }^{a}$ edição. Dordrecht: Springer, 2015. 378 p. Citado na(s) página(s). 45, 98

Edrah et al. (2015) M. Edrah, K. L. Lo e O. Anaya-Lara. Impacts of high penetration of DFIG wind turbines on rotor angle stability of power systems. IEEE Transactions on Sustainable Energy. v. 6, n. 3, p. 759-766, jul. 2015. Citado na(s) página(s). 26

EirGrid (2015) EirGrid. EirGrid grid code - version 6.0. EirGrid, Dublin, 2015. Citado na(s) página(s). xvii, 37

Ekanayake et al. (2003a) J. Ekanayake, L. Holdsworth e N. Jenkins. Comparison of 5th order and 3rd order machine models for doubly fed induction generator (DFIG) wind turbines. Electric Power System Research. v. 67, p. 207-215, abr. 2003. Citado na(s) página(s). 48, 75

Ekanayake et al. (2003b) J. B. Ekanayake, L. Holdsworth, X. G. Wu e N. Jenkins. Dynamic modeling of doubly fed induction generator wind turbines. IEEE Transactions on Power Systems. v. 18, n. 2, p. 803-809, mai. 2003. Citado na(s) página(s). 75

Energinet (2016) Energinet. Technical regulation 3.2.5 for wind power plants above 11 kW. Energinet.dk, 2016. Citado na(s) página(s). xvii, 36

Engelhardt et al. (2011) S. Engelhardt, I. Erlich, C. Feltes, J. Kretschmann e F. Shewarega. Reactive power capability of wind turbines based on doubly fed induction generators. IEEE Transactions on Energy Conversion. v. 26, n. 1, p. 364-372, mar. 2011. Citado na(s) página(s). 22 
E.ON (2006) E.ON. Grid code: high and extra high voltage. E.ON, Bayreuth, 2006. Citado na(s) página(s). xvii, 28, 35

Erlich e Bachmann (2005) I. Erlich e U. Bachmann. Grid code requirements concerning connection and operation of wind turbines in Germany. In: IEEE Power and Energy Society General Meeting, 2005, San Francisco. Anais... San Francisco: jun. 2005. p. 1253-1257. Citado na(s) página(s). 34

Erlich et al. (2007) I. Erlich, J. Kretschmann, J. Fortmann, S. Engelhardt e H. Wrede. Modeling of wind turbines based on doubly-fed induction generators for power system stability studies. IEEE Transactions on Power Systems. v. 22, n. 3, p. 909-919, ago. 2007. Citado na(s) página(s). 75

Feltes et al. (2008) C. Feltes, S. Engelhardt, J. Kretschmann, J. Fortmann, F. Koch e I. Erlich. High voltage ride-through of DFIG-based wind turbines. In: IEEE Power and Energy Society General Meeting - Conversion and Delivery of Electrical Energy in the 21st Century, 2008, Pittsburgh. Anais... Pittsburgh: jul. 2008. Citado na(s) página(s). 29

FERC (2005) FERC. Interconnection for wind energy (Docket No. RM05-4-000 - Order No. 661). FERC - Federal Energy Regulatory Commission, Washington, DC, 2005. Citado na(s) página(s). xvii, 42

Fink e Carlsen (1978) L. H. Fink e K. Carlsen. Operating under stress and strain. IEEE Spectrum. v. 15, n. 3, p. 48-53, mar. 1978. Citado na(s) página(s). 1

Fouad e Vittal (1991) A. A. Fouad e V. Vittal. Power system transient stability analysis: using the transient energy function method. 1. ${ }^{a}$ edição. Englewood Cliffs: Prentice Hall, 1991. 357 p. Citado na(s) página(s). 117

Franco (2007) N. M. B. Franco. Cálculo numérico. 1. ${ }^{a}$ edição. São Paulo: Pearson Education, 2007. 520 p. Citado na(s) página(s). 201, 204

Gaspareto e Reginatto (2006) R. Gaspareto e R. Reginatto. Refinamento dos modelos do gerador de indução. 19 f. Relatório técnico, Universidade Federal do Rio Grande do Sul, Porto Alegre, mai. 2006. Citado na(s) página(s). 48, 49, 71 
Grigsby (2012) L. L. Grigsby, editor. Power system stability and control. 3. ${ }^{a}$ edição. Boca Raton: CRC Press, 2012. 434 p. Citado na(s) página(s). 5

Grilo et al. (2007) A. P. Grilo, A. A. Mota, L. T. M. Mota e W. Freitas. An analytical method for analysis of large-disturbance stability of induction generators. IEEE Transactions on Power Systems. v. 22, n. 4, p. 1861-1869, nov. 2007. Citado na(s) página(s). 12

Grilo et al. (2015) A. P. Grilo, M. B. d. C. Salles, F. C. L. Trindade e W. Freitas. An analytical insight into large-disturbance stability of doubly fed induction generators. Electric Power Systems Research. v. 122, p. 29-32, jan. 2015. Citado na(s) página(s). 12

GWEC (2017) Global Wind Energy Council GWEC. Global Wind Report 2017. Citado na(s) página(s). xvii, 17

GWEC (2016) Global Wind Energy Council GWEC. Global Wind Energy Outlook 2016. Citado na(s) página(s). xvii, 17, 18

Hamon (2010) C. Hamon. Doubly-fed induction generator modeling and control on digsilent power factory. 40 f. Dissertação de mestrado, KTH Royal Institute of Technology, Estocolmo, 2010. Citado na(s) página(s). 75

Hansen e Michalke (2007) A. D. Hansen e G. Michalke. Fault ride-through capability of DFIG wind turbines. Renewable Energy. v. 32, n. 9, p. 1594-1610, jul. 2007. Citado na(s) página(s). 33

Hansen et al. (2003) A. D. Hansen, P. S $\phi$ rensen, F. lov e F. Blaabjerg. Initialisation of gridconnected wind turbine models in power-system simulations. Wind Engineering. v. 27, n. 1, p. 21-38, 2003. Citado na(s) página(s). 76

Hansen et al. (2007a) A. D. Hansen, F. Iov, P. E. Sprensen, N. A. Cutululis, C. Jauch e F. Blaabjerg. Dynamic wind turbine models in power system simulation tool DigSILENT. 96 f. Relatório técnico, Risø National Laboratory, Roskilde, ago. 2007. Citado na(s) página(s). 75 
Hansen et al. (2007b) A. D. Hansen, G. Michalke, P. Sørensen, T. Lund e F. Iov. Co-ordinated voltage control of DFIG wind turbines in uninterrupted operation during grid faults. Wind Energy. v. 10, n. 1, p. 51-68, fev. 2007. Citado na(s) página(s). 33

Holdsworth et al. (2003a) L. Holdsworth, X. G. Wu, J. B. Ekanayake e N. Jenkins. Comparison of fixed speed and doubly-fed induction wind turbines during power system disturbances. IEE Proceedings - Generation, Transmission and Distribution. v. 150, n. 3, p. 343-352, mai. 2003. Citado na(s) página(s). 48, 76

Holdsworth et al. (2003b) L. Holdsworth, X. G. Wu, J. B. Ekanayake e N. Jenkins. Direct solution method for initialising doubly-fed induction wind turbines in power system dynamic models. IEE Proceedings - Generation, Transmission and Distribution. v. 150, n. 3, p. 334-342, jul. 2003. Citado na(s) página(s). 76

Howlader e Senjyu (2016) A. M. Howlader e T. Senjyu. A comprehensive review of low voltage ride through capability strategies for the wind energy conversion systems. Renewable and Sustainable Energy Reviews. v. 56, p. 643 - 658, 2016. Citado na(s) página(s). 11, 32

Hu e Chen (2007) X.-B Hu e W.-H. Chen. Model predictive control of nonlinear systems: stability region and feasible initial control. International Journal of Automation and Computing. v. 4, n. 2, p. 195-202, abr. 2007. Citado na(s) página(s). 6

Hydro-Québec (2009) Hydro-Québec. Transmission provider technical requirements for the connection of power plants to the Hydro-Québec transmission system. Hydro-Québec, Québec, 2009. Citado na(s) página(s). xvii, 40

Ibrahim et al. (2012) R. A. Ibrahim, M. S. Hamad, Y. G. Dessouky e B. W. Williams. A review on recent low voltage ride-through solutions for pmsg wind turbine. In: International Symposium on Power Electronics, Electrical Drives, Automation and Motion, 2012, Sorrento. Anais... Sorrento: jun. 2012. p. 265-270. Citado na(s) página(s). 33, 34

Ibrahim (2015) R. A. E. Ibrahim. Low voltage ride-through of permanent magnet synchronous generator wind energy systems. $80 \mathrm{f}$. Tese de doutorado, University of Strathclyde, Glasgow, 2015. Citado na(s) página(s). 19, 22, 28, 32, 33 
IEA (2016) International Energy Agency IEA. World Energy Outlook 2016. Citado na(s) página(s). xvii, 8, 9, 17

lov et al. (2007) F. Iov, A. D. Hansen, P. S prensen e N. A. Cutululis. Mapping of grid faults and grid codes. $21 \mathrm{f}$. Relatório técnico, Risø DTU National Laboratory for Sustainable Energy, Technical University of Denmark, Kongens Lyngby, jul. 2007. Citado na(s) página(s). 34

Ishigame e Taniguchi (2003) A. Ishigame e T. Taniguchi. Transient stability analysis for power system using Lyapunov function with load characteristics. In: IEEE Power and Energy Society General Meeting, 2003, Toronto. Anais... Toronto: jul. 2003. Citado na(s) página(s). 12

Jessop e Campbell (2010) R. Jessop e S. A. Campbell. Approximating the stability region of a neural network with a general distribution of delays. Neural Networks - Elsevier. v. 23, n. 10, p. 1187-1201, jun. 2010. Citado na(s) página(s). 6

Joos (2008) G. Joos. Wind turbine generator low voltage ride through requirements and solutions. In: IEEE Power and Energy Society General Meeting - Conversion and Delivery of Electrical Energy in the 21st Century, 2008, Pittsburgh. Anais... Pittsburgh: jul. 2008. Citado na(s) página(s). 33

Kakimoto et al. (1978) N. Kakimoto, Y. Ohsawa e M. Hayashi. Transient stability analysis of electric power system via lure type lyapunov function. IEE of Japan. v. 98, (5/6), 1978. Citado na(s) página(s). 8, 110

Kausar et al. (2011) Z. Kausar, K. Stol e N. Patel. Stability region estimation of statically unstable two wheeled mobile robots. In: IEEE International Conference on Robotics and Biomimetics, 2011, Phuket. Anais... Phuket: dez. 2011. p. 1379-1384. Citado na(s) página(s). 6

Khaitan e Gupta (2013) S. K. Khaitan e A. Gupta, editores. High performance computing in power and energy systems. 1. ${ }^{a}$ edição. New York: Springer, 2013. 392 p. Citado na(s) página(s). 5

Kim e Lu (2010) H. S. Kim e D. D.-C. Lu. Wind energy conversion system from electrical perspective - a survey. Smart Grid and Renewable Energy. Citado na(s) página(s). 24 
Kimbark (1948) E. W. Kimbark. Power system stability: elements of stability calculations. 1. ${ }^{a}$ edição. New York: John Wiley \& Sons,1948. 362 p. Citado na(s) página(s). 5

Krause et al. (2013) P. Krause, O. Wasynczuk, S.D. Sudhoff e S. Pekarek. Analysis of electric machinery and drive systems. IEEE Press Series on Power Engineering. 3. ${ }^{a}$ edição. Hoboken: John Wiley \& Son, 2013. 659 p. ISBN 9781118524268. Citado na(s) página(s). $48,49,51,55,56$

Kundur (1994) P. Kundur. Power system stability and control. 1. ${ }^{a}$ edição. New York: McGraw-Hill, 1994. 1176 p. Citado na(s) página(s). 3, 45, 48, 49, 203

Kundur et al. (2004) P. Kundur, J. Paserba, V. Ajjarapu, G. Andersson, A. Bose, C. Canizares, N. Hatziargyriou, D. Hill, A. Stankovic, C. Taylor, T. Van Cutsem e V. Vittal. Definition and classification of power system stability IEEE/CICRE joint task force on stability terms and definitions. IEEE Transactions on Power Systems. v. 19, n. 2, p. 1387-1401, ago. 2004. Citado na(s) página(s). xvii, 3

Ledesma e Usaola (2005) P. Ledesma e J. Usaola. Doubly fed induction generator model for transient stability analysis. IEEE Transactions on Energy Conversion. v. 20, n. 2, p. 388-397, jun. 2005. Citado na(s) página(s). 75

Lee et al. (1984) R. J. Lee, P. Pillay e R. G. Harley. D, Q reference frames for the simulation of induction motors. Electric Power System Research. v. 8, n. 1, p. 15-26, out. 1984. Citado na(s) página(s). 49

Li e Chen (2008) H. Li e Z. Chen. Overview of different wind generator systems and their comparisons. IET Renewable Power Generation. v. 2, n. 2, p. 123-138, jun. 2008. Citado na(s) página(s). 19, 24

Lyapunov (1992) A. M. Lyapunov. The general problem of the stability of motion. 1. ${ }^{a}$ edição. Southampton: CRC Press, 1992. 270 p. Citado na(s) página(s). 5

Magnusson (1947) P. C. Magnusson. The transient-energy method of calculating stability. Transactions of the American Institute of Electrical Engineers. v. 66, n. 1, p. 747-755, jan. 1947. Citado na(s) página(s). 5 
Mahela e Shaik (2016) O. P. Mahela e A. G. Shaik. Comprehensive overview of grid interfaced wind energy generation systems. Renewable and Sustainable Energy Reviews. v. 57, p. 260-281, 2016. Citado na(s) página(s). 19, 24

Mali et al. (2014) S. Mali, S. James e I. Tank. Improving low voltage ride-through capabilities for grid connected wind turbine generator. Energy Procedia. v. 54, n. 1, p. 530-540, 2014. Citado na(s) página(s). 33

Manonmani e Sruthi (2014) N. Manonmani e J. Sruthi. A survey on low-voltage ride-through techniques for DFIG based wind turbines. IJISET - International Journal of Innovative Science, Engineering \& Technology. v. 1, n. 6, p. 570-575, ago. 2014. Citado na(s) página(s). 33

Margaris et al. (2011) I. Margaris, A. Hansen, P. Sørensen e N. Hatziargyriou. Dynamic security issues in autonomous power systems with increasing wind power penetration. Electric Power Systems Research. v. 81, n. 4, p. 880-887, 2011. Citado na(s) página(s). 12

MathWorks (2018a) MathWorks. Documentation - Simscape Power Systems - Model and simulate electrical power systems, 2018a. Disponível em: https://nl.mathworks.com/help/ physmod/sps/. Acesso em: 11/05/2018. Citado na(s) página(s). 201

MathWorks (2018b) MathWorks. Documentation - fsolve - Solve system of nonlinear equations, 2018b. Disponível em: https://www.mathworks.com/help/optim/ug/fsolve.html. Acesso em: 11/05/2018. Citado na(s) página(s). 201

MathWorks (2018c) MathWorks. Documentation - Choose an ODE Solver, 2018c. Disponível em: https://www.mathworks.com/help/matlab/math/choose-an-ode-solver.html. Acesso em: 11/05/2018. Citado na(s) página(s). 201

MathWorks (2018d) MathWorks. Documentation - Curve Fitting - Fit curves and surfaces to data, 2018d. Disponível em: https://nl.mathworks.com/help/curvefit/curvefitting-app.html. Acesso em: 11/05/2018. Citado na(s) página(s). 81

MathWorks (2018e) MathWorks. Cumulative trapezoidal numerical integration, 2018e. Disponível em: https://www.mathworks.com/help/matlab/ref/cumtrapz.html. Acesso em: 18/01/2018. Citado na(s) página(s). 124 
McPherson e Laramore (1990) G. McPherson e R. D. Laramore. An introduction to electric machines and transformers. 2. ${ }^{a}$ edição. New York: John Wiley \& Sons, 1990. 571 p. Citado na(s) página(s). 98

Michalke (2008) G. Michalke. Variable speed wind turbines - modelling, control, and impact on power systems. $114 \mathrm{f}$. Tese de doutorado, Darmstadt University of Technology, Darmstadt, 2008. Citado na(s) página(s). 23

Milano (2010) F. Milano. Power system modelling and scripting. 1. ${ }^{a}$ edição. London: Springer, 2010. 556 p. Citado na(s) página(s). 171

Mishra et al. (2017) C. Mishra, J. S. Thorp, V. A. Centeno e A. Pal. Stability region estimation under low voltage ride through constraints using sum of squares. In: NAPS North American Power Symposium, 2017, Morgantown. Anais... Morgantown: set. 2017. Citado na(s) página(s). 13

Moghadasi et al. (2016) A. Moghadasi, A. Sarwat e J. M. Guerrero. A comprehensive review of low-voltage-ride-through methods for fixed-speed wind power generators. Renewable and Sustainable Energy Reviews. v. 55, n. 1, p. 823-839, mar. 2016. Citado na(s) página(s). 20, 32

Mohseni e Islam (2012) M. Mohseni e S. Islam. Review of international grid codes for wind power integration: diversity, technology and a case for global standard. Renewable and Sustainable Energy Reviews - Elsevier. v. 16, p. 3876-3890, abr. 2012. Citado na(s) página(s). 10,25

Monticelli (1983) A. J. Monticelli. Fluxo de carga em redes de energia elétrica. $1 .^{a}$ edição. São Paulo: Edgard Blücher, 1983. 164 p. Citado na(s) página(s). 86, 203

Morison et al. (2004) K. Morison, L. Wang e P. Kundur. Power system security assessment. IEEE Power \& Energy Magazine. p. 30-39, out. 2004. Citado na(s) página(s). 9

Mullane et al. (2005) A. Mullane, G. Lightbody e R. Yacamini. Wind-turbine fault ridethrough enhancement. IEEE Transactions on Power Systems. v. 20, n. 4, p. 1929-1937, 2005. Citado na(s) página(s). 10, 29 
Muyeen et al. (2007) S. M. Muyeen, Md. Hasan, R. Takahashi, T. Murata, J. Tamura, Y. Tomaki, A. Sakahara e E. Sasano. Comparative study on transient stability analysis of wind turbine generator system using different drive train models. IET Renewable Power Generation. v. 1, n. 2, p. 131-141, dez. 2007. Citado na(s) página(s). 171

National Grid (2018) National Grid. The grid code - issue 5 - revision 25. National Grid Electricity Transmission, London, 2018. Citado na(s) página(s). xvii, 40, 41

Nazareno (2003) I. S. Nazareno. Método dinâmico para detecção do PEBS e "shadowing method" para cálculo do ponto de equilíbrio de controle em estudos de estabilidade transitória. 76 f. Dissertação de mestrado, Universidade de São Paulo, São Carlos, 2003. Citado na(s) página(s). 8

NERSA (2016) NERSA. Grid connection code for renewable power plants connected to the electricity transmission system or the distribution system in South Africa - version 2.9. NERSA - National Energy Regulator of South Africa, Pretoria, 2016. Citado na(s) página(s). xvii, 38

Nikolaev et al. (2014) N. Nikolaev, K. Gerasimov e F. Milano. Two stage approach for the initialization of doubly-fed induction generator models. In: International Scientific Symposium - Electrical Power Engineering, 2014, Varna. Anais... Varna: set. 2014. p. 52-57. Citado na(s) página(s). 75, 76, 79, 82

Oliveira et al. (2000) C. C. B. Oliveira, H. P. Schmidt, N. Kagan e E. J. Robba. Introdução a sistemas elétricos de potência - componentes simétricas. 2. ${ }^{a}$ edição. São Paulo: Blucher, 2000. 467 p. Citado na(s) página(s). 44

Ong (1998) C-M. Ong. Dynamic simulation of electric machinery using MATLAB/Simulink. 1. ${ }^{a}$ edição. New Jersey: Prentice Hall, 1998. 626 p. Citado na(s) página(s). 48

ONS (2016) ONS. Procedimentos de rede - submódulo 3.6 - requisitos técnicos mínimos para a conexão às instalações de transmissão, rev. 2016.12. ONS - Operador Nacional do Sistema Elétrico, Rio de Janeiro, 2016. Citado na(s) página(s). xvii, 11, 28, 41 
Padiyar e Kulkarni (2019) K. R. Padiyar e A. M. Kulkarni. Dynamics and control of electric transmission and microgrids. 1. ${ }^{a}$ edição. John Wiley \& Sons, 2019. 486 p. Citado na(s) página(s). 2

Pai (1989) M. A. Pai. Energy function analysis for power system stability. 1. ${ }^{a}$ edição. Norwell: Kluwer, 1989. 240 p. Citado na(s) página(s). 117

Pardalos et al. (2013) P. M. Pardalos, S. Rebennack, M. V. F. Pereira, N. A. Iliadis e V. Pappu, editores. Handbook of wind power systems. 1. ${ }^{a}$ edição. Heidelberg: Springer, 2013. 835 p. Citado na(s) página(s). 22, 23, 26, 27

Patel (2006) M. R. Patel. Wind and solar power systems: design, analysis, and operation. 2. ${ }^{a}$ edição. Boca Raton: CRC Press, 2006. 470 p. Citado na(s) página(s). 22, 79

Pavani (2008) A. P. G. Pavani. Métodos analíticos para análise de geradores de indução conectados em redes de distribuição de energia elétrica. 70 f. Tese de doutorado, Universidade Estadual de Campinas, Campinas, 2008. Citado na(s) página(s). 12

Pavella e Murthy (1994) M. Pavella e P. G. Murthy. Transient stability of power systems: theory and practice. 1. ${ }^{a}$ edição. New York: Wiley, 1994. 420 p. Citado na(s) página(s). 117

Pena et al. (1996) R. Pena, J. C. Clare e G. M. Asher. Doubly fed induction generator using back-to-back PWM converters and its application to variable-speed wind-energy generation. IEE Proceedings - Electric Power Applications. v. 143, n. 3, p. 231-241, mai. 1996. Citado na(s) página(s). 75

Pillco (2015) E. C. Pillco. Estudo da estabilidade de tensão em duas escalas de tempo por métodos diretos - análise quase estática. $63 \mathrm{f}$. Tese de doutorado, Universidade de São Paulo, São Carlos, 2015. Citado na(s) página(s). 5

Pinto (2013) M. de O. Pinto. Fundamentos de energia eólica. 1. ${ }^{a}$ edição. Rio de Janeiro: LTC, 2013. 368 p. Citado na(s) página(s). 23, 25, 29 
Praprost (1993) K. L. Praprost. Power system stability and security methods with applications to restorative state operation. $125 \mathrm{f}$. Tese de doutorado, Case Western Reserve University, Cleveland, 1993. Citado na(s) página(s). 112, 115

Praprost e Loparo (1996) K. L. Praprost e K. A. Loparo. A stability theory for constrained dynamic systems with applications to electric power systems. IEEE Transactions on Automatic Control. v. 41, n. 11, p. 1605-1617, nov. 1996. Citado na(s) página(s). 11, 110, 112, 115

Qiang e Zhong (2005) J. N. Qiang e S. W. Zhong. Clarifications on the integration path of transient energy function. IEEE Transactions on Power Systems. v. 20, n. 2, p. 883-887, mai. 2005. Citado na(s) página(s). 117

Rahimi et al. (1993) F. A. Rahimi, M. G. Lauby, J. N. Wrubel e K. L. Lee. Evaluation of the transient energy function method for on-line dynamic security analys. IEEE Transactions on Power Systems. v. 8, n. 2, p. 497-507, mai. 1993. Citado na(s) página(s). 117, 125

Rahimi e Parniani (2010) M. Rahimi e M. Parniani. Grid-fault ride-through analysis and control of wind turbines with doubly fed induction generators. Electric Power Systems Research. v. 80, n. 2, p. 184-195, fev. 2010. Citado na(s) página(s). 33

REE (2004) REE. Requisitos mínimos a efectos de garantizar la continuidad de suministro frente a huecos de tensión - P.O.12.3. REE - Red Eléctrica de España, Madrid, 2004. Citado na(s) página(s). xvii, 28, 39

Reginatto (2006) R. Reginatto. Modelagem do motor de indução. 26 f. Relatório técnico, Universidade Federal do Rio Grande do Sul, Porto Alegre, fev. 2006. Citado na(s) página(s). 49

REN21 (2017) Renewable Energy Policy Network for the 21st Century REN21. Renewables Global Futures Report: Great debates towards 100\% renewable energy. Citado na(s) página(s). 8, 17

Rocha (2005) M. S. Rocha. Comportamento dinâmico de gerador de indução com dupla alimentação em sistema de geração eólica. 60 f. Dissertação de mestrado, Universidade Federal do Rio de Janeiro, Rio de Janeiro, 2005. Citado na(s) página(s). 75 
Rogers (2000) G. Rogers. Power system oscillations. 1. ${ }^{a}$ edição. New York: Springer, 2000. 328 p. Citado na(s) página(s). 2

Salles (2009) M. B. de C. Salles. Modelagem e análises de geradores eólicos de velocidade variável conectados em sistemas de energia elétrica. 70 f. Tese de doutorado, Universidade de São Paulo, São Paulo, 2009. Citado na(s) página(s). 12, 28, 79, 101

Samuelsson e Lindahl (2005) O. Samuelsson e S. Lindahl. On speed stability. IEEE Transactions on Power Systems. v. 20, n. 2, p. 1179-1180, mai. 2005. Citado na(s) página(s). 10, 24

Sasaki (1979) H. Sasaki. An approximate incorporation of field flux decay into transient stability analyses of multimachine power systems by the second method of Lyapunov. IEEE Transactions on Power Apparatus and Systems PAS-98. v. 98, n. 2, p. 473-483, abr. 1979. Citado na(s) página(s). 117

Sauer e Pai (1998) P. W. Sauer e M. A. Pai. Power system dynamics and stability. 2. ${ }^{a}$ edição. Upper Saddle River: Prentice Hall, 1998. 364 p. Citado na(s) página(s). 4

Sauer et al. (1989) P. W. Sauer, A. K. Behera, M. A. Pai, J. R. Winkelman e J. H. Chow. Trajectory approximations for direct energy methods that use sustained faults with detailed power system models. IEEE Transactions on Power Systems. v. 4, n. 2, p. 499-506, mai. 1989. Citado na(s) página(s). 125

Sbarciog et al. (2010) M. Sbarciog, M. Loccufier e E. Noldus. Optimization of microorganisms growth processes. Computer Methods and Programs in Biomedicine - Elsevier. v. 104, n. 2, p. 112-119, abr. 2010. Citado na(s) página(s). 6

Schegner e La Seta (2004) P. Schegner e P. La Seta. Stability of asynchronous wind generators using Lyapunov's direct method. In: Bulk Power System Dynamics and Control, 2004, Cortina d'Ampezzo. Anais... Cortina d'Ampezzo: ago. 2004. p. 144-150. Citado na(s) página(s). 12 
Singh e Singh (2009) B. Singh e S. N. Singh. Wind power interconnection into the power system: a review of grid code requirements. The Electricity Journal - Elsevier. v. 22, n. 5, p. 54-63, jun. 2009. Citado na(s) página(s). 26, 34

Slootweg (2003) J. G. Slootweg. Wind power: modelling and impact on power system dynamics. $110 \mathrm{f}$. Tese de doutorado, Delft University of Technology, Delft, 2003. Citado na(s) página(s). 11, 22, 24, 25

Slootweg et al. (2001a) J. G. Slootweg, H. Polinder e W. L. Kling. Dynamic modelling of a wind turbine with doubly fed induction generator. In: IEEE Power Engineering Society Summer Meeting, 2001, Vancouver. Anais... Vancouver: jul. 2001. Citado na(s) página(s). 75

Slootweg et al. (2001b) J. G. Slootweg, H. Polinder e W. L. Kling. Initialization of wind turbine models in power system dynamics simulations. In: IEEE Porto Power Tech Conference, 2001, Porto. Anais... Porto: set. 2001. Citado na(s) página(s). 76

Slootweg et al. (2003) J. G. Slootweg, W. H. de Haan, H. Polinder e W. L. Kling. General model for representing variable speed wind turbines in power system dynamics simulations. IEEE Transactions on Power Systems. v. 18, n. 1, p. 144-151, fev. 2003. Citado na(s) página(s). 75

Stevenson Jr. (1986) W. D. Stevenson Jr. Elementos de análise de sistemas elétricos de potência. $2^{a}$ edição. São Paulo: McGraw-Hill, 1986. 458 p. Citado na(s) página(s). 44

Sundeep (2008) S. Sundeep. Transient stability analysis of a grid connected doubly fed induction generator. 37 f. Dissertação de mestrado, Indian Institute of Technology Roorkee, Roorkee, 2008. Citado na(s) página(s). 75

Tada et al. (2005) Y. Tada, T. Takazawa, H.-D. Chiang, H. Li e J. Tong. Transient stability evaluation of a 12,000 - bus power system data using TEPCO-BCU. In: Power System Computation Conference Liege PSCC, 2005, Liege. Anais... Liege: ago. 2005. Citado na(s) página(s). 5

Takazawa et al. (2006) T. Takazawa, Y. Tada, H.-D. Chiang e H. Li. Development of parallel TEPCO-BCU and BCU screening classifiers for on-line dynamic security assessment. In: 
Conference of the Electric Power Supply Industry Mumbai CEPSI, 2006, Mumbai. Anais... Mumbai: nov. 2006. Citado na(s) página(s). 5

Taylor (1994) C. W. Taylor. Power system voltage stability. 1. ${ }^{a}$ edição. New York: McGrawHill, 1994. 273 p. Citado na(s) página(s). 1

Tenaga (2016) Suruhanjaya Tenaga. Grid code for Peninsular Malaysia. Suruhanjaya Tenaga Energy Commission, Putrajaya, 2016. Citado na(s) página(s). xvii, 39

Tennakoon et al. (2007) A. P. Tennakoon, A. Atputharajah, S. G. Abeyratne e J. B. Ekanayake. Doubly-fed induction generators for wind power generation. In: International Conference on Industrial and Information Systems, 2007, Penadeniya. Anais... Penadeniya: ago. 2007. Citado na(s) página(s). 75

Theodoro (2013) E. A. R. Theodoro. Contribuição à análise de estabilidade transitória, em duas escalas de tempo, de sistemas elétricos de potência via métodos diretos. $80 \mathrm{f}$. Tese de doutorado, Universidade de São Paulo, São Carlos, 2013. Citado na(s) página(s). 5

Theodoro (2010) E. A. R. Theodoro. Desenvolvimento de uma ferramenta computacional para análise de segurança dinâmica, no contexto da estabilidade transitória, de sistemas elétricos de potência via métodos diretos. 69 f. Dissertação de mestrado, Universidade de São Paulo, São Carlos, 2010. Citado na(s) página(s). 5

Tsili e Papathanassiou (2009) M. Tsili e S. Papathanassiou. A review of grid code technical requirements for wind farms. IET Renewable Power Generation. v. 3, n. 3, p. 308-332, set. 2009. Citado na(s) página(s). 26, 34

Twidell e Weir (2015) J. Twidell e T. Weir. Renewable energy resources. 3. ${ }^{a}$ edição. New York: Routledge, 2015. 409 p. Citado na(s) página(s). 8

Ullah et al. (2009) N. Ullah, K. Bhattacharya e T. Thiringer. Wind farms as reactive power ancillary service providers - technical and economic issues. IEEE Transactions on Energy Conversion. v. 24, n. 3, p. 661-672, set. 2009. Citado na(s) página(s). 25 
Venkatasubramanian et al. (1992a) V. Venkatasubramanian, H. Schättler e J. Zaborszky. Stability regions for differential-algebraic systems. In: A. Isidori e T. J. Tarn, editores. Systems, Models and Feedback: Theory and Applications. Boston: Birkhauser Boston Inc, 1992. p. 385-402. Citado na(s) página(s). 111

Venkatasubramanian et al. (1992b) V. Venkatasubramanian, H. Schättler e J. Zaborszky. A stability theory of differential-algebraic systems such as the power system. In: IEEE International Symposium on Circuits and Systems, 1992, San Diego. Anais... San Diego: mai. 1992. Citado na(s) página(s). 111

Venkatasubramanian et al. (1994) V. Venkatasubramanian, H. Schattler e J. Zaborszky. On the dynamics of differential-algebraic systems such as the balanced large electric power system. In: J. H. Chow, P. V. Kokotovic e R. J. Thomas, editores. Systems and Control Theory for Power Systems. New York: Springer-Verlag, 1994. p. 381-398. Citado na(s) página(s). 111

Venkatasubramanian et al. (1995) V. Venkatasubramanian, H. Schättler e J. Zaborszky. Dynamics of large constrained nonlinear systems - a taxonomy theory. Proceedings of the IEEE. v. 83, n. 11, p. 1530-1561, nov. 1995. Citado na(s) página(s). 110, 111

Vittal e Ayyanar (2013) V. Vittal e R. Ayyanar. Grid integration and dynamic impact of wind energy. 1. ${ }^{a}$ edição. New York: Springer, 2013. 150 p. Citado na(s) página(s). 21, 23

Willis et al. (2018) D. J. Willis, C. Niezrecki, D. Kuchma, E. Hines, S. R. Arwade, R. J. Barthelmie, M. DiPaola, P. J. Drane, C. J. Hansen, M. Inalpolat, J. H. Mack, A. T. Myers e M. Rotea. Wind energy research: state-of-the-art and future research directions. Renewable Energy. v. 125, p. 133-154, 2018. Citado na(s) página(s). 18

Wu et al. (2011) B. Wu, Y. Lang, N. Zargari e S. Kouro. Power conversion and control of wind energy systems. 1. ${ }^{a}$ edição. Hoboken: John Wiley \& Sons, 2011. 476 p. Citado na(s) página(s). 19 
Yaramasu e Wu (2017) V. Yaramasu e B. Wu. Model of predictive control of wind energy conversion systems. 1. ${ }^{a}$ edição. Hoboken: John Wiley \& Sons, 2017. 467 p. Citado na(s) página(s). $127,195,219$

Yong e Lei (2007) M. Yong e C. Lei. A transient energy function for power systems including the induction motor model. Science in China Series E: Technological Sciences. v. 50, n. 5, p. 575-584, out. 2007. Citado na(s) página(s). 12 


\section{Apêndice A}

\section{Parâmetros da rede elétrica}

A Tabela A.1 reúne os parâmetros do modelo da rede elétrica do sistema teste. Para o cálculo dos valores por unidade, foi adotada a potência aparente base de 3 MVA, isto é, a mesma potência aparente base das máquinas. A susceptância shunt da barra terminal (capacitor) aplica-se apenas às configurações SCIG e WRIG. Para a configuração DFIG, esta susceptância é nula. Vale ressaltar que os capacitores foram ajustados para a tensão no PCC apresentar o valor 1 pu em regime permanente. Salienta-se para a configuração WRIG que para cada valor de tensão aplicada ao rotor obtém-se um ponto de operação específico. Desta forma, deve-se utilizar um capacitor particular em cada caso para a tensão no PCC apresentar o valor 1 pu em regime permanente.

Tabela A.1: Parâmetros da rede elétrica.

\begin{tabular}{|c|c|c|}
\hline Frequência da rede & $f$ & $60 \mathrm{~Hz}$ \\
\hline Susceptância da linha de transmissão & $b_{12}$ & $-10 \mathrm{pu}$ \\
\hline Susceptância do transformador & $b_{23}$ & $-10 \mathrm{pu}$ \\
\hline Susceptância shunt da linha de transmissão & $b_{12}^{s h}$ & 0 \\
\hline Susceptância shunt do transformador & $b_{23}^{\text {sh }}$ & 0 \\
\hline Susceptância shunt do PCC & $b_{2}^{s h}$ & 0 \\
\hline Condutância da linha de transmissão & $g_{12}$ & 0 \\
\hline Condutância do transformador & $g_{23}$ & 0 \\
\hline Condutância shunt da linha de transmissão & $g_{12}^{s h}$ & 0 \\
\hline Condutância shunt do transformador & $g_{23}^{s h}$ & 0 \\
\hline \multicolumn{3}{|c|}{ SCIG } \\
\hline Susceptância shunt da barra terminal & $b_{3}^{s h}$ & $0,4634 \mathrm{pu}$ \\
\hline \multicolumn{3}{|c|}{ WRIG } \\
\hline Susceptância shunt da barra terminal & $b_{3}^{s h}$ & $0,8231 \mathrm{pu}\left(u_{q r}=0, u_{d r}=0\right)$ \\
\hline Susceptância shunt da barra terminal & $b_{3}^{s h}$ & $0,15 \mathrm{pu}\left(u_{q r}=0, u_{d r}=-0,005 \mathrm{pu}\right)$ \\
\hline Susceptância shunt da barra terminal & $b_{3}^{s h}$ & $1,185 \mathrm{pu}\left(u_{q r}=0, u_{d r}=0,0025 \mathrm{pu}\right)$ \\
\hline
\end{tabular}




\section{Apêndice B}

\section{Parâmetros dos aerogeradores}

As Tabelas B.1, B.2 e B.3 a seguir resumem os parâmetros das configurações SCIG, WRIG e DFIG, respectivamente. Os parâmetros referentes a cada tipo de máquina são típicos de aerogeradores comerciais. Mais detalhes podem ser encontrados em Yaramasu e Wu (2017). Para o cálculo da constante de inércia e dos valores por unidade, foi adotada a potência aparente base de 3 MVA. Em Yaramasu e Wu (2017) os parâmetros por unidade para a configuração SCIG foram calculados a partir da potência aparente base de 3,3214 MW. Neste trabalho, os parâmetros para este gerador foram recalculados considerando a potência aparente base de 3 MVA. Para tanto, foram utilizadas as relações

$$
\begin{aligned}
& H_{1} S_{1}=H_{2} S_{2} \\
& x_{1} S_{2}=x_{2} S_{1},
\end{aligned}
$$

e

$$
r_{1} S_{2}=r_{2} S_{1}
$$

para o cálculo da constante de inércia, reatâncias e resistências (estator e rotor) na nova base, sendo

$S_{1}$ a potência aparente base da máquina,

$S_{2}$ a nova potência aparente base,

$H_{1}$ a constante de inércia na base da máquina,

$\mathrm{H}_{2}$ a constante de inércia na nova base,

$x_{1}$ a reatância na base da máquina,

$x_{2}$ a reatância na nova base,

$r_{1}$ a resistência na base da máquina e

$r_{2}$ a resistência na nova base. 
A Tabela B.1 reúne os parâmetros da configuração SCIG.

Tabela B.1: Parâmetros do modelo SCIG.

\begin{tabular}{lcc}
\hline Potência mecânica (saída da turbina) & $P_{m}$ & $3 \mathrm{MW}$ \\
Tensão de linha base & $U_{l b}$ & $3 \mathrm{kV}$ \\
Potência aparente trifásica base & $S_{3 b}$ & $3 \mathrm{MVA}$ \\
Coeficiente de atrito viscoso & $D$ & 0 \\
Constante de inércia da turbina & $H_{t}$ & $5,7789 \mathrm{~s}$ \\
Constante de inércia do gerador & $H_{g}$ & $0,6421 \mathrm{~s}$ \\
Constante de inércia combinada (turbina + gerador) & $H_{m}$ & $6,421 \mathrm{~s}$ \\
Resistência do estator & $r_{s}$ & $0,00630 \mathrm{pu}$ \\
Resistência do rotor & $r_{r}$ & $0,00713 \mathrm{pu}$ \\
Reatância de dispersão do estator & $x_{l s}$ & $0,1024 \mathrm{pu}$ \\
Reatância de dispersão do rotor & $x_{l r}$ & $0,1024 \mathrm{pu}$ \\
Reatância magnetizante & $x_{m}$ & $3,413 \mathrm{pu}$ \\
\hline
\end{tabular}

A Tabela B.2 reúne os parâmetros da configuração WRIG.

Tabela B.2: Parâmetros do modelo WRIG.

\begin{tabular}{lcc}
\hline Potência mecânica (saída da turbina) & $P_{m}$ & $3 \mathrm{MW}$ \\
Tensão de linha base & $U_{l b}$ & $3 \mathrm{kV}$ \\
Potência aparente trifásica base & $S_{3 b}$ & $3 \mathrm{MVA}$ \\
Coeficiente de atrito viscoso & $D$ & 0 \\
Constante de inércia da turbina & $H_{t}$ & $5,22 \mathrm{~s}$ \\
Constante de inércia do gerador & $H_{g}$ & $0,58 \mathrm{~s}$ \\
Constante de inércia combinada (turbina + gerador) & $H_{m}$ & $5,8 \mathrm{~s}$ \\
Resistência do estator & $r_{s}$ & $0,0091 \mathrm{pu}$ \\
Resistência do rotor & $r_{r}$ & $0,0071 \mathrm{pu}$ \\
Reatância de dispersão do estator & $x_{l s}$ & $0,2243 \mathrm{pu}$ \\
Reatância de dispersão do rotor & $x_{l r}$ & $0,2019 \mathrm{pu}$ \\
Reatância magnetizante & $x_{m}$ & $1,9061 \mathrm{pu}$ \\
\hline
\end{tabular}


A Tabela B.3 reúne os parâmetros da configuração DFIG.

Tabela B.3: Parâmetros do modelo DFIG.

\begin{tabular}{|c|c|c|}
\hline \multicolumn{3}{|l|}{ Gerador e turbina } \\
\hline Potência mecânica (saída da turbina) & $P_{m}$ & $3 \mathrm{MW}$ \\
\hline Tensão de linha base & $U_{l b}$ & $3 \mathrm{kV}$ \\
\hline Potência aparente trifásica base & $S_{3 b}$ & 3 MVA \\
\hline Coeficiente de atrito viscoso & $D$ & 0 \\
\hline Constante de inércia da turbina & $H_{t}$ & $5,22 \mathrm{~s}$ \\
\hline Constante de inércia do gerador & $H_{g}$ & $0,58 \mathrm{~s}$ \\
\hline Constante de inércia combinada (turbina + gerador) & $H_{m}$ & $5,8 \mathrm{~s}$ \\
\hline Resistência do estator & $r_{s}$ & 0,0091 pu \\
\hline Resistência do rotor & $r_{r}$ & 0,0071 pu \\
\hline Reatância de dispersão do estator & $x_{l s}$ & $0,2243 \mathrm{pu}$ \\
\hline Reatância de dispersão do rotor & $x_{l r}$ & $0,2019 \mathrm{pu}$ \\
\hline Reatância magnetizante & $x_{m}$ & $1,9061 \mathrm{pu}$ \\
\hline \multicolumn{3}{|l|}{ Conversor RSC } \\
\hline Ganho proporcional 1 & $K_{p 1}$ & 0,05 \\
\hline Ganho integral 1 & $K_{i 1}$ & 0,034 \\
\hline Ganho proporcional 2 & $K_{p 2}$ & 0,85 \\
\hline Ganho integral 2 & $K_{i 2}$ & 0,85 \\
\hline Ganho proporcional 3 & $K_{p 3}$ & 0,058 \\
\hline Ganho integral 3 & $K_{i 3}$ & 0,021 \\
\hline Ganho proporcional 4 & $K_{p 4}$ & 0,018 \\
\hline Ganho integral 4 & $K_{i 4}$ & 0,006 \\
\hline \multicolumn{3}{|l|}{ Conversor GSC } \\
\hline Ganho proporcional 5 & $K_{p 5}$ & 50 \\
\hline Ganho integral 5 & $K_{i 5}$ & 75 \\
\hline Ganho proporcional 6 & $K_{p 6}$ & 55 \\
\hline Ganho integral 6 & $K_{i 6}$ & 80 \\
\hline Ganho proporcional 7 & $K_{p 7}$ & 60 \\
\hline Ganho integral 7 & $K_{i 7}$ & 60 \\
\hline Resistência do filtro & $r_{f}$ & $0,01 \mathrm{pu}$ \\
\hline Reatância do filtro & $x_{f}$ & $0,2 \mathrm{pu}$ \\
\hline Capacitância do link DC & C & $4 \mathrm{pu}$ \\
\hline
\end{tabular}




\section{Apêndice C}

\section{Parâmetros das curvas $P_{m}$ e LVRT}

A Tabela C.1 a seguir apresenta os parâmetros referentes à curva $P_{m}$ real. Já as Tabelas C.2, C.3 e C.4 apresentam os parâmetros utilizados para aproximar as curvas $P_{m}$, LVRT do Brasil e LVRT dos EUA, respectivamente, a partir das equações desenvolvidas para tal propósito.

A Tabela C.1 reúne os parâmetros referentes à curva $P_{m}$ real.

Tabela C.1: Parâmetros da curva $P_{m}$ real.

\begin{tabular}{cc}
\hline$\omega_{A}$ & $0,7 \mathrm{pu}$ \\
$\omega_{B}$ & $0,71 \mathrm{pu}$ \\
$\omega_{C}$ & $1,2 \mathrm{pu}$ \\
$\omega_{D}$ & $1,21 \mathrm{pu}$ \\
$\omega_{E}$ & $1,4 \mathrm{pu}$ \\
$P_{A}$ & $0 \mathrm{pu}$ \\
$P_{B}$ & $0,1512 \mathrm{pu}$ \\
$P_{C}$ & $0,73 \mathrm{pu}$ \\
$P_{D}$ & $0,9 \mathrm{pu}$ \\
$P_{E}$ & $0,9 \mathrm{pu}$ \\
\hline
\end{tabular}

A Tabela C.2 reúne os parâmetros utilizados na equação que aproxima a curva $P_{m}$.

Tabela C.2: Parâmetros utilizados para aproximar a curva $P_{m}$.

\begin{tabular}{cccc}
\hline a0 & $-1,476$ & a5 & 0,2502 \\
a1 & 3,685 & b5 & 1,054 \\
b1 & 1,378 & a6 & 0,01683 \\
a2 & $-2,846$ & b6 & $-0,5416$ \\
b2 & $-1,799$ & a7 & $-0,07316$ \\
a3 & 1,757 & b7 & 0,216 \\
b3 & 1,87 & a8 & 0,02945 \\
a4 & $-0,8253$ & b8 & $-0,06014$ \\
b4 & $-1,577$ & w & 6,155 \\
\hline
\end{tabular}


A Tabela C.3 reúne os parâmetros utilizados na equação (4.17), que aproxima a curva LVRT real do Brasil.

Tabela C.3: Parâmetros utilizados para aproximar a curva LVRT do Brasil.

\begin{tabular}{cc}
\hline$k_{0}$ & 1,3 \\
$k_{1}$ & 10000 \\
$k_{2}$ & 2 \\
$k_{3}$ & $-1,004$ \\
$r_{0}$ & 0,2 \\
$r_{1}$ & 0,845 \\
$r_{2}$ & 0,85676 \\
$r_{3}$ & 0,9 \\
\hline
\end{tabular}

A Tabela C.4 reúne os parâmetros utilizados na equação (4.18), que aproxima a curva LVRT real dos EUA.

Tabela C.4: Parâmetros utilizados para aproximar a curva LVRT dos EUA.

\begin{tabular}{cc}
\hline$k_{0}$ & 0,319 \\
$k_{1}$ & 10000 \\
$r_{0}$ & 0,15362 \\
$r_{1}$ & 0,895 \\
\hline
\end{tabular}




\section{Apêndice D}

\section{Sobre as simulações computacionais}

Inicialmente utilizou-se o método de Newton-Raphson e o método de integração trapezoidal para reproduzir os comportamentos dinâmicos dos modelos. No entanto, verificou-se que as funções fsolve e ode15i apresentam uma forma mais simples de implementação computacional, reduzindo o tempo de elaboração dos programas MathWorks (2018a), MathWorks (2018b). Desta forma, uma vez constatado que as soluções proporcionadas por estas funções são muito parecidas àquelas fornecidas pelos métodos de Newton-Raphson e de integração trapezoidal, optou-se por utilizar as funções fsolve e ode15i neste trabalho. Salienta-se que as soluções encontradas foram comparadas para a configuração SCIG e as diferenças entre os resultados se devem às particularidades de cada método numérico de integração. Dentre estas particularidades, cita-se como exemplo o passo de integração: o método de integração trapezoidal apresenta um passo fixo e a função ode15i um passo variável. Também para a configuração SCIG foram comparados os resultados obtidos com aqueles proporcionados pelo software Simulink ${ }^{\circledR}$, via biblioteca Simscape (Asynchronous Machine) MathWorks (2018c). Mais uma vez, os resultados foram muito parecidos.

\section{D.1 Método de Newton-Raphson}

O método de Newton-Raphson pode ser usado para encontrar a raiz de uma função Franco (2007). Seja uma função $f(x)$, sua raiz $\hat{x}$, a reta tangente a esta função no ponto de coordenada $f\left(x^{0}\right)$ e de abcissa $x^{0}$, que cruza o eixo $x$ em $x^{1}$, conforme mostra a Figura D.1.

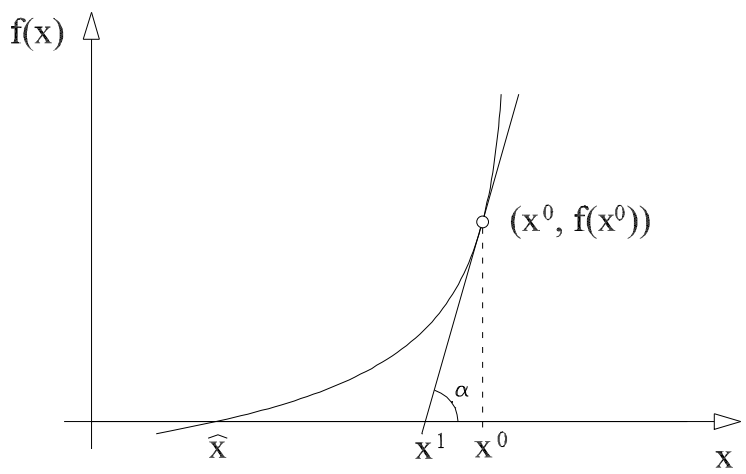

Figura D.1: Reta tangente para o ponto $\left(x^{0}, f\left(x^{0}\right)\right)$. 
Uma vez que o intuito é encontrar $\hat{x}$, inicialmente objetiva-se descobrir o valor de $x^{1}$, por meio da equação da reta tangente que passa pelo ponto $\left(x^{0}, f\left(x^{0}\right)\right)$, definida por

$$
f(x)-f\left(x^{0}\right)=f^{\prime}\left(x^{0}\right)\left(x-x^{0}\right)
$$

em que $f^{\prime}\left(x^{0}\right)$ é a inclinação $\alpha$ da reta tangente, definida como sendo a derivada de $f(x)$ em relação à $x$ no ponto de abcissa $x^{0}$.

Substituindo o ponto $\left(x^{1}, 0\right)$ em (D.1) é possível escrever

$$
x^{1}=x^{0}-\frac{f\left(x^{0}\right)}{f^{\prime}\left(x^{0}\right)}
$$

Para o próximo ponto tem-se uma nova reta tangente, em que $f^{\prime}\left(x^{1}\right)$ é a inclinação $\beta$ desta nova reta, definida como sendo a derivada de $f(x)$ em relação à $x$ no ponto de abcissa $x^{1}$, conforme mostra a Figura D.2.

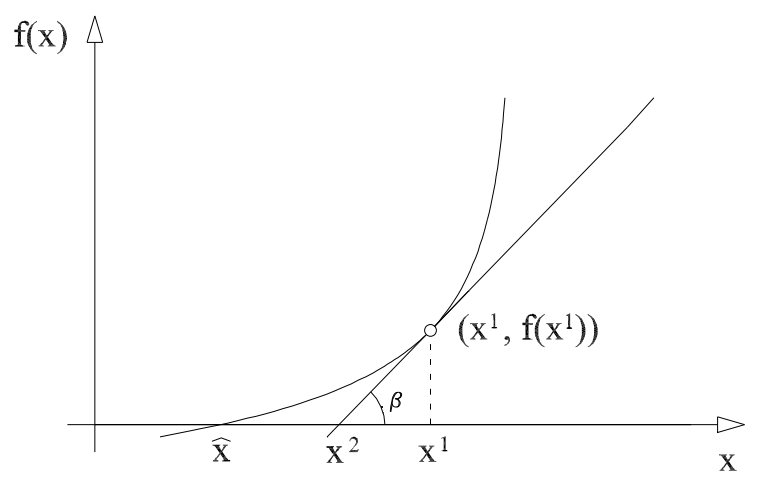

Figura D.2: Reta tangente para o ponto $\left(x^{1}, f\left(x^{1}\right)\right)$.

De forma análoga,

$$
x^{2}=x^{1}-\frac{f\left(x^{1}\right)}{f^{\prime}\left(x^{1}\right)}
$$

E o processo iterativo fica então definido por

$$
x^{k+1}=x^{k}-\frac{f\left(x^{k}\right)}{f^{\prime}\left(x^{k}\right)}
$$

cujo critério de parada pode ser especificado como 


$$
\left|x^{k+1}-x^{k}\right|<\epsilon
$$

sendo $\epsilon$ um erro preestabelecido, suficientemente pequeno.

O método de Newton-Raphson também pode ser utilizado para encontrar as raízes de um sistema de equações não lineares Monticelli (1983), Kundur (1994). Neste caso, seja este sistema dado por $\mathrm{n}$ equações e $\mathrm{n}$ incógnitas conforme

$$
\begin{aligned}
f_{1}\left(x_{1}, x_{2}, \ldots, x_{n}\right) & =0 \\
f_{2}\left(x_{1}, x_{2}, \ldots, x_{n}\right) & =0 \\
& \vdots \\
f_{3}\left(x_{1}, x_{2}, \ldots, x_{n}\right) & =0 .
\end{aligned}
$$

Tal sistema pode ser escrito na forma

$$
F(\vec{x})=\overrightarrow{0},
$$

cujo vetor de incógnitas e matriz de equações são definidos, respectivamente, por

$$
\vec{x}=\left[\begin{array}{c}
x_{1} \\
x_{2} \\
\vdots \\
x_{n}
\end{array}\right]
$$

e

$$
F(\vec{x})=\left[\begin{array}{c}
f_{1}\left(x_{1}, x_{2}, \ldots, x_{n}\right) \\
f_{2}\left(x_{1}, x_{2}, \ldots, x_{n}\right) \\
\vdots \\
f_{3}\left(x_{1}, x_{2}, \ldots, x_{n}\right)
\end{array}\right] .
$$

Utilizando a expansão em série de Taylor em torno do ponto $\vec{x}^{0}$ para a função $F(\vec{x})$, é possível escrever

$$
F(\vec{x})=F\left(\vec{x}^{0}\right)+J\left(\vec{x}^{0}\right)\left(\vec{x}-\vec{x}^{0}\right),
$$


sendo a matriz Jacobiana definida por

$$
J\left(\vec{x}^{0}\right)=\left[\begin{array}{cccc}
\frac{\partial f_{1}\left(x^{0}\right)}{\partial x_{1}} & \frac{\partial f_{1}\left(x^{0}\right)}{\partial x_{2}} & \ldots & \frac{\partial f_{1}\left(x^{0}\right)}{\partial x_{n}} \\
\frac{\partial f_{2}\left(x^{0}\right)}{\partial x_{1}} & \frac{\partial f_{2}\left(x^{0}\right)}{\partial x_{2}} & \ldots & \frac{\partial f_{2}\left(x^{0}\right)}{\partial x_{n}} \\
\vdots & \vdots & \ddots & \vdots \\
\frac{\partial f_{n}\left(\vec{x}^{0}\right)}{\partial x_{1}} & \frac{\partial f_{n}\left(\vec{x}^{0}\right)}{\partial x_{2}} & \cdots & \frac{\partial f_{n}\left(\vec{x}^{0}\right)}{\partial x_{n}}
\end{array}\right]
$$

A partir de (D.4), obtém-se a aproximação linear

$$
\digamma(\vec{x})=F\left(\vec{x}^{0}\right)+J\left(\vec{x}^{0}\right)\left(\vec{x}-\vec{x}^{0}\right)=0 .
$$

Conhecida uma aproximação linear $x^{k}$, o método de Newton-Raphson define $x^{k+1}$ como a solução de (D.12). Assim, a equação na forma genérica fica definida por

$$
\vec{x}^{k+1}=\vec{x}^{k}-\left[J\left(\vec{x}^{k}\right)\right]^{-1} F\left(\vec{x}^{k}\right) .
$$

Estabelecendo a igualdade

$$
\overrightarrow{\Delta x}^{k}=\vec{x}^{k+1}-\vec{x}^{k}
$$

a equação final para o processo iterativo pode ser escrita na forma

$$
J\left(\vec{x}^{k}\right) \Delta \vec{x}^{k}=-F\left(\vec{x}^{*}\right)
$$

Assim, tem-se agora um sistema de equações lineares que pode ser resolvido até que um critério de parada seja satisfeito. Tal critério pode ser especificado como

$$
\left|\vec{x}^{k+1}-\vec{x}^{k}\right|<\zeta
$$

sendo $\zeta$ um erro preestabelecido, suficientemente pequeno.

\section{D.2 Método de integração trapezoidal}

A regra do trapézio é uma fórmula de Newton-Cotes do tipo fechado Franco (2007). Sua interpretação geométrica pode ser observada na Figura D.3. 


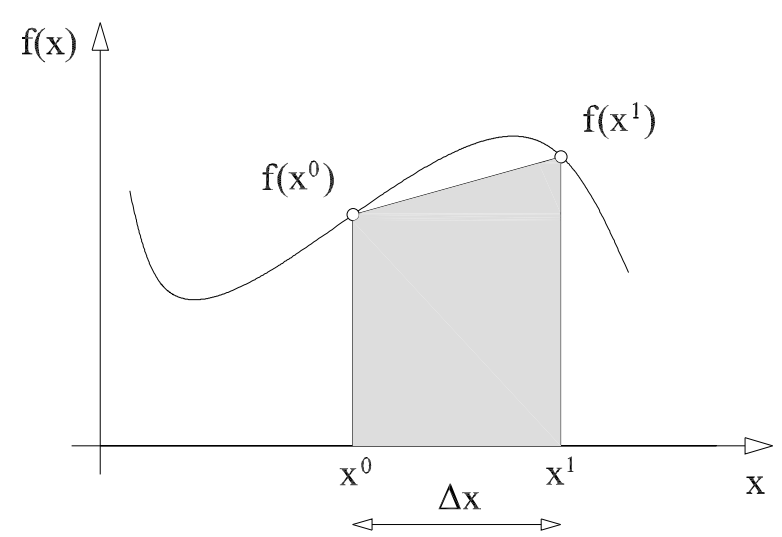

Figura D.3: Regra dos trapézios para $f(x)$.

Pelos pontos extremos do intervalo $\Delta x$, a função $f(x)$ é interpolada por uma reta, cuja integral foi aproximada pela área sob esta reta, a área hachurada. Uma vez que a área deste trapézio é calculada por

$$
A=\frac{\Delta x}{2}\left[f\left(x^{0}\right)+f\left(x^{1}\right)\right]
$$

a integral da função $f(x)$ neste respectivo intervalo pode então ser aproximada conforme

$$
\int_{x^{0}}^{x^{1}} f(x) d x=x^{1}-x^{0}=\frac{\Delta x}{2}\left[f\left(x^{0}\right)+f\left(x^{1}\right)\right] .
$$

Seja a equação diferencial

$$
\frac{d x}{d t}=f(x, t)
$$

em que $x$ é o estado, $t$ é a variável independente tempo e $x=x^{0}$ em $t=t^{0}$. A solução para $x$ em $t^{1}=t^{0}+\Delta t$ pode ser expressa na forma integral por

$$
x^{1}=x^{0}+\int_{t^{0}}^{t^{1}} f(x, \tau) d \tau
$$

Utilizando a regra do trapézio para aproximar a integral $f(x, \tau)$ de (D.20) no intervalo $\Delta t$, tem-se como resultado

$$
x^{1}=x^{0}+\frac{\Delta t}{2}\left[f\left(x^{0}, t^{0}\right)+f\left(x^{1}, t^{1}\right)\right]
$$


Desta forma, a integral de $f(x)$ no intervalo de tempo $\Delta t$ torna-se

$$
\int_{t^{0}}^{t^{1}} f(x, \tau) d \tau=x^{1}-x^{0}=\frac{\Delta t}{2}\left[f\left(x^{0}, t^{0}\right)+f\left(x^{1}, t^{1}\right)\right] .
$$

Sua interpretação geométrica pode ser observada na Figura D.4.

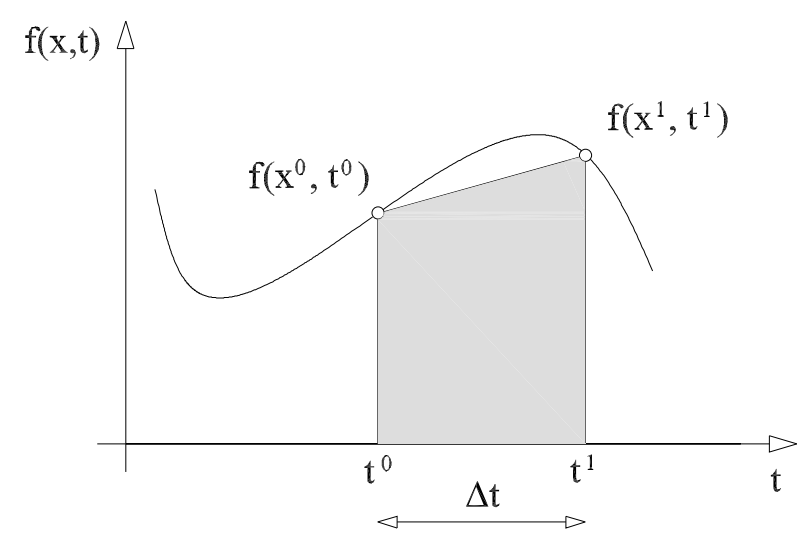

Figura D.4: Regra dos trapézios para $f(x, t)$.

E finalmente a equação para obter $x$ em $t=t^{k+1}$ pode ser escrita na forma

$$
x^{k+1}=x^{k}+\frac{\Delta t}{2}\left[f\left(x^{k}, t^{k}\right)+f\left(x^{k+1}, t^{k+1}\right)\right]
$$

Como pode ser observado, a solução aproximada da equação diferencial (D.19) foi viabilizada pelo método trapezoidal por uma equação algébrica que deverá ser resolvida para cada passo de integração fixo $\Delta t$. Para a completa resolução do sistema de equações algébricas e diferenciais que modela o problema, deverá ser encontrado o vetor solução $\vec{x}^{k+1}$ através, por exemplo, do método de Newton-Raphson, para cada passo fixo $\Delta t$.

\section{D.3 Implementação em MATLAB ${ }^{\circledR}$}

A seguir, são apresentados scripts implementados em MATLAB ${ }^{\circledR}$, utilizados para reproduzir o comportamento dinâmico de um aerogerador modelo SCIG 0,75 MW conectado a uma barra infinita, cujo sistema é modelado pelas equações apresentadas na seção 3.9 do capítulo 3. Tais scripts são apenas simples sugestões de como podem ser implementados os métodos de Newton-Raphson e de integração trapezoidal, além das funções fsolve e ode15i. No final, são apresentados os resultados para algumas variáveis. Como pode ser observado nas Figuras D.17 e D.18, os resultados para ambos os modos de implementação são numericamente equivalentes. 
Script principal para simulação no tempo a partir do método de

Newton-Raphson e integração trapezoidal

**** Parte 1

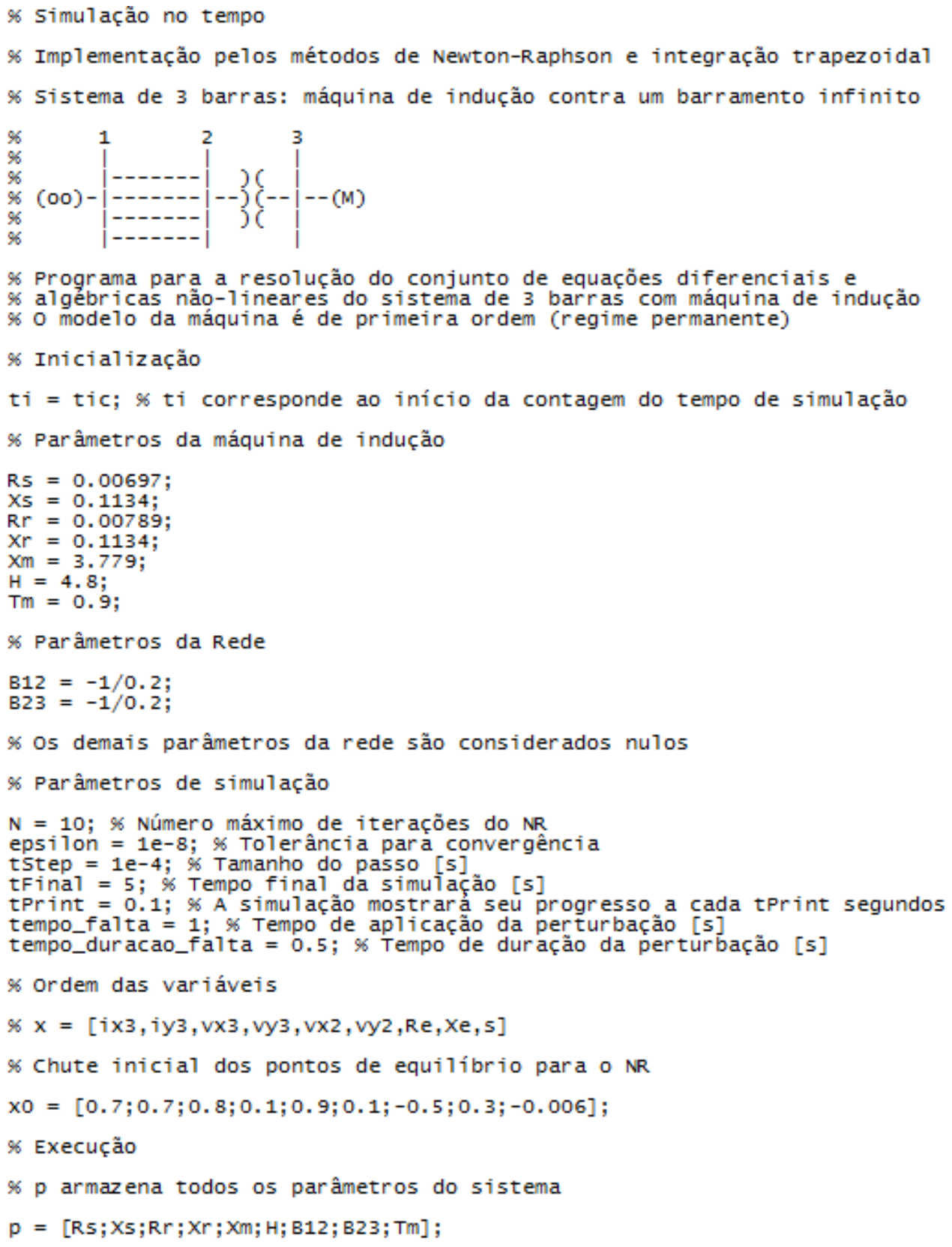


Script principal para simulação no tempo a partir do método de

Newton-Raphson e integração trapezoidal

**** Parte 2 *****

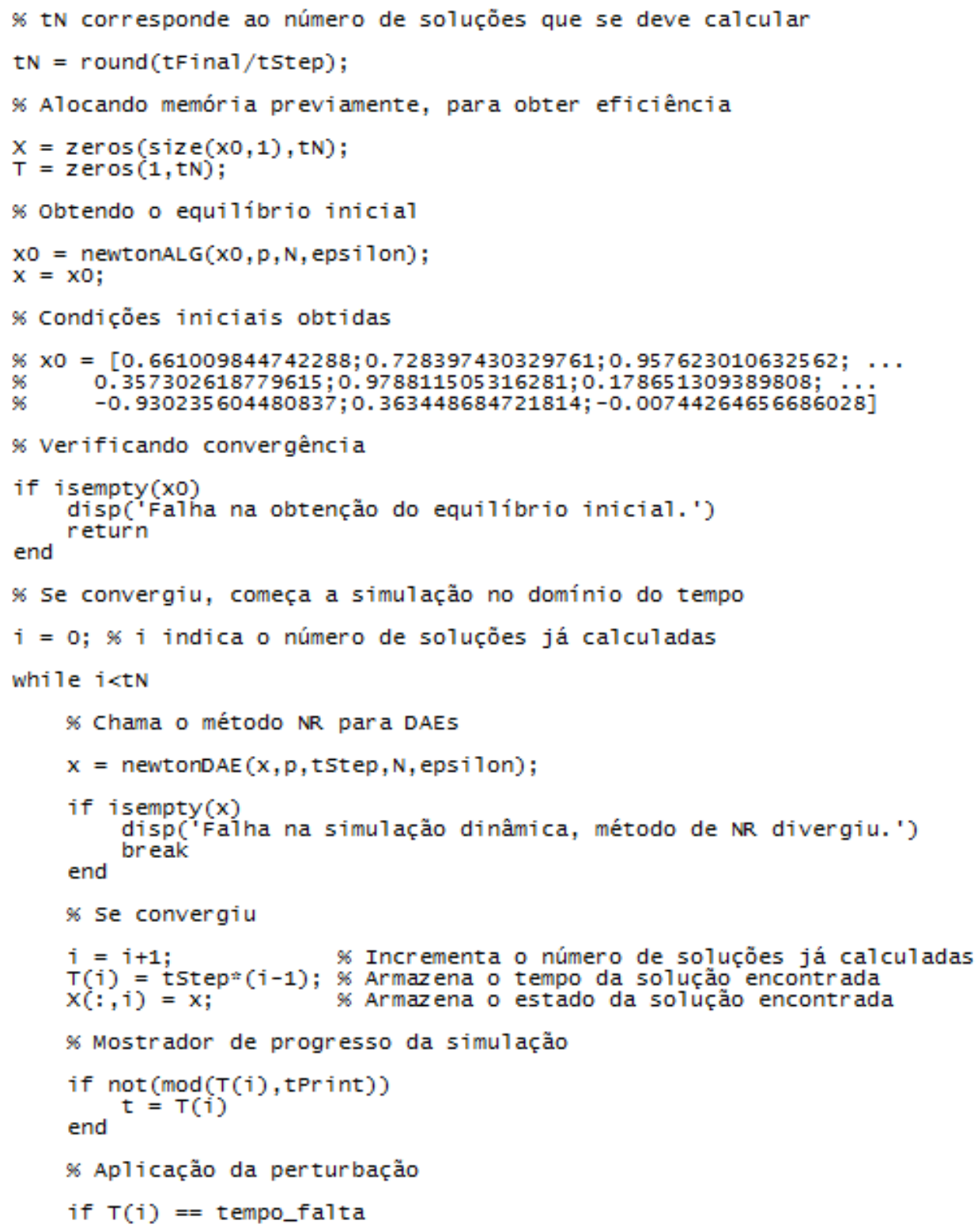


Script principal para simulação no tempo a partir do método de

Newton-Raphson e integração trapezoidal

**** Parte 3 ****

$p(7)=-2.5 ; \%$ susceptância menor devido

$\%$ à perda de 2 linhas de transmissão

$x=$ newtondAE $(x, p$, tstep, $N$, epsi1on);

if isempty( $x)$

disp("Falha na obtenção do equilíbrio pós perturbação. ')

end return

\% Reescrevendo o estado obtido

$x(:, i)=x$;

elseif $T(i)==$ (tempo_falta + tempo_duracao_falta)

xEstrela $=$ x; \% Registram os valores correspondentes ao tempo

$\%$ de duracão da falta. Para o tempo crítico, estes pontos pertencem

$\%$ à fronteira da região de estabilidade

$p(7)=-5 ; \%$ Retorno das linhas de transmissão

$x=$ newtondAE ( $x, p$, tstep, $\mathrm{N}$, epsi1on);

if isempty( $x)$

disp("Falha na obtenção do equilíbrio pós restauração. ')

end return

\% Reescrevendo o estado obtido

$x(:, i)=x ;$

end

end

tempo_de_simulacao $=\operatorname{toc}(t i) \%$ tempo total de simulação

\% Caso o método tenha divergido, teremos valores não preenchidos em $\mathrm{T}$ e $\mathrm{X}$

index = find(T,1,'last'); \% index será o índice do último elemento não

$\mathrm{T}=\mathrm{T}(1$ : index $) ;$ nulo de $\mathrm{T}$. Dessa forma, gar ant imos que $\mathrm{T}$ e $\mathrm{X}$

$\mathrm{x}=\mathrm{x}(\mathrm{:}, 1:$ index $) ; \quad \%$ não possuem dados nulos ínválidos

\% saída de dados

\% calculando representação polar e armazenando variáveis de plotagem

I3mag $=\operatorname{abs}(x(1,:)+1 i * x(2,:))$

I 3 ang $=$ phase $(x(1,:)+1 i * x(2,:))$

$\mathrm{V} 2 \mathrm{mag}=\operatorname{abs}(x(5,:)+1 i * x(6,:))$

V 2 ang $=$ phase $(x(5,:)+1 j * x(6,:))$

$\mathrm{V} 3 \mathrm{mag}=\operatorname{abs}(x(3,:)+1 j * x(4,:))$

V3ang $=$ phase $(x(3,:)+1 j * x(4,:))$

$\mathrm{Te}=-\left(\mathrm{p}(3) \cdot{ }^{*} \mathrm{p}(5) \cdot \wedge 2{ }^{*}(x(3,:) \cdot \wedge 2+x(4,:) \cdot \wedge 2)\right) \cdot /\left(x(9,:) \cdot{ }^{*}((\mathrm{p}(5)+\mathrm{p}(2)) \cdot \wedge 2 \ldots\right.$

$+p(1) \cdot \wedge 2) \cdot{ }^{*}\left(\left(p(3) \cdot / x(9,:)+\left(p(1) \cdot{ }^{*} p(5) \wedge 2\right) \cdot /((p(5)+p(2)) \cdot \wedge 2+p(1) \cdot \wedge 2)\right) \cdot \wedge 2 \ldots\right.$

$+\left(p(4)+\left(p(1) \cdot \wedge 2^{*} p(5)+p(5) \cdot \wedge 2 \cdot{ }^{*} p(2)+p(5) \cdot{ }^{*} p(2) \cdot \wedge 2\right) \cdot /((p(5)+p(2)) \cdot \wedge 2 \ldots\right.$

$+\mathrm{p}(1) \cdot \wedge 2)) \cdot \wedge 2))$;

\% Gráficos

figure ('Color", [1 11 1 $]$, 'Name', 'simu1acão no Domínio do Tempo")

plot (T, I3mag, ' b- ", T, V3mag, 'k-.' ", T, Te, 'g--")

ylabel ("Corrente no estator, tensắo no estator \new1ine e torque eletromagnético (pu)")

$\mathrm{x} 1$ abel ("Tempo (s)")

set (gca, 'YLim', , [0.75 1.25])

legend ('i_s', 'u_s', "T_e")

legend boxoff

set (gca, 'TickDir', 'out') 
Equações e matriz Jacobiana para o método de Newton-Raphson

*erk*

Parte 1

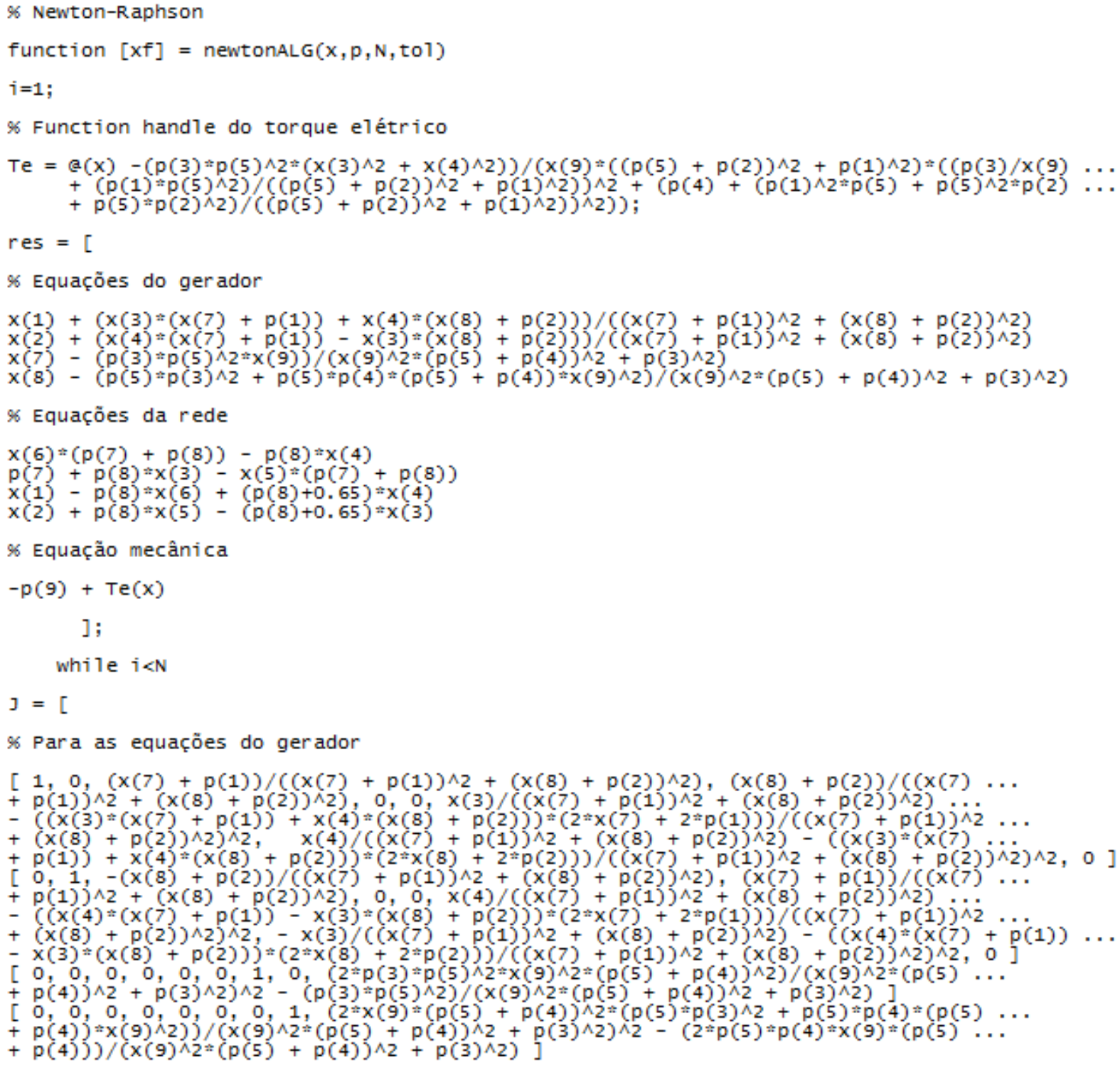


Equações e matriz Jacobiana para o método de Newton-Raphson

*将将

Parte 2

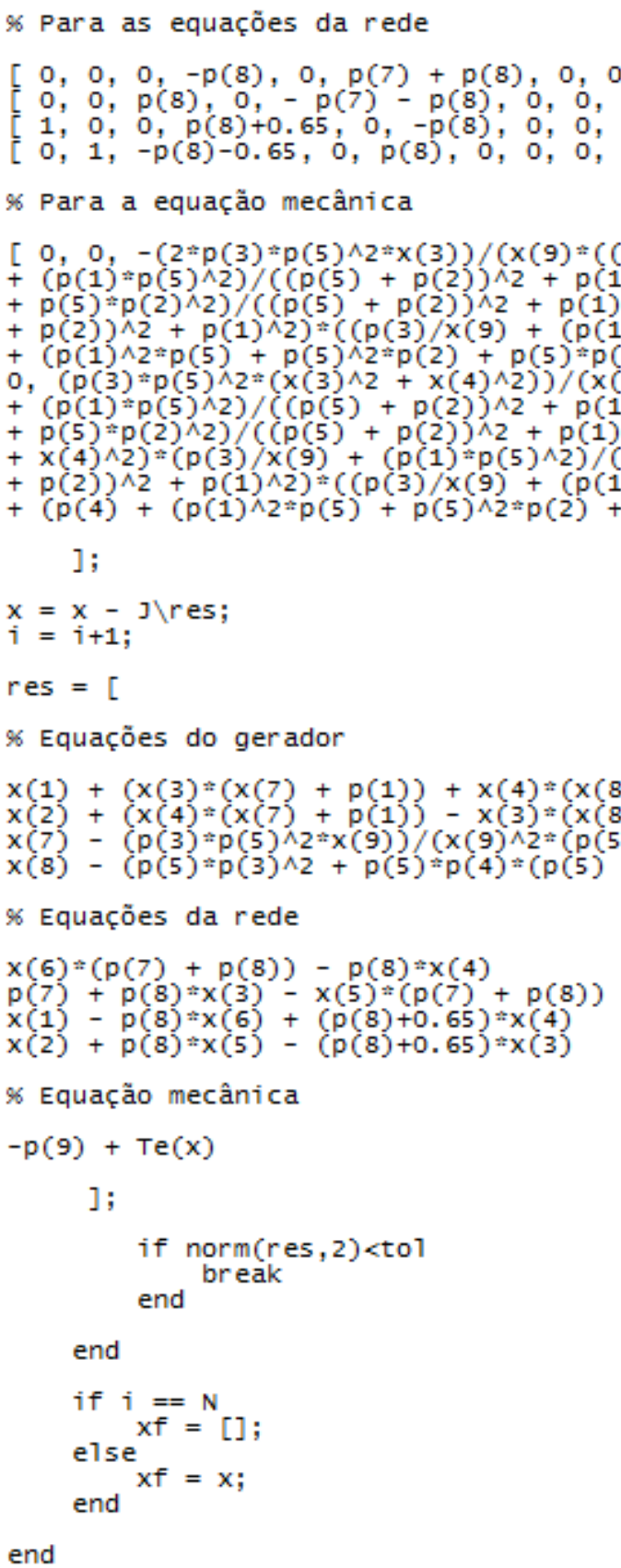


Equações e matriz Jacobiana para o método de integração trapezoidal *erk* Parte 1 *****

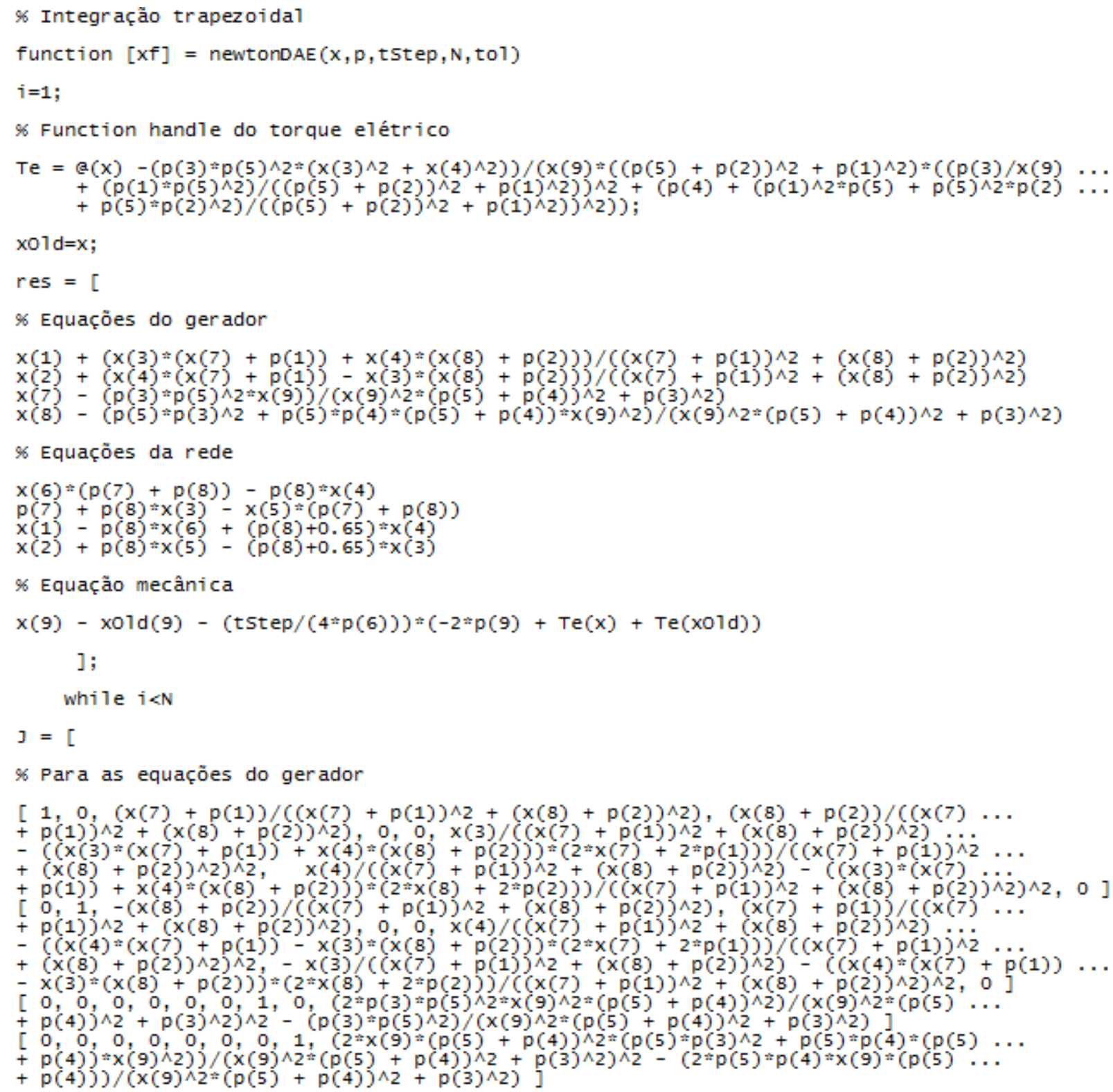


Equações e matriz Jacobiana para o método de integração trapezoidal ****⿰丬幺小

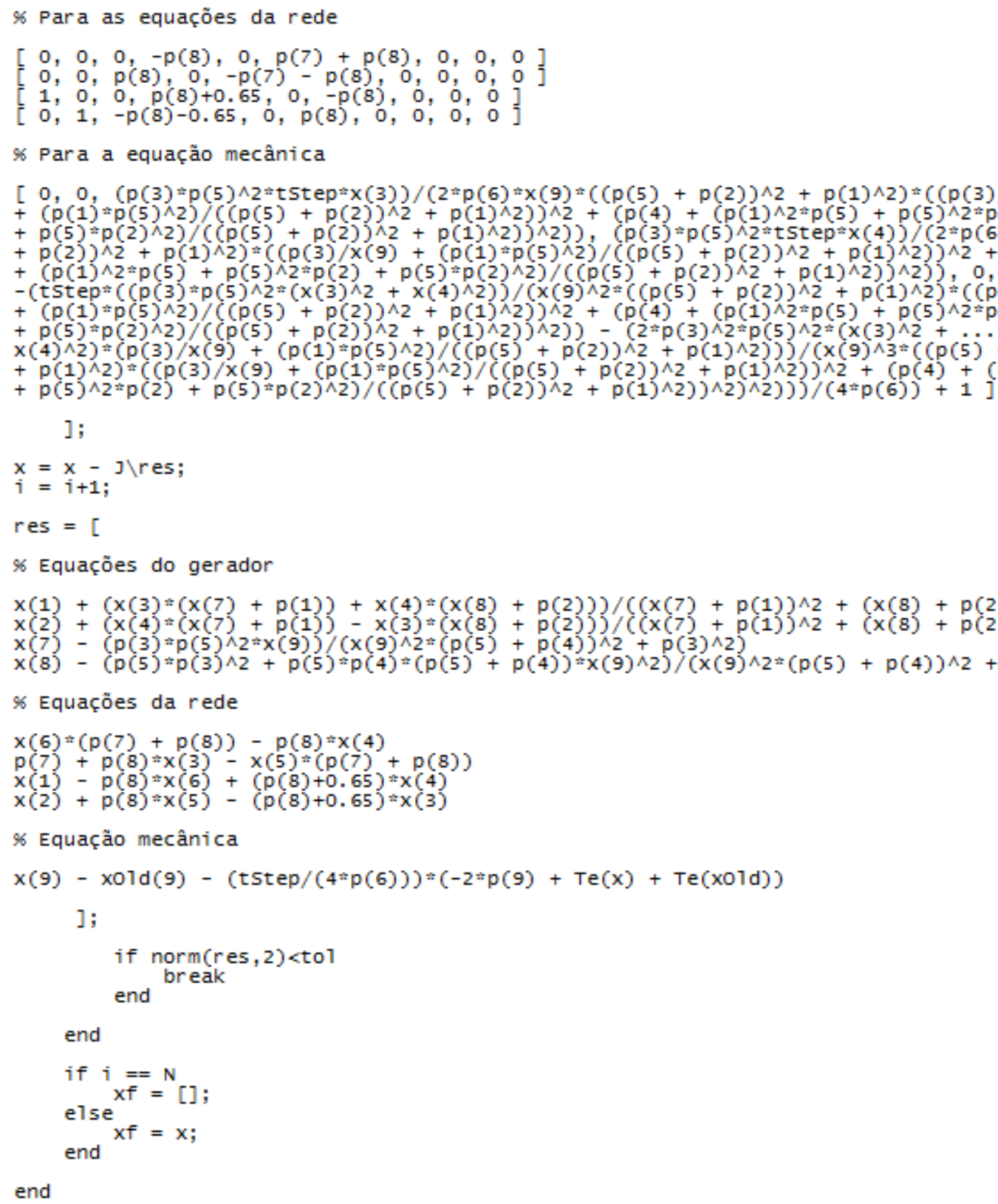


Script principal para simulação no tempo a partir das funções fsolve e ode15i

**** Parte 1 ****

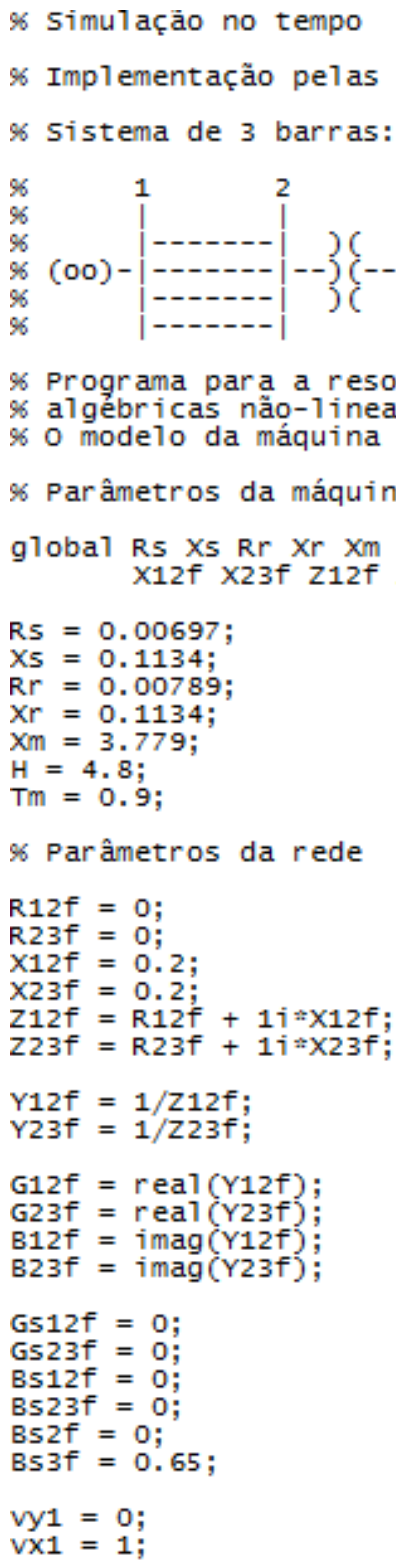


Script principal para simulação no tempo a partir das funções fsolve e ode15i

**** Parte 2 ****

\% Parâmetros da simulação

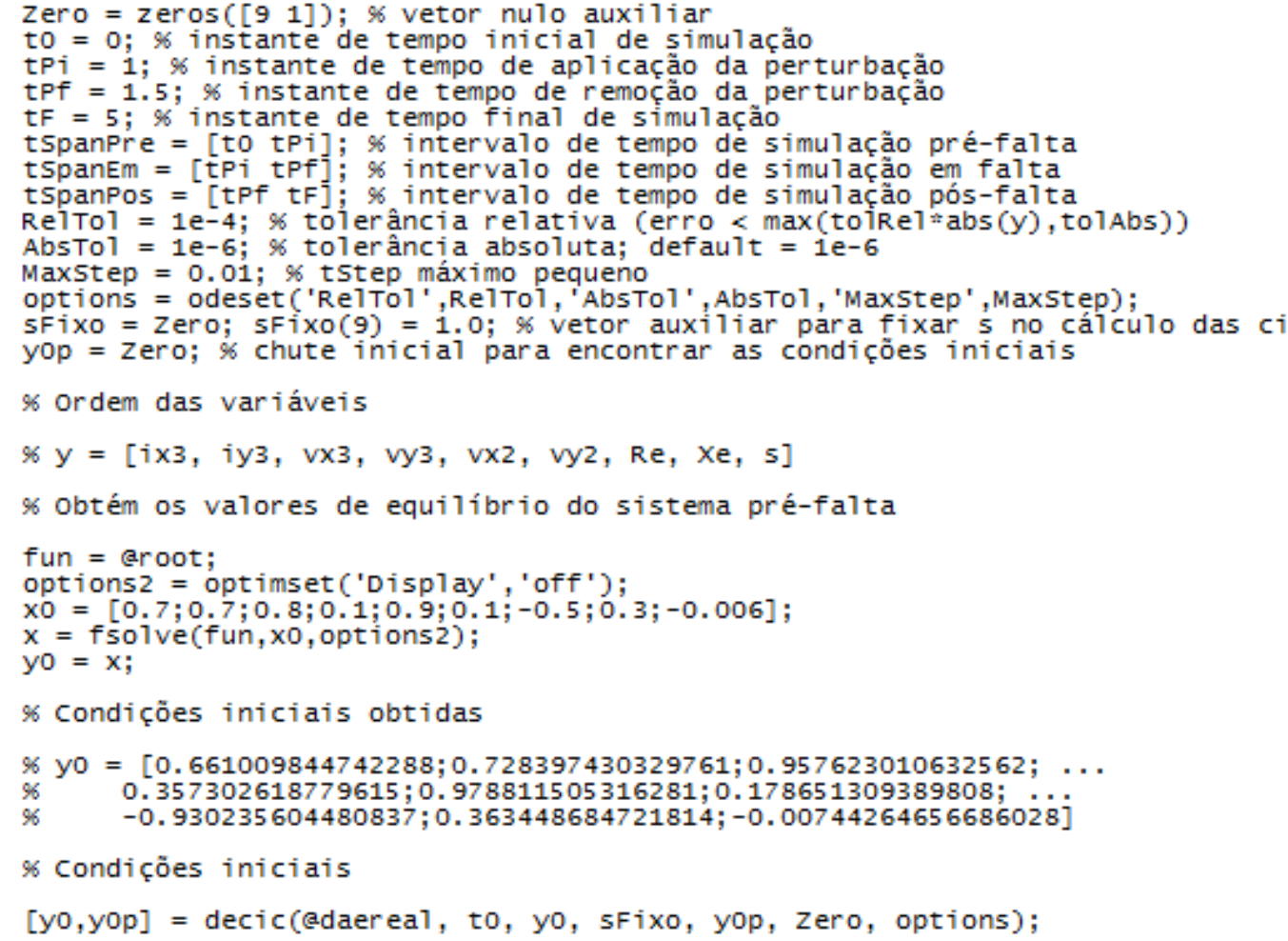


Script principal para simulação no tempo a partir das funções fsolve e ode15i

**** Parte 3 ****

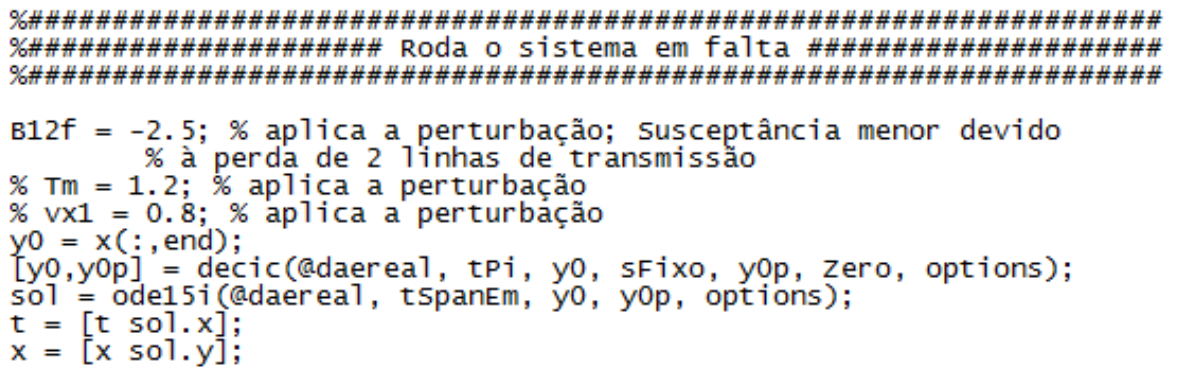

B12f $=-2.5 ; \%$ aplica a perturbação; Susceptância menor devido

$\%$ à perda de 2 inhas de transmissão

$\% \mathrm{Tm}=1.2 ; \%$ aplica a perturbação

$\%$ vx1 $=0.8 ; \%$ aplica a perturbação

$\mathrm{y} 0=\mathrm{x}($ : , end $)$;

[y0,y0p] = decic(@daerea], tpi, y0, sfixo, y0p, zero, options);

sol= ode15i(@daerea1, tspanEm, yo, y0p, options);

$t=[t$ sol. $x]$

$\mathrm{x}=[\mathrm{x}$ sol. $\mathrm{y}]$

\%\#\#\#\#\#\#\#\#\#\#\#\#\#\#\#\#\#\#\#\#\#\#\#\#\#\#\#\#\#\#\#\#\#\#\#\#\#\#\#\#\#\#\#\#\#\#\#\#\#\#\#\#\#\#\#\#\#\#\#\#\#\#\#\#\#\#\#

\%\#\#\#\#\#\#\#\#\#\#\#\#\#\#\#\#\#\#\#\#\# Roda o sistema pós-falta \#\#\#\#\#\#\#\#\#\#\#\#\#\#\#\#\#\#\#\#

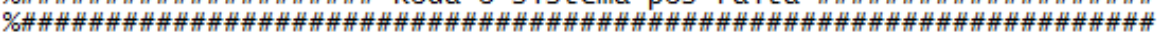

$\mathrm{B} 12 \mathrm{f}=-5 ; \%$ remove a perturbacão; Retorno das 1 inhas de transmissão

$\% \mathrm{Tm}=0.9 ; \%$ remove a perturbacão

$\%$ vx1 $=1 ; \%$ remove a perturbaçẳo

$\mathrm{y} 0=x(:$, end $)$;

$[y 0, y 0 p]=$ decic(@daereal, tpf, y0, sfixo, y0p, zero, options);

sol = ode15i(@daerea1, tspanPos, y0, y0p, options);

$\mathrm{t}=[\mathrm{t}$ sol. $\mathrm{x}]$

\% saída de dados

\% calculando representação polar e armazenando variáveis de plotagem

I 3 mag $=\operatorname{abs}(x(1,:)+1 j * x(2,:))$

I 3 ang $=$ phase $\left(x(1,:)+1 i^{*} \times(2,:)\right)$

$\mathrm{v} 2 \mathrm{mag}=\operatorname{abs}\left(x(5,:)+1 j^{*} \times(6,:)\right)$

$\mathrm{v} 2 \mathrm{ang}=\operatorname{phase}\left(x(5,:)+1 j^{*} \times(6,:)\right)$

$\mathrm{v} 3 \mathrm{mag}=\operatorname{abs}\left(x(3,:)+1 i^{*} \times(4,:)\right) ;$

v3ang $=$ phase $\left(x(3,:)+1 i^{*} \times(4,:)\right)$

$\mathrm{Te}=-\left(\mathrm{Rr} \cdot{ }^{*} \mathrm{Xm} \cdot \wedge 2 \cdot{ }^{*}(\mathrm{x}(3,:) \cdot \wedge 2+\mathrm{x}(4,:) \cdot \wedge 2)\right) \cdot /\left(\mathrm{x}(9,:) \cdot{ }^{*}((\mathrm{Xm}+\mathrm{Xs}) \cdot \wedge 2 \ldots\right.$

+ Rs. $\wedge 2) \cdot{ }^{*}\left(\left(\mathrm{Rr} \cdot / x(9,:)+\left(\mathrm{Rs} \cdot{ }^{*} \mathrm{Xm} \cdot \wedge 2\right) \cdot /((\mathrm{Xm}+\mathrm{Xs}) \cdot \wedge 2+\mathrm{Rs} \cdot \wedge 2)\right) \cdot \wedge 2\right.$.

$\left.\left.+\left(\mathrm{Xr}+\left(\mathrm{Rs} \cdot \wedge 2 .{ }^{*} \mathrm{Xm}+\mathrm{Xm} \cdot \wedge 2 .{ }^{*} \mathrm{Xs}+\mathrm{Xm} \cdot{ }^{*} \mathrm{Xs} \cdot \wedge 2\right) \cdot /((\mathrm{Xm}+\mathrm{Xs}) \cdot \wedge 2+\mathrm{Rs} \cdot \wedge 2)\right) \cdot \wedge 2\right)\right) ; \ldots$

\% Gráficos

figure ("Color", [1 11 1] , "Name", "simulação no Domínio do Tempo")

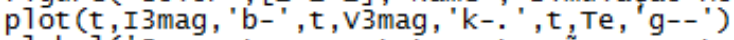

ylabel ("Corrente no estator, tensăo no estator \newline e torque eletromagnético (pu)')

xlabel ("Tempo (s)")

set (gca, "YLim", [0.75 1.25])

legend (i_s", "uss", "T_e")

legend boxoff

set (gca, "TickDir', 'out ') 
Equações para a função fsolve

\% fsolve

function $F=\operatorname{root}(x)$

\% Importando parâmetros globais

global Xs Rr Xr Xm Rs Tm Vy1 Vx1 G12f B12f G23f B23f Gs12f Gs23f Bs12f Bs23f Bs2f Bs3f \% Function handle do torque elétrico

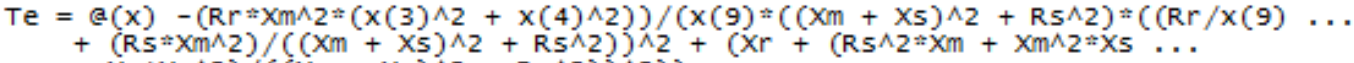

$\left.\left.\left.\left.+X m^{\prime \prime} X s^{\wedge} 2\right) /\left((X m+X s) \wedge^{2}+R s \wedge 2\right)\right) \wedge_{2}\right)\right) ;$

\% Equações a serem resolvidas (1ado direito igualado a zero) (derivadas

$\%$ nulas)

\% Equações do gerador

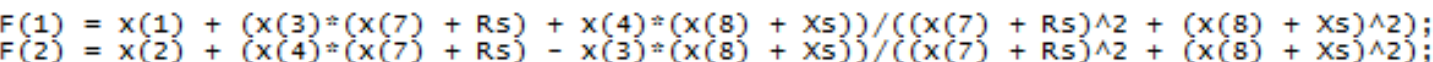

$F(3)=x(7)-(R r * X m \wedge 2 * x(9)) /(x(9) \wedge 2 *(X m+X r) \wedge 2+R r \wedge 2)$

$F(4)=x(8)-(X m * R r \wedge 2+X m * X r *(X m+X r) * x(9) \wedge 2) /(X(9) \wedge 2 *(X m+X r) \wedge 2+R r \wedge 2)$;

\% Equações da rede

$F(5)=G 12 f * V x 1-B 12 f * V y 1+(-G 512 f-G 523 f-G 12 f-G 23 f) * x(5) \ldots$

$+(B 52 f+B 512 f+B 523 f+B 12 f+B 23 f) * x(6)+G 23 f^{*} x(3)-B 23 f^{*} x(4)$

$F(6)=B 12 f * v x 1+G 12 f * V y 1+(-B S 2 f-B S 12 f-B S 23 f-B 12 f-B 23 f) * x(5) \cdots$

$+(-G 512 f-G S 23 f-G 12 f-G 23 f) * x(6)+B 23 f * x(3)+G 23 f * x(4)$

$F(7)=x(1)+G 23 f * x(5)-B 23 f * x(6)+(-G 523 f-G 23 f) * x(3)+(B 53 f+B 523 f+B 23 f) * x(4) ;$

$F(8)=x(2)+B 23 f=x(5)+G 23 f \div x(6)+(-B s 3 f-B 523 f-B 23 f) * x(3)+(-G 523 f-G 23 f) * x(4) ;$

\% Equação mecânica

$F(9)=T e(x)-T m ;$

end 


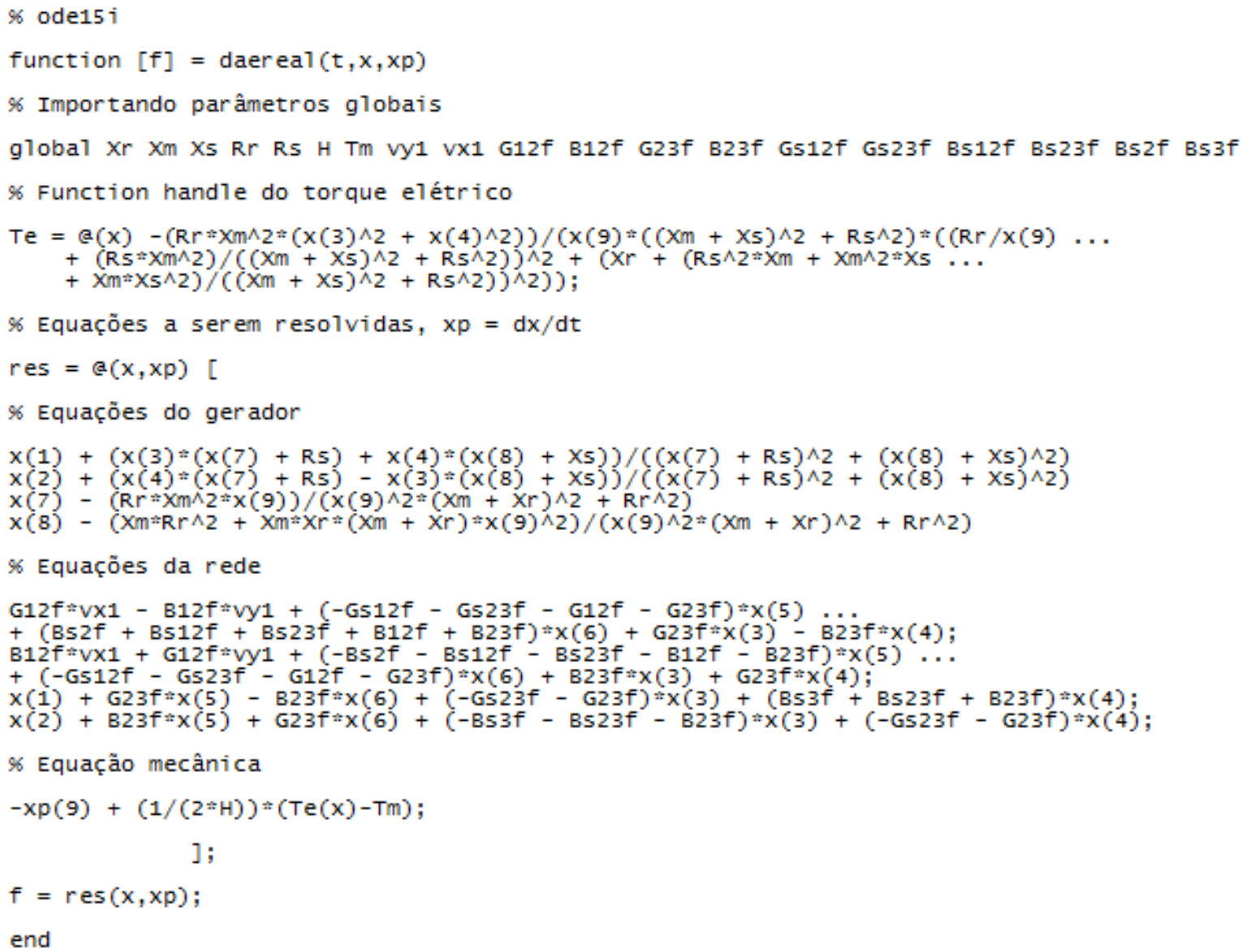


Comportamento dinâmico do SCIG 0.75 MW. Os parâmetros deste aerogerador podem ser encontrados em Yaramasu e Wu (2017).

Perturbação: perda de duas linhas de transmissão durante 500 ms.

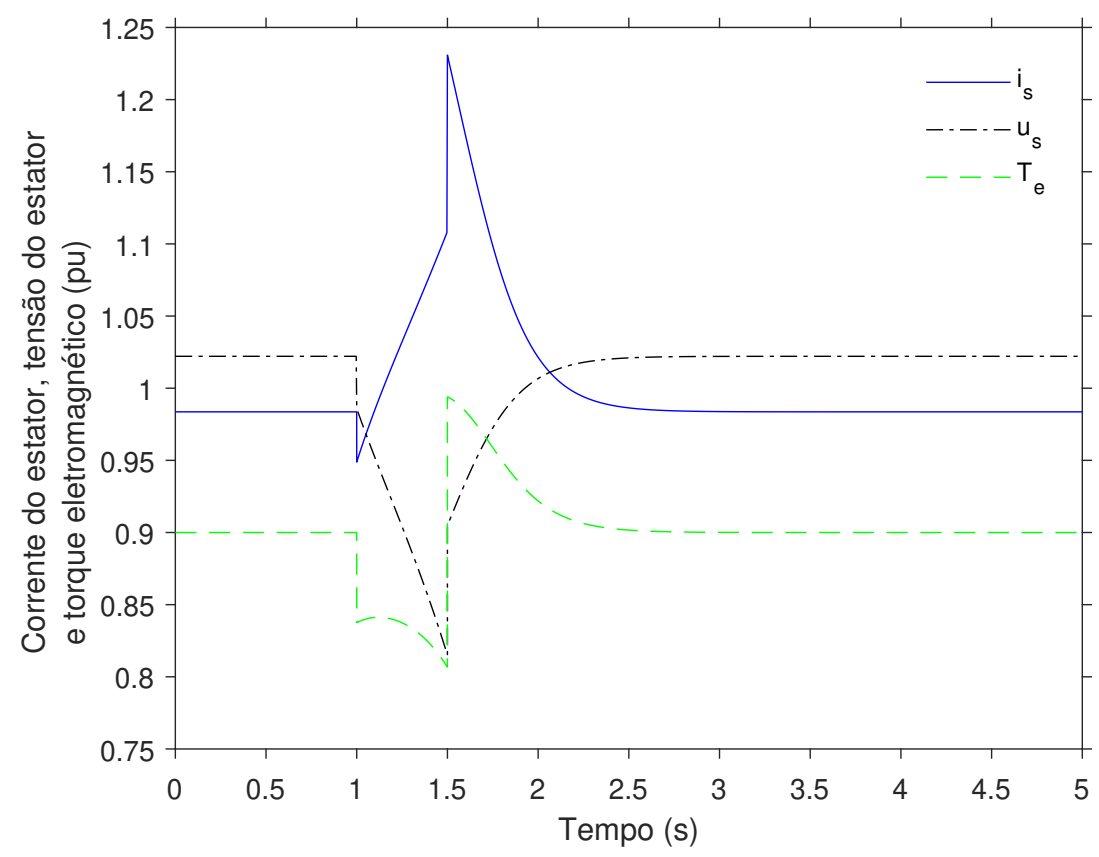

Figura D.17: Resposta a partir dos métodos de Newton-Raphson e integração trapezoidal.

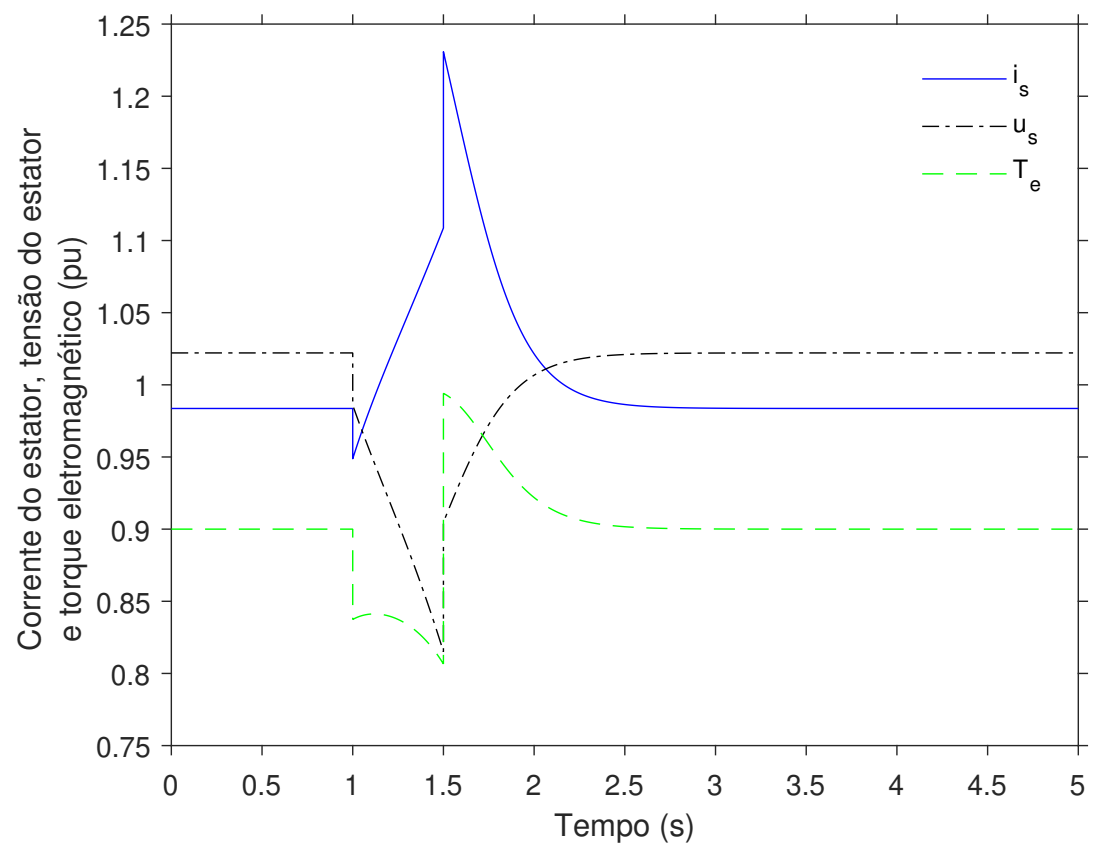

Figura D.18: Resposta a partir das funções fsolve e ode15i. 


\section{Apêndice $E$}

\section{Condições iniciais}

As Tabelas E.1 à E.9 apresentam as condições iniciais para as simulações deste trabalho. Para as configurações SCIG e WRIG considera-se um torque mecânico de entrada (saída da turbina) $T_{m}=0,7$ pu. Para a configuração DFIG a barra terminal é considerada uma barra PQ com $P_{g}=0,6933$ pu e $Q_{g}=0,0722$ pu. Também para a configuração DFIG considera-se $i_{d c}^{r e f}=0,1 \mathrm{pu}, u_{D C}^{r e f}=3,062 \mathrm{pu}, P_{g}^{r e f}=0,6933 \mathrm{pu}$ e $Q_{g}^{r e f}=0,0722 \mathrm{pu}$. Com estes valores obtém-se $P_{m}=0,7015592567778$ pu como condição inicial, o que resulta em $T_{m}=0,597655213895746$ pu. Todos os valores a seguir estão especificados por unidade, exceto os ângulos, que estão em graus. É importante observar que para diferentes resistências do rotor, considerando a tensão nula no rotor, a única variável que sofre alteração em seu valor corresponde ao escorregamento, tanto para o modelo em regime permanente como para os modelos no sistema de coordenadas $d q$. Quando não especificada a tensão no rotor para a configuração WRIG, a mesma é considerada nula.

Tabela E.1: Condições iniciais para a configuração SCIG modelada em regime permanente.

\begin{tabular}{cccccc}
\hline$i_{x 3}$ & 0,631498115323367 & $i_{y 3}$ & 0,485321310006536 & $u_{x 3}$ & 0,995167898865552 \\
$u_{y 3}$ & 0,139200748429081 & $u_{x 2}$ & 0,997583949432776 & $u_{y 2}$ & 0,0696003742145403 \\
$r_{e}$ & $-1,10353239464073$ & $x_{e}$ & 0,520419775983218 & $s$ & $-0,00531636888531532$ \\
\hline
\end{tabular}

Tabela E.2: Condições iniciais para a configuração SCIG modelada nos eixos d e q.

\begin{tabular}{cccccc}
\hline$i_{x 3}$ & 0,485321310006499 & $i_{y 3}$ & 0,631498115323273 & $u_{x 3}$ & 0,139200748429060 \\
$u_{y 3}$ & 0,995167898865560 & $u_{x 2}$ & 0,0696003742145299 & $u_{y 2}$ & 0,997583949432780 \\
$e_{d}$ & 0,269705449652537 & $e_{q}$ & 0,901200152541081 & $s$ & $-0,00531636888531538$ \\
\hline
\end{tabular}

Tabela E.3: Condições iniciais para a configuração WRIG considerando diferentes resistências do rotor.

\begin{tabular}{llllll}
\hline$s\left(r_{r} \cdot 1\right)$ & $-0,0070418990$ & $s\left(r_{r} \cdot 2\right)$ & $-0,0140837980$ & $s\left(r_{r} \cdot 3\right)$ & $-0,0211256971$ \\
$s\left(r_{r} \cdot 4\right)$ & $-0,0281675961$ & $s\left(r_{r} \cdot 5\right)$ & $-0,0352094952$ & $s\left(r_{r} \cdot 10\right)$ & $-0,070418990$ \\
\hline
\end{tabular}


Tabela E.4: Condições iniciais para a configuração WRIG modelada em regime permanente.

\begin{tabular}{cccccc}
\hline$i_{x 3}$ & 0,576834144137336 & $i_{y 3}$ & 0,843005809884702 & $u_{x 3}$ & 0,995234310161914 \\
$u_{y 3}$ & 0,138101018491545 & $u_{x 2}$ & 0,997617155080957 & $u_{y 2}$ & 0,0690505092457727 \\
$r_{e}$ & $-0,670885947974076$ & $x_{e}$ & 0,503445375021889 & $s$ & $-0,00704189904789520$ \\
$r_{2}$ & $-0,866841071829569$ & $x_{2}$ & $-2,12879459886957$ & $P_{r}$ & 0 \\
$i_{r}$ & 0,833229702450263 & $u_{x 1}^{t h}$ & 0 & $u_{y 1}^{t h}$ & 0 \\
\hline
\end{tabular}

Tabela E.5: Condições iniciais para a configuração WRIG modelada nos eixos d e q.

\begin{tabular}{cccccc}
\hline$i_{x 3}$ & 0,843005809985710 & $i_{y 3}$ & 0,576834144195396 & $u_{x 3}$ & 0,138101018505446 \\
$u_{y 3}$ & 0,995234310137730 & $u_{x 2}$ & 0,0690505092527228 & $u_{y 2}$ & 0,997617155068865 \\
$e_{d}$ & 0,380464509586537 & $e_{q}$ & 0,657496113469858 & $s$ & $-0,00704189904929810$ \\
\hline
\end{tabular}

Tabela E.6: Condições iniciais para a configuração WRIG modelada nos eixos d e q com $u_{q r}=0$ e $u_{d r}=-0,005$

\begin{tabular}{cccccc}
\hline$i_{x 3}$ & 0,169944170855622 & $i_{y 3}$ & 0,674726523558976 & $u_{x 3}$ & 0,139118870836902 \\
$u_{y 3}$ & 0,995887799823584 & $u_{x 2}$ & 0,0695594354184511 & $u_{y 2}$ & 0,997943899911792 \\
$e_{d}$ & 0,415186231770560 & $e_{q}$ & 0,932883913872214 & $s$ & $-0,00569764536221571$ \\
\hline
\end{tabular}

Tabela E.7: Condições iniciais para a configuração WRIG modelada nos eixos d e q com $u_{q r}=0$ e $u_{d r}=0,0025$

\begin{tabular}{cccccc}
\hline$i_{x 3}$ & 1,20104097705530 & $i_{y 3}$ & 0,522190970995670 & $u_{x 3}$ & 0,136878367233465 \\
$u_{y 3}$ & 0,995795287796776 & $u_{x 2}$ & 0,0684391836167327 & $u_{y 2}$ & 0,997897643898388 \\
$e_{d}$ & 0,360267724426406 & $e_{q}$ & 0,511888782266281 & $s$ & $-0,00829240252012444$ \\
\hline
\end{tabular}

Tabela E.8: Fluxo de carga para a configuração DFIG.

\begin{tabular}{llllll}
\hline$u_{3}$ & 1,00480359820905 & $\theta_{3}$ & 7,93196458789795 & $u_{2}$ & 1,00000135161114 \\
$\theta_{2}$ & 3,97550016952106 & & & & \\
\hline
\end{tabular}

As grandezas relativas ao chute inicial para a configuração DFIG são calculadas pelas relações

$$
\begin{aligned}
& P_{3}=P_{m}=P_{g}=0,693300000000000, \\
& P_{s}=P_{m} /(1-s)=-0,593106239201155, \\
& P_{r}=s P_{m} /(1-s)=0,100193760798845, \\
& i_{d c}=i_{d c}^{r e f}=0,100000000000000 \\
& i_{d s}=i_{y 3}-i_{d c}=-0,124048645283936, \\
& i_{q s}=\left(P_{s}-u_{y 3} i_{d s}\right) / u_{x 3}=-0,578688991305165,
\end{aligned}
$$




$$
\begin{aligned}
& i_{q c}=\left(P_{r}-u_{y 3} i_{d c}\right) / u_{x 3}=-0,114611008695372, \\
& u_{d c}=u_{y 3}-r_{f} i_{d c}-x_{f} i_{q c}=0,160582201716847, \\
& u_{q c}=u_{x 3}-r_{f} i_{q c}+x_{f} i_{d c}=1,01633638103017 \\
& i_{d r}=\left(-u_{x 3}+r_{s} i_{q s}-x_{s} i_{d s}\right) / x_{m}=-0,386224808169138 \\
& i_{q r}=\left(u_{y 3}-r_{s} i_{d s}-x_{s} i_{q s}\right) / x_{m}=0,720123744675715 \\
& u_{d r}=r_{r} i_{d r}+s\left(x_{r} i_{q r}+x_{m} i_{q s}\right)=-0,0728452926755315 \\
& u_{q r}=r_{r} i_{q r}-s\left(x_{r} i_{d r}+x_{m} i_{d s}\right)=-0,172367414339082 \\
& e_{d}=\left[\left(x_{r} i_{q r}+x_{m} i_{q s}\right) x_{m}\right] / x_{r}=0,375235648451492 \mathrm{e} \\
& e_{q}=-\left[\left(x_{r} i_{d r}+x_{m} i_{d s}\right) x_{m}\right] / x_{r}=0,949985608237712 .
\end{aligned}
$$

Com este chute inicial, resolve-se o sistema de equações apresentado no item 3.6.4.2 da seção 3.6 do capítulo 3. As demais variáveis são calculadas para completar o vetor das condições iniciais. Tal vetor, necessário para executar as simulações dinâmicas, fica então completo com

$$
\begin{aligned}
& u_{D C}=u_{D C}^{r e f}=3,062000000000000, \\
& i_{d c}^{u}=-i_{q c} \operatorname{sen}(\theta)+i_{d c} \cos (\theta)=0,100000000000000, \\
& i_{q c}^{u}=i_{q c} \cos (\theta)+i_{d c} \operatorname{sen}(\theta)=-0,098364630248646, \\
& i_{q c}^{r e f}=i_{q c}^{u}=-0,098364630248646, \\
& u_{d c}^{u}=-u_{q c} \operatorname{sen}(\theta)+u_{d c} \cos (\theta)=0,018672926049729, \\
& u_{q c}^{u}=u_{q c} \cos (\theta)+u_{d c} \operatorname{sen}(\theta)=1,025787244511540, \\
& P_{m d 2}^{u}=u_{d c}^{u} 2 \sqrt{2} /\left(\sqrt{3} u_{D C}\right)=0,009958445640444, \\
& P_{m q 2}^{u}=u_{q c}^{u} 2 \sqrt{2} /\left(\sqrt{3} u_{D C}\right)=0,547061905880435, \\
& \alpha=\operatorname{tg}^{-1}\left(e_{d} / e_{q}\right)=21,496447488167380 \\
& i_{d r}^{e}=-i_{q r} \operatorname{sen}(\alpha)+i_{d r} \cos (\alpha)=-0,639731930285222, \\
& i_{q r}^{e}=i_{q r} \cos (\alpha)+i_{d r} \operatorname{sen}(\alpha)=0,526003825840230, \\
& i_{d r}^{r e f}=i_{d r}^{e}=-0,639731930285222 \\
& i_{q r}^{r e f}=i_{q r}^{e}=0,526003825840230, \\
& u_{d r}^{e}=-u_{q r} \operatorname{sen}(\alpha)+u_{d r} \cos (\alpha)=-0,004542096705931, \\
& u_{q r}^{e}=u_{q r} \cos (\alpha)+u_{d r} \operatorname{sen}(\alpha)=-0,193800139272721, \\
& P_{m d 1}^{e}=u_{d r}^{e} 2 \sqrt{2} /\left(\sqrt{3} u_{D C}\right)=-0,002422342541238 \mathrm{e} \\
& P_{m q 1}^{e}=u_{q r}^{e} 2 \sqrt{2} /\left(\sqrt{3} u_{D C}\right)=-0,103355422011426 .
\end{aligned}
$$

A Tabela E.9 reúne as condições iniciais para a configuração DFIG.

Tabela E.9: Condições iniciais para a configuração DFIG.

\begin{tabular}{cccccc}
\hline$s$ & $-0,1738528175882$ & $i_{d r}$ & $-0,4024816603984$ & $i_{q s}$ & $-0,5820767487848$ \\
$i_{q r}$ & 0,7238407839213 & $i_{d s}$ & $-0,1095178729213$ & $u_{q r}$ & $-0,1786550358767$ \\
\hline
\end{tabular}


Tabela E.9 - Continuação da página anterior

\begin{tabular}{cccccc}
\hline$u_{d r}$ & $-0,07524295834487$ & $u_{y 3}$ & 0,1386599999777 & $u_{x 3}$ & 0,9951902709432 \\
$u_{q c}$ & 1,013396348982 & $i_{q c}$ & $-0,1112232512158$ & $i_{d c}$ & 0,08546922763742 \\
$u_{d c}$ & 0,1600499579445 & $i_{x 3}$ & $-0,6932999998888$ & $u_{D c}$ & 3,062000000000 \\
$i_{y 3}$ & $-0,02404864528393$ & $\theta$ & 7,931964587897 & $i_{q c}^{u}$ & $-0,09836463024864$ \\
$i_{d c}^{u}$ & 0,09999999999999 & $i_{q c}^{r e f}$ & $-0,09836463024864$ & $P_{m q 2}^{u}$ & 0,5470619058804 \\
$P_{m d 2}^{u}$ & 0,009958445640444 & $e_{d}$ & 0,3764817696434 & $e_{q}$ & 0,9559284620982 \\
$\alpha$ & 21,49644748816 & $i_{q r}^{e}$ & 0,5260038258402 & $i_{d r}^{e}$ & $-0,6397319302852$ \\
$i_{q r}^{r e f}$ & 0,5260038258402 & $P_{m q 1}^{e}$ & $-0,1033554220114$ & $i_{d r}^{r e f}$ & $-0,6397319302852$ \\
$P_{m d 1}^{e}$ & $-0,002422342541238$ & $u_{q r}^{e}$ & $-0,1938001392727$ & $u_{d r}^{e}$ & $-0,004542096705930$ \\
$u_{q c}^{u}$ & 1,025787244511 & $u_{d c}^{u}$ & 0,01867292604972 & $P_{g}$ & $-0,6933000000000$ \\
$Q_{g}$ & $-0,07220000000000$ & $P_{m}$ & 0,7015592567778 & $u_{x 2}$ & 0,9975951354755 \\
$u_{y 2}$ & 0,06932999999758 & & & & \\
\hline
\end{tabular}




\section{Apêndice $F$}

\section{Gráficos de simulações}

As Figuras F.1 à F.9 mostram outras variáveis referentes às simulações elaboradas na seção 5.2 do capítulo 5 .

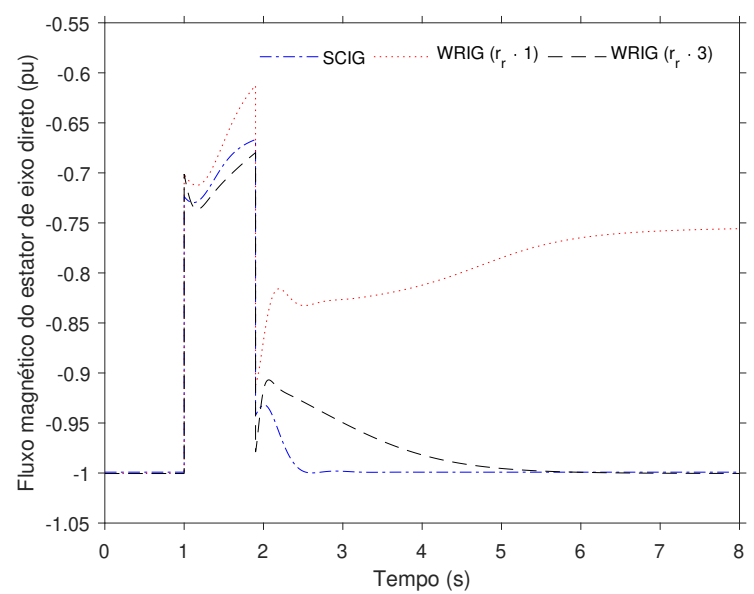

(a) Fluxo magnético do estator de eixo direto.

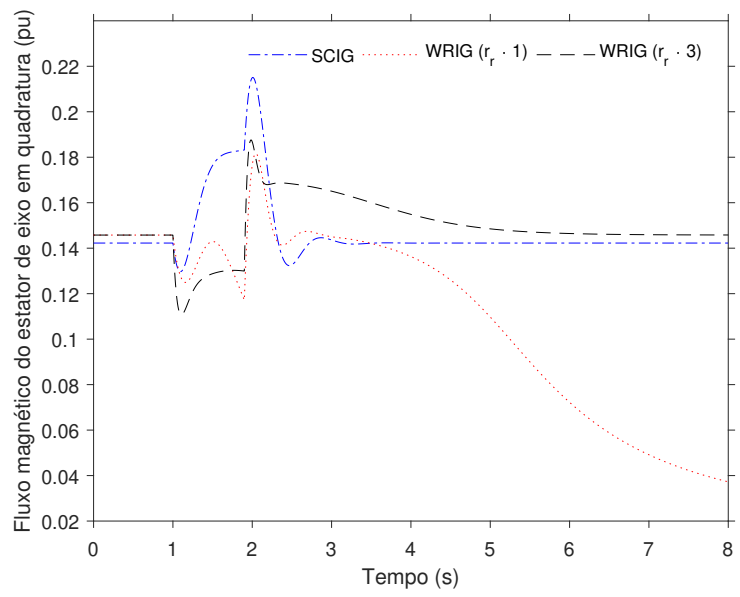

(b) Fluxo magnético do estator de eixo em quadratura.

Figura F.1: Fluxos magnéticos do estator para as configurações SCIG e WRIG.

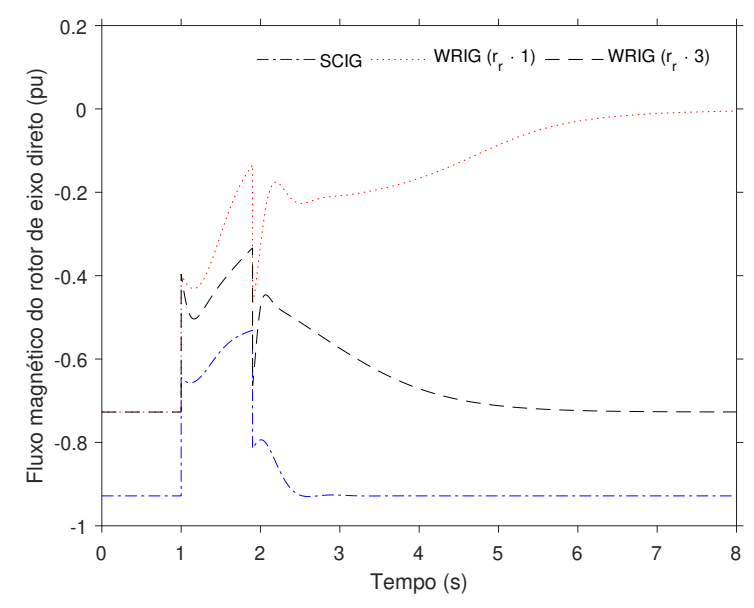

(a) Fluxo magnético do rotor de eixo direto.

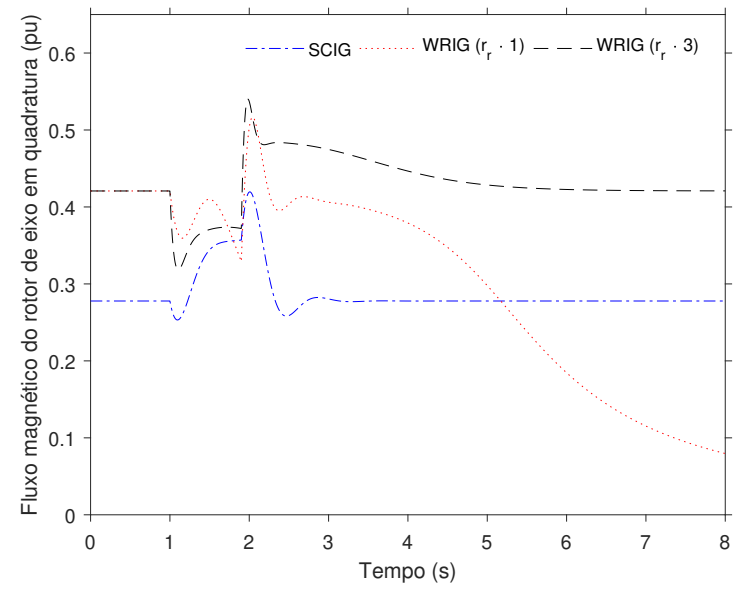

(b) Fluxo magnético do rotor de eixo em quadratura.

Figura F.2: Fluxos magnéticos do rotor para as configurações SCIG e WRIG. 


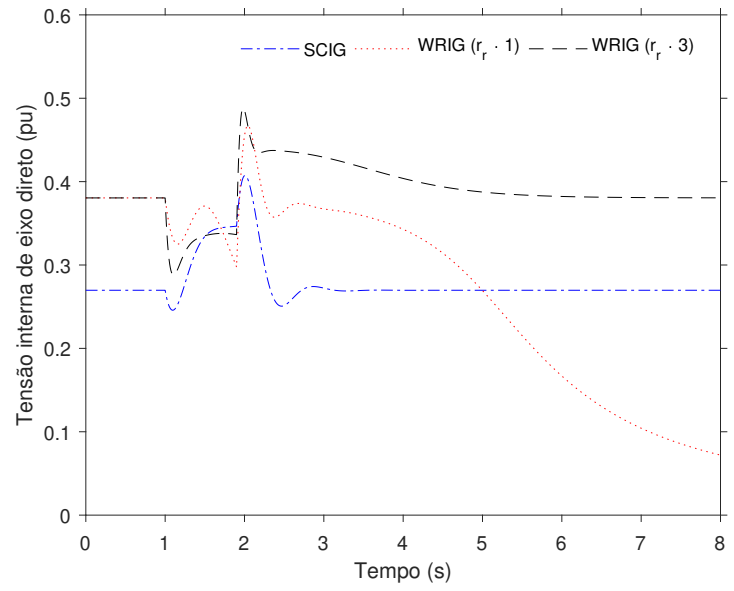

(a) Tensão interna de eixo direto.

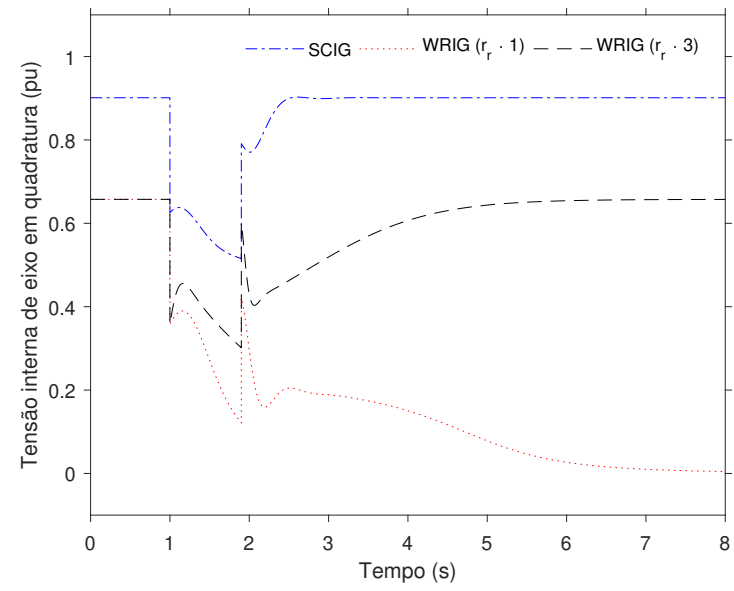

(b) Tensão interna de eixo em quadratura.

Figura F.3: Tensões internas para as configurações SCIG e WRIG.

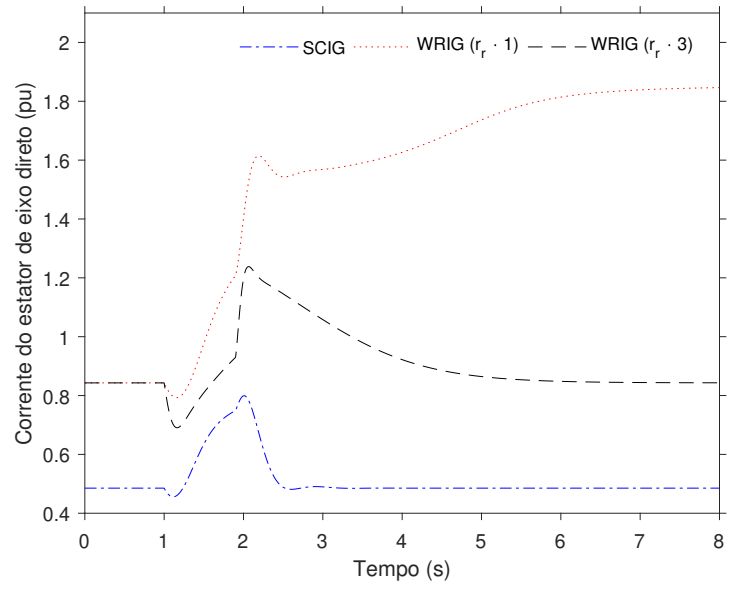

(a) Corrente do estator de eixo direto.

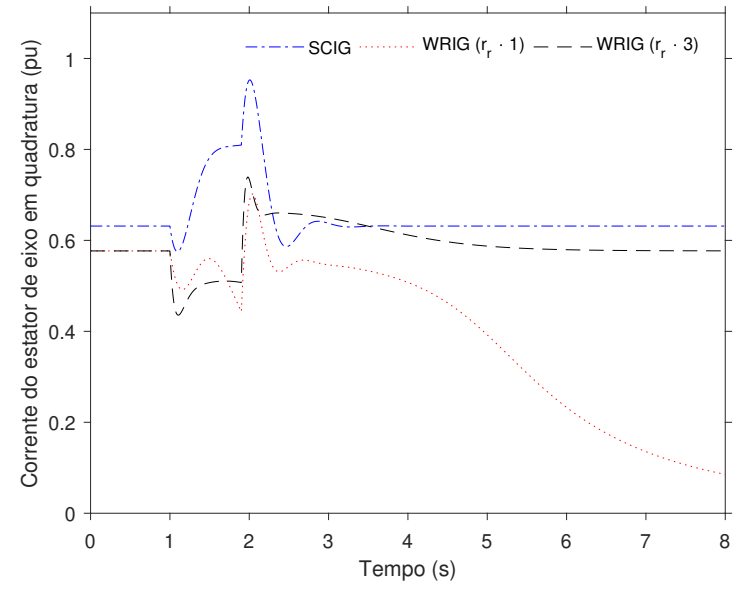

(b) Corrente do estator de eixo em quadratura.

Figura F.4: Correntes do estator para as configurações SCIG e WRIG.

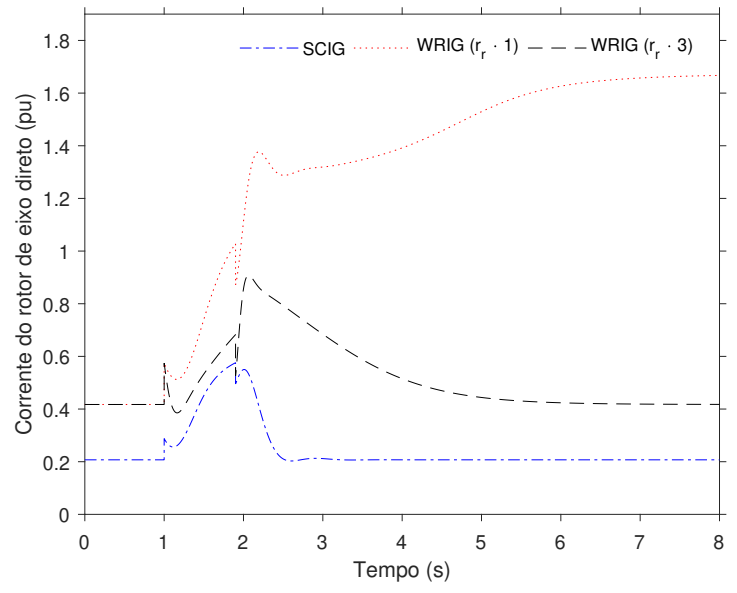

(a) Corrente do rotor de eixo direto.

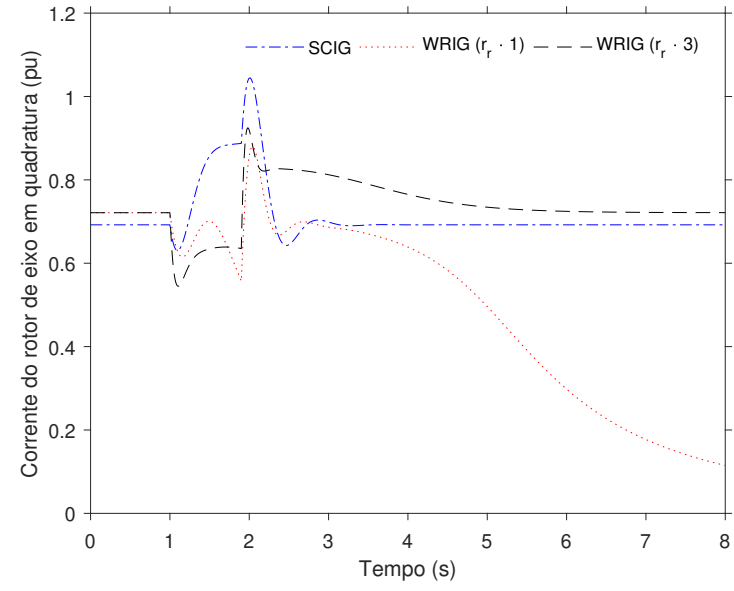

(b) Corrente do rotor de eixo em quadratura.

Figura F.5: Correntes do rotor para as configurações SCIG e WRIG. 


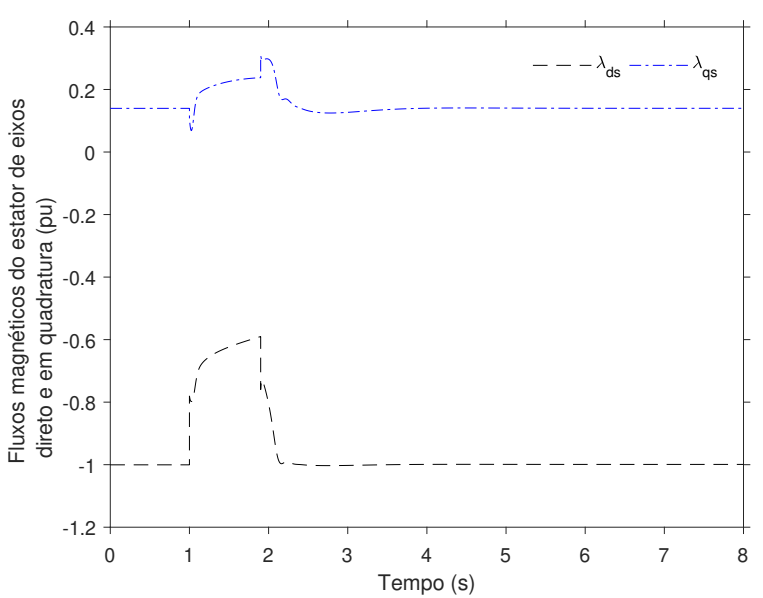

(a) Fluxos magnéticos do estator de eixos direto e em quadratura.

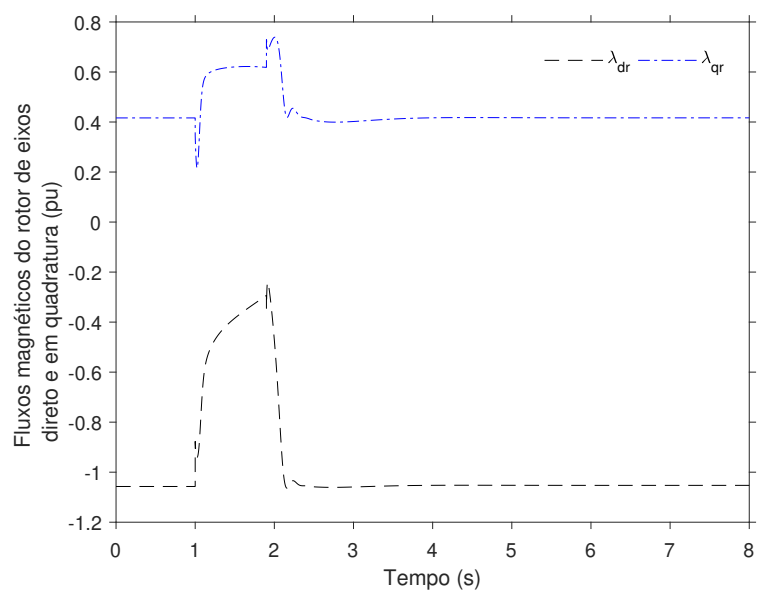

(b) Fluxos magnéticos do rotor de eixos direto e em quadratura.

Figura F.6: Fluxos magnéticos do estator e do rotor para a configuração DFIG.

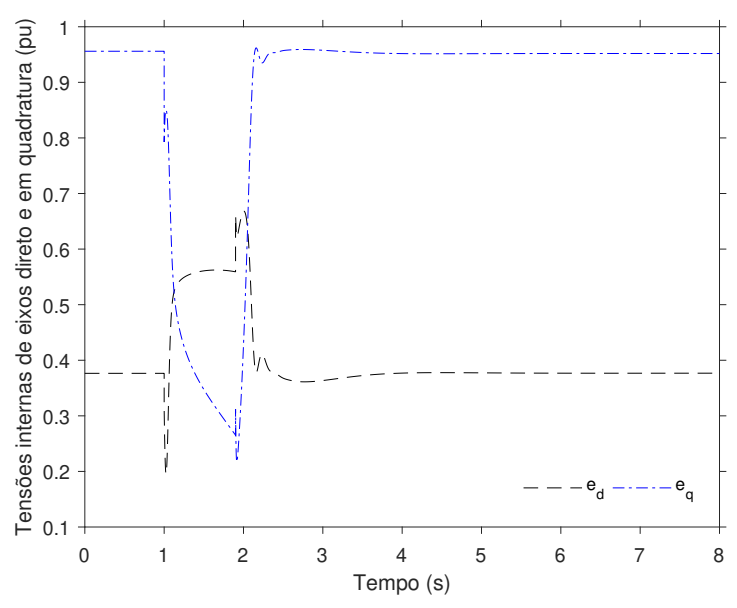

(a) Tensões internas de eixos direto e em quadratura.

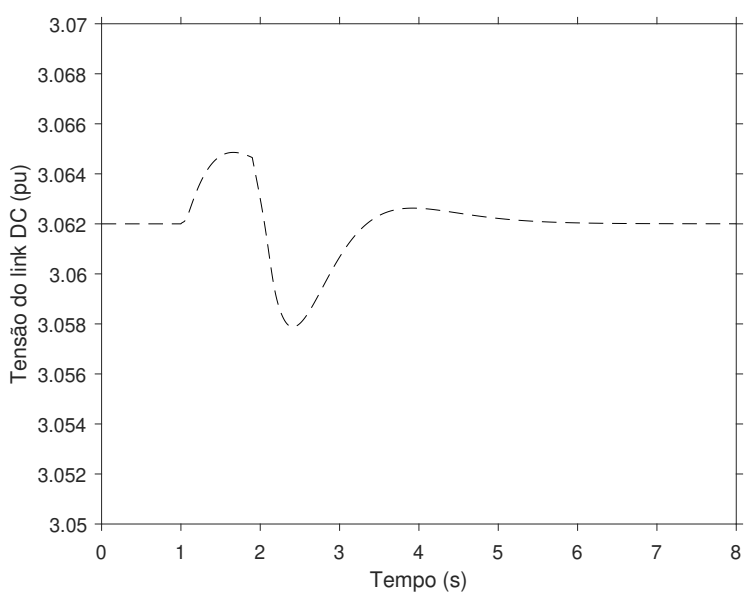

(b) Tensão do link DC.

Figura F.7: Tensões internas e tensão do link DC para a configuração DFIG.

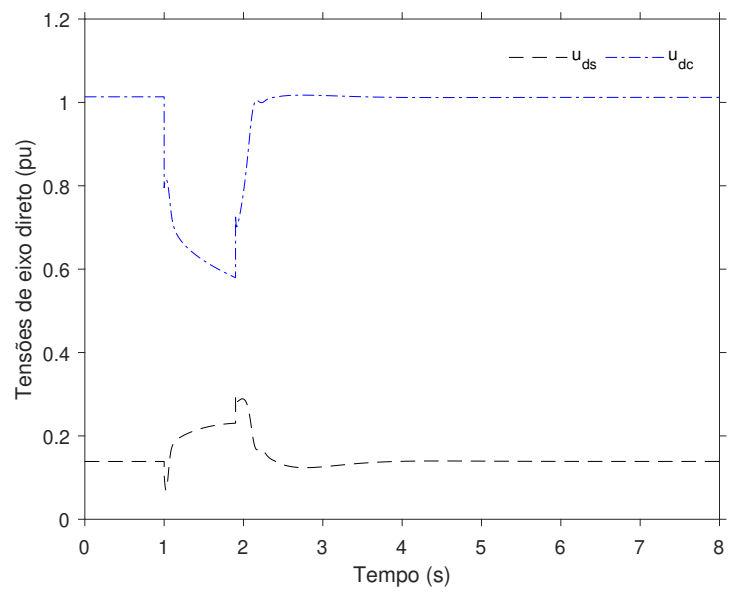

(a) Tensões de eixo direto.

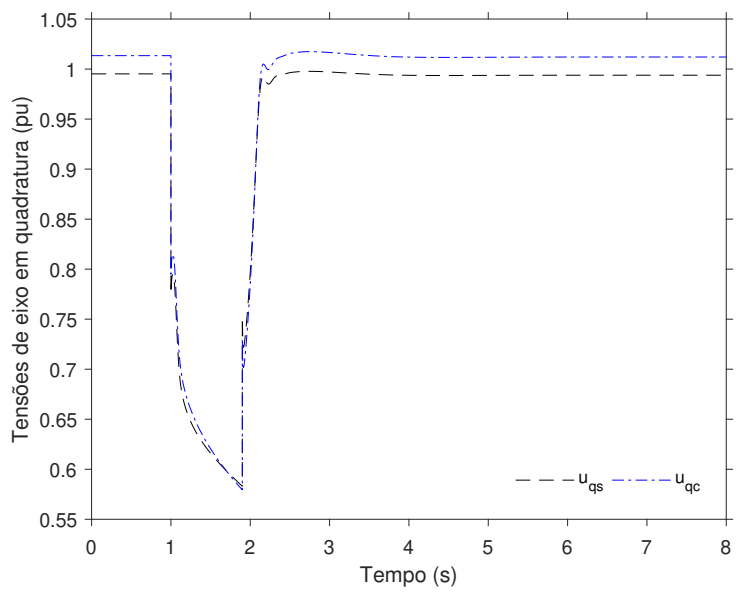

(b) Tensões de eixo em quadratura.

Figura F.8: Tensões de eixos direto e em quadratura para a configuração DFIG. 


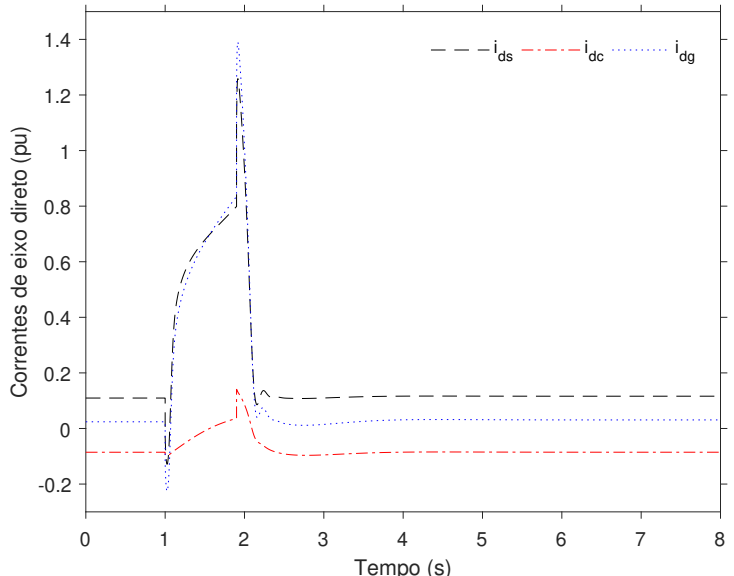

(a) Correntes de eixo direto

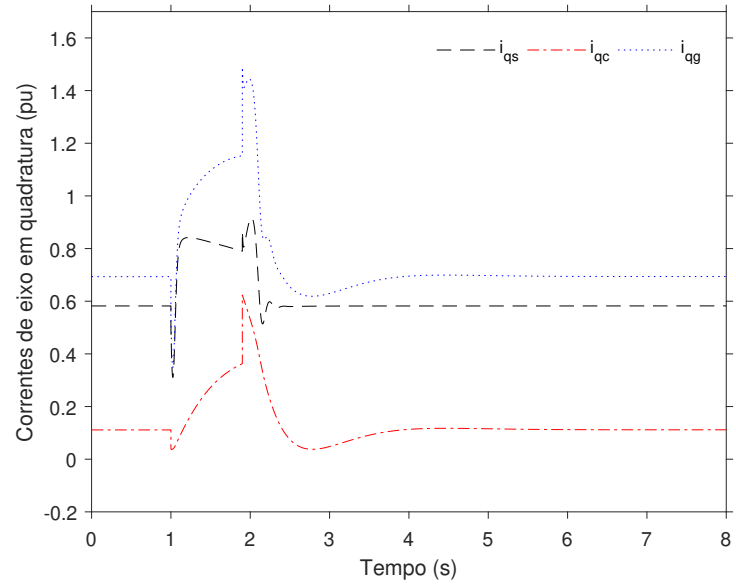

(b) Correntes de eixo em quadratura.

Figura F.9: Correntes de eixos direto e em quadratura para a configuração DFIG.

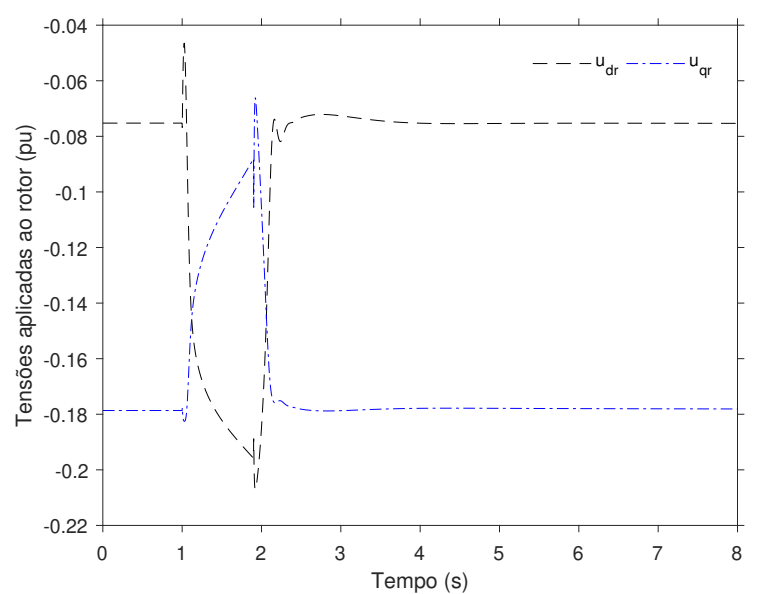

(a) Tensões aplicadas ao rotor.

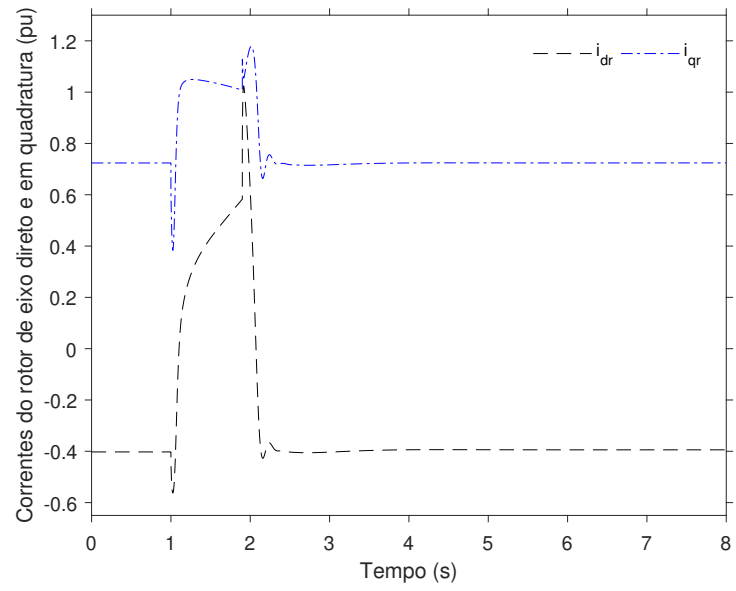

(b) Correntes do rotor.

Figura F.10: Tensões aplicadas ao rotor e correntes do rotor para a configuração DFIG

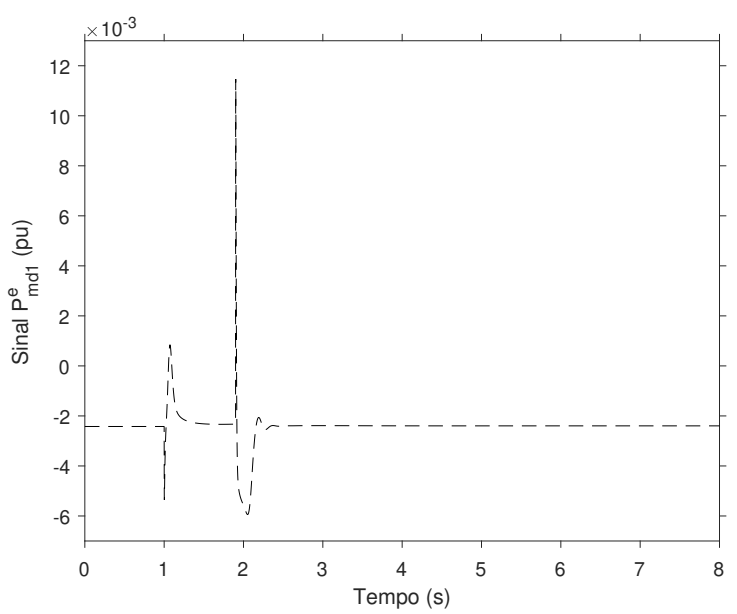

(a) Sinal $P_{m d 1}^{e}$

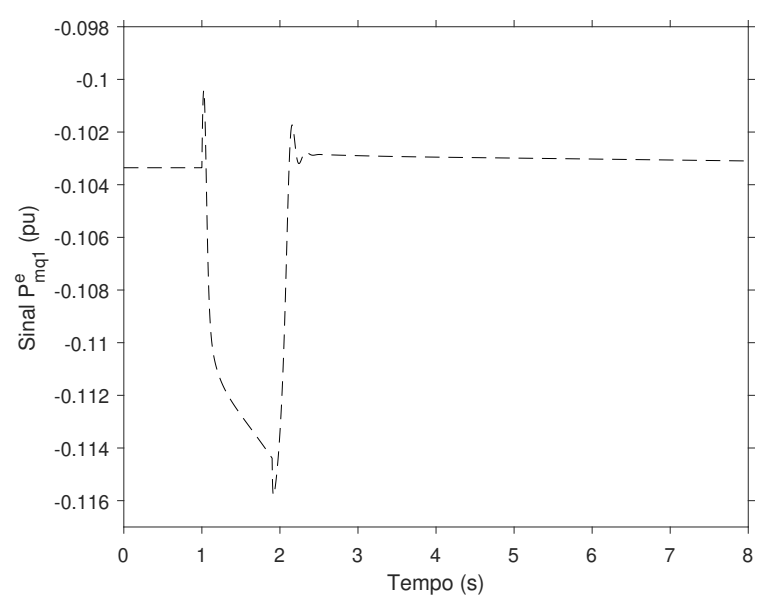

(b) Sinal $P_{m q 1}^{e}$.

Figura F.11: Sinais dos controladores do RSC para a configuração DFIG. 


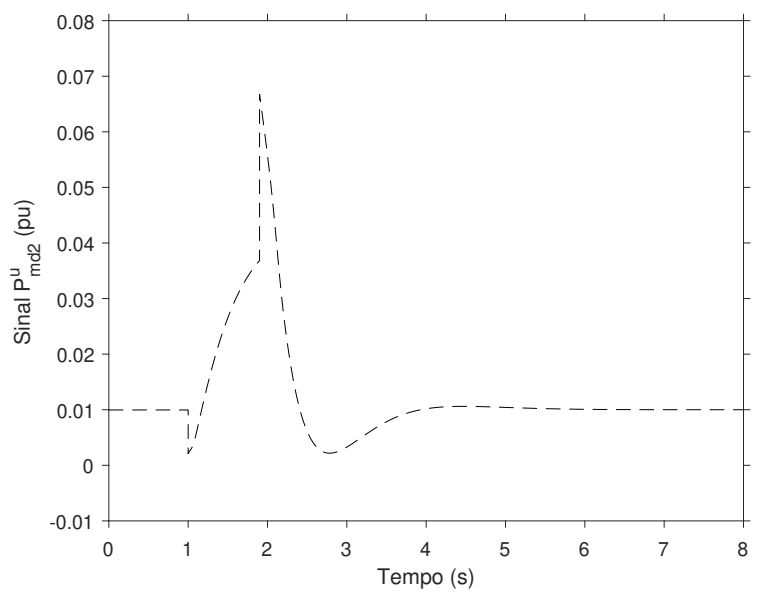

(a) Sinal $P_{m d 2}^{u}$

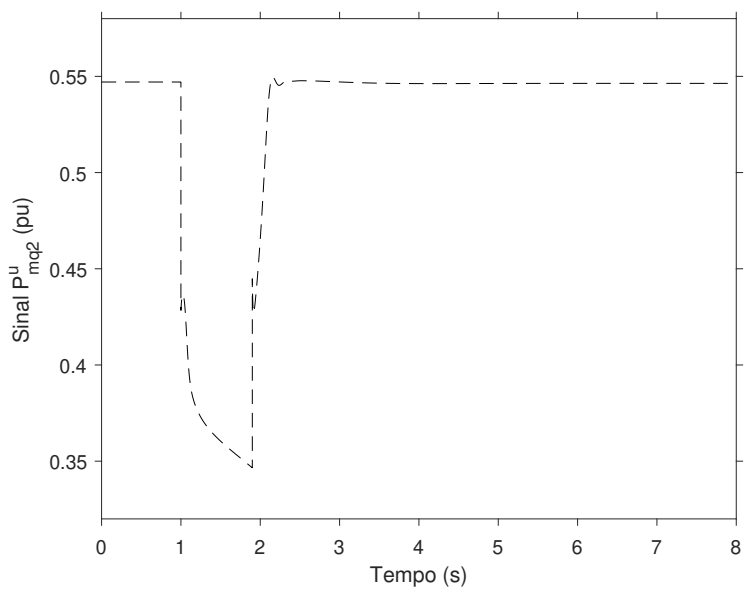

(b) Sinal $P_{m q 2}^{u}$.

Figura F.12: Sinais dos controladores do GSC para a configuração DFIG. 


\section{Apêndice $G$}

\section{Cálculo da RER e da RE do sistema auxiliar}

Nesta e nas próximas páginas são apresentados os scripts utilizados para calcular a RER e a RE do sistema auxiliar para o sistema teste equipado com a configuração SCIG modelada em primeira ordem nos eixos $d$ e $q$, considerando a curva LVRT do Brasil para a restrição do problema. Os resultados são apresentados na subseção 5.3 .1 do capítulo 5.

Função para o cálculo da curva LVRT real

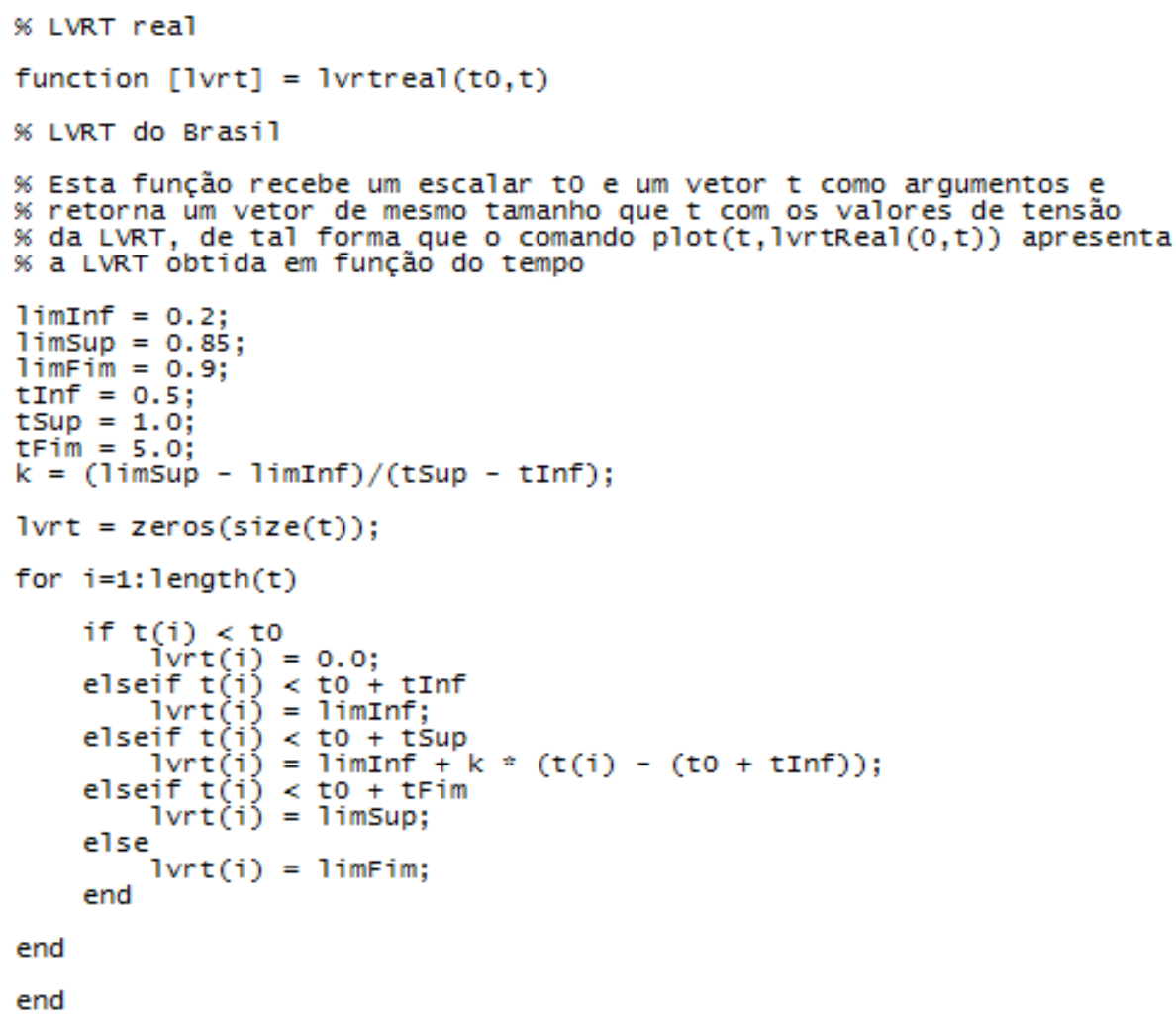


Função para a resolução das equações do sistema original

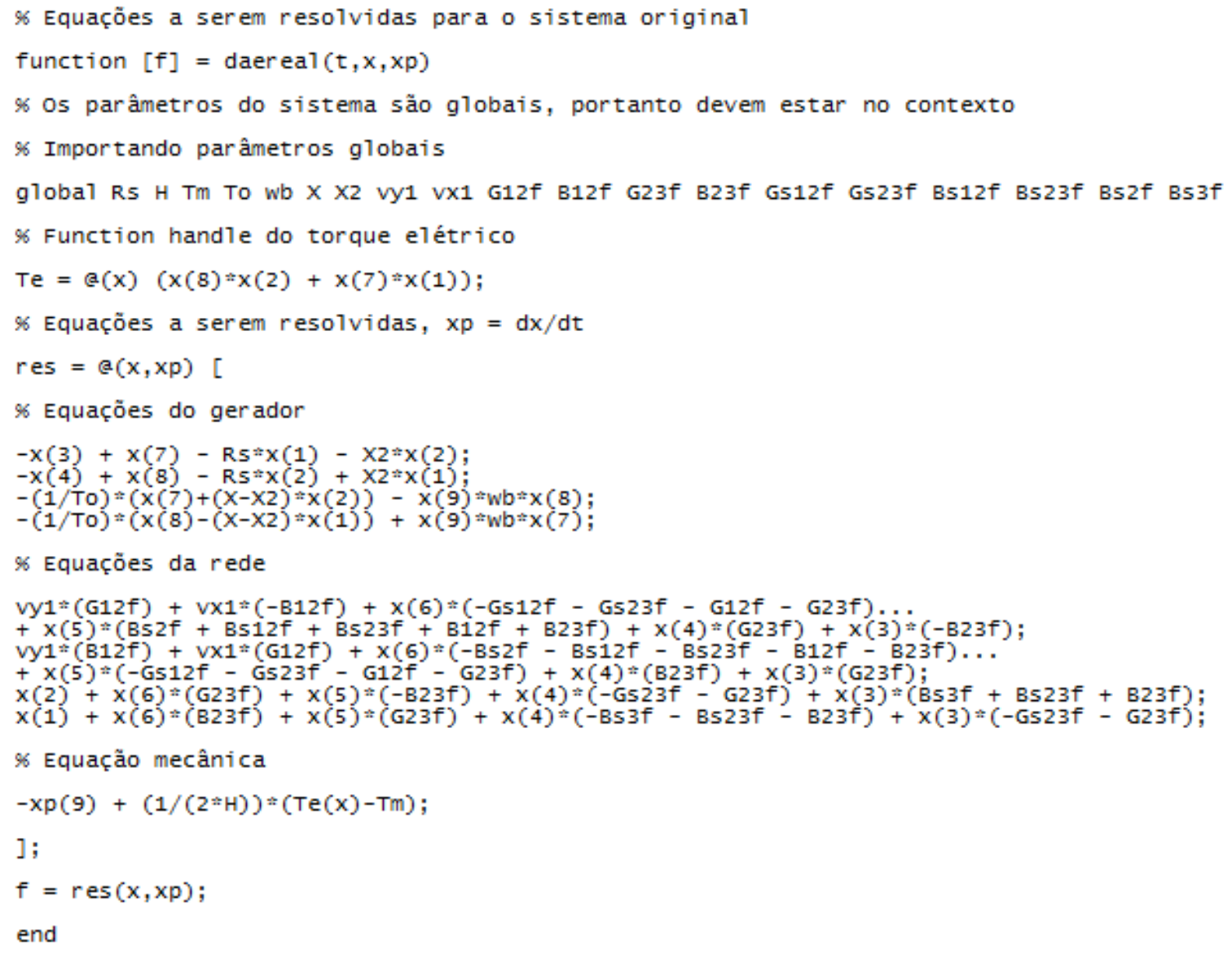


Script principal para o cálculo da RER

***** Parte 1 ****

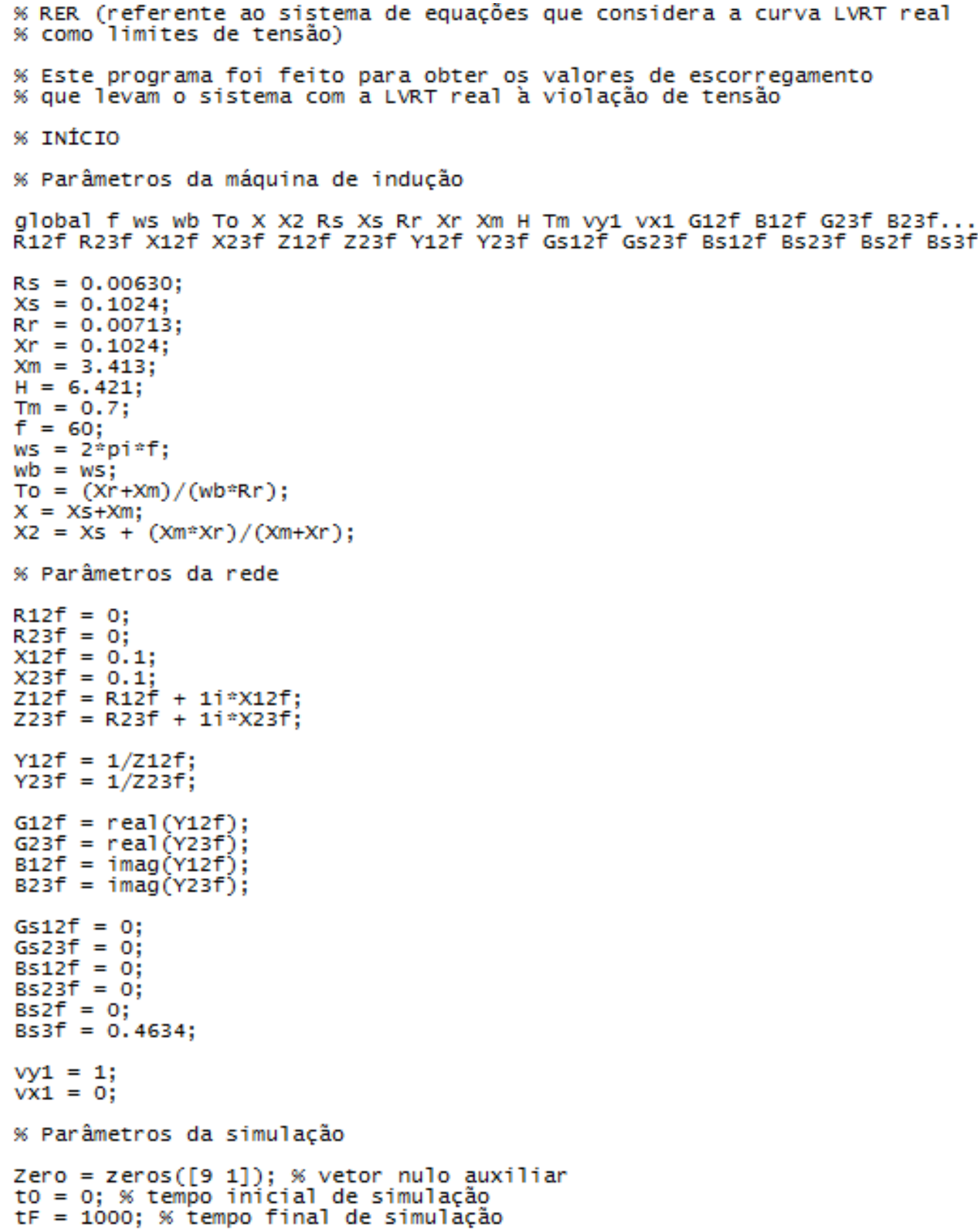


Script principal para o cálculo da RER

***** Parte 2 ****

tSpan $=[$ to tF $] ; \%$ intervalo de tempo de simulação

RelTol $=1 \mathrm{e}-4 ; \%$ tolerância relativa (erro $<\max ($ tolRel*abs (y), tolAbs)) \% default $=1 \mathrm{e}-3$

AbsTol = 1e-6; \% tolerância absoluta \% default $=1 \mathrm{e}-6$

Maxstep $=0.5 ; \%$ tstep máximo pequeno

options = odeset ('Re1To1', Re1To1, 'AbsTo1' ', AbsTo1, 'Maxstep', Maxstep); ...

\% substitui pelos valores estabelecidos

sFixo = Zero; $\operatorname{sFixo}(9)=1.0 ;$

\% vetor auxiliar para fixar $s$ no cálculo das condições iniciais

yop = Zero; $\%$ chute inicial para encontrar as condiçöes iniciais

\% ordem das variáveis

\% $y=[i x 3, i y 3, v x 3, v y 3, v x 2, v y 2, E d, E q, 5]$

$y_{0}=[0.485321310006499 ; 0.631498115323273 ; 0.139200748429060 ; 0.995167898865561 ; \ldots$

$0.0696003742145299 ; 0.997583949432780 ; 0.269705449652537 ; 0.901200152541082 ; \ldots$

$-0.00531636888531537]$;

\% obtenção das condições iniciais

$[y 0, y p 0]=\operatorname{decic}($ edaerea $1, \ldots$

to, ...

yo, ...

SFixo, ...

yop,...

zero,ions;

\% Obtenção da trajetória

sol = ode15i (edaerea1, tspan,yo,ypo,options);

yeq $=\operatorname{sol} \cdot y(:$, end $)$;

$96 \# \# \# \# \# \# \# \# \# \# \# \# \# \# \# \# \# \# \# \# \# \# \# \# \# \# \# \# \# \# \# \# \# \# \# \# \# \# \# \# \# \# \# \# \# \# \# \# \# \# \# \# \# \# \# \# \# \# \# \# \# \# \# \# \# \#$

96\#\#\#\#\#\#\#\#\#\# Obtencão da região de estabilidade restrita \#\#\#\#\#\#\#\#\#\#\#

$96 \# \# \# \# \# \# \# \# \# \# \# \# \# \# \# \# \# \# \# \# \# \# \# \# \# \# \# \# \# \# \# \# \# \# \# \# \# \# \# \# \# \# \# \# \# \# \# \# \# \# \# \# \# \# \# \# \# \# \# \# \# \# \# \# \# \#$

\% observação: não utilize escorregamento nulo como c.i. pois isso

\% torna o sistema insolúvel

sMin $=-0.04821 ; \%$ LVRT é respeitada até $s=-0.04821$

SMax $=0.1278 ; \%$ LVRT é respeitada até $s=0.1278$

$\mathrm{NS}=10000$

sstep $=($ sMax-sMin $) /$ Ns;

\% Desloca o tempo na LVRT, assim conseguimos diferentes valores

\% iniciais para a mesma

tMin $=0$;

$\operatorname{tmax}=10$

$\mathrm{Nt}=10000$

tstep $=($ tmax-tMin $) / N$;

\% Armazenamento de pontos de violação

sviolacao $=[]$

1Violacao $=$ []

\% Armazenamento de pontos de perda de estabilidade

SEstabilidade $=[]$

lEstabilidade $=[]$ 
Script principal para o cálculo da RER

**** Parte 3 ***\%

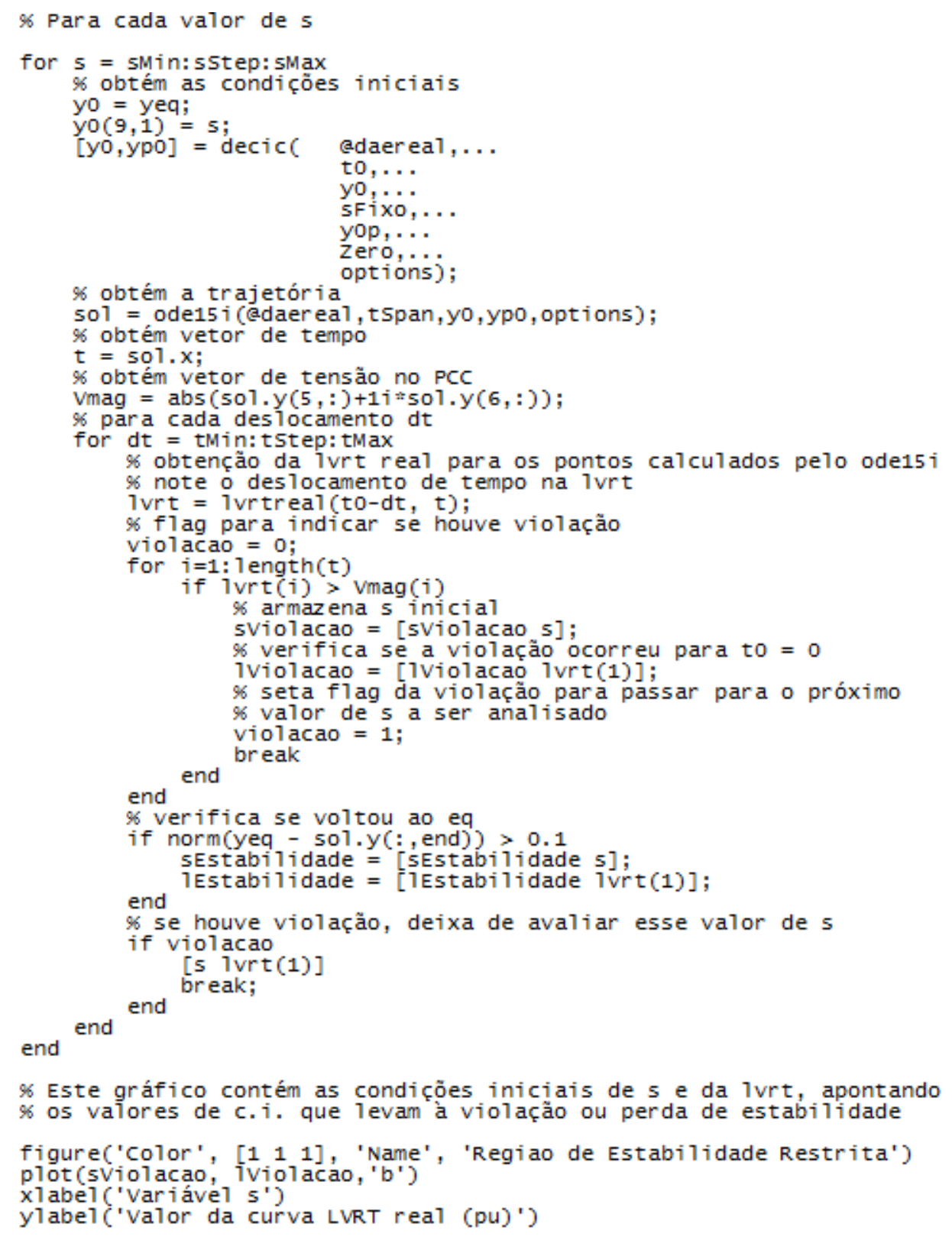


Função para a resolução das equações do sistema auxiliar

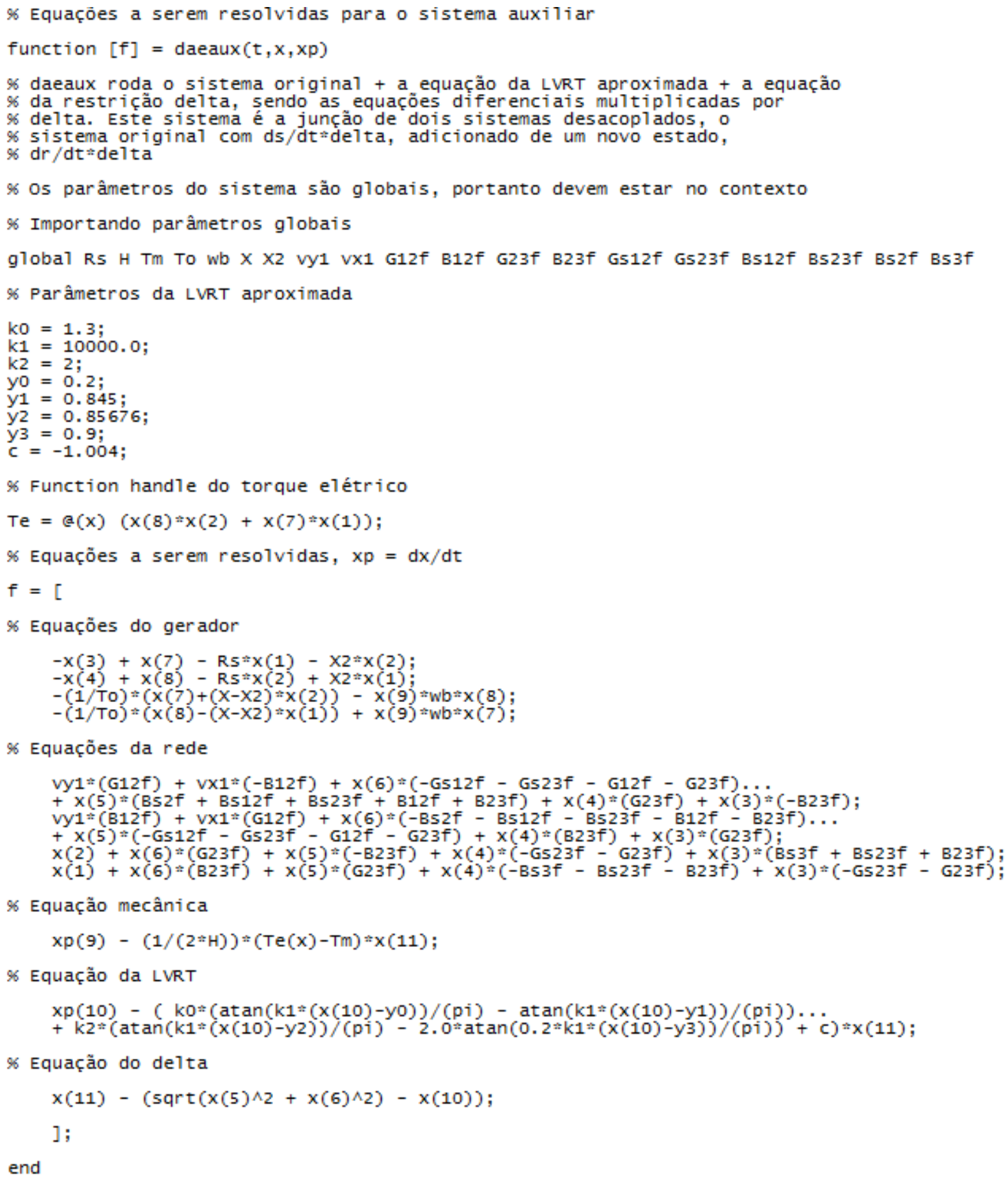


Script principal para o cálculo da RE do sistema auxiliar

**** Parte 1 ****

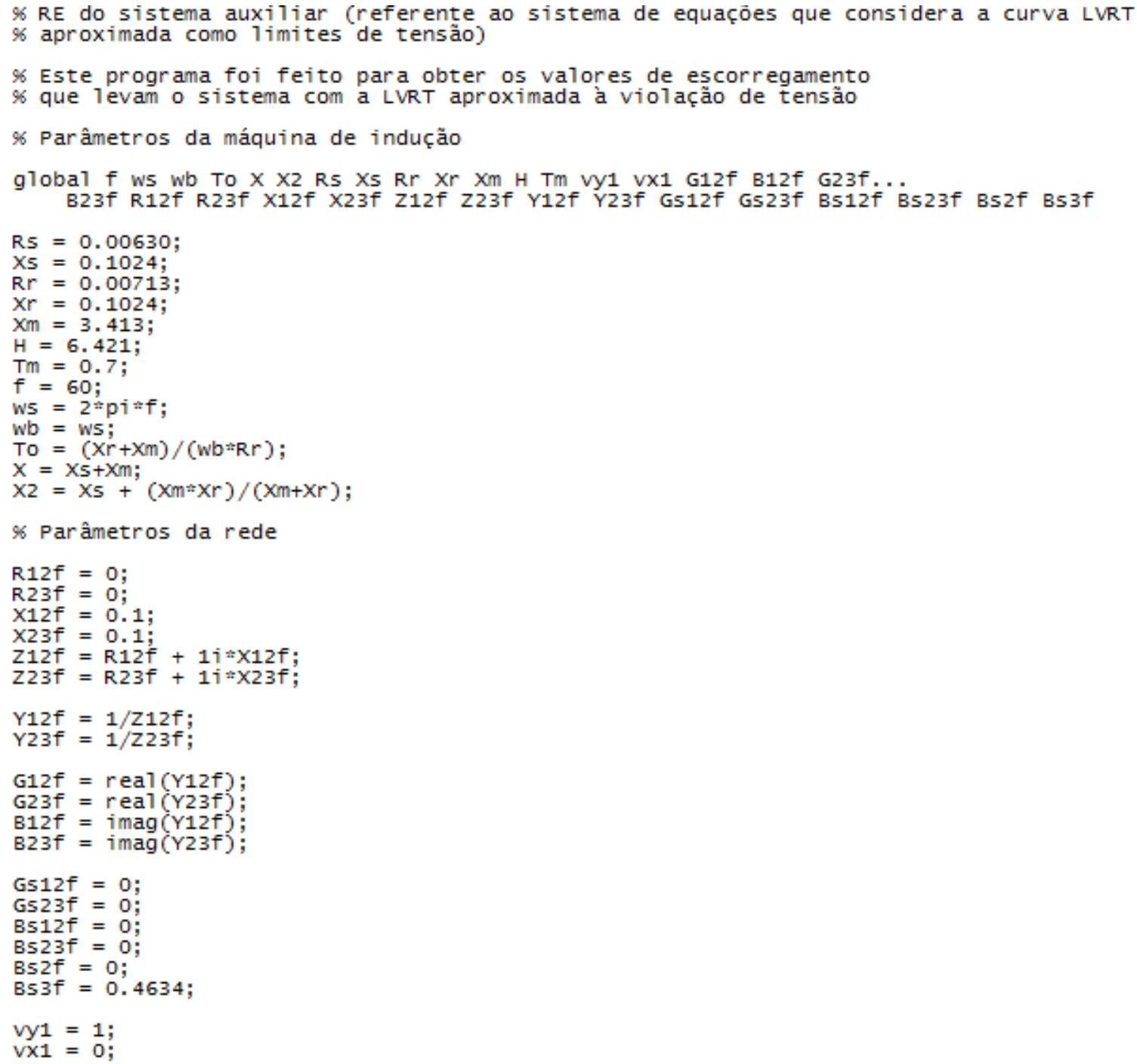


Script principal para o cálculo da RE do sistema auxiliar **** Parte 2 ****

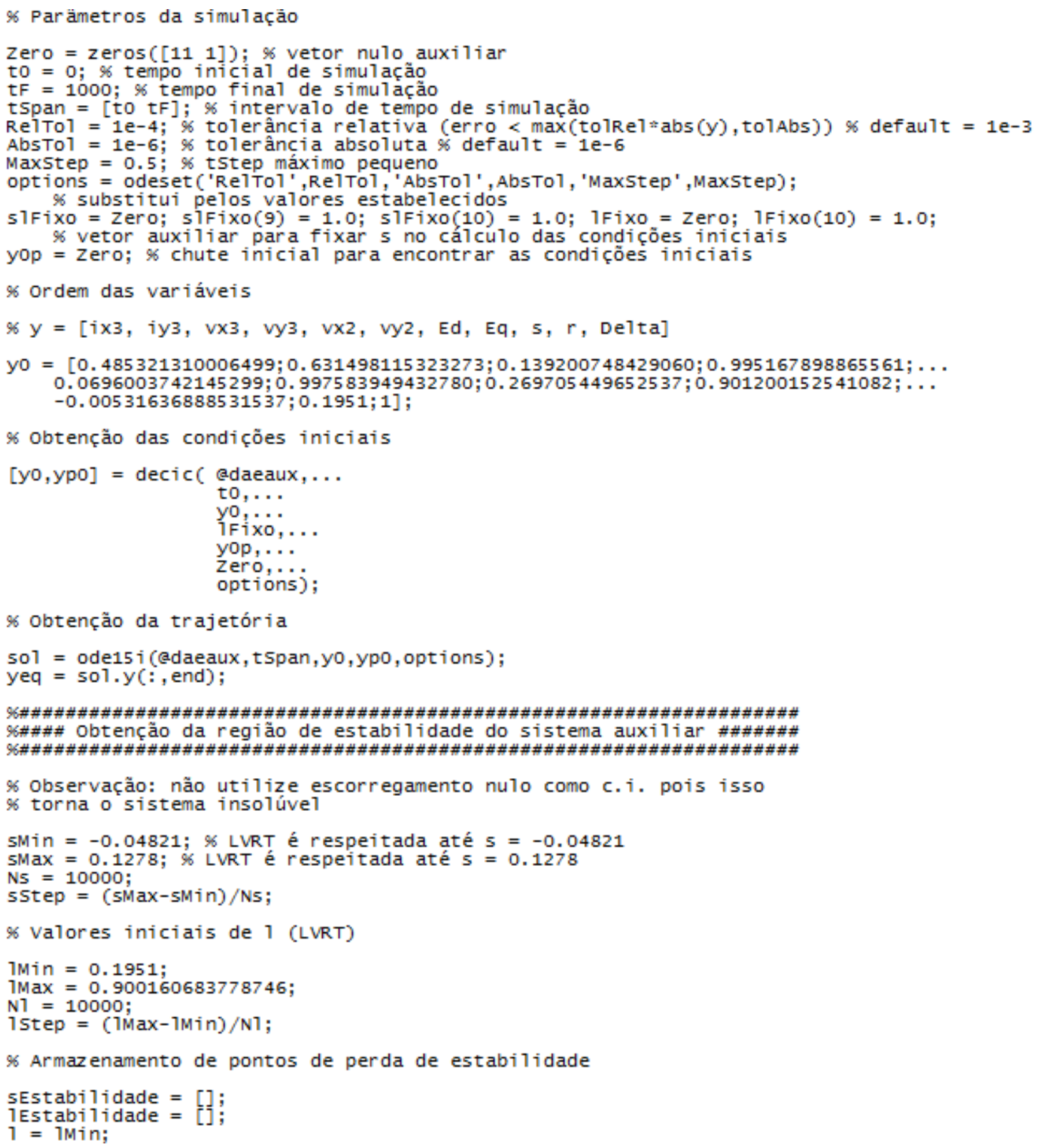


Script principal para o cálculo da RE do sistema auxiliar **** Parte 3 ****

96 Para cada valor de s

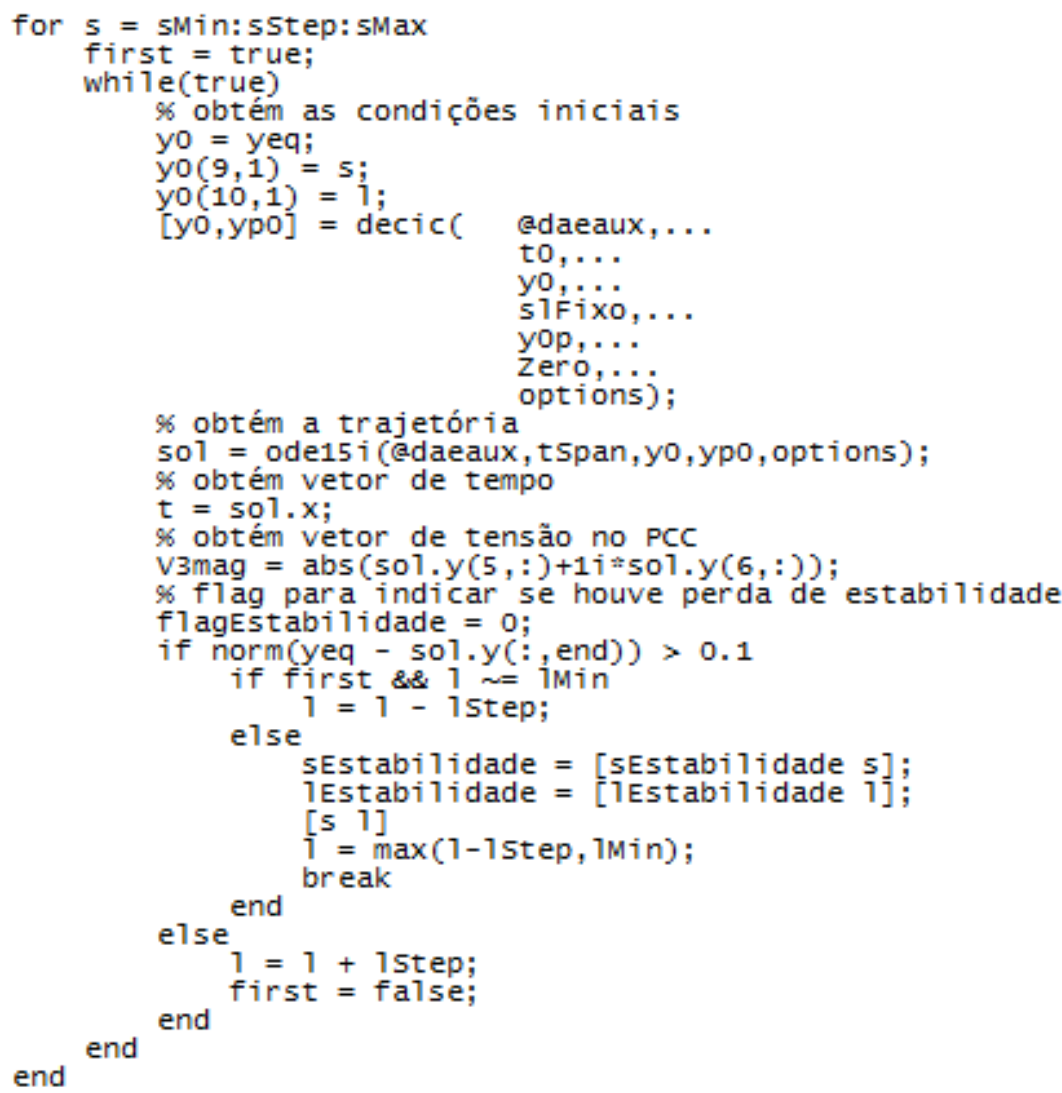

\% Este gráfico contém as condições iniciais de $s$ e da 1vrt, apontando 9 os valores de c.i. que levam à violação ou perda de estabilidade

figure('Color', [1 11 1 $]$, 'Name', 'Regiao de Estabilidade do sistema Auxiliar') plot (sEstabilidade, 1Estabilidadé, 'b')

xlabel ('variável $\mathrm{s}^{\prime}$ )

ylabel('variável r (pu)') 


\section{Apêndice $\mathrm{H}$}

\section{Regiões de estabilidade e trajetórias}

As Figuras $\mathrm{H} .1$ a $\mathrm{H} .7$ mostram as demais trajetórias em falta e pós-falta no domínio do tempo e no espaço de estados, referentes à seção 5.3 do capítulo 5.

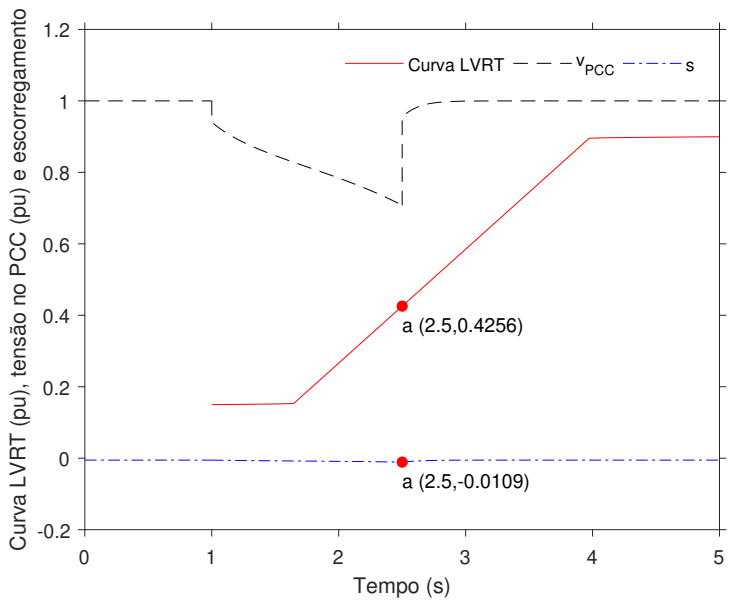

(a) Trajetórias no domínio do tempo.

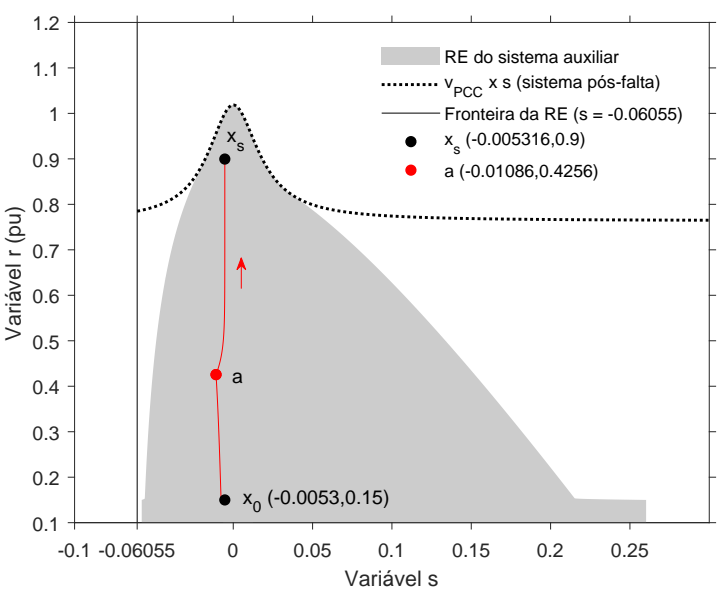

(b) Trajetórias no espaço de estados.

Figura H.1: Trajetórias referentes ao ponto a. A susceptância da linha de transmissão é alterada em $t_{0}=1 \mathrm{~s}$ de $B_{12}=-10$ pu para $B_{12}=-1,75$ pu, retornando a $B_{12}=-10$ pu em $t_{a b}=2,5 \mathrm{~s}$.

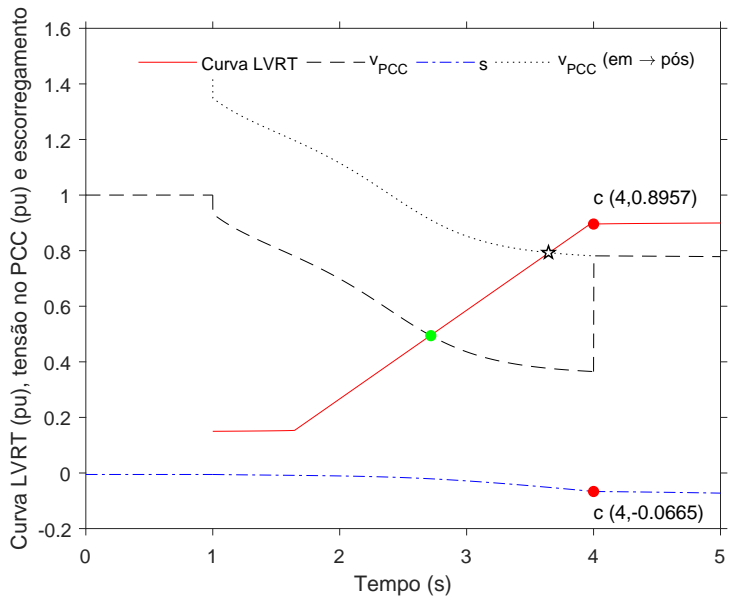

(a) Trajetórias no domínio do tempo.

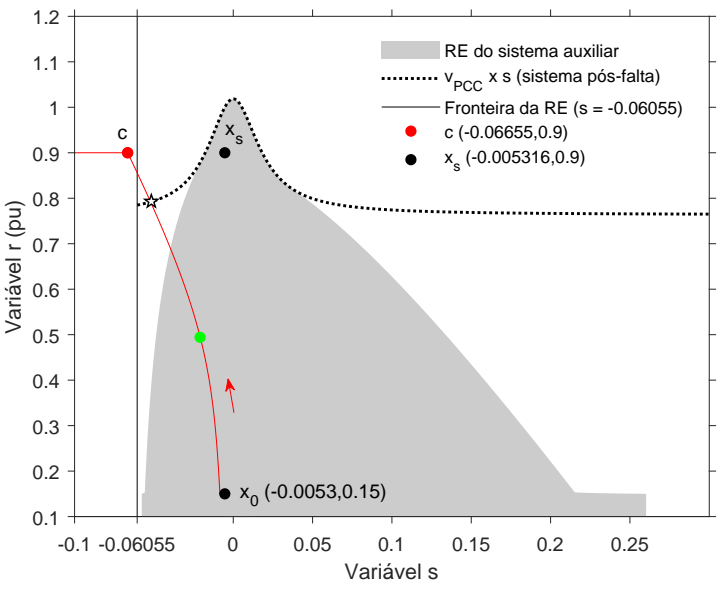

(b) Trajetórias no espaço de estados.

Figura H.2: Trajetórias referentes ao ponto c. A susceptância da linha de transmissão é alterada em $t_{0}=1 \mathrm{~s}$ de $B_{12}=-10$ pu para $B_{12}=-1,75 \mathrm{pu}$, retornando a $B_{12}=-10 \mathrm{pu}$ em $t_{a b}=4 \mathrm{~s}$. 


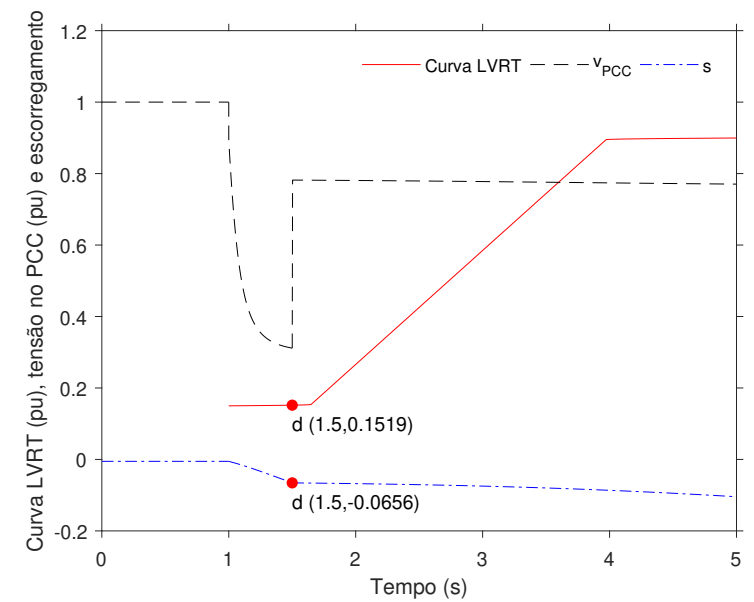

(a) Trajetórias no domínio do tempo.

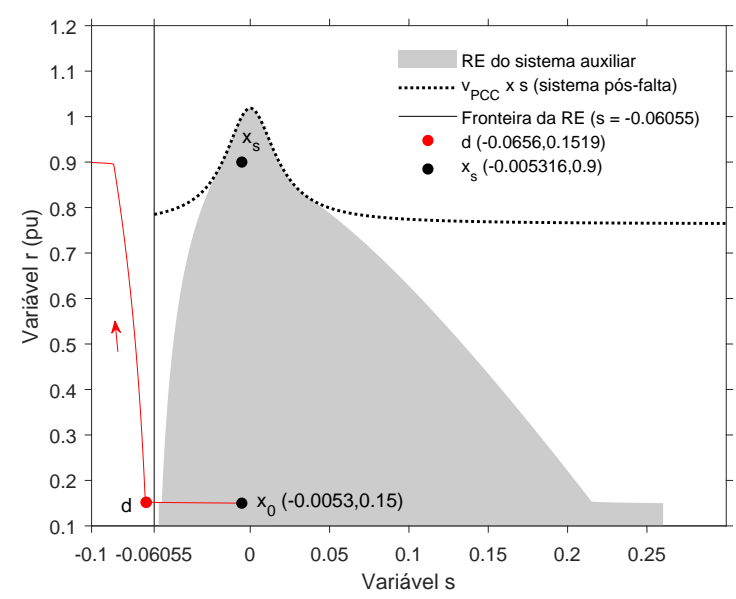

(b) Trajetórias no espaço de estados.

Figura H.3: Trajetórias referentes ao ponto d. O torque mecânico e a susceptância da linha de transmissão são alterados em $t_{0}=1 \mathrm{~s}$ de $T_{m}=0,7$ pu e $B_{12}=-10$ pu para $T_{m}=1,8$ pu e $B_{12}=$ $-1,3$ pu, retornando a $T_{m}=0,7$ pu e $B_{12}=-10$ pu em $t_{a b}=1,5 \mathrm{~s}$.

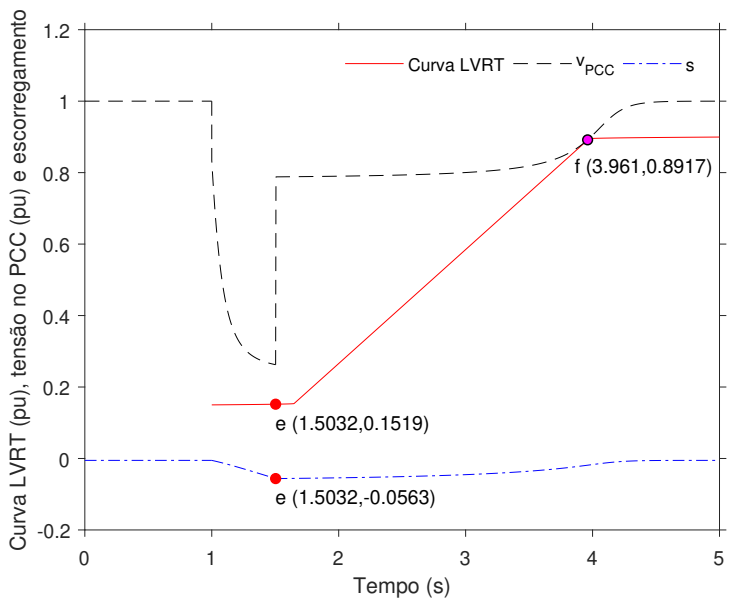

(a) Trajetórias no domínio do tempo.

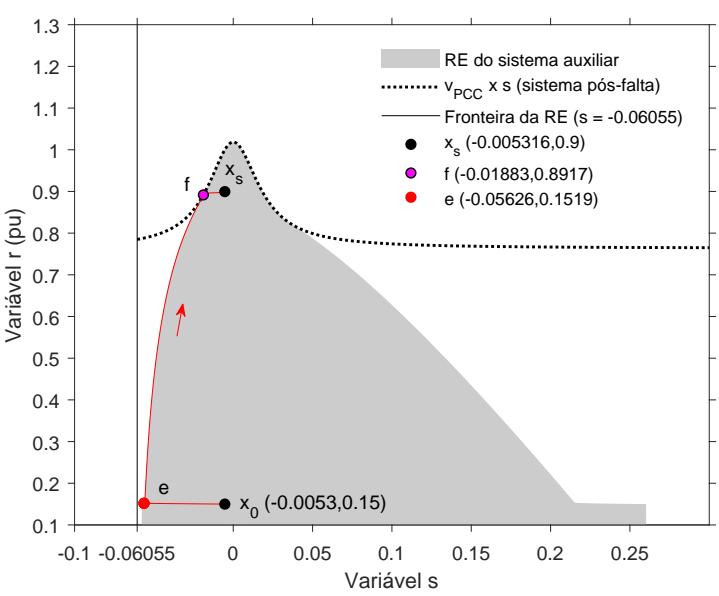

(b) Trajetórias no espaço de estados.

Figura H.4: Trajetórias referentes ao ponto e, $f$. $O$ torque mecânico e a susceptância da linha de transmissão são alterados em $t_{0}=1 \mathrm{~s}$ de $T_{m}=0,7$ pu e $B_{12}=-10$ pu para $T_{m}=1,5$ pu e $B_{12}=-1$ pu, retornando a $T_{m}=0,7$ pu e $B_{12}=-10$ pu em $t_{a b}=1,5032 \mathrm{~s}$. 


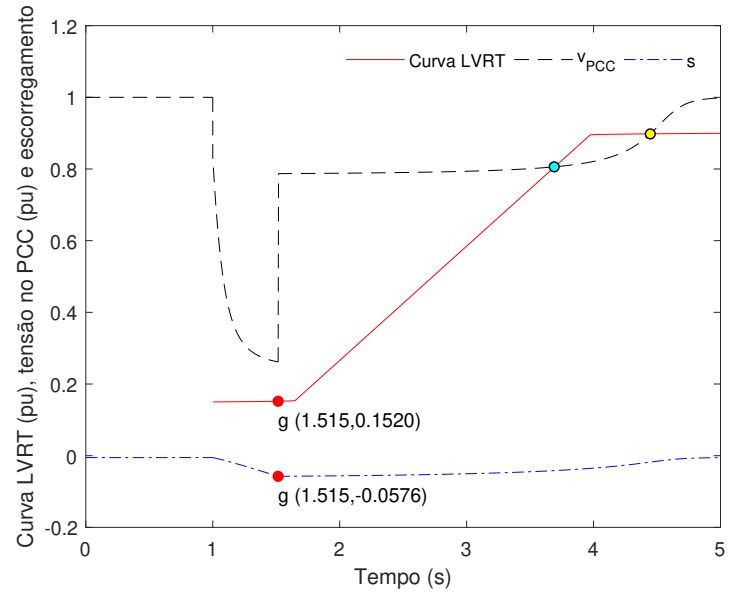

(a) Trajetórias no domínio do tempo.

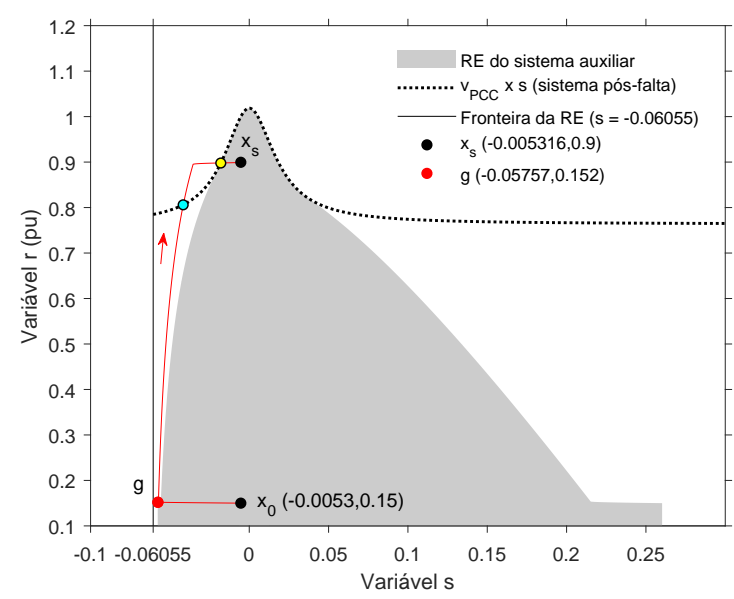

(b) Trajetórias no espaço de estados.

Figura H.5: Trajetórias referentes ao ponto g. O torque mecânico e a susceptância da linha de transmissão são alterados em $t_{0}=1 \mathrm{~s}$ de $T_{m}=0,7$ pu e $B_{12}=-10$ pu para $T_{m}=1,5$ pu e $B_{12}=-1$ pu, retornando a $T_{m}=0,7$ pu e $B_{12}=-10$ pu em $t_{a b}=1,515 \mathrm{~s}$.

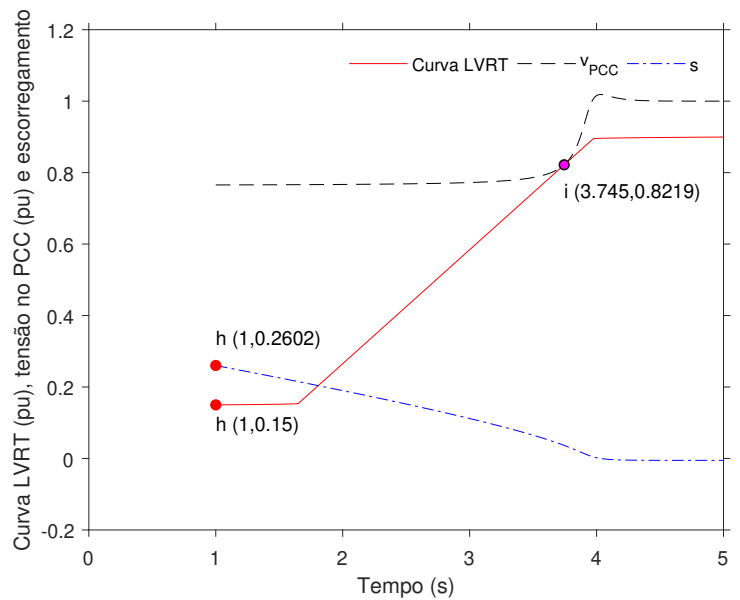

(a) Trajetórias no domínio do tempo.

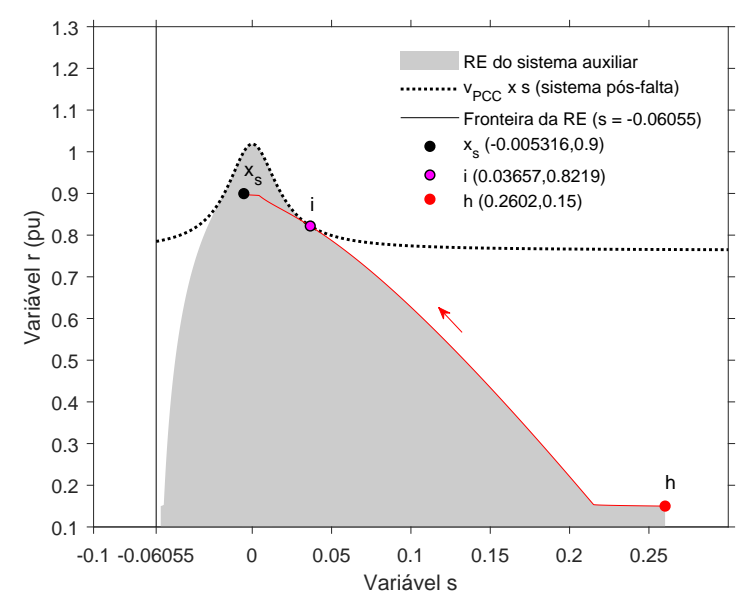

(b) Trajetórias no espaço de estados.

Figura H.6: Trajetórias referentes ao ponto $h, i$. 


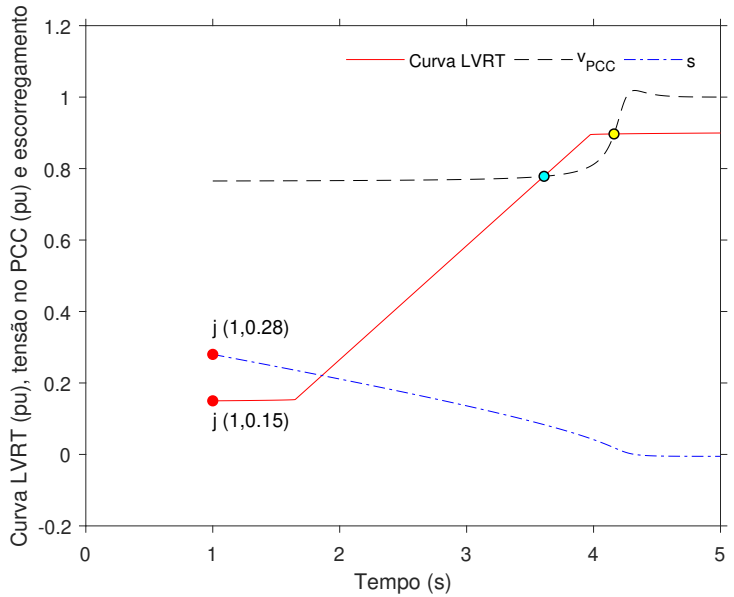

(a) Trajetórias no domínio do tempo.

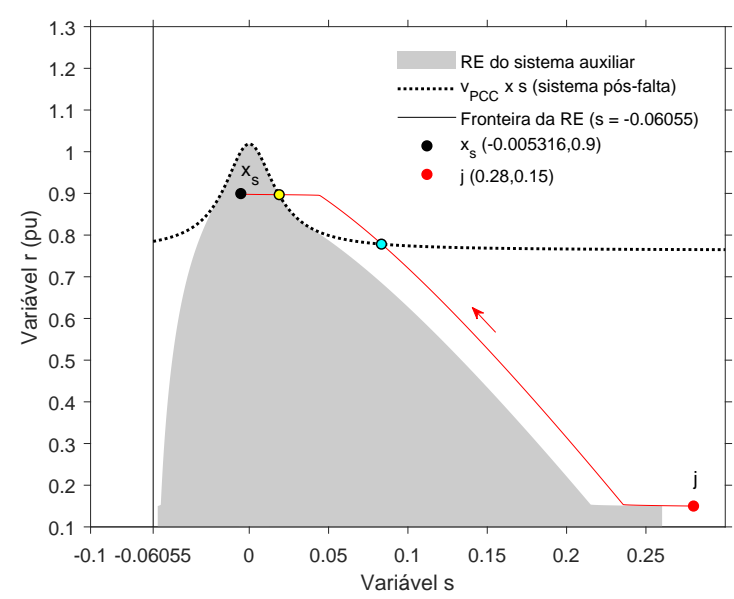

(b) Trajetórias no espaço de estados.

Figura H.7: Trajetórias referentes ao ponto j. 


\section{Sobre os trabalhos publicados}

O autor desta tese tem trabalhos publicados na área de concentração de sistemas elétricos de potência. Sugere-se para consulta:

http://lattes.cnpq.br/0668872699643602

Esclarecimentos sobre esta tese e outros trabalhos elaborados pelo autor podem ser solicitados por e-mail através da plataforma Lattes CNPq. 